\title{
LOS LAGARTOS CONTINENTALES FÓSILES DE LA ARGENTINA (EXCEPTO IGUANIA)
}

\author{
Tesis Doctoral \\ Santiago Brizuela \\ Directora \\ Adriana M. Albino \\ Co-Directora \\ Zulma Brandoni de Gasparini
}

Facultad de Ciencias Naturales y Museo

Universidad Nacional de La Plata

- 2010 - 


\section{RESUMEN}

El trabajo llevado a cabo en la presente Tesis representa una puesta al día del registro fósil conocido de lagartos continentales (excepto Iguania) de Argentina, donde la identificación del material fue realizada empleando criterios modernos dentro de un marco cladístico y mediante el contraste directo con abundantes ejemplares actuales del grupo.

Durante el desarrollo de la Tesis, se presenta en forma introductoria el marco sistemático y las relaciones filogenéticas de los lagartos, así como una actualización del registro conocido de lagartos fósiles en el mundo, y particularmente, en América del Sur y en Argentina. El objetivo general del trabajo de Tesis doctoral se resume en el estudio sistemático de los fósiles de lagartos continentales presentes en el territorio argentino bajo la consideración de las relaciones filogenéticas planteadas en la Tesis y basadas únicamente en caracteres osteológicos.

Debido a que la mayor parte del material fósil estudiado corresponde a la familia Teiidae se describió escuetamente el cráneo del teido actual Tupinambis merianae. Si bien esta especie es ampliamente reconocida y su osteología ya ha sido descripta, aquí se describieron estructuras previamente no observadas. En particular, se describió la dentición de T. merianae, la cual no había sido previamente descripta en detalle teniendo en cuenta todas sus variaciones, que fueron de particular importancia para la interpretación del material fósil. También se reconocieron las diferencias en las características dentarias y estructuras postcraneanas de otros teidos.

Los resultados obtenidos en la sistemática paleontológica manifiestan, en forma general, que los lagartos continentales fósiles de Argentina (excepto Iguania) poseen un registro desde el Cretácico tardío (Campaniano) hasta la actualidad con algunos importantes hiatos temporales (Oligoceno, Pleistoceno), donde no hay hallazgos o éstos son muy escasos. Tales momentos están intercalados con períodos caracterizados por una abundancia de registros (Mioceno). El registro fósil, previo a la realización de este trabajo, constaba de varios géneros y especies descriptos a finales del siglo XIX y principios del siglo XX, así como algunos dados a conocer más recientemente. En este estudio se redescribieron los materiales correspondientes a dichas citas y se estudiaron restos inéditos y citados en la literatura paleoherpetológica aunque sin una apropiada descripción. En conjunto, esta revisión resultó en un 
registro de menor diversidad que el previamente sostenido debido a que se invalidaron, con sólidos fundamentos morfológicos, varios géneros y especies. En este aspecto se destaca la falta de fundamentación para el género Lumbrerasaurus Donadío 1985 del Eoceno del noroeste argentino, que debe ser considerado como un Teiidae Tupinambinae indeterminado. Asimismo, los géneros Diasemosaurus Ameghino 1893 y Dibolosodon Ameghino 1893 del Mioceno del extremo austral de nuestro país, se sinonimizaron con el género actual Tupinambis, y su asignación específica permanece indeterminada. Las especies extintas de Tupinambis de la provincia de Buenos Aires T. teguixin Rovereto 1914, T. prerufescens Rovereto 1914, T. multidentatus Rovereto 1914 , T. brevirostris Rovereto 1914 y T. onyxodon Kraglievich 1947 son reevaluadas en este trabajo, de modo tal que se designan como Tupinambis sp.. De forma comparable, las asignaciones a especies actuales de Tupinambis, incluidas las referencias provenientes de sitios arqueológicos, fueron desconsideradas. Dichos registros son aceptados en este trabajo como Tupinambis sp. Contrariamente a estos casos, fue posible validar la única especie extinta del género Callopistes procedente del Mioceno tardío-Plioceno temprano de la provincia de Buenos Aires, C. bicuspidatus Chani 1976. En este caso, la reevaluación permitió fundamentar el reconocimiento de una entidad taxonómica distinta a las dos especies actuales del género pero sobre la base de caracteres completamente diferentes a aquellos considerados por el autor original del nombre.

Como se mencionó, el predominio de los Teiidae en el registro fósil ameritó el análisis filogenético de la familia, aportando caracteres para una más adecuada determinación taxonómica de los fósiles. El análisis confirmó la monofilia de la familia; sin embargo, las relaciones intergenéricas difieren de las propuestas por otros estudios, principalmente en la posición basal de Teius: (Teius) ((Ameiva (Kentropyx + Cnemidophorus)) (Callopistes (Crocodilurus (Tupinambis (Dracaena + Paradracaena))))). Las relaciones entre los Tupinambinae se distinguen de los restantes estudios filogenéticos con base en la osteología, observándose una más cercana relación entre Tupinambis y Dracaena. Del análisis surgió la validez del género extinto Paradracaena (Mioceno de Colombia y Perú) y su estrecha relación con Dracaena. Las relaciones entre las diferentes especies de Tupinambis no pueden ser satisfactoriamente resueltas sólo con caracteres osteológicos, por lo cual los fósiles del género resultan indeterminables a nivel específico. 
En conclusión, todos los taxones evaluados en el registro paleontológico corresponden a alguno de los diferentes grupos actualmente representados en la herpetofauna argentina, aunque esta última incluye familias sin representantes fósiles (Gymnophtalmidae, Anguidae, Scincidae, Rhineuridae). La mayor cantidad de registros corresponde a los Scincomorpha y en mucha menor medida a los Amphisbaenia. Entre los Scincomorpha, el clado Scleroglossa tiene su registro más temprano en América del Sur en el Cretácico superior de la provincia de Río Negro, con un resto de un probable Scincoidea. Los Teiidae dominan el registro fósil del Cenozoico, en particular la subfamilia Tupinambinae con el género Tupinambis. Esta familia se remonta al Eoceno temprano de la provincia de Salta (previamente Lumbrerasaurus scagliai). La presencia de estos lagartos en sedimentos de similar antigüedad en Brasil y las diferentes hipótesis referidas a la filogenia de la familia Teiidae estarían indicando una temprana diferenciación del grupo en América del Sur. El género actual que primero aparece en el registro corresponde a Tupinambis, el cual se encuentra durante el Mioceno temprano a medio en territorios patagónicos donde actualmente no se distribuye. Si bien no es posible una asignación específica de estos materiales, se destaca el aumento de tamaño registrado en los fósiles desde el Mioceno temprano (Colhuehuapense) al Mioceno medio y tardío. En el Mioceno tardío se registra por primera vez en América del Sur un “cnemidoforino” (grupo hermano de los Tupinambinae), en la provincia de La Pampa, mientras que en el Mioceno tardío - Plioceno temprano de la provincia de Buenos Aires se registra un segundo género actual de Tupinambinae, representado por una especie extinta, Callopistes bicuspidatus. Este género actualmente se distribuye sólo al oeste de los Andes, por lo cual su presencia en la costa Atlántica bonaerense indica una larga y desconocida historia evolutiva al este de la cadena montañosa. El otro grupo representado en el registro fósil es el de los Amphisbaenia, que se registran por primera vez en el Plioceno temprano-medio de la provincia Buenos Aires.

Dado que Tupinambis es el género mejor representado en el registro fósil, se revisaron los parámetros ambientales de las dos especies que actualmente habitan en Argentina, T. merianane y T. rufescens, que son las de distribución más extrema. Las dos especies se distribuyen por encima de la isoterma de $14{ }^{\circ} \mathrm{C}$ mientras que responden diferencialmente a la humedad ambiental. Por un lado T. rufescens es una especie adaptada a ambientes xéricos que se distribuye entre las isohietas de 200 mm/año - $1000 \mathrm{~mm} / \mathrm{año,} \mathrm{mientras} \mathrm{que} \mathrm{T.} \mathrm{merianae} \mathrm{sólo} \mathrm{se} \mathrm{encuentra} \mathrm{en} \mathrm{ambientes}$ 
donde las precipitaciones superan los $600 \mathrm{~mm} / \mathrm{año}$. Estos valores límites permitieron una mejor aproximación a la evaluación paleoambiental de aquellos sitios en donde este género fue documentado, contrastando dicha evidencia con hipótesis de otras fuentes. El género Tupinambis presenta su máxima extensión geográfica en el Mioceno, donde se registra el Óptimo Climático del Cenozoico, ya que se lo encuentra en varias localidades patagónicas, llegando hasta una latitud de $50{ }^{\circ} \mathrm{S}$. La disminución de la temperatura y humedad ocurrida desde entonces habrían relegado la distribución del género al norte del Río Negro, quedando sólo una presencia relictual en la región patagónica, en el Gran Bajo del Gualicho (aprox. 40³0’ S). La trasgresión "Paranaense" habría sido la causa de la diferenciación por vicariancia del antecesor de T. rufescens $+T$. duseni y T. merianae. Los gradientes de precipitación media anual, ascendentes en sentido oeste-este, habrían profundizado la diferenciacón de T. rufescens y T. merianae en Argentina, de modo tal que la primera quedaría adaptada a condiciones más áridas que la segunda.

En suma, con una historia desarrollada desde el Mesozoico hasta nuestros días, los lagartos continentales no iguanios de nuestro país componen el registro más abundante y completo de lagartos fósiles sudamericanos. La marcada dominancia de la actual familia Teiidae se traduce en la posibilidad de evaluar restos fósiles de reptiles con una sólida base sustentada en el conocimiento de la osteología de las formas vivientes, de forma tal que hace posible limitar la nominación de nuevos taxa. Su evolución biogeográfica, dramáticamente influenciada por los cambios climáticos y ambientales de comienzos del Neógeno, adquiere fundamental importancia al momento de interpretar las filogenias moleculares, y al mismo tiempo, aportan información útil sobre la antigüedad mínima de sus componentes para utilizar como referencias en el reloj molecular. Al mismo tiempo, las controversiales relaciones filogenéticas entre los diferentes géneros de teidos demuestran la complejidad de estos análisis cuando el grupo de reptiles estudiado posee representantes vivientes. 


\begin{abstract}
The following dissertation represents an update of the known fossil record of the continental lizards of Argentina (except Iguania), where the identification of the fossil material was achieved following modern criteria within a cladistic framework, contrasting the fossils with abundant specimens of the group.

The dissertation presents a brief introduction to the systematic standing and phylogenetic relationships of the lizards, as well as an update of the known fossil record of the world and especially South America, and particularly those of Argentina. The main objective of this thesis can be summarized in the systematic study of the fossils of continental lizards (except Iguania) of Argentina under the phylogenetic considerations presented herein based exclusively on osteological characters. The phylogenetic analysis was conducted for the Teiidae family, which is the best represented in the fossil record. This phylogenetic analysis is followed by an interpretation of the biogeographic evolution of this family that takes into account past and present distributions, as well as the tectonic and climatic evolution of South America.

Because the majority of the fossil material studied corresponds to the family Teiidae, a succinct description of the skull of Tupinambis merianae is presented as a guide for the subsequent descriptions. Though this species is widely known and its osteology has been described, identifying structures previously not recognized. Particularly, the dentition of T. merianae is described. The dentition of the species has not been previously described in detail, regarding all its variation. This description was of fundamental importance in the interpretation of the fossil material. Dentition and postcranial differences of other Teiidae species were recognized.

The result of the paleontological systematics showed, in general, that the fossil record of the continental lizards of Argentina (except Iguania) dates back to the Late Cretaceous (Campanian) with important temporal hiatus (Oligocene, Pleistocene) where lizards are scarce or absent. These temporal hiatus are interspersed between periods where lizards are very abundant (e.g. Miocene). The fossil record previous to this thesis consisted of various genera and species described at the end of the XIX beginning of the XX centuries, and a few described more recently. In this study these materials are re-described. New material and fossils mentioned in the paleoherpetological without a proper description are also studied. All together this
\end{abstract}


revision resulted in a less diverse fossil record because much of the former genera and species were invalidated with sound morphological sustentation. In this way the genus Lumbrerasaurus Ameghino 1985 from the Eocene of northwest Argentina is invalidated and should be considered as an indeterminate Tupinambinae Teiidae. Likewise, the genera Diasemosaurus Ameghino 1893 and Dibolosodon Ameghino 1893 from the Miocene of southern Argentina are synonymized with the present-day genus Tupinambis, while their specific assignations remain undetermined. The extinct species of Tupinambis from the province of Buenos Aires T. teguixin Rovereto 1914, T. prerufescens Rovereto 1914, T. multidentatus Rovereto 1914 , T. brevirostris Rovereto 1914 y T. onyxodon Kraglievich 1947 were also reassigned to the genus Tupinambis sp.. In the same sense, the assignment to species of Tupinambis including those of arqueological sites were dismissed and considered as Tupinambis sp.. Contrary to the former cases, it was possible to validate the only extinct species of the genus Callopistes from the late Miocene - early Pliocene of Buenos Aires province, C. bicuspidatus chain 1976. In this case, the reevaluation of the fossil allowed the recognition of a taxonomic entity different from the two present-day species of the genus, although based on different characters from those consider by the original author.

The preponderance of the Teiidae in the fossil record merited the phylogenetic analysis of the family, contributing characters for a more adequate taxonomic determination of the fossils. The analysis confirmed the monophyly of the family, nevertheless the intergeneric relationships differed from that of other studies, particularly regarding the position of Teius: (Teius) ((Ameiva (Kentropyx + Cnemidophorus)) (Callopistes (Crocodilurus (Tupinambis (Dracaena + Paradracaena))))). The relation between the Tupinambinae differed from other osteological-based phylogenies in the close relationship of Dracaena and Tupinambis. The extinct taxon Paradracaena (Miocene of Colombia and Peru) emerged as valid from the analysis, closely related to Dracaena. The relationships among the different species of Tupinambis were not satisfactory resolved based only on osteological characters. Therefore the fossils of this genus remain indeterminated at the species level.

In short, all the taxa assessed in the fossil record correspond to one of the groups presently represented in the argentine herpetofauna, although there are families without fossil record (Gymnophthalmidae, Anguidae, Scincidae, 
Rhineuridae).The majority of the fossils correspond to the Scincomopha and in much lower number to the Amphisbaenia. Among the Scincomorpha, the Scleroglossa have their earliest presence in south America in the late Cretaceous of Río Negro province, with a putative Scincoidea. The Teiidae dominate the Cenozoic fossil record, particularly the Tupinambinae subfamily with the genus Tupinambis. This family dates back to the early Eocene of Salta province (previously Lumbrerasaurus). The presence of these lizards in sediments of similar age in Brazil, and the different phylogenetic hypothesis of the family indicate an early differentiation of the group in South America. The first extant genus to appear in the fossil record is Tupinambis. During the early-mid Miocene this genus is found in Patagonia where it currently does not inhabit. Though a specific assignation of these fossils was not possible, an increase in size from the early Miocene (Colhuehuapense) to the middle - late Miocene was noticed. In the late Miocene of La Pampa province the "cnemidophorine" (sister group to the Tupinambinae) appear for the first time in South America, whereas in the late Miocene - early Pliocene of Buenos Aires province, a second extant Tupinambinae genus is recorded, represented by the extinct species Callopistes bicuspidatus. The present-day distribution of Callopistes is restricted to the west of the Andes, therefore its presences in the Atlantic coast indicates a long and unknown history east of these mountains. The other groups with fossil representatives, Amphisbaenia, have their earliest appearance in the early middle Pliocene of Buenos Aires province.

Given that Tupinambis is the genus best represented in the fossil record, the environmental parameters of the two present-day species that inhabit Argentina, Tupinambis merianae and Tupinambis rufescens, were reviewed. Both species are found above the $14{ }^{\circ} \mathrm{C}$ isotherm, while they respond differently to humidity. Tupinambis rufescens, the more xeric-adapted species, is found between the precipitation lines of $200 \mathrm{~mm} /$ year - $1000 \mathrm{~mm} /$ year, while $T$. merianae is only found where precipitation exceeds $600 \mathrm{~mm} /$ year. These distributional limits allowed a more accurate environmental evaluation of those sites where this genus has been documented. These evaluations were contrasted with environmental hypothesis from other sources from the same sites. Tupinambis presents its maximum geographical distribution during the Miocene, during the Cenozoic Climatic Optimum, where it is found in different Patagonian localities, reaching latitudes of $50{ }^{\circ} \mathrm{S}$. The decline in temperature and humidity that occurred since is considered responsible for the retreat 
of the distribution of Tupinambis north of the Río Negro river. Only a relictual population if found south of the Negro river, at Gran Bajo del Gualicho (aprox. $\left.40^{\circ} 30^{\prime} \mathrm{S}\right)$. The "Paranaense" marine transgression is considered the cause of the differentiation of the ancestors of T. rufescens $+T$. duseni and T. merianae. The mean annual precipitation trend, rising from west to east, would have marked the differentiation of T. rufescens y T. merianae in Argentina, where T. rufescens is adapted to more arid environmental conditions than T. merianae.

With a history that dates back to the Cretaceous the continental non-iguanian lizards of Argentina constitute the most abundant and complete lizard fossil record of South America. The supremacy of the present-day Teiidae enables the possibility to evaluate the fossil lizard remains with a solid base in the osteology of the modern forms, limiting the nomination of new taxa. Their biogeographic evolution, dramatically influenced by the climatic and environmental changes at the beginning of the Neogene, acquires fundamental importance when interpreting molecular phylogenies and, at the same time, contributes important information for the calibration of the molecular clock. At the same time, the controversial phylogenetic relationships among the different Teiidae genera, exhibit the complexity of these analysis when the group of reptiles considered present living representatives. 


\section{CAPÍTULO I}

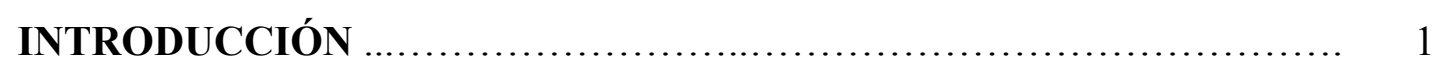

1. Marco sistemático y filogenia ............................................ 1

2. El registro fósil de lagartos .......................................... 7

3. El registro fósil de lagartos en América del Sur ............................ 10

4. Antecedentes sobre lagartos continentales fósiles (excepto iguania) de la

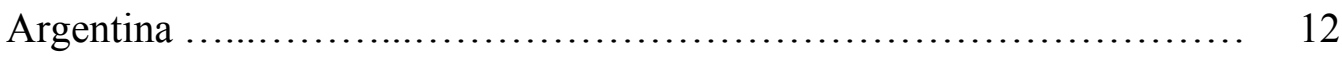

5. Adiciones al registro de lagartos continentales fósiles (excepto iguania)

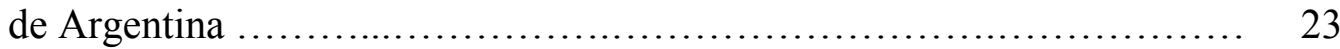

6. Objetivos ....................................................... 25

6.1. Objetivo General ............................................ 25

6.2. Objetivos Particulares ............................................. 26

\section{CAPÍTULO II}

MATERIALES Y MÉTODOS E........................................ 28

1. Materiales ..................................................... 28

1.1. Material fósil ................................................. 28

1.2. Material actual ................................................. 31

2. Métodos....................................................... 36

2.1. Preparación técnica del material ............................... 36

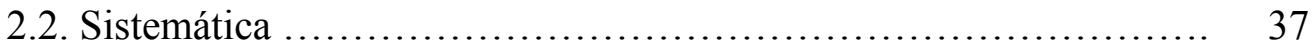

2.3. Análisis morfológico ........................................... 41

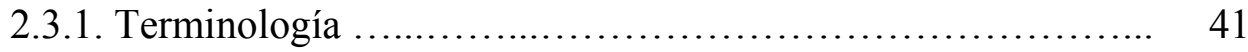

2.3.2. Abreviaturas ............................................ 43

2.4. Análisis filogenético ....................................... 48

2.5. Escala temporal y orden de presentación de los materiales estudiados 


\section{CAPÍTULO III}

\section{ESQUELETO CRANEAL, DENTICIÓN Y ESQUELETO AXIAL DE}

TUPINAMBIS MERIANAE ......................................... 52

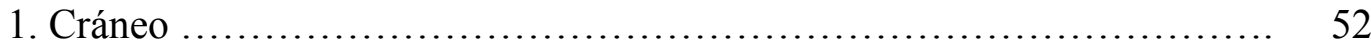

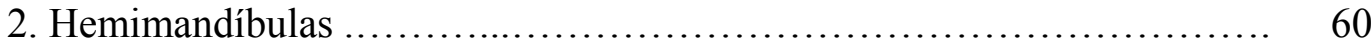

3. Dentición ....................................................... 62

3.1. Dentición en los Teiidae ....................................... 67

3.2. Tipos morfológicos dentales en T. merianae ........................ 69

3.3. Distribución de los tipos morfológicos dentales en T. merianae ..... 73

3.4. Dentición en las especies de Tupinambis ........................ 79

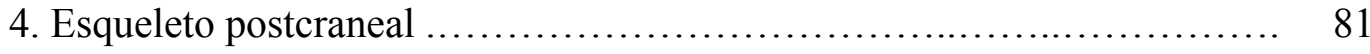

\section{CAPÍTULO IV}

DESCRIPCIONES SISTEMÁTICAS ................................. 83

1. Mesozoico ............................................................ 83

1.1. Formación Anacleto ........................................ 83

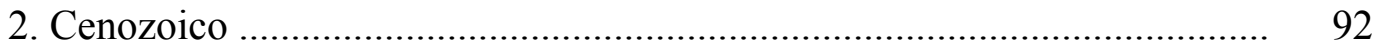

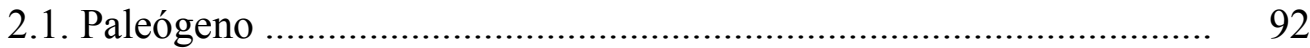

2.1.1. Formación Lumbrera .......................................................... 92

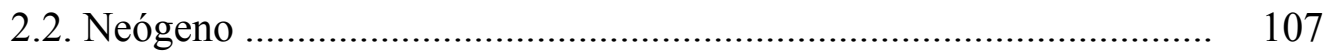

2.2.1. Formación Sarmiento ............................................................... 107

2.2.2. Formación Santa Cruz …................................................... 116

2.2.3. Formación Collón Cura ................................. 125

2.2.4. Formación Cerro Azul ............................................................ 133

2.2.5. Formación La Playa ............................................................... $\quad 150$

2.2.6. Formación Monte Hermoso …................................................ 156

2.2.7. "Formación” Chapadmalal ....................................................... 243

2.2.8. "Formación" Vorohué ........................................................... 256

2.2.9. Las Grutas - Punta Negra, Necochea ............................. 261

3. SITIOS ARQUEOLÓGICOS ..................................... 266

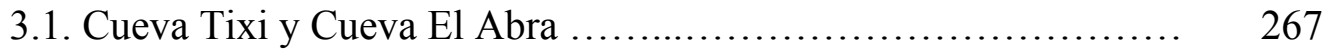




\section{CAPÍTULO V}

ANÁLISIS FILOGENÉTICO DE LA FAMILIA TEIIDAE .............. 281

1. Antecedentes ................................................. 281

2. Análisis filogenético ............................................ 293

2.1. Taxones …............................................... 293

2.2. Caracteres .................................................. 293

2.2.2. Análisis de los caracteres ................................ 294

Cráneo ................................................. 295

Hemimandíbula ....................................... 308

Dentición ............................................... 314

Aparato hioideo ............................................ 316

Esqueleto postcraneal ................................. 316

3. Descripción de la corrida ........................................ 320

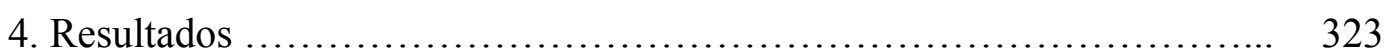

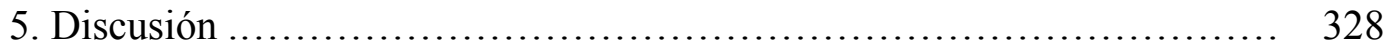

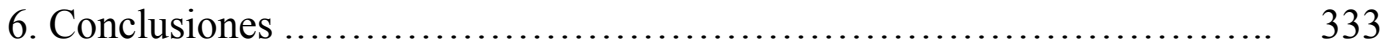

\section{CAPÍTULO VI}

EVOLUCIÓN BIOGEOGRÁFICA DE LOS TEIDOS ........................... 335

1. Introducción .................................................... 335

2. Parámetros climáticos y ambientales de la distribución de Tupinambis en

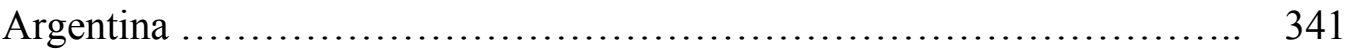

3. Distribución de las diferentes especies de Tupinambis en América del Sur 342

4. Distribución actual de Tupinambis en Argentina ......................... 345

5. Parámetros ambientales ............................................. 348

6. Historia evolutiva y biogeográfica de Tupinambis ........................ 350 


\section{CAPÍTULO VII}

CONCLUSIONES FINALES

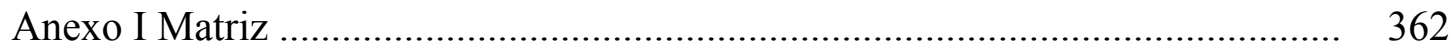

Anexo II Sinapomorfías del Consenso Estricto ........................... 368

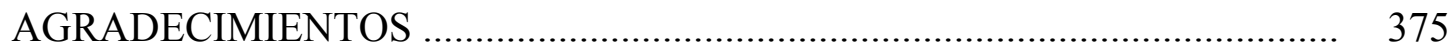

REFERENENCIAS BIBLIOGRÁFICAS _.................................................... 377 


\section{CAPÍTULO I}

\section{INTRODUCCIÓN}

\section{MARCO SISTEMÁTICO Y FILOGENIA}

Los Lepidosauria (lepidosaurios) constituyen el grupo dominante de reptiles actuales sin considerar a las aves, incluyendo aproximadamente 8000 especies (Vidal y Hedges, 2005). La primer gran dicotomía dentro de los Lepidosauria se produce entre Rhynchocephalia (esfenodontes) y Squamata (escamosos). Estos últimos comprenden a la casi totalidad de las especies actuales de lepidosaurios con la excepción de las dos únicas especies de esfenodontes (Sphenodon punctatus y Sphenodon guntheri) (Zug, 1993; Pough et al., 1998; Zug et al., 2001; Evans, 2003).

La clasificación tradicional (e.g. Romer, 1956) considera dentro de los escamosos a dos grupos principales: Lacertilia o Sauria (lagartos y anfisbenios) y Ophidia o Serpentes (serpientes). El reconocimiento de un grupo morfológicamente distinto, los Amphisbaenia (anfisbenios), aportó una mayor resolución a la clasificación de los escamosos (Gans, 1978). Sin embargo, la idea de que los Lacertilia por sí solos constituyen un grupo monofilético ha sido abandonada recién hace un par de décadas, cuando los análisis cladísticos demostraron su parafilia (e.g. Estes et al., 1988). Es unánimemente aceptado que serpientes y anfisbenios, que sí constituyen grupos naturales, están anidados dentro de los lagartos (Estes et al., 1988; Lee, 1998; Evans, 2003; Townsend et al., 2004; Vidal y Hedges, 2005; Fry et al., 2006). En el presente trabajo, se considera, en el uso informal, la acepción más amplia y tradicional del término, excluyendo a las serpientes pero incluyendo a los anfisbenios (Bellairs, 1957; Romer, 1956), debido a que estos últimos aún son clasificados junto con los lagartos en textos de extendido uso universitario (e.g. Carroll, 1997). No obstante, se destaca que el término "lagarto" no se refiere a un grupo natural.

Desde el punto de vista formal, Squamata se define como el grupo que incluye al más reciente antecesor común de Iguania (iguanios) y Scleroglossa (escleroglosos) 
y a todos sus descendientes, y se diagnostica por una importante cantidad de caracteres derivados en común (véase Evans, 2003). Los trabajos filogenéticos basados en osteología y el registro paleontológico conocido sugieren que esta dicotomía basal entre iguanios y escleroglosos ocurrió antes del Jurásico (Evans, 2003) (Fig. 1), lo cual implica que estos dos clados llevan evolucionando independientemente 200 MA como mínimo (Fig. 1), un tiempo similar al transcurrido entre mamíferos monotremas y placentarios (Evans, 2003). No obstante, dicho esquema no es reconocido por trabajos filogenéticos recientes basados en datos moleculares (Townsend et al., 2004; Vidal y Hedges, 2005; Fry et al., 2006) (Fig. 2 C), donde se rechaza la monofilia de los Scleroglossa, a pesar que está claramente sustentada por datos morfológicos con varias sinapomorfías (e.g. Estes et al., 1988; Lee, 1998).

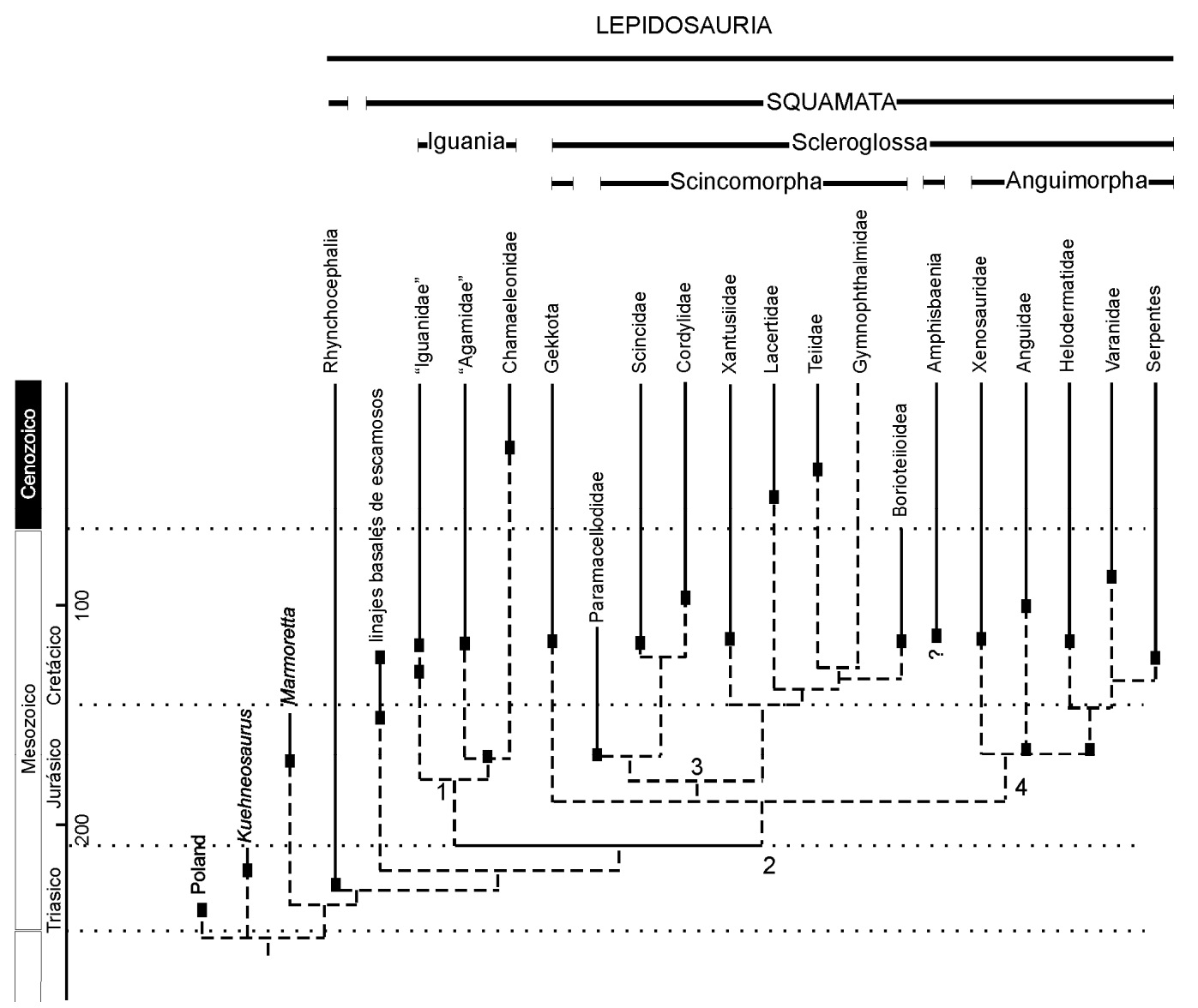

Figura 1. Cladograma de los principales linajes de lepidosaurios. Los puntos indican primeras apariciones en el registro fósil. Las líneas punteadas corresponden a la estimación mínima de extensión de los linajes. La línea sólida horizontal indica el momento de divergencia entre Iguania y Scleroglossa. (1) Iguania; (2) Scleroglossa; (3) Scincomorpha; (4) Anguimorpha. Modificado de Evans (2003). 
Siguiendo a Estes et al. (1988), los Scleroglossa se dividen en tres linajes principales: Gekkota, Scincomorpha y Anguimorpha (Fig. 2 A). Evans (2003) resume claramente los principales puntos en común entre el trabajo de Estes et al. (1988) y trabajos posteriores (e.g. Lee, 1998) (Fig. 2 A y B). De esta manera, es posible reconocer la monofilia de Iguania, Gekkota y Anguimorpha y la ubicación de Serpentes dentro de los Scleroglossa. Evans (2003) también advierte que los principales puntos conflictivos entre estos trabajos son: (1) las relaciones entre los tres grupos principales de Scleroglossa (Gekkota, Scincomorpha y Anguimorpha); (2) las relaciones entre los grupos que integran los Scincomorpha; y (3) la posición de Amphisbaenia y los supuestamente relacionados Dibamidae. Más recientemente, Conrad (2008), sobre la base de caractres osteológicos y una importante cantidad de taxones analizados llega a conclusiones algo diferentes. 


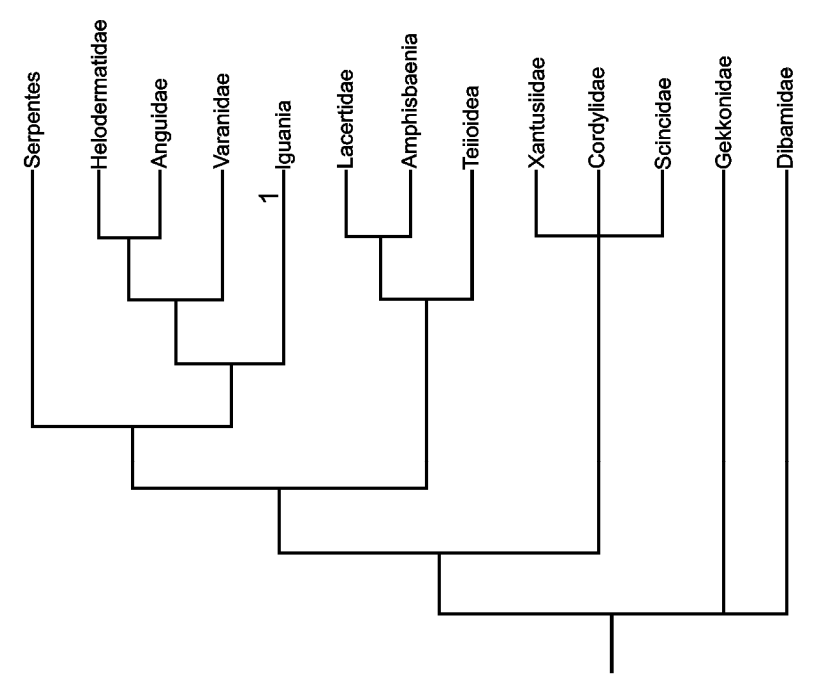

?
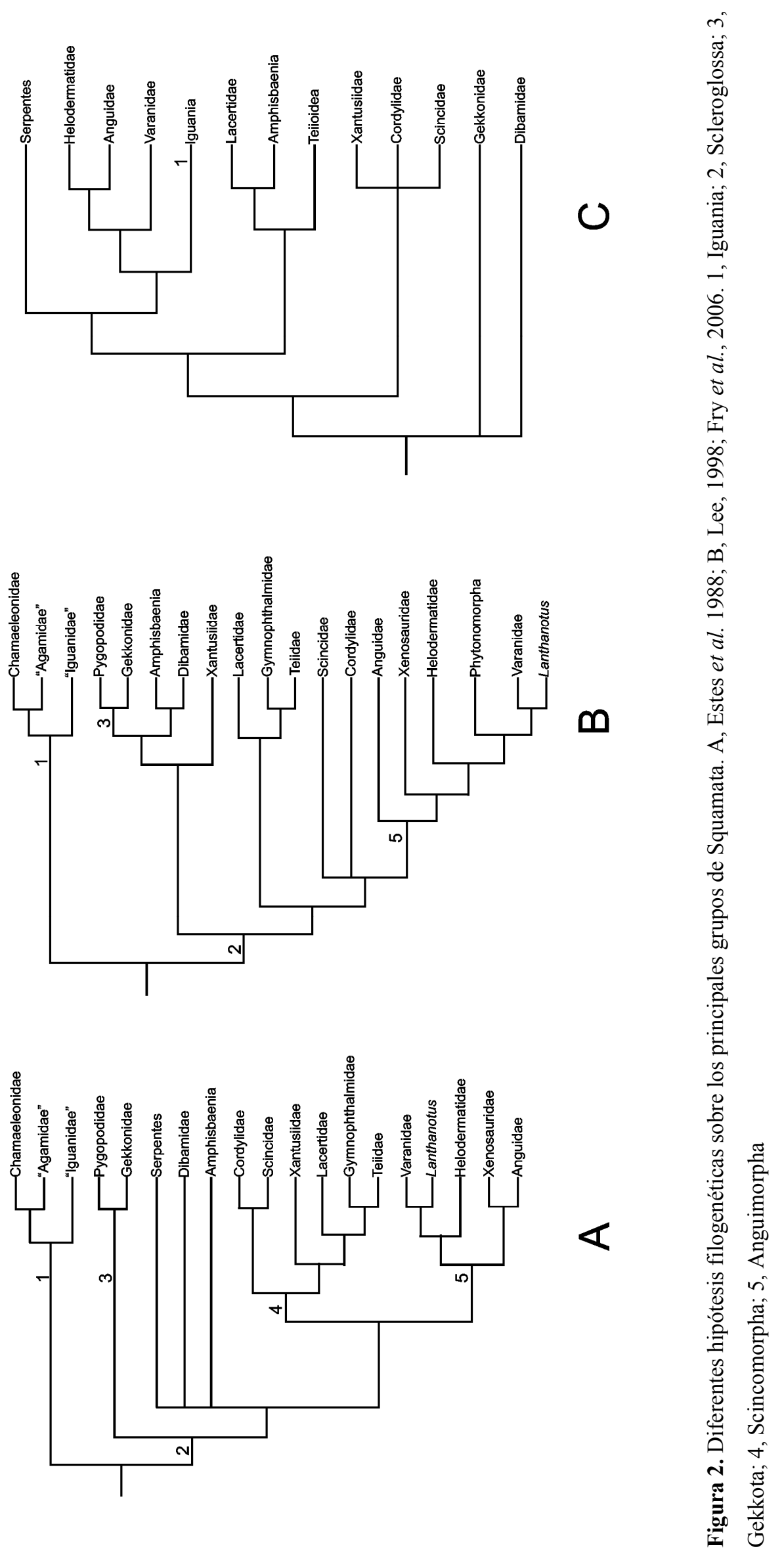
En este trabajo se sigue la propuesta de Estes et al. (1988) (Fig. 2 A), cuyos datos han sido utilizado, en mayor o menor medida, por la totalidad de los trabajos posteriores (ver Conrad, 2008), y se asumen las sinapomorfías para cada uno de los grupos de lagartos presentadas en dicha publicación. Sólo se consideran aquellos grupos de lagartos no iguanios de Argentina que tienen hábitos continentales, quedando excluidos, por lo tanto, los Mosasauroidea (Anguimorpha). La clasificación de los lagartos Scleroglossa (i.e. no iguanios) se presenta en la Tabla 1.

\section{SCLEROGLOSSA}

Dibamidae sedis mutabilis

Amphisbaenia sedis mutabilis

Gekkota

Autarchoglossa

Gekkonidae*

Pygopodidae

Scincomorpha

Lacertoidea

Xantusiidae

Lacertiformes

Lacertidae

Teiioidea

Teiidae

Scincoidea

Gymnophthalmidae

Scincidae

Cordylidae

Anguimorpha

Anguidae

Xenosauridae

Varanoidea

Tabla 1. Clasificación de los lagartos Scleroglossa sensu Estes et al. (1988). El asterisco (*) indica metataxón 
Estes et al. (1988) reconocen 27 sinapomorfías para Scleroglossa, las cuales presentan en algunos casos reversiones (entre los escleroglosos) y convergencias (con iguanios). Las principales sinapomorfías osteológicas de los mayores taxones de Scleroglossa son:

El clado Gekkota se caracteriza por 46 sinapomorfías (Estes et al., 1988), entre las que se destacan: (1) fusión ontogenética de los frontales; (2) unión ventromedial de los procesos ventrales del frontal formando un tubo olfatorio; (3) ausencia del postorbital y arco supratemporal; (4) ausencia del foramen parietal; (5) pérdida del lacrimal; (6) reducción o pérdida del yugal; (7) el epipterigoides apoya sobre el proceso alar del proótico; (8) la crista prootica se extiende sobre el proceso basipterigoideo, entubando a la vena lateral del cráneo; (9) cóndilo occipital bipartito; (10) canal de Meckel cerrado y fusionado; (11) esplenial reducido, de modo que no supera el nivel medio de la serie dentaria o está ausente; (12) proceso retroarticular inflexionado medialmente; (13) proceso retroarticular con muesca medial; (14) proceso retroarticular expandido distalmente; (15) ausencia de dientes pterigoideos; (16) el canal de la notocorda persiste en el centro vertebral de los adultos; (17) vértebra anficélicas y procélicas; (17) huesos postcloacales.

Los Scincomorpha presentan nueve sinapomorfías, de las cuales sólo cinco son osteológicas (Estes et al., 1988): (1) ausencia de contacto nasal-prefrontal; (2) procesos descendentes del parietal desarrollados; (3) proceso anterolateral del coronoides solapado anteriormente por el dentario; (4) pubis largo en vista ventral, con el proceso sinfisial elongado y anteriormente dispuesto; (5) rugosidades dérmicas presentes.

Estes et al. (1988) listan 22 sinapomorfías para los Anguimorpha, entre las que se destacan: (1) presencia de palpebrales; (2) septo intermadibular bien desarrollado, dividiendo posteriormente el canal de Meckel; (3) el canal de Meckel se abre ventralmente por delante del foramen de ingreso al canal alveolar inferior; (4) presencia de una muesca suprangular en el borde posterolateral del dentario; (5) reemplazo dental posterior al diente funcional, con una pequeña zona de reabsorción.

Los Amphisbaenia son formas alargadas, ápodas (excepto Bipes), de cola corta, con el cráneo compacto; todas modificaciones asociadas a la vida fosorial. Estes et al. (1988) reconocen 42 sinapomorfías para este grupo de escamosos, entre las cuales se destacan: (1) contacto prefrontal-postfrontal; (2) unión ventromedial de los procesos ventrales del frontal en un tubo olfatorio; (3) pérdida del supratemporal; (4) 
epipterigoides reducido o ausente; (5) cráneo muy sólido, con suturas muy interdigitadas; (6) diente premaxilar medio muy desarrollado; (7) neurocráneo anteriormente osificado; (8) fenestra ovalis grande, lateroventralmente dispuesta; (9) reducción y pérdida del esplenial; (10) ausencia de dientes pterigoideos; (11) reemplazo dental posterolingual al diente funcional; (12) vértebra caudal con dos pares convergentes de procesos transversos.

\section{EL REGISTRO FÓSIL DE LOS LAGARTOS}

Como se advierte en las líneas previas, los lagartos constituyen un grupo parafilético de reptiles escamosos sumamente diverso y abundante en la actualidad. Conocidos desde el Jurásico (Evans, 2003), han logrado sobrevivir a la gran extinción de fines del Cretácico para diversificarse ampliamente y conquistar los ambientes más disímiles. El gran éxito actual de estos animales se contrapone con su fragmentario y limitado registro fósil; a pesar de ello, este registro ha permitido conocer más claramente la historia de las diversas formas de lagartos actuales. Excepto por los mosasaurios (lagartos marinos del Mesozoico), que son de grandes dimensiones, los lagartos son animales generalmente pequeños, cuya longitud y masa están por debajo de los $300 \mathrm{~mm}$ y 100 gr respectivamente (Zug, 1993). Su delicada constitución osteológica (e.g. cráneo muy fenestrado y cinético, ausencia de paladar secundario, etc.) implica que su registro fósil esté compuesto principalmente por pequeños huesos aislados, a menudo fragmentarios. Muchas veces estos fragmentos son poco diagnósticos, lo que conlleva a una baja resolución sistemática. En consecuencia, el registro fósil de lagartos presenta poca diversidad en relación con los lagartos vivientes (Albino, 1996a).

A pesar que su grupo hermano, los Rhynchocephalia, se registran desde el Triásico, no existe registro de Squamata en ese período. Esta ausencia es considerada como un artefacto de muestreo y preservación (Evans, 2003) ya que los registros más antiguos de Squamata corresponden a integrantes de los dos clados principales (Iguania y Scleroglossa). En el Jurásico temprano-medio de la India se registran iguanios pleurodontes (indeterminados) y acrodontes (Bharatagama) (Evans et al., 2002), mientras que para el Jurásico medio de Inglaterra se conocen 5-7 taxones de Scleroglossa entre los que se distinguen Scincomorpha (e.g. Bellairsia, Balnealacerta), Anguimorpha (e.g. Parviraptor) y, con menos certeza, Gekkota (ver 
referencias en Evans, 2003). Squamata basales se registran más recientemente. Los más conocidos de estos lagartos provienen del Jurásico tardío de Alemania (Bavarisaurus, Eichstaettisaurus y Ardeosaurus) y del Cretácico temprano de España (Hoyalacerta, Scandensia) y México (Huehuecuetzpalli, Tepexisaurus) (Evans y Baradillo, 1997; Reynoso, 1998; Reynoso y Callison, 2000; Evans, 2003). Formas aparentemente basales también se registran en el Cretácico de Brasil (ver sección 3).

Los Iguania, presentes desde el Jurásico, están ampliamente representados en el Cretácico superior de Laurasia (ver referencias en Evans, 2003). Los registros más tempranos de estos lagartos corresponden a los del Aptiano-Albiano de Mongolia (Alifanov, 1993) y Asia central (Gao y Nessov, 1998). En América del Sur se encuentran a partir del Cretácico tardío (Pristiguana y un "Iguanidae" indeterminado), como se verá más adelante (sección 3 ).

El primer registro fehaciente de Gekkota, según Evans (2003), sería Hoburogeckko (Alifanov, 1989) del Aptiano-Albiano de Mongolia. Un conjunto de géneros provenientes del Jurásico (Titoniano) de Alemania son excluidos de Gekkota por esta autora (contra Hoffstetter, 1962 y Estes, 1983a, b). Este grupo se registra en América del Sur por primera vez en el Eoceno (Carvalho, 2001).

Los Scincomorpha son los lagartos mejor representados en el Mesozoico. Entre ellos, se destacan dos clados extintos, los Paramacellodidae y los Borioteiioidea (Fig. 1). Los Paramacellodidae, considerados grupo hermano de los Scincoidea (Evans y Chure, 1998), se encuentran en el registro desde el Jurásico medio hasta el Cretácico inferior, y tendrían una distribución gondwánica. Los Borioteiioidea, recientemente escindidos de los Teiioidea (Nydam et al., 2007), se registran en el Cretácico de Laurasia. Otros Scincomorpha del Cretácico han sido referidos a clados con representantes actuales. Meyasaurus es considerado basal al clado BorioteiioideaTeiioidea, mientras que Cuencasaurus es considerado un posible Scincidae (Richter, 1994; Evans y Baradillo, 1997). Los primeros registros de las familias actuales Cordylidae, Scincidae y Xantusiidae ocurren en el Cretácico tardío de Laurasia (Estes, 1983a; Alifanov, 1992, 1993; Gao y Fox, 1996). Los representantes actuales de los Lacertoidea se encuentran en sedimentos a partir del Cenozoico; Lacertidae desde el Plioceno de Europa (e.g. Plesiolacerta, Eolacerta) (Estes, 1983b), y Teiidae desde el Eoceno de América del Sur (Carvalho, 2001), mientras que los Gymnophthalmidae carecen de registro fósil. 
Parviraptor y Changetisaurus, Anguimorpha de afinidad incierta, se registran en Laurasia desde el Jurásico al Cretácico temprano (Nydam y Cifelli, 2002a; Evans, 2003). El primer registro de una familia actual de Anguimorpha corresponde a Primaderma (Monstersauria) del Cretácico medio de América del Norte (Nydam, 2000). Las restantes familias Anguidae, Varanidae y Xenosauridae también aparecen por primera vez en el Cretácico de América del Norte (Gao y Fox, 1996; Alifanov, 2000; Nydam y Cifelli, 2002a). En América del Sur el registro de estos lagartos es mínimo, estando solamente compuesto por dos taxones indeterminados del Eoceno de Brasil (Carvalho, 2001).

El lagarto fosorial Sineoamphisbaena (Wu et al., 1993), del Cretácico de Asia, es considerado un Amphisbaenia, o al menos muy relacionado a este grupo de lagartos. Como se mencionó anteriormente (sección 1), la relación de los Amphisbaenia entre los Squamata no ha sido resuelta, por lo cual esta incertidumbre complica la posición filogenética de este fósil. Wu et al. (1996) lo incluyen entre los Amphisbaenia vivientes a los que consideran como grupo hermano de los Borioteiioidea asiáticos y a este último como clado hermano de los restantes Lacertiformes. Otros autores consideran a Sineoamphisbaena basal al clado Amphisbaenia-Dibamidae (Lee, 1998) o al clado Amphisbaenia-Dibamidae-Serpentes (Rieppel y Zaher, 2000). Contrariamente Conrad (2008) ubican a este taxón entre los Borioteiioidea (dados como Polyglyphanodontidae) por fuera de los Amphisbaenia. Los pocos registros adicionales del Mesozoico referidos a Amphisbaenia son fragmentarios o permanecen indeterminados (Wu et al., 1996). En el Cenozoico, el registro es más rico particularmente en América del Norte (Estes, 1983a), mientras que en América del Sur es muy pobre, remontándose al Plioceno (Donadío, 1982) o posiblemente al Mioceno (Hsiou et al., 2007). Los Dibamidae carecen de registro fósil (Estes, 1983a).

El evidente sesgo geográfico del registro fósil temprano de los Squamata, con muy pocos datos de Gondwana, se mantiene, aunque menos marcado, en el Cenozoico. Aún así, se puede apreciar que los dos principales grupos de lagartos vivientes, Iguania y Scleroglossa, aparecen tempranamente en el registro fósil, mientras que lagartos morfológicamente más basales lo hacen posteriormente. En el Jurásico ya se encuentran diferenciados los principales linajes de Squamata y para el Cretácico tardío ya se han originado la mayoría de las familias actuales (Fig. 1), indicando que la larga y antigua historia evolutiva del grupo permanece aún si 
elucidar y cuyo origen debe buscarse en el Triásico. Actualmente, la fauna de lagartos en América del Sur está integrada por los principales clados de Squamata: Iguania ("Iguanidae"), Gekkota (Gekkonidae), Anguimorpha (Anguidae), Scincomorpha (Scincidae, Gymnophthalmidae y Teiidae) y Amphisbaenia (Amphisbaenidae y Rhineuridae) (Cei, 1986, 1993; Zug, 1993; Pough et al., 1998; Zug et al., 2001).

\section{EL REGISTRO FÓSIL DE LAGARTOS EN AMÉRICA DEL SUR}

En América del Sur, los lagartos continentales del Mesozoico están representados por unos pocos registros del Cretácico, ya que restos del Jurásico no pudieron ser corroborados como pertenecientes a lagartos (véase punto 4). Los restos más completos provienen de Brasil (Estes y Price, 1973; Bonfim Jr. y Marques, 1997; Evans y Yabumoto, 1998; Candeiro, 2007), incluyendo formas basales de inciertas relaciones filogenéticas; mientras que en Argentina sólo se ha descripto formalmente un único fragmento asignado a los "Iguanidae" (Apesteguía et al., 2005; Albino, 2007; de la Fuente et al. 2007), aunque informalmente se han citado otras presencias tanto en Argentina como en Chile (Gayet et al., 1992; Albino, 2002a, 2007).

El registro de lagartos del Cenozoico de América del Sur se caracteriza por ser escaso en el Paleógeno y mucho más abundante en el Neógeno. Tradicionalmente, la distribución de los vertebrados durante el Cenozoico ha respondido a un esquema bioestratigráfico conocido como "Edades Mamífero", actualmente puesto en discusión (Cione et al., 2007). Como los restos de lagartos son habitualmente hallados en niveles ricos en fauna mamaliana referida a alguna Edad Mamífero en particular, los registros conocidos de lagartos para las diversas épocas geológicas responden a este esquema. Así, de acuerdo a las más recientes calibraciones de las Edades Mamífero del Paleógeno sudamericano (Vucetich et al., 2007; Gelfo et al., 2009) se ha modificado el registro conocido. Teniendo en cuenta ésto, se puede reportar la presencia de lagartos (Iguania) en un único sitio del Paleoceno sudamericano (Tiupampa, Bolivia) cuya fauna de mamíferos corresponde al Tiupampense (Muizon et al., 1983; Rage, 1992; Albino; 1996a). Para el Eoceno, en cambio, se pueden mencionar registros en Argentina (Donadío, 1985) y en Brasil (Estes, 1970, 1983a; Donadío, 1985; Báez y Gasparini, 1977, 1979; Albino; 1996a; Carvalho y Zaher, 1998; Carvalho, 2001). Los únicos dados a conocer formalmente son los procedentes de Argentina (Teiidae, Donadío, 1985), mientras que los de Brasil (Itaboraiense) muestran una importante diversidad de géneros y especies indeterminados de Iguania, 
Gekkonidae, Scincomorpha, Teiidae y Anguimorpha (Carvalho, 2001). El Oligoceno no ha aportado todavía ningún resto de lagarto en todo el continente sudamericano. Esta situación cambia sustancialmente para el Neógeno, donde se cuenta con un importante número citas y descripciones de lagartos continentales procedentes del Mioceno de Argentina, Brasil y Colombia (Gasparini y Báez, 1975; Báez y Gasparini, 1977, 1979; Estes, 1961, 1983a; Gasparini et al., 1986; Albino, 1996a; Sullivan y Estes, 1997; Hsiou et al., 2007). La fauna miocénica se caracteriza por presentar los primeros registros de géneros actuales de Iguania y Teiidae (Sullivan y Estes, 1997; Brizuela y Albino, 2004; Albino, 1998, 2008; Albino y Etheridge, 2000) y varios géneros extintos de Teiidae (Ameghino, 1893, 1899; Gasparini y Báez, 1975; Báez y Gasparini, 1977, 1979; Estes, 1983a; Gasparini et al., 1986; Donadío, 1984a; Sullivan y Estes, 1997; Pujos et al., 2009), entre los cuales algunos fueron considerados nomina dubia (véase punto 4).

En el Mioceno-Plioceno y Plioceno sudamericano se registran escasos iguanios mientras que los escleroglosos están representados exclusivamente por géneros vivientes de Teiidae, restringidos a Argentina (Rovereto, 1914; Reig, 1958; Kraglievich, 1947, 1947; Chani, 1976; Donadío, 1983b; Donadío, 1984b; Albino et $a l ., 2009)$. Se destaca también que para el Plioceno sudamericano se reportan los más antiguos restos de anfisbenios (Donadío, 1982).

El Cuaternario se caracteriza por un registro geográficamente más amplio. Los iguanios se han citado para el Pleistoceno de Ecuador y Argentina (Hoffstteter, 1970; Albino y Brizuela, en prensa); mientras que los escleroglosos están muy bien representados a nivel continental, en Bolivia, Brasil, Uruguay, Ecuador y Argentina (Hoffstteter, 1963, 1968, 1970; Estes, 1983a; Ubilla y Perea, 1999; Camolez, 2006; Hsiou, 2007; véase sección 4), principalmente a través de la familia Teiidae. Se reconoce también la presencia de géneros actuales de anfisbenios en Argentina, Bolivia y Brasil (Hoffstetter, 1968; Donadío, 1982; Gans y Montero, 1998; Torres y Montero, 1998a, b; Camolez, 2006; Scanferla et al., 2006). Camolez (2006) destaca la presencia de Anguimorpha en el Pleistoceno de Brasil. El Pleistoceno-Holoceno presenta registros de iguanios en Argentina, además de escleroglosos de la familia Gekkonidae y Teiidae (Albino, 2005). A éstos se agregan otros registros holocenos, particularmente aquellos de sitios arqueológicos de Chile, Brasil y Argentina, donde se registran principalmente Iguania, Teiidae, Amphisbaenidae y Scincidae (véase Albino y Albino, 2004; Núñez et al., 2005; Camolez et al., 2005). 


\section{ANTECEDENTES SOBRE LAGARTOS CONTINENTALES FÓSILES (EXCEPTO IGUANIA) DE LA ARGENTINA. (Tabla 2)}

Las primeras referencias sobre lagartos continentales fósiles del territorio argentino aparecen en la literatura paleontológica de fines del siglo XIX (Ambrosetti, 1890; Ameghino, 1893, 1898, 1899). Desde entonces, se han ido acumulando diferentes citas y descripciones aisladas (e.g. Rovereto, 1914; Kraglievich, 1947). No fue sino hasta la revisión de la herpetofauna Terciaria de la Argentina realizada por Gasparini y Báez (1975) que el registro fósil de este grupo fue documentado sistemáticamente y en su totalidad. Posteriormente, estas autoras revisaron y ampliaron los registros de América del Sur (Báez y Gasparini, 1977, 1979). Una década después del trabajo de Gasparini y Báez (1975), Gasparini et al. (1986) efectuaron una nueva revisión del registro Cenozoico argentino, con la incorporación de hallazgos más recientes. Durante la década de los ochenta, Donadío contribuyó a la paleontología de los lagartos continentales con la incorporación de varias citas y descripciones nuevas (1983a, 1983b, 1984a, 1984b, 1985). Más recientemente, Albino (1996a, 2007) realizó una síntesis del registro fósil de los lepidosaurios de América del Sur y contribuyó al conocimiento de los lagartos fósiles sudamericanos con varios trabajos (Albino, 1998, 2002a, 2002b, 2005, 2007, 2008; Albino y Etheridge, 2000; Albino y Kligmann, 2007, en prensa; Brizuela y Albino, 2004; de la Fuente et al., 2007; Pujos et al., 2009). A pesar de estos valiosos aportes, el registro fósil de lagartos continentales de América del Sur y, en particular, de Argentina, sigue siendo pobre y fragmentario (Albino, 1996a, 2007), en especial si se lo compara con el del hemisferio norte (Evans, 2003). Son aún válidas las consideraciones sobre la herpetofauna fósil sudamericana realizadas por Báez y Gasparini (1977:

151): "Distintos hechos han contribuido a que dicho aporte fuera escaso en muchas oportunidades, quedando aún sin dilucidar numerosos problemas planteados en la historia de la herpetofauna de ese continente. A pesar que las menciones de anfibios y reptiles fósiles en la literatura son abundantes, con frecuencia sólo se trata de fragmentos difíciles o imposible de ubicar taxonómicamente. En muchos casos el material permanece todavía sin ser estudiado, y en otros los restos fueron coleccionados y descriptos a fines del siglo pasado, a veces con criterios muy diferentes a los actuales, lo que hace necesaria su revisión. A diferencia de lo ocurrido con los mamíferos, prácticamente no se han efectuado búsquedas 
sistemáticas de aquellos grupos, siendo su registro muy incompleto hasta el momento”. A este escenario se agrega, como ya reconocía Reig (1958: 258) al referirse a materiales de lagartos fósiles, que "no es posible, por el momento, una referencia específica precisa, pues no se cuenta con datos adecuados sobre la osteología de las especies vivientes".

Los materiales referidos a lagartos más antiguos de la Argentina son los publicados por Casamiquela $(1962,1975,1980)$. Sin embargo, Neorotodactylus leonardii (Casamiquela 1962, 1980) y Protolacerta patagonica (Casamiquela 1975) fueron removidos de los escamosos por Estes (1983a). N. leonardii, una pequeña pisada en relieve de un tetrápodo pentadáctilo de la Fm. Piedra Pintada (Jurásico inferior) de Neuquén, no presenta evidencias claras de pertenecer a un escamoso (Estes, 1983a). Estes (1983a) considera a P. patagonica, de la Fm. Roca Blanca (Jurásico inferior), de la provincia de Santa Cruz, como nomen dubium por estar compuesto de elementos de un pez y un tetrápodo indeterminado y no poseer caracteres comparables con los de los escamosos (Estes, 1983a). Por lo tanto, no existe registro fósil de lagartos para el Jurásico de la Argentina.

Huene (1931) describió una mandíbula del Cretácico inferior de la provincia de Jujuy (Grupo Salta, Subgrupo Piragua) y nominó el nuevo género de lagarto Dicarlesia incognita. Actualmente este material está perdido. Estes (1983a) señala que de la ilustración de Huene (1931) se infiere que se trataría de un pez, motivo por el cual considera a $D$. incognita como nomen dubium.

Albino (2002a) cita el primer registro fehaciente de un lagarto no iguanio del Mesozoico de Argentina. Se trata de un pequeña mandíbula con dientes procedente de sedimentitas de la Fm. Anacleto (Campaniano) aflorantes en la provincia de Río Negro (Fig. 3 A). El dentario presenta características similares a Pristiguana brasiliensis Estes y Price, 1973 del Cretácico de Brasil (Albino, 2002a, 2007; de la Fuente et al., 2007). No obstante, la asignación sistemática de Pristiguana es controversial, presentando caracteres afines a Iguania y a Scincomorpha de la familia Teiidae (Estes y Price, 1973).

El registro del Paleógeno de Argentina es muy escaso, ya que se carece de hallazgos para el Paleoceno y Oligoceno. Donadío (1985) describió y nominó un nuevo lagarto de la familia Teiidae (Scincomorpha) como Lumbrerasaurus scagliai sobre la base de un conjunto de elementos craneales y postcraneales asociados procedentes de la Fm. Lumbrera (Eoceno temprano) de la provincia de Salta (Fig. 3 
A). Sullivan y Estes (1997) consideraron que este taxón, establecido sobre la base de la sección de los dientes y variaciones vertebrales, está inadecuadamente diagnosticado por lo que lo consideran un nomen dubium.

Como se mencionó anteriormente, el Neógeno se caracteriza por un registro mucho más rico, especialmente en el Mioceno. Gasparini et al. (1986) mencionaron la existencia en niveles del Miembro Trelew de la Fm. Sarmiento (Colhuehuapense, Mioceno temprano) de la localidad de Gaiman, provincia de Chubut, un conjunto de fósiles de la familia Teiidae, entre los cuales estaría presente el extinto Diasemosaurus sp., el actual Tupinambis sp. y nuevos taxones. Brizuela y Albino (2004) sólo reconocieron al género Tupinambis entre estos materiales, constituyéndose éste en el registro más antiguo de un género actual de teido en territorio sudamericano. Tupinambis está presente abundantemente en el registro fósil argentino (Fig. 3).

Ameghino (1893) describió escuetamente dos taxones fósiles de lagartos de la Fm. Sarmiento (Santacrucense, Mioceno temprano-medio): Diasemosaurus occidentalis y Dibolosodon typicus. Estos fósiles, procedentes del sitio Monte León en la provincia de Santa Cruz, se destacan por ser los lagartos más australes recuperados hasta el momento. La ubicación taxonómica y validez de estos taxones se discute desde su descripción original, por Ameghino mismo (Ameghino, 1898, 1899) y por varios autores posteriores. Sin embargo mucho de lo escrito sobre estos taxones no ha sido adecuadamente fundamentado (e.g. Donadío, 1983b, 1984a) y Estes (1983a) los considera nomina dubia, destacando la afinidad de Diasemosaurus con los Teiidae.

Para la Fm. La Playa (Huayqueriense, Mioceno tardío) de la provincia de Córdoba, Donadío (1983b, 1984b) hace referencia a la presencia de Tupinambis merianae (citado como T. teguixin). Este autor no describe ni figura a este fósil, y teniendo en cuenta que las especies del género no muestran distinciones en sus maxilares, el material (maxilar con dientes) ha sido tratado como Tupinambis sp. (Albino et al., 2006).

Para la Fm. Ituzaingó (Huayqueriense, Mioceno tardío) expuesta en las barrancas del Río Paraná, cercanas a la ciudad homónima, en la provincia de Entre Ríos, Ambrosetti (1890) describe dos especies de Teiidae: Propodinema paranensis Scalabrini, 1890 y Propodinema oligocena Ambrosetti, 1890. Romer (1967) incluye al género en la sinonimia de Teius (Teiidae, Teiinae), pero Báez y Gasparini (1977, 
1979) destacan que estos fósiles difieren de Teius y se asemejan a Tupinambis. Donadío (1983a) considera que la descripción original no amerita género y especie nuevas y refiere el material como Tupinambis $\operatorname{cf} T$. merianae (citado como $T$. teguixin). La idea de que estos fósiles se asemejan a Tupinambis es mencionada por varios autores (Ameghino, 1898; Hoffstetter, 1955; Estes, 1983a; Albino, 1996a), pero, debido a que el material está perdido y nunca fue figurado, no es posible su reestudio, motivo por el cual se lo admite como Tupinambis sp. (Albino et al., 2006).

Rovereto (1914) describe cuatro especies extintas de Tupinambis (T. preteguixin, T. prerufescens, T. brevirostris y T. multidentatus) procedentes de niveles imprecisos de la Fm. Monte Hermoso (Montehermosense sensu lato, Mioceno tardíoPlioceno) aflorantes en la localidad comúnmente conocida como Farola Monte Hermoso (Cione y Tonni, 1995a). Estes (1983a) sinonimiza todas estas especies con T. preteguixin. Adicionalmente, Albino et al. (2009) describen nuevos materiales de Tupinambis sp. procedentes de niveles correspondientes a los Pisos Montehermosense (Mioceno tardío-Plioceno temprano, Cione y Tonni, 2005) y Chapadmalalense inferior (Plioceno temprano, Cione y Tonni, 2005) de esta localidad.

De la misma localidad Farola Monte Hermoso, pero de niveles de la Fm. Monte Hermoso claramente referidos al Piso Montehermosense, provienen restos craneales asociados que sirven a Chani (1976) para describir una especie extinta del género Callopistes (Teiidae: Tupinambinae), a la que nomina C. bicuspidatus. Esta designación se ha aceptado como válida por la totalidad de quienes la han mencionado (e.g. Estes, 1983a). Sin embargo, siempre se ha resaltado lo significativo de este fósil por no coincidir con la distribución actual del género Callopistes que actualmente se encuentra al oeste de los Andes (Krause, 1985).

Kraglievich (1947) describe otra especie extinta de teido, Tupinambis onyxodon, a partir de una hemimandíbula proveniente de la costa bonaerense en cercanías de Miramar, provincia de Buenos Aires. Kraglievich (1947) interpreta que los sedimentos que contenían al fósil pertenecen a la "Fm.” Chapadmalal. Posteriormente, Reig (1958) corrige la procedencia estratigráfica original a "Fm." Vorohué (Marplatense medio, Plioceno tardío, Cione y Tonni, 2005). Al igual que con las especies nominadas por Rovereto (1914), este taxón es considerado inválido por no presentar características que claramente lo diferencien de las especies actuales, motivo por el cual fue asignado a Tupinambis merianae (citado como T. teguixin) (Reig, 1958; Báez y Gasparini, 1977, 1979; Gasparini et al. 1986; Albino, 1996a). 
Además de las descripciones de Rovereto (1914) y Kraglievich (1947), otras citas documentan la presencia de Tupinambis en el Plioceno del sudeste bonaerense (Reig, 1958). Extrañamente no hay un claro registro pleistocénico de Tupinambis, con sólo la presencia de Tupinambis en el Lujanense (Pleistoceno tardío - Holoceno) (Rusconi, 1937). El registro holocénico de este género es nuevamente abundante (Tabla 2).

Recientemente, Albino (2005) ha descripto los primeros restos de los géneros vivientes Homonota (Gekkota: Gekkonidae) y Cnemidophorus (Teiidae: Teiinae) del Pleistoceno tardío-Holoceno temprano del sur de la provincia de Buenos Aires. En sedimentos del Holoceno de la provincia de Córdoba, Donadío (1983b, 1984b) cita la presencia de T. rufescens, pero este material se hallaría perdido (de la Fuente, 1999) y no puede ser revisado. Lamentablemente, Donadío (1983b, 1984b) tampoco detalla los elementos que están representados entre el material fósil.

Con respecto a los Amphisbaenia, el grupo presenta un registro Neógeno escaso y no se los registra en el Paleógeno. Donadío (1982) cita la presencia de un Amphisbaenia indeterminado en las "Fm." Chapadmalal (Chapadmalalense superior, Plioceno medio, Cione y Tonni, 2005) y “Fm." San Andrés (Marplatense superior, Plioceno tardío, Cione y Tonni, 2005) de Miramar y Necochea respectivamente, en la provincia de Buenos Aires. Torres y Montero (1998a, 1998b) reinterpretan y redescriben restos provenientes de la Fm. Ensenada (Plioceno tardío-Pleistoceno, Cione y Tonni, 2005; Vucetich et al., 2007; Pomi, 2008) en San Isidro (Estación Anchorena), provincia de Buenos Aires. Dichos fósiles fueron originalmente descriptos como Leiosaurus marellii Rusconi 1937, un lagarto iguanio extinto, pero Torres y Montero (1998b) los reasignan a Amphisbaena marelli, especie extinta del género. El más antiguo registro de una especie viviente de anfisbena corresponde a Amphisbaena heterozonata de la Fm. Luján (Pleistoceno tardío) aflorante en cercanías de la localidad de Luján, provincia de Buenos Aires (Scanferla et al., 2006).

En varios sitios arqueológicos de Argentina se han recuperado restos de lagartos (Albino y Albino, 2004). Una importante cantidad de elementos craneanos y postcraneanos asignados a Tupinambis cf. merianae fueron obtenidos en el sitio arqueológico Cueva Tixi, (límite inferior 10375-4865 años AP) y Cueva El Abra (límite inferior $9834 \pm 65$ años AP) del sistema Serrano de Tandilia, provincia de Buenos Aires (Albino, 1999, 2001; Quintana et al., 2000, 2004). Tupinambis también se registra en el sitio La Toma del sistema Serrano de Ventania, provincia de Buenos 
Aires (límite inferior 5505 200 años AP) y en Cañada de Rocha y Río Luján, en el norte de la provincia (sin dataciones absolutas) (Salemme, 1990). En el sitio "Lomas del Veinte", de la provincia de Santiago de Estero (aprox. 1000-800 años AP) se ha citado Tupinambis sp. (Cione et al., 1979), referido como T. rufescens por Donadío (1983a) y de la Fuente (1999). Rodríguez Loredo (1998) menciona la presencia de Scincidae en el sitio Potrero Chaquiago, de la Provincia de Catamarca. En Shincal de Quimivil y en Mesada de Carrizal, en la misma provincia, y en Tolombón (800-350 años AP, Williams, 2003), provincia de Salta, se han registrado restos asignados al género Amphisbaena (Capparelli y Raffino, 1997; de la Fuente, 1999; Tobisch et al., 2005; Albino y Kligmann, en prensa).

Con el conocimiento de este registro, que se extiende desde el Cretácico a la actualidad, y teniendo en cuenta que muchos de los materiales citados requieren una reevaluación sistemática o una redescripción basada en conceptos más modernos, se desarrolló el presente trabajo de Tesis Doctoral, adicionando nuevos materiales disponibles para su estudio (punto 5).

\begin{tabular}{|c|c|c|c|}
\hline Localidad & Formación-Edad & Antecedentes & Condición \\
\hline $\begin{array}{l}\text { Cinco Saltos, Río } \\
\text { Negro }\end{array}$ & Fm. Anacleto & $\begin{array}{l}\text { Squamata indet. } \\
\text { Albino (2002a, 2007) } \\
\text { (no descripto) }\end{array}$ & Esta Tesis \\
\hline $\begin{array}{l}\text { Ea. Pampa Grande, } \\
\text { Salta }\end{array}$ & Fm. Lumbrera & $\begin{array}{l}\text { Lumbrerasaurus } \\
\text { scagliai } \\
\text { Donadío (1985) } \\
\text { nomen dubium } \\
\text { Sullivan y Estes (1997) }\end{array}$ & Esta Tesis \\
\hline Gaiman, Chubut & $\begin{array}{l}\text { Fm. Sarmiento, } \\
\text { Miembro Trelew }\end{array}$ & $\begin{array}{l}\text { Tupinambis sp. } \\
\text { Gasparini et al. (1986), } \\
\text { Albino (1996a), } \\
\text { Brizuela y Albino } \\
(2004)\end{array}$ & \\
\hline $\begin{array}{l}\text { Monte León, Santa } \\
\text { Cruz }\end{array}$ & Fm. Santa Cruz & $\begin{array}{l}\text { Diasemosaurus } \\
\text { occidentalis } \\
\text { Ameghino (1893, 1898, } \\
1899)\end{array}$ & $\begin{array}{c}\text { Esta Tesis, } \\
\text { reasignado a } \\
\text { Tupinambis sp. } \\
\text { (Brizuela y Albino, }\end{array}$ \\
\hline
\end{tabular}




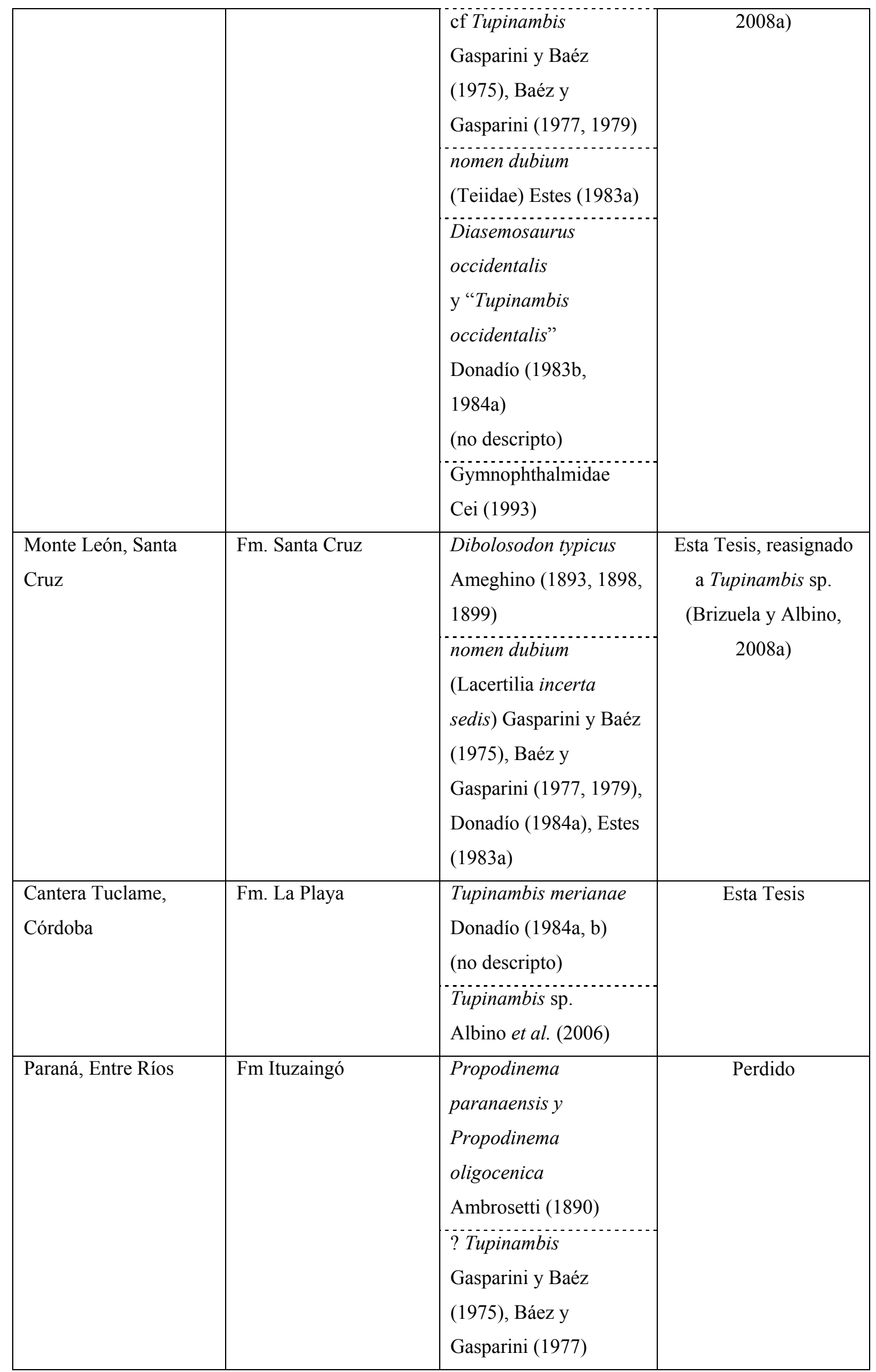




\begin{tabular}{|c|c|c|c|}
\hline $\begin{array}{l}\text { Farola Monte } \\
\text { Hermoso, Buenos } \\
\text { Aires }\end{array}$ & Fm. Monte Hermoso & $\begin{array}{l}\text { Tupinambis } \\
\text { multidentatus, } T \text {. } \\
\text { brevirostris, } T \text {. } \\
\text { prerufescens, } T \text {. } \\
\text { preteguixin } \\
\text { Rovereto (1914) } \\
\text { Tupinambis preteguixin } \\
\text { Estes (1983a) } \\
\text { Tupinambis sp. } \\
\text { Donadío (1983b), } \\
\text { Albino (1996a) }\end{array}$ & Esta Tesis \\
\hline $\begin{array}{l}\text { Farola Monte } \\
\text { Hermoso, Buenos } \\
\text { Aires }\end{array}$ & Fm. Monte Hermoso & - & Esta Tesis \\
\hline $\begin{array}{l}\text { Farola Monte } \\
\text { Hermoso, Buenos } \\
\text { Aires }\end{array}$ & Fm. Monte Hermoso & $\begin{array}{l}\text { Callopistes } \\
\text { bicuspidatus Chani } \\
\text { (1976) }\end{array}$ & Esta Tesis \\
\hline $\begin{array}{l}\text { Farola Monte } \\
\text { Hermoso, Buenos } \\
\text { Aires }\end{array}$ & Fm. Monte Hermoso & $\begin{array}{l}\text { Tupinambis sp. } \\
\text { Albino et al. (2009) }\end{array}$ & \\
\hline $\begin{array}{l}\text { Chapadmalal, Buenos } \\
\text { Aires }\end{array}$ & "Fm." Chapadmalal & $\begin{array}{l}\text { Tupinambis sp } \\
\text { Reig (1958) } \\
\text { (no descripto) }\end{array}$ & Esta Tesis \\
\hline $\begin{array}{l}\text { Barranca de los Lobos, } \\
\text { Buenos Aires }\end{array}$ & "Fm." Chapadmalal & $\begin{array}{l}\text { Tupinambis sp } \\
\text { Reig (1958) } \\
\text { (no descripto) }\end{array}$ & Esta Tesis \\
\hline $\begin{array}{l}\text { Chapadmalal, Buenos } \\
\text { Aires }\end{array}$ & "Fm." Chapadmalal & - & Esta Tesis \\
\hline Miramar, Buenos Aires & "Fm." Chapadmalal & $\begin{array}{l}\text { Amphisbaenia indet., } \\
\text { Donadío (1982) } \\
\text { (no descripto) }\end{array}$ & Esta Tesis \\
\hline $\begin{array}{l}\text { Barranca Parodi, } \\
\text { Miramar, Buenos Aires }\end{array}$ & "Fm." Vorohué & $\begin{array}{l}\text { Tupinambis onyxodon, } \\
\text { Kraglievich (1947), } \\
\text { Reig (1958) } \\
\text { Tupinambis sp., } \\
\text { Donadío (1983b) }\end{array}$ & Esta Tesis \\
\hline- & "Fm." Vorohué & $\begin{array}{l}\text { Tupinambis sp., } \\
\text { Donadío (1983b) } \\
\text { (no descripto) }\end{array}$ & No localizado \\
\hline Las Grutas - Punta & - & Amphisbaenia indet., & Esta Tesis \\
\hline
\end{tabular}




\begin{tabular}{|c|c|c|c|}
\hline $\begin{array}{l}\text { Negra, Necochea, } \\
\text { Buenos Aires }\end{array}$ & & $\begin{array}{l}\text { Donadío (1982) } \\
\text { (no descripto) }\end{array}$ & \\
\hline $\begin{array}{l}\text { San Isidro, Buenos } \\
\text { Aires }\end{array}$ & Fm. Ensenada & $\begin{array}{l}\text { Amphisbaena marelli } \\
\text { Rusconi (1937), Torres } \\
\text { y Montero (1998b) }\end{array}$ & \\
\hline $\begin{array}{l}\text { Villa Lugano, Buenos } \\
\text { Aires }\end{array}$ & $\begin{array}{l}\text { Lujanense, Pleistoceno } \\
\text { tardío - Holoceno }\end{array}$ & $\begin{array}{l}\text { Tupinambis sp. } \\
\text { Rusconi (1937) }\end{array}$ & Perdido \\
\hline $\begin{array}{l}\text { Camping Americano, } \\
\text { Buenos Aires }\end{array}$ & $\begin{array}{l}\text { Pleistoceno tardío- } \\
\text { Holoceno temprano }\end{array}$ & $\begin{array}{l}\text { Homonota sp. } \\
\text { Albino (2005) }\end{array}$ & \\
\hline $\begin{array}{l}\text { Camping Americano, } \\
\text { Buenos Aires }\end{array}$ & $\begin{array}{l}\text { Pleistoceno tardío- } \\
\text { Holoceno temprano }\end{array}$ & $\begin{array}{l}\text { Cnemidophorus sp. } \\
\text { Albino (2005) }\end{array}$ & \\
\hline Observatorio, Córdoba & Holoceno & $\begin{array}{l}\text { Tupinambis sp. } \\
\text { Donadío (1984b) } \\
\text { (no descripto) }\end{array}$ & No localizado \\
\hline Castelli, Buenos Aires & $\begin{array}{l}\text { Fm. Luján, Miembro } \\
\text { Guerrero }\end{array}$ & $\begin{array}{l}\text { Amphisbaena } \\
\text { heterozonata } \\
\text { Scanferla } \text { et al., } 2006\end{array}$ & \\
\hline $\begin{array}{l}\text { Cueva Tixi, Buenos } \\
\text { Aires }\end{array}$ & sitio arqueológico & $\begin{array}{l}\text { Tupinambis } \mathrm{cf} . \\
\text { merianae } \\
\text { Albino (2001), } \\
\text { Quintana et al. (2000, } \\
2004)\end{array}$ & Esta Tesis \\
\hline $\begin{array}{l}\text { Cueva El Abra, Buenos } \\
\text { Aires }\end{array}$ & sitio arqueológico & $\begin{array}{l}\text { Tupinambis } \text { cf. } \\
\text { merianae } \\
\text { Quintana et al. (2000, } \\
2004)\end{array}$ & Esta Tesis \\
\hline $\begin{array}{l}\text { Cañada de Rocha, } \\
\text { Buenos Aires }\end{array}$ & sitio arqueológico & $\begin{array}{l}\text { Tupinambis sp. } \\
\text { Salemme (1990) } \\
\text { (no descripto) }\end{array}$ & No localizado \\
\hline $\begin{array}{l}\text { Río Luján, Buenos } \\
\text { Aires }\end{array}$ & sitio arqueológico & $\begin{array}{l}\text { Tupinambis cf. } \\
\text { merianae Salemme } \\
\text { (1990) } \\
\text { (no descripto) }\end{array}$ & No localizado \\
\hline $\begin{array}{l}\text { La Toma, Buenos } \\
\text { Aires }\end{array}$ & sitio arqueológico & $\begin{array}{l}\text { Tupinambis } \mathrm{cf} . \\
\text { merianae } \\
\text { Salemme (1990) } \\
\text { (no descripto) }\end{array}$ & No localizado \\
\hline $\begin{array}{l}\text { "Lomas del Veinte" } \\
\text { Santiago del Estero }\end{array}$ & sitio arqueológico & $\begin{array}{l}\text { Tupinambis rufescens } \\
\text { Cione et al. (1979); } \\
\text { Donadío (1983a) }\end{array}$ & Esta Tesis \\
\hline
\end{tabular}




\begin{tabular}{|c|c|c|c|}
\hline & & (no descripto) & \\
\hline $\begin{array}{l}\text { Potrero Chaquiago, } \\
\text { Catamarca }\end{array}$ & sitio arqueológico & $\begin{array}{l}\text { Scincidae indet., } \\
\text { Rodriguez Loredo } \\
\text { (1998) } \\
\text { (no descripto) }\end{array}$ & No localizado \\
\hline $\begin{array}{l}\text { Mesada de Carrizal, } \\
\text { Salta }\end{array}$ & sitio arqueológico & $\begin{array}{l}\text { Amphisbaena bolivica } \\
\text { Tobisch et al. (2005), } \\
\text { Albino y Kligmann (en } \\
\text { prensa) } \\
\text { (no descripto) }\end{array}$ & \\
\hline $\begin{array}{l}\text { Shincal Quimivil, } \\
\text { Catamarca }\end{array}$ & sitio arqueológico & $\begin{array}{l}\text { Amphisbaena sp., } \\
\text { Capparelli y Raffino } \\
\text { (1997) }\end{array}$ & No localizado \\
\hline Tolombón, Salta & sitio arqueológico & $\begin{array}{l}\text { Amphisbaena } \\
\text { heterozonata } \\
\text { Albino y Kligmann (en } \\
\text { prensa) }\end{array}$ & \\
\hline
\end{tabular}

Tabla 2. Registro fósil de lagartos continentales (excepto Iguania) de la Argentina. 

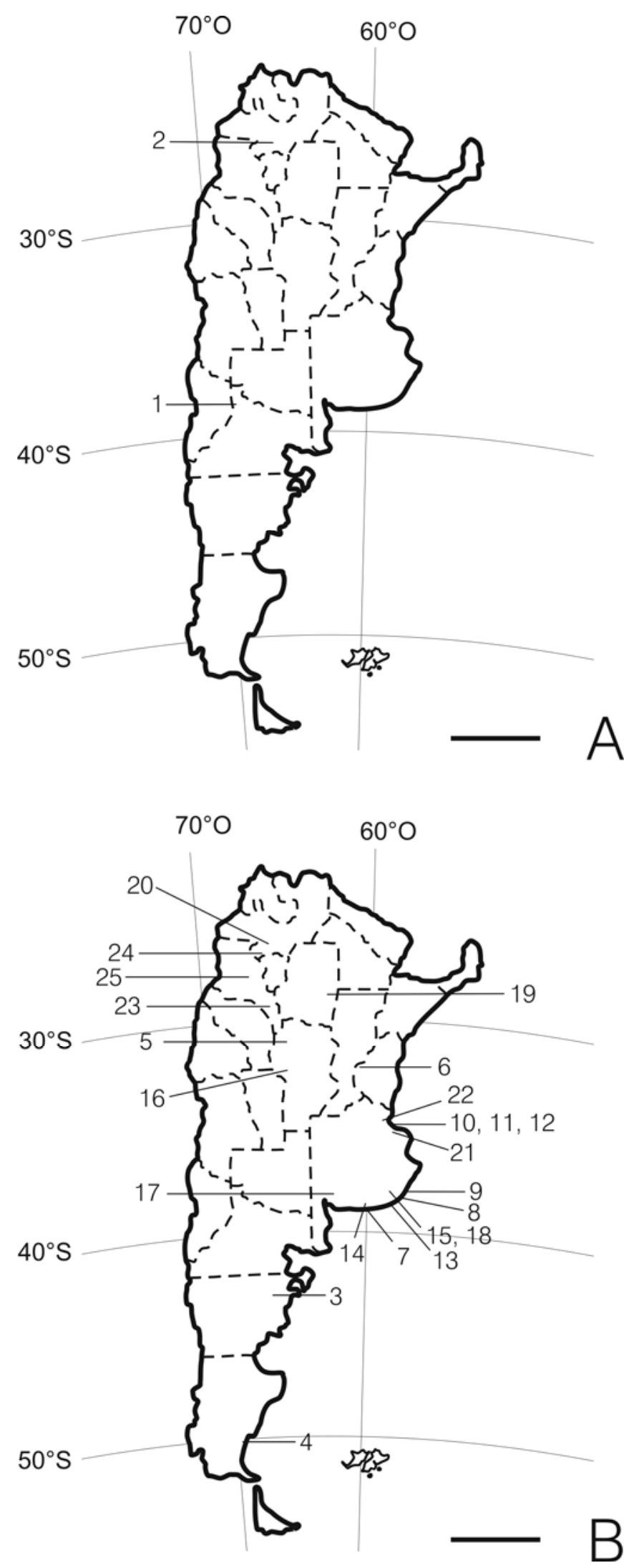
Figura 3. Distribución de sitios fosilíferos con lagartos (no iguanios) en Argentina. A, sitios Cretácicos - Paleógenos; B, sitios Neógenos. 1, Cinco Saltos (Campaniano temprano); 2, Estancia Pampa Grande (Eoceno temprano); 3, Gaiman (Mioceno temprano); 4, Monte León (Mioceno temprano-medio); 5, Las Playas (Mioceno tardío); 6, Paraná (Mioceno tardío); 7, Farola Monte Hermoso (Mioceno tardíoPlioceno temprano); 8, Miramar (Plioceno temprano); 9, zona entre Mar del Plata y Miramar (Plioceno); 10, Villa Lugano (Plioceno tardío); 11, San Isidro (Plioceno tardío-Pleistoceno medio); 12, Castelli (Pleistoceno); 13, Necochea (Plioceno tardío); 14, Camping Americano (Pleistoceno tardíoHoloceno temprano); 15, Cueva Tixi (Pleistoceno tardío-Holoceno); 16, Observatorio (Holoceno); 17, La Toma (Holoceno); 18, Cueva El Abra (Holoceno); 19, Lomas del Veinte (Holoceno); 20,

Tolombón, Salta (Holoceno); 21, Cañada de Rocha (Holoceno); 22, Río Lujan (Holoceno); 23, Shincal Quimivil (Holoceno tardío); 24, Mesada de Carrizal (Holoceno); 25, Potrero Chaquiago (Holoceno). La escala temporal sigue a Cione et al. (2007) y Vucetich et al. (2007). Escala $=500 \mathrm{~km}$.

\section{ADICIONES AL REGISTRO DE LAGARTOS CONTINENTALES FÓSILES (EXCEPTO IGUANIA) DE ARGENTINA.}

A pesar de no haberse desarrollado búsquedas sistemáticas y específicas de fósiles de lagartos, las campañas dirigidas a la obtención de otros grupos de microvertebrados han provisto nuevos materiales para su estudio. En la Tabla 3 se listan los restos colectados en los últimos años que se incluyeron en el objetivo de esta Tesis, algunos de los cuales ya fueron publicados. 


\begin{tabular}{|c|c|c|}
\hline Localidad & $\begin{array}{c}\text { Formación- } \\
\text { Edad }\end{array}$ & Condición \\
\hline $\begin{array}{l}\text { Chapadmalal, } \\
\text { Buenos Aires }\end{array}$ & $\begin{array}{l}\text { "Fm." } \\
\text { Chapadmalal }\end{array}$ & Esta tesis \\
\hline $\begin{array}{l}\text { Telén, La Pampa } \\
\text { Bajo Giuliani, La } \\
\text { Pampa }\end{array}$ & \multirow{5}{*}{ Fm. Cerro Azul } & \multirow{5}{*}{$\begin{array}{l}\text { Esta tesis, en parte asignado a Tupinambis sp., Albino et al. } \\
\qquad \text { (2006) }\end{array}$} \\
\hline Quehué, La Pampa & & \\
\hline $\begin{array}{l}\text { Loventué, La } \\
\text { Pampa }\end{array}$ & & \\
\hline Caleufú, La Pampa & & \\
\hline $\begin{array}{l}\text { Chacharramendi, } \\
\text { La Pampa }\end{array}$ & & \\
\hline $\begin{array}{l}\text { Cañadón del } \\
\text { Tordillo, Río } \\
\text { Negro }\end{array}$ & Fm. Collón Cura & $\begin{array}{l}\text { Esta tesis, asignado a Tupinambis o Crocodilurus, Brizuela } \\
\text { y Albino (2008b) }\end{array}$ \\
\hline Gaiman, Chubut & Fm. Sarmiento & Esta tesis \\
\hline
\end{tabular}

Tabla 3. Material nuevo de lagartos continentales (no Iguania) de Argentina.

La mayoría de los materiales nuevos son del Mioceno de Patagonia y del sur de la región Pampeana (Fig. 4). Parte de los materiales patagónicos provienen de la localidad de Gaiman (Mioceno temprano), provincia de Chubut, de donde ya se describieron lagartos iguanios (Albino, 2008) y escleroglosos (Teiidae, Brizuela y Albino, 2004). Los restantes materiales patagónicos proceden de la localidad Cañadón del Tordillo (Mioceno medio), provincia del Neuquén (Brizuela y Albino, 2008b). El Mioceno tardío de la provincia de La Pampa ha provisto un importante número de fragmentos de reptiles de varias localidades, algunos ya publicados durante el desarrollo de esta Tesis (Albino et al., 2006) y otros que se presentan en la misma. Adicionalmente, del Neógeno más tardío (Chapadmalalense) se estudió un fósil perteneciente a la colección del Museo Argentino de Ciencias Naturales que no había sido mencionado en la literatura. 


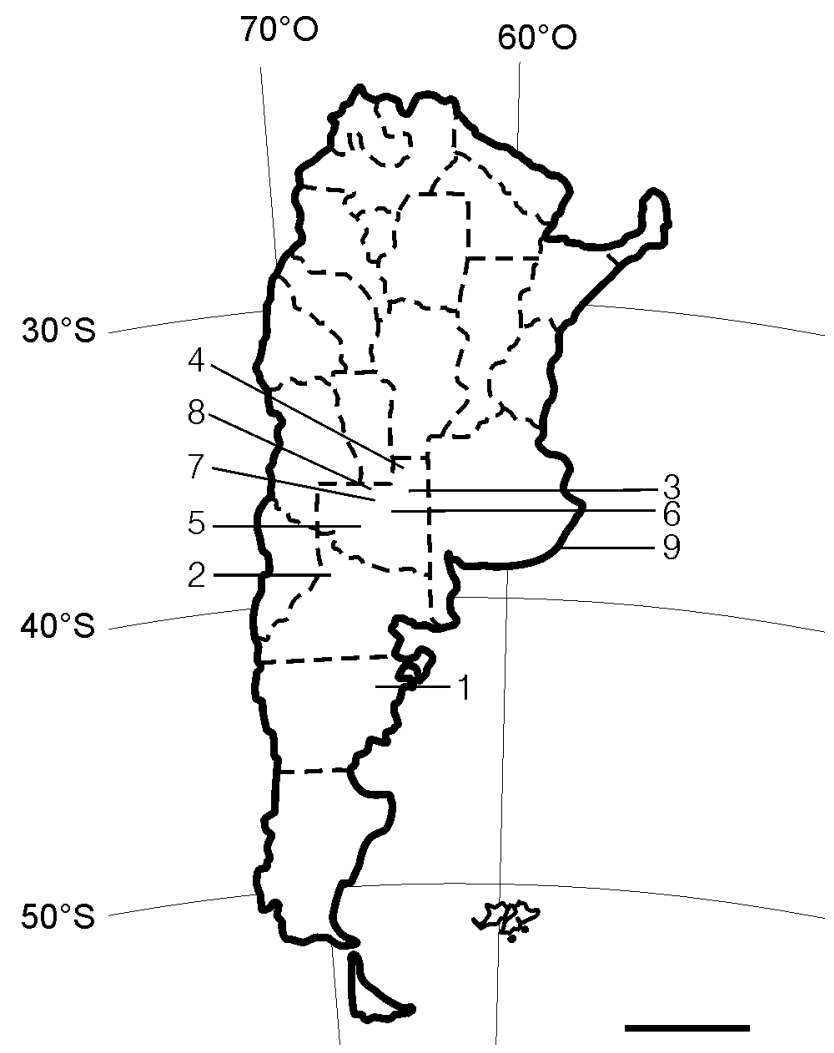

Figura 4. Distribución de sitios fosilíferos con nuevos restos de lagartos continentales (no iguanios) en Argentina. 1, Gaiman (Mioceno temprano); 2, Cañadón del Tordillo (Mioceno medio); 3, Bajo Giuliani (Mioceno tardío); 4, Caleufú (Mioceno tardío); 5, Chacharramendi (Mioceno tardío); 6, Quehué (Mioceno tardío); 7, Loventué (Mioceno tardío); 8, Telén (Mioceno tardío); 9, Chapadmalal (Plioceno medio). Escala $=500 \mathrm{~km}$.

\section{OBJETIVOS}

\subsection{Objetivo General}

Como se ha visto en los puntos anteriores, muchas de las descripciones de lagartos fósiles de Argentina son antiguas o informales, por lo que requieren una revisión. Al mismo tiempo, existen nuevos materiales no dados a conocer con antelación a este trabajo. De esta manera, en esta Tesis, se aborda la descripción y análisis de materiales que han sido sólo mencionados en trabajos generales o citados en comunicaciones, así como de restos recientemente obtenidos que aún permanecen inéditos. Igualmente, se realiza la re-descripción, bajo un concepto actual, de los materiales estudiados en el pasado por otros autores. 
El objetivo general de esta Tesis se centra en realizar el estudio sistemático de los fósiles de lagartos continentales (excepto Iguania) presentes en el territorio argentino, y reconstruir la evolución biogeográfica de los taxones representados en el registro fósil de América del Sur considerando sus relaciones filogenéticas y su distribución geográfica pasada y actual.

\subsection{Objetivos Particulares}

Los objetivos particulares del presente trabajo de Tesis son:

A. Sistemática Paleontológica.

A.a. Re-describir y analizar los restos de lagartos continentales del Cenozoico de la Argentina correspondientes a diversas citas, evaluando el estatus de taxones extintos y fósiles de dudosa asignación taxonómica (Tabla 2).

A.b. Describir y analizar restos nuevos, inéditos o no descriptos (sólo citados) procedentes del Mesozoico y Cenozoico de la Argentina (Tabla 2 y $3)$.

B. Realizar el análisis filogenético de la familia Teiidae (Scincomorpha) sobre la base de la osteología, incluyendo las formas actuales y fósiles. Los teidos constituyen la familia mejor representada en el registro de lagartos fósiles de Argentina, e incluye taxones extintos sudamericanos.

C. Realizar el análisis de la distribución biogeográfica y cronológica de los taxones de lagartos representados en el registro fósil sudamericano considerando sus relaciones filogenéticas, así como la evolución climática y tectónica de América del Sur durante el Mesozoico y Cenozoico. De esta forma se puede dar un marco para discutir diferentes hipótesis sobre el origen y la evolución biogeográfica de los taxones representados.

D. Realizar la identificación de los parámetros climático-ambientales que determinan la distribución actual de los taxones representados en el registro fósil de América del Sur y evaluar su importancia como indicadores paleoclimáticos y paleoambientales. 
E. Relevar la presencia de lagartos (excepto Iguania) en sitios arqueológicos de Argentina y evaluar su significado. 


\section{CAPITULO II}

\section{MATERIALES Y MÉTODOS}

\section{MATERIALES}

\subsection{Material fósil}

Los materiales fósiles examinados en esta Tesis pertenecen a colecciones de instituciones nacionales (Tabla 4). En general, se trata de fragmentos aislados, principalmente de huesos craneales, entre los que se destacan los maxilares y dentarios portadores de dientes. Es frecuente la presencia de fragmentos articulados de hemimandíbulas, pero es raro encontrar elementos craneales articulados. Del esqueleto postcraneal son frecuentes las vértebras aisladas, completas e incompletas. No es extraño encontrar que varios materiales estén representados por un único número de colección (e.g. 33 elementos esqueletarios en MACN Pv 14314, T. prerufescens).

\begin{tabular}{|l|l|l|l|}
\hline \multicolumn{1}{|c|}{ Especimen } & \multicolumn{1}{|c|}{ Localidad } & \multicolumn{1}{c|}{ Procedencia } & \multicolumn{1}{c|}{$\begin{array}{c}\text { Elementos } \\
\text { representados }\end{array}$} \\
\hline MCS-Pv 41 & Cinco Saltos, Neuquén & Fm. Anacleto & dentario izquierdo \\
\hline MMP 4618 & Ea. Pampa Grande, Salta & Fm. Lumbrera & elementos craneales \\
\hline MACN Pv CH819 & Gaiman, Chubut & Fm. Sarmiento & maxilar derecho \\
\hline MACN Pv CH998-3 & Gaiman, Chubut & Fm. Sarmiento & vértebras \\
\hline MACN Pv CH1860-3 & Gaiman, Chubut & Fm. Sarmiento & vértebra \\
\hline MACN Pv CH1860-4 & Gaiman, Chubut & Fm. Sarmiento & vértebra \\
\hline MACN Pv CH1860-5 & Gaiman, Chubut & Fm. Sarmiento & vértebra \\
\hline MACN Pv CH1860-7 & Gaiman, Chubut & Fm. Sarmiento & vértebra \\
\hline MACN Pv CH815-1 & Gaiman, Chubut & Fm. Sarmiento & vértebra \\
\hline MACN A 621 & Mte. León, Santa Cruz & Fm. Santa Cruz & dentario derecho \\
\hline MACN A 5806-1 & Mte. León, Santa Cruz & Fm. Santa Cruz & dentario izquierdo \\
\hline MACN A 5806-2 & Mte. León, Santa Cruz & Fm. Santa Cruz & maxilar derecho \\
\hline MLP 91-IV-1-139 & Cañadón del Tordillo, & Fm. Collón Cura & dentario y esplenial \\
\hline
\end{tabular}




\begin{tabular}{|c|c|c|c|}
\hline & Neuquén & & izquierdos \\
\hline MLP 91-IX-1-72 & $\begin{array}{l}\text { Cañadón del Tordillo, } \\
\text { Neuquén }\end{array}$ & Fm. Collón Cura & dentario derecho \\
\hline MLP 91-IX-1-75 & $\begin{array}{l}\text { Cañadón del Tordillo, } \\
\text { Neuquén }\end{array}$ & Fm. Collón Cura & dentario derecho \\
\hline MLP 91-IX-1-74 & $\begin{array}{l}\text { Cañadón del Tordillo, } \\
\text { Neuquén }\end{array}$ & Fm. Collón Cura & maxilar derecho \\
\hline MLP 91-IV-1-140 & $\begin{array}{l}\text { Cañadón del Tordillo, } \\
\text { Neuquén }\end{array}$ & Fm. Collón Cura & vértebra cervical \\
\hline MLP 91-IV-1-141 & $\begin{array}{l}\text { Cañadón del Tordillo, } \\
\text { Neuquén }\end{array}$ & Fm. Collón Cura & vértebra caudal \\
\hline GHUNLPam 2274 & Bajo Giuliani, La Pampa & Fm. Cerro Azul & ?maxilar derecho \\
\hline GHUNLPam 2313 & Bajo Giuliani, La Pampa & Fm. Cerro Azul & vértera caudal \\
\hline GHUNLPam 2340 & Bajo Giuliani, La Pampa & Fm. Cerro Azul & $\begin{array}{l}\text { dentario y esplenial } \\
\text { izquierdos }\end{array}$ \\
\hline GHUNLPam 2396 & Bajo Giuliani, La Pampa & Fm. Cerro Azul & dentario derecho \\
\hline GHUNLPam 5413 & Bajo Giuliani, La Pampa & Fm. Cerro Azul & dentario izquierdo \\
\hline GHUNLPam 5493 & Bajo Giuliani, La Pampa & Fm. Cerro Azul & dentario derecho \\
\hline GHUNLPam 5494 & Bajo Giuliani, La Pampa & Fm. Cerro Azul & $\begin{array}{l}\text { indeterminado con } \\
\text { dientes }\end{array}$ \\
\hline GHUNLPam 8550 & Bajo Giuliani, La Pampa & Fm. Cerro Azul & dentario derecho \\
\hline GHUNLPam 9674 & Quehué, La Pampa & Fm. Cerro Azul & dentario derecho \\
\hline GHUNLPam 14283 & Loventué, La Pampa & Fm. Cerro Azul & maxilar derecho \\
\hline GHUNLPam 14284 & Loventué, La Pampa & Fm. Cerro Azul & maxilar derecho \\
\hline GHUNLPam 19608 & Caleufú, La Pampa & Fm. Cerro Azul & dentario derecho \\
\hline GHUNLPam 19609 & Caleufú, La Pampa & Fm. Cerro Azul & $\begin{array}{l}\text { indeterminado con } \\
\text { dientes }\end{array}$ \\
\hline GHUNLPam 19610 & Caleufú, La Pampa & Fm. Cerro Azul & dentario derecho \\
\hline GHUNLPam 19854 & Caleufú, La Pampa & Fm. Cerro Azul & dentario derecho \\
\hline GHUNLPam 19856 & Caleufú, La Pampa & Fm. Cerro Azul & $\begin{array}{l}\text { dentario y esplenial } \\
\text { izquierdos }\end{array}$ \\
\hline GHUNLPam 19914 & Caleufú, La Pampa & Fm. Cerro Azul & $\begin{array}{l}\text { hemimandíbula } \\
\text { izquierda }\end{array}$ \\
\hline GHUNLPam 19855 & Caleufú, La Pampa & Fm. Cerro Azul & $\begin{array}{l}\text { indeterminado con } \\
\text { dientes }\end{array}$ \\
\hline GHUNLPam 19612/4 & Caleufú, La Pampa & Fm. Cerro Azul & vértebra \\
\hline GHUNLPam 19865/30 & Caleufú, La Pampa & Fm. Cerro Azul & vértebra caudal \\
\hline GHUNLPam 19874/42 & Caleufú, La Pampa & Fm. Cerro Azul & vértebras articuladas \\
\hline GHUNLPam 21669 & Telén, La Pampa & Fm. Cerro Azul & dentario izquierdo \\
\hline
\end{tabular}




\begin{tabular}{|c|c|c|c|}
\hline GHUNLPam 21712 & Bajo Giuliani, La Pampa & Fm. Cerro Azul & maxilar izquierdo \\
\hline GHUNLPam 21745 & $\begin{array}{l}\text { Chacharramendi, La } \\
\text { Pampa }\end{array}$ & Fm. Cerro Azul & dentario derecho \\
\hline MMP 637-S & La Playa, Córdoba & Fm. La Playa & maxilar derecho \\
\hline MACN Pv 14310 & $\begin{array}{l}\text { Farola Monte Hermoso, } \\
\text { Buenos Aires }\end{array}$ & Fm. Monte Hermoso & $\begin{array}{l}\text { elementos craneales y } \\
\text { postcraneales }\end{array}$ \\
\hline MACN Pv 14311 & $\begin{array}{l}\text { Farola Monte Hermoso, } \\
\text { Buenos Aires }\end{array}$ & Fm. Monte Hermoso & $\begin{array}{l}\text { elementos craneales y } \\
\text { postcraneales }\end{array}$ \\
\hline MACN Pv 14312 & $\begin{array}{l}\text { Farola Monte Hermoso, } \\
\text { Buenos Aires }\end{array}$ & Fm. Monte Hermoso & $\begin{array}{l}\text { elementos craneales y } \\
\text { postcraneales }\end{array}$ \\
\hline MACN Pv 14313 & $\begin{array}{l}\text { Farola Monte Hermoso, } \\
\text { Buenos Aires }\end{array}$ & Fm. Monte Hermoso & $\begin{array}{l}\text { elementos craneales y } \\
\text { postcraneales }\end{array}$ \\
\hline MACN Pv 14314 & $\begin{array}{l}\text { Farola Monte Hermoso, } \\
\text { Buenos Aires }\end{array}$ & Fm. Monte Hermoso & $\begin{array}{l}\text { elementos craneales y } \\
\text { postcraneales }\end{array}$ \\
\hline MACN Pv 14338 & $\begin{array}{l}\text { Farola Monte Hermoso, } \\
\text { Buenos Aires }\end{array}$ & Fm. Monte Hermoso & serie dentaria \\
\hline MACN Pv 14344 & $\begin{array}{l}\text { Farola Monte Hermoso, } \\
\text { Buenos Aires }\end{array}$ & Fm. Monte Hermoso & dentario derecho \\
\hline FML 4618 & $\begin{array}{l}\text { Farola Monte Hermoso, } \\
\text { Buenos Aires }\end{array}$ & Fm. Monte Hermoso & elementos craneales \\
\hline MACN Pv 10247 & $\begin{array}{l}\text { Chapadmalal, Buenos } \\
\text { Aires }\end{array}$ & "Fm." Chapadmalal & hemimandíbula derecha \\
\hline MACN Pv 19394 & $\begin{array}{l}\text { Chapadmalal, Buenos } \\
\text { Aires }\end{array}$ & "Fm." Chapadmalal & dentario derecho \\
\hline MACN Pv 16831 & $\begin{array}{l}\text { Chapadmalal, Buenos } \\
\text { Aires }\end{array}$ & "Fm." Chapadmalal & elementos postcraneales \\
\hline MACN Pv 16815 & $\begin{array}{l}\text { Chapadmalal, Buenos } \\
\text { Aires }\end{array}$ & "Fm." Chapadmalal & vértebras \\
\hline MACN Pv 17452 & $\begin{array}{l}\text { Chapadmalal, Buenos } \\
\text { Aires }\end{array}$ & "Fm." Chapadmalal & vértebra \\
\hline MACN Pv 16791 & $\begin{array}{l}\text { Chapadmalal, Buenos } \\
\text { Aires }\end{array}$ & "Fm." Chapadmalal & vértebra \\
\hline MACN Pv 6878 & $\begin{array}{l}\text { entre Mar del Plata y } \\
\text { Miramar, Buenos Aires }\end{array}$ & "Fm." Chapadmalal & vértebras \\
\hline MACN Pv 17136 & Miramar, Buenos Aires & "Fm." Vorohué & $\begin{array}{l}\text { hemimandíbula } \\
\text { izquierda }\end{array}$ \\
\hline MACN Pv 10577 & Necochea, Buenos Aires & "Fm." San Andrés & vértebras \\
\hline UNMdP sin numerar & $\begin{array}{l}\text { Cueva Tixi y El Abra, } \\
\text { Buenos Aires }\end{array}$ & sitio arqueológico & $\begin{array}{l}\text { elementos craneales y } \\
\text { postcraneales }\end{array}$ \\
\hline
\end{tabular}




\begin{tabular}{|l|l|l|l|}
\hline MACN Pv 18821 & $\begin{array}{l}\text { "Lomas del Veinte", } \\
\text { Santiago del Estero }\end{array}$ & Sitio arqueológico & frontal \\
\hline MACN Pv 18822 & $\begin{array}{l}\text { "Lomas del Veinte", } \\
\text { Santiago del Estero }\end{array}$ & Sitio arqueológico & dentario derecho \\
\hline MACN Pv 18823 & $\begin{array}{l}\text { "Lomas del Veinte", } \\
\text { Santiago del Estero }\end{array}$ & Sitio arqueológico & maxilar derecho \\
\hline MACN Pv 18824 & $\begin{array}{l}\text { "Lomas del Veinte", } \\
\text { Santiago del Estero }\end{array}$ & Sitio arqueológico & maxilar izquierdo \\
\hline MACN Pv 18825 & $\begin{array}{l}\text { "Lomas del Veinte", } \\
\text { Santiago del Estero }\end{array}$ & Sitio arqueológico & maxilar izquierdo \\
\hline
\end{tabular}

Tabla 4. Materiales fósiles examinados en este trabajo.

\subsection{Material actual}

La comparación directa de los fósiles con material osteológico de especies actuales es fundamental para su determinación taxonómica. En los casos donde no se dispone de material de referencia se recurre a datos bibliográficos, pero el material de referencia permite clarificar y reevaluar caracteres previamente descriptos además de reconocer nuevos caracteres. A la vez, con un número adecuado de ejemplares de una misma especie es posible descartar variación intraespecífica y ontegenética que muchas veces ha dado lugar a la nominación de especies inválidas.

Como se mencionó previamente (Cap. I), los Scincomorpha de la familia Teiidae dominan cuanti y cualitativamente el registro fósil de lagartos argentinos. Esta familia presenta actualmente una distribución principalmente Neotropical con un sólo género alcanzando la región Holártica (Krause, 1985; Pough et al., 1998; Zug et al., 2001; Reeder et al., 2002). Como los géneros y especies no se distribuyen homogéneamente en el espacio, sino respondiendo a su historia evolutiva y condiciones climático-ambientales, es razonable que en Argentina no estén representados todos los géneros y especies de esta familia. Esta distribución explica, en parte, que las colecciones herpetológicas del país estén sesgadas a la fauna autóctona. Además, las colecciones institucionales (MACN, MLP, UNC, UNNE, UNRC) poseen poco material con preparación esqueletaria para las necesidades de esta tesis. Por estas razones, fue necesario obtener y preparar material de referencia de las especies autóctonas y visitar colecciones del exterior $\mathrm{u}$ obtener especímenes en préstamo para estudiar especies que no se distribuyen en la Argentina. 
El material osteológico de referencia utilizado en este trabajo se obtuvo en dos condiciones: material esqueletario y ejemplares frescos a partir de los cuales se realizaron preparaciones esqueletarias. El detalle de los taxones utilizados en la comparación de los fósiles y en el análisis filogenético se expresa en la Tabla 5. Ejemplares adicionales de Tupinambis rufescens (cráneos), T. merianae (cráneos), $T$. teguixin (molde de dentición) y Teius sp. (cráneos), que no pertenecen a colecciones institucionales, también fueron utilizados en las comparaciones.

\begin{tabular}{|c|c|c|c|}
\hline $\begin{array}{l}\text { Número de } \\
\text { Colección }\end{array}$ & Taxón & Localidad & Datos Adicionales \\
\hline \multicolumn{4}{|c|}{ Anguidae } \\
\hline UNMdP 162 & Ophiodes vertebralis & - & esqueleto completo \\
\hline \multicolumn{4}{|c|}{ Scincidae } \\
\hline UNMdP 1599 & Mabuya frenata & - & cráneo y postcráneo $(\mathrm{T})$ \\
\hline \multicolumn{4}{|c|}{ Gymnophthalmidae } \\
\hline UMMZ 192802 & Anadia bogotensis & Cundinamarca, Colombia & $\hat{o}$, completo $(\mathrm{T})$ \\
\hline UMMZ 172147 & Bachia dorbignyi & Santa Cruz, Bolivia & completo $(\mathrm{T})$ \\
\hline UNRC 5058 & Cercosauria schreibersii & Córdoba, Argentina & esqueleto desarticulado \\
\hline UNNE 8284 & Cercosauria schreibersii & Corrientes, Argentina & esqueleto completo? (T) \\
\hline UNNE 8285 & Cercosauria schreibersii & Corrientes, Argentina & cráneo y postcráneo $(\mathrm{T})$ \\
\hline UNC C119 & Cercosauria schreibersii & Córdoba, Argentina & ô, cráneo \\
\hline UNC C182 & Cercosauria schreibersii & Córdoba, Argentina & $\hat{o}$, cráneo \\
\hline UNC C253 & Cercosauria schreibersii & Córdoba, Argentina & $\hat{o}$, cráneo \\
\hline UNC C316 & Cercosauria schreibersii & Córdoba, Argentina & $\hat{\partial}$, cráneo \\
\hline UNC C318 & Cercosauria schreibersii & Córdoba, Argentina & $\widehat{o}$, cráneo \\
\hline UNC C255 & Cercosauria schreibersii & Córdoba, Argentina & ô, cráneo \\
\hline UNC C081 & Cercosauria schreibersii & Córdoba, Argentina & †, cráneo \\
\hline UNC C137 & Cercosauria schreibersii & Córdoba, Argentina & q, cráneo \\
\hline UNC C155 & Cercosauria schreibersii & Córdoba, Argentina & q, cráneo \\
\hline UNC C180 & Cercosauria schreibersii & Córdoba, Argentina & +, cráneo \\
\hline UNC C181 & Cercosauria schreibersii & Córdoba, Argentina & + , cráneo parcial \\
\hline UNC C292 & Cercosauria schreibersii & Córdoba, Argentina & O, cráneo \\
\hline UNMdP 649 & Vanzosaura rubricauda & - & esqueleto completo $(\mathrm{T})$ \\
\hline \multicolumn{4}{|c|}{ Teiidae } \\
\hline UNMdP 796 & Ameiva ameiva & - & esqueleto parcial \\
\hline UNMdP 1235 & Ameiva ameiva & - & esqueleto completo $(\mathrm{T})$ \\
\hline UNNE 1374 & Ameiva ameiva & Chaco, Argentina & esqueleto completo $(\mathrm{T})$ \\
\hline
\end{tabular}




\begin{tabular}{|c|c|c|c|}
\hline UNNE 1365 & Ameiva ameiva & Formosa, Argentina & esqueleto completo \\
\hline UNMdP-O 27 & Ameiva ameiva & - & esqueleto completo (D) \\
\hline UMMZ 149442 & Ameiva ameiva & Tachira,Venezuela & cráneo \\
\hline UMMZ 176270 & Ameiva ameiva & Magdalena, Colombia & + , esqueleto completo \\
\hline NMNH 257529 & Ameiva ameiva & $\begin{array}{l}\text { Mazaruni/Potaro, } \\
\text { Guayana }\end{array}$ & $\widehat{\partial}$, cráneo \\
\hline NMNH 257530 & Ameiva ameiva & $\begin{array}{l}\text { Mazaruni/Potaro, } \\
\text { Guayana }\end{array}$ & esqueleto completo \\
\hline NMNH 292414 & Ameiva ameiva & Mondonia, Brasil & q juvenil, cráneo \\
\hline NMNH 292419 & Ameiva ameiva & Rondônia, Brasil & esqueleto completo \\
\hline NMNH 290898 & Ameiva ameiva & Itaituba, Brasil & ô juvenil, cráneo \\
\hline UMMZ 149443 & Ameiva bifrontata & Perú & ô, cráneo \\
\hline UMMZ 149444 & Ameiva bifrontata & $\begin{array}{l}\text { Aruba, Antillas } \\
\text { Holandesas }\end{array}$ & $\hat{o}$, cráneo \\
\hline UMMZ 150782 & Ameiva bifrontata & $\begin{array}{l}\text { Aruba, Antillas } \\
\text { Holandesas }\end{array}$ & +, cráneo \\
\hline UMMZ 149449 & Ameiva bifrontata & Magdalena, Colombia & cráneo \\
\hline UMMZ 149448 & Ameiva exsul & Culebra, Puerto Rico & q, cráneo \\
\hline UMMZ 200865 & Ameiva exsul & Guana, Islas Vírgenes & esqueleto completo \\
\hline UNRC 4468 & Cnemidophorus lacertoides & Córdoba, Argentina & esqueleto completo (T) \\
\hline UMMZ 189452 & Cnemidophorus lemniscatus & Amazonia, Brasil & $\hat{0}$, esqueleto completo \\
\hline HAA 85 & Cnemidophorus longicaudus & Mendoza, Argentina & esqueleto completo \\
\hline HAA 115 & Cnemidophorus longicaudus & Mendoza, Argentina & cráneo y postcráneo $(\mathrm{T})$ \\
\hline UNRC 7523 & Cnemidophorus longicaudus & San Juan, Argentina & esqueleto completo \\
\hline UMMZ 149522 & Cnemidophorus ocelifer & Bahía, Brasil & cráneo \\
\hline UNC C371 & Cnemidophorus serranus & Córdoba, Argentina & cráneo \\
\hline UNRC 5011 & Cnemidophorus serranus & Córdoba, Argentina & esqueleto completo \\
\hline UNRC 5796 & Cnemidophorus tergolaevigatus & La Rioja, Argentina & cráneo y postcraneo $(\mathrm{T})$ \\
\hline UNNE 4647 & Kentropyx viridistriga & Corrientes, Argentina & $\begin{array}{l}\text { J, cráneo y postcráneo } \\
\text { (T) }\end{array}$ \\
\hline UNNE 1062 & Kentropyx viridistriga & Corrientes, Argentina & $\begin{array}{l}\text { O, cráneo y postcráneo } \\
\text { (T) }\end{array}$ \\
\hline NMNH 292412 & Kentropyx calcarata & Rondônia, Brasil & esqueleto completo \\
\hline MZUSP 81580 & Kentropyx calcarata & - & cráneo \\
\hline MZUSP 82978 & Kentropyx calcarata & - & cráneo \\
\hline UMMZ 149550 & Aspidoscelis cadilipes & Michoacan, Méjico & esqueleto completo \\
\hline UMMZ 149457 & Aspidoscelis cadilipes & Michoacan, Méjico & o, cráneo \\
\hline UMMZ 149459 & Aspidoscelis cadilipes & Michoacan, Méjico & $\widehat{o}$, cráneo \\
\hline UMMZ 149460 & Aspidoscelis cadilipes & Michoacan, Méjico & Q subadulto, cráneo \\
\hline
\end{tabular}




\begin{tabular}{|c|c|c|c|}
\hline UMMZ 149574 & Aspidoscelis communis & Michoacan, Méjico & $\hat{o}$, esqueleto completo \\
\hline UMMZ 149464 & Aspidoscelis cozumela & Peten, Guatemala & cráneo \\
\hline UMMZ 149551 & Aspidoscelis deppii & Colima, Méjico & cráneo \\
\hline UMMZ 149552 & Aspidoscelis deppii & Oaxaca, Méjico & esqueleto completo \\
\hline UMMZ 138822 & Aspidoscelis exsanguis & New Mexico, EE.UU. &, , esqueleto completo \\
\hline UMMZ 149569 & Aspidoscelis exsanguis & Texas, EE.UU. & q, cráneo \\
\hline UMMZ 149553 & Aspidoscelis gularis & Texas, EE.UU. &, esqueleto completo \\
\hline NMNH 313460 & Aspidoscelis sexlineata & $\begin{array}{l}\text { Carolina del Norte, } \\
\text { EE.UU. }\end{array}$ & $\hat{\sigma}$, esqueleto completo \\
\hline UMMZ 149576 & Aspidoscelis sexlineata & Kansas, EE.UU. & q, esqueleto completo \\
\hline UNMdP-O 15 & Teius teyou & - & esqueleto desarticulado \\
\hline UNMdP-O 16 & Teius teyou & - & esqueleto completo \\
\hline UNMdP-O 22 & Teius teyou & - & esqueleto completo $(\mathrm{T})$ \\
\hline UNMdP-O 23 & Teius teyou & - & esqueleto completo $(\mathrm{T})$ \\
\hline UNC C365 & Teius teyou & Córdoba, Argentina & q, cráneo \\
\hline UNNE 1398 & Teius teyou & Formosa, Argentina & esqueleto completo $(\mathrm{T})$ \\
\hline UNNE 8715 & Teius teyou & Chaco, Argentina & $\widehat{\partial}$, esqueleto completo \\
\hline UNC C360 & Teius oculatus & Córdoba, Argentina & cráneo \\
\hline UNC C368 & Teius oculatus & Córdoba, Argentina & cráneo \\
\hline UNC C369 & Teius oculatus & Córdoba, Argentina & cráneo \\
\hline HAA 24 & Teius oculatus & - & esqueleto completo \\
\hline UNNE 4464 & Teius oculatus & Santa Fé, Argentina & cráneo y postcráneo $(\mathrm{T})$ \\
\hline UNNE 4462 & Teius oculatus & Santa Fé, Argentina & esqueleto completo \\
\hline UNC C366 & Teius suquiensis & - & cráneo \\
\hline UNC C367 & Teius suquiensis & - & cráneo \\
\hline UNRC 784 & Teius suquiensis & Córdoba, Argentina & esqueleto completo \\
\hline UNRC 1434 & Teius suquiensis & Córdoba, Argentina & esqueleto completo \\
\hline MNHN-cl-4112 & Callopistes maculatus & Pudahuel, Chile & $\hat{o}$, completo \\
\hline MNHN-cl-4113 & Callopistes maculatus & Lampa, Chile & $\hat{o}$, completo (D) \\
\hline MZUSP 92131 & Tupinambis duseni & Goiás, Brasil & cráneo \\
\hline UNMdP-O 1 & Tupinambis merianae & Córdoba, Argentina & cráneo (D) \\
\hline UNMdP-O 2 & Tupinambis merianae & Córdoba, Argentina & cráneo (D) \\
\hline UNMdP-O 3 & Tupinambis merianae & Córdoba, Argentina & cráneo (D) \\
\hline UNMdP-O 4 & Tupinambis merianae & Córdoba, Argentina & cráneo (D) \\
\hline UNMdP-O 5 & Tupinambis merianae & Córdoba, Argentina & cráneo (D) \\
\hline UNMdP-O 6 & Tupinambis merianae & Córdoba, Argentina & cráneo (D) \\
\hline UNMdP-O 7 & Tupinambis merianae & Córdoba, Argentina & cráneo (D) \\
\hline UNMdP-O 8 & Tupinambis merianae & Córdoba, Argentina & cráneo (D) \\
\hline UNMdP-O 9 & Tupinambis merianae & Córdoba, Argentina & cráneo (D) \\
\hline
\end{tabular}




\begin{tabular}{|c|c|c|c|}
\hline UNMdP-O 10 & Tupinambis merianae & Córdoba, Argentina & cráneo (D) \\
\hline UNMdP-O 11 & Tupinambis merianae & Córdoba, Argentina & cráneo (D) \\
\hline UNMdP-O 12 & Tupinambis merianae & Córdoba, Argentina & cráneo (D) \\
\hline UNMdP-O 13 & Tupinambis merianae & Córdoba, Argentina & cráneo (D) \\
\hline UNMdP-O 14 & Tupinambis merianae & Mar del Plata, Argentina & esqueleto completo \\
\hline UNMdP-O 17 & Tupinambis merianae & Córdoba, Argentina & cráneo (D) \\
\hline UNMdP-O 18 & Tupinambis merianae & Córdoba, Argentina & cráneo (D) \\
\hline UNMdP-O 19 & Tupinambis merianae & Córdoba, Argentina & cráneo (D) \\
\hline UNMdP-O 20 & Tupinambis merianae & Córdoba, Argentina & cráneo (D) \\
\hline UNMdP-O 24 & Tupinambis merianae & - & esqueleto completo $(\mathrm{T})$ \\
\hline UNMdP-O 25 & Tupinambis merianae & Córdoba, Argentina & cráneo $(\mathrm{T})$ \\
\hline UNMdP-O 26 & Tupinambis merianae & - & esqueleto completo \\
\hline UNMdP-O 28 & Tupinambis merianae & - & esqueleto completo \\
\hline UNMdP-O 32 & Tupinambis merianae & Córdoba, Argentina & esqueleto completo \\
\hline UNMdP-O 33 & Tupinambis merianae & Córdoba, Argentina & esqueleto completo \\
\hline UNMdP-O 35 & Tupinambis merianae & Córdoba, Argentina & esqueleto parcial \\
\hline UMMZ 190109 & Tupinambis merianae & - & cráneo \\
\hline MZUSP 84921 & Tupinambis quadrilineatus & - & $\begin{array}{l}\text { cráneo y postcráneo } \\
\text { parcial }\end{array}$ \\
\hline MZUSP 84928 & Tupinambis quadrilineatus & Goiás, Brasil & cráneo \\
\hline UNMdP-O 36 & Tupinambis rufescens & - & $\begin{array}{l}\text { juvenil, esqueleto } \\
\text { completo }\end{array}$ \\
\hline FML 7545 & Tupinambis rufescens & Salta, Argentina & Cráneo \\
\hline FML 7547 & Tupinambis rufescens & - & cráneo (D) y postcráneo \\
\hline FML 1336 & Tupinambis rufescens & Salta, Argentina & juvenil, cráneo completo \\
\hline FML 2560 & Tupinambis rufescens & $\begin{array}{l}\text { Santiago del Estero, } \\
\text { Argentina }\end{array}$ & $\begin{array}{l}+ \text {, juvenil, esqueleto } \\
\text { completo }\end{array}$ \\
\hline MZUSP 93082 & Tupinambis rufescens & Salta, Argentina & cráneo (D) \\
\hline MZUSP 93083 & Tupinambis rufescens & Salta, Argentina & cráneo (D) \\
\hline MZUSP 93084 & Tupinambis rufescens & Salta, Argentina & cráneo (D) \\
\hline NMNH 342486 & Tupinambis rufescens & Alto Paraguay, Paraguay & Cráneo \\
\hline NMNH 220279 & Tupinambis teguixin & - & $\sigma^{\lambda}$, esqueleto completo \\
\hline MZUSP 92087 & Tupinambis teguixin & $\begin{array}{l}\text { Límite São Paulo-Mato } \\
\text { Grosso, Brasil }\end{array}$ & cráneo (D) y postcráneo \\
\hline MZUSP 92149 & Tupinambis teguixin & $\begin{array}{l}\text { Límite São Paulo-Mato } \\
\text { Grosso, Brasil }\end{array}$ & cráneo (D) \\
\hline MZUSP 43042 & Tupinambis sp & - & cráneo (D) \\
\hline MZUSP 73309 & Tupinambis sp & Roraima, Brasil & cráneo (D) \\
\hline MZUSP 8526 & Crocodilurus amazonicus & - & cráneo \\
\hline
\end{tabular}




\begin{tabular}{|l|l|l|l|}
\hline MZUSP 12624 & Crocodilurus amazonicus & Pará, Brasil & esqueleto parcial \\
\hline MZUSP 92074 & Crocodilurus amazonicus & Pará, Brasil & cráneo (D) y postcráneo \\
\hline MZUSP 40082 & Dracaena guianensis & - & esqueleto completo \\
\hline NMNH 220278 & Dracaena guianensis & Mato Grosso, Brasil & cráneo (D) \\
\hline MZUSP 62849 & Dracaena paraguayensis & Misiones, Argentina & esqueleto parcial (D) \\
\hline \multicolumn{5}{|l|}{ Amphisbaenia } \\
\hline
\end{tabular}

Tabla 5. Especímenes actuales utilizados en este trabajo. Abreviaturas: D, desarticulado, T, transparentado.

\section{MÉTODOS}

\subsection{Preparación técnica del material}

El material fósil, salvo excepciones, no necesitó preparación. En aquellos casos en que fue necesario prepararlo, se hizo de forma mecánica utilizando aguja y laca bajo lupa estereoscópica.

La preparación del material osteológico se realizó removiendo manualmente cuero, vísceras y musculatura. A la carcasa en este estado se la sumergió en una solución concentrada de cloro (aprox. 80\%). El tiempo de permanencia en esta solución varió según el tamaño del ejemplar, desde un minuto (gimnoftálmidos) a más de diez minutos (Tupinambis). La solución se revisó constantemente comprobando que no afectara fuertemente a los cartílagos, que al desintegrarse más rápido que los huesos, sirven de indicador del avance del proceso de maceración. El material posteriormente fue lavado con abundante agua corriente. Mediante la utilización de una lupa estereoscópica se extrajeron los remanentes de tejido blando. En los casos donde se contaba con varios ejemplares de una misma especie, se desarticuló el cráneo completamente. Esto se logró sumergiendo el material en agua caliente (no hervida); el tiempo de inmersión dependió del tamaño del ejemplar. Se retiró el material del agua y se le aplicó una ligera fuerza desarticulando los huesos; si ésto no era logrado, entonces se sumergió nuevamente al ejemplar en agua caliente. Una técnica similar, pero menos agresiva sobre el tejido óseo, fue dejar las carcasas en agua con un calentador eléctrico (estándar de acuario) y jabón enzimático de uso común ya que este método facilita la desarticulación total de los ejemplares. El blanqueado de los huesos con peróxido de hidrógeno $\left(\mathrm{H}_{2} \mathrm{O}_{2}\right)$ diluido fue contraproducente a la hora de estudiar los huesos, razón por la cual no se realizó en la 
mayoría de los ejemplares. Un conjunto menor de ejemplares fueron transparentados siguiendo el método de Wassersug (1976), que permite observar el esqueleto articulado diferenciando huesos (teñidos de rojo) de cartílagos (teñidos de azul).

\subsection{Sistemática}

Como se mencionó en el Capítulo I, se sigue la clasificación de Estes et al. (1988) para niveles taxonómicos supragenéricos (Tabla 1). La sistemática de los géneros y especies argentinas responde esencialmente a Cei $(1986,1993)$, con algunas modificaciones posteriores. Entre estas últimas se destaca el arreglo sistemático de Doan (2003) para los Gymnophthalmidae y las modificaciones de la familia Teiidae.

Debido a que la mayoría de los materiales fósiles estudiados pueden referirse a la familia Teiidae se considera particularmente la taxonomía de la misma. La clasificación de esta familia ha sido compleja y cambiante. Boulenger (1885) la subdivide en cuatro Grupos (i.e. I, II, III y IV) diferenciados por su morfología externa. El Grupo I de Boulenger pasó a ser conocido como los macroteidos, mientras que los microteidos abarcan a los Grupos restantes (II al IV). MacLean (1974) y Presch (1974a) consideran a los macroteidos y microteidos, como dos subfamilias de los Teiidae sensu Boulenger, las cuales denominan como los Teiinae y los Gymnophthalminae, respectivamente. Presch (1974a), en base a un análisis de similitud, reconoce dos tribus entre los Teiinae: Teiini y Tupinambini. Estes (1983a) modifica el esquema de Boulenger (1885) al considerar que los microteidos (Gymnophthalminae) presentan diferencias osteológicas que ameritan su reconocimiento como una familia aparte, Gymnophthalmidae. La Familia Teiidae sensu Estes (1983a) comprende dos subfamilias: Teiinae y Polyglyphanodontinae. Entre los Teiinae, Estes (1983a) reconoce las dos tribus propuestas por Presch (1974a), donde ubica a todos los géneros actuales y algunas formas fósiles como Meniscognatus, Peneteius y posiblemente Leptochamops entre los Teiini, y Chamops entre los Tupinambini. En la subfamilia Polyglyphanodontinae, este autor incluye un importante número de lagartos fósiles del Cretácico de América del Norte, Asia central y Europa (Sulimski, 1975, Estes, 1983a; Nydam y Cifelli, 2002a, b; Folie y Cordera, 2005; Makádi, 2006; Nydam y Voci, 2007). De esta manera, Estes (1983a) desestima la división hecha por Sulimski $(1975,1978)$ de este grupo de lagartos cretácicos (Polyglyphanodontidae, Macrocephalosauridae y Adamisauridae). E1 
arreglo de Estes (1983a) ha sido modificado posteriormente por varios autores. Por un lado, Ávila-Pires (1995) eleva a la categoría de subfamilia a las dos tribus de Presch (1974a) (Teiinae y Tupinambinae), mientras que los demás arreglos (Alifanov, 1993; Denton y O’Neill, 1995; Nydam y Cifelli, 2002b) coinciden en excluir los fósiles Cretácicos de los Tupinambinae y Teiinae pero mantenerlos dentro de la familia Teiidae. Recientemente, Nydam et al. (2007) separan de la Familia Teiidae a los fósiles del Cretácico, incluyéndolos en la familia Borioteiioidea, grupo hermano de los Teiioidea (Teiidae + Gymnophthalmidae). La afinidad de los Teiidae sensu Nydam et al. (2007) y los Borioteiioidea se refleja en las siguientes características que comparten: abundante cemento sobre las bases de los dientes; alvéolos de reemplazo profundos y subcirculares; y un esplenial hipertrofiado, anteriormente desarrollado. Estos caracteres se revierten en los Gymnophthalmidae. Conrad (2008) presenta una hipótesis filogenética y taxonomia distinta. Para este autor los Teiioidae son escencialmente los Teiioidea de Estes et al. (1988) más los Polyglyphanodontidae entre los cuales ubica a Sineoamphisbaena. Al mismo tiempo Conrad (2008) agrupa en un nuevo taxón, Macroteiida, a todos sus Teiioidea a excepción de los Gymnophthalmidae y Chamops. Entre los Macroteiida Conrad (2008) reconoce dos agrupamientos: los Teiidae y los Polyglyphanodontidae. En los Teiidae se observa la dicotomia Teiinae - Tupinambinae, mientras que los Polyglyphanodontidae presenta una composición diferente a la propuesta por otros autores (e.g. Nydam et al., 2007). A lo largo de la tesis se siguen las conclusiones de Nydam et al. (2008) por ser este un trabajo más acotado a los objetivos aquí planteados.

La subdivisión entre Teiinae y Tupinambinae es generalmente aceptada (Presch, 1974a; Estes 1983a; Denton y O’Neill, 1995; Giugliano et al. 2007; Nydam y Cifelli, 2002b; Nydam et al., 2007; Conrad, 2008) aunque con variaciones en su composición en algunos casos (Teixeira, 2003: en Giugliano et al. 2007). Algunos autores no reconocen estas subfamilias (Moro y Abdala, 2000) u obtienen un bajo soporte para las mismas (Nydam y Cifelli, 2002b). Entre los Teiinae, Dicrodon y Teius se consideran basales a los "cnemidoforinos". Este último es un grupo monofilético informal que incluye a los géneros "Ameiva", Aspidoscelis, “Cnemidophorus" y Kentropyx (Norell, 1989; Reeder et al., 2002: Giugliano et al., 2007), donde “Ameiva" y "Cnemidophorus" son considerados parafiléticos (Presch, 1974a; Reeder et al., 2002; Giugliano et al., 2007) (Tabla 6). El reconocimiento de Aspidoscelis como género válido por Reeder et al. (2002) ha implicado cambios 
nomenclaturales de masculino a fenemino de los epítetos específicos de varias especies (e.g. "C." sexlineatus a A. sexlineata).

\section{TEIIDAE Gray 1827}

TEIINAE Presch, 1974a

Dicrodon Duméril y Bibron, 1839

Teius Merrem, 1820

"cnemidoforinos"

“Ameiva” Meyer, 1795

Aspidoscelis (Reeder et al., 2002)

"Cnemidophorus" Wagler, 1830

Kentropyx Spix, 1825
TUPINAMBINAE Presch, 1974a

Callopistes Gravenhorst 1838

Crocodilurus Spix, 1825

Dracaena Daudin, 1802

Paradracaena Sullivan y Estes, 1997

Tupinambis Daudin, 1802

Tabla 6. Clasificación de la familia Teiidae según el esquema tradicional.

La situación entre los Tupinambinae no es menos compleja (Tabla 7). Las relaciones genéricas de esta subfamilia no están resueltas, a excepción de la posición basal de Callopistes (Presch, 1974a; Denton y O'Neill, 1995; Sullivan y Estes, 1997; Nydam y Cifelli, 2002b; Giugliano et al. 2007; Nydam et al., 2007). Los géneros Callopistes, Crocodilurus y Dracaena han tenido una historia nomenclatural sin mayores cambios, posiblemente dado su bajo número de especies. Se destaca el cambio nomenclatural sufrido por Crocodilurus lacertinus Daudin 1802, considerado inválido, y su reemplazo por Crocodilurus amazonicus (Massary y Hoogmoed, 2001). El restante género de Tupinambinae, Tupinambis, ha tenido una historia nomenclatural confusa y cambiante a pesar de ser uno de los lagartos más conspicuos de la herpetofauna sudamericana por su tamaño corporal. Hasta el trabajo de Presch (1973) se reconocían cuatro especies: T. duseni, T. nigropunctatus, T. rufescens y T. teguixin. Este autor sinonimiza T. nigropunctatus con T. teguixin y $T$. duseni con $T$. 
rufescens, reduciendo a dos las especies del género. Más recientemente Ávila-Pires (1995), contra lo propuesto por Presch (1973), valida las especies T. merianae (previamente T. teguixin), T. teguixin (previamente T. nigropunctatus) y describe una nueva especie, T. longilineus. Posteriormente, Manzani y Abe (1997) describen $T$. quadrilineatus que tiene prioridad sobre la descripción de Colli et al. (1998: T. cerradensis). Manzani y Abe (2002) describen un nueva especie, T. palustris, considerada sinónimo de T. teguixin por Péres Jr (2003). Por último, Péres Jr y Colli (2004) validan las especies T. duseni y T. rufescens. Hsiou (2007) describe la única especie extinta del género, T. uruguaianensis, del Pleistoceno tardío de Rio Grande do Sul (Brazil).

TUPINAMBINAE Presch, 1974a

Callopistes Gravenhorst 1838

Callopistes flavipunctatus Duméril y Bibron 1839

Callopistes maculatus Gravenhorst 1838

† Callopistes bicuspidatus Chani 1976

Crocodilurus Spix, 1825

Crocodilurus amazonicus Daudin, 1802

Dracaena Daudin, 1802

Dracaena guianensis Daudin 1802

Dracaena paraguayensis Amaral 1950

Paradracaena Sullivan y Estes, 1997

† Paradracaena colombiana Sullivan y Estes, 1997

Tupinambis Daudin, 1802

Tupinambis duseni Lönnberg 1896

Tupinambis longilineus Ávila-Pires 1995

Tupinambis merianae (Duméril y Bibron 1839)

Tupinambis quadrilineatus Manzani y Abe 1997

Tupinambis rufescens (Günther 1871)

Tupinambis teguixin (Linnaeus 1758)

$\dagger$ Tupinambis uruguaianensis Hsiou 2007

Tabla 7. Integrantes de la subfamilia Tupinambinae. 


\subsection{Análisis morfológico}

Una importante parte del desarrollo de la Tesis corresponde a las descripciones morfológicas de los diferentes fósiles. Estas descripciones se realizaron a partir de la observación directa del material fósil a través de un microscopio estereoscópico y la confrontación con el material de referencia. En el caso de no disponer de ejemplares se recurrió a la bibliografía. Los fósiles fueron fotografiados con una cámara digital estándar (Nikon Coolpix 4600) sobre un pequeño trípode o montada sobre un microscopio estereoscópico (Arcano ZTX 1:4). Los fósiles más relevantes fueron fotografiados, sin metalizar, mediante un Microscopio Electrónico de Barrido (Philips XL series 30) en el Museo Argentino de Ciencias Naturales "Bernardino Rivadavia". Todas las figuras fueron luego preparadas digitalmente con diferentes programas de diseño.

El análisis y comparación de los fósiles permitió reconocer diferentes caracteres y sus distintos estados (ver Análisis Filogenético). Estos últimos se utilizaron para la asignación taxonómica de los fósiles. A lo largo del texto, se hace referencia a los diferentes caracteres citando el número particular de un carácter, entre corchetes, según la numeración que se le asignó en la sección de Análisis Filogenético.

La estimación de la edad relativa de los individuos asignados a Tupinambis sp., representados en los ejemplares fósiles, se basó en la morfología de los dientes comparada con una serie ontogenética de la especie T. merianae. Esta estimación es aproximada ya que se desconoce el patrón de variación ontogenético en otras especies del género.

\subsubsection{Terminología}

La terminología osteológica de los lagartos es compleja y en la literatura se encuentran a menudo diferentes nombres para la misma estructura. La sinonimia implica homología, pero el mal uso de los términos puede, en el caso de cladística, llevar a interpretaciones filogenéticas erróneas. En este trabajo se sigue, para la anatomía craneal, principalmente a Montero et al. (2004). Estos autores plantean una base para la estandarización de los nombres de los elementos esqueléticos de Tupinambis rufescens en español, basándose en trabajos fundamentales como los de Oelrich (1956), Romer (1956) y Barberena et al. (1975), entre otros. Al igual que 
Montero et al. (2004) la terminología de los elementos postcraneales que se adoptó en este trabajo sigue principalmente a Krause (1978a, b, 1990) y Veronese y Krause (1997).

Para la dentición se adoptaron las consideraciones terminológicas planteadas por Peyer (1968), Edmund (1969) y, más recientemente, Smith y Dodson (2003). En cuanto a la implantación dentaria se sigue el criterio de Presch (1974b) y las consideraciones de Budney et al. (2006) y Caldwell et al. (2003).

Los elementos seriales (e.g. dientes, forámenes mentales, etc) son numerados con caracteres arábicos en sentido anteroposterior. Las posiciones dentarias absolutas son numeradas con caracteres romanos, pero esta numeración no implica homología serial. 
2.3.2. Abreviaturas

Institucionales

GHUNLPam Facultad de Cs. Exactas y Naturales, Universidad Nacional de La Pampa, Santa Rosa, provincia de La Pampa, Argentina

HAA Colección herpetológica privada de Adriana Albino, Mar del Plata, provincia de Buenos Aires, Argentina

MACN Museo Argentino de Ciencias Naturales "Bernardino Rivadavia", Ciudad Autónoma de Buenos Aires, Argentina

MCS Museo Regional Cinco Saltos, Cinco Saltos, provincia de Río Negro, Argentina

MLP Museo de La Plata, La Plata, provincia de Buenos Aires, Argentina

MMP Museo Municipal de Ciencias Naturales "Lorenzo Scaglia", Mar del Plata, provincia de Buenos Aires, Argentina

MNHN cl Museo Nacional de Historia Natural, Santiago, región Metropolitana, Chile

MZUSP Museu da Zoologia, Universidade de São Paulo, São Paulo, Estado de São Paulo, Brasil

NMNH National Museum of Natural History, Washington D.C., EE.UU.

FML Fundación Miguel Lillo, Universidad Nacional de Tucumán, San Miguel de Tucumán, provincia de Tucumán, Argentina

UMMZ University of Michigan Museum of Zoology, Ann Arbor, Michigan, EE.UU.

UNC Universidad Nacional de Córdoba, Córdoba, provincia de Córdoba, Argentina

UNMdP Colección Herpetológica Laboratorio de Vertebrados, Facultad de Ciencias Exactas y Naturales, Universidad Nacional de Mar del Plata, Mar del Plata, provincia de Buenos Aires, Argentina

UNMdP-O Colección Herpetológica- Sección Osteología, Departamento de Biología, Universidad Nacional de Mar del Plata, Mar del Plata, provincia de Buenos Aires, Argentina

UNNE Universidad Nacional del Noreste, Resistencia y Corrientes, provincias de Chaco y Corrientes, Argentina

UNRC Universidad Nacional de Río Cuarto, Río Cuarto, provincia de Córdoba, Argentina

\section{Osteológicas}

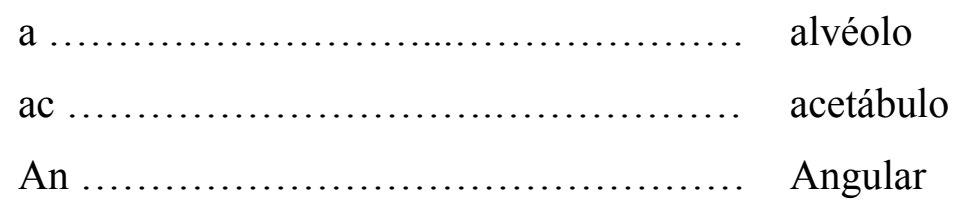




\begin{tabular}{|c|c|}
\hline 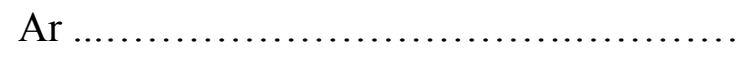 & Articular \\
\hline a.r . & alvéolo de reemplazo \\
\hline bO ......... & Basioccipital \\
\hline$c \ldots \ldots \ldots$ & carpal \\
\hline $\mathrm{cM}$.. & canal de Meckel \\
\hline Co ..... & Coronoides \\
\hline co.t $\ldots \ldots \ldots \ldots$ & concha timpánica \\
\hline Cor .......... & Coracoides \\
\hline 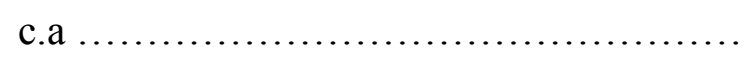 & cóndilo anterior del Fémur \\
\hline c.a.E ... & carilla de articulación para el Escamoso \\
\hline c.a.Es ... & carilla de articulación para el Esplenial \\
\hline c.a.i. ..... & canal alveolar inferior \\
\hline c.a.s. ... & canal alveolar superior \\
\hline c.a.Y ... & carilla de articulación para el Yugal \\
\hline c.a.V ... & carilla de articulación para el Vómer \\
\hline c.c .... & canal de carótida \\
\hline c.ce ... & cóndilo cefálico del cuadrado \\
\hline c.cn ..... & cresta cnemial de la Tibia \\
\hline c.dp . & cresta deltopectoral del Húmero \\
\hline c.h . & cresta horizontal del proceso retroarticular \\
\hline c.in . & cresta innominada de la Tibia \\
\hline c.iz . & cresta interzigapofisiaria \\
\hline c.g .... & cavidad gleniodea \\
\hline c.m . & cresta medial del Cuadrado \\
\hline c.m.i . & canal mental inferior \\
\hline c.p .. & cóndilo posterior del Fémur \\
\hline c.p.C....... & cresta posterior del Cuadrado \\
\hline$\ldots \ldots \ldots \ldots \ldots \ldots \ldots \ldots \ldots \ldots \ldots \ldots \ldots \ldots$ & cresta prearticular \\
\hline c.rar . & cresta retroarticular \\
\hline$\ldots \ldots \ldots \ldots \ldots \ldots$ & cresta sagital del centro vertebral \\
\hline c.sl . & cresta semilunar \\
\hline$\ldots \ldots \ldots \ldots \ldots \ldots$ & cresta timpánica del cuadrado \\
\hline & canal vidiano \\
\hline
\end{tabular}




\begin{tabular}{|c|c|}
\hline 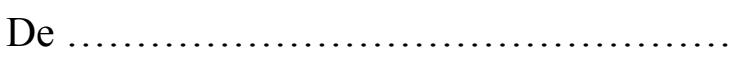 & Dentario \\
\hline 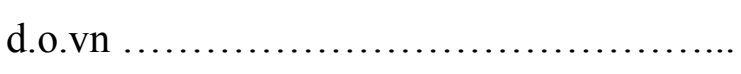 & depresión del órgano vómero-nasal \\
\hline$\ldots \ldots \ldots \ldots \ldots \ldots \ldots \ldots \ldots \ldots \ldots \ldots$ & diente pterigoideo \\
\hline d.r . & diente de reemplazo \\
\hline e.n . & espina neural \\
\hline Eppt ..... & Epipterigoides \\
\hline Ecpt & Ectopterigoides \\
\hline Es . & Esplenial \\
\hline Esc .... & Escápula \\
\hline Esca .... & Escamoso \\
\hline e.sbd ... & estante subdental \\
\hline e.spd .. & estante supradental $=$ plataforma palatal \\
\hline Fr. & Frontal \\
\hline f.al ..... & foramen alveolar \\
\hline f.an .. & foramen anterior del Suprangular \\
\hline f.bpt ..... & fosa basipterigoidea \\
\hline f.c ....... & fosa columelar del Pterigoides \\
\hline f.c.a .. & fenestra coracoidea anterior \\
\hline f.c.a.i ... & foramen del canal alveolar inferior \\
\hline$\ldots \ldots \ldots \ldots \ldots \ldots$ & foramen del canal alveolar superior \\
\hline f.c.p ... & fenestra coracoidea posterior \\
\hline (n................... & fenestra escapulocoracoidea \\
\hline f.infe ... & faceta infracoronoidea del Suprangular \\
\hline f.f.p ... & foramen de la fosa poplítea \\
\hline f.ic ...... & fosa intercondilar del Fémur \\
\hline f.la .. & foramen labial \\
\hline f.m . & foramen mental \\
\hline f.mh.a .... & foramen milohioideo anterior \\
\hline f.mh.p .. & foramen milohioideo posterior \\
\hline$\ldots \ldots \ldots \ldots \ldots \ldots \ldots$ & fosa pterigoidea del Pterigoides \\
\hline$\ldots \ldots \ldots \ldots \ldots \ldots \ldots \ldots \ldots \ldots \ldots \ldots \ldots \ldots \ldots \ldots \ldots \ldots \ldots \ldots \ldots$ & foramen supracoracoideo \\
\hline$\ldots \ldots \ldots \ldots \ldots \ldots \ldots \ldots$ & foramen suborbital del Yugal \\
\hline 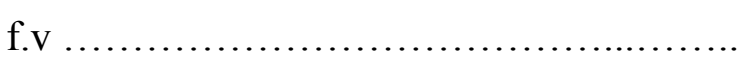 & foramen ventral centro vertebral \\
\hline
\end{tabular}




\begin{tabular}{|c|c|}
\hline hp $\ldots \ldots \ldots \ldots \ldots \ldots \ldots \ldots \ldots \ldots \ldots \ldots \ldots \ldots \ldots \ldots$ & hipapófisis \\
\hline$\ldots \ldots \ldots \ldots \ldots \ldots \ldots \ldots \ldots \ldots \ldots \ldots$ & lámina transversal del Maxilar \\
\hline $\mathrm{mc} \ldots .$. & Metacarpal \\
\hline $\mathrm{msc} \ldots$ & Mesocoracoides \\
\hline $\operatorname{mtc} \ldots$. & Metacoracoides \\
\hline$m . v \ldots \ldots$ & margo ventralis \\
\hline n.a.i ........... & foramen del nervio alveolar inferior \\
\hline oes ... & Orbitoesfenoides \\
\hline $\mathrm{oO} \ldots$ & Otooccipital \\
\hline $\mathrm{Pa} \ldots . .$. & Parietal \\
\hline 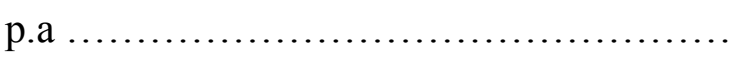 & proceso alar del Cuadrado \\
\hline Pal . & Palatino \\
\hline $\mathrm{pbE}$. & Parabasiesfenoides \\
\hline $\mathrm{pF}$ & Prefrontal \\
\hline poF $\ldots . . .$. & Postfrontal \\
\hline poO ......... & Postorbital \\
\hline poZ . & postzigapófisis \\
\hline $\operatorname{prO} \ldots$. & Proótico \\
\hline $\operatorname{prZ}$. & Prezigapófisis \\
\hline p.a.ar ....... & proceso anterior del Articular \\
\hline p.al .................................... & proceso anterolateral del Parietal \\
\hline p.al.Ecpt . & proceso anterolateral del Ectopterigoides \\
\hline p.ala.pbE . & proceso alar del Parabasiesfenoides \\
\hline p.am . & proceso anteromedial del Parietal \\
\hline p.am.poF . & proceso anteromedial del Postfrontal \\
\hline p.an .. & proceso Angular \\
\hline p.b . & proceso Basipterigoideo \\
\hline p.c ... & proceso cuadrado del Pterigoides \\
\hline p.F . & proceso frontal del Maxilar \\
\hline p.i $\ldots$. & proceso inferior del Proótico \\
\hline 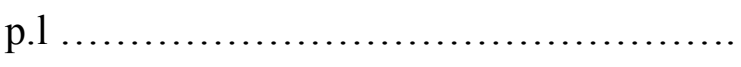 & proceso lateral del Postfrontal \\
\hline p.1.B.. & proceso lateral del Basiesfenoides \\
\hline p.1.pF . & proceso lacrimal del Prefrontal \\
\hline
\end{tabular}


p.la.s.d

p.li.s.d

p.m

p.Mx

p.Mx.Pa

p.od

p.Pa

p.pac

p.pc

p.pd

p.pF

p.pl

p.pl.Ecpt

p.pm.Co

p.pm.poF

p.pv

p.pz

p.ra

p.sa

p.so

p.t . .

p.t.Pt

p.te

r.l.s.n

si

$\sin$

$\mathrm{sO}$

St .

$\mathrm{Su}$

s.a.Es

s.a.h

s.a.Y

s.d pared labial del surco dental

pared lingual del surco dental

proceso medial vertebral

proceso maxilar del Prefrontal

proceso maxilar del Palatino

proceso odontoideo

proceso palatino del Prefrontal

proceso preacetabular del Ilion

proceso procoracoides

proceso posterodorsal del Dentario

proceso prefrontal del Maxilar

proceso posterolateral del Ectopterigoides

proceso posterolateral del Ectopterigoides

proceso posteromedial del Coronoides

proceso posteromedial del Postfrontal

proceso posteroventral del Dentario

proceso prezigapoficiario

proceso retroarticular

proceso sacro del Ilion

proceso supraorbital del Prefrontal

proceso transverso de la vértebra

proceso transverso del Pterigoides

proceso temporal

receso lateral del saco nasal del Maxilar

sínfisis mandibular

sinapófisis

Supraoccipital

Supratemporal

Suprangular

superficie de articulación para el Esplenial superficie de articulación de la hipapófisis superficie de articulación para el Yugal sulcus dentalis 


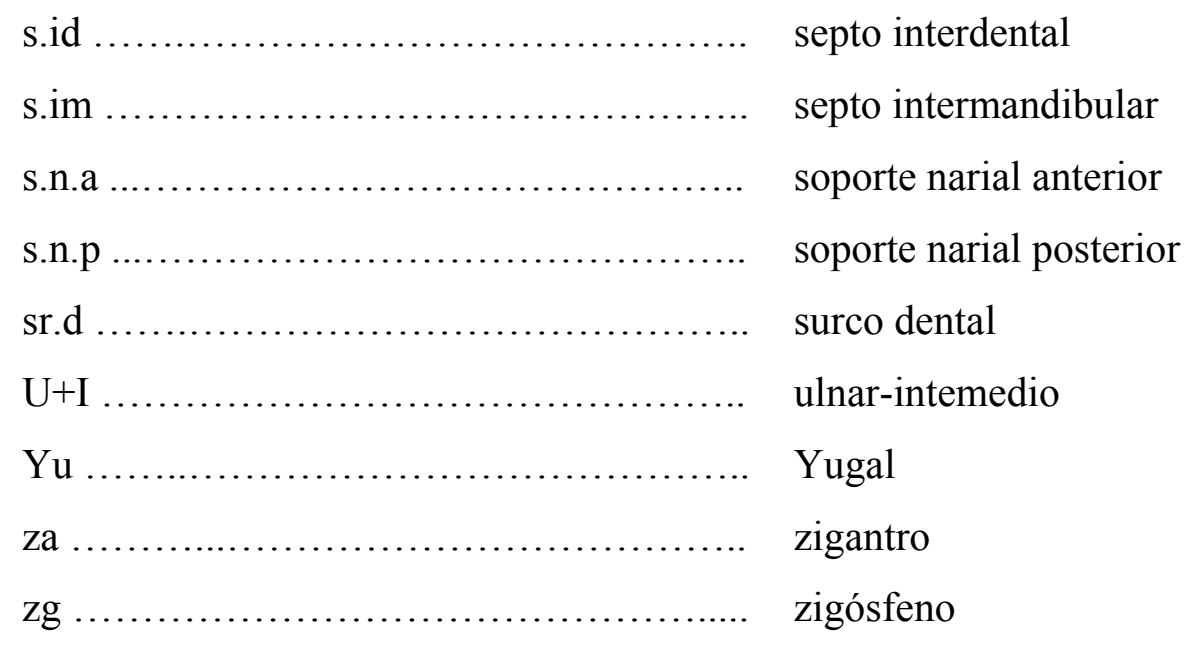

Abreviaturas de medidas

anatómicas

LHC longitud hocico-cloaca

LSDd

longitud de la serie dentaria del dentario. Promedio de valor izuierdo y derecho cuando están disponibles.

LSDm

longitud de la serie dentaria del dentario. Promedio de valor izuierdo y derecho cuando están disponibles.

\subsection{Análisis filogenético}

El análisis filogenético realizado en esta tesis se centró en la familia Teiidae. Como grupo externo se utilizaron representantes de diferentes familias de Scleroglossa, las cuales incluyeron a los Gymnophthalmidae, considerado el grupo externo más cercano a los Teiidae (ver punto 2.2 y Fig. 1), los Scincidae, que son Scincomorpha no Teiioidea, y los Anguidae, que son Scleroglossa no Scincomorpha.

Del estudio del material de referencia, y de diferentes fósiles, se tomaron caracteres osteológicos, en su mayoría discretos (binarios y multiestado), los cuales fueron considerados no aditivos. Por lo tanto, el criterio de parsimonia utilizado fue el de Fitch (1971). Cuando no fue posible identificar un estado en algún taxón, se lo codificó como entrada faltante (codificada con un signo de interrogación). En los casos donde un carácter no fuese aplicable, se agregó un estado adicional "no aplicable”. La matriz de datos final (36 taxones x 158 caracteres) fue analizada con el 
programa TNT (Tree analisys using new technology, Goloboff et al., 2003, 2008). El análisis de la matriz fue heurístico ya que el elevado número de taxones imposibilita una búsqueda exacta.

\subsection{Escala temporal y orden de presentación de los materiales estudiados}

Con modificaciones, la escala de pisos continentales propuesta por Ameghino (1909) constituye todavía hoy el esquema básico de la escala temporal sudamericana (ver referencias en Cione et al., 2007). Ameghino (1909) reconocía conjuntos de rocas ordenadas, "formaciones" subdivididas en pisos caracterizadas por su contenido fósiles, lo que permitía su correlación, resultando en una escala cronológica relativa. Sin embargo, no fue hasta el trabajo de Pascual et al. (1965), basándose en el de Simpson (1940), que se definen para el Cenozoico de América del Sur un conjunto de Edades Mamíferos secuenciales que sirven de escala bioestratigráfica relativa. Una de las razones que motivaron la proposición de Edades Mamífero fue la falta de subdivisiones litoestratigráficas formales de la gran mayoría de las unidades mamalíferas de Argentina (Pascual et al., 1965). Estos autores consideran que su concepto de Edad Mamífero es similar a la de los pisos de Ameghino. Diferentes trabajos han observado un ordenamiento jerárquico de las Edades Mamíferos en subciclos, ciclos, episodios y eventos faunísticos (Ortiz Jaureguizar, 1986; Pascual y Ortiz Jaureguizar, 1990; Pascual et al. 1996), reflotando el esquema de Kraglievich (1930) e indicando una correlación de la estructura faunística con cambios climáticoambientales de escala creciente. La mayoría de las localidades tipo de las Edades Mamíferos del Paleógeno se encuentran en Patagonia. Recientemente, Vucetich et al. (2007) presentaron las correlaciones actualizadas de las diferentes Edades Mamíferos del Paleógeno de Argentina (Fig. 5). 


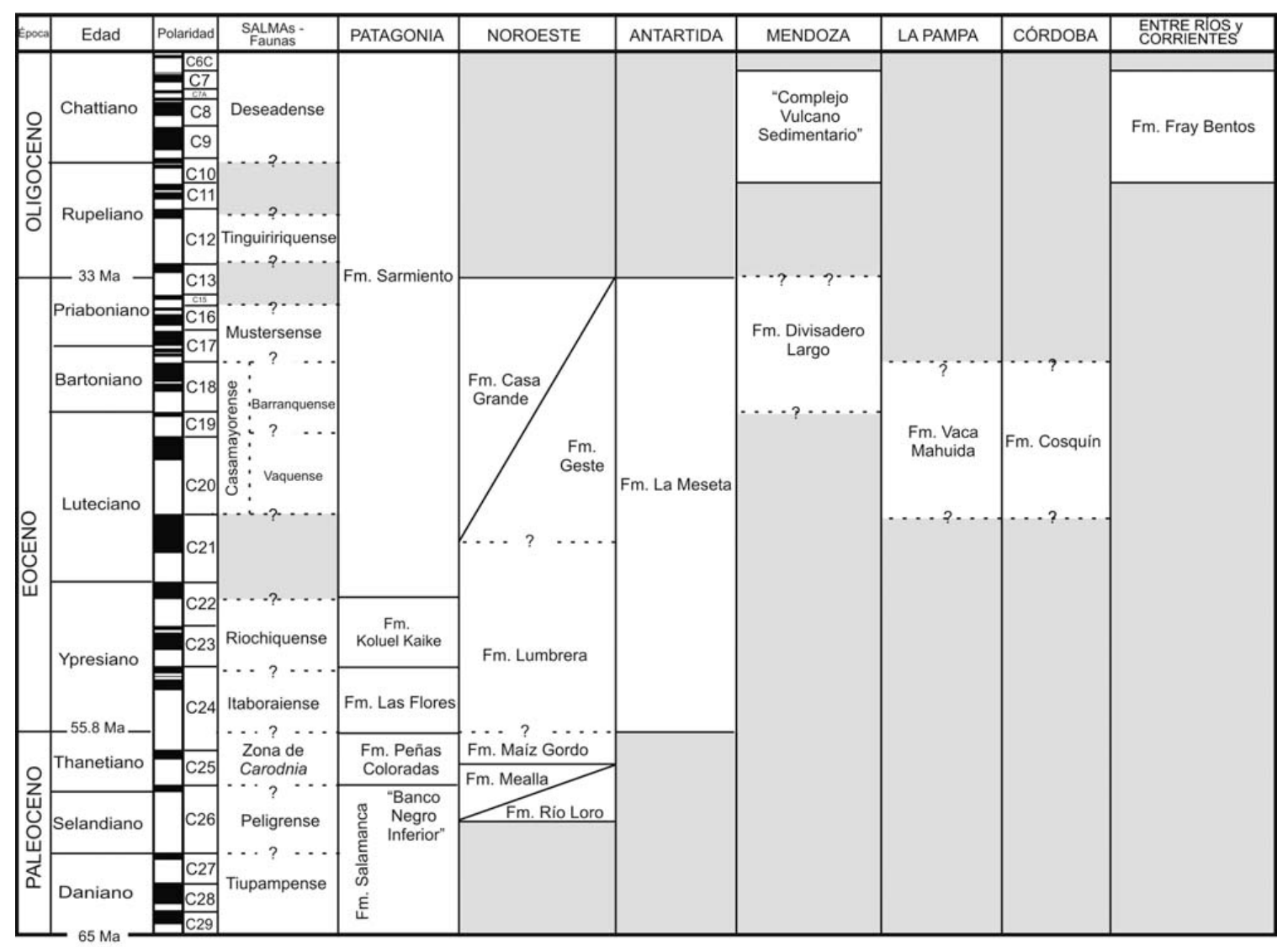

Figura 5. Cuadro estratigráfico del Paleógeno de Argentina y su comparación con la escala global. (tomado de Vucetich et al. 2007).

Como ocurre para el Paleógeno, el esquema bioestratigráfico vigente para el Neógeno está basado en los trabajos de Ameghino (1880, 1889), Kraglievich (1952), y modificaciones propuestas por Pascual et al. (1965) sobre el concepto de Edades Mamífero (Fucks y Deschamps, 2008). La mayoría de las localidades tipo de las Edades Mamíferos del Neógeno se distribuyen mayoritariamente en la región pampeana (Tonni y Fidalgo 1979; Cione y Tonni 2005).

El uso de las Edades Mamíferos ha sido cuestionado (ver Cione y Tonni, 1995b) ya que se considera que presentan un pobre respaldo estratigráfico (Cione y Tonni, 1995b: 144) y se ha sugerido el abandono de los términos "Edad Mamífero" y el uso de los términos "Piso/Edad" (Cione y Tonni, 1995b). Esta visión se refleja en el esquema bioestratigráfico propuesto por Cione y Tonni (2005) para los sedimentos Neógenos de la región Pampeana, seguido por otros autores (e.g. Cione et al., 2007). Los Pisos/Edad están definidos por biozonas que dan soporte al esquema de unidades cronoestratigráficas presentado en la Figura 6. 


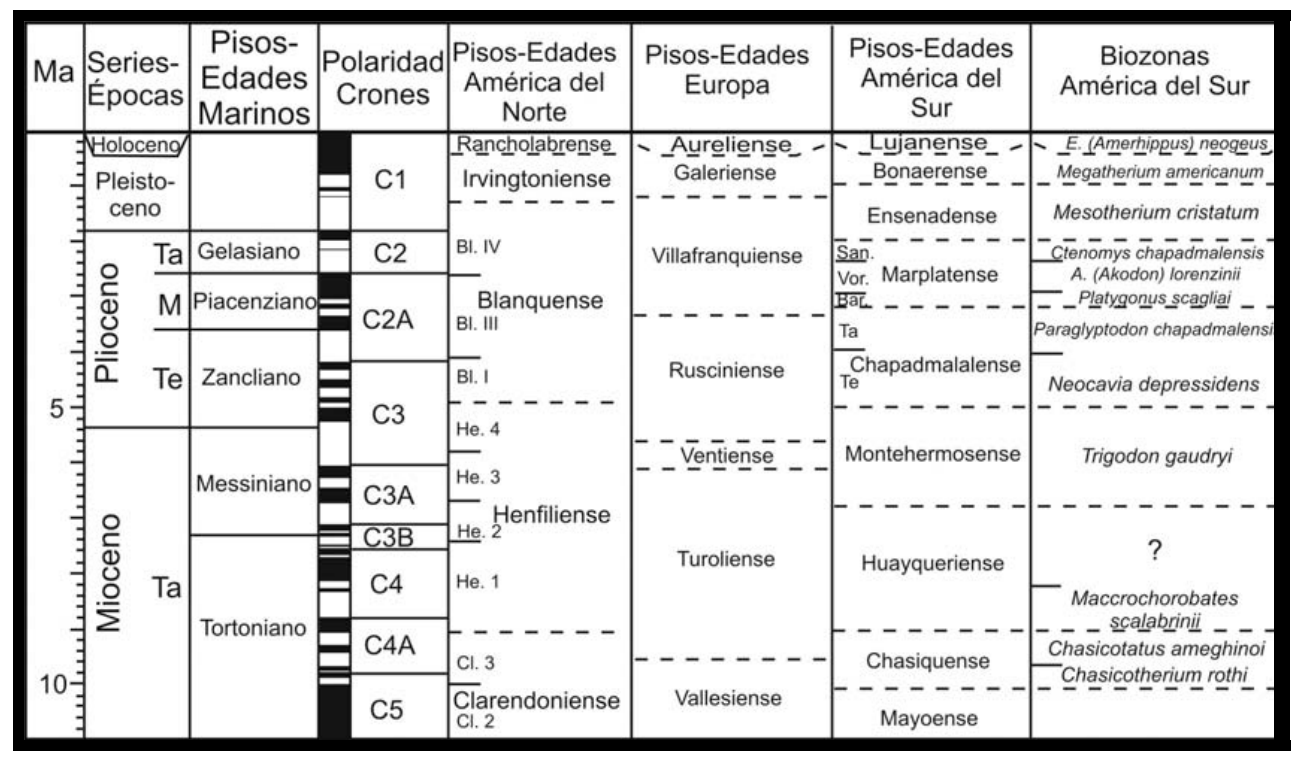

Figura 6. Cuadro cronológico comparativo continental del Neógeno tardío hasta la actualidad. A causa de la escala no se incluye al Platense (modificado de Cione et al., 2007).

Por lo expuesto, la escala temporal seguida en este trabajo es relativa. Para el Mesozoico se basa en una secuencia de Formaciones geológicas, mientras que la cronología y biocronología de las unidades litoestratigráficas del Cenozoico siguen las recientes revisiones de Vucetich et al. (2007) y Cione et al (2007).

El material fósil descripto a lo largo de la Tesis se presenta en orden cronológico, ordenado en tres intervalos de tiempo: Mesozoico, Paleógeno y Neógeno. 


\section{CAPITULO III}

\section{ESQUELETO CRANEAL, DENTICIÓN Y ESQUELETO AXIAL DE TUPINAMBIS MERIANAE}

Con motivo de facilitar la comprensión por parte del lector de las descripciones de los fósiles y debido a que un porcentaje importante de los materiales corresponden al género de lagarto actual Tupinambis (Scincomorpha: Teiidae), se presenta a continuación una breve descripción general del esqueleto craneal de Tupinambis merianae. Esta descripción hace hincapié en estructuras poco mencionadas en la bibliografía, destaca aspectos útiles para la asignación sistemática y define la nomenclatura utilizada.

El cráneo de T. merianae ha sido descripto por Barberena et al. (1970), mientras que Krause describió el esqueleto axial (1978a) y apendicular (1978b). Los trabajos de Reese (1923) y Montero et al. (2004), donde se describe el esqueleto de $T$. nigropuctatus (T. teguixin según Ávila-Pires, 1995) y figura el de T. rufescens respectivamente, son los dos únicos trabajos adicionales sobre la osteología de este género. MacLean (1974) y Veronese y Krause (1997) han hecho aportes generales adicionales a la osteología del género.

\section{CRÁNEO}

El cráneo de T. merianae está compuesto por 46 huesos, que se describen de acuerdo a su exposición en vistas dorsal, lateral, ventral y posterior.

Vista dorsal (Fig. 7 A). El hueso más anterior es el premaxilar (impar). Presenta dos procesos: el proceso ascendente y el proceso maxilar (par, izquierdo-derecho). El proceso ascendente es recorrido ventralmente por la cresta del septo nasal que se desarrolla dorsoposteriormente. La base del proceso ascendente presenta unas marcada constricción basal. El proceso maxilar porta los dientes y limita ventralmente a la fenestra exonarina. Posteriormente, sobre la cara labial, presenta una marcada depresión que recibe al maxilar. Lingualmente, el proceso maxilar presenta un estante palatal poco desarrollado (Fig. 7 C). 
Los nasales (par) se interponen entre el premaxilar y frontal. Anteriormente delimitan la fenestra exonarina. Lateralmente están en contacto con el proceso frontal del maxilar, de forma tal que excluyen al prefrontal del contacto con el nasal.

En vista dorsal, por debajo de los nasales, se ubican los septomaxilares (par), que se unen entre sí en la línea media. Son huesos marcadamente convexos que cubren al órgano vómero-nasal. En vista anterior son escalonados, sobre el borde del escalón se desarrolla un cresta transversal que no llega al plano sagital. Esta cresta está pinzada lateralmente.

El frontal (impar) es un hueso largo. Anteriormente presenta tres procesos, un proceso medial y dos procesos laterales. Los bordes laterales del frontal son levemente cóncavos. En detalle se observa que esta concavidad es doble; existe una concavidad anterior, donde articula con el prefrontal, y otra más posterior, que forma el borde dorsal de la órbita. Ventralmente, el frontal presenta dos procesos ventrales (cristae cranii), orientados anteroposteriormente. Estos últimos no se unen en la línea media y no tienen participación importante en la fenestra orbitonasal. Posteriormente, el frontal se une al parietal a través de una sutura ancha y recta. Cuando está desarticulado, en vista ventral, por delante de la sutura frontoparietal, se observan dos superficies triangulares de articulación para los procesos anteromediales del parietal.

El parietal (impar) es el hueso dorsal más posterior; es ancho anteriormente, estrecho medialmente y los largos procesos supratemporales divergen posteriormente. Los procesos anterolaterales son robustos y delimitan el borde anteromedial de la fenestra supratemporal. La musculatura adductora mandibular cubre gran parte de la tabla parietal (i.e. el parietal sin considerar los procesos supratemporales); la superficie de la tabla parietal no cubierta por esta musculatura es aquí referida como "meseta parietal". Esta última es triangular, de vértice posteriormente orientado, con bordes poco marcados, suaves y cóncavos. La superficie dorsal presenta sutiles rugosidades. La meseta parietal se continúa posteriormente como un angosta y baja cresta sagital. Ventralmente, y medial a los procesos anterolaterales, se proyectan los procesos anteromediales en forma de dos láminas triangulares. Posteriormente, también en vista ventral, en el ápice de la cuña que forman los procesos supratemporales, se ubica la fosa parietal en el extremo terminal. La fosa está abierta posteriormente. En vista lateral, se observan los procesos descendentes, desarrollados $\mathrm{y}$ triangulares. 
Vista lateral (Fig. 7 B). El maxilar (par) es el hueso de mayor desarrollo en vista lateral. La superficie labial es lisa y presenta una hilera ventral de forámenes labiales. Presenta tres procesos: proceso premaxilar, proceso posterior y lámina facial. El proceso premaxilar es bífido, la superficie dorsal es ligeramente cóncava; constituye la base de la cavidad nasal y de la fenestra exonarina. Este proceso articula anteriormente con el premaxilar a través de una rama labial robusta y cónica; lingualmente articula con el vómer a través de la rama lingual. El proceso posterior articula dorsalmente con el yugal y posterolingualmente con el ectopterigoides y el palatino. El proceso posterior es cuneiforme en vista lateral, con una extensión posterior que llega hasta la parte media de la órbita. Cuando se observa desarticulado, este proceso presenta un amplio surco medial que se continúa posteriormente al foramen de ingreso del canal alveolar superior y delimita el borde ventral del foramen infraorbital. Labialmente se observa un angosto y profundo surco que corresponde a la articulación (por encastre) con el yugal. La lámina facial es amplia, con un importante desarrollo anteroposterior del extremo dorsal donde se diferencian los procesos frontal (anterior) y prefrontal (posterior). El primero de éstos es de base angosta y largo, mientras que el segundo es de base ancha y bajo. Lingualmente, la topología del maxilar es más compleja (Fig. 8 B). Ventralmente es recorrido por el estante supradental, que delimita lateralmente a la fenestra del órgano vómero-nasal (anterior) y a la coana (posterior). Dorsalmente al estante supradental, el maxilar es atravesado anteroposteriormente por el canal alveolar superior, cuyos forámenes de ingreso y egreso se encuentra dorsalmente sobre los procesos posterior y premaxilar respectivamente. Anteriormente, desde el foramen de egreso del canal alveolar superior y sobre la rama lingual del proceso premaxilar, se desarrolla la lámina transversal anterior, que en su extremo medial lleva una cresta dorsal. Por detrás de la lámina transversal se ubica el cuenco/depresión para el órgano vómero-nasal. Labialmente, esta depresión está delimitada por un surco poco definido y superficial que se dispone sobre la lámina facial. Posteriormente, se encuentra delimitado por una cresta baja y desdibujada (no hay un claro soporte narial) que se continúa posterodorsalmente sobre la lámina facial como cresta semilunar, la que demarca, ventralmente, el receso lateral del saco nasal.

El prefrontal (par) delimita el borde anterodorsal de la órbita. Es un hueso complejo donde se distinguen tres procesos principales: proceso maxilar, proceso palatal y proceso supraorbital. Se reconoce un cuarto proceso menor, el proceso 
lacrimal. El proceso maxilar es una importante superficie que articula principalmente con el maxilar El borde posterior del prefrontal está delimitado por el proceso supraorbital, que articula con el frontal, y el proceso lacrimal, entre los cuales hay una profunda depresión donde existe un foramen. Sobre el proceso supraorbital se desarrolla una importante protuberancia oval anteroposteriormente dispuesta. El proceso lacrimal ocasionalmente puede presentarse engrosado, como una segunda protuberancia, que tiende a converger anteriormente con la protuberancia dorsal. El proceso palatino se dispone transversalmente, delimitando posteriormente la cavidad nasal. Este proceso articula con el palatino; entre ambos delimitan la mayor parte de la fenestra orbitonasal. Lateralmente entre el proceso lacrimal y el proceso palatino se delimita el borde medial del foramen lacrimal; el puente del proceso palatal hacia el lacrimal conforma el borde dorsal del foramen infraorbital.

El lacrimal (par), se presenta siempre como un hueso individual, aplanado y participando de la órbita.

El yugal (par) es un hueso con forma de bumerang. Presenta un delgado proceso temporal, que articula con el postorbital, y un profundo proceso maxilar. La superficie labial de este último proceso es levemente cóncava y lleva varios forámenes suborbitales.

El postfrontal (par) delimita el borde posterior de la órbita y articula dorsalmente con el frontal y el parietal. Dorsalmente es bifurcado, con un desarrollado proceso anteromedial y un muy reducido proceso posteromedial. Ventralmente se proyecta el proceso ventral que excluye a gran parte del postorbital de la órbita.

El postorbital (par) es un hueso principalmente de posición temporal, aunque el proceso ventral participa muy levemente de la órbita. El proceso posterior presenta un importante desarrollo anteroposterior, que conforma la mayor parte del hueso y articula con el escamoso. El proceso medial está reducido y constituye el borde lateral de la fenestra supratemporal.

El escamoso (par) presenta un proceso anterior cilíndrico, con una importante superficie de articulación para el postorbital dorsalmente. No presenta proceso dorsal. Entre el escamoso y el proceso supratemporal del parietal se encuentra el supratemporal (par). Los supratemporales son simples láminas cuneiformes, con un proceso anterior y un proceso posterior, anterior y posteroventralmente dirigidos, respectivamente. 
Los cuadrados (par) se encuentran en el extremo posterior del cráneo y son de estructura compleja. En vista lateral, presentan una robusta cresta timpánica, la cual está interrumpida y separada del cóndilo cefálico posterior por la escotadura cuadrática. En vista caudal, la cresta posterior delimita dos área de similar desarrollo, medial y lateral. Ventralmente, se encuentra el cóndilo mandibular, que no ocupa completamente la superficie ventral del cuadrado. En vista medial, se observa una desarrollada ala pterigoidea sobre la cresta medial.

El epipterigoides (par) es visible lateralmente. Es un hueso columnar, medialmente plano, lateralmente convexo; esta convexidad da lugar a una cresta dorsoventral cuyo lado posterior avanza anteriormente sobre el anterior en la parte media del hueso. Ventralmente, presenta el cóndilo articular, lateralmente comprimido, que encastra en la fosa columelar del pterigoides.

Vista ventral (Fig. 7 C). Se observa un muy fenestrado paladar. El vómer (par) es un hueso grácil y alargado que articula anteriormente con el maxilar y posteriormente con el palatino. Con el maxilar delimitan la parte anterior de la fenestra exocoanalis (narina interna). El estante supradental, avanza sobre la fenestra exocoanalis delimitando anteriormente la fenestra del órgano-vómero nasal.

El palatino (par) presenta tres procesos. Ventralmente, entre el proceso maxilar y el proceso vomerino, se observa un ancho y profundo surco palatino. El proceso maxilar articula posterolateralmente con el ectopterigoides, excluyendo al maxilar de la fenestra suborbital. El borde anterior del palatino, entre los procesos maxilar y vomerino, se orienta dorsalmente y articula con el palatino. El proceso pterigoideo articula posteriormente con el pterigoides.

El pterigoides (par) es un hueso largo, los procesos anteriores, procesos palatino y proceso transverso, delimitan el borde posteromedial de la fenestra suborbital. Esta área del pterigoides se encuentra levemente excavada, de modo que el borde de la fenestra suborbital y del receso piriforme quedan más elevados que el borde lateral. El proceso cuadrado es largo, con una desarrollada fosa pterigoidea pero sin expansión medial. Dorsalmente, en su parte proximal, se encuentra la fosa columelar que recibe al epipterigoides. Medialmente a esta fosa, articulan los procesos basipterigoideos del parabasiesfenoides.

El ectopterigoides (par) es un hueso irregular, que presenta cuatro procesos. Los procesos anterolateral y posterolateral están expuestos en vista ventral. El 
posterolateral es más robusto que el anterolateral. Medial al proceso anterolateral articula el maxilar, que está delimitado medialmente por la cresta palatina. Los procesos maxilar y medial son dorsales y se orientan anterior y posteriormente respectivamente.

El esfenoides (paraesfenoides y basiesfenoides), o parabasiesfenoides (impar) (Estes et al.,1988; Bever et al., 2005), a través de sus procesos basipterigoideos delimita el borde posterior del receso piriforme. Los procesos basipterigoideos son robustos, levemente aplanados dorsoventralmente, con la superficie de articulación ligeramente cóncava. Posteriormente al parabasiesfenoides articula, a través de una sutura transversal, el basioccipital (impar). Los tubérculos esfenoccipitales son robustos y se encuentran bien desarrollados. Su extensión posterior aporta la parte media del cóndilo occipital. 

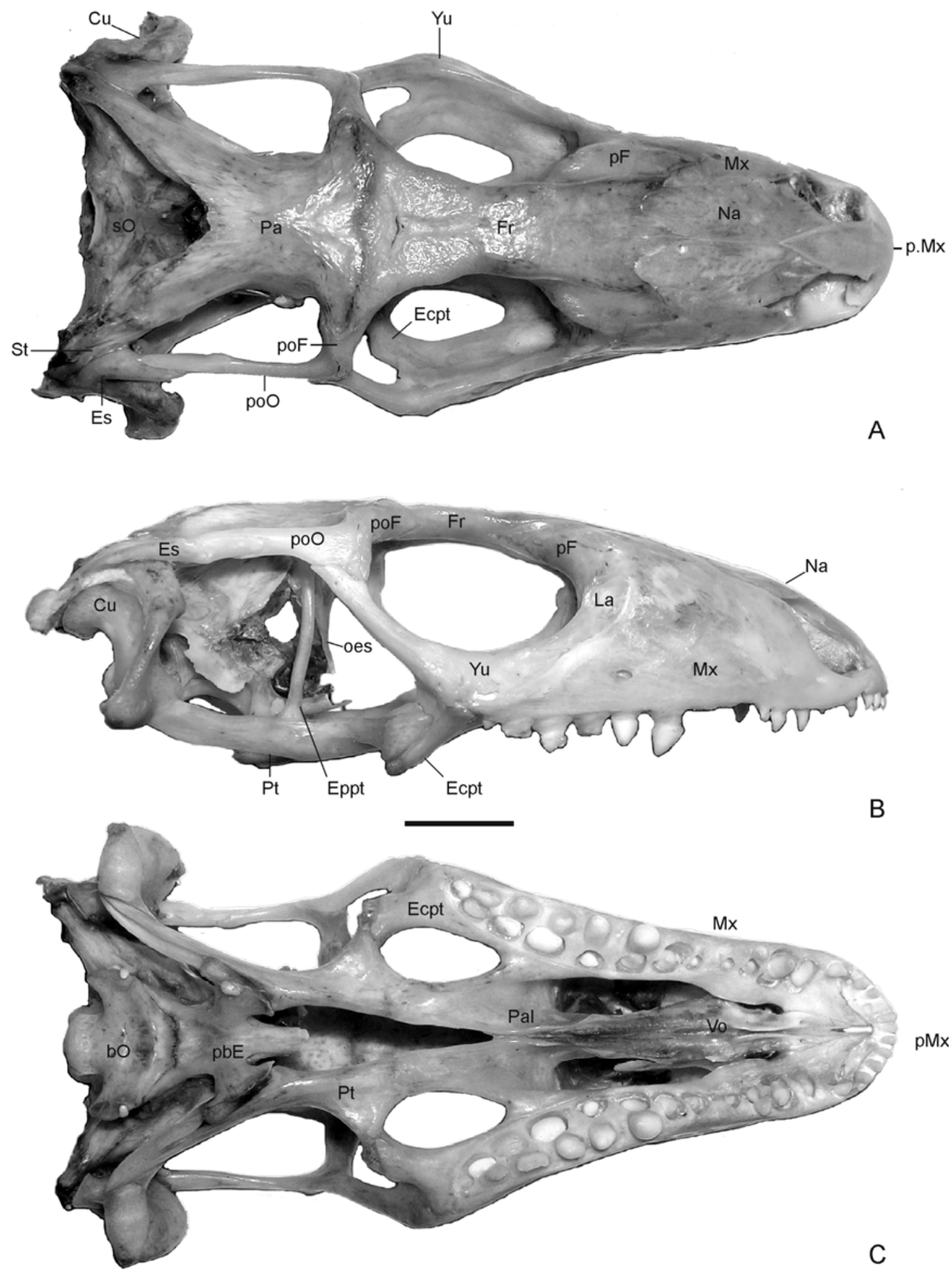

pMx

Figura 7. Cráneo de Tupinambis merianae (UNMdP-O 32). A, vista dorsal; B, vista lateral; C, vista ventral. Escala $=10 \mathrm{~mm}$. 


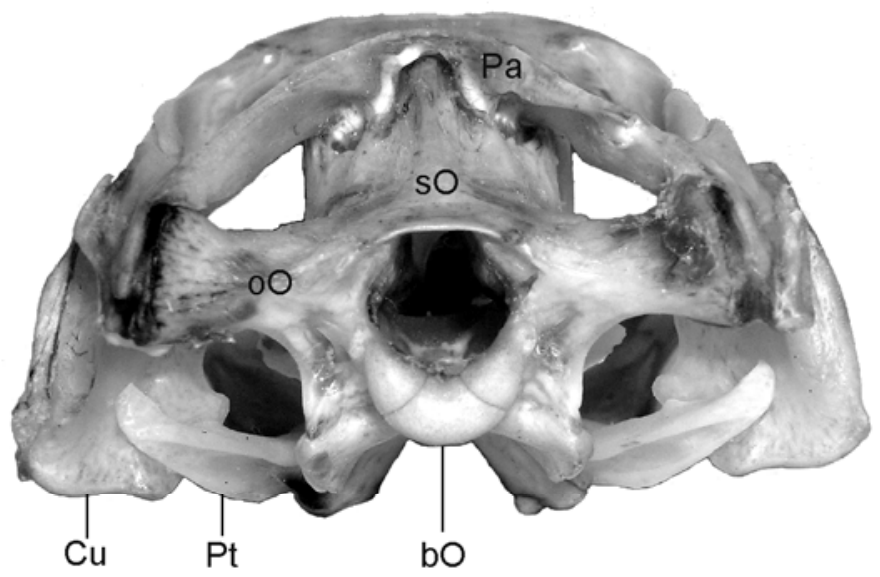

A

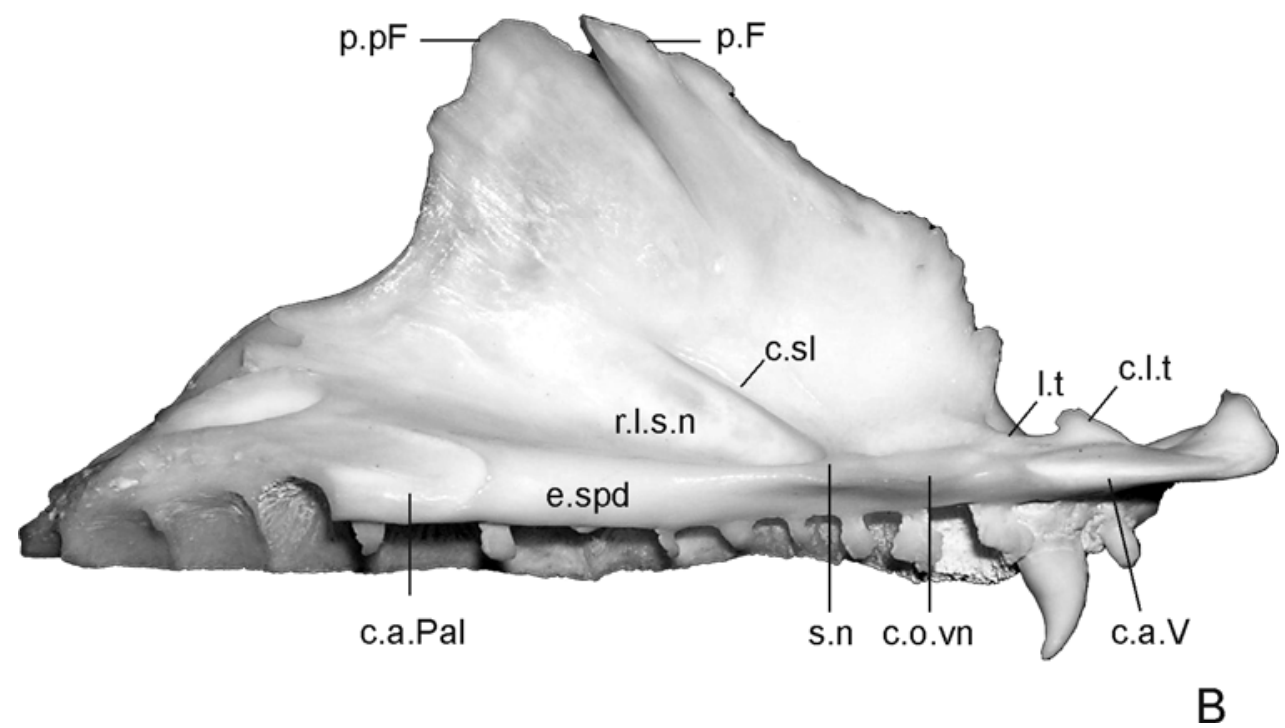

Figura 8. Cráneo de Tupinambis merianae. A, vista posterior (UNMdP-O 32); B, maxilar, vista lingual (UNMdP-0 2). Escala $=10 \mathrm{~mm}$. 
Vista posterior (Fig. 8 A). Dorsalmente, delimitando al foramen magnum, se observa el supraoccipital (impar), con un proceso ascendente flanqueado por importantes fenestras postemporales. Dorsalmente, sobre el supraoccipital, se observa la cresta supraoccipital.

A ambos lados del foramen magnum se encuentran los otoccipitales (fusión opistótico-exoccipital) (par). Los procesos laterales aportan a los robustos procesos paraoccipitales.

El hiomandibular o columela (par), el orbitoesfenoides (par) y el proótico (par) no son claramente visibles en vistas externas.

\section{HEMIMANDÍBULAS}

Cada hemimandíbula está compuesta por seis huesos (Fig. 9). El dentario (par) constituye la parte anterolateral de la hemimandíbula y porta la serie dentaria. Labialmente es liso y presenta, ventral al borde dorsal, una serie de forámenes mentales. El contorno dorsal del dentario es levemente cóncavo pero anteriormente presenta una ligera convexidad. Posteriormente, los procesos posterodorsal y posteroventral delimitan una cuña que recibe al suprangular y angular. Lingualmente, el canal de Meckel está ampliamente expuesto a lo largo de toda su extensión, terminando en la sínfisis y sin presentar mayor restricción. Sobre el techo del canal de Meckel, en una posición media, se observa el foramen de ingreso al canal alveolar inferior. El septo intermandibular no se continúa posteriormente separando el esplenial del suprangular, sino que estos huesos se yuxtaponen, dejando dos surcos superficiales sobre el techo del dentario, por detrás del foramen de ingreso al canal alveolar inferior. Este foramen se encuentra generalmente a una distancia levemente retrasada respecto al último foramen mental. Dorsalmente al canal de Meckel, a lo largo de todo el dentario, se desarrolla el estante subdental. La serie dentaria se ubica en el surco dental, ubicado dorsalmente respecto al estante.

El esplenial (par) es el único hueso de la hemimandíbula que no se puede apreciar labialmente. Es un hueso cuneiforme, muy extendido anteriormente; posteriormente no avanza sobre los huesos postdentarios de la hemimandíbula. Es esencialmente plano, pero por delante de los forámenes alveolar y milohioideo anterior, es levemente cóncavo. 
El coronoides (par) presenta cuatro procesos definidos: proceso anterolateral, proceso anteromedial, proceso posteromedial y proceso dorsal. De éstos, el posteromedial es el más desarrollado. Un quinto proceso, el proceso posterolateral, se encuentra muy reducido, sobre el borde anterior de la fosa mandibular.

El suprangular (par) es un hueso grande, plano, que constituye el borde lateral y dorsal de la fosa mandibular. Labialmente presenta dos forámenes, el anterior y el posterior. El suprangular ocupa el vértice y la mayor parte de la escotadura posterior del dentario. La faceta infracoronoidea, sobre la lámina medial, está expuesta lingualmente, delimitada por los procesos mediales del coronoides y el proceso anterior del articular. No hay contacto del esplenial con el suprangular en vista labial. En individuos de talla grande no se observa la línea se sutura entre el suprangular y articular, como se advierte en individuos de menor tamaño.

El angular (par) es un hueso alargado que conforma el borde posterior no terminal de la hemimandíbula. Ventrolingualmente presenta el foramen milohioideo posterior.

El articular (complejo articular-prearticular) (par) es un hueso complejo. Inmediatamente posterior a la fosa mandibular, en vista dorsal, se observa la superficie articular, delimitada anterior y posteriormente por crestas transversales bien definidas. El proceso retroarticular se proyecta desde la superficie articular posteriormente, y está recorrido anteroposteriormente por la cresta timpánica que se dispone oblicuamente. Medialmente, sobre el proceso retroarticular, se desarrolla una delgada cresta horizontal. El proceso anterior constituye la pared lingual de la hemimandíbula, entre el esplenial y el proceso posteromedial del coronoides. Entre el proceso retroarticular y el proceso anterior, a lo largo del borde ventral, se desarrolla la cresta articular (cresta prearticular de Estes et al., 1988). Sobre la cresta articular se diferencian, en sentido anteroposterior, la cresta prearticular y la cresta retroarticular; entre ambas, sobre la superficie lingual, se encuentra encerrado el proceso angular. Anteroventralmente se proyecta el proceso anterior, medialmente curvado, que articula con el dentario y suprangular, y recibe al proceso posteromedial del coronoides. 


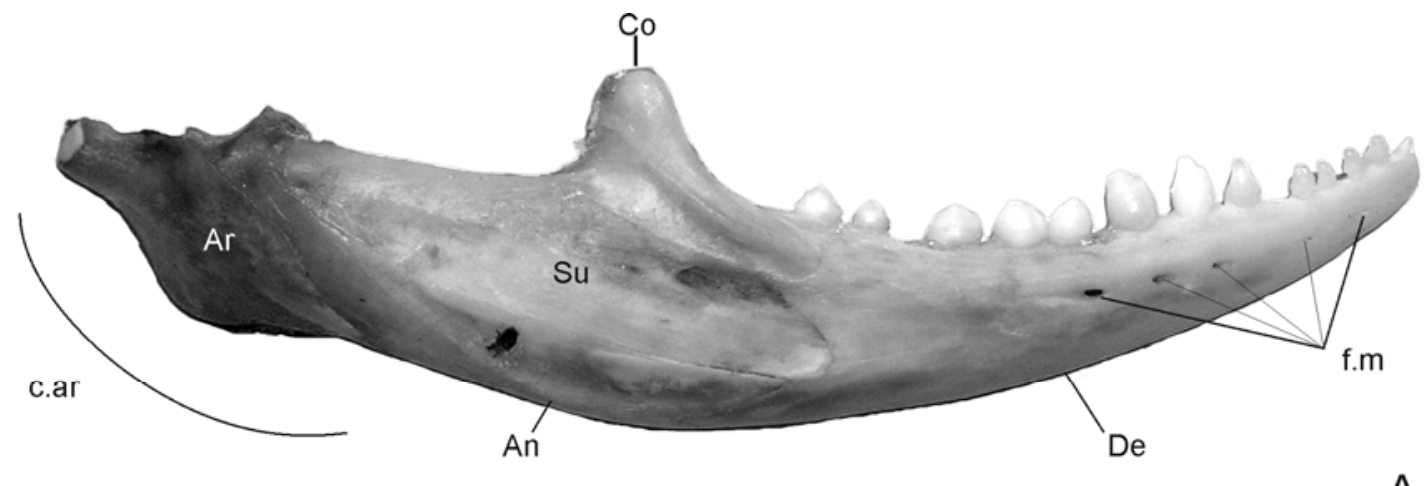

A

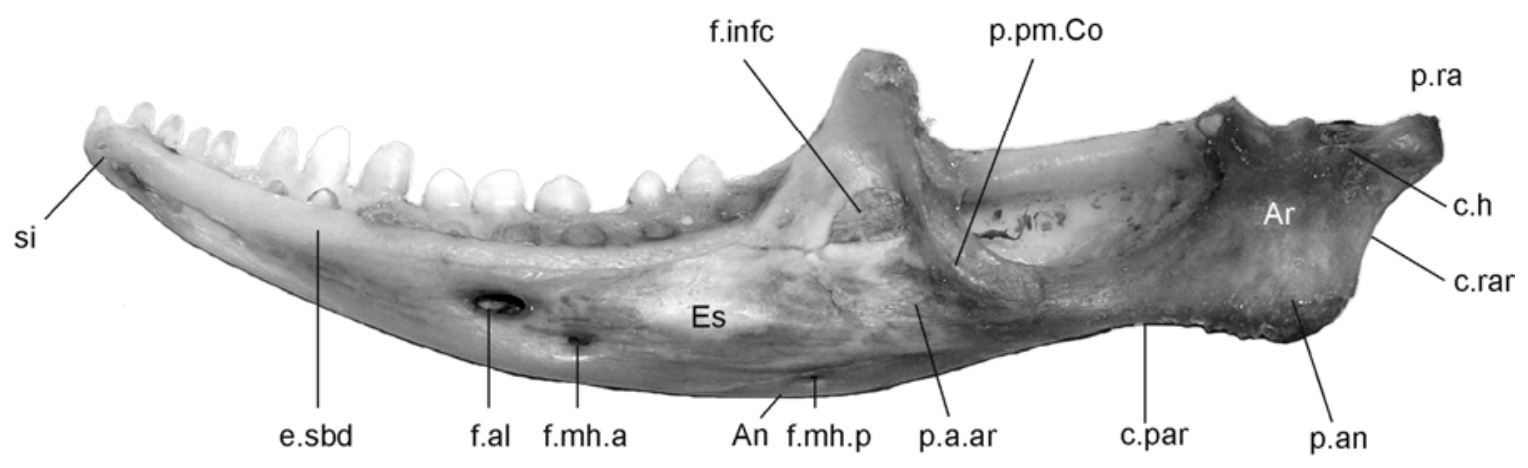

B

Figura 9. Hemimandíbula de Tupinambis merianae (UNMdP-O 33). A, vista labial; B, vista lingual. Escala $=10 \mathrm{~mm}$.

\section{DENTICIÓN}

La descripción de la dentición, en particular de las piezas dentarias individuales, presenta una nomenclatura particular (Peyer, 1968; Edmund, 1969; Smith y Dodson, 2003). La dentición marginal (dentarios, maxilares y premaxilar) se presenta como una parábola, por lo que los dientes anteriores están orientados en forma diferente que los posteriores (Fig. $10 \mathrm{~A}$ ). Los términos labial y lingual son utilizados para referir a las paredes de los dientes que están expuestas hacia el exterior y hacia el interior de la cavidad bucal respectivamente. A su vez, los términos mesial y distal son utilizados para referir a las superficies orientadas hacia o alejándose de la sínfisis mandibular a lo largo de la serie dentaria respectivamente (Smith y Dodson, 2003). Esta terminología no siempre muestra coincidencia con la orientación anterior (craneal) y posterior (caudal) del individuo (Fig. 10 B, C). Aquí queda manifestado el problema suscitado por el empleo de la palabra "distal" en términos clínicos, que 
difiere del uso en anatomía comparada, que se ha impuesto en la literatura (Peyer 1968: 16). De esta forma, el término "distal" tiene una acepción diferente cuando es utilizado para describir dientes individuales.

Por otro lado, la diferenciación en un diente de vertebrado de cuello, corona y raíz sólo es posible si la cavidad de la pulpa se estrecha basalmente, diferenciando un canal de la raíz, lo cual sólo ocurre en mamíferos y con excepciones (Peyer, 1968). Estos términos han sido históricamente definidos para dientes mamalianos y no pueden ser usados para los reptiles. Por ejemplo, los dientes de Tupinambis están totalmente cubiertos por esmalte, de forma que es imposible diferenciar un cuello (i.e. zona donde se encuentran el esmalte y el cemento que cubre la dentina de la raíz), y, de este modo, la ausencia de un cuello impide delimitar una corona. Entonces, en vertebrados no mamalinos, es conveniente utilizar los términos apical y basal para referirse a la punta o base de los dientes respectivamente (Fig. 10 D), aunque abunda la denominación de "coronas dentarias" (tooth crowns) en la literatura, entendiéndose por tales a los extremos apicales de los dientes.
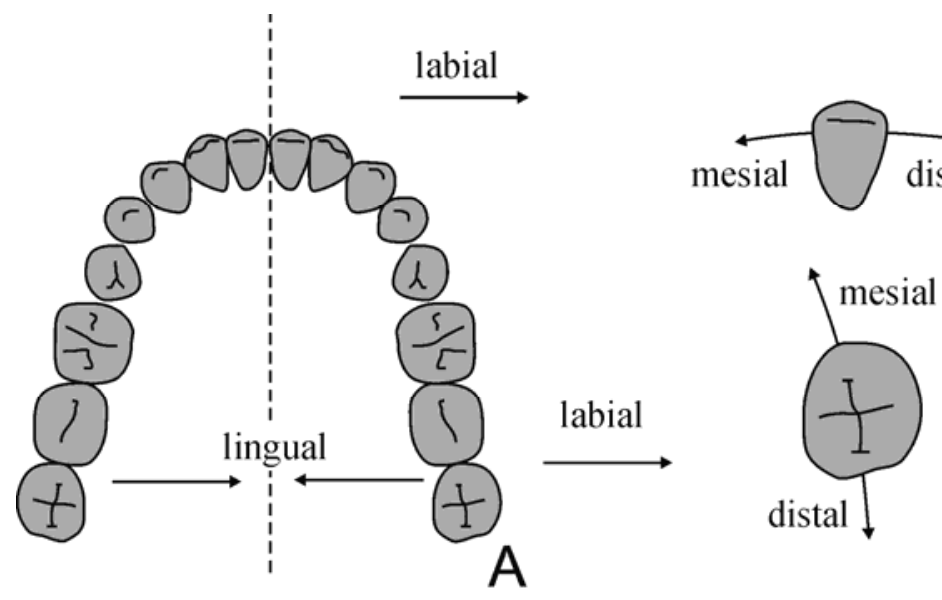

\section{distal}

B

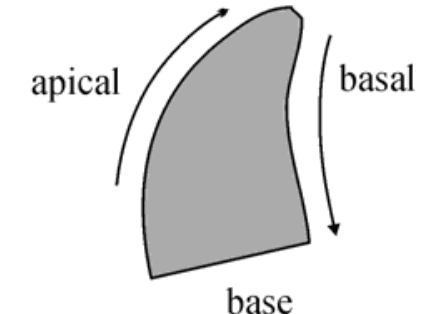

base

Figura 10. Terminología seguida en este trabajo (modificada de Smith y Dodson, 2003). A, hemimandíbula humana, vista oclusal; B, incisivo; C, molar; D, diente unicuspidado hipotético de Squamata, vista lateral. La línea punteada en A muestra el plano sagital.

La dentición en T. merianae se caracteriza por presentar: (1) implantación subpleurodonte; (2) polifiodoncia; (3) heterodoncia; (4) dientes marginales, en el premaxilar, maxilar y dentario, sin dientes palatinos ni pterigoideos; y (5) cambios ontogenéticos. 
En la consideración de la implantación dentaria, es necesario definir que se utiliza el término "alvéolo" para hacer referencia a la depresión, cuenco o foso (= dental socket) donde se ubica cada diente, funcional o de reemplazo. Este "alvéolo" no es sinónimo del alvéolo tecodonte, el cual es más profundo, excavado en el hueso portador, y más estable en el tiempo. Caldwell et al. (2003) consideran que la mayoría de los lagartos presentan alvéolos de tres lados: mesial, distal y labial. Estos alvéolos varían de someros a profundos. Los mosasaurios y la mayoría de las serpientes presenta alvéolos de cuatro lados, mientras que los varanoideos presentan sitios de unión apenas deprimidos en los huesos para la ubicación de los dientes, además de débiles pliegues basales para la consolidación de los mismos (que se corresponde con la morfología particular de los dientes de los varanoideos conocida como plicidentina; Kearney y Rieppel, 2006). En el caso de los Iguania Acrodonta, los dientes carecen de alvéolos o sitios de unión nítidos, ya que se fijan a la superficie de los huesos portadores, sin encajar en ellos.

El tipo particular de implantación dentaria observada en los teidos ha sido definida como subpleurodonte por Presch (1974b). En este tipo de implantación los dientes ocupan alvéolos de tres lados (la pared lingual está reducida), delimitados por delgadas y bien desarrolladas paredes transversales denominadas septos interdentales. Estos últimos están formados por hueso alveolar (ver Budney et al., 2006) y se disponen transversalmente, entre la pared labial y una más baja pared lingual del surco dental (Fig. 11 A). La unión de los dientes en los alvéolos es reforzada por el depósito de abundante cemento dental sobre la base de los dientes. Dentro de los teidos, la cantidad de cemento presente en T. merianae es mayor a la depositada en los “cnemidoforinos" (grupo informal integrado por "Ameiva”, "Cnemidophorus” y Kentropyx) y Callopistes, pero menor a la depositada en Teius, Dicrodon y Dracaena (Fig. 11 B). Esta variación permite diferenciar tres estados de subpleurodoncia según los septos interdentales estén visibles, disimulados (Crocodilurus y Tupinambis), o no sea posible su observación (Teius, Dicrodon, Paradracaena y Dracaena). Otros autores (e.g. Gao y Fox, 1996) definen la implantación subpleurodonte, con un criterio cuantitativo, de acuerdo al porcentaje (1/2 a 1/3) del diente que se encuentra unido a la pared labial del surco dental, el cual es menor al porcentaje observado en una implantación pleurodonte así definida. Esta definición es problemática por diferentes motivos, entre los que se destaca que depende de la orientación de la 
observación y del desarrollo de los dientes, razón por la cual se prefiere la definición morfológica anteriormente expuesta.

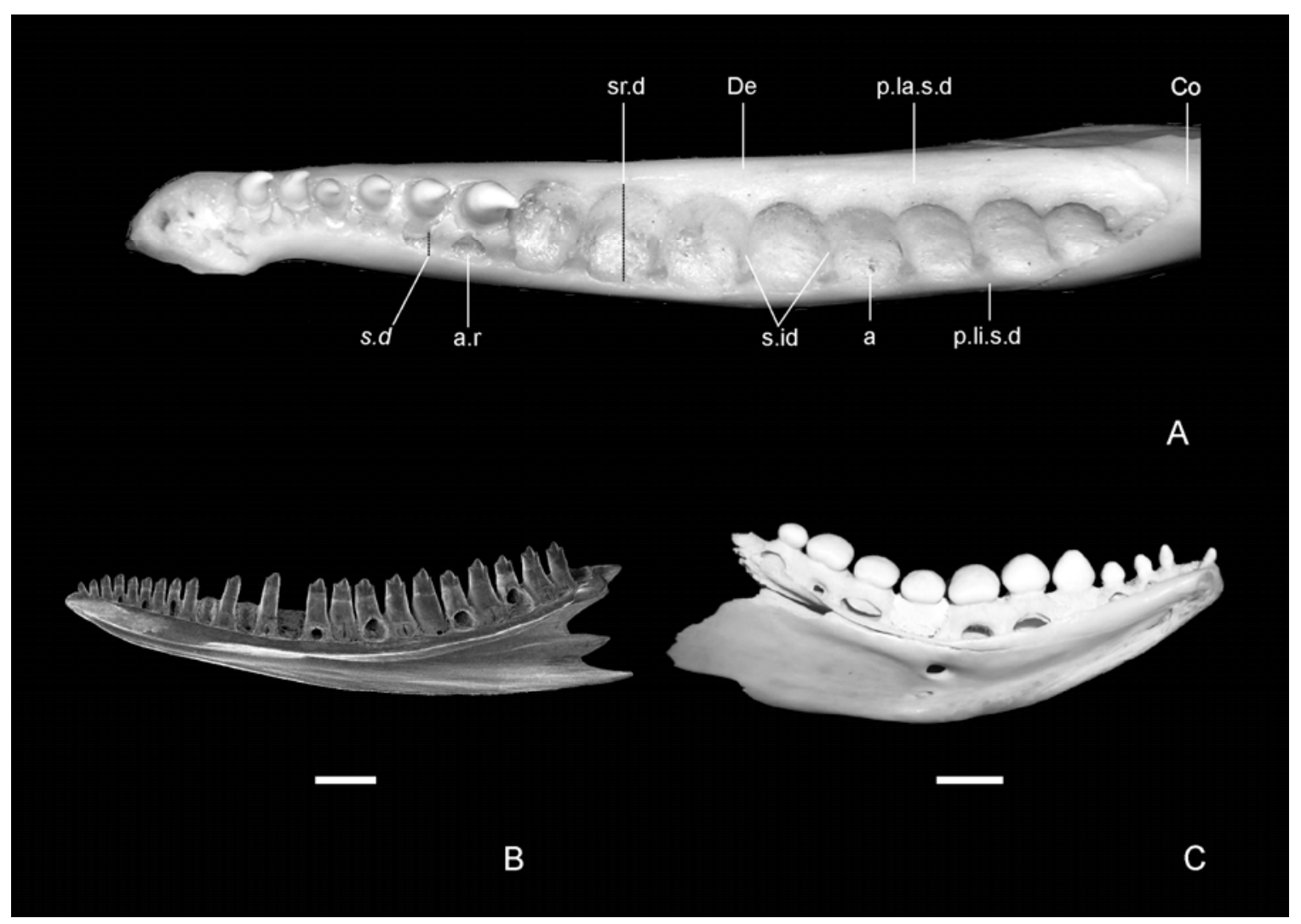

Figura 11. Detalle de implantación dentaria en la familia Teiidae. A, dentario derecho de T. merianae (UNMdP-O) en vista oclusal; B, dentario derecho de " $A$." ameiva (UNMdP-O 27) en vista lingual; C, dentario y esplenial izquierdos de D. paraguayensis (MZUSP 62489) en vista lingual. Abreviaturas: a, alvéolo; a.r, alvéolo de reemplazo; Co, coronoides; De, dentario; p.la.s.d, pared labial del surco dental; p.li.s.d, pared lingual del surco dental; s.d, sulcus dentalis; s.id, septo interdental; sr.d, surco dental. Escala $=10 \mathrm{~mm}$ en $\mathrm{A}$ y C, $2 \mathrm{~mm}$ en B. 
Otra característica destacable de la implantación dentaria de los teidos es que los dientes no ocupan todo el ancho del surco dental, dejando entre la serie dentaria y el estante dental (subdental o supradental) un canal de ancho variable denominado sulcus dentalis (Gao y Fox, 1991). Por lo tanto, la implantación subpleurodonte difiere de la típica implantación pleurodonte en: (1) un reducido contacto de los dientes con la pared labial; (2) un marcado desarrollo de los septos interdentales, que son altos y unen la pared labial y la lingual; y (3) la presencia de cemento sobre las bases de los dientes.

Con respecto a la polifiodoncia, Edmund (1969), y luego Rieppel (1978), sostienen que el reemplazo dentario en los teidos se aparta del clásico reemplazo observado en los iguánidos, donde la zona de reabsorción es grande y los alvéolos de reemplazo se encuentran lingualmente sobre las bases de los dientes. En los ejemplares aquí analizados de la familia Teiidae, y en particular en T. merianae, se han observado zonas de reabsorción moderadas, excavadas en el cemento, situación que le confiere forma de alvéolos. Estos últimos son profundos, subcirculares y de ubicación lingual o distolingual. Un aspecto interesante observado en T. merianae, ya notado por Barberena et al. (1970), es que la presencia de alvéolos de reemplazo en cada hueso portador no es constante. Se han observado maxilares y dentarios sin alvéolos de reemplazo; $y$, en aquellos en que se presentan, pueden hacerlo en forma alternada entre posiciones dentales funcionales o como una serie complementaria a la serie dentaria de alvéolos funcionales. Si bien Edmund (1969) sostiene que no hay evidencia que indique que el reemplazo dental cesa o disminuye significativamente en la mayoría de los lagartos y serpientes, MacLean (1974) y Barberena et al. (1970) sostienen que en Tupinambis existe una supresión del reemplazo en los ejemplares adultos; sin embargo, en los ejemplares de mayor tamaño analizados en este trabajo hay clara evidencia de actividad de reemplazo en la parte posterior de maxilares y dentarios, que sugiere que esta última propuesta es errónea.

Una dentición heterodonte es aquella en la que se puede reconocer más de una categoría dentaria, que pueden responder a variación en tamaño y/o morfología (Peyer 1968; Dessem, 1985). Denton y O’Neill (1995) consideran la heterodoncia en los Teiidae como aquella que incluye dientes unicuspidados y al menos algún diente bicuspidado, con diferenciación a lo largo de la serie dentaria desde su parte anterior a la posterior. La condición heterodonte de Tupinambis ha sido reconocida por varios autores (Owen, 1866; Romer, 1956; Edmund, 1969; MacLean, 1974; Barberena et al., 
1970). Uno de los aspectos más llamativos de la dentición de Tupinambis es la presencia de dientes romos y "molariformes", que son poco comunes entre los escamosos (Estes y Williams, 1984). Entre los Tupinambinae, los dientes “molariformes" también se observan en Dracaena y Paradracaena, aunque en estos géneros son mucho más desarrollados, formando grandes placas ensanchadas (Estes y Williams, 1984; Presch, 1974b; Sullivan y Estes, 1997). Presch (1974b) presenta una descripción general de la dentición de Tupinambis, ampliando la breve mención de Maclean (1974) y reconociendo la presencia de diente unicuspidados, bicuspidados, dos tipos de dientes tricuspidados y dientes romos, considerados "molariformes". Más recientemente, Dessem (1985) reconoce los mismos tipos morfológicos en Tupinambis merianae (este autor sinonimiza T. teguixin y T. merianae), aunque no advierte la presencia de dientes bicuspidados. Como parte de este trabajo de Tesis doctoral se analizó detalladamente la dentición de T. merianae, utilizando un conjunto abundante de material esqueletario.

\subsection{Dentición en los Teiidae}

La dentición de la familia Teiidae ha sido descripta por Presch (1974b), permitiendo reconocer tres tendencias en la dentición posterior de estos lagartos. Por un lado, los "cnemidoforinos", Callopistes y Crocodilurus presentan dientes labiolingualmente comprimidos con una, dos o tres cúspides mesodistalmente alineadas (Presch, 1974b; Dessem, 1985; obs. pers.). Este tipo de dentición esta asociada a una dieta insectívora (Dessem, 1985; Tedesco et al., 1999; Herrel et al., 2004). La dentición en Teius y Dicrodon también está asociada a la insectivoría, pero los dientes de estos géneros son transversalmente bicuspidados con mayor desarrollo labiolingual de las bases (Presch, 1974b; obs. pers.). El tercer y último tipo de dentición se observa en Tupinambis, Dracaena y Paradracaena, en donde los dientes posteriores son robustos, agrandados, con aumento de la superficie de oclusión (i.e. molarización) (Presch, 1974b; Estes y Williams, 1984; Dessem, 1985; Sullivan y Estes, 1997; obs. pers.). Este tipo de dentición esta asociada una dieta durófaga (Presch, 1974b).

De esta manera, entre los Tupinambinae se advierte una importante diferenciación en cuanto a la dentición de los géneros que lo integran. En primer lugar, se observa un menor número de dientes en Dracaena (Tabla 8), aunque, por el bajo número de ejemplares analizados, debe considerarse con cautela. Según Presch 
(1974b), en Callopistes se observan diferencias en la dentición de las dos especies actuales, donde, aunque ambas presentan dientes bicuspidados (con la cúspide distal dominante), sólo C. flavipunctatus tiene los dientes posteriores tricuspidados (de cúspide media dominante). Estas apreciaciones de Presch (1974b) se ven contradecidas por la revisión de material osteológico de C. maculatus donde se observan dientes tricuspidados. Crocodilurus presenta un patrón similar a Callopistes, con dientes tricuspidados de cúspides mejor definidas. Dracaena y Paradracaena presentan dientes posteriores agrandados, muy expandidos, marcadamente molariformes y estriados, a menudo formando placas con forma de hongo (Presch, 1974b; Estes y Williams, 1984; Sullivan y Estes, 1997; Pujos et al., 2009). Estos dientes están algo más desarrollados en Dracaena donde además presentan contorno oclusal cuadrangular, mientras que en Paradracaena el contorno es circular-suboval (Sullivan y Estes, 1997). La presencia de dientes posteriores robustos en ejemplares juveniles de Dracaena (Dalrymple, 1979) sugieren la ausencia de variación ontogenética en la dentición de este género. La dentición entre las especies de Tupinambis es más diversa, T. longilineus y T. quadrilineatus presentan una dentición similar a la de Crocodilurus (Presch, 1974b; Ávila-Pires, 1995; obs. pers.), mientras que las restante especies de Tupinambis presentan diferentes grados de molarización de los dientes posteriores, aunque no tan marcada como en Dracaena y Paradracaena. En algunas de estas especies (T. merianae y T. rufescens) se ha documentado variación ontogenética (Presch, 1974b; Dessem, 1985; Montero et al., 2004). 


\begin{tabular}{|c|c|c|c|c|c|c|c|c|c|}
\hline & 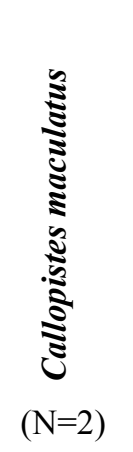 & 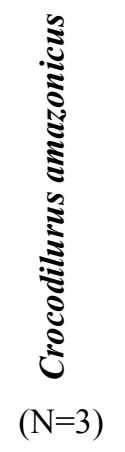 & 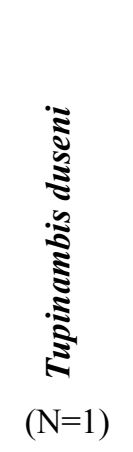 & 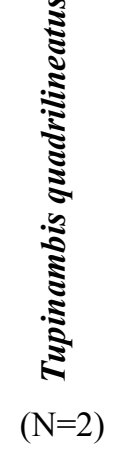 & 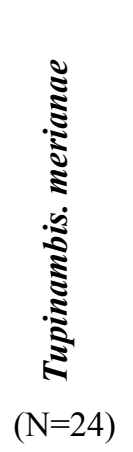 & 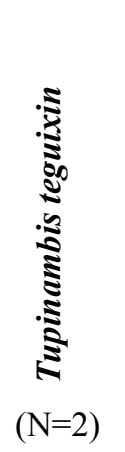 & 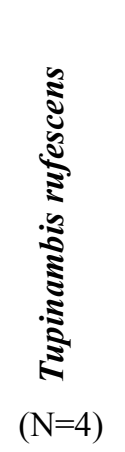 & 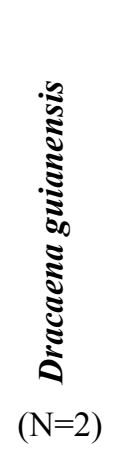 & 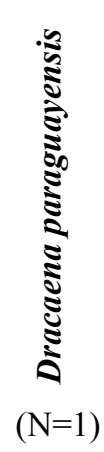 \\
\hline Maxilar & $13-16$ & $14-17$ & $13-14$ & $15-16$ & $11-15$ & $13-14$ & $12-14$ & $10-11$ & 11 \\
\hline Dentario & $19-21$ & $16-19$ & $15-16$ & $17-21$ & $13-18$ & $15-21$ & $15-18$ & $10-12$ & 12 \\
\hline Premaxilar & 7 & 9 & 7 & 11 & $8-12$ & $10-11$ & $9-11$ & $5-10$ & 8 \\
\hline Pterigoides & $3-4$ & - & - & - & - & - & - & - & - \\
\hline
\end{tabular}

Tabla 8. Máximo y mínimo de dientes en diferentes especies de Tupinambinae.

Por último, se destaca el caso particular de "Ameiva" exsul albogutta entre los “cnemidoforinos", donde Estes y Williams (1984) describen variación ontogenética de los dientes. Los dientes posteriores bi y tricuspidados de la dentición juvenil son reemplazados por dientes robustos en los ejemplares adultos. Estos dientes robustos son relativamente altos y más gráciles al compararlos con los de Tupinambis. Estes y Williams (1984) destacan que con el aumento en la talla de los individuos, los dientes robustos pierden las cúspides, primero la distal y luego la mesial.

\subsection{Tipos morfológicos dentales en $T$. merianae}

Siguiendo un criterio clásico se puede agrupar los dientes de T. merianae en función del número de cúspides mesodistalmente dispuestas en las siguientes categorías de tipos morfológicos: unicuspidados, bicuspidados, tricuspidados y romos (sin cúspides). A su vez, dentro de cada uno de estos tipos morfológicos es posible reconocer diferentes estados que varían en: el grado de definición de las cúspides, la compresión lateral, la curvatura, el tamaño y la robustez. A continuación se detallan las variaciones (diferentes estados) dentro de cada tipo morfológico reconocido (Fig. 12). 
Dientes unicuspidados — Se distinguen dientes gráciles (u) y robustos (U). Los dientes gráciles son cilíndricos, apicalmente cónicos, pudiendo ser punzantes o no, y rectos o distalmente curvos (u1) (Fig. 12 A). También se observan otros con compresión labiolingual sobre el cono apical; cuyo contorno lateral es mesialmente convexo y distalmente recto (u2) (Fig. 12 B). Entre los dientes unicuspidados robustos es posible reconocer dientes de bases grandes y cilíndricas, que apicalmente presentan un cono estilizado, punzante, y dirigido posteriormente (U1) (Fig. 12 C). Estos últimos dientes son similares a los (u1) pero más grandes y marcadamente más curvos. Menos comunes son los dientes unicuspidados rectos, altos, robustos y apicalmente romos (U2) (Fig. 12 D). El esmalte de estos dientes presenta tenues estrías verticales. En el premaxilar se observan dientes unicuspidados, espatulados, donde la superficie lingual es cóncava y con contornos apicales convexos.

Dientes bicuspidados - En estos dientes la cúspide distal es siempre la dominante, de mayor tamaño y más alta. Se distinguen dientes bicuspidados de conformación grácil (b) y dientes robustos (B). Los dientes gráciles son altos, mientras que los robustos son más bajos. Se reconocen diferentes tipos de dientes bicuspidados gráciles; en los ejemplares de menor talla la diferencia de altura entre cúspides es menor: la cúspide mesial llega a desarrollarse como un pequeño cono lateralmente comprimido (b1) (Fig. 12 E). En los ejemplares mayores, la cúspide mesial puede ser sólo una protuberancia sobre la cara mesial de la cúspide dominante de un diente distalmente curvo (b2) o recto (b3) (Fig. 12 F). Los dientes bicuspidados agrandados y robustos (B) son de sección oval, con diferentes grados de compresión lateral (Fig. 12 G, H). Hay una fuerte tendencia a la molarización, ya que aumenta la superficie de oclusión. La cúspide mesial es pequeña y se diferencia de la cúspide dominante a través de un somero y corto surco vertical (i.e. surco intercuspidal), que se desarrolla labiolingualmente. Desde la cúspide mesial y a lo largo de la superficie oclusal de la cúspide distal se desarrolla un cresta sigmoide, cuyo extremo posterior se curva hacia la superficie labial. En algunos casos, la parte distal de esta cresta se halla labiolingualmente comprimida. El esmalte de los dientes bicuspidados gráciles presenta ligeras estriaciones, las que son más marcadas en los bicuspidados robustos. En el premaxilar, además de los dientes unicuspidados, se observan dientes cilíndricos, levemente espatulados en su extremo apical y con una cúspide poco diferenciada sobre la cara mesial. 
Dientes tricuspidados - Los dientes tricuspidados del dentario y maxilar pueden ser gráciles $(\mathrm{t}) \mathrm{o}$ agrandados y robustos $(\mathrm{T})$. Los dientes gráciles son rectos, labiolingualmente comprimidos, simétricos, con la cúspide central dominante cónica (t1) (Fig. 12 I). Las cúspides menores son similares entre sí, pero más pequeñas y en posición más baja que la cúspide central. Los ejes verticales de las cúspides menores pueden presentar una ligera inclinación divergente respecto al eje de la cúspide central. Entre los dientes tricuspidados robustos es posible diferenciar dos subtipos. Uno de estos subtipos (T1) presenta las cúspides accesorias pequeñas, verticales, diferenciadas por tenues surcos intercuspidales (Fig. $12 \mathrm{~J}$ ). El otro subtipo es un diente molariforme (T2) con mayor desarrollo labiolingual, cuyas cúspides accesorias no se destacan ya que se repliegan sobre la dominante (Fig. 12 K, L). La superficie oclusal es recorrida por una cresta mesodistal. El esmalte de los dientes tricuspidados presenta las mismas características que el de los bicuspidados donde las estrías convergen sobre la cresta mesodistal. El premaxilar presenta dientes tricuspidados donde las cúspides secundarias no están delimitadas por marcados surcos verticales, sino sólo por cortas y sutiles depresiones (Fig. $12 \mathrm{M}$ ); estos dientes son de base cilíndrica, con una importante compresión labiolingual y lados marcadamente divergentes en el extremo apical, resultando en un diente espatulado (t2).

Dientes romos - Son dientes agrandados, bajos y robustos, molariformes de amplia sección circular o levemente oval (Fig. 12 N, N). Oclusalmente presentan una protuberancia central, la cual es atravesada por un baja e irregular cresta mesodistal. El esmalte de estos dientes presenta finas estrías, muy bien marcadas, que convergen en la protuberancia central.

Dientes pentacuspidados - En un ejemplar juvenil (UNMdP-O 26) se observaron dientes pentacuspidados (Fig. $12 \mathrm{O}$ ). Se caracterizan por ser labiolingualmente comprimidos. La cúspide central dominante está flanqueada por dos cúspides menores internas, mesial y distal, poco delimitadas de la central. Las cúspides más externas, también en posición mesial y distal, son de mayor tamaño que las internas y más bajas. Las cúspides externas se diferencian claramente del conjunto que conforman las cúspides central e internas por surcos verticales profundos y definidos. Los lados del diente son rectos y paralelos. 


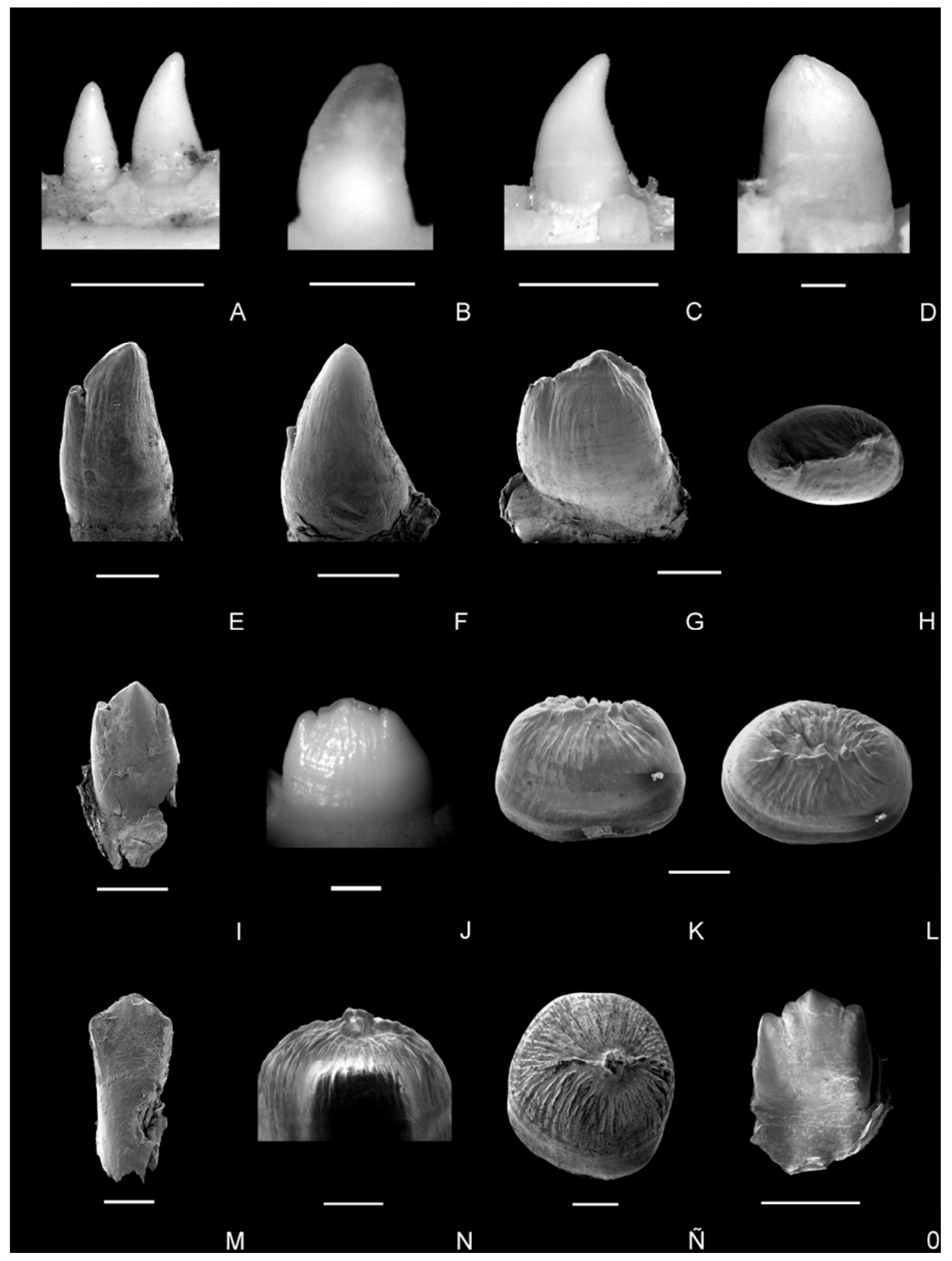


Figura 12. Tipos morfológicos de dientes de T. merianae Duméril y Bibron 1839. A, dientes unicuspidados, recto y curvo (u1) (UNMdP-O 13); B, diente unicuspidado apicalmente redondeado y labiolingualmente comprimido (u2) (UNMdP-O 33); C, diente unicuspidados agrandado, robusto y apicalmente punzante (U1) (UNMdP-O 1); D, diente unicuspidado agrandado robusto recto y apicalmente redondeado (U2) (UNMdP-O 2); E, diente bicuspidado (UNMdP-O 14); F, diente débilmente bicuspidado (UNMdP-O 11); G, H, diente bicuspidados robusto molariforme (B) (UNMdP-O 14); I, diente tricuspidado labiolingualmente comprimido (t1) (UNMdP-O 26); J, diente tricuspidado agrandado (UNMdP-O 14); K, L, diente tricuspidado robusto molariforme (T) (UNMdP-O 17), cúspide mesial a la derecha; M, diente tricuspidado espatulado (t2) (UNMdP-O 26); N, Ñ dientes romos molariformes (R) (N, UNMdP-O 17; N, UNMdP-O 13); O, diente pentacuspidado (UNMdP-O 26). Imágenes en vista lingual, excepto (H), (L) y $(\tilde{N})$ donde la vista es oclusal y $(\mathrm{O})$ donde es labial. Escala $=1 \mathrm{~mm}$, menos en $\mathrm{M}$ donde la escala es $=0,2$ $\mathrm{mm}$.

\subsection{Distribución de los tipos morfológicos dentales en $T$. merianae}

En la Tabla 9 se muestra el número de dientes presentes en el premaxilar, maxilar y dentario de la muestra estudiada de T. merianae. El número promedio de dientes (68) coincide aproximadamente con el valor dado por Dessem (1985). Si bien los ejemplares de menor talla presentan valores más bajos, éstos no son significativos.

El premaxilar presenta entre 8 y 10, con una moda de 10 dientes, de los cuales la mayoría son del tipo tricuspidado espatulado (t2). Se observa una tendencia a la pérdida de la cúspide distal y luego la mesial; de forma tal que los dientes tricuspidados, de posición central, están flanqueados por dientes bicuspidados y éstos por dientes unicuspidados. No se apreciaron diferencias ontogenéticas en el premaxilar.

El maxilar y dentario difieren en el número de dientes, entre 11 - 15 (media de 13) y 13 - 18 (moda de 16) respectivamente (Tabla 8,9). Sin embargo presentan el mismo patrón de distribución de los diferentes tipos morfológicos de dientes a lo largo de la serie dentaria y los mismos cambios ontogenéticos. En la figura 13 se observan las primeras y últimas apariciones de los diferentes tipos morfológicos en dentarios y maxilares, referidos a posiciones dentarias absolutas. Mientras que en la figura 14 se indica la presencia o ausencia de los diferentes tipos morfológicos en la serie ontogenética crecientemente ordenada. A partir de estas figuras es posible describir el patrón de distribución de los diferentes tipos morfológicos y su cambio a lo largo de la ontogenia. 


\begin{tabular}{|c|c|c|c|c|c|c|}
\hline espécimen & D i & D d & $\mathbf{M} \mathbf{i}$ & M d & $\mathbf{p M}$ & TOTAL \\
\hline UNMdP-O 28 & 15 & 16 & 12 & 12 & 9 & 64 \\
\hline UNMdP-O 26 & 16 & 16 & 11 & 11 & 10 & 64 \\
\hline UNMdP-O 14 & 14 & 16 & 12 & 12 & 9 & 63 \\
\hline UNMdP-O 33 & 16 & 15 & 12 & 11 & 8 & 62 \\
\hline UNMdP-O 32 & 15 & 15 & 14 & 14 & 9 & 67 \\
\hline UNMdP-O 6 & 15 & 15 & 13 & 12 & 9 & 64 \\
\hline UNMdP-O 10 & 16 & 16 & 12 & 13 & 10 & 67 \\
\hline UNMdP-O 35 & 16 & 17 & 15 & 14 & 9 & 71 \\
\hline UNMdP-O 4 & 16 & 16 & 14 & 14 & 9 & 69 \\
\hline UNMdP-O 9 & 17 & $17 *$ & 14 & $14^{*}$ & 9 & 71 \\
\hline UNMdP-O 12 & 15 & 15 & 13 & 13 & 8 & 64 \\
\hline UNMdP-O 11 & 17 & 17 & 15 & 14 & 12 & 75 \\
\hline UNMdP-O 3 & 16 & 15 & 14 & 14 & 11 & 70 \\
\hline UNMdP-O 8 & 16 & 16 & 14 & 13 & 9 & 67 \\
\hline UNMdP-O 7 & 16 & 16 & 13 & 14 & 9 & 68 \\
\hline UNMdP-O 2 & 16 & 16 & 14 & 14 & 10 & 70 \\
\hline UNMdP-O 18 & 16 & 16 & 14 & 15 & 9 & 70 \\
\hline UNMdP-O 13 & 18 & 17 & 14 & 14 & 12 & 75 \\
\hline UNMdP-O 17 & 16 & 16 & 12 & 14 & 9 & 67 \\
\hline UNMdP-O 5 & 16 & 16 & 15 & 14 & 10 & 71 \\
\hline UNMdP-O 19 & 16 & 16 & 14 & 13 & 9 & 68 \\
\hline UNMdP-O 20 & 13 & 15 & 13 & 13 & 10 & 64 \\
\hline UNLP s/n 1 & 18 & $18^{*}$ & 13 & 14 & 9 & 72 \\
\hline UNMdP-O 1 & 15 & 16 & 13 & 12 & 10 & 66 \\
\hline Media & 15,83 & 16,00 & 13,29 & 13,25 & 9,50 & 67,88 \\
\hline variación & 1,19 & 0,61 & 1,17 & 1,15 & 1,04 & 13,16 \\
\hline desvío & 1,09 & 0,78 & 1,08 & 1,07 & 1,02 & 3,63 \\
\hline
\end{tabular}

Tabla 9. Número de dientes por hueso portador en T. merianae. Los ejemplares están ordenados en valor creciente de tamaño, calculado de la longitud de la serie dentaria del dentario. Los valores marcados con un asterisco fueron inferidos de su contraparte por inexistencia de ese hueso.

Varios autores (Owen, 1866; MacLean, 1974; Presch 1974b; Barberena et al., 1970) han mencionado la variación ontogenética presente en Tupinambis; la que en líneas generales puede resumirse como el cambio de dientes posteriores tricuspidados por dientes romos. Sin embargo, Dessem (1985) es quien describe en mayor detalle esta variación ontogenética de la dentición en Tupinambis merianae (este autor sinonimiza T. teguixin y T. merianae). Dessem (1985) sostiene que los cambios ontogenéticos en la dentición se producen en: (1) la morfología dentaria; (2) las 
proporciones relativas de los diferentes tipos morfológicos; y (3) el ancho de los dientes en relación al largo de la serie dentaria. Este último punto marca la hipótesis de Dessem (1985), que el número de dientes se mantiene constante, alrededor de 70, durante toda la vida, contrariamente a lo que sostiene Presch (1974b) quien indica que el número de dientes aumenta con la edad del individuo. A partir de la muestra de especímenes de T. merianae aquí analizada se elaboró la figura 15, donde se observa que no hay correlación entre el tamaño (estimado a partir de la LSDd) y el número de dientes en el dentario $\left(\mathrm{R}^{2}=0,01\right)$ y que en el maxilar es mínima $\left(\mathrm{R}^{2}=0,39: \alpha=0,5 ; \mathrm{p}\right.$ $<0,1)$, confirmando la hipótesis de Dessem (1985). 

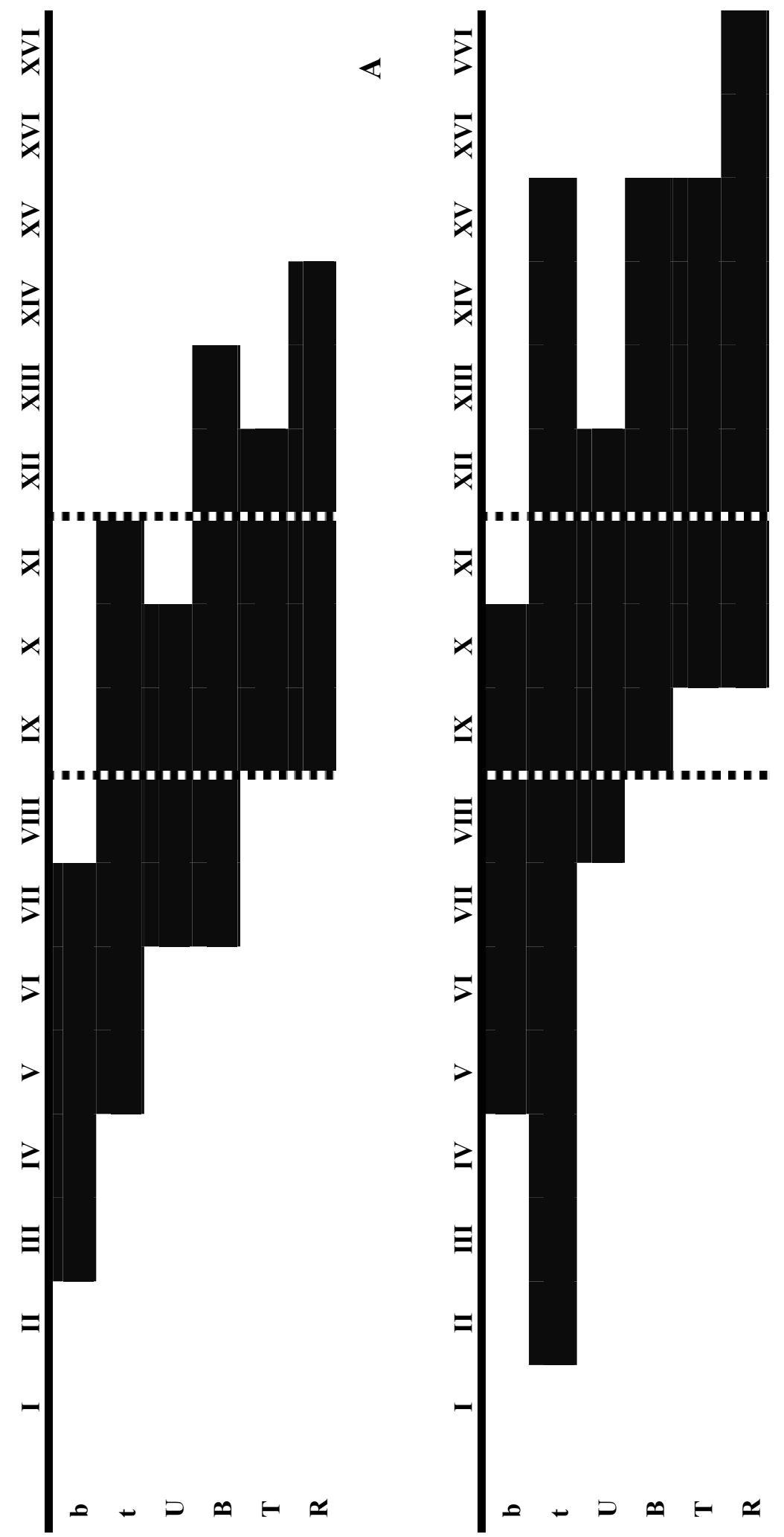

$\infty$

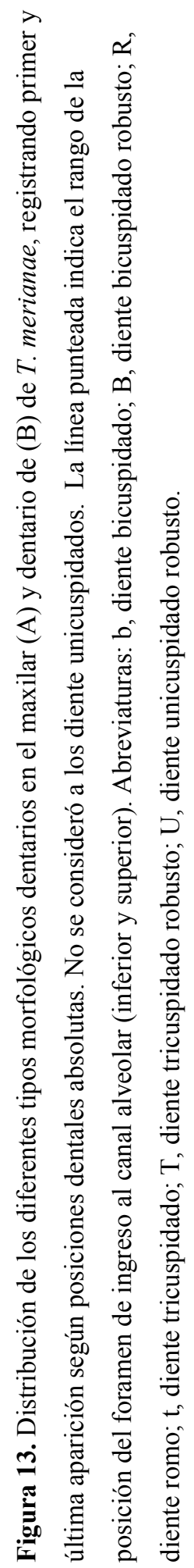




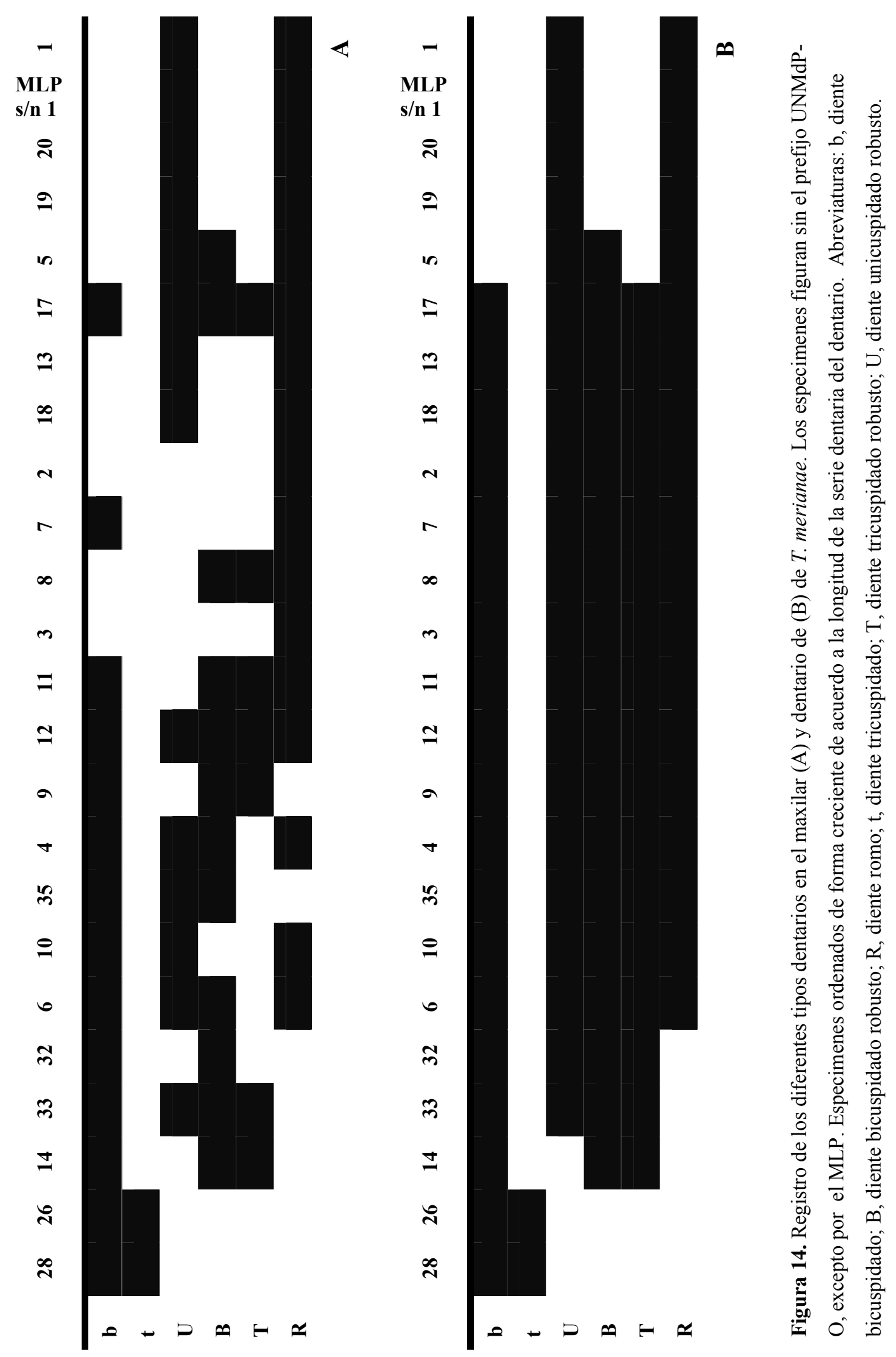




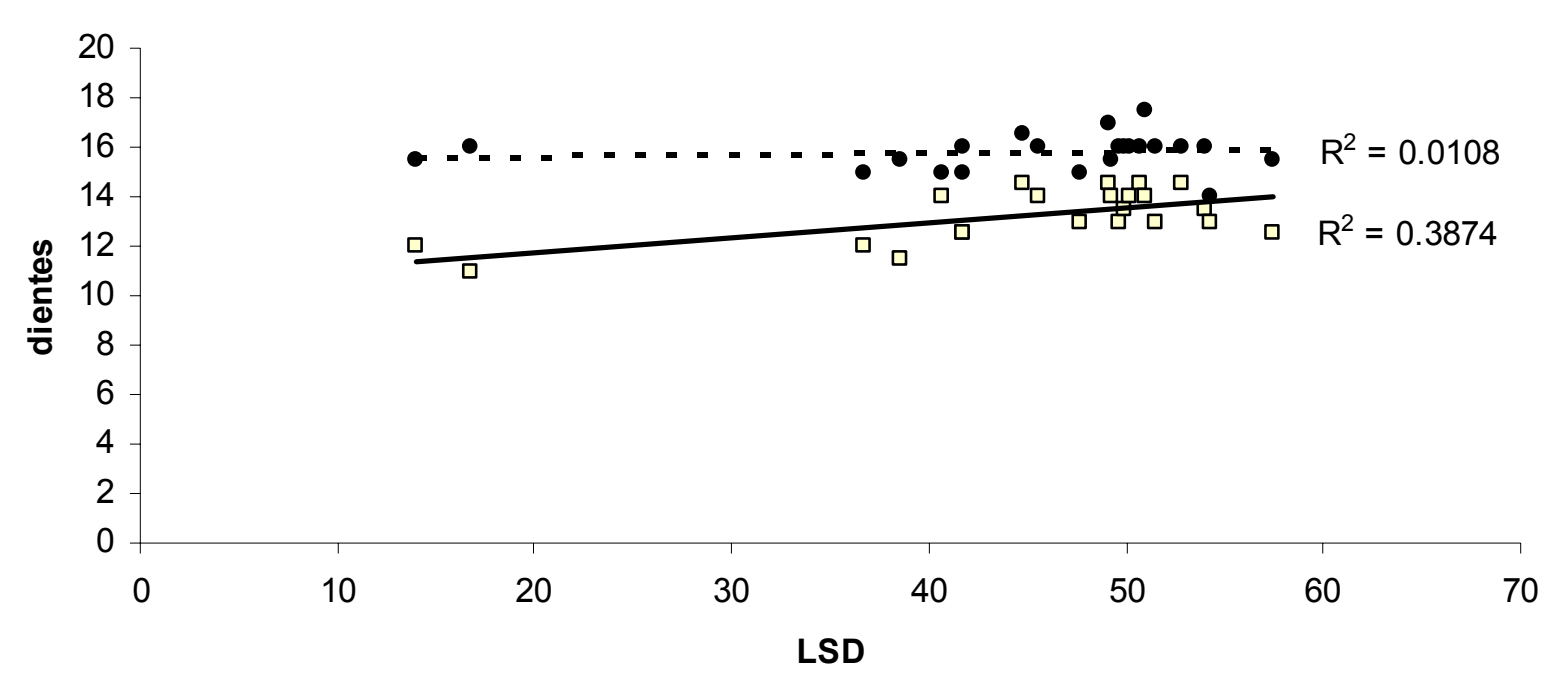

Figura 15. Valores de longitud de serie dentaria (LSD) vs número de dientes. Círculos negros corresponden al dentario, cuadrados blancos al maxilar. $\mathrm{n}=23$.

Chani et al. (1993) estiman que los embriones de T. merianae miden alrededor de 56,5-59,1 mm de LHC en el momento del nacimiento, auque Arias y Lobo (2006) registran tallas mayores acordando con los datos de Yanosky y Mercolli (1995) quienes consideran una LHC de nacimiento entre 70 y $80 \mathrm{~mm}$. Las hembras de esta especie alcanzarían la madurez sexual con más de $300 \mathrm{~mm}$ de LHC, aunque su tamaño máximo puede superar los 390 mm de LHC (Yanosky y Mercolli, 1995). Los machos superan este valor, alcanzando los $420 \mathrm{~mm}$ de LHC. Para este trabajo se contó con una serie ontogenética donde la mayoría de los ejemplares carecían de los datos de LHC y no estaban sexados. Por esta razón, la serie dentaria se ordenó de acuerdo a la longitud de la serie dentaria de los dentarios (LSDd). La serie dentaria de los maxilares ordena a los ejemplares de forma similar. De esta forma fue posible describir un patrón general de cambio ontogenético de la dentición.

En los ejemplares pequeños, jóvenes, (LSDd $<36,69$ mm y LHC $<315$ mm) la mayor parte de la serie dentaria está compuesta por dientes tricuspidados gráciles (t1), que se desarrollan claramente a partir de un nivel anterior al del foramen de ingreso al canal alveolar (f.c.a.) superior (para el caso del maxilar) o inferior (para el dentario). El f.c.a. del dentario indica aproximadamente la longitud media del hueso. 
Los dientes tricuspidados están precedidos por unos pocos dientes unicuspidados; entre éstos y los tricuspidados se presentan unos pocos dientes bicuspidados.

Al superar los $300 \mathrm{~mm}$ de $\mathrm{LHC}$, que corresponde a individuos probablemente adultos o subadultos (LSDd > 36,69 mm y LHC > 315 mm: UNMdP-O 14), el número relativo de dientes unicuspidados aumenta y se ubican en posición más posterior, acercándose a la ubicación del f.c.a.. El último diente unicuspidado generalmente es recto, alto, romo y robusto (U4). Este tipo morfológico sólo ocasionalmente se ubica superando posteriormente el nivel del f.c.a.. Es frecuente encontrar dientes bicuspidados gráciles (b) entremezclados con los dientes unicuspidados posteriores. Los dientes bicuspidados gráciles se presentan en bajo número y se ubican más posteriormente que en los individuos más pequeños. Dichos dientes se distribuyen entre las posiciones VI-VII en los maxilares y V-X en los dentarios (Fig. 13).

Los dientes tricuspidados posteriores de los ejemplares de menor tamaño son reemplazados por dientes bicuspidados y tricuspidados robustos (B y T) en individuos más grandes. Los dientes bicuspidados robustos preceden siempre a los tricuspidados robustos.

Los dientes bi y tricuspidados robustos son a su vez reemplazados por dientes robustos y romos a medida que aumenta la talla/edad de los ejemplares. Los primeros dientes robustos y romos aparecen como dientes funcionales en ejemplares con una LSDd $>$ 41,69 mm (UNMdP-O 6). A partir de una LSDd = 51,49 mm (UNMdP-O 17) ya no se observan dientes biscuspidados gráciles y todos los dientes posteriores son romos, robustos y de sección circular.

\subsection{Dentición en las especies de Tupinambis}

Como se mencionó previamente (punto 3.1.) entre las especies de este género existen diferencias a nivel dental, la principal de las cuales radica en la ausencia de dientes molariformes en T. quadrilineatus y T. longilineus. Estos géneros presentan una dentición similar a la de los ejemplares pequeños de T. merianae.

Adicionalmente, se comprobó que la dentición del premaxilar de T. quadrilineatus es homodonte, con dientes marcadamente tricuspidados, difiriendo de la condición ligeramente heterodonte de T. merianae; donde se observan dientes espatulados principalmete débilmente tricuspidados ( $\mathrm{t} 2$ ) con dientes que pierden las cúspides acesorias, primero la medial (espatulado ligeramente bicuspidado) y luego la distal 
(espatulado sin cúspides accesorias). Dientes como los observados en $T$.

quadrilineatus (MZUSP 84921, MZUSP 84928), marcadamente tricuspidados con las tres cúspides de igual desarrollo y con marcados surcos intercuspidales, son figurados por Edmund (1969), quien cita al ejemplar como T. teguixin (Royal Ontario Museum R351); sin embargo, la dentición del premaxilar de T. teguixin se asemeja a la de $T$. merianae (obs. pers.) (Fig. 16).

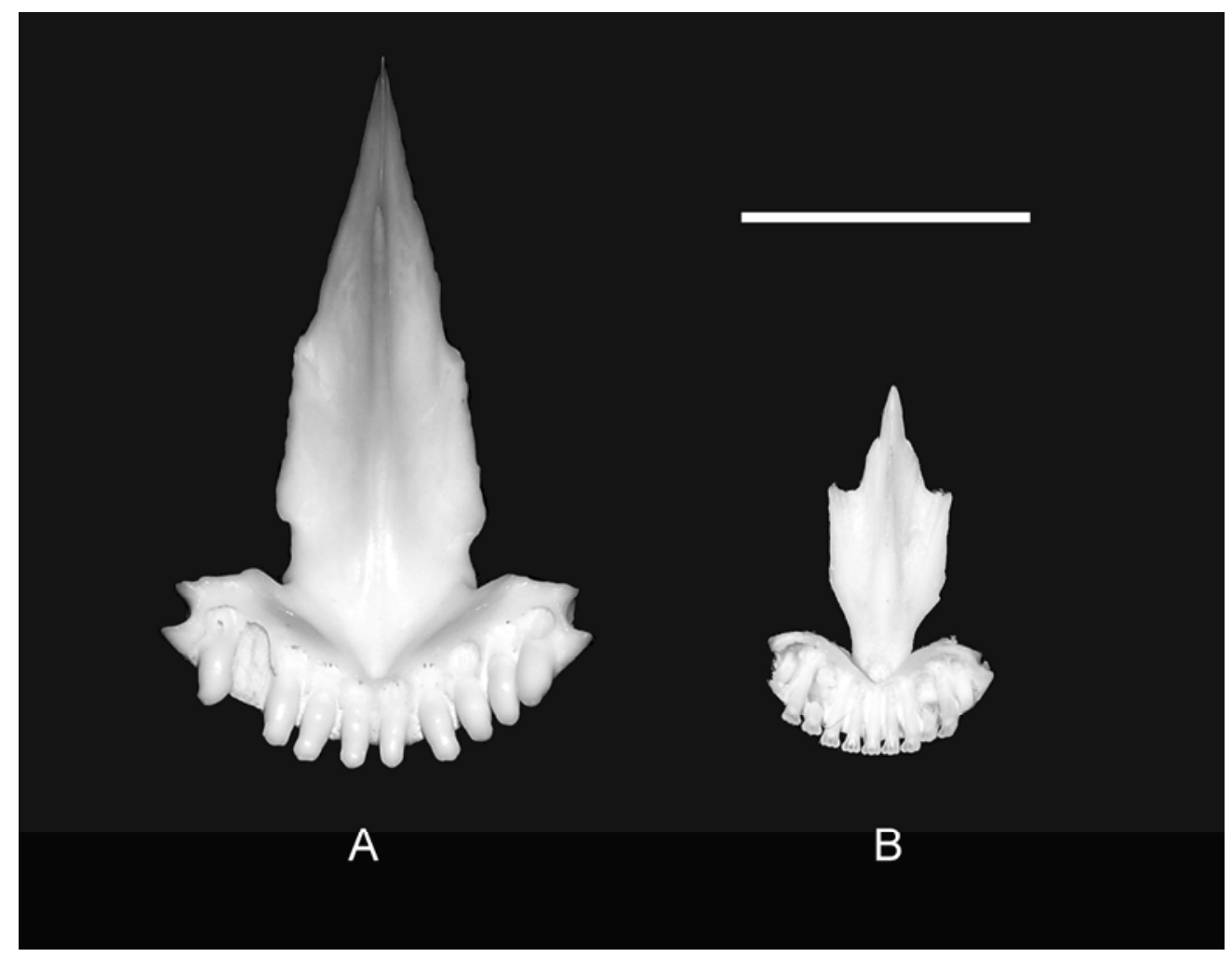

Figura 16. Premaxilares de Tupinambis merianae y Tupinambis quadrilineatus. A, Tupinambis merianane (UNMdP-O 2); B, Tupinambis quadrilineatus (MZUSP 84921). Vistas ventrales. Escala = $10 \mathrm{~mm}$.

Se notaron algunas diferencias en los dientes robustos de las restantes especies, pero dado el bajo número de ejemplares comparados deben tomarse con cautela. Los dientes posteriores de T. teguixin y T. duseni son altos, romos, robustos, con una ligera molarización y generalmente con vestigios de cúspides accesorias mesial y distal. Estas cúspides son más marcadas en $T$. duseni, que además presenta el contorno lateral del extremo apical de los dientes posteriores recto y horizontal; mientras que T. teguixin presenta un contorno lateral apical convexo. Los dientes posteriores de T. merianae y T. rufescens son más bajos, y de mayor sección 
transversal (i.e. más molariformes), que es circular y oval, respectivamente. Los dientes romos no presentan indicios de las cúspides accesorias, a pesar que estas especies tienen dientes robustos bi y tricuspidados.

\section{ESQUELETO POSTCRANEAL}

Merece hacerse aquí un breve comentario respecto al esqueleto axial de $T$. merianae, que, como ya se mencionó, fue descripto por Krause (1978a) y Veronese y Krause (1997).

Las vértebras son procélicas, con sistema de articulación zigósfeno-zigantro desarrollado, donde el borde anterior del zigósfeno es escotado. Las prezigapófisis no presentan procesos prezigapofisiarios. En las vértebras dorsales, el centro vertebral es cónico, posteriormente truncado. El cótilo y cóndilo son ovales comprimidos dorsoventralmente e inclinados ventral y dorsalmente, en forma respectiva. El cóndilo está precedido por un marcado cuello condilar. Sin embargo, estas características no son exclusivas de los Teiidae (Hoffstetter y Gasc, 1969), ya que no existen autapomorfias vertebrales para esta familia. Las vértebras cervicales en esta familia presentan hipapófisis articuladas (no fusionadas) a la parte anterior del centro vertebral (Hoffstetter y Gasc, 1969; Lee, 1998), condición que comparte con algunos integrantes de las familias Agamidae, Xantusiidae, Lacertidae y Gymnophthalmidae. Contrariamente a lo sostenido por Montero et al. (2004), en el material de referencia de T. rufescens, no se observó vértebras cervicales sin hipapófisis, o alguna cicatriz que sugiera que estaban articuladas.

Adicionalmente, y si bien existen diferencias vertebrales a nivel genérico entre los Teiidae (Veronese y Krause, 1997), estas diferencias en la mayoría de los casos no pueden reconocerse sobre vértebras aisladas ya que es necesario saber su ubicación absoluta en la columna vertebral. Aunque Veronese y Krause (1997) han realizado comparaciones del esqueleto axial de los Teiidae, se hace de notar aquí dos aspectos observados en T. merianae y compartidos por los Tupinambinae que no han sido mencionados por estos autores y que pueden resultar significativos para determinaciones de material fósil. El canal neural de $T$. merianae es reducido y de contorno triangular en vista anterior, en una condición similar a la que se aprecia en los restantes Tupinambinae, mientras que en los Teiinae el canal neural es amplio y transversalmente oval en vista anterior, con una pequeña evaginación por debajo del zigósfeno (Fig. 17 A, D). El otro aspecto corresponde a la cresta sagital del centro 
vertebral, que es poco desarrollada pero marcada (bordes laterales marcados) en los Teiinae, mientras que en Tupinambis y los restantes Tupinambinae, los bordes de esta cresta no son tan nítidos (en Crocodilurus la cresta es algo más definida) (Fig. 17 B, C).

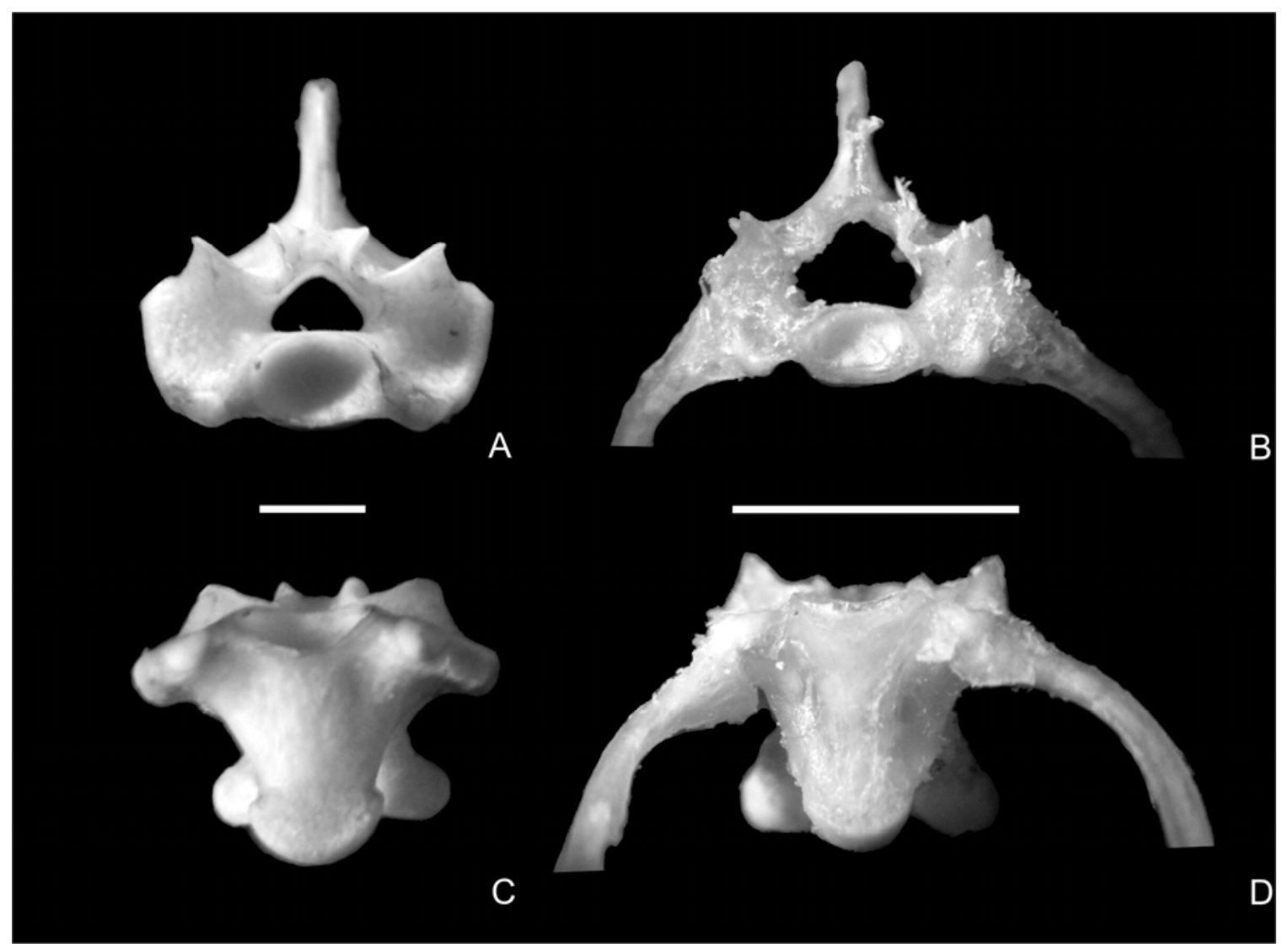

Figura 17. Primer vértebra dorsal de Tupinambis merianae y "Ameiva" ameiva. A, C, Tupinambis merianae (UNMdP-O 33) en vista anterior (A) y ventral (C); B, D, “Ameiva” ameiva (UNMdP-O 27) en vistas anterior (B) y ventral (D). Escala $=5 \mathrm{~mm}$. 


\section{CAPÍTULO IV}

\section{DESCRIPCIONES SISTEMÁTICAS}

\section{MESOZOICO}

\subsection{Formación Anacleto}

\section{Geología}

La Formación Anacleto del Grupo Neuquén aflorante en la ciudad de Cinco Saltos (Fig. 18), en la provincia de Río Negro, ha provisto el único resto de lagarto no iguanio del Mesozoico de Patagonia.

El Grupo Neuquén (Stipanicic et al., 1968) se encuentra disconformemente sobre el Grupo Rayoso y subyace disconformemente al Grupo Malargüe (Laenza y Hugo, 2001; Laenza et al. 2004; Veralli y Calvo, 2004; González Riga et al., 2008); aunque otros autores consideran que el cambio es transicional (Dingus et al., 2000; Coria et al., 2002a, b). Este Grupo consiste en una secuencia continental de conglomerados, areniscas y fangolitas depositadas en ambientes fluviales durante el Cretácico tardío (Cenomaniano a Campaniano temprano) (Laenza y Hugo, 2001; Veralli y Calvo, 2004). Se reconocen tres ciclos o Subgrupos en el Grupo Neuquén que de mayor a menor edad son: Río Limay, Río Neuquén y Río Colorado (Cazau y Uliana, 1973; Laenza y Hugo, 2001) (Fig. 19).

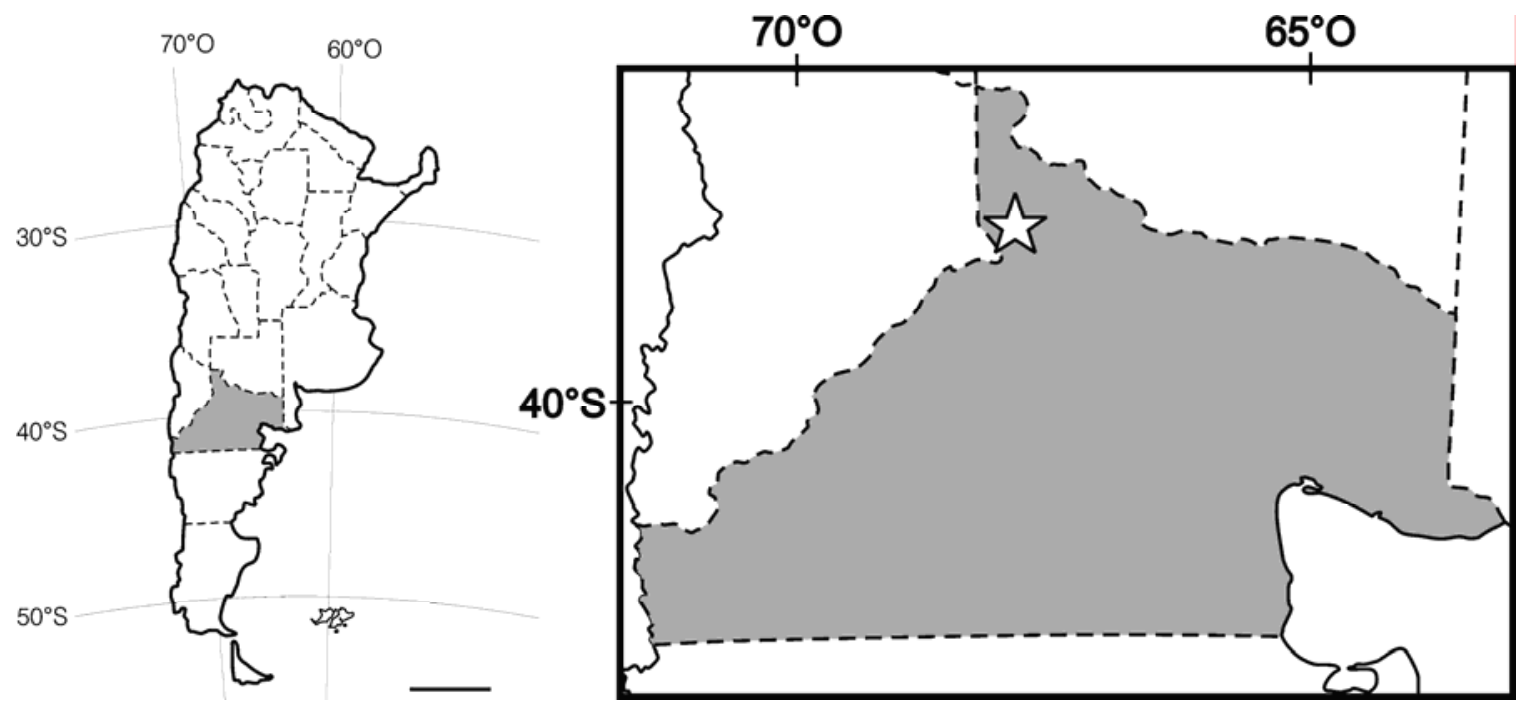

Figura 18. Mapa de ubicación de la Ciudad de Cinco Saltos (3849’S, 6804’O), Provincia de Río Negro 
Es de destacar que dentro del Grupo Neuquén existen diferencias en cuanto a la jerarquía, donde los Subgrupos y Formaciones (Veralli y Calvo, 2004) son considerados Formaciones y Miembros respectivamente (Dingus et al., 2000; Coria et al., 2002a). También es de notar que, según Musacchio (2006), el nombre Grupo Neuquén no sería válido por estar pre-ocupado por Weaver (1931) y que el nombre válido de los "Estratos con Dinosaurios" sería Grupo Pehuenche de Doering.

El subgrupo Río Colorado consta de dos Formaciones: la inferior es la Fm. Bajo la Carpa y la superior es la Fm. Anacleto (Cazau y Uliana, 1973; Laenza y Hugo, 2001). La localidad típica de la Fm. Anacleto se encuentra en Aguada de Anacleto, a $40 \mathrm{~km}$ de la ciudad de Neuquén (Ducloux en Fossa Mancini et al., 1938). Heredia y Calvo (2004) describen a la Fm. Anacleto como facies aluvio-fluviales, conformada por areniscas conglomerádicas a gruesas en la base y areniscas más finas ubicadas más arriba en la columna. Estos autores interpretan que estos sedimentos se depositaron en un ambiente de tipo aluvional, controlado por avenidas estacionales, seguidos por una llanura de inundación que luego fue colonizada por vegetación, transformándose en suelos. Estudios magnetoestratigráficos en el sitio Auca Mahuevo, única medición absoluta de la Fm. Anacleto hasta el momento, indican que esta formación fue depositada entre 83,5 y 79,5 Ma, confirmando una edad Campaniana temprana (Dingus et al. 2000).

\section{Antecedentes}

El Grupo Neuquén es una de las unidades portadora de dinosaurios más rica de Patagonia (Chiappe et al., 2000). El contenido de tetrápodos de la Fm. Anacleto ha sido recientemente resumida por Leanza et al. (2004). En particular, se registran dinosaurios titanosaúridos y huevos asignados a este grupo, terópodos abelisaúridos, varios icnogéneros de aves, dinosaurios ornitisquios, y mamíferos (Laenza et al., 2004). Entre los reptiles escamosos recuperados en la Fm. Anacleto se registra la serpiente primitiva Dinilysia patagonica Woodward, 1901, constituyendo el registro más reciente de la misma (Albino, 2007), además de un resto de lagarto procedente de la localidad de Cinco Saltos y comunicado preliminarmente en Albino (2002a, 2007). El dentario de lagarto es descripto formalmente por primera vez en esta sección. 


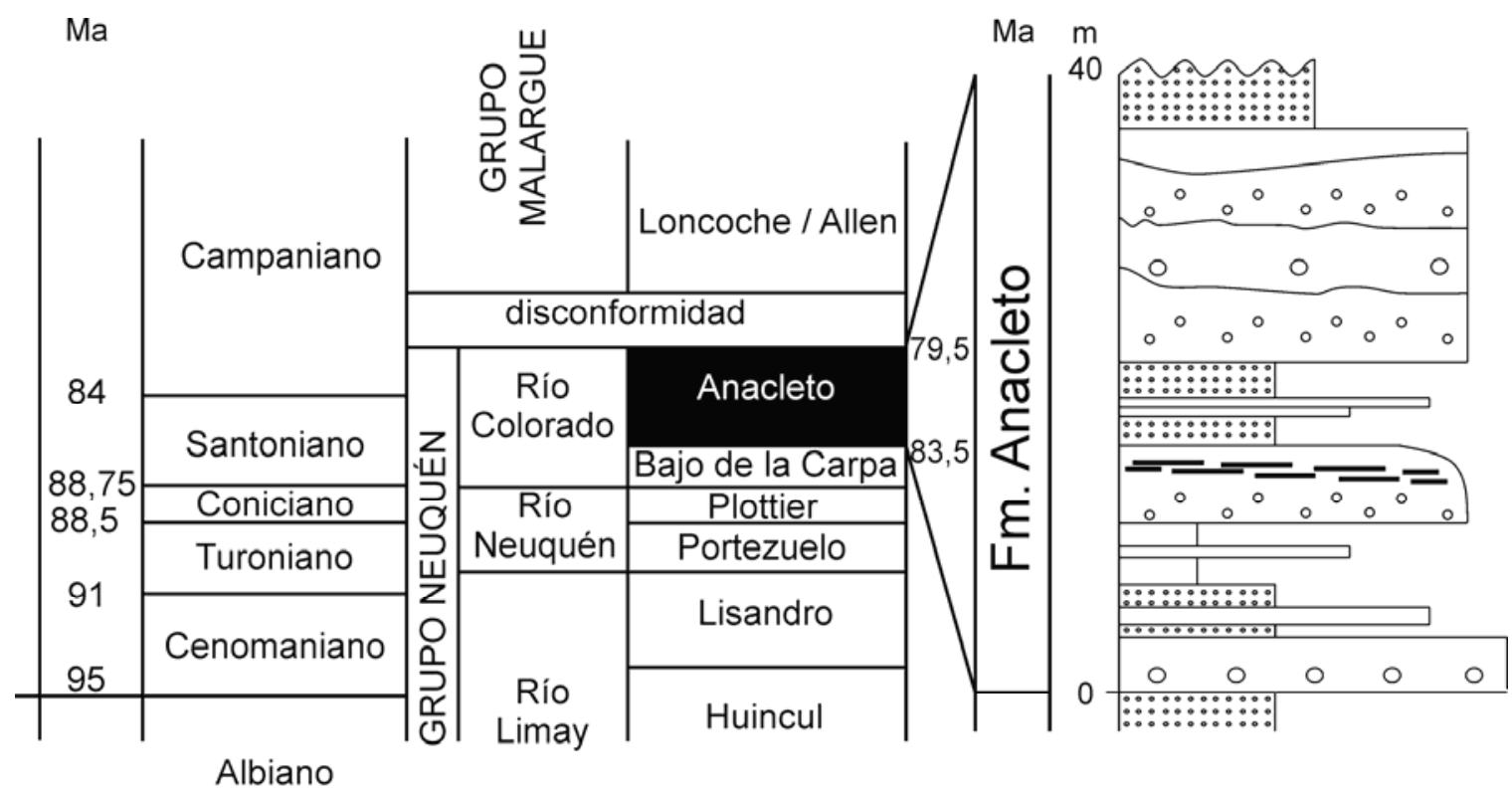

A

Figura 19. Estratigrafía de la Formación Anacleto. A, Ubicación de la Fm. Anacleto en la columna sedimentaria del Grupo Neuquén (modificada de Veralli y Calvo, 2004); B, Columna estratigrafía de la Formación Anacleto (modificada de Coria et al., 2002a). Escala temporal tomada de Dingus et al. (2000).

\section{Sistemática}

SQUAMATA Oppel, 1811

SCINCOMORPHA Camp, 1923

SCINCOIDEA Estes et al., 1988

? Scincoidea

(Fig. 20)

Material referido: MCS-PV 41, dentario izquierdo incompleto con dientes.

Procedencia geográfica: alrededores de la ciudad de Cinco Saltos $\left(38^{\circ} 49^{\prime} \mathrm{S}\right.$, $\left.68^{\circ} 04^{\prime} \mathrm{O}\right)$, provincia de Río Negro.

Procedencia estratigráfica: Formación Anacleto (Grupo Neuquén), Campaniano temprano.

Descripción. El fragmento MCS-PV 41 (Fig. 20 A, B) corresponde a la parte media de un dentario izquierdo robusto y de tamaño regular. El fósil fue cubierto por un importante depósito de laca que imposibilita observar algunos detalles. Labialmente 
es liso y presenta tres forámenes mentales a la altura de las posiciones dentarias (a), (d) y (h). El borde posteroventral se encuentra roto y algo desplazado. Lingualmente se observa el canal de Meckel expuesto medialmente. El mismo está ampliamente abierto en su parte posterior pero muy restringido anteriormente debido al importante desarrollo ventral del estante subdental. El estante subdental es cuneiforme, con el ápice en posición posterior y sin superar el nivel del diente (i); la superficie lingual es plana y no se une ventralmente al borde ventral del dentario, sino que ambos bordes (el del estante subdental y el del dentario) quedan próximos y paralelos entre sí en la parte anterior del resto conservado. Ventral al diente (i), sobre el techo del canal de Meckel, se observa el foramen de ingreso al canal alveolar inferior (c.a.i.). No aparenta haber proyección posterior del septo intermandibular. Dorsalmente se observa la serie dentaria dispuesta sobre el surco dental. Las bases de los dientes no pueden ser observadas debido al sedimento y al depósito de laca; sin embargo, se nota que los dientes se unen a la pared labial del dentario principalmente a través de sus bases. La pared labial, sobre la que están apoyados los dientes, es baja. Estos últimos sobresalen como máximo en un $50 \%$. Entre las bases de los dientes y el estante subdental hay un angosto espacio que correspondería a un poco desarrollado sulcus dentalis. De la serie dentaria se conservan 11 posiciones dentarias. Faltan los dientes (a), (c) y (e) y del diente (b) sólo se conserva su base. Los dientes (g) a (i) se conservan completos. Los dientes se disponen en empalizada cerrada, con estrecho contacto entre sí. Las bases de los dientes presentan compresión mesodistal y desarrollo labiolingual (Fig. 20 A). La cara labial de los dientes es recta y vertical, mientras que la lingual es más oblicua. Apicalmente son romos, con una ligera compresión lateral; la cara lingual del extremo apical es ligeramente cóncava mientras que la labial es recta. Lingualmente sobre el diente (h), se observa una zona de reabsorción. El depósito de laca imposibilita una óptima observación, pero se infiere que esta zona de reabsorción sería amplia, abarcando gran parte de la base del diente. 


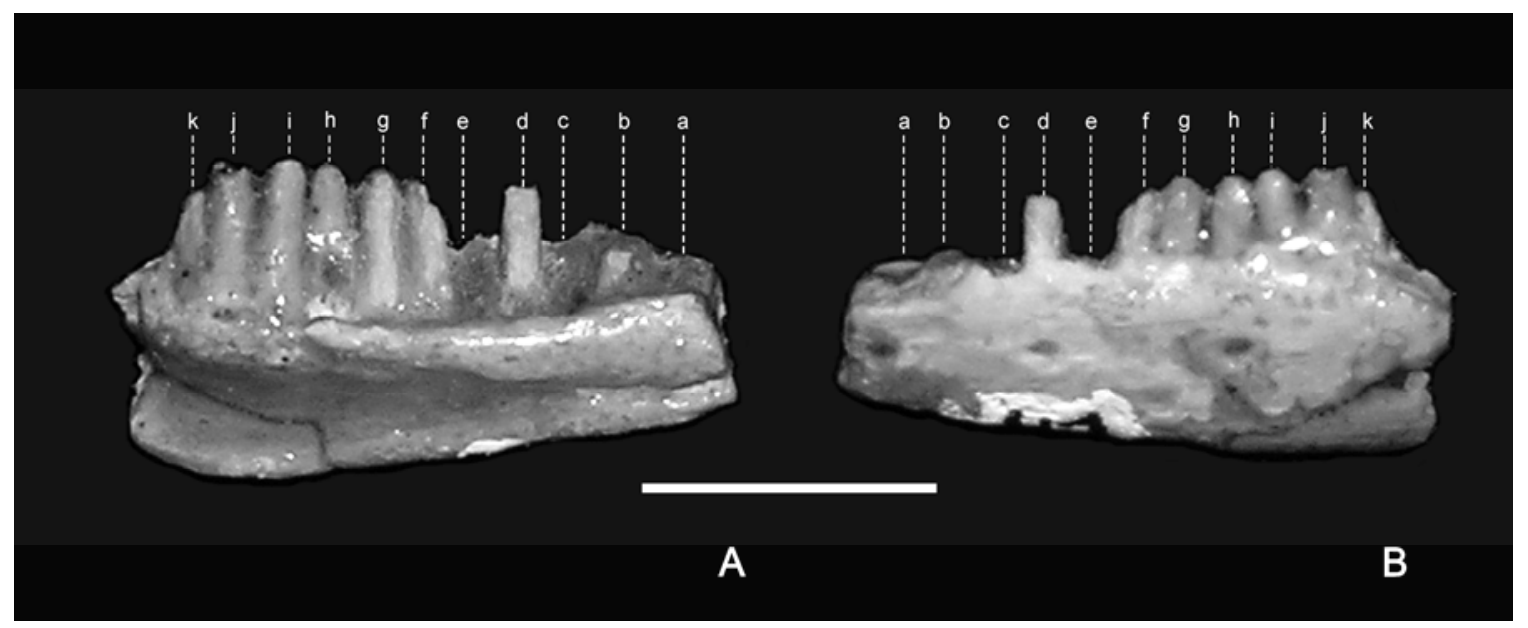

Figura 20. ?Scincoidea indeterminado (MCS-PV 41) de la Formación Anacleto (Campaniano temprano), en los alrededores de la ciudad de Cinco Saltos, provincia Río Negro. A, vista lingual; B, vista labial. Escala $=5 \mathrm{~mm}$.

Comentarios taxonómicos. Albino (2002a) da a conocer preliminarmente el dentario procedente de la Fm. Anacleto y lo relaciona tentativamente con la familia Teiidae. Más tarde, considera que este resto presenta afinidades con Pristiguana brasiliensis Estes y Price 1973, un Iguania o Teiidae del Cretácico de Brasil (Albino, 2007). En la reevaluación de este fósil, se advierte que presenta un desarrollado estante subdental, lo cual es una sinapomorfía de los Scleroglossa (Estes et al., 1988). El desarrollo del sulcus dentalis afianza la inclusión del fósil en este grupo de escamosos (Gao y Fox, 1996). Dentro de los Scleroglossa, el tipo de reemplazo dental, que es interpretado como el "tipo iguánido" de Edmund (1969), indica afinidad con los Scincomorpha más que con los Anguimorpha. En este mismo sentido, se reconoce como sinapomorfía de los Anguimorpha la presencia de un septo intermandibular desarrollado, con una importante extensión posterior. (Este et al., 1988: Fig. 9A, carácter 56; Lee y Scanlon, 2001). Esta morfología no es la observada en el dentario estudiado, donde el septo intermandibular se encontraría anteriormente al punto medio de la articulación esplenial-angular y al último diente conservado. Denton y O’Neill (1995) consideran que esta estructura puede también presentarse como una cresta, ventralmente libre, que se continúa medial y posterior al foramen de ingreso al c.a.i. como en los Borioteiioidea (dados como "Cretaceous teiids"), pero éste tampoco es el caso del fósil. 
El canal de Meckel en el dentario fósil está abierto medialmente, al menos en la parte representada por este fragmento, pero se restringe rápidamente apenas supera anteriormente el foramen de ingreso del c.a.i.. Esta situación difiere claramente de la condición de canal de Meckel cerrado que se observa uniformemente en los Gekkota y Xantusiidae, y en algunas especies de otras familias (Estes et al., 1988), como ocurre en la mayoría de los Gymnophthalmidae (Presch, 1980). También difiere de la condición observada en los Lacertidae y Teiidae donde el canal de Meckel está marcadamente abierto anteriormente al foramen de ingreso del c.a.i. Entre los Teiidae “cnemidoforinos" y Teius, existe una constricción anterior del canal, pero no es tan severa como en el fósil (obs. pers.). Entre los Scincoidea se observa una variación importante en este carácter, donde, según los taxones, puede haber un canal de Meckel cerrado (e.g. Mabuya), muy restringido, o abierto (Estes et al. 1988). El fósil presenta la segunda de estas condiciones.

Los dientes del dentario fósil son de contorno apical lateral romo, contrario a lo que ocurre en la mayoría de los Lacertoidea (sensu Estes et al. 1988) donde presentan extremos apicales punzantes y con varias cúspides (Presch, 1974b; Herrel et al, 2004). Además, los dientes se ubican en empalizada, muy cercanos entre sí y son de similar altura, difiriendo de la condición más espaciada y de altura variable presente en los Teiioidea. Una condición similar a la presente en el fósil se observó en el género actual Mabuya (Scincoidea: Scincidae), que, sin embargo, se diferencia por presentar los dientes algo más espaciados (Fig. 21). Los dientes del fósil y Mabuya presentan contornos laterales apicales convexos, aunque los ápices dentarios del fósil son simples, mientras que los del género actual son más complejos. 


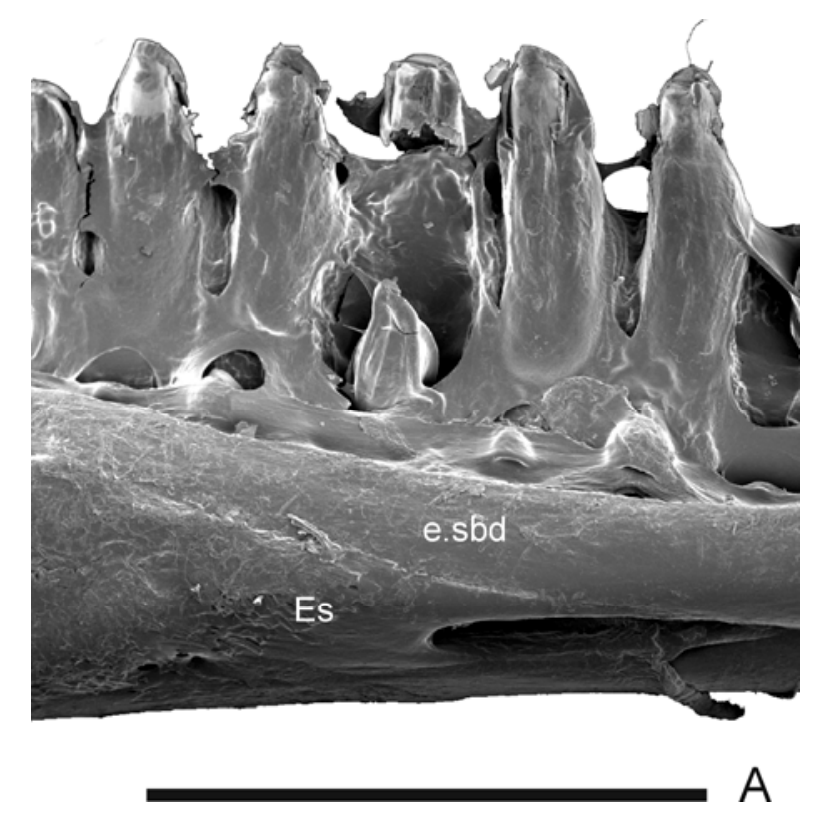

Figura 21. Parte medio-posterior de la hemimandíbula de Mabuya frenata (UNMdP 1599) en vista lingual. Abreviaturas: Es, esplenial; e.sbd, estante subdental. Escala $=2 \mathrm{~mm}$.

Como se mencionó anteriormente, se ha sugerido afinidad de este fósil con Pristiguana del Cretácico de Brasil (Albino, 2007), con quien comparte las siguientes características: un septo intermandibular anteriormente ubicado (no del tipo Anguimorpha), un surco dental poco desarrollado, con dientes que sobresalen de la pared labial menos de la mitad de su altura, y dientes en estrecho contacto entre sí y de similar altura. Difiere de Pristiguana por no presentar ninguna diferenciación de cúspides, ni aún levemente, para definir un tipo de diente tricuspidado como en dicho género. Otra diferencia es que en Pristiguana el canal de Meckel no se cierra tan abruptamente como ocurre en este fósil. Estes (1983a) sostiene que la afinidad de Pristiguana con los iguanios se basa principalmente en los caracteres mandibulares; sin embargo, el desarrollado estante subdental, que es interpretado por Estes et al. (1988) como sinapomorfía de Scleroglossa, está aparentemente presente en Pristiguana. Lamentablemente no se ha podido evaluar exactamente este carácter ni otros en Pristiguana debido a que no se observan con claridad en las figuras de Estes y Price (1973) y Estes (1983a), y a que aparentemente el fósil se encuentra perdido. De esta manera, la afinidad de Pristiguana debe ser revisada.

El desarrollado estante subdental es el único elemento diagnóstico que permite referir el dentario de la Fm. Anacleto a los Scleroglossa (Estes et al., 1988). Los restantes caracteres no son sinapomórficos, pero permiten la exclusión del fósil de los 
Gekkota y Anguimorpha. Entre los Scincomorpha, difiere de los Lacertoidea. La abrupta restricción anterior del canal de Meckel y los dientes en empalizada, en estrecho contacto entre sí, y el ser distalmente romos y lateralmente comprimidos, son caracteres presentes en algunos Scincoidea, auque no de forma exclusiva, permitiendo una asignación tentativa a dicho grupo. Los Scincoidea (Scincidae, Cordylidae y Gerrhosauridae) se distinguen entre sí por caracteres craneales y postcraneales no conservados o no conocidos en el fósil (Estes et al., 1988), motivo por el cual, no puede ser evaluado a niveles inferiores.

\section{Comentarios biogeográficos}

Como se mencionara en la Introducción, el registro comprobado de lagartos continentales del Mesozoico argentino está restringido al fósil descripto aquí y a un "Iguanidae" indeterminado (Apesteguía et al., 2005).

Estes (1983b) hace mención a la presencia de un escincoideo similar a Contogenys en el Eoceno de Brasil (Itaboraí). Dicha cita, y la de Rodriguez Loredo (1998) para un posible Scincidae del Holoceno de Argentina, constituyen todo el registro fósil de Scincoidea para América del Sur. Sin embargo, Contogenys no es considerado unánimemente un Scincidae (Estes et al., 1983a, b; Eaton et al., 1999) sino que sería un Xantusiidae (Gao y Fox, 1996; Nydam, 2002). Carvalho (2001), quien estudió el material de Itaboraí al que alude Estes (1983b), no puede confirmar la presencia de Scincidae, pero reconoce la presencia de un taxón similar a Contogenys (Taxón 4 de Carvalho, 2001) y a Paracontogenys, a los que considera integrantes del "stem group" de Xantusiidae (Xantusia, Palaeoxantusia, Lepidophyma y Cricosaura). El taxón descripto por Carvalho (2001) presenta similitudes dentarias con el ejemplar MCS-PV 41 (e.g. dientes en empalizada cerrada) pero, a diferencia de éste, posee el canal de Meckel cerrado.

La presencia en el Paleógeno de Brasil de una importante diversidad de lagartos Scleroglossa, con los tres principales clados representados (Gekkota, Scincomorpha y Anguimorpha) (Carvalho, 2001), estaría indicando una prolongada presencia de este grupo en territorio sudamericano. El hallazgo de un probable Scincoidea en la Formación Anacleto de Patagonia apoya esta suposición.

El material de la Fm. Anacleto constituye el primer registro de un lagarto Scleroglossa en el Cretácico de América del Sur (Albino, 2002a, 2007). La 
corroboración de su pertenencia a Scincoidea, significaría que es el primer registro del grupo en territorios gondwánicos. 


\section{CENOZOICO}

\subsection{PALEÓGENO}

\subsubsection{Formación Lumbrera}

\section{Geología}

La Fm. Lumbrera (Moreno, 1970) que aflora en los alrededores de Estancia Pampa Grande, provincia de Salta (Fig. 22), ha aportado los restos de lagartos continentales no iguanios más antiguos del Cenozoico de Argentina.
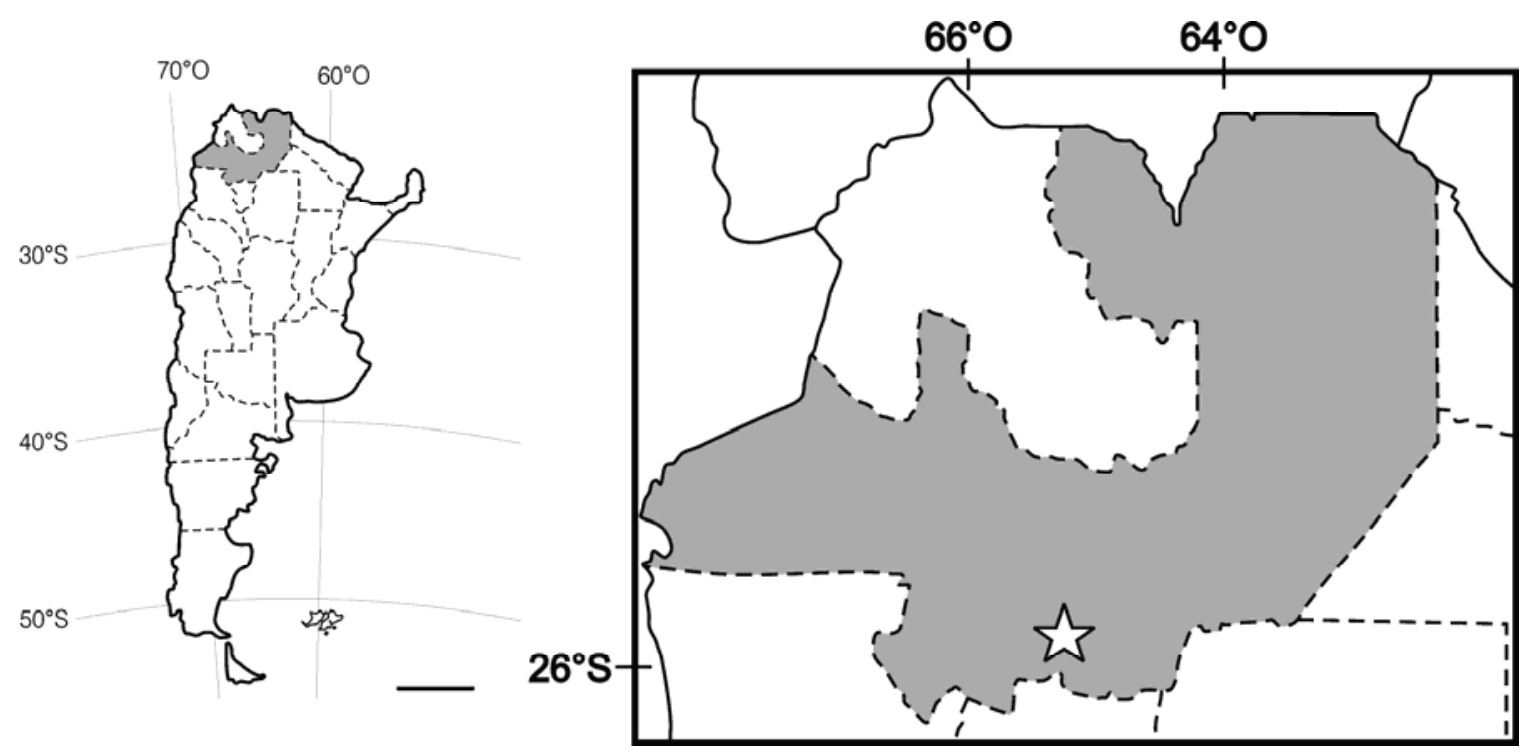

Figura 22. Mapa de ubicación de Estancia Pampa Grande $\left(25^{\circ} 52^{\prime} \mathrm{S}, 65^{\circ} 30^{\prime} \mathrm{O}\right)$, provincia de Salta.

La Fm. Lumbrera corresponde a la unidad superior del Subgrupo Santa Bárbara, del Grupo Salta (Fig. 23). Recientemente, del Papa (2006) ha caracterizado sedimentológicamente a esta Formación, en la que reconoce dos secciones: inferior y superior. El contacto entre la Fm. Lumbrera inferior (FLI) y Fm. Lumbrera superior (FLS) está representado por una discontinuidad que separa a dos ciclos sedimentarios (del Papa, 2006). Intercaladas en la FLI se presentan las denominadas "Fajas Verdes"; la Faja Verde I (o inferior) y la Faja Verde II (o superior), entre las cuales sólo la primera es constante a lo largo de la FLI (Babot et al., 2002; del Papa, 2006). La FLI se depositó en un paleoambiente fluvial arenoso de moderada sinuosidad asociado a un sistema lacustre perenne representado por las Fajas Verdes. Mientras que la FLS presenta variación geográfica de sus ambientes de depositación, con un sistema 
aluvial efímero al oeste y un lago clástico efímero al este (del Papa, 2006). Esta autora sostiene que la Fm. Lumbrera muestra un cambio de condiciones climáticas de húmedas (FLI) a áridas (FLS), el que concuerda con el cambio climático registrado del Eoceno al Oligoceno en otras regiones del planeta (Zachos et al. 1991).

Quattrocchio (1978a, b: en Pascual et al., 1981 y Marshal et al., 1997) en base al análisis polínico de la Fm. Lumbrera le asigna una antigüedad Paleoceno superior Eoceno inferior. Más recientemente Quattrocchio (2006) considera a la Fm. Lumbrera de antigüedad ?Eoceno medio-tardío. La fauna de vertebrados de la Fm. Lumbrera fue inicialmente referida, aunque en forma tentativa, a la Edad Mamífero Casamayorense sensu lato (Carbajal et al., 1977; Pascual et al., 1978, 1981), la cual convencionalmente se asigna al Eoceno temprano, entre 55 y $50 \mathrm{Ma}$ (Pascual et al., 1981, Deraco et al., 2008). La incertidumbre en la asignación a esta Edad Mamífero reside en que la fauna exhumada del Paleógeno del Noroeste argentino corresponde a géneros y/o especies diferentes a la de las localidades patagónicas (Pascual et al., 1981), lo que determina que las faunas del NOA presenten un fuerte endemismo a estos niveles sistemáticos, que dificulta la correlación con otras faunas extintas (Vucetich et al., 2007; Reguero et al., 2008). Cifelli (1985) sugiere subdividir a la Edad Casamayorense en dos “subedades", Barranquense y Vaquense. Dataciones radioisotópicas y datos magnetoestratigráficos del Barranquense (i.e. Casamayorense superior) de Patagonia permiten asignarle una antigüedad entre 36,62 y 35,34 Ma (Eoceno tardío) (Kay et al., 1999) o algo más antiguo, 38 Ma en el techo (Flynn et al., 2003). Por otro lado, datos radioisotópicos datan al Vaquense de la localidad Paso del Sapo entre 56 y 43 Ma. (Goin et al., 2000a). Esta situación ha llevado a Deraco et al. (2008) a plantear la equivalencia de la FLI al Vaquense y la FLS al Barranquense o Musterense. Marshall et al. (1997) consideran que la Fm. Lumbrera se correlaciona con los chrons 25n y 26n, y que las Fajas Verdes lo hacen con el chron 24r, lo que permitiría inferir una antigüedad entre 58-55,5 Ma.; es decir, Paleoceno tardío. Estos datos coinciden con los de Sempere et al. (1997) cuyo análisis magnetoestratigráfico estima una antigüedad de $\pm 54,5 \mathrm{Ma}$ (límite Paleoceno-Eoceno) al tope de su Fm. "Lumbrera 1" (= FLI?). Los datos de Marshall et al. (1997) y Sempere et al. (1997) indican una edad más antigua para la Fm. Lumbrera que la de los autores previamente mencionados. En el presente trabajo, se adopta la postura de Vucetich et al. (2007), quienes consideran que la Fm. Lumbrera es de antigüedad Eoceno temprano. La 
ausencia de dataciones absolutas (Malabarba et al., 2006) imposibilita una mayor resolución.

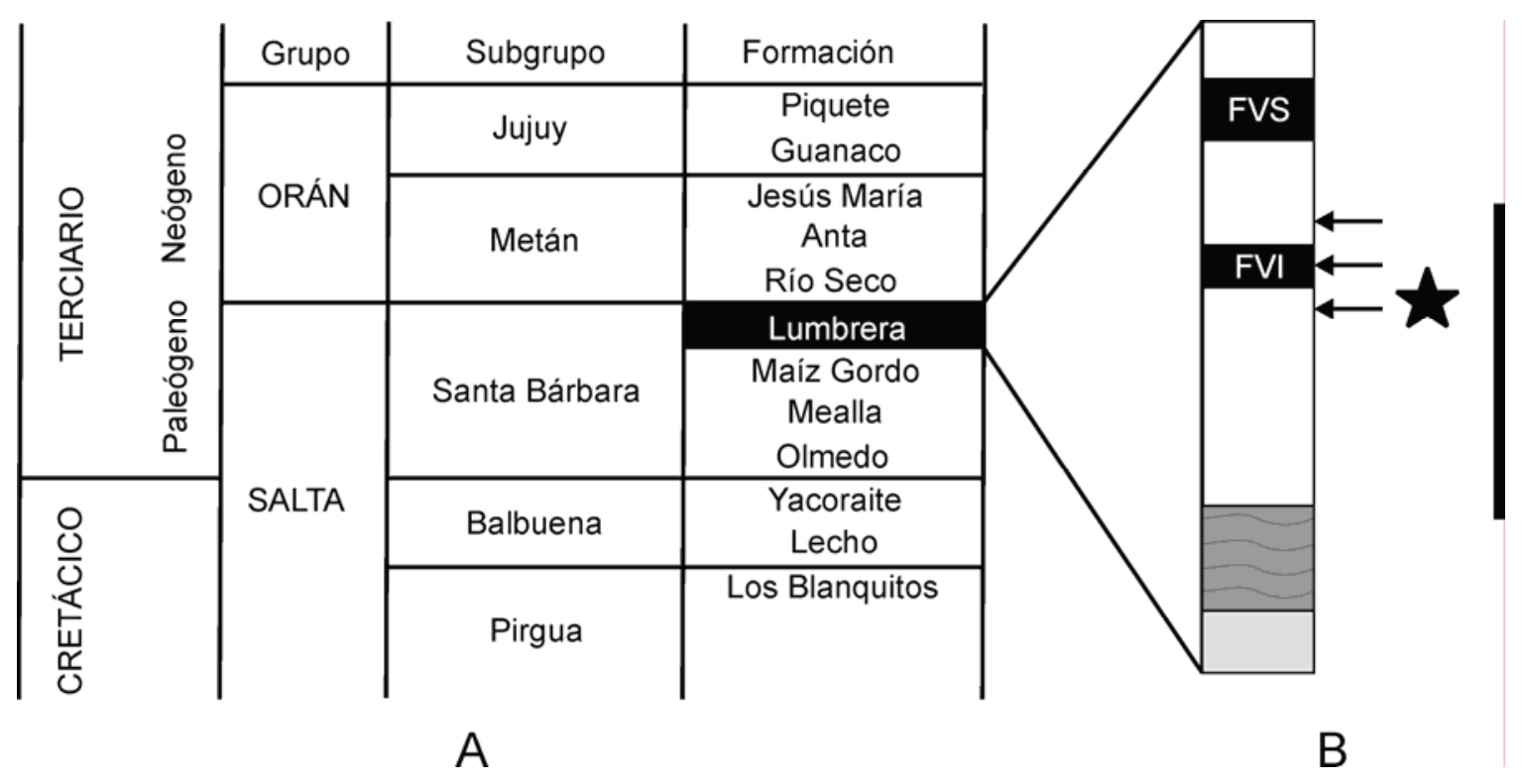

Figura 23. Estratigrafía de la Formación Lumbrera. A, ubicación de la Fm. Lumbrera en el Grupo Salta (modificado de Quattrocchio et al., 2003). B, Estratigrafía de la Fm. Lumbrera Inferior en Estancia Pampa Grande (modificado de Marshall et al., 1997). Las flechas indican fósiles mamalianos; la estrella indica la procedencia de los restos de lagarto. Abreviaturas: FVS, Faja Verde Superior; FVI, Faja Verde Inferior. Escala $=100 \mathrm{~m}$

\section{Antecedentes}

Quattrocchio (2006) identifica en la Fm. Lumbrera una vegetación subtropical con elementos de flora de zonas más templadas. En este ambiente se desarrolló una rica fauna de vertebrados que ha sido resumida por Pascual et al. (1981) y refinada posteriormente por varios autores (Gasparini, 1984; Gasparini et al., 1986; Bond y López, 1993; Marshall et al., 1997; Babot et al., 2002; Powell y Deraco, 2003; Malabarba et al., 2006). Entre los reptiles se destaca la presencia de cocodrilos sebécidos (Gasparini, 1984; Gasparini et al., 1986), tortugas pelomedúsidas (Gasparini et al., 1986) y escamosos, entre los cuales hay un boideo indeterminado (Albino, 1989, 1993) y el teido tupinambino que aquí se redescribe.

El material de lagartos de la Fm. Lumbrera fue primeramente descripto por Donadío (1985), quien diagnostica un nuevo género y especie de Teiidae:

Lumbrerasaurus scagliai. Posteriormente, Sullivan y Estes (1997) consideran a Lumbrerasaurus como nomen dubium debido a que estaría inadecuadamente 
diagnosticado y basado en sutiles diferencias vertebrales y de la sección transversal de los dientes. No obstante, estos autores nunca observaron el material directamente. En la presente sección se realiza un reanálisis de estos restos de lagarto.

\section{Sistemática}

SQUAMATA Oppel 1811

SCLEROGLOSSA Estes, de Queiroz y Gauthier 1988

SCINCOMORPHA Camp 1923

TEIIOIDEA Estes, de Queiroz y Gauthier 1988

TEIIDAE Gray 1827

TUPINAMBINAE Presch 1974a

Género y especie indeterminado

(Fig. 24, 25, 26 C)

Material referido: MMP 1418. Incluye parte anterior (MMP 1418-1) y posterior (MMP 1418-2) del maxilar izquierdo con dientes fragmentarios; parte proximal de1 epipterigoides izquierdo (MMP 1418-3); tres vértebras dorsales (MMP 1418-4 a 1418-6), una vértebra sacra (MMP 1418-7); dos vértebras caudales (MMP 1418-8, 1418-9); y un fragmento indeterminado (MMP 1418-10). Todos los elementos corresponden al mismo individuo y previamente fueron descriptos como Lumbrerasaurus scagliai por Donadío (1985)

Procedencia geográfica: El material proviene de un pequeño cañadón entre los ríos Bordo y Toro, en la estancia Pampa Grande (2552’S, 65³0’O), al Este de la Ruta Nacional $N^{\circ}$ 9, provincia de Salta.

Procedencia estratigráfica: Cinco metros por debajo de la Faja Verde inferior (Faja Verde I) en la Fm. Lumbrera (Eoceno temprano) (Babot et al., 2002; Malabarba et al. 2006, Cione y Báez, 2007; Vucetich et al., 2007) (Fig. 23 B).

Re-descripción. Los fragmentos del maxilar presentan dientes de implantación subpleurodonte, que se encuentran en alvéolos rectangulares delimitados por septos interdentales de hueso alveolar. La unión de los dientes al hueso es principalmente a través de sus bases, las cuales están cubiertas por abundante cemento basal. El cemento disimula los septos interdentales y llena parcialmente el sulcus dentalis. 
El ejemplar MMP 1418-1 (Fig. 24 A, B) corresponde a la parte anterior del maxilar izquierdo, con excepción del proceso premaxilar. Su superficie labial es lisa, sin ornamentación y lleva tres forámenes labiales a la altura de las posiciones dentarias (b), (c) y posterior a esta última. Se conserva la parte posteroventral de la fenestra exonarina, que tiene un desarrollo dorsal suave (no abrupto). Su superficie dorsal es algo convexa y se extiende desde el foramen de egreso del canal alveolar superior (c.a.s.) en sentido anterolabial, La lámina transversal anterior no está bien definida. En vista lingual, se observa el estante supradental de poco desarrollo dorsoventral. Medialmente, sobre el extremo anterior del estante supradental, se encuentra la carilla de articulación para el vómer. Posterior a esta carilla, pero dorsalmente sobre el estante supradental, hay una somera depresión para el órgano vómero-nasal, delimitada labialmente por un surco angosto y profundo, que está muy marcado probablemente como consecuencia de la deformación del fragmento fósil. La depresión para el órgano vómero-nasal se encuentra claramente por detrás del borde posterior de la fenestra exonarina. Posteriormente, se encuentra separado del receso medial del saco nasal por una convexidad suave y baja, interpretada como el soporte narial posterior. Este último se continúa sobre la lámina facial como la cresta semilunar. El borde posteromedial del estante supradental no se conserva. E1 surco dental, que porta la serie dentaria, es amplio y tiene la pared labial más alta que la lingual. Se conservan sólo tres alvéolos completos, los que no corresponden a los tres primeros de la serie, y dos dientes que carecen de sus extremos apicales. El diente anterior, sobre el primer alvéolo completo (a), es alto, presenta sección transversal suboval en sentido mesodistal, con una compresión labiolingual especialmente notoria en su cara distal. De esta compresión resulta una muy fina cresta que se desarrolla desde la base hasta el extremo del diente y que es más nítida en su parte apical. Paralelo a esta cresta (i.e. en posición vertical), en vista labial, se observa una somera y poco marcada depresión (Fig. 24 B, 26 D). El otro diente conservado, que está sobre el último alvéolo funcional preservado (c), presenta sólo su base, que es comprimida labiolingualmente, de dimensiones mayores a la del diente en el alvéolo (a). Lingualmente a los dos dientes conservados, se observan dos alvéolos de reemplazo, que son profundos y excavados en el cemento de modo que dejan al descubierto el esmalte de los dientes funcionales.

El fragmento MMP 1418-2 (Fig. 24 C, D) corresponde a la parte posterior del mismo maxilar izquierdo. Su cara labial es plana y se observa el último foramen labial 
en la parte anterior, a la altura del primer alvéolo conservado (a). Dorsalmente, la preservación no es buena, pero se distingue el borde de la lámina facial.

Lingualmente, quedó expuesto el sedimento que rellena el c.a.s.. En la parte posterior se observan, con escasa definición, el canal posterior al foramen de ingreso al c.a.s., y, labial a éste, el surco que recibe al yugal. En vista lingual, se encuentra el estante supradental mal preservado, posterior al cual se conserva la carilla de articulación para el palatino y ectopterigoides. Ventralmente, están el surco dental, la serie dentaria y el sulcus dentalis. Como en el fragmento maxilar anterior, la pared labial del surco dental es alta. Se observan cinco alvéolos funcionales en los que se conservaron solamente las bases de tres dientes (alvéolos b, d y e). A diferencia de los descriptos para el fragmento anterior del maxilar, estos alvéolos son más circulares y grandes. Las bases de los dientes son labiolingualmente comprimidas, especialmente en la cara distal. Se conservan dos alvéolos de reemplazo (b) y (d) de similares características a las descriptas para el fragmento anterior.

El elemento MMP 1418-3 es un fragmento de hueso aplanado que se infiere que corresponde al extremo ventral del epipterigoides izquierdo. Es recto, medialmente plano y lateralmente convexo. Su extremo ventral se encuentra más desarrollado, en especial en su borde anterior. El contorno del borde anterior es levemente cóncavo. La superficie posterior de la cara lateral es más alta y se interpreta que corresponde a la base de la cresta que recorre dorsoventralmente al epipterigoides. 


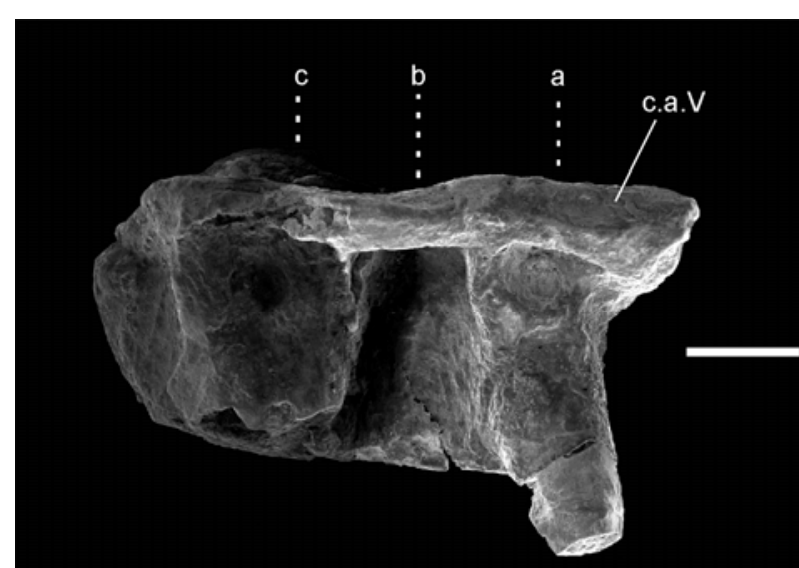

A

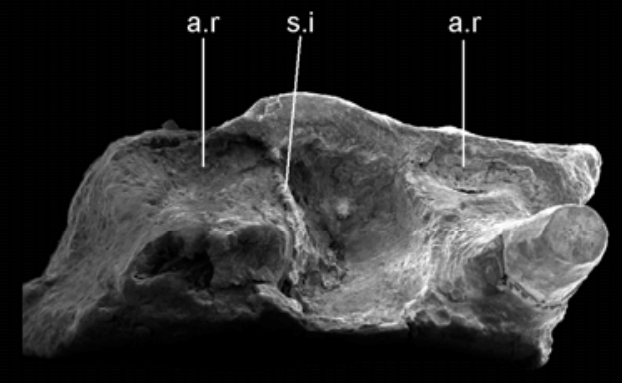

B
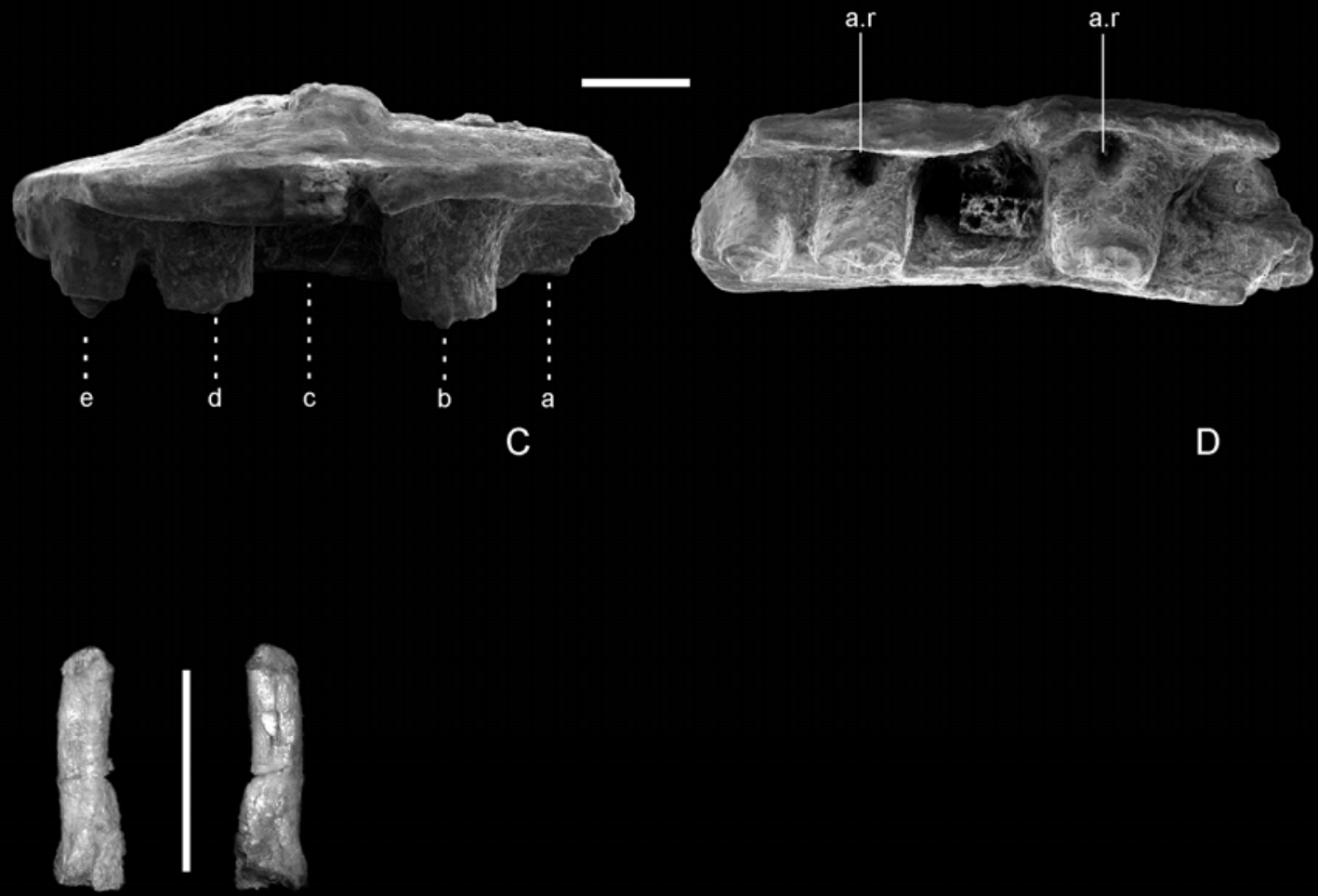

E

F

Figura 24. Elementos craneales del Tupinambinae indet. de la Fm. Lumbrera. A, B fragmento de maxilar izquierdo anterior (MMP 1418-1) en vistas lingual (A) y oclusal (B); C, D fragmento de maxilar izquierdo posterior (MMP 1418-2) en vista lingual (C) y oclusal (D); E, F epipterigoides (MMP 1418-3) en vista lateral (E) y medial (F). Abreviaturas: a.r, alvéolo de reemplazo; c.a.V. carilla de articulación para el vómer; s.i, septo interdental. Escalas $=2 \mathrm{~mm}$ para A-D; $10 \mathrm{~mm}$ para E-F.

La vértebra dorsal MMP 1418-4 (Fig. 25 A-D) es grande, deformada por una compresión que produjo la obliteración del canal neural debido al aplastamiento del arco neural sobre el centro vertebral. Esta vértebra no conserva el cóndilo y el proceso 
transverso izquierdo está sólo parcialmente preservado. Las prezigapófisis se orientan anterolateralmente; sus superficies de articulación son ovales y muy inclinadas sobre el plano horizontal en vista anterior. La espina neural se conserva sobre la parte posterior del arco neural, y, aunque está bien desarrollada, se deduce que no ha sido muy alta. Anteriormente a la parte conservada de la espina neural, se observa la cicatriz dejada por la rotura de la misma sobre el arco neural, alcanzando el techo zigosfenal. Lateralmente, por detrás de la prezigapófisis, se ubican los procesos transversos que distalmente llevan las sinapófisis ovales y de disposición vertical. El centro vertebral es cónico y ventralmente plano, con una convexidad suave y poco nítida a lo largo de la línea media en forma de una cresta sagital poco desarrollada. A ambos lados de la misma se aprecian dos pequeñas hendiduras longitudinales pareadas, aquí llamados forámenes ventrales, que son pequeños y de presencia irregular a lo largo de la columna vertebral en el material de referencia. Su homología con los forámenes subcentrales, más grandes y de presencia más regular a lo largo de la columna y por donde pasa la arteria intersegnmentaria, no puede establecerse. El cótilo es oval, más ancho que alto, y anteroventralmente orientado.

La vértebra dorsal MMP 1418-5 (Fig. 25 E-H) es de menor tamaño que la anteriormente descripta. También está dorsoventralmente comprimida por deformación, pero en este caso hay, además, un desplazamiento de la parte dorsal hacia la izquierda del centro vertebral. No conserva la prezigapófisis y postzigapófisis derechas, ni los procesos transversos. La prezigapófisis izquierda es grande y está anterolateralmente orientada. Su superficie de articulación, aunque está mal preservada, es subtriangular y está diferenciada de la parte dorsoproximal, posiblemente por efecto de la deformación. Medialmente a la prezigapófisis se observa parte del techo zigosfenal. A lo largo de la línea medial se observa la cicatriz dejada por la espina neural, que no se conserva. En la parte posterior de la vértebra se observa la postzigapófisis izquierda. La carilla de articulación de la postzigapófisis, aunque mal preservada, es oval y posterolateralmente orientada. En vista ventral, se aprecia el centro vertebral de forma cónica que termina en el cóndilo, separado por un cuello condilar distintivo. La superficie ventral del centro vertebral es similar a la descripta para la vértebra MMP 1418-5. Se observa un probable foramen ventral del lado derecho. El cótilo es profundo, transversalmente oval e inclinado ventralmente. El cóndilo también es oval. 
La vértebra dorsal MMP 1418-6 (Fig. 25 I) conserva sólo su lado izquierdo anterior. Se observa la parte izquierda del zigósfeno, el cual es escotado en su parte media. La superficie de articulación del mismo se dispone horizontalmente, debido a la deformación de la vértebra. De la espina neural se conserva la parte anterior que, por la deformación, está expuesta lateralmente. La prezigapófisis izquierda es grande, anterolateralmente orientada y presenta una amplia carilla de articulación subcircular. Posteriormente a la prezigapófisis, se observa una marcada cresta interzigapofisaria. El proceso transverso es corto y porta una sinapófisis rectangular dispuesta verticalmente. El cótilo está muy deformado, pero puede advertirse que era profundo.

La vértebra sacra MMP 1418-7 (Fig. 25 K-Ñ) no conserva su parte dorsal, excepto por la prezigapófisis izquierda y la superficie dorsoanterior del proceso transverso izquierdo. La prezigapófisis es pequeña y orientada anteriormente. $\mathrm{Su}$ carilla de articulación es subtriangular, dispuesta casi verticalmente debido a la deformación de la vértebra. En vista ventral, se observa el centro vertebral corto y de forma rectangular. En el extremo posterior puede apreciarse el cóndilo, orientado dorsoposteriormente y con un cuello condilar bien definido. A ambos lados del centro vertebral se conserva la parte proximal de los procesos transversos. Estos procesos están bien desarrollados y son dorsoventralmente aplanados. Ventralmente presentan surcos longitudinales poco profundos pero no se conservan los forámenes ventrales.

La vértebra caudal MMP 1418-8 conserva parte de su lado izquierdo y el centro vertebral. Este último es largo, cilíndrico y más estrecho en su parte media. Posteriormente, se observa un claro cuello condilar. Por detrás del cótilo, se advierten dos forámenes ventrales, de los cuales el derecho es mayor que el izquierdo. En vista lateral, el lado izquierdo presenta parte del arco neural donde se destaca la cresta interzigapofisaria. Entre el arco neural y el centro vertebral se observa la larga cicatriz dejada por la rotura del proceso transverso izquierdo, el cual era dorsoventralmente comprimido.

La vértebra caudal MMP 1418-9 consiste en parte del lado derecho y el centro vertebral. No se conserva el cóndilo. El centro es más corto pero más robusto que el descripto para el ejemplar MMP 1418-8. En los restantes aspectos se asemeja a dicha vértebra.

El fragmento indeterminado MMP 1418-10 podría corresponder a la parte posterior de un centro vertebral de una vértebra dorsal. Se infiere parte del cóndilo y del borde posteroventral derecho del arco neural. 

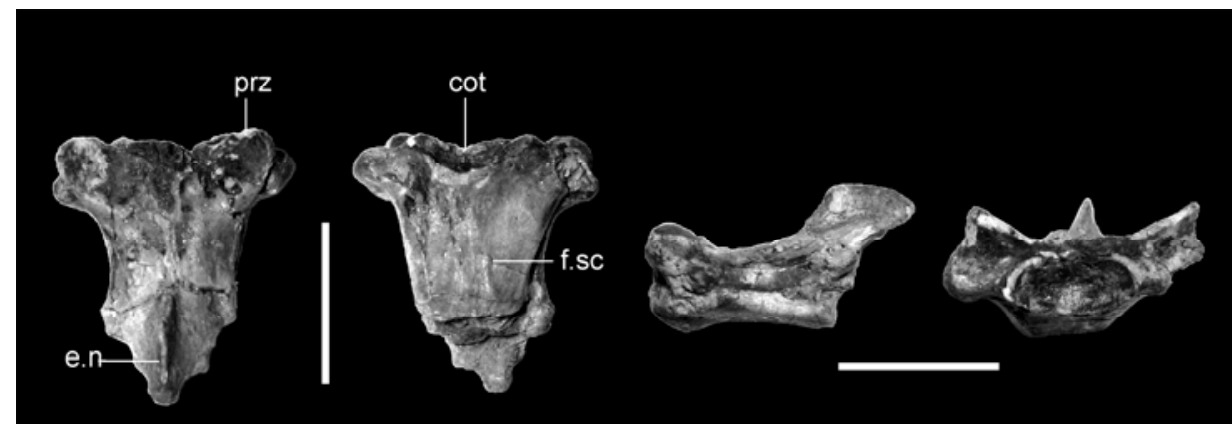

A

B

C

D
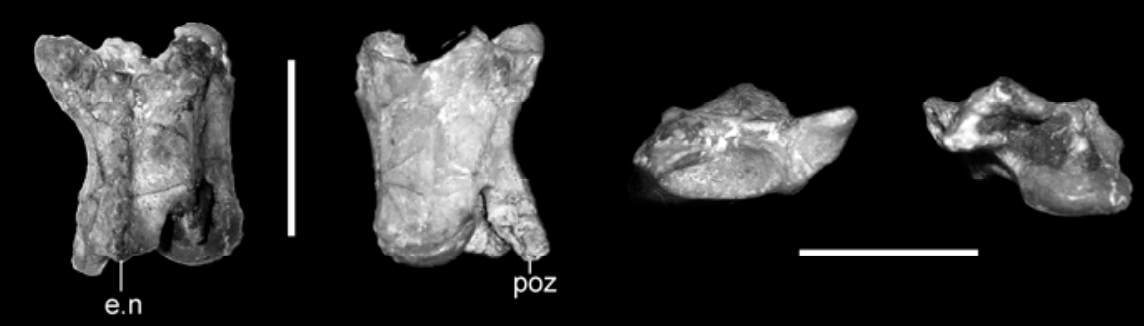

E

F

G

$\mathrm{H}$
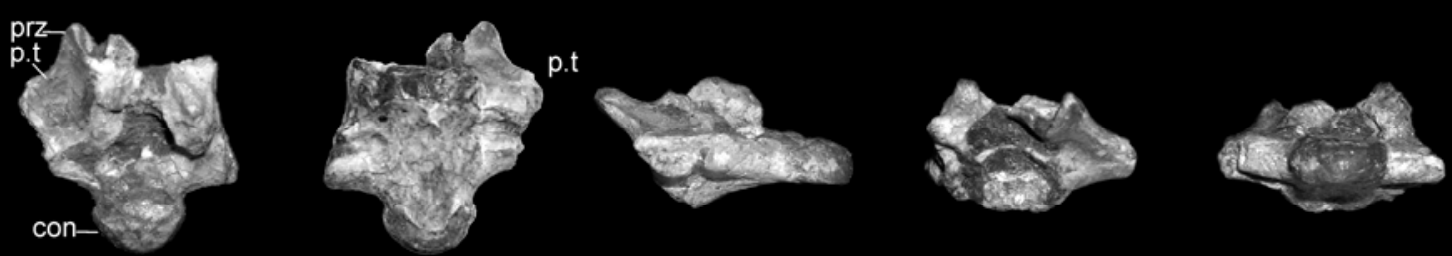

I

J

K

L

M
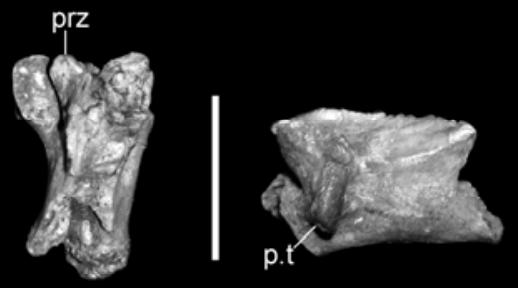

f.v
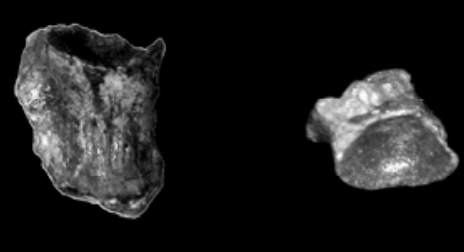

N 
Figura 25. Elementos del esqueleto axial del Tupinambinae indet. de la Fm. Lumbrera. A-D vértebra dorsal (MMP 1418-4) en vistas dorsal (A), ventral (B), lateral (C) y anterior (D); E-H vértebra dorsal (MMP 1418-5) en vista dorsal (E), ventral (F), anterior (G) y posterior (H); I-M, segunda vértebra sacra (MMP 1418-7) en vista dorsal (I), ventral (J), lateral (K), anterior (L) y posterior $(\mathrm{M})$; $\mathrm{N}$, Ñ, vértebra dorsal (MMP 1418-6) en vista dorsal (N) y lateral (Ñ); O, vértebra caudal (MMP 1418-8) en vista ventral; P, Q vértebra caudal (MMP 1418-9) en vista ventral (P) y anterior (Q). Abreviaturas: cot, cótilo; con, cóndilo; e.n, espina neural; poz, postzigapófisis; prz, prezigapófisis; p.t, proceso transverso; f.v, foramen ventral. Escalas $=10 \mathrm{~mm}$.

Comentarios taxonómicos. Sobre la base de la redescripción aquí presentada es posible discutir la identidad taxonómica de este material con nuevos elementos de juicio que aquellos vertidos por Donadío (1985) y Sullivan y Estes (1997).

El receso para el saco nasal, ubicado ventralmente a la cresta semilunar, que se observa en el maxilar fósil (MMP 1418-1), ha sido reconocido como un carácter propio de los Lacertiformes actuales (Bell et al., 2003). Los alvéolos de reemplazo subcirculares y profundos son uno de los atributos que caracterizan al clado de los Borioteiioidea-Teiioidea (excepto Gymnophthalmidae) (Nydam et al., 2007). Este clado, además, presenta implantación dental subpleurodonte, como es evidente en el fósil. El espécimen fósil difiere de los Borioteiioidea en la estructura medial del maxilar. En este grupo, la depresión para el órgano vómero-nasal está delimitada por dos septos (Fig. 26 A). Una de estas estructuras fue originalmente descripta en forma algo confusa por Denton y O’Neill (1995: 240) como “narial buttress/mesial process of maxillary narial border", refiriéndose a un septo de orientación medial, el soporte narial anterior, que se encuentra sobre el borde posterior de la fenestra exonarina, anterior a la depresión para el órgano vómero-nasal (Fig. 26 A). Posteriormente a esta depresión, se observa un segundo septo (no mencionado por Denton y O’Neill, 1995), aquí llamado "soporte narial posterior”, que se continúa dorsalmente sobre la lámina facial como la cresta semilunar. Los Teiioidea no presentan el soporte narial anterior, sino que en esa posición se encuentra el septomaxilar. En Cercosaura schreibersii (Teiioidea: Gymnophthalmidae) (Fig. 26 B), el soporte narial posterior se encuentra a la altura del borde posterior de la fenestra exonarina. Una situación similar se observa en Neusticurus ecpleopus (Gymnophthalmidae; Bell et al., 2003: Fig. 4 A).

Contrariamente, en los Teiidae, el soporte narial posterior se encuentra ubicado posteriormente a la fenestra exonarina. Esta última situación es la que se aprecia en el fragmento MMP 1418-1 (Fig. 26 C). El estado desdibujado que presenta el soporte 
narial posterior se asemeja a lo observado en los Tupinambinae, mientras que los “cnemidoforinos” y Teius lo tienen más marcado y nítido ([C16], [C17]).

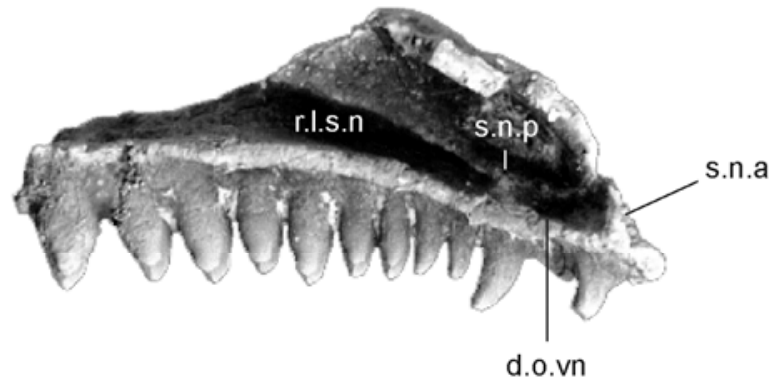

A

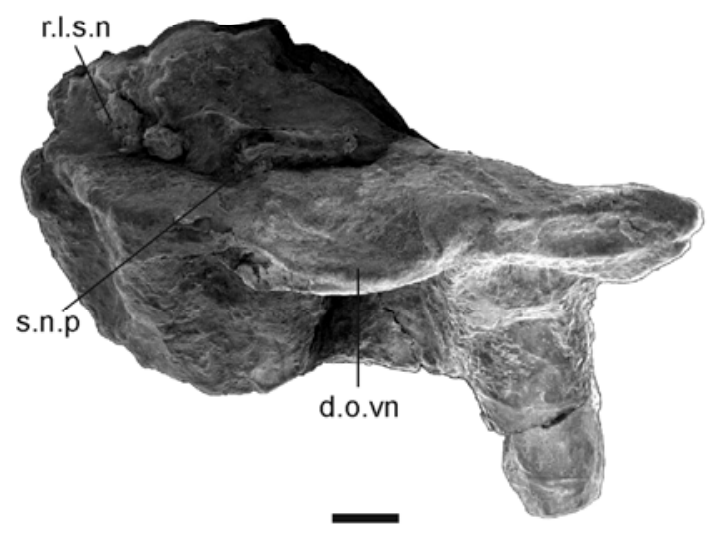

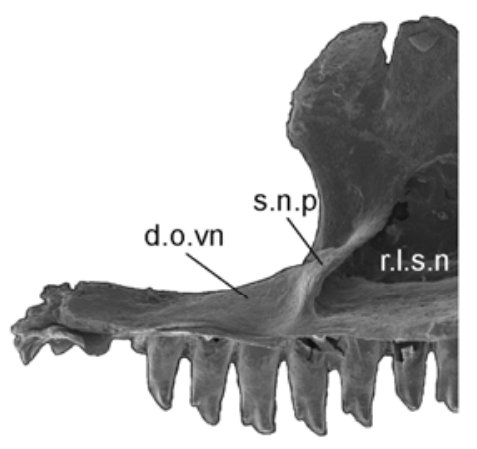

B

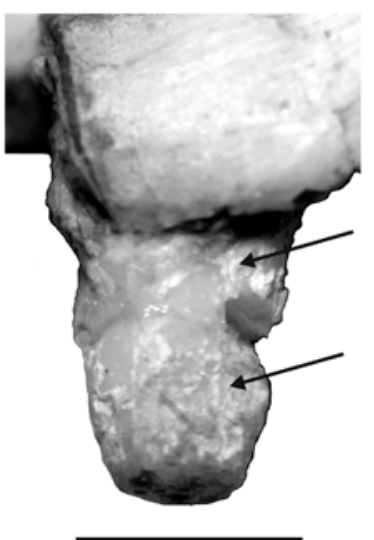

C

Figura 26. A-B, maxilares en vista medial de Borioteiioidea y Teiioidea; C-D, Tupinambinae indet. de la Fm. Lumbrera. (A) Bicuspidon numerosus, maxilar izquierdo (Borioteiioidea, tomado de Nydam et al., 2002), (B) Cercosaura schreibersii, maxilar derecho (Gymnophthalmidae) (UNRC 5058), (C) maxilar izquierdo MMP 1418-1; (D) diente anterior del maxilar MMP 1418-1 en vista labial. Las flechas indican la posición de la depresión distal sobre la cara labial. Abreviaturas: d.o.vn, depresión para el órgano vómeronasal; r.l.s.n, receso lateral del saco nasal; s.n, soporte narial posterior; s.n.a, soporte narial anterior. Escalas $=1 \mathrm{~mm}$ en $\mathrm{A}, \mathrm{C}$ y $\mathrm{D} ; 0,5 \mathrm{~mm}$ en $\mathrm{B}$.

La carilla de articulación para el palatino y el ectopterigoides en el fragmento MMP 1418-2 es importante ya que abarca toda la parte posterior del fósil y permite inferir, como sostiene Donadío (1985), que el maxilar está excluido de la fenestra suborbital. Este estado es reconocido por varios autores como presente en los Teiioidea, aunque no exclusivamente (MacLean, 1974; Presch, 1980; Estes et al., 
1988; Denton y O’Neill, 1995; Lee 1998; Nydam y Cifelli, 2002b; Nydam et al., 2007) ([C77]).

Donadío (1985) hace referencia a la condición heterodonte de la dentición del material fósil basándose en los contornos transversales de las bases conservadas. A pesar de observar diferencias en la forma de los alvéolos, la falta de conservación de los extremos apicales de los dientes y la similitud de sus bases a lo largo de las series dentarias, que están sólo muy parcialmente conservadas, imposibilitan confirmar lo expresado por Donadío (1985). Sin embargo, otros aspectos de la dentición son destacables. Por un lado, el contorno suboval de las bases de los dientes, con una mayor compresión distal, es un carácter propio del ejemplar fósil que no se observó en ningún teido actual o fósil. Si bien este carácter fue desestimado por Sullivan y Estes (1997), parece poco probable que se trate de un artefacto resultante de la deformación que sufrieron los restos ya que se observa en todas las bases dentales conservadas (Fig. 24 B, D). El contorno suboval de los dientes del fósil difiere del contorno más circular observado en los tupinambinos Paradracaena y los ejemplares adultos de la mayoría de las especies de Tupinambis (Presch, 1974b; Ávila-Pires, 1995; Sullivan y Estes, 1997; obs. pers.) y del contorno más cuadrangular de Dracaena. La sutil, pero nítida cresta distal que se observa en el diente mejor conservado (ubicado en alvéolo (a) del fragmento MMP 1418-1, Fig. 24 B) parecería ser la terminación fina de la compresión labiolingual existente en la cara distal de los dientes. La depresión vertical sobre la cara labial del diente (a) del fragmento MMP 1418-1 acompaña a la cresta distal y tampoco ha sido observada en ningún otro teido; esta depresión es poco marcada y podría interpretarse como resultado de la deformación a la que ha sido sometido el fósil, más que un carácter diagnóstico. Es necesario destacar aquí que las características dentarias del material fósil podrían interpretarse similares a las observadas en el "taxón 5" descripto por Carvalho (2001) para el Paleógeno de Itaboraí (Brasil). El "taxón 5" es referido por este autor a un género y especie nuevo de Teiidae, sin nominar, que se caracteriza por presentar dientes uni, bi y tricuspidados, lateralmente comprimidos y espaciados entre sí. Estos dientes son similares a los de Crocodilurus, pero difieren de los de este género porque, a lo largo de la serie dentaria, se desarrolla anteriormente la cúspide distal (diente bicuspidado) y posteriormente se anexa la cúspide mesial (diente tricuspidado). Aunque Carvalho (2001) no hace referencia a la sección transversal de los dientes, se interpreta que ésta sería oval (Fig. 25 y 26 de Carvalho, 2001). La diferenciación primaria de la cúspide 
distal podría implicar una mayor compresión posterior del contorno transversal, resultando en un contorno similar al observado en el espécimen MMP 1418. Sin embargo, el material fósil disponible está insuficientemente conservado para asegurar que se trate del mismo taxón.

En cuanto al esqueleto postcraneal, la morfología observada en las vértebras del material fósil es encontrada en la familia Teiidae, aunque no en forma exclusiva (Hoffstetter y Gasc, 1969) (Cap. III). Los caracteres que comparten son: vértebras relativamente grandes, procélicas, con sistema de articulación zigósfeno-zigantro desarrollado, borde anterior del zigósfeno escotado, sin procesos prezigapofisiarios, centro vertebral cónico y posteriormente truncado, cótilo y cóndilo ovales comprimidos dorsoventralmente, y cuello condilar bien delimitado. El material fósil no presenta una cresta sagital bien desarrollada (“carena hemal” de Donadío, 1985) en las vértebras dorsales como tampoco se observa en los Tupinambinae, y a diferencia de los restantes Teiidae, donde la cresta sagital de las vértebras dorsales es baja, ancha y está bien definida ([C155]). El tamaño grande de las vértebras también las asemeja a los Tupinambinae. Contrariamente a lo expresado por Donadío (1985), se observan pequeños forámenes sobre el centro vertebral de las vértebras dorsales (MMP 1418-4, Fig. $25 \mathrm{~B}$ ), aunque de menores dimensiones que los presentes en las vértebras caudales (MMP 1418-8, Fig. 25 O). Forámenes pequeños como los observados en el fósil existen en las vértebras dorsales de los teidos, aunque de forma irregular. Donadío (1985) le otorga valor sistemático a la presencia de estos forámenes y a la forma de las carillas de articulación de las prezigapófisis y postzigapófisis, pero Sullivan y Estes (1997) desestiman estos caracteres como diagnósticos. La variabilidad individual que presentan estas estructuras y la irregularidad de los forámenes observada en el material de teidos actuales permiten acordar con Sullivan y Estes (1997), de manera que la morfología postcraneana no es útil para reconocer posibles afinidades con géneros actuales.

Los teidos tupinambinos se caracterizan por notables variaciones dentarias entre géneros, pero también entre especies e individuos, especialmente aquellas relacionadas con la ontogenia (véase Cap. III); por consiguiente, no puede descartarse que las características de los dientes sea algún tipo de variación no representada entre los materiales de teidos actuales disponibles como muestra. Así, la ausencia de caracteres claramente diagnósticos y la mala preservación del material impiden fundamentar el resurgimiento del género Lumbrerasaurus nominado por Donadío 
(1985). Sin embargo, a diferencia de Sullivan y Estes (1997), se soporta la asignación de los restos de lagartos de la Fm. Lumbrera a los Teiidae Tupinambinae y se destaca la posibilidad de que se trate de un taxón extinto. Materiales adicionales en mejores condiciones de preservación son requeridos para sostener esta posibilidad.

\section{Comentarios biogeográficos}

Como se mencionó anteriormente, en la Fm. Lumbrera los escamosos están representados por los fósiles aquí descriptos y un boideo indeterminado (Albino, 1989, 1993). Otro posible Teiidae ha sido registrado en el Itaboraiense (Eoceno, ver Gelfo et al., 2009) de Brasil (Carvalho, 2001). De esta forma, se puede sugerir que los Teiidae del Paleógeno sudamericano habrían tenido una amplia distribución geográfica en sentido longitudinal, al menos desde el Noroeste de Argentina hasta la costa atlántica de Brasil, como en la actualidad. En el presente, la especie xérica Tupinambis rufescens es el único Tupinambinae que habita en el área de Estancia Pampa Grande, donde se encuentra el yacimiento fosilífero de la Fm. Lumbrera (Cei, 1993). De esta manera, no se advierten, sobre la base del registro de teidos, diferencias ambientales notables respecto al presente. 


\subsection{NEÓGENO}

\subsubsection{Formación Sarmiento}

\section{Geología}

Los sedimentos del Miembro Trelew de la Fm. Sarmiento (Spalletti y Mazzoni, 1979), que afloran en el valle inferior del río Chubut, entre las ciudades de Trelew y Gaiman (Fig. 27), es muy rico en una microfauna de vertebrados del Neógeno, entre los que se encuentran los restos más abundantes de lagartos del Mioceno de Argentina.

La Fm. Sarmiento resulta de la depositación de sedimentos eólicos en amplias llanuras surcadas por cauces temporales en un clima cálido intertropical (Mendía y Bayarsky, 1981). Este episodio habría ocurrido rápidamente (Marshall et al., 1986), entre las transgresiones Leonense y Superpatagoniense (Goin et al., 2007). En el valle del río Chubut, Mendía y Bayarsky (1981) reconocen dos Miembros, el Miembro Pan de Azúcar (inferior) y el Miembro Trelew (superior). El Miembro Pan de Azúcar sucede concordantemente a la Fm. Río Chico, mientras que un plano erosivo lo separa del Miembro Trelew. Sobre éste, en forma transgresiva, se encuentra la Fm. Gaiman (Mendía y Bayarsky, 1981), de origen marino.
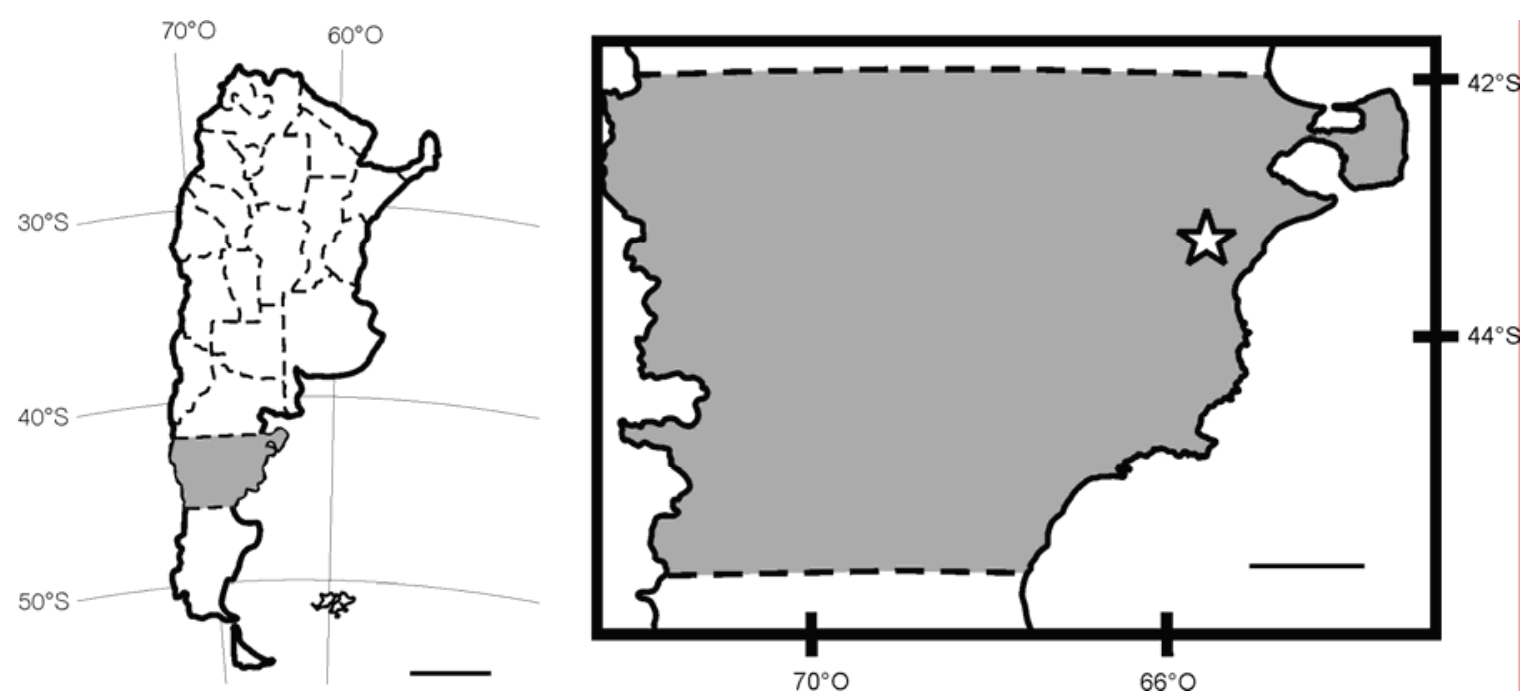

Figura 27. Mapa de ubicación de Gaiman $\left(43^{\circ} 17^{\prime} \mathrm{S}, 65^{\circ} 29^{\prime} \mathrm{O}\right)$, provincia del Chubut.

El Miembro Trelew está constituido por tobas arenosas portadoras de una gran cantidad de restos fósiles (Mendía y Bayarsky, 1981). La fauna de mamíferos 
procedente de estos niveles ha sido referida a la Edad Mamífero Colhuehuapense (Simpson, 1935). Inicialmente, esta fauna fue considerada del Oligoceno tardío; pero luego Marshall et al. (1986) propusieron una edad más joven, entre 19-18 Ma. Coincidentemente, el Miembro Cohuel Huapi de la Fm. Sarmiento en el sitio Gran Barranca, cuya fauna también es referida al Colhuehuapense, ha sido datado entre 20,5 y 19,1 Ma (Kay et al., 1999). Además, los sedimentos del Miembro Trelew han sido datados por trazas de fisión en 15,8 $\pm 2,5 \mathrm{Ma}$ (Bown et al., 1988: en Goin et al., 2007). De esta manera, la edad Colhuehuapense es actualmente referida al Mioceno temprano.

\section{Antecedentes}

Los depósitos más importantes del Colhuehuapense son los de Gran Barranca, al sur de la provincia del Chubut, de donde se ha recuperado una gran cantidad y variedad de vertebrados, (Pascual y Odreman Rivas, 1971; Goin et al., 2007). Sin embargo, una importante colección de microvertebrados, que incluye marsupiales, roedores, primates y reptiles escamosos, ha sido recolectada en afloramientos colhuehuapenses en la barranca sur del río Chubut, en el área de Gaiman (Fleagle y Bown, 1983; Gasparini et al., 1986; Vucetich, 1985, 1990; Vucetich y Verzi, 1991, 1993; Albino, 1996b, c, 1998, 2008; Albino y Etheridge, 2000; Kramarz, 2001). Entre los escamosos se reconocen serpientes y lagartos. Albino (1996b, c, 2008) describió un género extinto de boideo (Gaimanophis) y asignó otros restos al boideo Waincophis, a un probable Erycinae, y a un colúbrido indeterminado. Entre los lagartos, los iguanios han sido recientemente referidos a los géneros actuales Pristidactylus y Liolaemus (Albino, 2008), mientras que los escleroglosos están representados hasta el momento sólo por el teido Tupinambis sp. (Gasparini et al., 1986; Brizuela y Albino, 2004; Albino et al., 2006). En esta sección se describen nuevos materiales de lagartos que proceden de niveles colhuehuapenses de la Fm. Sarmiento en la zona de Gaiman. 
Sistemática

\author{
SQUAMATA Oppel 1811 \\ SCLEROGLOSSA Estes, de Queiroz y Gauthier 1988 \\ SCINCOMORPHA Camp 1923 \\ TEIIOIDEA Estes, de Queiroz y Gauthier 1988 \\ TEIIDAE Gray 1827 \\ TUPINAMBINAE Presch 1974a \\ Tupinambis Daudin, 1802 \\ Tupinambis sp.
}

(Fig. 28 A, B y 29 A, B)

Material referido: MACN Pv CH819, maxilar derecho incompleto. MACN Pv CH998-3, fragmento vertebral; MACN Pv CH1860-3, vértebra cervical incompleta; MACN Pv CH1860-4, vértebra caudal incompleta; MACN Pv CH1860-5, vértebra caudal incompleta; MACN Pv CH1860-7, vértebra incompleta. Todos los materiales se hallaron en forma aislada y corresponden a diferentes individuos.

Procedencia geográfica: Gaiman $\left(43^{\circ} 17^{\prime} \mathrm{S}, 65^{\circ} 29^{\prime} \mathrm{O}\right)$, departamento de Gaiman, provincia de Chubut.

Procedencia estratigráfica: Miembro Trelew (Formación Sarmiento), Edad Mamífero Colhuehuapense, Mioceno temprano.

Descripción. El fragmento del maxilar derecho corresponde a la parte posterior. Labialmente es liso, presenta un foramen labial dorsal a la primera posición dental conservada (a). Lingualmente, se observa la superficie de articulación para el palatino y el ectopterigoides. El fragmento es atravesado en sentido anteroposterior por el canal alveolar superior, cuyo foramen de ingreso no se conserva. En vista oclusal, se observa el surco dental, donde se conservan tres alvéolos de la serie dentaria. Lingualmente a la serie dentaria se observa un sulcus dentalis poco profundo. El primer (a) y último (c) alvéolo están incompletos, y conservan sólo parte de las bases de los dientes correspondientes. El segundo alvéolo (b) se conserva completo, es rectangular, transversalmente dispuesto al eje longitudinal del maxilar. Este alvéolo conserva el diente entero, el cual es de implantación subpleurodonte y presenta abundante cemento basal que disimula los septos interdentales. Es un diente unicuspidado, robusto y alto. Apicalmente es bajo y cónico, aparentemente sin punta 
punzante. El eje del cono apical se encuentra levemente desplazado distalmente respecto de la base. Lingualmente, en el alvéolo funcional (b) se observa un marcado alvéolo de reemplazo, que es profundo y oval, paralelo a la serie dentaria.

Con respecto a los elementos vertebrales, el fragmento MACN Pv CH998-3 corresponde a una prezigapófisis y proceso transverso derechos (Fig. 29 A). La superficie de articulación de la prezigapófisis es amplia y oval. La extensión lateral de la prezigapófisis supera la del proceso transverso. No se observa proceso prezigapofisial. El proceso transverso es robusto, corto y verticalmente dispuesto. La superficie distal es de contorno oval y convexo a lo largo de todo su desarrollo.

El fragmento MACN Pv CH1860-3 corresponde al centro vertebral de una vértebra cervical (Fig. 29 B). El centro vertebral es cilíndrico, levemente restringido en la parte media. El cótilo es oval, profundo y poco inclinado ventralmente. El borde ventral del cótilo está interrumpido por una amplia zona donde articulaba la hipapófisis. La preservación del cóndilo es pobre.

El fragmento MACN Pv CH1860-4 corresponde al centro vertebral de una vértebra caudal (Fig. 29 C). El centro vertebral es cilíndrico, más estrecho en la parte media. El cótilo es circular, profundo, no inclinado ventralmente y de perímetro continuo. De los procesos transversos se conservan los extremos proximales, con desarrollo anteroposterior y compresión dorsoventral. El cóndilo está pobremente preservado, es circular en vista posterior.

El fragmento MACN Pv CH 1860-5 corresponde al techo del arco neural de una vértebra más grande que las previamente descriptas, que conserva la parte basal de la espina neural y las postzigapófisis (Fig. 29 D). La espina neural está incompleta, en especial distal y posteriormente. Las postzigapófisis son robustas, poco distanciadas una de la otra y orientadas posteriormente. Las carillas de articulación son ligeramente convexas y de contornos subcirculares y se encuentran inclinadas hacia arriba respecto a la horizontal. Entre ellas no se observan las carillas de articulación del zigantro. 


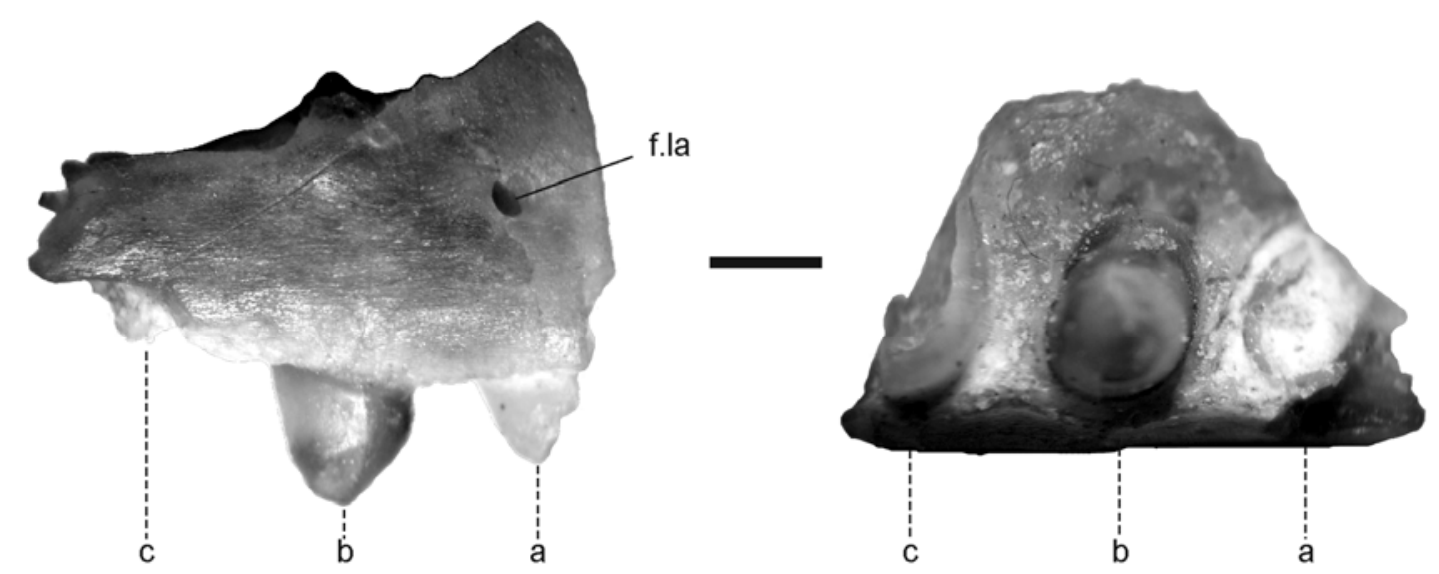

A

Figura 28. Tupinambis sp. de la Fm. Sarmiento (Mioceno temprano) de Gaiman. Maxilar MACN Pv CH819 en vista labial (A) y oclusal (B). Abreviaturas: f.la, foramen labial. Escala $=1 \mathrm{~mm}$.

Comentarios taxonómicos. El alvéolo de reemplazo profundo y oval del maxilar soporta la asignación al clado Borioteiioidea-Teiioidea. Este carácter se revierten en los Gymnophthalmidae (Nydam et al., 2007; Cap. III) donde, además, la implantación es subpleurodonte permitiendo la exclusión de los fósiles de esta familia. Como se mencionó en el Capítulo III, la implantación subpleurodonte de los Teiidae presenta diferentes estados asociados a la cantidad de cemento basal y la manera en que dicho cemento disimula o no los septos interdentales. En este sentido, el único diente preservado del maxilar fósil se asemeja al observado en los Tupinambinae Tupinambis y Crocodilurus (Cap. III, [119]).

Por otro lado, la presencia de dientes unicuspidados robustos puede advertirse en individuos no juveniles de T. merianae (LHC $>300 \mathrm{~mm}$ ). En particular, por su altura y leve molarización, el diente del maxilar fósil se asemeja a los dientes tipo U2 que en T. merianae preceden a los dientes romos y robustos (Cap. III). Las diferentes especies de Tupinambis presentan ligeras diferencias en la dentición posterior (Cap. III), pero la falta de conservación de los dientes posteriores en el material fósil impide una comparación a niveles específicos. Las dimensiones del único diente completo conservado $(\mathrm{b})($ largo $=1,24 \mathrm{~mm}$, ancho $=1,31 \mathrm{~mm})$ no se diferencian de los valores observados por Brizuela y Albino (2004) para un importante número de fósiles de la misma localidad asignados a Tupinambis, y se caracterizan por ser de menor tamaño que los de las especies actuales del género que presentan este tipo de dientes. 
Con respecto a los elementos vertebrales, las Serpentes y los Amphisbaenia presentan procesos prezigapofisiarios ventralmente a las prezigapófisis (Hoffstetter y Gasc, 1969), de modo que la ausencia de este proceso en la vértebra MACN Pv CH998-3 permite su exclusión de estos clados. La presencia de hipapófisis articulada anteriormente al centro vertebral de las vértebras cervicales, como se observa en el ejemplar MACN Pv CH1860-3, se registra en los Teiidae ([153]), entre otros (Hoffstetter y Gasc, 1969; Lee, 1998). En esta familia, las postzigapófisis se desplazan medialmente en las vértebras a medida que se alejan de la región sacra, de modo que desaparece el zigantro, como en la vértebra caudal MACN Pv CH1860-5. Debido a la asociación de estos materiales con los asignados a Tupinambis sp. en la misma localidad y nivel estratigráfico (Brizuela y Albino, 2004), y considerando que no se han reconocido otros géneros de teidos en niveles colhuehuapenses de Patagonia, las vértebras aquí descriptas también son asignadas al género Tupinambis sp. con el cual comparten todas las características descriptas, aunque no son exclusivas del mismo.
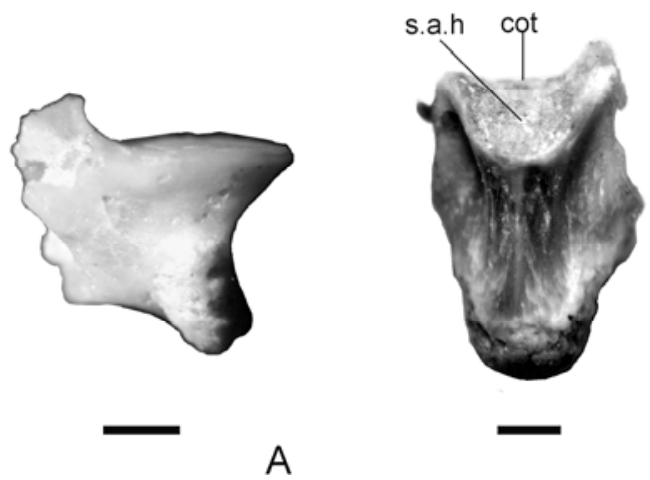

B

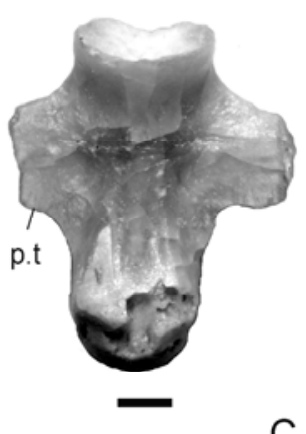

C

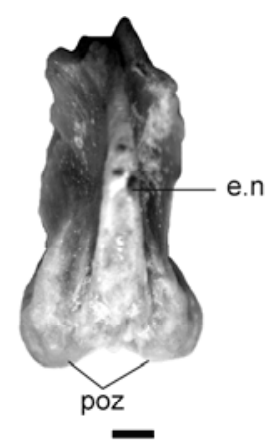

D

Figura 29. Tupinambis sp. de la Fm. Sarmiento (Mioceno temprano) de Gaiman. A, vértebra MACN Pv CH998-3 en vista anterior; B, vértebra cervical MACN Pv CH1860-3 en vista ventral; C, vértebra caudal MACN Pv CH1860-4 en vista ventral; D, vértebra MACN Pv CH1860-5 en vista dorsal; vértebra dorsal MACN Pv CH1860-7 en vista ventral. Abreviaturas: cot, cótilo; e.n, espina neural; p.t, proceso transverso; poz, postzigapófisis; s.a.h, superficie de articulación la hipapófisis; zg, zigósfeno. Escala $=1 \mathrm{~mm}$. 
SCLEROGLOSSA Estes, de Queiroz y Gauthier 1988

Scleroglossa indeterminado

(Fig. 30 A-C)

Material referido: MACN Pv CH815-1, centro vertebral.

Procedencia geográfica: Gaiman $\left(43^{\circ} 17^{\prime} \mathrm{S}, 65^{\circ} 29^{\prime} \mathrm{O}\right)$, departamento de Gaiman, provincia de Chubut.

Procedencia estratigráfica: Miembro Trelew (Formación Sarmiento), Edad Mamífero Colhuehuapense, Mioceno temprano.

Descripción. El fósil MACN Pv CH815-1 corresponde a una vértebra procélica de la que se conserva el centro vertebral y el proceso transverso derecho (Fig. 30). El cótilo es marcadamente oval, deprimido dorsoventralmente, profundo y ventralmente inclinado. El centro vertebral es largo y angosto, ventralmente aplanado, de límites laterales paralelos (ligeramente cóncavos). La superficie ventral del centro vertebral está diferenciada de la superficie lateral derecha de la vértebra por una cresta subcentral desdibujada (= margo ventralis), que del lado izquierdo no se ha conservado. No se observan forámenes subcentrales. En vista posterior, el cóndilo es oval, marcadamente comprimido dorsoventralmente e inclinado dorsalmente. El cóndilo no se encuentra precedido por un cuello condilar. El proceso transverso es robusto y semiesférico. En vista anterior se observa que es corto, aproximadamente la mitad del ancho del cótilo. En su parte posteroventral está diferenciado del centro vertebral por una depresión poco marcada. La superficie semiesférica es interpretada como la sinapófisis. 


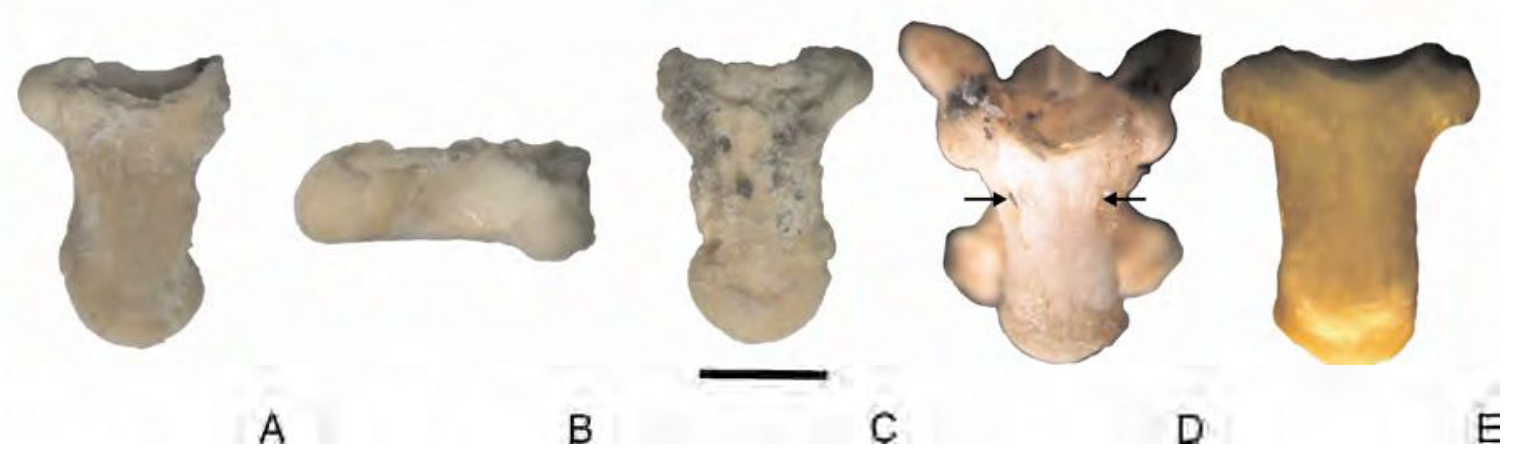

Figura 30. Scleroglossa indeterminado de la Fm. Sarmiento (Mioceno temprano) de Gaiman. A-C, MACN Pv CH815-1 en vista ventral (A), lateral (B) y dorsal (C); D, vértebra de Amphisbaena prunicolor (Amphisbaenia) (UNMDP-0 39) en vista ventral; E, vértebra de Ophiodes vertebralis (Anguidae) (UNMdP 162) en vista ventral. Flechas indican forámenes subcentrales. Escala $=1 \mathrm{~mm}$.

Comentarios taxonómicos. A excepción de algunos Gekkota, donde pueden presentarse vértebras anficélicas, los restantes Squamata se caracterizan por tener centros vertebrales procélicos (Hoffstetter y Gasc, 1969). El centro vertebral MACN Pv CH815-1 es procélico y no presenta reminiscencia de la notocorda, carácter que lo diferencia de los Gekkonidae y Pygopodidae (Hoffstetter y Gasc, 1969; Lee, 1998). Hoffstetter y Gasc (1969) señalan que en los Amphisbaenia, Dibamidae, numerosos Anguimorpha (Varanidae, Helodermatidae y Anguidae ápodos), Scincomorpha ápodos (Feylinia, Acontias) y algunos otros grupos de lagartos tetrápodos (e.g. Uromastyx), los centros vertebrales son ventralmente aplanados. La ausencia de cuello condilar en el fósil permite excluirlo de Varanidae (excepto Heloderma) y Uromastyx (Hoffstetter y Gasc, 1969; Lee, 1998). De los restantes grupos de lagartos mencionados, los Amphisbaenia y los Anguidae, son los únicos entre el material de referencia disponible, que presentan un centro vertebral plano, sin cuello vertebral ([C149]), como en el ejemplar fósil. Las vértebras de estos lagartos se diferencian principalmente por características del arco neural (Hoffstetter y Gasc, 1969), pero lamentablemente esta parte de la vértebra no se conserva en el fósil, razón por la cual el espécimen MACN Pv CH815-1 sólo puede ser referido como un Scleroglossa indeterminado. 


\section{Comentarios biogeográficos}

La localidad de Gaiman es un importante sitio de hallazgo de microvertebrados de edad Colhuehuapense. Como se mencionó al comienzo de esta sección, en estos niveles se ha recuperado una importante asociación de escamosos. Gasparini et al. (1986) ya reconocieron la presencia de Tupinambis en el Colhuehuapense de Gaiman pero citaron también la presencia de un género extinto de teido ("Diasemosaurus") y nuevos taxones. En Brizuela y Albino (2004) se analizan esos mismos materiales y sólo se reconoce Tupinambis sp. ya que el género Diasemosaurus es sinonimizado con este último en Brizuela y Albino (2008a).

La localidad de Gaiman se encuentra en el sur de la Provincia Biogeográfica del Monte (Cabrera y Willink, 1980), caracterizada por un clima árido, seco y frío. Estas condiciones ambientales impiden actualmente la presencia de Tupinambis que, salvo por una población aislada de T. rufescens en Bajo del Gualicho, se distribuye al norte del Río Negro (Cei, 1986). La presencia del género en el Mioceno temprano de esta localidad sugiere que las condiciones climáticas durante el Colhuehuapense habrían sido más cálidas y húmedas que en la actualidad, como lo sostienen otras evidencias basadas en la fauna de mamíferos (Fleagle y Bown, 1983; Vucetich, 1985, 1990; Vucetich y Verzi, 1991, 1993; Kramarz, 2001) y la presencia de boideos (Albino, 1996b). Datos palinológicos y los tipos tróficos de los mamíferos representados han permitido deducir que, durante el Mioceno temprano, Patagonia presentaba un aspecto complejo, con la coexistencia de extensas áreas boscosas y áreas abiertas, conformando un equilibrio de parque-sabana (ver citas en Ortiz Jaureguizar y Caldera, 2006). Sin embargo, diferentes elementos de la fauna de vertebrados (roedores) sugieren para la localidad de Gaiman un ambiente de dunas (Vucetich y Verzi, 1993), que es compatible con el morfotipo vertebral semi-fosorial de las serpientes reconocidas (Albino, 1996b). Entre las especies del género Tupinambis, T. merianae y T. rufescens han sido observadas en ambientes de médanos con vegetación arbustiva en Brasil y Argentina (Krause, 1985; Videla y Puig, 1994); de manera que el hallazgo de Tupinambis en los niveles colhuehuapenses de Gaiman son coherentes con las hipótesis paleoambientales mencionadas.

Con respecto al ejemplar MACN Pv H815-1, que sólo puede ser considerado un Scleroglossa indeterminado, es claro que no se trata de Teiidae ni Serpentes y que presenta afinidad con grupos previamente no registrados en el Mioceno sudamericano 
(Amphisbaenia o Anguidae). Dicha evidencia sugiere que la diversidad de Squamata durante el Colhuehuapense habría sido mayor a la reportada hasta el momento.

El Colhuehuapense también aflora en el sitio Gran Barranca, al sur de la provincia del Chubut, representando uno de los depósitos más ricos en fósiles de esta edad. Sin embargo, no hay registro documentado de Squamata en esta localidad (sólo una vértebra de boideo sin catalogar, Albino, com. pers.), contrastando con la abundante diversidad presente en Gaiman. Tal disparidad podría responder a un problema de recuperación o identificación de materiales pequeños o ser debidas a diferencias estratigráficas o paleoambientales entre ambos yacimientos.

\subsubsection{Formación Santa Cruz}

Geología

La Fm. Santa Cruz es una de las formaciones del Cenozoico continental de mayor distribución espacial de América del Sur (Marshall et al., 1986). Aflora en varias regiones de la Patagonia pero está mejor expuesta en la costa Atlántica de la provincia de Santa Cruz (Fleagle et al., 1995).

La Fm. Santa Cruz suprayace confortablemente sobre la Formación marina Monte León (Marshall et al. 1986) y subyace a la Fm. Collón Cura (Flynn et al. 2002). Tauber (1997) divide a la Fm. Santa Cruz en dos miembros: Miembro Estancia La Costa (inferior, de $120 \mathrm{~m}$ de potencia, con 18 niveles fosilíferos) (Fig. 31) y Miembro Estancia Angelina (superior, de $103 \mathrm{~m}$ de potencia, con cuatro niveles fosilíferos). Madden et al. (1997) resumen los datos radioisotópicos y magnetoestratigráficos de varias localidades de la Fm. Santa Cruz y le asignan a la Formación, en su conjunto, una antigüedad de 15,4-17,3 Ma para el clásico Santacrucense costero. En particular, para el área de Monte León, datos de K-Ar indican un rango de 16,5-17,3 Ma (Marshall et al., 1986), valores similares a los propuestos por Flynn et al. (2002) de 16,3-17,5 Ma. Dataciones de ${ }^{40} \mathrm{Ar} /{ }^{39} \mathrm{Ar}$ para las localidades Monte León y Monte Observación sugieren un intervalo más acotado de 16,06-16,57 Ma (Bown y Fleagle, 1993). Tejedor et al. (2006) consideran que el límite basal de $17 \mathrm{Ma}$, sustentados en los datos K-Ar, pueden ser erróneos y sugieren que las principales unidades fosilíferas continentales de la Fm. Santa Cruz se habrían depositado rápidamente en un tiempo relativamente corto (400,000 años), aproximadamente entre 16,1-16,5 Ma. La fauna de mamíferos de esta Formación ha 
sido referida a la Edad Mamífero Santacrucense (Simpson, 1940; Marshall et al., 1986; Tauber 1997; Tejedor et al., 2006).

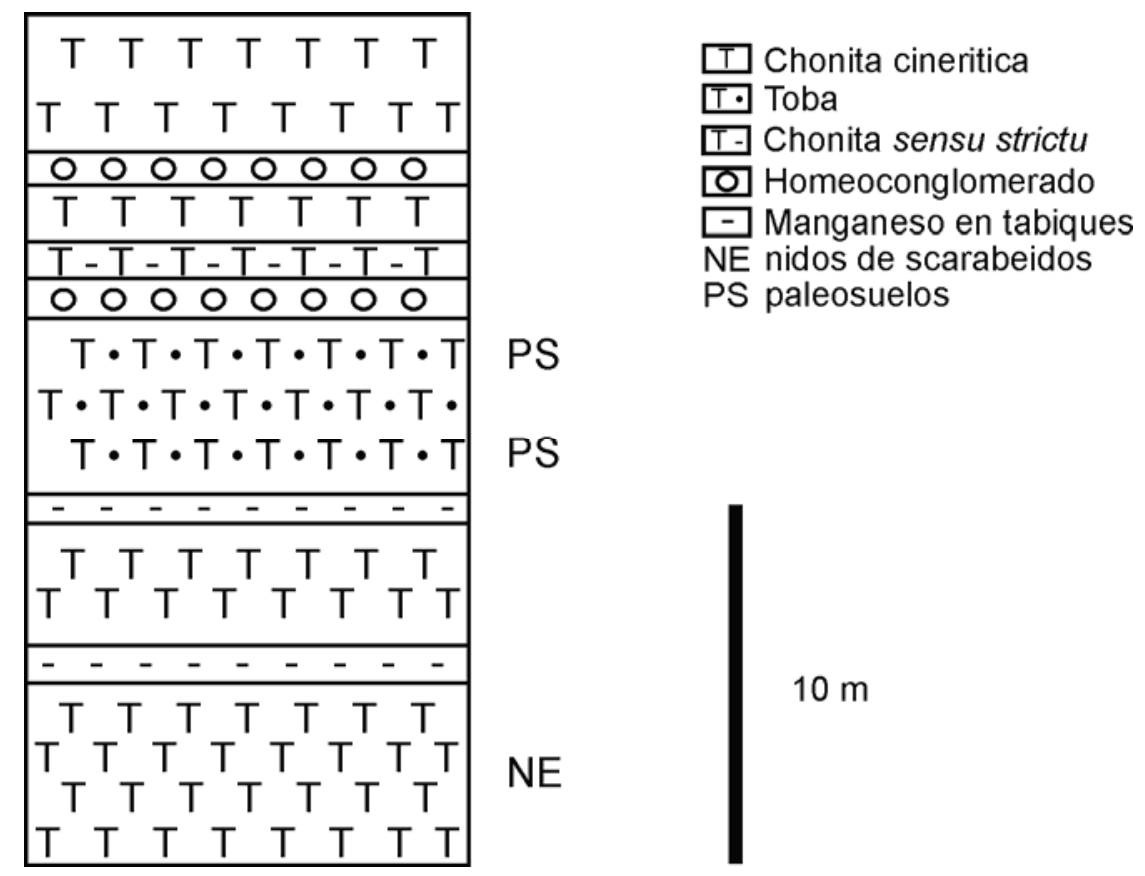

Figura 31. Columna estratigráfica de la Fm. Santa Cruz en Monte León (modificada de Fleagle et al., 1995).

\section{Antecedentes}

La Fm. Santa Cruz es fosilíferamente muy rica. En 22 niveles fosilíferos (Tauber, 1997) se han reconocido más de 70 especies de vertebrados (Tauber et al., 2004), entre los que se incluyen escamosos, aves y una gran variedad de mamíferos (Albino, 1996b; Tauber, 1997). Ameghino (1895) refiere restos de la Fm. Santa Cruz a una boa, aunque Albino (1996b) la considera como una referencia dudosa debido a que su procedencia es desconocida y el material está perdido. Sin embargo, Albino (1996 c) describe restos pertenecientes a un Colubridae indeterminado procedente de esta Formación.

Con respecto a los lagartos, en 1893 y 1899, Florentino Ameghino dio a conocer restos procedentes de niveles de esta formación aflorantes en el extremo sur de la región costera de la provincia de Santa Cruz. Para la localidad de La Cueva, Ameghino (1899) nominó un nuevo género de Iguanidae extinto (Erichosaurus) conteniendo tres especies. También describió un resto vertebral como una nueva especie del género Saniwa (Saniwa australis), correspondiente a un varánido extinto 
(Báez y Gasparini, 1977); sin embargo, este último material fue reinterpretado como un anuro por Gasparini et al. (1986). En su trabajo de 1893, Ameghino describió tres fragmentos de lagartos recolectados en sedimentitas de esta Formación, nominando dos nuevos géneros y especies extintos: Dibolosodon typicus y Diasemosaurus occidentalis. Sin embargo, no presentó una referencia clara sobre la procedencia geográfica de los fragmentos. Donadío (1984a) pudo rastrear, en la correspondencia de los hermanos Ameghino, que estos fósiles provienen de Monte León, localidad nominal de la Fm. Santa Cruz (Marshall et al., 1983) (Fig. 32).
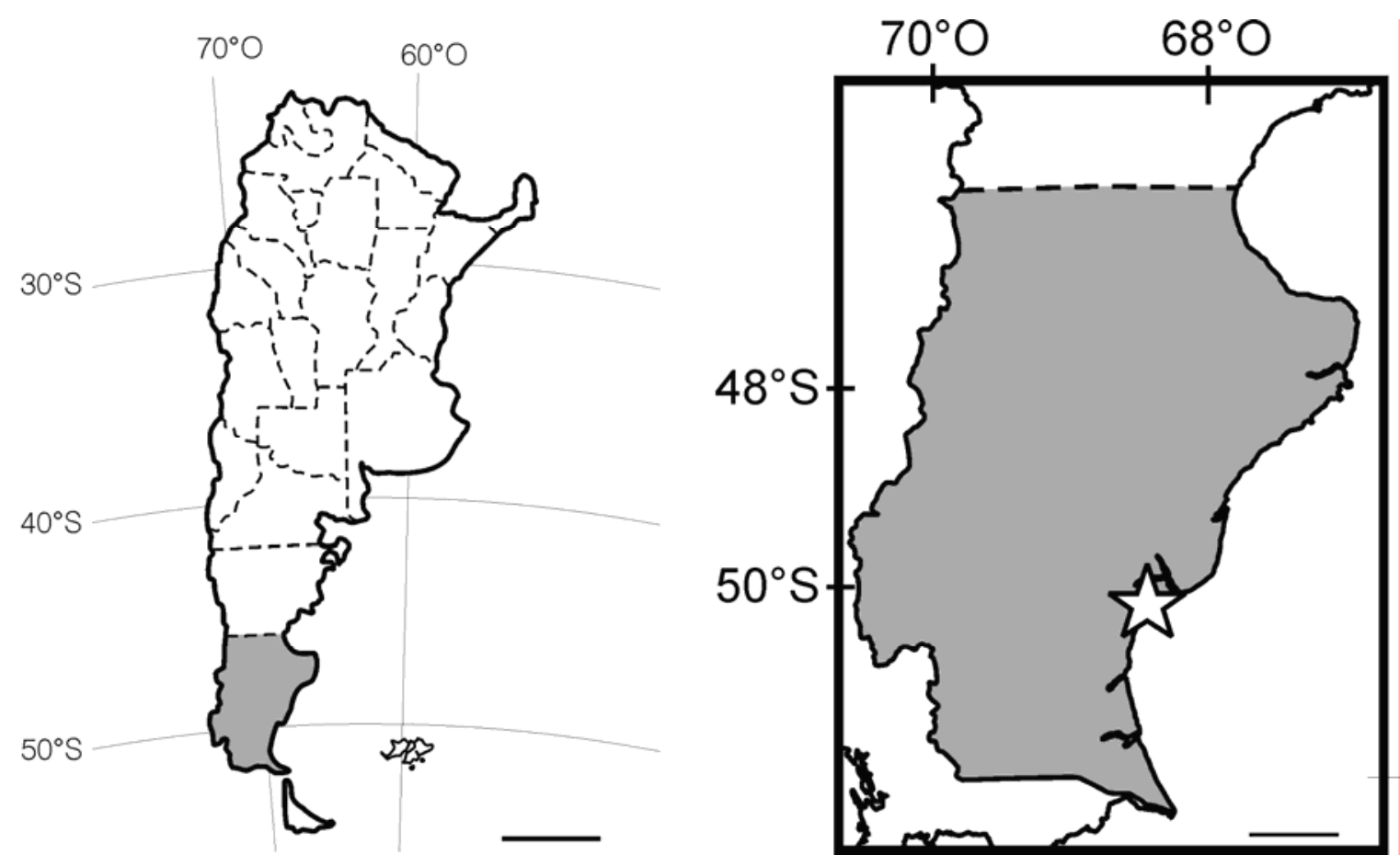

Figura 32. Mapa de ubicación de Monte León, provincia de Santa Cruz.

Ameghino (1893) originalmente consideró a Diasemosaurus como un Agamidae (Iguania) porque interpretó que poseía una dentición acrodonte. En Ameghino (1898), este taxón figura por error como Iguanidae, como fuera reconocido luego por el propio Ameghino (1899). Dibolosodon fue considerado cercano a los Proterosauridae (Ameghino, 1893) o Champsosauridae (Ameghino, 1898). Estos lagartos del Santacrucense han aparecido reiteradamente en la bibliografía. Romer $(1956,1967)$ incluye tentativamente a Diasemosaurus en la familia Teiidae. Gasparini y Báez (1975) y Báez y Gasparini $(1977,1979)$ sugieren que parte del material de Diasemosaurus presenta afinidad con el género actual Tupinambis (Teiidae: 
Tupinambinae). Estes (1983a), quien desconocía las descripciones originales de Ameghino (1893) y lista a Ameghino (1898) como autor de los dos taxones, los considera como nomina dubia, ubicando a Diasemosaurus en la familia Teiidae y a Dibolosodon como Lacertilia incertae sedis. Donadío (1983b, 1984a), refiriéndose a estos restos de Diasemosaurus, sugiere que se trata de una nueva especie a la que nomina "Tupinambis occidentalis", pero nunca la describe formalmente.

Contrariamente a estos autores, Cei (1993), siguiendo a Presch (1980), incluye a Diasemosaurus dentro de la familia Gymnophthalmidae pero sin aportar fundamentos. Como se desprende de lo antedicho, estos fósiles han tenido una larga y compleja historia sistemática.

A pesar que estos dos géneros extintos han estado presentes en la literatura paleoherpetológica desde la descripción realizada por Ameghino (1893), su ubicación sistemática no ha sido resuelta. Esto se debe, en parte, a la naturaleza fragmentaria y escasa de los materiales fósiles, pero también a otras tres causas: que la única descripción conocida de los mismos es la realizada hace más de 100 años por Ameghino, que muy pocos de los autores que lo mencionaron posteriormente tuvieron la oportunidad de observar directamente el material, y que no todos los autores han justificado satisfactoriamente sus afirmaciones. Estas razones hacen necesaria la redescripción de estos fósiles del Santacrucense de Monte León.

\section{Sistemática}

SQUAMATA Oppel 1811

SCLEROGLOSSA Estes, de Queiroz y Gauthier 1988

SCINCOMORPHA Camp 1923

TEIIOIDEA Estes, de Queiroz y Gauthier 1988

TEIIDAE Gray 1827

TUPINAMBINAE Presch 1974a

Tupinambis Daudin, 1802

Tupinambis sp.

(Fig. 33) 
Material referido: MACN-A 621, dentario derecho fragmentario, originalmente descripto como "Dibolosodon typicus" (Ameghino, 1893); MACN-A 5806-1, dentario izquierdo fragmentario y MACN-A 5806-2, maxilar derecho fragmentario, ambos originalmente descriptos como "Diasemosaurus occidentalis" (Ameghino, 1893). Todos los fragmentos portan dientes y corresponden a diferentes individuos.

Procedencia geográfica: Monte León $\left(50^{\circ} 19^{\prime} \mathrm{S}, 68^{\circ} 54^{\prime} \mathrm{O}\right)$, departamento Corpen Aike, provincia de Santa Cruz (Fig. 31).

Procedencia estratigráfica: Formación Santa Cruz. Ubicación en la columna estratigráfica desconocida, posiblemente Miembro Estancia La Costa (Tauber, 1997). Re-descripción. El fragmento MACN-A 621 (Fig. 33 A, B) corresponde a la parte media-posterior de un dentario derecho pobremente conservado. El estante subdental se extiende lingualmente a lo largo de todo el fragmento; es poco profundo, algo convexo y se encuentra parcialmente roto en su extremo anterior. La superficie de articulación para el esplenial se extiende horizontalmente por debajo del estante subdental y no conserva su extremo anterior, lo cual revela que el esplenial debió prolongarse más allá del extremo anterior del fragmento. El importante desarrollo de esta superficie de articulación indica una firme unión entre el esplenial y el dentario. Además, la disposición de la superficie de articulación permite inferir que el canal de Meckel estaba medialmente expuesto. En vista ventral, se observa parte de la pared labial del dentario; lingualmente sobre el techo del canal de Meckel ha quedado expuesto el techo del canal alveolar inferior, y se puede inferir el foramen de ingreso al mismo. También sobre el techo del canal de Meckel, pero posterior al foramen de ingreso al canal alveolar inferior, se proyectan posteriormente dos surcos paralelos. Estos surcos recibirían al proceso anteromedial del coronoides y suprangular, indicando la presencia de un septo intermandibular anteriormente emplazado. Dorsalmente, se observa el surco dental en el cual se dispone la serie dentaria. Ésta preserva seis alvéolos, en los cuales sólo hay dos dientes completos en las posiciones (d) y (e). Los alvéolos son ovales, perpendiculares al eje longitudinal de la serie dentaria, y están delimitados por septos interdentales de hueso alveolar. Los dientes son subpleurodonates, donde la unión de los dientes al dentario es principalmente a través de sus bases, sobre las que, además, se deposita abundante cemento. Las bases no ocupan todo el ancho del surco dental, dejando lingualmente un nítido sulcus dentalis. Los dientes son cilíndricos basalmente y labiolingualmente comprimidos en su extremo apical. Son altos, rectos y bicuspidados; con sus cúspides mesodistalmente 
alineadas (Fig. 33 G). Las cúspides están separadas por un surco vertical superficial que se origina a media altura sobre el diente y lo recorre labiolingualmente a través de la superficie oclusal. La cúspide mesial es un pequeño cono recto, mientras que la distal es de mayor tamaño, también cónica, pero labiolingualmente comprimida, distalmente curvada y no punzante. El esmalte es liso, sin estrías. Se conservan tres alvéolos de reemplazo sobre los alvéolos funcionales (a), (c) y (f).

El fragmento MACN-A 5806-1 (Fig. 33 C, D) corresponde a la parte posterior de un dentario izquierdo. El surco dental está bien desarrollado y conserva un único diente. Lingualmente se preserva parte del estante subdental. Entre el diente y el estante subdental, se observa un sulcus dentalis bien desarrollado. Sobre la base del diente se encuentra depositado abundante cemento; la forma del depósito permite inferir que el diente se encontraba en un alvéolo transversalmente dispuesto al eje longitudinal de la serie dentaria. La implantación sería subpleurodonte, aunque no se conservan los septos interdentales. En vista ventral, se observa el techo del canal de Meckel limitado lingualmente por la superficie de articulación para el esplenial. El diente es robusto, romo y bajo; basalmente cilíndrico y apicalmente de sección oval (Fig. $33 \mathrm{H}$ ). Una cresta delgada y baja recorre longitudinalmente la superficie oclusal del diente. En la parte media de esta cresta se observa una protuberancia central. El esmalte presenta finas estrías que convergen hacia dicha protuberancia.

El fragmento MACN-A 5806-2 (Fig. 33 E, F) corresponde a la parte proximal del proceso posterior de un maxilar derecho. No se conserva la superficie labial, razón por la cual, por detrás del último diente, está expuesta la superficie lingual del surco que recibe al yugal. El surco dental se conserva parcialmente completo. En vista oclusal se observan tres alvéolos; sólo los dos anteriores ( $\mathrm{a}$ y b) conservan dientes completos. Los dientes son subpleurodontes, fijados basalmente a alvéolos delimitados por septos interdentales. Sobre las bases de los dientes se observa un abundante depósito de cemento. Por la forma de la base y la depositación de cemento del segundo diente (b) es posible inferir la presencia de un sulcus dentalis poco desarrollado. Los dientes son robustos, particularmente en sus bases; apicalmente están comprimidos labiolingualmente y ligeramente curvados en dirección distal (Fig. 33 I, J). En sección transversal son asimétricos; el borde labial es convexo y el lingual es más recto (Fig. $33 \mathrm{~J}$ ). Ambas caras se encuentran oclusalmente a lo largo de una cresta sigmoidal desarrollada mesodistalmente, cuya parte distal se dispone más labialmente que la medial. El contorno lateral de los dientes presenta dos pequeñas 
muescas apicales verticalmente dispuestas (Fig. 33 I, J). Una se ubica en la mitad anterior del extremo apical del diente, formando un surco poco nítido, superficial y corto. La otra muesca está más desarrollada; es más larga y profunda, y se encuentra sobre la mitad distal del diente. Al unirse el surco posterior labial con el lingual conforman una alta cresta cuyo extremo distal corresponde a la parte posterior de la cresta sigmoidal oclusal.
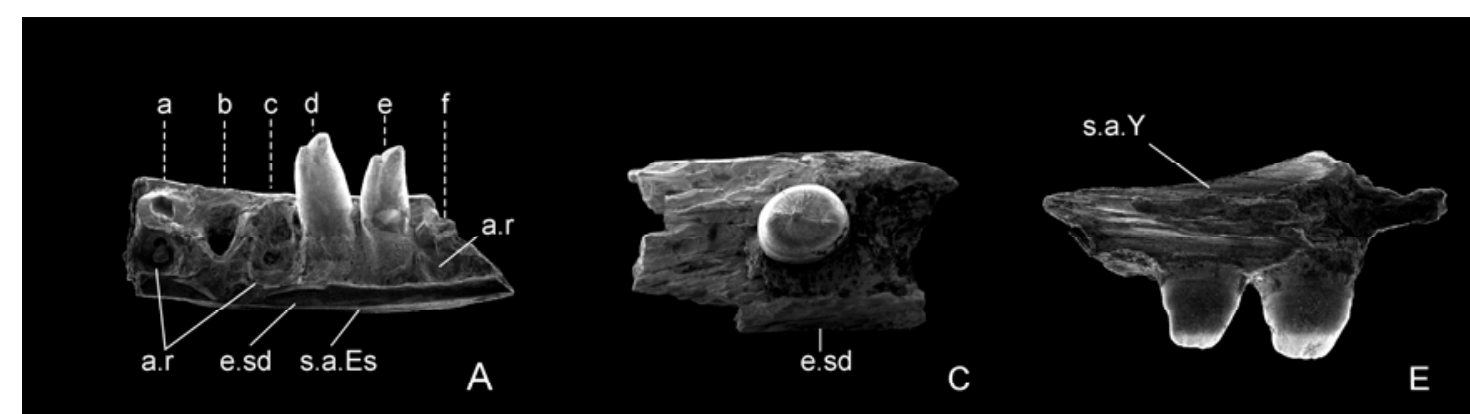

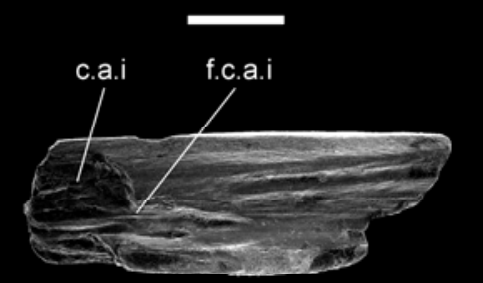

B

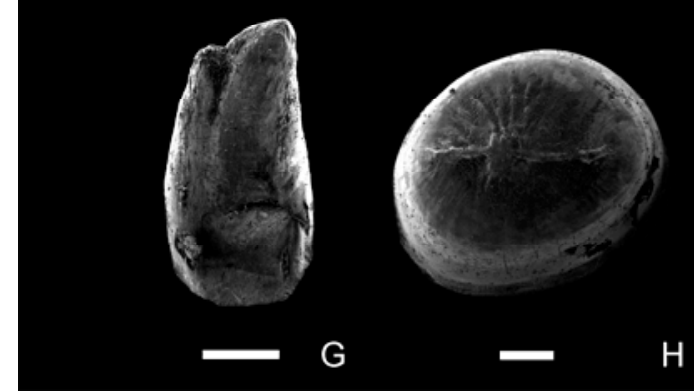

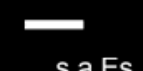

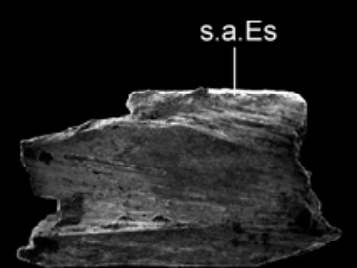

D
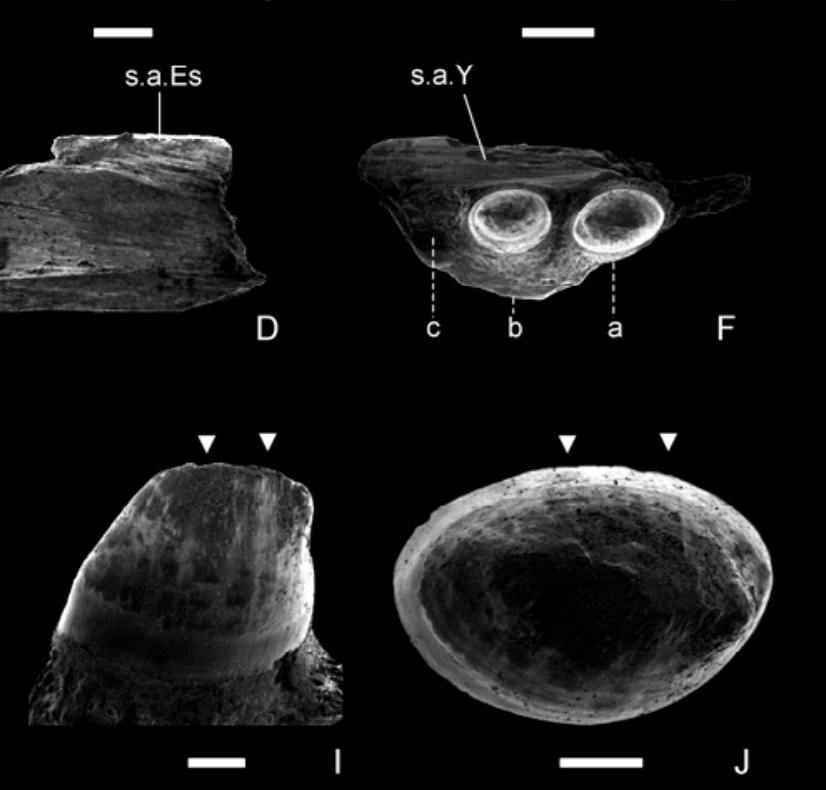

Figura 33. Tupinambis sp. de la Formación Santa Cruz (Mioceno temprano-medio) de Monte León, provincia de Santa Cruz. A, B, dentario derecho (MACN-A 621), en vista labial (A) y ventral (B); C, D dentario izquierdo (MACN-A 5806-1), en vista oclusal (C) y ventral (D); E, F maxilar derecho (MACN-A 5806-2), en vista labial (E) y oclusal (F); G, segundo diente conservado del dentario derecho (MACN-A 621) en vista lingual; $\mathrm{H}$, diente del dentario izquierdo (MACN-A 5806-1) en vista oclusal; I, J primer diente conservado del maxilar derecho (MACN-A 5806-2), en vista labial (I) y oclusal (J). Abreviaturas: a.r; alvéolo de reemplazo; c.a.i; canal alveolar inferior; e.sd, estante subdental; f.c.a.i; foramen del canal alveolar inferior; s.a.Es, superficie de articulación para el esplenial; s.a.Y, superficie de articulación para el yugal. Escala $=2 \mathrm{~mm}$ en dentarios y el maxilar; 0,5 $\mathrm{mm}$ en los dientes. 
Comentarios taxonómicos. Los restos fósiles analizados en conjunto permiten indicar que el taxón de lagarto presente en el Santacrucense de Monte León presenta profundos alvéolos de reemplazo, abundante cemento basal, y un esplenial que se extendería anteriormente al foramen de ingreso del canal alveolar inferior. Estos caracteres permiten su inclusión en el clado Borioteiioidea-Teiioidea y, dentro de éstos, su exclusión de los Gymnophthalmidae (Cap. III). El maxilar MACN-A 621 difiere de los Borioteiioidea por la ausencia de la extensión posterior del septo intermandibular (Denton y O’Neill, 1995; Nydam y Cifelli, 2002b; Nydam et al., 2007), permitiendo la exclusión también de este taxón.

Como se mencionó en el Capítulo III, la dentición subpleurodonte puede variar según la cantidad de cemento basal ([C120]). En el material fósil estudiado, los dientes se encuentran en alvéolos cuyos septos están algo disimulados por el cemento, condición compartida por los Teiidae Tupinambis y Crocodilurus (Cap. III).

Tupinambis es el único género de Teiidae con especies que en su condición adulta presentan dientes robustos, agrandados, sin cúspides diferenciadas, como los observados en los fósiles MACN-A 5806-a y -b. De esta manera, este material es referido a dicho género.

En la comparación de los fósiles MACN-A 5806-a y -b con la serie ontogenética de T. merianae se observa que el diente del fragmento MACN-A 5806-a (Fig. $33 \mathrm{H}$ ) es indistinguible de los dientes romos, robustos y molariformes, con una protuberancia central, observados en individuos de talla grande, probablemente cercanos al máximo. La morfología de los dientes del ejemplar MACN-A 5806-b (Fig. 33 I, J) es similar a la de individuos grandes pero no necesariamente de máximo tamaño. Donadío (1984a) sugiere que los caracteres de la morfología dentaria e implantación, ninguno de los cuales describe, y en particular el tamaño del fósil MACN-A 5806-a, menor al de los individuos adultos de Tupinambis, son indicativos de que se trata de una nueva especie. Sin embargo, la implantación y la morfología dentaria de los fósiles MACN-A 5806-a y -b son indistinguibles de lo observado en $T$. duseni, T. merianae, T. rufescens y T. teguixin (Cap. III). En cuanto al tamaño, el diente del fósil MACN-A 5806-a se encuentra dentro del rango de variación observado en la muestra de T. merianae, aunque cercano a los valores mínimos. Este carácter no se considera por sí solo suficientemente robusto como para diagnosticar un nuevo taxón, por lo que la propuesta de Donadío (1984a) es desestimada hasta tanto no se cuente con material en mejores condiciones de preservación. 
Por otro lado, los dientes mesodistalmente bicuspidados observados en el fósil MACN-A 621 son comunes en los Teiidae (Cap. III). En T. merianae, este tipo morfológico se presenta en individuos no adultos, en bajo número, y generalmente en una ubicación anterior a la del foramen de ingreso al canal alveolar inferior. El ejemplar MACN-A 621, además de los dientes bicuspidados, tiene un tamaño menor al de los ejemplares MACN-A 5806-a y -b, que son considerados de individuos de talla adulta cercana a sus tamaños máximos. Por estos motivos, puede interpretarse que se trataría de un individuo de la misma especie pero en un estadío de menor edad, probablemente subadulto. De esta manera el ejemplar MACN-A 621, también es asignado al género Tupinambis.

El material aquí descripto, como el del Colhuehuapense de Gaiman (ver Fm. Sarmiento y Brizuela y Albino, 2004), es muy fragmentario y en su mayoría correspondiente a fragmentos portadores de dientes, a pesar de lo cual se ha podido referir al género Tupinambis por las características de la dentición. Al comparar el diente molariforme del fragmento MACN-A 5806-a de la Formación Santa Cruz con los dientes molariformes observados entre el abundante material del Colhuehuapense de Gaiman, se aprecia que las dimensiones del primero son mayores que las de este último material, más antiguo. Sin embargo, como se mencionó previamente, el tamaño por sí sólo no es considerado suficiente como para diagnosticar un taxón diferente, aunque puede advertirse una tendencia al aumento de tamaño de los individuos de Tupinambis desde el Colhuehuapense al Santacrucense (Albino et al., 2006).

\section{Comentarios biogeográficos}

La presencia de Tupinambis en el Santacrucense del extremo sur de la provincia de Santa Cruz representa la distribución más austral del género tanto en relación al pasado como para la actualidad, ya que, como se mencionó previamente, sólo una población aislada de T. rufescens supera al sur al Río Negro (Cei, 1986). El sitio Monte León se encuentra actualmente en la provincia biogeográfica Patagónica, la cual presenta un clima frío, seco, con heladas anuales y nieve en el invierno (Cabrera y Willink, 1980), inadecuada para la supervivencia de lagartos teidos. El límite de distribución de esta familia es el río Colorado (desembocadura aprox. $40^{\circ}$ $\mathrm{S})$, aunque se registran algunas poblaciones más al sur de los teiinos 
Buenos Aires) entre los ríos Colorado y Negro (Cei, 1986), pero, a diferencia de $T$. rufescens, a estos géneros no se los registra al sur del río Negro. De esta manera, la presencia de Tupinambis en el Santacrucense de Monte León está indicando que las condiciones cálidas y húmedas inferidas para el Colhuehuapense de Gaiman habrían estado extendidas hacia el extremo sur del continente al menos hasta el Santacrucense, como también lo sostienen otras evidencias (Pascual y Odreman Rivas, 1971; Pascual et al., 1996; Tauber, 1997; Ortiz Jaureguizar y Caldera, 2006). Incluso, la presencia de colúbridos en niveles de la Fm. Santa Cruz en Monte Observación y de la Fm Pinturas en Ea. Los Toldos, ambos en la provincia de Santa Cruz, apoya esta inferencia (Albino, 1996c).

\subsubsection{Formación Collón Cura}

Geología

Cañadón del Tordillo es una localidad fosilífera ubicada en cercanías de la ciudad de Piedra del Águila, provincia del Neuquén (Fig. 34) y originada por la acción de un río temporario sobre sedimentos de origen piroclásticos (Pardiñas, 1991). La Fm. Collón Cura (Roth, 1899) suprayace al basamento cristalino, aunque en algunas zonas se intercala el Basalto O (Vucetich et al., 1993). El techo de la Fm. Collón Cura no se ha conservado (Vucetich et al., 1993). 

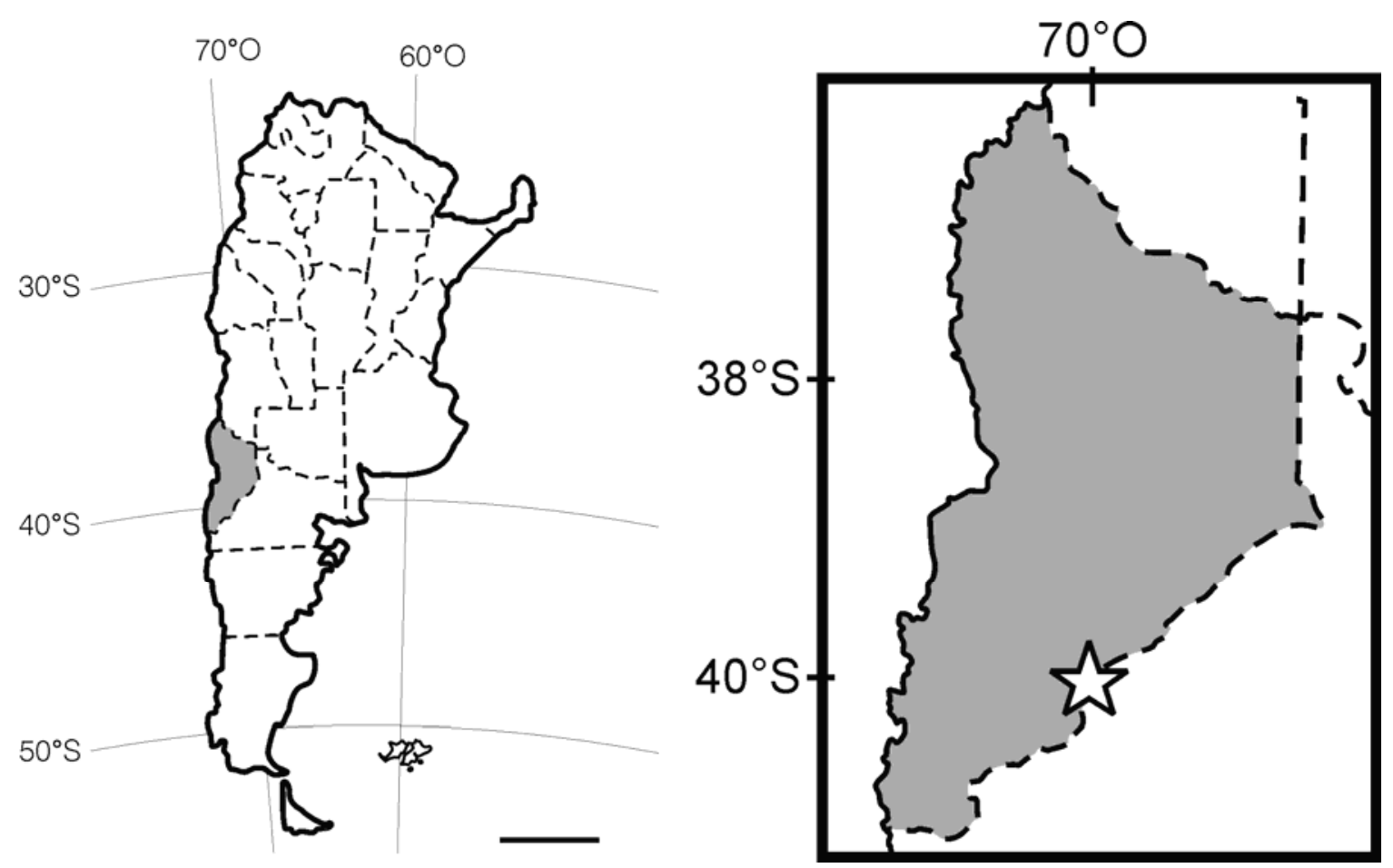

Figura 34. Mapa de ubicación de Cañadón del Tordillo, provincia de Neuquén.

La Fm. Collón Cura se compone de un conjunto integrado de aproximadamente $35 \mathrm{~m}$ de sedimentos, donde se reconocen tres miembros informales: Miembro Inferior, Miembro Ignimbrita Pilcaniyeu y Miembro Superior (Vucetich, et al., 1993) (Fig. 35). El Miembro Ignimbrita Pilcaniyeu es fácilmente reconocible y representa un nivel guía para el Mioceno medio de la Fm. Collón Cura (Vucetich et al., 1993). Aunque las condiciones de sedimentación no han sido detalladas, esta Formación se habría depositado rápidamente. Los datos radiométricos estiman una antigüedad de 14,2 Ma para el Miembro Ignimbrita Pilcaniyeu (Mazzoni y Benvenuto, 1990), aunque podría ser más antiguo (Vucetich et al., 1993). 


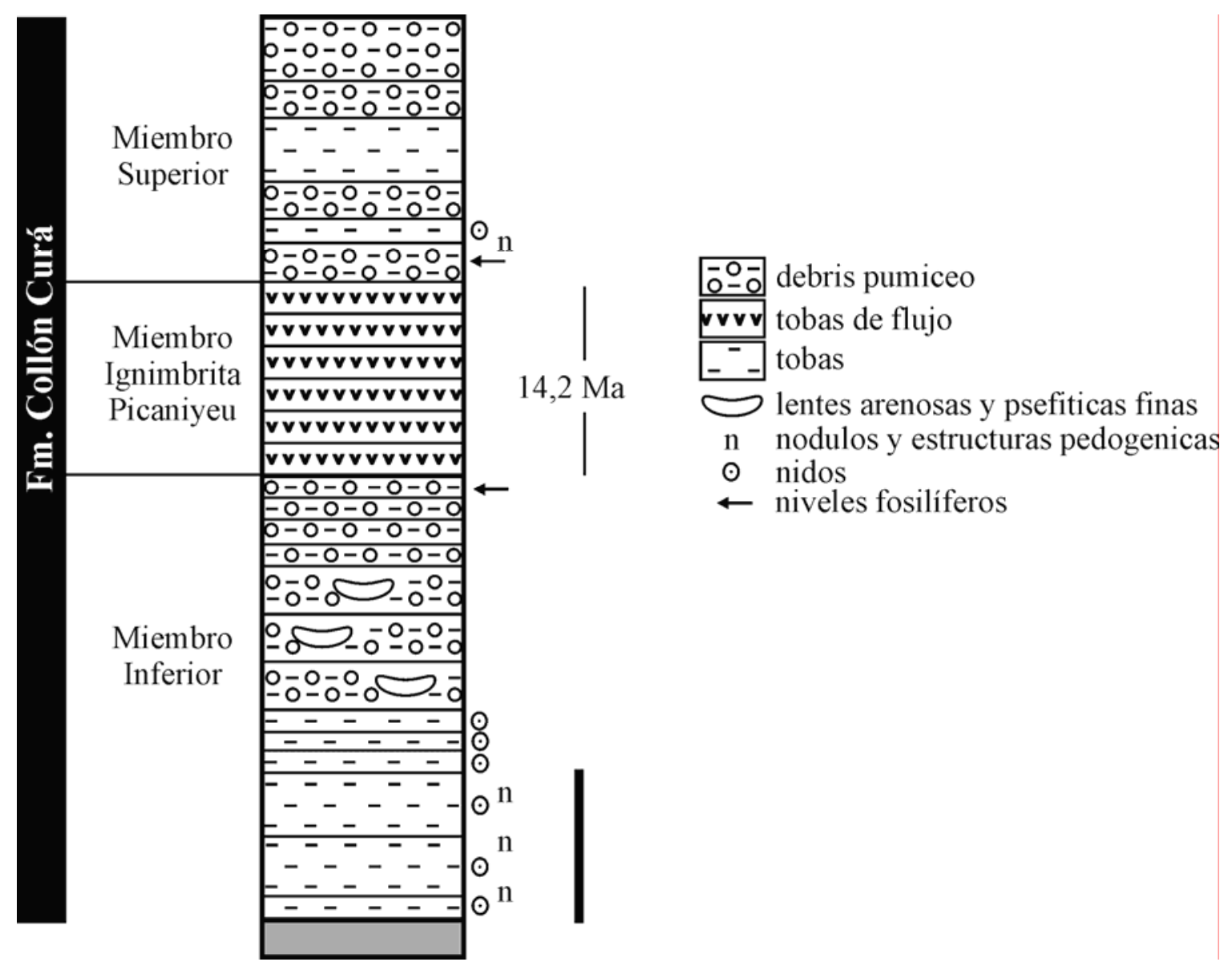

Figura 35. Perfil estratigráfico integrado de la Fm. Collón Cura en Cañadón del Tordillo, Neuquén (modificado de Vucetich et al., 1993).

La fauna de mamíferos de la Fm. Collón Cura fue referida al Friasense por Bondesio et al. (1980). Estudios posteriores propusieron la asimilación del Friasense s.s. al Santacrucense y el uso del Colloncurense para la fauna de la Fm. Collón Cura (Marshall, 1990; Marshall y Salinas, 1990: en Vucetich et al., 1993), de forma tal que el Colloncurense sería intermedio entre el Santacrucense y el Chasiquense. Vucetich et al. (1993), en base a una bien documentada fauna de roedores, consideran a la fauna de la Fm. Collón Cura como Colloncurense s.s. y sugieren preferible tratar al Santacrucense, Friasense s.s. y Colloncurense s.s. como faunas sucesivas. 


\section{Antecedentes}

Entre los microvertebrados hallados en Cañadón del Tordillo se encuentran mamíferos y escamosos. La fauna de mamíferos incluye primates (Cebidae), cenoléstidos (cf. Paleothentinae), boriénidos (cf. Arctodictis), dasipópidos (Stegotheriini), y varios roedores (Erethizontidae, Echimidae y Dasyproctidae) (Pardiñas, 1991; Vucetich et al., 1993). Entre los escamosos, se encuentran restos vertebrales de Waincophis australis (Serpentes) descriptos por Albino (1996b) y el material de lagartos que se describe a continuación (Brizuela y Albino, 2008b).

\section{Sistemática}

SQUAMATA Oppel 1811

SCLEROGLOSSA Estes, de Queiroz y Gauthier 1988

SCINCOMORPHA Camp 1923

TEIIOIDEA Estes, de Queiroz y Gauthier 1988

TEIIDAE Gray 1827

TUPINAMBINAE Presch 1974a

Tupinambis sp. o Crocodilurus sp.

(Fig. 36)

Material referido: MLP 91-IV-1-139, dentario y esplenial izquierdos articulados e incompletos; MLP 91-IX-1-72, MLP 91-IX-1-75, dentarios incompletos; MLP 91-IX1-74, maxilar derecho incompleto; MLP 91-IV-1-140, MLP 91-IV-1-141, vértebras incompletas. Los fragmentos de dentarios y maxilar conservan dientes y corresponden a individuos distintos.

Procedencia geográfica: Cañadón del Tordillo, 39 km sobre la Ruta Nacional 237, al sur de Piedra del Águila (400' S, $70^{\circ} 05^{\prime}$ O), departamento Collón Cura, provincia de Neuquén.

Procedencia estratigráfica: Miembro superior de la Formación Collón Cura, Edad Mamífero Colloncurense, Mioceno medio (Vucetich et al., 1993).

Descripción. Se conservan tres fragmentos en mal estado, de la parte anterior y media de diferentes dentarios (MLP 91-IV-1-139, MLP 91-IX-1-72, MLP 91-IX-1-75) (Fig. 36 A, B). Son labialmente lisos, sin ornamentación, y convexos. El ejemplar MLP 91IX-1-72 presenta como mínimo cinco forámenes mentales. El surco dental porta la 
serie dentaria y un nítido sulcus dentalis; lingualmente se observa el estante subdental. La sínfisis mandibular es simple, sin ornamentación (MLP 91-IX-1-72); posterior a ella se observa que el estante subdental adquiere forma de silla de montar (MLP 91IV-1-139, MLP 91-IX-1-72). El canal de Meckel está medialmente expuesto, no presenta restricción anterior y llega hasta la sínfisis. Los dientes son subpleurodontes, se ubican en alvéolos transversales al eje longitudinal de la serie dentaria y están delimitados por septos interdentales. La unión de los dientes al dentario es principalmente basal, y las bases presentan importantes depósitos de cemento. El fragmento MLP 91-IX-1-72 posee 13 alvéolos, pero sólo conserva las bases de los dientes II y IV (Fig. 36 A). El fragmento MLP 91-IV-1-139 conserva tres dientes (a, c y d), proximalmente cilíndricos, de los cuales sólo se conserva el extremo apical del anterior. Este diente es unicuspidado, cónico, con una leve compresión labiolingual; los dientes restantes son similares (Fig. 36 B). El fragmento MLP 91-IX-1-75 corresponde a la parte media de un dentario derecho y conserva un diente que es más robusto que los anteriormente descriptos. No se conserva ningún diente de la parte posterior de la serie dentaria; no obstante, la forma de los alvéolos posteriores del fragmento MLP 91-IX-1-72 indican que los dientes posteriores no presentaban expansión. Se observan varios alvéolos de reemplazo subcirculares, profundos y situados lingualmente sobre los alvéolos funcionales. Ninguno conserva dientes de reemplazo.

El ejemplar MLP 91-IV-1-139 incluye restos del esplenial. Este hueso es plano, con forma de una cuña extendida muy anteriormente. La superficie de articulación para el esplenial, expuesta en el fragmento MLP 91-IX-1-72, indica una fuerte unión con el dentario.

El fragmento MLP 91-IX-1-74 corresponde a la parte anterior de un maxilar derecho, más grácil y pequeño que los dentarios (Fig. 36 C, D). La superficie labial es lisa y conserva cuatro forámenes mentales. El proceso premaxilar es corto y aparentemente bífido; el foramen alveolar anterior abre dorsalmente sobre este proceso. Sobre el extremo anterolingual del proceso premaxilar se observa parte de la carilla de articulación para el vómer. El sulcus dentalis y el estante supradental están bien desarrollados. Dorsalmente, posterior a la fenestra exonarina, se observa la depresión donde se ubica el órgano vómero-nasal. Ésta está mal preservada, no presenta soporte narial anterior; la parte posterior no se conserva. La implantación y las características de los dientes funcionales y de reemplazo son como las descriptas 
para los dentarios. Los dientes II y III se conservan completos; son unicuspidados, rectos y de tamaño similar. El diente IV está roto apicalmente, pero sería similar a los precedentes. Los dientes I y V están rotos en la base.

Se conservan restos aislados de vértebras incompletas, procélicas y con articulación zigósfeno-zigantro. La vértebra MLP 91-IV-1-140 es presacral, no conserva la prezigapófisis izquierda, postzigapófisis derecha, zigósfeno ni la espina neural (Fig. 36 E-G). El arco neural es más largo que alto. La cresta interzigapofisiaria y el margo ventralis se distinguen nítidamente en vista lateral. La prezigapófisis es grande y nace a nivel de la parte media del canal neural; la carilla de articulación es oval, anterolateralmente orientada y poco inclinada respecto a la horizontal. La postzigapófisis es grande, anteroposteriormente orientada, con carilla de articulación oval. Se conserva parte del zigantro derecho sobre la parte posterior del arco neural; su carilla de articulación presenta una marcada pendiente. El centro vertebral es de forma cónica, largo, truncado posteriormente, con una prominente cresta sagital y cuello condilar bien demarcado. En la parte anterior de la vértebra, ventral a la prezigapófisis, se observa un robusto proceso transverso que se proyecta ventrolateralmente. Distalmente, sobre el proceso transverso, se observa una sinapófisis grande, oval y horizontalmente orientada. El cótilo es grande, transversalmente oval, profundo e inclinado ventralmente. Sobre el borde ventral del cótilo se observa la superficie de articulación para la hipapófisis. El cóndilo, al igual que el cótilo, es grande y transversalmente oval; es convexo e inclinado dorsalmente. La disposición horizontal de los procesos transversos, la cresta sagital bien desarrollada y la presencia de una zona de unión anterior para la hipapófisis indican que se trata de una vértebra cervical.

La vértebra caudal anterior MLP 91-IV-1-141 (Fig. 36 H, I) es más pequeña que la previamente descripta. La parte posterior de la vértebra, la espina neural y los extremos distales de los procesos transversos no se conservan. Lateralmente, el arco neural es bajo, y el canal neural es grande y subcircular. El zigósfeno es pequeño, más angosto que el cótilo. Las prezigapófisis están bien desarrolladas, ubicadas en posición elevada, por sobre el techo del canal neural, y fuertemente inclinadas sobre el plano horizontal. El centro vertebral es cilíndrico, largo y algo estrecho en el centro. De los procesos transversos se conserva sólo las partes proximales, que son dorsoventralmete comprimidas y con desarrollo anteroposterior. Se puede inferir que 
los procesos transversos estaban lateralmente orientados. No se observa plano de autotomía.
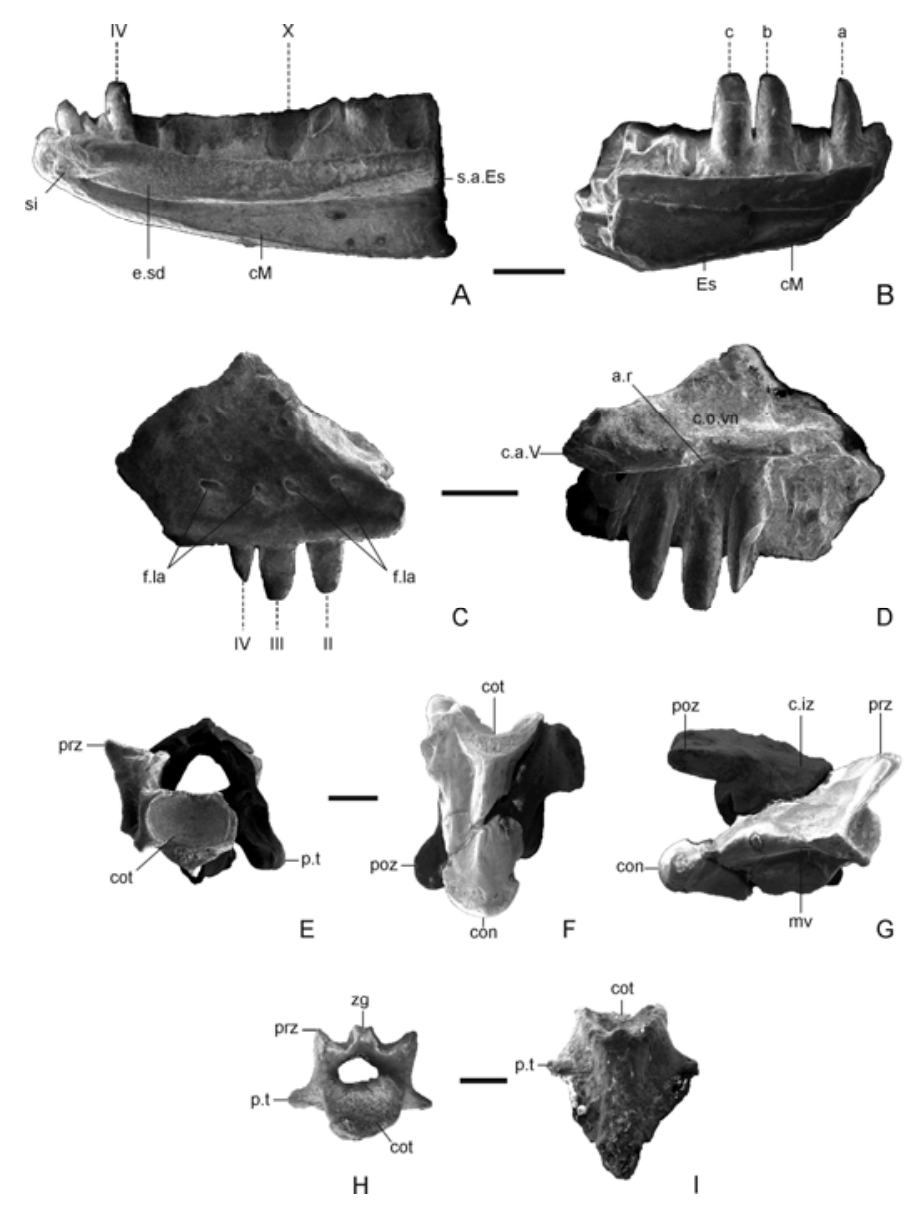

Figura 36. Tupinambinae (Tupinambis sp. o Crocodilurus sp.) de la Formación Collón Cura (Mioceno medio), Cañadón del Tordillo, provincia de Neuquén. A, dentario derecho (MLP 91-IX-1-72) en vista lingual; B, dentario y esplenial izquierdos (MLP 91-IV-1-139) en vista lingual; C, D maxilar derecho (MLP 91-IX-1-74) en vistas labial (C) y lingual (D); E-G, vértebra presacra (MLP 91-IV-1-140) en vistas anterior (E), ventral (F) y lateral (G); H, I, vértebra caudal anterior (MLP 91-IV-1-141) en vistas anterior (H) y ventral (I). Abreviaturas: a.r; alvéolo de reemplazo; cM, canal de Meckel; c.a.V, carilla de articulación para el vómer; c.iz; cresta interzigaposisiaria; cot, cótilo; con, cóndilo; Es, esplenial; e.sd, estante subdental; f.la, foramen labial; m.v, margo ventralis; poz, postzigapófisis; prz, prezigapófisis; p.t, proceso transverso; s.a.Es, superficie de articulación para el esplenial; zg, zigósfeno. La escala de los dentarios y el maxilar equivale a $2 \mathrm{~mm}$, la escala de los las vértebras equivale a $1 \mathrm{~mm}$. 
Comentarios taxonómicos. Los alvéolos de reemplazo profundos y el esplenial hipertrofiado, anteriormente extendido, son caracteres del clado BorioteiioideaTeiioidea (excepto Gymnophthalmidae) (Cap. III). La ausencia del soporte narial anterior excluye a los fósiles de los Borioteiioidea. La posición de la depresión del órgano vómero-nasal, posterior a la fenestra exonarina, y el canal de Meckel medialmente abierto a lo largo del dentario impide su asignación a los Gymnophthalmidae. Esta exclusión es confirmada por la condición subpleurodonte de la dentición y el tamaño relativamente grande de los restos craneales y vertebrales. La ausencia de estrechamiento anterior del canal de Meckel asemeja el fósil a los Tupinambinae, incluyendo Callopistes ([C132], [C134]). Esta afinidad se refleja también en la extensión del canal de Meckel hasta la sínfisis, contrariamente a lo observado en los "cnemidoforinos" y Teius donde el canal de Meckel se continúa ventralmente a la misma (Fig. 11, [C89]). Entre los Tupinambinae, la ausencia de un depósito excesivo de cemento que cubra completamente los septos interdentales excluye a los géneros Dracaena y Paradracaena. Sin embargo, la cantidad de cemento es suficientemente importante como para disimular los septos, como ocurre en Tupinambis y Crocodilurus pero no en Callopistes (Cap. III).

Lamentablemente, por lo parcial de los elementos preservados que no incluye las series posteriores, las diferencias en la dentición de Tupinambis y Crocodilurus mencionadas en el Capítulo III no pueden ser evaluadas en el material fósil, impidiendo la resolución de la asignación genérica. La ausencia de dientes posteriores también impide una comparación directa con los Tupinambis del Colhuehuapense y del Santacrucense, aunque las dimensiones de los fósiles no difieren de los de dichas procedencias.

Por otro lado, las características de las vértebras fósiles no permiten distinguirlas de las de los Teiidae, aunque esta familia no tiene caracteres vertebrales exclusivos (Cap. III). Vértebras cervicales con hipapófisis articuladas en la parte anterior del centro vertebral, como se observa en el fósil MLP 91-IV-1-140, están presentes en los Lacertoidea (principalmente los Teiidae), así como en algunos miembros de los Cordylidae, Agamidae (Hoffstetter y Gasc, 1969) y Xantusiidae (Lee, 1998). La presencia de una hipapófisis anterior y articulada fue confirmada en el material de referencia para todos los integrantes de la familia Teiidae ([C154]). Etheridge (1967), Krause (1974a) y Veronese y Krause (1997) han tratado la morfología vertebral de los Teiidae. Si embargo, las diferencias observadas por estos 
autores requiere conocer la posición absoluta de las vértebras, y aún así, no siempre se pueden diferenciar vértebras individuales de diferentes géneros. Dado que los restos fósiles craneales son referibles a Tupinambis o Crocodilurus, y que no se ha identificado ningún otro lagarto en esta localidad, las vértebras fósiles son asignadas tentativamente al mismo taxón.

\section{Comentarios biogeográficos}

Actualmente en la provincia de Neuquén sólo se encuentra una especie de teido, "Cnemidophorus “longicaudus (Cei, 1986), el cual únicamente ha sido registrado cerca de la capital provincial, más de $200 \mathrm{~km}$ al norte del área de Cañadón del Tordillo. El Tupinambinae descripto aquí corresponde al primer registro de un lagarto de esta subfamilia para el noroeste de Patagonia. De esta forma, se amplía geográficamente la distribución miocénica de los Tupinambinae que, hasta el momento, estaba restringida a las localidades costeras de Monte León (Santa Cruz) y Gaiman (Chubut).

El área de Cañadón del Tordillo, al igual que la localidad de Gaiman (Colhuehuapense), se encuentra en la provincia biogeográfica del Monte (ver Fm. Sarmiento) donde se desarrolla un clima árido, seco y frío (Cabrera y Willink, 1980). La presencia de Tupinambis o Crocodilurus en esta localidad sugiere condiciones climáticas más cálidas y húmedas durante el Colloncurense respecto a la actualidad. Coincidentemente, Vucetich et al. (1993), en base al estudio de primates y roedores también procedentes de Cañadón del Tordillo, aunados a datos entomológicos y sedimentológicos, obtienen una caracterización ambiental similar.

\subsubsection{Formación Cerro Azul}

\section{Geología}

La Fm. Cerro Azul (Linares et al., 1980) en la provincia de La Pampa ha provisto los materiales más ricos de lagartos del Mioceno tardío sudamericano. Esta formación aflora en varias localidades de la provincia (Fig. 37) y posiblemente también en el oeste de la provincia de Buenos Aires (Goin et al., 2000b). En la mayoría de las localidades descansa sobre la Fm. Chasicó, de la cual es indistinguible, excepto en la localidad de Caleufú donde se intercala la Fm. Río Negro (Albino et al., 2006). 

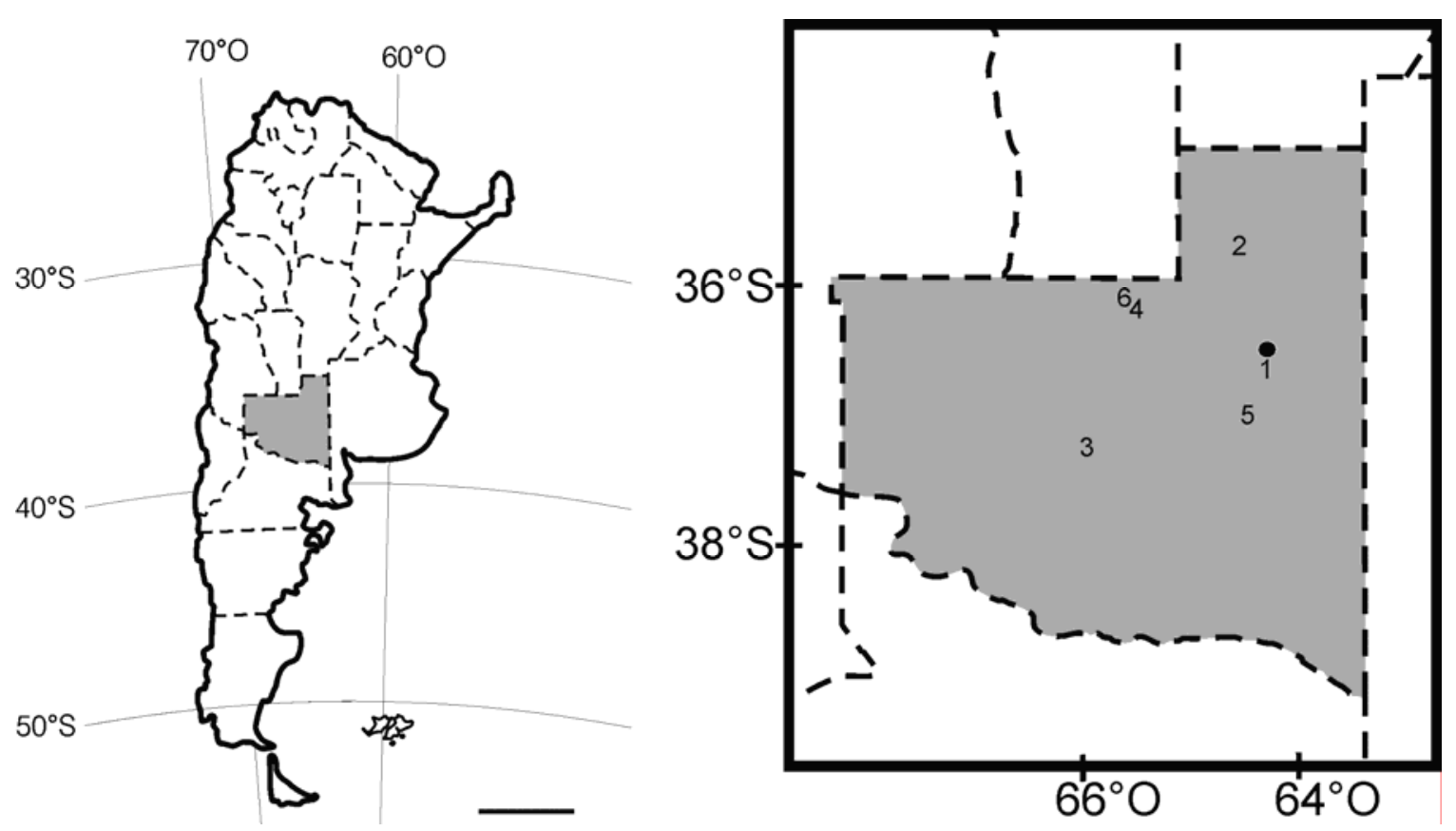

Figura 37. Mapa de ubicación de los diferentes sitios de la Fm. Cerro Azul (La Pampa) de donde se han recuperado restos de Teiiade. 1, Bajo Giuliani; 2, Caleufú; 3, Chacharramendi; 4, Loventué; 5, Quehué; 6, Telén. Escala $500 \mathrm{~km}$.

En el análisis estratigráfico de la Formación realizado por Goin et al. (2000b) se reconocen tres asociaciones de facies (Fig. 38). Estos autores concluyen que el ciclo depositacional comenzó con depósitos lacustres (asociación de facies A, basal), sobre la que se depositaron estratos eólicos más potentes y de mayor distribución donde se registra la formación de suelos (asociación de facies $\mathrm{B}$, media); por último, se depositaron sedimentitas propias de cursos fluviales (asociación de facies $\mathrm{C}$, superior). 


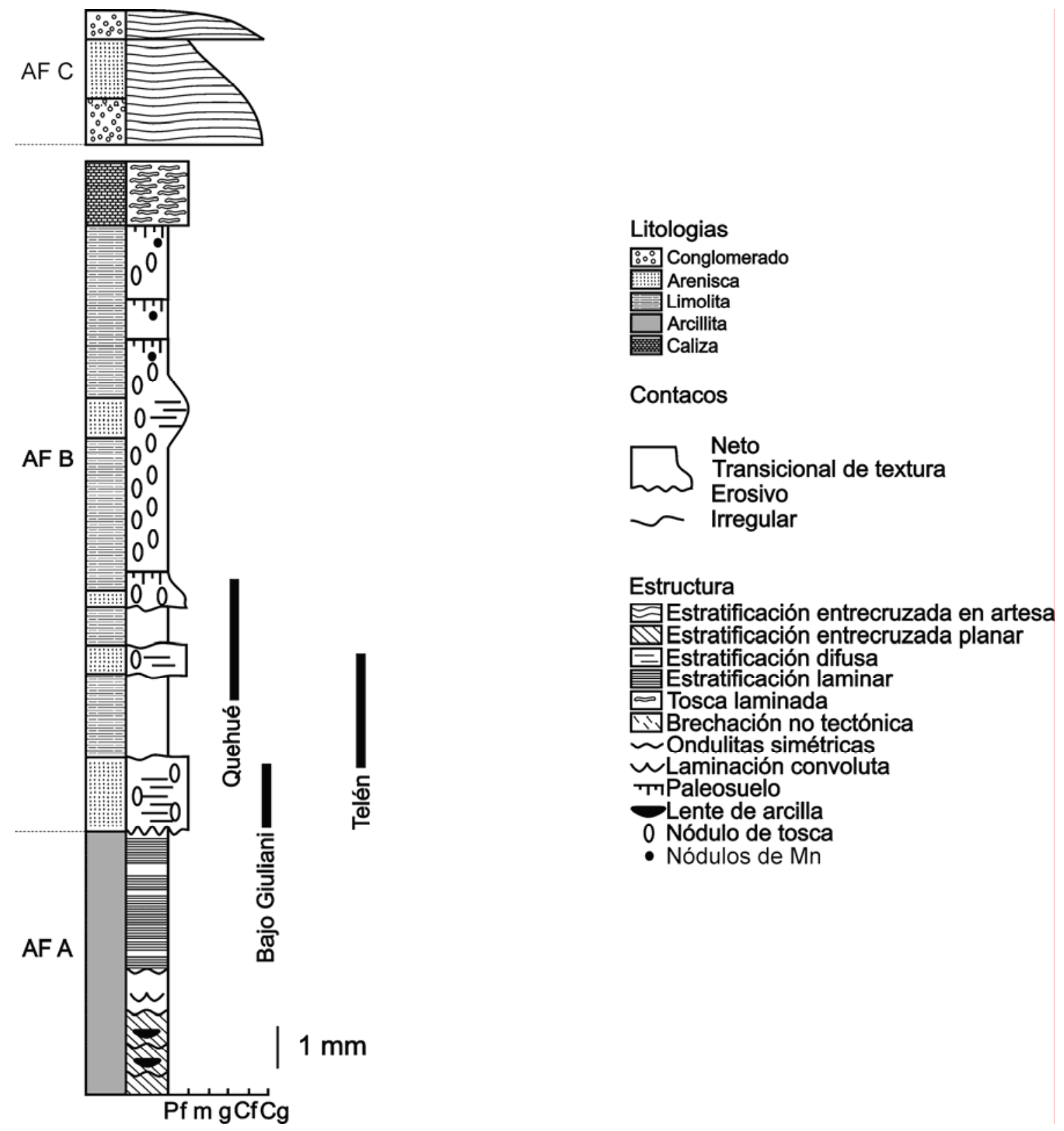

Figura 38. Columna estratigráfica de la Fm. Cerro Azul (modificado de Goin et al., 2000b).

En la figura 38 se muestran las distribuciones de varias localidades en la columna estratigráfica de la Fm. Cerro Azul. Allí se observa que la mayoría de las localidades corresponde a la posición de facies B (Montalvo et al., 1996, 2002; Goin et al., 2000b; Melchor et al., 2000). La fauna de mamíferos de estas localidades ha sido asignada a la Edad Mamífero Huayqueriense (Verzi et al., 1995, 1999; Montalvo et al., 1996, 1998; Verzi, 1999), actualmente considerada de edad Mioceno tardío (Cione et al., 2007). Verzi et al. (2003) sostienen, en base a la fauna de roedores y su 
estado evolutivo, que la fauna de la localidad Caleufú sería de menor antigüedad, probablemente más cercana al Montehermosense.

\section{Antecedentes}

En el Huayqueriense de la provincia de la Pampa se ha reconocido un importante número de mamíferos, y en menor medida, aves, tortugas y reptiles escamosos (Pascual y Odreman Rivas., 1971; Goin et al., 2000b; Albino y Montalvo, 2006; Albino et al., 2006). Entre los escamosos, Albino y Montalvo (2006) reconocen la presencia de serpientes de las familias Viperidae y "Colubridae", mientras que Albino et al. (2006) describen restos asignables al teido Tupinambis, que se presentan a continuación.

\section{Sistemática}

SQUAMATA Oppel 1811

SCLEROGLOSSA Estes, de Queiroz y Gauthier 1988

SCINCOMORPHA Camp 1923

TEIIOIDEA Estes, de Queiroz y Gauthier 1988

TEIIDAE Gray 1827

TUPINAMBINAE Presch 1974a

Tupinambis Daudin, 1802

Tupinambis sp.

(Fig. 39, 40)

Material referido: Localidad Bajo Giuliani: GHUNLPam 2340, 2396, 5413, 5493, 8550, dentarios fragmentarios; GHUNLPam 2274, 21712, maxilares fragmentarios; GHUNLPam 5494, fragmento de maxilar o dentario; GHUNLPam 2313 vértebra. Localidad Quehué: GHUNLPam 9674, dentario fragmentario. Localidad Caleufú: GHUNLPam 19608, 19610, 19854, dentarios fragmentarios, GHUNLPam 19856, 19914, dentarios y espleniales articulados fragmentarios; GHUNLPam 19855, 19609, fragmento de maxilar o dentario; GHUNLPam 19612/4, 19865/30, 19874/42 vértebras fragmentarias. Localidad Telén: GHUNLPam 21669, dentario fragmentario. Localidad Loventué GHUNLPam 14283, 14284 maxilares fragmentarios. Ninguno de los materiales corresponde a un mismo individuo. 
Procedencia geográfica: Los fósiles provienen de cinco localidades de la provincia de La Pampa: Bajo Giuliani (GHUNLPam 2274, 2340, 2396, 5413, 5493, 5494, 8550, 21712, 2313), departamento Capital; Quehué (GHUNLPam 9674), departamento Utracán; Caleufú (GHUNLPam 19608, 19609, 19610, 19612/4, 19854, 19855, 19856, 19865/30, 19874/42,19914,), departamento Rancul; Telén (GHUNLPam 21669) y Loventué (GHUNLPam 14283, 14284), departamento Loventué.

Procedencia estratigráfica: Formación Cerro Azul, Edad Mamífero Huayqueriense, Mioceno tardío.

Descripción. La dentición en maxilares y dentarios es de tipo subpleurodonte. El fragmento GHUNLPam 14284 corresponde a la parte proximal del proceso premaxilar de un maxilar izquierdo deficientemente conservado (Fig. 39 A). Lingualmente, se observa la depresión para el órgano vómero-nasal, posteriormente a la cual se insinúa el receso lateral del saco nasal. El soporte narial posterior está débilmente insinuado. Conserva un diente unicuspidado apicalmente cónico y dirigido hacia el extremo distal.

El fósil GHUNLPam 21712 corresponde a la parte posterior terminal de un maxilar izquierdo (Fig. 39 B). Labialmente es liso y conserva dos forámenes labiales a la altura del primer alvéolo conservado (a). En vista dorsal se observa el canal ancho y somero que lleva al foramen de ingreso del canal alveolar superior; mientras que lingualmente se advierte el angosto y profundo surco que recibe al yugal. Lingual a la serie dentaria se conserva un nítido sulcus dentalis. Se conservan cuatro alvéolos; el anterior (a) preserva sólo la base del diente correspondiente, mientras que los siguientes (b, c y d) portan dientes romos que conforman un gradiente decreciente en tamaño. En el mismo sentido se observa una leve compresión lateral. Oclusalmente, hay una fina cresta mesodistalmente orientada sobre los últimos dos dientes (c) y (d).

El fósil GHUNLPam 2274 corresponde, posiblemente, a un maxilar derecho parcialmente conservado, por la forma cóncava del contorno labial en vista dorsal. Se conservan cuatro alvéolos, con un diente completo (a) y tres incompletos (b, c y d). Los dientes son de sección circular. El diente completo es unicuspidado, apicalmente cónico y curvado distalmente.

El fósil GHUNLPam 14283 posiblemente corresponda a un maxilar derecho. Conserva dos alvéolos, de las cuales sólo el anterior (a) conserva el diente. El diente es unicuspidado, robusto basalmente; apicalmente es cónico y curvado distalmente. En el alvéolo funcional (a) se conserva un alvéolo de reemplazo subcircular. 
El fósil GHUNLPam 19856 corresponde a parte de una hemimandíbula izquierda, de la que se conservan el dentario y el esplenial (Fig. 39 C). Del esplenial está preservado sólo el extremo cuneiforme anterior. El dentario es labialmente liso y presenta tres forámenes mentales, de los cuales los dos anteriores son mayores que el posterior. Lingualmente se observa la sínfisis mandibular simple, por detrás de la cual el estante subdental presenta forma de silla de montar. Posteriormente, el estante subdental es plano-convexo de disposición vertical. El canal de Meckel se encuentra medialmente abierto hasta la sínfisis, sin restricción anterior. Sobre el surco dental se conservan nueve alvéolos. En ellos, los dientes II, III, V y VIII están completos, mientras que de los restantes se preservan sólo las bases. Los dientes son unicuspidados cónicos. Los dientes II y VIII presentan su extremo apical distalmente curvado, los otros dientes son rectos. Se conservan siete alvéolos de reemplazo subcirculares ubicados posterolingualmente en los alvéolos funcionales (a), (c), (e), (f), (g) y (h); el alvéolo (d) se ubica anteromedialmente. En los alvéolos de reemplazo (d) y (c) se conservan dientes.

El fragmento GHUNLPam 8550 corresponde a la parte posterior de un dentario derecho mal preservado (Fig. 39 D), que conserva tres dientes completos (a, b y c) y uno incompleto (d). Los dientes son romos, robustos y de sección circular. Apicalmente presentan una protuberancia central, atravesada por una fina cresta irregular mesodistalmente dispuesta (Fig. 39 C). El conjunto de dientes forma un gradiente decreciente de tamaño. El esmalte de los dientes presenta finas estrías de orientación basal-apical que convergen en la protuberancia central.

El fósil GHUNLPam 9674 corresponde al extremo terminal de un dentario derecho. Labialmente es liso y conserva tres forámenes mentales, de los cuales sólo el anterior está completo. Lingualmente se observa la sínfisis mandibular, posterior a la cual el canal de Meckel se encuentra medialmente abierto. Dorsalmente al canal de Meckel, se conserva la parte anterior del estante subdental. En vista oclusal, en el surco dental se aprecian cuatro alvéolos. Lingualmente a la serie dentaria se observa el sulcus dentalis. Se conservan pobremente los dos dientes centrales (b y c). El diente (c) es el mejor conservado; es recto, ligeramente comprimido mesodistalmente en la base, mientras que el extremo apical está distalmente curvado.

El fósil GHUNLPam 2340 corresponde a un dentario y esplenial izquierdo articulados, parciales y mal preservados. Del esplenial se conserva un pequeña parte plana. El dentario posee cinco alvéolos en el surco dental, Se conserva un único diente 
en el alvéolo (d). La base del diente es robusta y de sección circular, pero el ápice esta mal preservado.

El fósil GHUNLPam 5493 corresponde a la parte anterior de un dentario derecho. Labialmente es liso y presenta tres forámenes mentales. Lingualmente se observa una sínfisis mandibular simple, la terminación medialmente abierta del canal de Meckel y el estante subdental. En vista oclusal, conserva los seis alvéolos anteriores, de las cuales, el II y el III son de mayor tamaño que el resto. Se conservan los dientes IV al VI. Éstos son de base subcilíndrica con una ligera compresión mesodistal; apicalmente están mal conservados.

El fósil GHUNLPam 5413 corresponde a un fragmento medio-anterior de un dentario izquierdo que no conserva la pared labial. Ventralmente sólo se presenta el techo del canal de Meckel, que se infiere medialmente abierto. Dorsalmente, en el surco dental, se notan tres alvéolos completos (a-c) y uno incompleto (d). Se conservan dientes completos en los alvéolos (b) y (c) y la base del diente en el alvéolo (a). Los dientes son basalmente cilíndricos y apicalmente cónicos, de punta curvada hacia el extremo distal. Las bases de los dientes aumentan progresivamente de tamaño en sentido mesodistal.

El fósil GHUNLPam 2396 corresponde a la parte anterior de un dentario derecho. Labialmente es liso y conserva un foramen mental. Lingualmente no conserva la sínfisis. El canal de Meckel se encuentra medialmente abierto ventral al estante subdental. Sobre el surco dental se observan cuatro alvéolos, el último de los cuales (d) está incompleto. Se conservan dientes completos en las dos últimas posiciones dentarias ( $\mathrm{c}$ y d). Los dientes son unicuspidados, apicalmente cónicos y distalmente curvados. El diente anterior (c) es más alto que el posterior (d) y se encuentran ampliamente separados.

El fósil GHUNLPam 21669 está pobremente preservado; corresponde a la parte media-posterior de un dentario izquierdo. Lingualmente se distingue el estante subdental. El surco dental conserva tres alvéolos funcionales delimitados lingualmente por el sulcus dentalis. Se conservan tres dientes unicuspidados que son basalmente cilíndricos, con una ligera compresión labiolingual, y apicalmente presentan una leve curvatura distal, más marcada en el diente anterior (a). Lingualmente, en los tres alvéolos funcionales, se conservan tres alvéolos de reemplazo subovales y profundos, ninguno de los cuales conserva dientes. 
El fósil GHUNLPam 19608 es un fragmento de dentario derecho pobremente conservado. Labialmente es liso y con un foramen labial. Lingualmente sólo se conserva parte del estante subdental, que es plano-convexo de disposición vertical. En el surco dental se advierten tres alvéolos funcionales delimitados lingualmente por un angosto sulcus dentalis. Hay tres dientes completos, que son basalmente grandes y cilíndricos, y apicalmente cónicos de punta distalmente dirigida. Los tres dientes constituyen un gradiente de tamaño creciente en sentido mesodistal. Se conservan dos alvéolos de reemplazo subcirculares sobre los dos alvéolos funcionales anteriores (a y b), pero no existen restos dentarios.

El fósil GHUNLPam 19610 corresponde a la parte anterior de un dentario derecho. Se destaca del resto de los elementos descriptos por el menor tamaño. Labialmente es liso, presenta cinco forámenes mentales completos y uno posterior incompleto. No se conserva la sínfisis a excepción de una parte ventral a la terminación del canal de Meckel. Este último está medialmente abierto, delimitado dorsalmente por el estante subdental, el cual presenta forma de silla de montar en su parte más anterior. El surco dental conserva ocho alvéolos, delimitados lingualmente por un angosto sulcus dentalis. Sólo se encuentra completo el diente III; de los dientes I, V - VIII se conservan sólo las bases, mientras que los dientes II y IV faltan. Todos los dientes conservados son de sección circular y cercanos entre sí. El diente III es unicuspidado, apicalmente está comprimido labiolingualmente y no presenta punta punzante. Se conserva un alvéolo de reemplazo lingual al alvéolo funcional VII.

El fósil GHUNLPam 19854 corresponde a parte anterior de un dentario derecho. Labialmente es liso y conserva cuatro forámenes mentales, de los cuales los dos anteriores están fusionados entre sí. El canal de Meckel termina en la sínfisis, posterior a la cual el estante subdental presenta forma de silla de montar. En el surco dental se observan los cuatro alvéolos anteriores, que conservan los primeros dientes completos. Los dientes son unicuspidados y apicalmente curvados hacia el extremo distal. El diente II es de mayor tamaño que los restantes que son de similares dimensiones entre sí. Se conservan dos alvéolos subcirculares lingualmente a los alvéolos funcionales II y III.

El fósil GHUNLPam 19914 corresponde a un fragmento de una hemimandíbula izquierda articulada que conserva parcialmente y en mal estado el dentario y el esplenial, así como fragmentos del suprangular y angular. El esplenial es plano y conserva los forámenes alveolar anterior y milohioideo. Lingualmente, el 
dentario es ligeramente convexo. Posteriormente al dentario, se observan restos pequeños del suprangular y angular. Lingualmente sobre el dentario, se observa un estante subdental bajo. El canal de Meckel está medialmente abierto, aunque se encuentra cubierto por el esplenial. Sobre el surco dental se conservan seis alvéolos sin dientes. En los alvéolos (a) y (c) se encuentran las bases de los respectivos dientes. Un alvéolo de reemplazo subcircular se ubica lingualmente al alvéolo funcional (c).

Varios fósiles (GHUNLPam 5494, GHUNLPam 19855, GHUNLPam 19609) que corresponden a huesos portadores de dientes no pueden ser determinados, ni siquiera en forma tentativa, como dentarios o maxilares, debido al pobre estado de preservación. Sin embargo, estos fósiles presentan características dentarias (i.e. implantación, tipos morfológicos de dientes) como las de los fósiles ya descriptos.
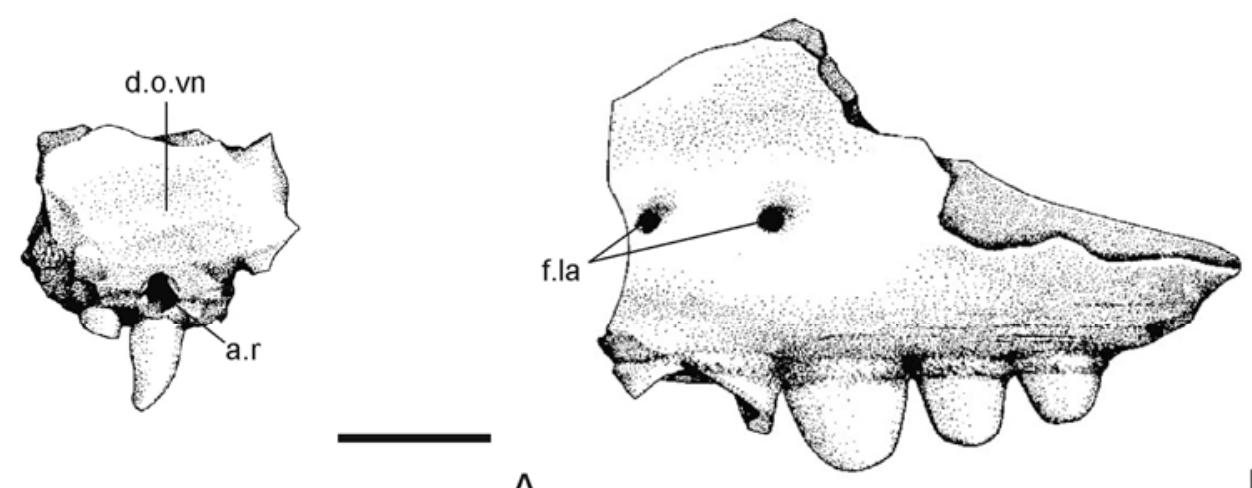

A

B
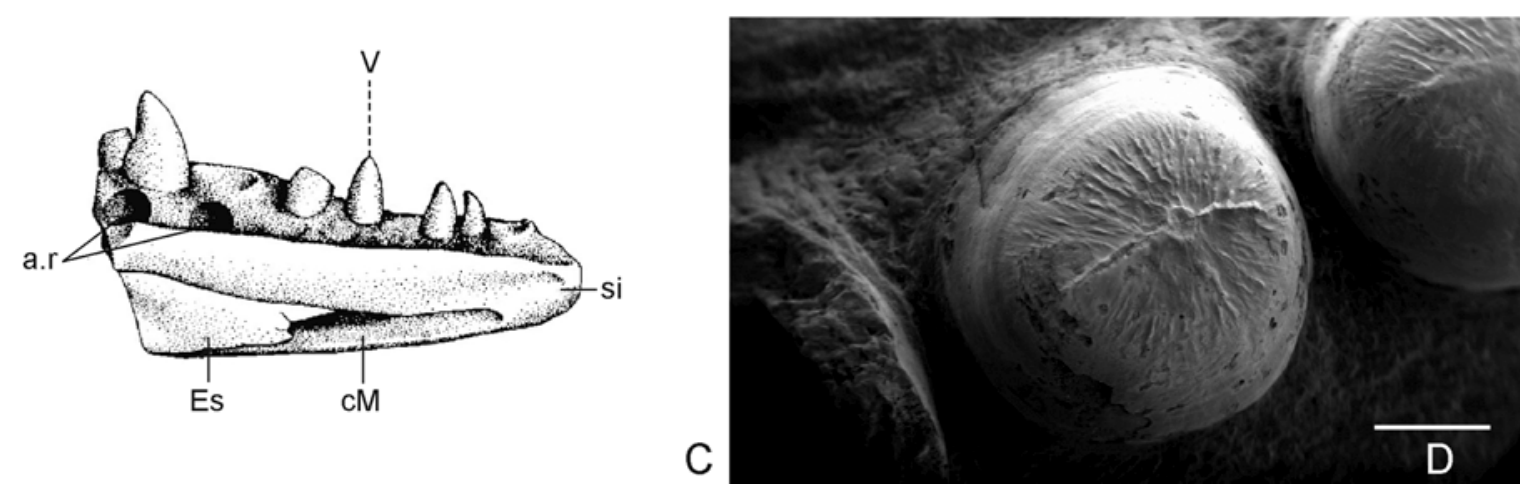

Figura 39. Elementos craneales de Tupinambis sp. de la Formación Cerro Azul, provincia de La Pampa (tomado de Albino et al., 2006). A, maxilar izquierdo GHUNLPam 14284 en vista lingual; B, maxilar izquierdo GHUNLPam 21712 en vista labial; C, dentario y esplenial izquierdos GHUNLPam 19856 en vista lingual; D, magnificación de los dientes del fragmento GHUNLPam 8550 en vista oclusal. Abreviaturas: a.r; alvéolo de reemplazo; cM, canal de Meckel; d.o.vn, depresión para el órgano vómeronasal; e.sd, estante subdental; Es, esplenial; f.la, foramen labial; si, sínfisis. Escala de los dentarios y el maxilar equivale a $2 \mathrm{~mm}$, la escala en la magnificación de los dientes equivale a $0,5 \mathrm{~mm}$. 
El ejemplar GHUNLPam 19612/4 (Fig. 40 A) es un centro vertebral largo y cónico. Ventralmente es ligeramente convexo, con una suave y ancha cresta sagital a lo largo de la línea media. A ambos lados de la cresta sagital, en una posición media, se encuentran un par de forámenes subcentrales. El cótilo y el cóndilo son grandes, transversalmente ovales e inclinados ventral y dorsalmente respectivamente. El cuello condilar está bien definido. Anteriormente, se conserva la parte próximo-ventral del proceso transverso derecho, el cual está restringido a la parte anterior del centro vertebral. Aunque no se conserva la parte dorsal, se infiere que el proceso transverso presentaba desarrollo dorsoventral.

El fósil GHUNLPam 19874/42 corresponde a dos vértebras dorsales articuladas (Fig. 40 B, C). De la vértebra anterior se conserva la parte posterior, sin la espina neural. Las postzigapófisis son cortas y están posterolatralmente orientadas. El centro vertebral no conserva el cótilo. Ventralmente es convexo, con una suave y ancha cresta sagital. En la parte anterior izquierda se observa un minúsculo foramen subcentral. El cóndilo está dorsalmente orientado y precedido por un marcado cuello condilar. De la segunda vértebra se conserva la parte anterior. Las prezigapófisis son cortas, levemente inclinadas sobre la horizontal y anteriormente orientadas. Entre las prezigapófisis, el techo del canal neural se extiende por debajo de la vértebra precedente, por lo que se infiere la presencia de articulación zigósfeno/zigantro. Ventral a las prezigapófisis se observan procesos transversos relativamente pequeños y de moderado desarrollo dorsoventral. Éstos tienen un mayor desarrollo lateral que las prezigapófisis. En vista lateral, sobre el extremo distal de los procesos transversos, se observan las sinapófisis, que son levemente ovales y verticalmente dispuestas. El centro vertebral se infiere cónico; es levemente convexo con una suave y ancha cresta sagital como en la vértebra anterior.

El fósil GHUNLPam 2313 es una vértebra caudal grande (Fig. 40 D-H). Se conserva completa a excepción de los extremos distales de los procesos transversos. La espina neural es alta, vertical y ubicada posteriormente sobre el arco neural. $\mathrm{Su}$ extremo se encuentra a la altura del cóndilo. El canal neural es triangular y pequeño, de similar altura que el zigósfeno. El arco neural es bajo y largo, anteriormente presenta un desarrollado zigósfeno. Éste último es escotado con las carillas de articulación inclinadas respecto del plano sagital y de contorno subcircular. Las prezigapófisis se originan algo dorsalmente respecto a la parte media del arco neural; son cortas, inclinadas sobre la horizontal (aunque apenas sobrepasan al zigósfeno) y 
orientadas anterolateralmente. Las carillas de articulación de las prezigapófisis son ovales, algo más desarrolladas anteroposteriormente en su extremo proximal. Las postzigapófisis son de menor tamaño que las prezigapófisis y sus carillas de articulación son ovales, con el eje mayor perpendicular al eje longitudinal de la vértebra. Los procesos transversos, como se infiere de los extremos proximales, están anteroposteriormente desarrollados y comprimidos dorsoventralmente. El cótilo es grande, circular, profundo y ventralmente inclinado. El centro vertebral es cilíndrico, con una leve constricción en su parte media. No se observa un marcado cuello condilar. El cóndilo es oval en vista posterior y se encuentra dorsalmente inclinado.

La vértebra GHUNLPam 19865/30 (Fig. 40 I-L) corresponde a la región caudal proximal; es alta, larga y algo comprimida lateralmente. No se conserva la prezigapófisis derecha, la postzigapófisis izquierda, la espina neural ni el proceso transverso izquierdo. El arco neural es bajo y largo, lateralmente recorrido por la cresta interzigapofisiaria. En vista anterior, el canal neural es subtriangular y bajo. La prezigapófisis izquierda se origina a un nivel medio sobre el arco neural; las superficies de articulación están fuertemente inclinadas sobre el plano horizontal. El zigósfeno es pequeño, mucho más angosto que el cótilo; las carillas de articulación se encuentran cercanas al plano sagital y se orientan dorsoanteriormente. En vista dorsal, el margen anterior del zigósfeno está profundamente escotado. El centro vertebral es cilíndrico, algo estrecho en la mitad, con un marcado cuello condilar en su parte posterior. El cótilo y el cóndilo son grandes y subcirculares, con escasa inclinación ventral y dorsal respectivamente. Del proceso transverso derecho se conserva sólo la parte proximal; ésta es dorsoventralmente plana y se desarrolla anteroposteriormente a lo largo del centro vertebral. Se infiere que estaría orientado perpendicular al eje longitudinal de la vértebra. 

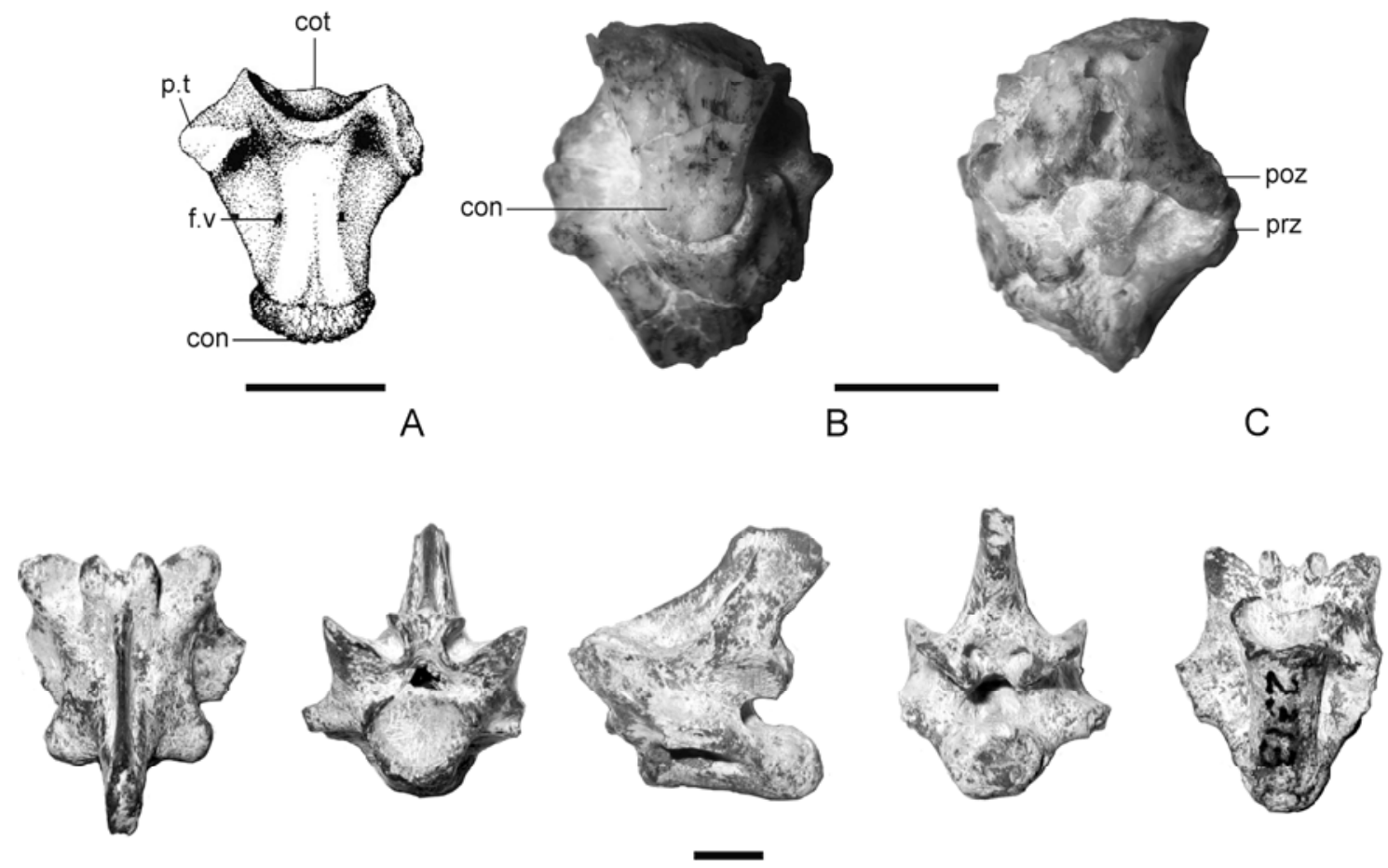

D

E

$\mathrm{F}$

G

$\mathrm{H}$
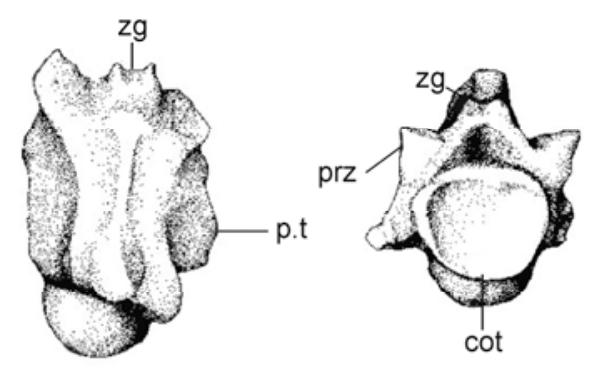

I
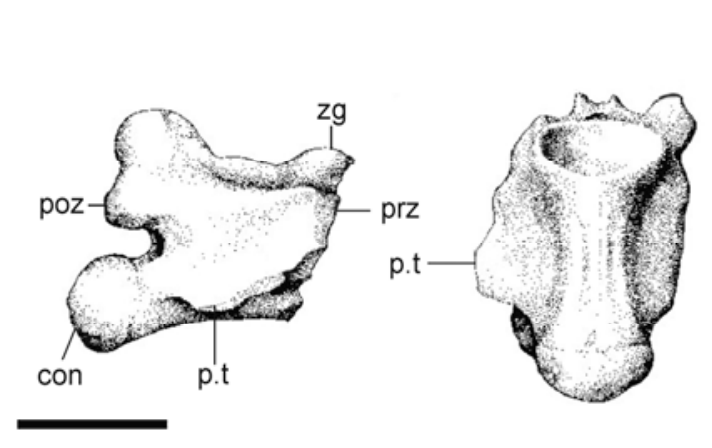

K

Figura 40. Elementos vertebrales de Tupinambis sp. de la Formación Cerro Azul, provincia de La Pampa. A, vértebra dorsal GHUNLPam 19612/4 en vista ventral; B-C, vértebras dorsales articuladas GHUNLPam 19874/42 en vista (B) ventral y (C) dorsal; D-H, vértebra caudal anterior GHUNLPam 2313 en vistas dorsal (D), frontal (E), lateral (f), posterior (G) y ventral (H); I-L vértebra caudal GHUNLPam 19865/30 en vistas dorsal (I), frontal (J), lateral (K) y ventral (L). Abreviaturas: cot, cótilo; con, cóndilo; f.v, foramen ventral; poz, postzigapófisis; prz, prezigapófisis; p.t, proceso transverso; $\mathrm{zg}$, zigósfeno. Escala = $5 \mathrm{~mm}$.

Comentarios taxonómicos. Albino et al. (2006) asignan la mayoría de estos restos (excepto GHUNLPam 2313 y GHUNLPam 19874/42 que no estaban disponibles entonces) al género Tupinambis. Dicha asignación se basó en una combinación de caracteres presentes en el conjunto de los fósiles, principalmente de los restos craneales. Los alvéolos de reemplazo subcirculares y profundos (GHUNLPam: 14283, 19608, 19610, 19854, 19856, 19914, 21669) así como el esplenial hipertrofiado, 
extendido anteriormente (GHUNLPam: 2340, 19856, 19914), son atributos que caracterizan al clado de los Borioteiioidea-Teiioidea (Nydam et al., 2007; Cap. III). La implantación pleurodonte de los Gymnophthalmidae (López y Cabrera, 1995; Bell et al., 2002; Tarazona et al., 2008; obs. pers.), así como la reversión de los caracteres mencionados permite la diferenciación de estos fósiles respecto a dicha familia. El maxilar GHUNLPam 14284 (Fig. 39 A), aunque en mal estado, sugiere que, como en los Tupinambinae, hay ausencia del soporte narial anterior y de un marcado soporte narial posterior, a diferencia de los "cnemidoforinos" y Teius, en los cuales estas estructuras sí están presentes ([C16], [C17]). Entre los Tupinambinae, la implantación subpleurodonte con cemento que disimula los septos interdentales, aunque no totalmente, es característica de Tupinambis y Crocodilurus (Cap. III). Los dientes posteriores romos de sección transversal circular con una protuberancia central, una fina cresta mesodistal en vista oclusal y un esmalte nítidamente estriado (Fig. 39 D) son caracteres presentes sólo en Tupinambis (Cap. III). En su conjunto, se observa que los elementos anteriores de maxilares y dentarios son portadores de dientes unicuspidados, mientras que los elementos posteriores tienen dientes romos. Este patrón de distribución presenta mayor afinidad con el género Tupinambis, y dentro de él, con las especies T. duseni, T. merianae, T. rufescens y T. teguixin (Cap. III).

Las vértebras son asignadas a Tupinambis por no observarse ninguna diferencia respecto de las de este género, recordando la ausencia de caracteres vertebrales diagnósticos (Cap. III). La cresta sagital de las vértebras dorsales fósiles GHUNLPam 19612/4 y GHUNLPam 19874/42, son débilmente marcadas, asemejándose a la de los Tupinambinae (Cap. III), lo cual es coherente con la asignación a Tupinambis. Las vértebras caudales GHUNLPam 2313 y GHUNLPam 19865/30 son morfológicamente similares y corresponden a la región proximal por la ausencia de planos de autotomía. La asignación genérica de las vértebras caudales es menos categórica ya que estas vértebras no presentan mayores diferencias entre los distintos géneros de Teiidae. Sin embargo, el tamaño, en particular de la vértebra GHUNLPam 2313, que incluso supera las dimensiones de las mayores vértebras caudales de especímenes de $T$. merianae con $\mathrm{LHC}=315 \mathrm{~mm}$, favorece la inclusión en Tupinambis.

Al comparar estos fósiles con los asignados a Tupinambis de las formaciones Sarmiento y Santa Cruz descriptos en las secciones previas, se observa que las dimensiones de la sección transversal de los dientes molariformes son mayores que 
las dimensiones registradas en el material del Santacrucense, que, a su vez, es mayor a la observada en los restos del Colhuehuapense. Sin embargo, tanto el material del Santacrucense como el del Huayqueriense se encuentran dentro de la variación observada en T. merianae, aunque, en el caso de los del Santacrucense, están cerca de los valores mínimos. El tamaño de la vértebra caudal GHUNLPam 2313 también sugiere que el material del Huayqueriense se encuentra dentro de los tamaños posibles para esta especie.

\section{TEIIDAE Gray 1827 \\ “CNEMIDOPHORINAE"}

Género y especie indeterminado

(Fig. 41 A-C)

Material referido: GHUNLPam 21745, dentario derecho incompleto.

Procedencia geográfica: Cerro a $27 \mathrm{~km}$ al este de Chacharramendi, provincia de La Pampa.

Procedencia estratigráfica: Formación Cerro Azul, Edad Mamífero Huayqueriense, Mioceno tardío.

Descripción. El fósil GHUNLPam 21745 corresponde al extremo anterior de un dentario derecho (Fig. 41). El dentario es poco profundo, labialmente liso y con cuatro forámenes mentales, el último a la altura del alvéolo X. Lingualmente se observa el estante subdental, que es plano-convexo y de desarrollo moderado, disminuyendo su desarrollo dorsoventral hacia el extremo posterior. Acompañando a este decrecimiento, se observa ventralmente la superficie de articulación del esplenial, la cual está bien desarrollada y llega anteriormente hasta la sexta posición dentaria. El canal de Meckel está medialmente abierto y se extiende anteriormente ventral a la sínfisis. Presenta una moderada restricción en su parte anterior, definida por la curvatura medial del dentario. El surco dental lleva la serie dentaria, que está delimitada lingualmente por un sulcus dentalis poco definido. Se conservan 11 alvéolos funcionales. El único diente completo es el III; del resto se conservan sólo las bases. Los dientes son de implantación subpleurodonte, con depositación de cemento sobre sus bases, pero sin disimular los septos interdentales. Las bases de los dientes están en estrecho contacto; de éstas, las seis anteriores presentan una ligera 
compresión mesodistal, mientras que las posteriores son de sección circular. El diente III es unicuspidado, recto y no conserva su extremo apical. Hay tres alvéolos de reemplazo en posición posterolingual a los dientes IV, VII y X. Estos alvéolos son subcirculares, profundos y no conservan dientes.
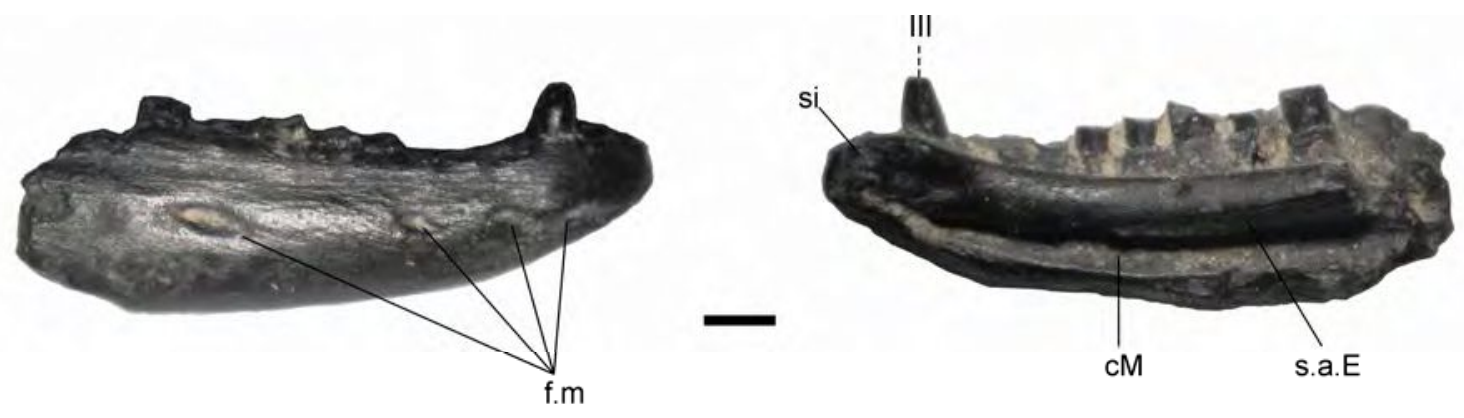

A

B

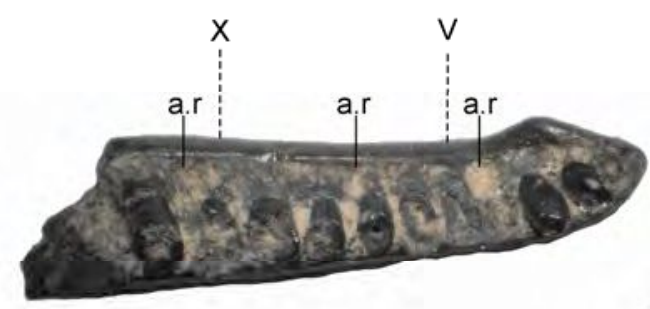

C

Figura 41. "Cnemidoforino" de la Formación Cerro Azul, Chacharramendi, provincia de La Pampa. A-C, GHUNLPam 21745 en vista labial (A), lingual (C) y oclusal (D). Abreviaturas: a.r, alvéolo de reemplazo; cM, canal de Meckel, f.m, foramen mental; s.a.E, superficie de articulación para el esplenial; si, sínfisis mandibular. Escala $=1 \mathrm{~mm}$.

Comentarios taxonómicos. Los alvéolos de reemplazo subcirculares y profundos, y la inferencia de un esplenial anteriormente desarrollado, permiten la inclusión del ejemplar fósil en el clado Borioteiioidea-Teiioidea (excepto Gymnophthalmidae) (Nydam et al., 2007; Cap. III). La implantación subpleurodonte también excluye a los Gymnophthalmidae (López y Cabrera, 1995; Bell et al., 2002; Tarazona et al., 2008; obs. pers.). Varios autores reconocen que los "cnemidoforinos", Teius y Dicrodon, (Teiinae sensu Presch, 1974a) se diferencian de los Tupinambinae (excepto Callopistes) por presentar el canal de Meckel anteriormente restringido (Denton y O'Neill, 1995; Nydam y Cifelli, 2002b; Nydam et al., 2007). En el material de referencia se observa que esta restricción no existe en ningún Tupinambinae (incluido Callopistes) ([C88]). En los “cnemidoforinos” y Teius, la restricción se observa por la 
extensión del estante subdental sobre la parte anterior del canal de Meckel, en un dentario relativamente bajo, reduciendo su espacio a la vez que impide un mayor avance anterior del esplenial. Esta condición es exactamente la que se observa en el fósil.

En el ejemplar fósil, el canal de Meckel se continúa anteriormente por debajo de la sínfisis, situación que también se observa en los "cnemidoforinos" y Teius, a diferencia de los Tupinambinae donde este canal termina en la sínfisis, sin prolongarse anteriormente ([C89]). La parte anterior del canal de Meckel del dentario fósil está delimitada ventralmente por la curvatura medial del dentario. Esta condición es compartida por la mayoría de los “cnemidoforinos" (la condición no es tan nítida en Kentropyx), mientras que Teius presenta el borde ventral del canal de Meckel libre (i.e. no hay una marcada curvatura medial del dentario). La condición en Dicrodon no pudo ser observada directamente, pero de la figura presentada por MacLean (1974) se estima que existiría una coincidencia con lo notado en Teius ([C141]).

Como se destacó en el Capítulo III, la escasa depositación de cemento basal que disimula muy débilmente los septos interdentales se observa solamente en el grupo informal de los "cnemidoforinos" (“Ameiva", Aspidoscelis, "Cnemidophorus" y Kentropyx), permitiendo la asignación del ejemplar GHUNLPam 21745 a este grupo y excluyéndolo de Teius y Dicrodon. No es posible realizar una asignación genérica; sin embargo, comparado con material disponible de especies actuales, el tamaño del dentario fósil es similar al de las especies de "Ameiva" y Kentropyx.

\section{Comentarios biogeográficos}

De las dos especies de Tupinambis que habitan actualmente en Argentina, $T$. rufescens se encuentra sólo en la provincia biogeográfica del Monte, alcanzando sus poblaciones más australes las provincias argentinas de Río Negro y La Pampa, mientras que T. merianae tiene una distribución más oriental, en ambientes subtropicales (véase Cap. VI). Tiranti y Ávila $(1994,1997)$ reconocen sólo a $T$. rufescens como integrante de la fauna actual de teidos tupinambinos de la provincia de La Pampa. Aunque otros autores también citan la presencia de T. merianae (Donadío, 1984b; Cei, 1993), esta aseveración sería errónea ya que no existen materiales de dicha especie en las colecciones de esta provincia (Tiranti y Ávila, 1994, 1997). De esta manera, la presencia de Tupinambis en el Huayqueriense de La Pampa es coincidente con su distribución presente. 
Por otro lado, el material reconocido en este trabajo como perteneciente a un "cnemidoforino" representa el primer registro del grupo para el Mioceno de América del Sur. Previamente, los registros más antiguos para estos teidos correspondían a varios hallazgos de "Cnemidophorus" sp. en los estados de Florida y Nebraska de EE.UU. (Estes, 1983a). Diferentes especies asignadas a este género han sido citadas desde el Mioceno de América del Norte (ver Estes, 1983a). Estas asignaciones deben tomarse con cautela ya que actualmente en América del Norte sólo se registra Aspidoscelis, género escindido de "Cnemidophorus" (Reeder et al., 2002). Además, las determinaciones de varios de estos fósiles se basan en sutiles diferencias de morfología dental, número de dientes y tamaño de los elementos óseos que ameritarían su revisión. Los restantes "cnemidoforinos" incluyen al género "Ameiva", registrado en el Pleistoceno de Brasil y diferentes islas del Caribe, y a Kentropyx, sin registro fósil (Estes, 1983a).

Actualmente, en la provincia de La Pampa se encuentran sólo dos géneros de Teiidae no Tupinambinae, Teius y “Cnemidophorus", representados por las especies T. oculatus, T. teyou (una población aislada) y “C C' longicaudus (Cei, 1986, 1993). Esta última especie es característica de la fauna de Monte, mientras que las restantes especies de este género se distribuyen principalmente en el Chaco y en menor medida en el Espinal y en la región Pampeana (Cei, 1993). Los restantes géneros de "cnemidoforinos" con presencia en Argentina ("Ameiva" y Kentropyx) se distribuyen al norte del paralelo $30^{\circ} \mathrm{S}$ (aprox.), “A." ameiva y $K$. viridistriga en la provincia biogeográfica de Chaco y K. lagartija en la provincia biogeográfica Paranaense (Cei, 1986, 1993; Tedesco y Cei, 1997). Por todo lo expuesto, es destacable que la asociación faunística de lagartos que se observa en el Huayqueriense de La Pampa es similar a la que actualmente existe en el norte de Argentina, incluyendo el norte del Chaco y la provincia biogeográfica Paranaense. Esta asociación se caracteriza por la presencia de Tupinambis y de un "cnemidoforino" que probablemente sea "Ameiva" o Kentropyx. Lamentablemente, no es posible diferenciar a nivel específico los fósiles ya que aportarían una mayor definición ambiental. Montalvo y Verzi (2004) consideran que la presencia de Echimyidae (Rodentia) y Protabrocoma (Rodentia, Abrocomidae) en la mayoría de las asociaciones faunísticas de la Fm. Cerro Azul en la provincia de La Pampa sugieren un ambiente similar al de la provincia biogeográfica del Chaco. De esta manera, la asociación de lagartos del Huayqueriense 
es perfectamente compatible con las inferencias realizadas a partir de la fauna mamaliana.

\subsubsection{Formación La Playa}

\section{Geología}

Olsacher (1960) en su descripción de la geología de la provincia de Córdoba describe la Fm. La Playa, que aflora con claridad en dos áreas del departamento de Minas en el noroeste de la provincia (Fig. 42): La Playa y Mesa La Argentina. Esta Formación corresponde a travertinos, de composición mayoritariamente cálcica, de origen hidrotermal, ligados a eventos de vulcanismo del Cenozoico (Bondesio y Pascual, 1981). Los travertinos de Fm. La Playa comprendían una formación litológica unitaria que ha sido erosionada y se presenta en bancos aislados (Vullo, 1951). Este banco calcáreo se apoya en forma discordante sobre el basamento metamórfico (Olsacher, 1960).
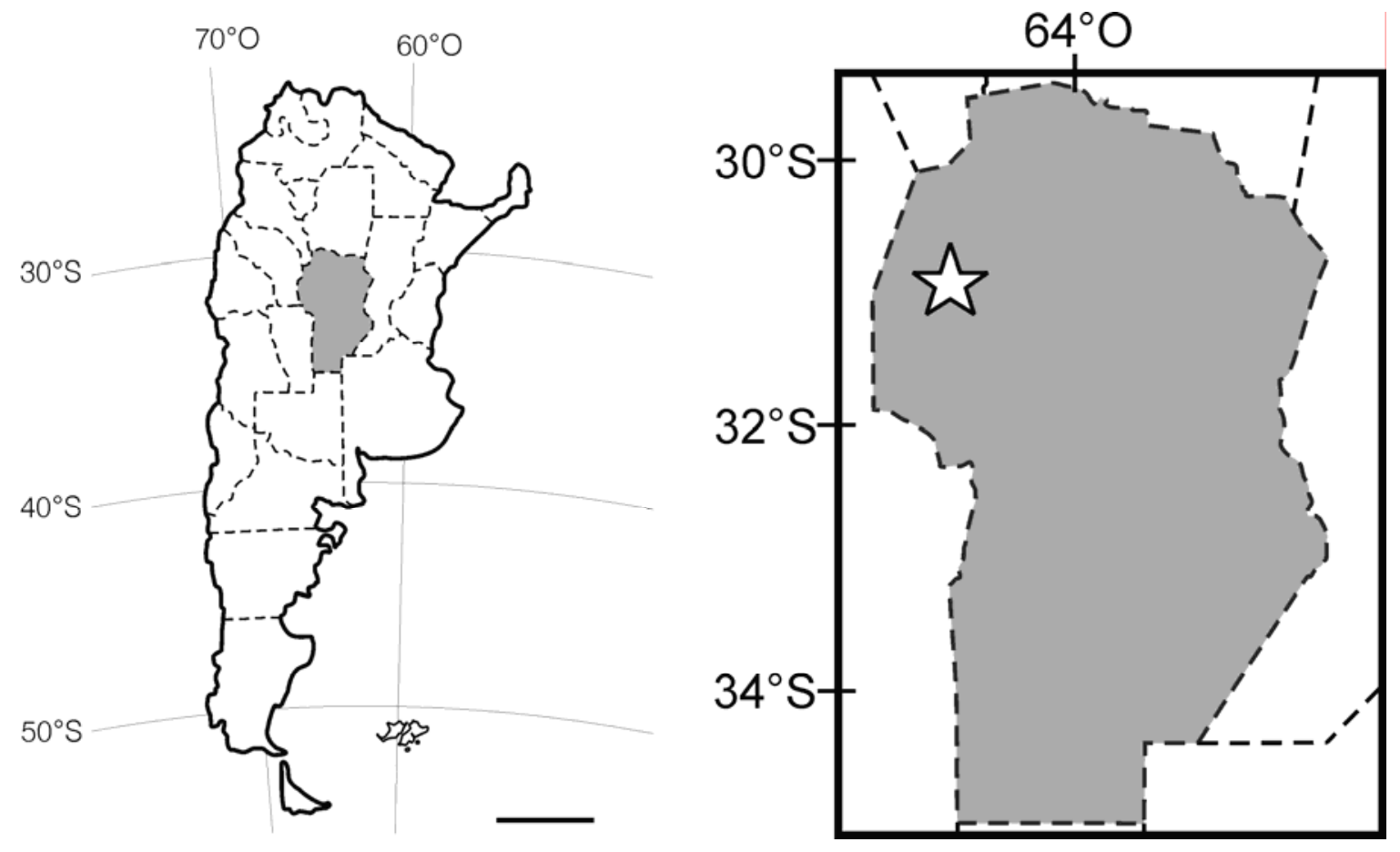

Figura 42. Mapa de ubicación de la Cantera de Tulcame, La Playa, departamento de Minas provincia de Córdoba (Kraglievich y Reig, 1945). Escala $=500 \mathrm{~km}$. 
Gordillo y Lencinas (1879) correlacionan estos depósitos con los similares del Valle El Pantano de la provincia de San Luis. El análisis de la fauna de estos dos afloramientos ratifica su contemporaneidad (Bondesio y Pascual, 1981).

Kraglievich y Reig (1945) citan varios elementos de la fauna de vertebrados de esta Formación a la que denominan Fm. "Las Playas". La denominación de la Formación dada por Kraglievich y Reig (1945) y seguida por otros autores (Bondesio, 1978; Bondesio y Pascual, 1981; Donadío, 1984b) estaría en error dado que la localidad tipo de la Fm. La Playa (Olsacher, 1960) sería la localidad homónima del departamento de Minas (Córdoba). A su vez La ubicación geográfica del sitio es dudosa, Kraglievich y Reig (1945) lo denominan Cantera Tuclame y lo ubican en el departamento de Minas, al igual que Bondesio y Pascual (1981), mientras que Donadío (1984b) lo ubica en el departamento de Cruz del Eje, en cercanías de la localidad de Tuclame. Según información de la Secretaría de Minería de la Nación (Programa de Asistencia Técnica para el Desarrollo del Sector Minero - Inventario de Recursos Naturales) el sitio de donde provendrían estos fósiles corresponde a las coordenadas $31^{\circ} 00^{\prime} 47,6^{\prime \prime} \mathrm{S}$ y $65^{\circ} 21^{\prime} 31^{\prime \prime} \mathrm{O}$, en el departamento de Minas (Córdoba). En este sitio los niveles fosilíferos se ubican a un metro por debajo del techo de esta unidad a 941 m.s.n.m. Entre el material de vertebrados de esta procedencia se determinó la presencia de Cyonasua groeberi Kraglievich y Reig 1954 (Carnívora, Procyonidae) y Cardiatherium sp. (Rodentia, Hydrochoeridae) (Bondesio, 1978; Bondesio y Pascual, 1981). La mayoría de los taxones de este sitio representan a la Edad Mamífero Huayqueriense, y algunos pocos a la Edad Mamífero

Montehermosense, por lo que la edad de los travertinos estaría comprendida entre el Mioceno tardío y el Plioceno temprano (9 a 5 Ma.) (Bondesio y Pascual, 1981; Cione et al., 2007).

\section{Antecedentes}

Kraglievich y Reig (1954) y Donadío (1983b) citan la presencia de Tupinambis sp. en el sitio Cantera de Tuclame. Donadío (1984b) vuelve a citar a este fósil pero como T. merianae (presentado como T. teguixin), aunque sin describir el material ni argumentar su asignación. Albino et al. (2006) consideran que la asignación específica no puede realizarse debido al tipo de material preservado (maxilar con dientes). A pesar de haber sido citado varias veces en la literatura, la siguiente es la primera descripción formal de estos restos. 
Sistemática

\author{
SQUAMATA Oppel 1811 \\ SCLEROGLOSSA Estes, de Queiroz y Gauthier 1988 \\ SCINCOMORPHA Camp 1923 \\ TEIIOIDEA Estes, de Queiroz y Gauthier 1988 \\ TEIIDAE Gray 1827 \\ TUPINAMBINAE Presch 1974a \\ Tupinambis Daudin, 1802 \\ Tupinambis sp. \\ (Fig. 43 A-C)
}

Material referido: MMP 637-S, maxilar derecho completo.

Procedencia estratigráfica: Formación La Playa, un metro por debajo del techo, Huayqueriense - Montehermosense, Mioceno tardío - Plioceno temprano.

Procedencia geográfica: Cantera de Tuclame ( $31^{\circ} 00^{\prime} 47,6^{\prime \prime} \mathrm{S}$ y $\left.65^{\circ} 21^{\prime} 31^{\prime \prime}\right)$,

Departamento de Minas, provincia de Córdoba.

Descripción. El fósil MMP 637-S corresponde a un maxilar derecho incluido en un bloque de sedimento muy consolidado de forma tal que está expuesta sólo la cara labial (Fig. 43). El maxilar se conserva completo pero mal preservado, principalmente la parte ventrolabial. Labialmente es liso y conserva seis forámenes labiales, el último a la altura del diente (g). La lámina facial es alta, su extremo distal presenta un importante desarrollo anteroposterior. La fenestra exonarina es cóncava, posteriormente alta. Ventralmente se conserva la serie dentaria y se observa el sulcus dentalis pero no se puede apreciar la implantación dentaria. En la parte anterior de la serie dentaria y labialmente expuesta, se conservan las bases de dos dientes (a y b), que se infieren cilíndricas (Fig. 43 A). A estas posiciones dentarias le sigue un espacio que no conserva dientes. Luego se preservan las bases de dos dientes más (c y d) de sección circular y algo mayores que las de los dientes (a) y (b). El diente (e) presenta una base robusta y de sección circular; apicalmente está pobremente conservado, pero se infiere cónico. El espacio de un diente, no conservado, separa al diente (e) de los últimos cuatro dientes conservados. Estos últimos son romos, robustos y de sección circular, ligeramente oval. El primero de estos dientes (f) es de dimensiones algo 
menores y conserva su extremo apical. El diente (i) no conserva su cara labial. Los dientes (g) y (h) se conservan completos. Las bases de los dientes son ligeramente más robustas que los ápices, en la zona de transición se observa una débil y suave depresión horizontal, que se nota mejor en vista labial. En vista oclusal estos dientes presentan una cresta mesodistal que en su parte media se encuentra con una protuberancia central. El esmalte de los dientes posee finas estrías que convergen apicalmente sobre la protuberancia central.
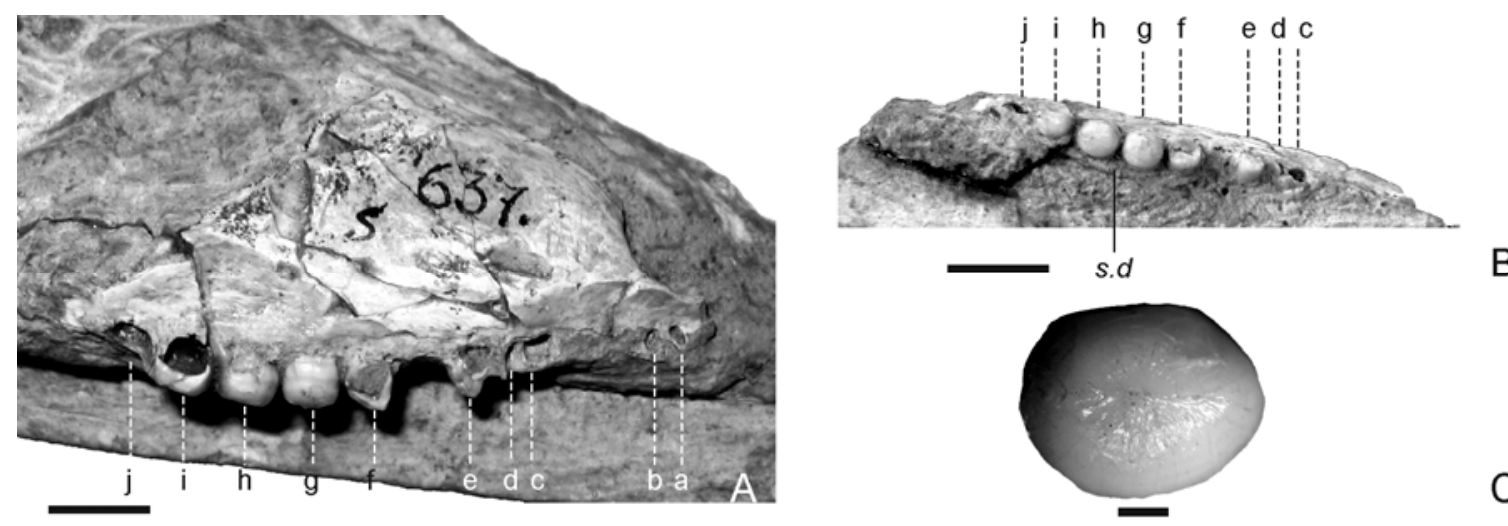

Figura 43. Tupinambis sp. (MMP 637-S) de la Fm. La Playa, departamento Cruz del Eje, provincia de Córdoba. A, maxilar en vista labial; B, maxilar en vista oclusal; C, magnificación del diente (h). Abreviaturas: s.1, sulcus dentalis. Escala 10 mm en A y B, 1 mm en C.

Comentarios taxonómicos. Donadío (1984b) no explicita sobre qué base asigna el material de la Fm. La Playa en Cantera de Tuclame a Tupinambis merianae (citado como T. teguixin). Aunque el material fósil no presenta mayores caracteres diagnósticos, su tamaño y dientes posteriores romos y molariformes lo asemejan a Tupinambis. Los dientes molariformes permiten excluir a Callopistes y Crocodilurus y difieren de los de Dracaena y Paradracaena que presentan un desarrollo aún mayor (Cap. III).

Aunque la mayor semejanza del ejemplar es con la especie T. merianae, por el tamaño y la sección transversal circular de los dientes, lo reducido de la muestras de especímenes actuales de otras especies del género impiden una determinación específica segura, contra Donadío (1983b, 1984b).

La presencia de dientes romos precedidos de dientes de base cilíndrica, posiblemente unicuspidados, es el patrón observado en individuos de mayor talla/edad de T. merianae (Cap. III), aunque los dientes romos ya aparecen en ejemplares que 
superan $\operatorname{LSDd}=41,69 \mathrm{~mm}$ y LSDm $=37,9 \mathrm{~mm}$. La serie dentaria del fósil MMP 637$\mathrm{S}$ tiene un valor de $\mathrm{LSDm}=44,26 \mathrm{~mm}$; por lo tanto, es coherente con lo observado en especímenes grandes/adultos de T. merianae, por lo que se infiere una edad similar para este ejemplar.

\section{Comentarios biogeográficos}

Actualmente, en la provincia de Córdoba, están presentes las dos especies de Tupinambis que se distribuyen en territorio argentino (Cei, 1986, 1993), con $T$. rufescens al noroeste y T. merianae al sureste, y zonas de simpatría en la parte norte de la provincia. Esta distribución refleja las diferencias ecológicas de las especies, ya que $T$. rufescens se encuentra en ambientes más áridos que T. merianae (Donadío, 1984b, Cap. VI). En el presente, en el departamento de Minas, donde se encuentra emplazado el sitio fosilífero, se distribuye únicamente T. rufescens. Esta zona está incluida en el el distrito Serrano del Dominio Chaqueño, caracterizado por bosques xerófilos alternando con gramíneas duras, bajo un clima cálido (Cabrera, 1976). Donadío (1984b), basándose en la asignación del ejemplar fósil de la Fm La Playa en Tuclane a T. merianae, indica condiciones más húmedas que las actuales, ya que esta especie es más mesófila que la que actualmente habita en el sitio. El origen hidrotermal de los sedimentos portadores del material fósil, y la presencia de un prociónido y un hidrocérido, que son mamíferos asociados a ambientes húmedos, indica el desarrollo de un ambiente ácueo en este sitio durante el Mioceno tardío Plioceno temprano (Bondesio y Pascual, 1981). Esta caracterización paleoambiental contrasta con el ambiente actual y es compatible con la presencia de T. merianae indicada por Donadío (1984b). Sin embargo, la imposibilidad de determinar este fósil a nivel específico por sus caracteres morfológicos (contra Donadío, 1984b), no permite corroborar estas inferencias.

\section{Comentarios sobre los lagartos del Huayqueriense}

El Huayqueriense representa un momento importante en el registro de lagartos fósiles sudamericanos. Los teidos tupinambinos, ya conocidos desde el Eoceno, aparecen representados por el género Tupinambis durante todo el Mioceno y con una amplia distribución. Los Teiidae no Tupinambinae, previamente citados para el Itaboraiense de Brasil por Estes (1983a) no fueron reconocido por Carvalho (2001) 
entre el material de lagartos de dicha edad, siendo el fósil del Huayqueriense de La Pampa (Fm. Cerro Azul) la primer aparición confirmada en América del Sur.

Durante el Huayqueriense, el género Tupinambis está bien representado geográficamente en el centro del país. Se lo registra en varias localidades de la provincia de La Pampa (ver Fm. Cerro Azul), en Entre Ríos (Fm. Ituzaingó, Ambrosetti, 1890) y en la provincia de Córdoba (ver Fm. La Playa). En esta Tesis se describieron los materiales correspondientes a las provincias de La Pampa y Córdoba; sin embargo, los que proceden de la Fm. Ituzaingó en Entre Ríos se encuentran perdidos (Cap. I). La fauna de vertebrados de la Fm. Ituzaingó es actualmente considerada de edad Huayqueriense, aunque el material de lagartos procedente de estos niveles en las barrancas del río Paraná fuera mencionado como del Plioceno superior por Estes (1983a). Ambrosetti (1890) describe, para esta Formación, un nuevo género de lagarto nominado Propodinema, con dos especies, Propodinema paranensis Scalabrini 1890 y Propodinema oligocena Ambrosetti 1890, ambas descriptas a partir de la dentición de hemimandíbulas parciales. Este género fue sinonimizado con Tupinambis por Estes (1983a). Si bien el material de la Fm. Ituzaingó se encuentra perdido, la detallada descripción de la dentición realizada por Ambrosetti (1890) permite asumir que ambas especies presentan el mismo patrón de distribución de tipos morfológicos dentarios observados en T. merianae de talla grande (Cap. III). Propodinema paranensis posee 17 dientes, un valor dentro del rango de variación de $T$. merianae, mientras que $P$. oligocenica posee 13 dientes, valor mínimo registrado en dicha especie actual (Cap. III). Los primeros siete dientes de $P$. paranensis son unicuspidados del tipo u2 (véase Cap. III). El séptimo diente, más robusto que los anteriores y “caniniforme” según Ambrosetti (1980), sería del tipo U1. Ambrosetti (1890) reconoce dos tipos de dientes robustos. Los más anteriores en la serie dentaria presentan "pequeñas escotaduras" distales en posición mesial y distal que son interpretadas como los surcos intercuspidales que diferencian las pequeñas cúspides débilmente desarrolladas; estos dientes corresponderían al tipo T2. Los dientes robustos posteriores son romos, bajos, con una marcada protuberancia oclusal y esmalte estriado, correspondiendo al tipo morfológico R. Propodinema oligocenica presenta los mismos tipos morfológicos y el mismo patrón, variando solamente en el número de dientes por tipo morfológico. Comparando con la serie ontogenética de T. merianae, estos ejemplares corresponderían a individuos jóvenes, ya que presentarían dientes robustos tricuspidados (aquellos con "escotaduras") y 
romos asociados, y no únicamente romos como se observa en los individuos de $T$. merianae de mayor talla. De esta manera, se acepta la sinonimia de Propodinema con Tupinambis que ya fuera propuesta por Estes (1983a).

\subsubsection{Formación Monte Hermoso}

\section{Geología}

La localidad fosilífera conocida como Farola Monte Hermoso se encuentra ubicada sobre la costa atlántica bonaerense, en el partido de Coronel Rosales, a unos $17 \mathrm{~km}$ al Oeste del balneario Pehuén-Co y $37 \mathrm{~km}$ de la actual ciudad de Monte Hermoso (Fig. 44). El topónimo Monte Hermoso fue utilizado durante mucho tiempo para denominar a toda la franja costera desde las proximidades de Pehuén-Co hasta Farola Monte Hermoso, incluyendo yacimientos de distintas edades (Cione y Tonni, 1995a). Estos afloramientos han recibido diferentes denominaciones en la literatura paleontológica: "Monte Hermoso", "Yacimiento de Monte Hermoso", "Barrancas de Monte Hermoso", entre otros (ver Albino et al., 2009). Farola Monte Hermoso (38 $\left.58^{\prime} \mathrm{S}, 61^{\circ} 41^{\prime} \mathrm{O}\right)$ constituye la localidad tipo de la Formación Monte Hermoso (Zavala, 1993), de la Edad Mamífero Montehermosense (Pascual et al., 1965) y de las biozonas de Trigodon gaudryi (base) y Neocavia depressidens (techo) (Cione y Tonni, 1995a, b, c, 1996). La importancia paleontológica del área fue reconocida tempranamente (Darwin, 1846; Bravard, 1857; Ameghino, 1887) ya que de este sitio procede un importante número de fósiles, entre los que se encuentran todos aquellos asignados al Montehermosense s.l. (i.e. Montehermosense y Chapadmalalense inferior) recolectados previamente al trabajo sistemático de Parodi y Kraglievich, (Cione y Tonni, 1995a). 


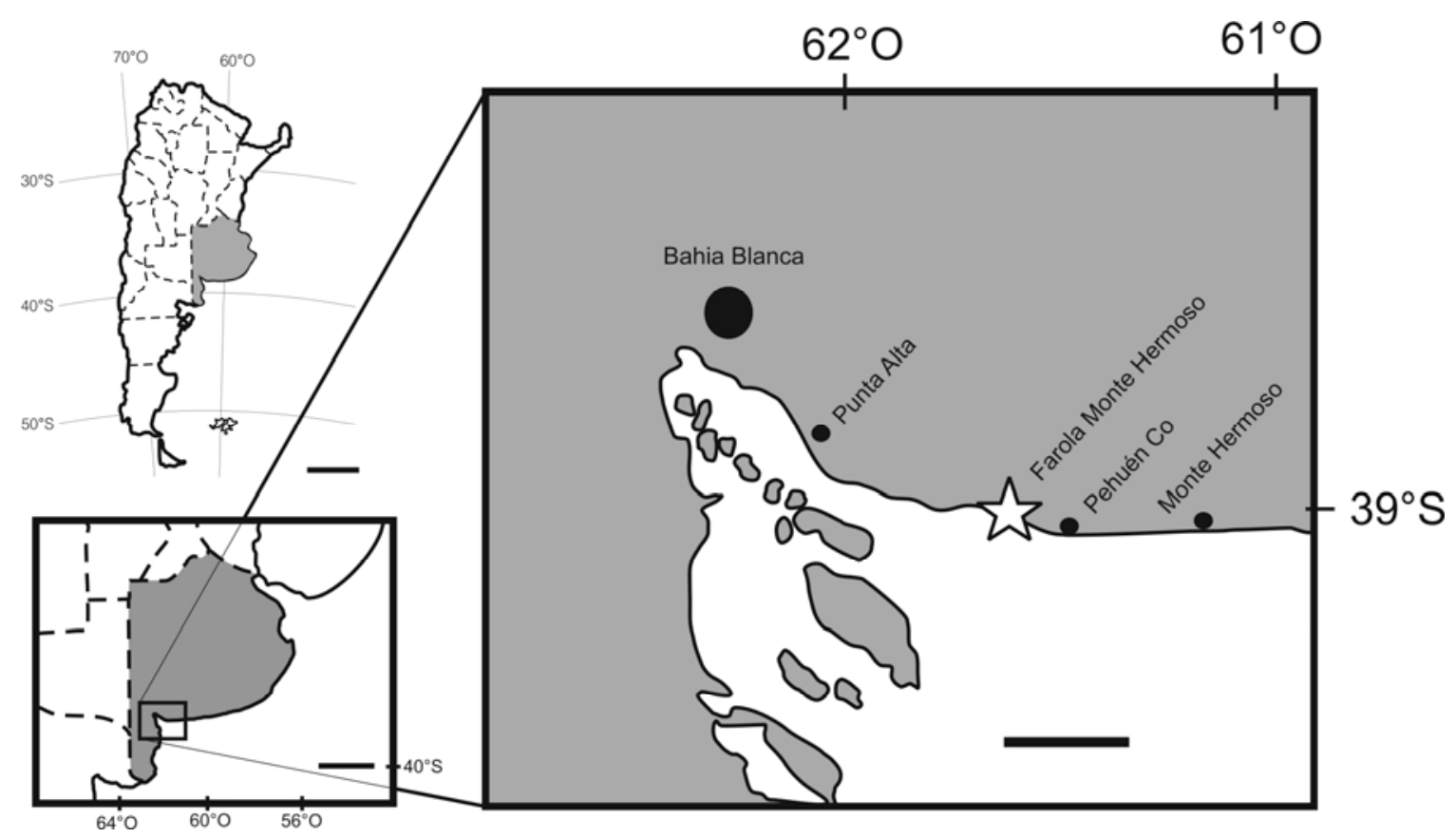

Figura 44. Mapa de ubicación de Farola Monte Hermoso (38 $\left.58^{\prime} \mathrm{S}, 61^{\circ} 41^{\prime} \mathrm{O}\right)$ provincia de Buenos Aires. Escala $=500 \mathrm{~km}, 200 \mathrm{~km}$ y $20 \mathrm{~km}$.

La base de la Fm. Monte Hermoso (Zabala, 1993) (Fig. 45) se corresponde estratigráficamente con la asociación de facies F1 de Zavala y Navarro (1993) y representa una llanura de inundación, dentro de un sistema fluvial de alta sinuosidad y elevada carga en suspensión (Albino et al., 2009). Este nivel se corresponde con la parte inferior del "Piso Hermósico" de Ameghino (1889), el "Hermosense típico" de Vignati (1925) y Bonaparte (1960), la Formación I de Leanza (1948), la Unidad Litoestratigráfica I de Fidalgo y Tonni (1982), y también con la Biozona de Trigodon gaudryi (base bioestratigráfica del Piso/Edad Montehermosense) de Cione y Tonni (1995a, b, c, 1996, 2005). La base de la Fm. Monte Hermoso no coincide con la base del Montehermosense ya que está última no aflora en el área tipo (Cione y Tonni, 2005). Los niveles medios de la Formación se corresponden con la facies St de Zavala y Navarro (1993), la que representa la carga tractiva de un curso fluvial, mientras que la parte superior pertenece a la facies Fcf de Zavala y Navarro (1993), que representa un depósito de acreción lateral (Albino et al., 2009). Las facies St y Fcf se corresponden con el "Piso Chapadmalense" de Vignati (1925), la Formación III de Leanza (1948), el "Miembro de Limolitas Claras" y "Miembro de Limolitas Estratificadas” de Bonaparte (1960), la Unidad Litoestratigráfica II de Fidalgo y 
Tonni (1982), y la Biozona de Neocavia depressidens (base bioestratigráfica del Piso/Edad Chapadmalalense inferior) de Cione y Tonni (1995a, b, c, 1996, 2005).

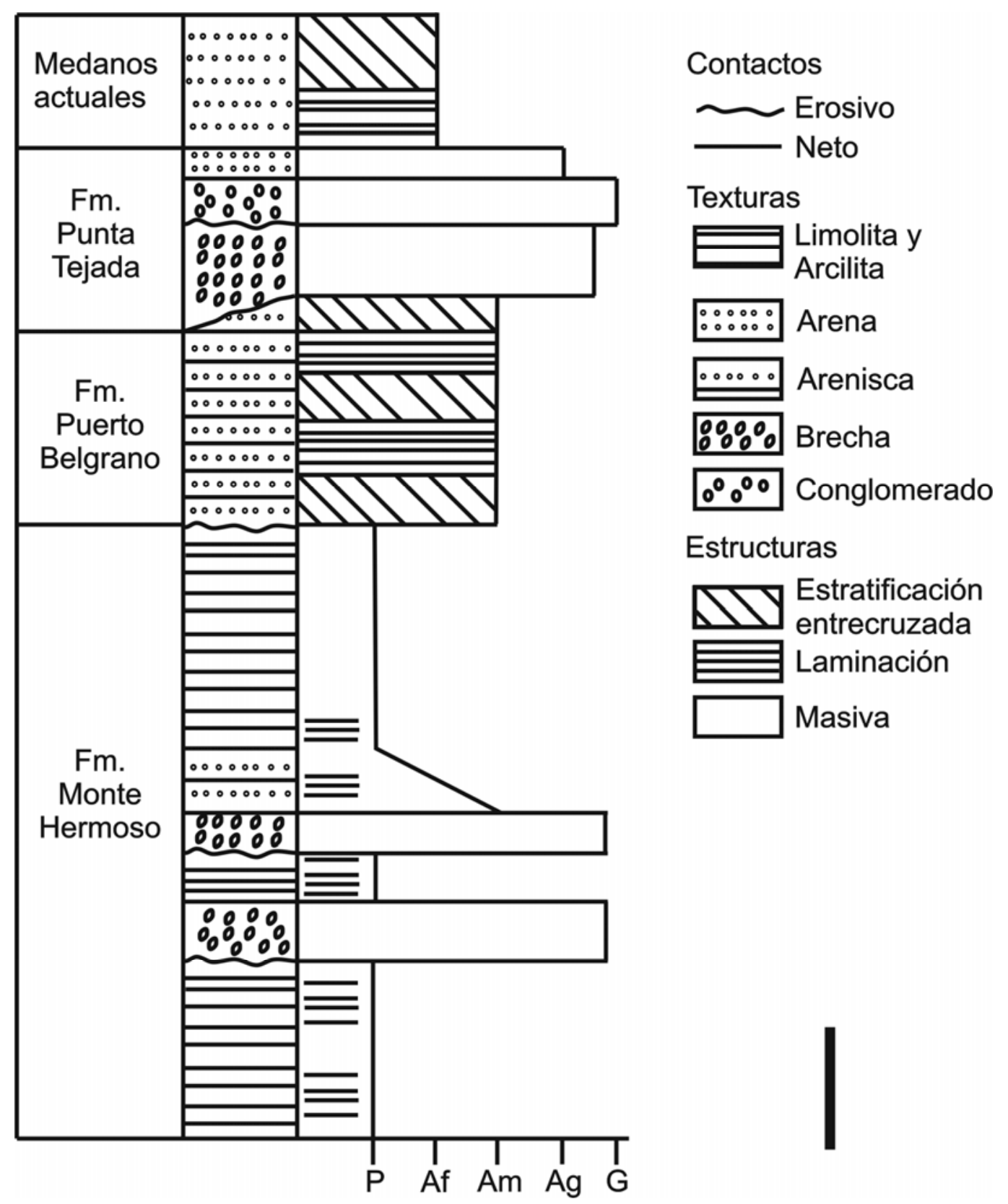

Figura 45. Columna estratigráfica del sitio Farola Monte Hermoso ( $\left.38^{\circ} 58^{\prime} \mathrm{S}, 61^{\circ} 41^{\prime} \mathrm{O}\right)$ provincia de Buenos Aires (tomado de Albino et al., 2009). Escala $=1 \mathrm{~m}$.

Ameghino (1887) definió el "Piso Hermósico", asignando la fauna de este área al Mioceno superior, Posteriormente, Rovereto (1914) lista y describe la fauna del Montehermosense s.l. de Farola Monte Hermoso. Pascual et al. (1965) y Pascual y Odreman Rivas (1973) sostienen que el Montehermosense y el Chapadmalalense son 
faunísticamente indistinguibles y no merecen ser reconocidos independientemente. Cione y Tonni (1995b) consideran que las conclusiones de los autores precedentes se deben a que incluyen en su análisis faunístico fósiles provenientes de la localidad típica sin reconocer que los niveles superiores (biozona Neocavia depressidens) son considerados por otros autores como Chapadmalalense. Este último criterio es seguido en este trabajo.

\section{Antecedentes}

La lista faunística del Montehermosense es extensa (Rovereto, 1914; Pascual et al., 1965; Pascual y Odreman Rivas, 1973; Marshall et al., 1983; Cione y Tonni, 1995b). La herpetofauna del Montehermosense s.l. presenta anfibios del género Ceratophrys (Ameghino, 1899; Rovereto, 1914; Cione y Báez 2007), el Testudinidae Geochelone gailardi (Gasparini et al., 1986) y diferentes escamosos. Entre las serpientes se reconoce un Boinae indeterminado (Albino, 1992, 1996a; Albino y Carlini, 2008), un Colubridae indeterminado (Albino, 1989; 1996a) y un Viperidae aff Bothrops (Albino, 1989; Albino y Montalvo, 2006), mientras que los lagartos están representados por la Familia Teiidae (Rovereto, 1914; Chani, 1976; Albino et al., 2009). Entre estos últimos, Rovereto (1914) describió cuatro especies extintas del género Tupinambis (T. preteguixin, $T$. prerufescens, $T$. brevirostris y $T$. multidentatus), mientras que Chani (1976) dio a conocer una especie extinta de Callopistes que nominó C. bicuspidatus. Albino et al. (2009) describieron materiales de teidos recientemente colectados y los asignaron a Tupinambis sp. La procedencia estratigráfica de aquellos restos descriptos por Rovereto (1914) es incierta y se los considera de edad Montehermosense s.l.. De niveles correspondientes al "Hermosense típico" (sensu Bonaparte, 1960) y, por lo tanto, de edad Montehermosense s. s., provienen los elementos correspondientes a Callopistes bicuspidatus, mientras que los materiales asignados a Tupinambis por Albino et al. (2009) proceden de niveles de la columna estratigráfica de la Fm. Monte Hermoso que incluyen el Montehermosense s.s. y el Chapadmalalense inferior.

Rovereto (1914) describió muy escuetamente las cuatro especies extintas de Tupinambis. Este autor basa las diagnosis de estas especies en mediciones y conteos dentarios que compara con datos de las dos especies del género que habitan actualmente en territorio argentino (T. merianae -mencionada como T. teguixin- y $T$. rufescens). Varios autores han planteado que las especies extintas descriptas por 
Rovereto (1914) no tendrían validez (Reig, 1958; Báez y Gasparini, 1977, 1979; Donadío, 1978, 1983b; Estes, 1983a). En particular, Estes (1983a) sinonimiza todas estas especies con T. preteguixin; ya que considera que T. brevirostris fue fundada tan sólo sobre la base de un maxilar roto y los dos taxones restantes presentan caracteres atribuibles a una variación individual u ontogenética. No obstante, dicho autor sugiere que podrían adjudicarse a la especie actual T. merianae (citada como T. teguixin), como lo asumen Donadío (1983b) y Albino (1996a).

En esta sección se redescriben y analizan los materiales de la familia Teiidae dados a conocer por Rovereto (1914) y Chani (1976), y se describen materiales inéditos de la misma procedencia.

Con el fin de analizar y comparar detalladamente los taxones propuestos por Rovereto (1914), la sistemática y descripción se presenta considerando cada uno de ellos en forma particular.

\section{Sistemática}

Reevaluación sistemática de los taxones descriptos previamente por Rovereto (1914)

SQUAMATA Oppel 1811

SCLEROGLOSSA Estes, de Queiroz y Gauthier 1988

SCINCOMORPHA Camp 1923

TEIIOIDEA Estes, de Queiroz y Gauthier 1988

TEIIDAE Gray 1827

TUPINAMBINAE Presch, 1974a

Tupinambis Daudin, 1802

Tupinambis $\mathrm{sp}$

(“T. preteguixin” juvenil, Rovereto, 1914)

(Fig. 46, 47, 48)

Material referido: MACN Pv 14310. Incluye varios elementos aislados y articulados, que están catalogados bajo el mismo número. Estos elementos representan como mínimo a cuatro individuos. Rovereto (1914) describió parte de estos restos como individuos juveniles de la especie “T. preteguixin” sobre la base de algunos elementos de este conjunto: dos cráneos parcialmente completos (MACN Pv 14310-1 
y MACN Pv 14310-2); hemimandíbula izquierda incompleta (MACN Pv 14310-3); un conjunto de vértebras articuladas (MACN Pv 14310-8) y el carpo derecho incompleto (MACN Pv 14310). Los restantes huesos no fueron descriptos por este autor. Los elementos referidos son: nasal, maxilar, yugal, prefrontal, postfrontal y postorbital, todos del lado izquierdo, premaxilar y frontal, todos articulados (MACN Pv 14310-1); premaxilar, maxilares, nasales fragmentarios, vómeres, palatinos, yugal derecho incompleto y prefrontal derecho incompleto, todos articulados (MACN Pv 14310-2); dentario con dientes, esplenial, suprangular y angular izquierdos todos articulados (MACN Pv 14310-3); dentario con dientes y esplenial derechos incompletos articulados (MACN Pv 14310-4); dentario con dientes y esplenial izquierdos incompletos articulados (MACN Pv 14310-5); dentario con dientes y esplenial derechos incompletos articulados (MACN Pv 14310-6); cuadrado izquierdo incompleto (MACN Pv 14310-7); 10 vértebras dorsales articuladas, las 8 anteriores con sus respectivas costillas (MACN Pv 14310-8); carpo derecho (MACN Pv 143109); tres fragmentos indeterminados (MACN Pv 14310-misceláneas).

Procedencia geográfica: Farola Monte Hermoso (38 $\left.58^{\prime} \mathrm{S}, 61^{\circ} 41^{\prime} \mathrm{O}\right)$ (Cione y Tonni, 1995a: 54), provincia de Buenos Aires.

Procedencia estratigráfica: Formación Monte Hermoso (Zavala, 1993), Montehermosense s.l., Mioceno tardío - Plioceno temprano.

Re-descripción. La dentición en los elementos portadores de dientes descriptos en esta sección es de tipo subpleurodonte. Los dientes presentan depósitos abundantes de cemento sobre sus bases disimulando los septos interdentales (Cap. III).

El cráneo parcial MACN Pv 14310-1 se encuentra comprimido de tal forma que su cara derecha, que no se conserva, no sería visible (Fig. 46 A). El premaxilar presenta una constricción entre el proceso ascendente y los procesos maxilares. Labialmente, sobre el proceso maxilar, se observa una depresión, abierta anterior y posteriormente, que recibe al maxilar. Lingualmente la plataforma palatal está levemente desarrollada, con bordes rectos, que delimitan un espacio medial en forma de "V". El surco dental presenta siete alvéolos. Los dientes son basalmente cilíndricos y apicalmente espatulados; con la cara lingual cóncava y la labial convexa. El contorno apical varía según el número de débiles cúspides accesorias que presentan; ninguna en los unicuspidados y dos en los tricuspidados. El primer diente de la derecha falta, le sigue un diente unicuspidado y tres tricuspidados; la serie termina con dos dientes unicuspidados del lado izquierdo. Lingualmente, sobre los alvéolos 
funcionales de los anteúltimos dientes de cada lado, se observan alvéolos de reemplazo, circulares y excavados en el cemento.

El maxilar es labialmente liso, presenta seis forámenes labiales, el último de los cuales está a la altura del $\mathrm{X}$ diente. La rama labial del proceso premaxilar es cónica, robusta y curvada dorsalmente. Esta rama delimita el borde ventral de la fenestra exonarina; el borde posterior de la fenestra exonarina es vertical, levemente inclinado posteriormente. El proceso posterior se extiende posteriormente alcanzando el nivel medio de la órbita. El contorno de la lámina facial se preserva deficientemente, aunque se observan las bases de los procesos frontal y prefrontal. En vista ventral se advierte el surco dental, que porta la serie dentaria. Los dientes no ocupan todo el surco dental, dejando lingualmente un nítido sulcus dentalis. La serie dentaria se conserva completa con 13 alvéolos; faltando los dientes II, IV-VII y XI. Los dientes I y III son unicuspidados, apicalmente cónicos de punta punzante y distalmente dirigida. El VIII diente es más robusto y recto. El IX diente es unicuspidado robusto, distalmente romo. El X diente está colapsado en el alvéolo funcional, es un diente robusto, romo, de sección aparentemente circular. Los últimos dos dientes conservados son similares, pero más pequeños. El pobre estado de conservación del lado lingual impide identificar adecuadamente la presencia de alvéolos de reemplazo.

El nasal es un hueso largo, romboidal, con dos forámenes laterales. El borde anterior, que delimita a la fenestra exonarina, es recto y oblicuo al eje longitudinal del nasal.

El frontal se encuentra levemente desplazado. No conserva el proceso lateral ni la parte posterodistal derechas. Es un hueso esencialmente rectangular de bordes laterales cóncavos; presenta dos leves, pero amplias concavidades: la posterior que conforma la parte dorsal de la órbita y la anterior que recibe al prefrontal. La superficie dorsal presenta irregularidades superficiales, las que en la parte posterior parecen reflejar la posición de las escamas frontoparietales.

El prefrontal también está desplazado de su posición natural. Sólo se observan claramente las dos crestas, dorsal y ventral, flanqueando la depresión posterior.

El yugal se encuentra articulado tanto con el maxilar como con el postorbital. Es un hueso de importantes dimensiones. El proceso maxilar es profundo y cóncavo labialmente; mientras que el proceso temporal es más grácil. 
El postfrontal presenta un desarrollado proceso anteromedial y un muy reducido proceso posteromedial. El proceso ventral es columnar, bajo y se encuentra expandido ventralmente. Es principalmente a través de este último proceso que el postfrontal articula con el postorbital. El postorbital es un hueso cilíndrico, de desarrollo horizontal. Ventralmente presenta dos carillas de articulación claramente diferenciadas; la anterior para el yugal y la posterior para el escamoso.

El cráneo MACN Pv 14310-2 no presenta deformación y los huesos responden a las características ya descriptas (Fig. 46 B-D). Del premaxilar se destaca el proceso ascendente largo, proximalmente ancho y aguzado distalmente. El premaxilar conserva nueve alvéolos, los derechos mejor preservados. Se conservan sólo cinco dientes, que de derecha a izquierda son el II, III, IV, V y IX. La conservación apical es pobre, pero se infiere que los dientes más externos (II, III y IX) son más cónicos y los centrales espatulados. A ambos lados del proceso ascendente se conservan los extremos anteriores de los nasales.

El maxilar izquierdo no conserva la parte posterior de la lámina facial, mientras que el maxilar derecho está fracturado y peor conservado (Fig. 46 B). En vista ventral (Fig. $46 \mathrm{C}$ ) ambos maxilares presenta sulcus dentalis y estante supradental bien desarrollados. El sulcus dentalis está más desarrollado en la parte posterior del maxilar, mientras que el desarrollo horizontal del estante supradental es mayor anteriormente. El estante supradental se proyecta medialmente, diferenciando la fenestra del órgano vómero-nasal de la coana posterior. El maxilar izquierdo conserva los 12 alvéolos anteriores; posteriormente está roto, pero presentaría al menos un alvéolo adicional. Se conservan sólo cinco dientes: I, V, IX, X y el XI. El diente I es pequeño, unicuspidado, recto y apicalmente cónico. Los tres dientes siguientes se infieren mucho más grandes por el mayor tamaño de los alvéolos. El V diente es levemente mayor al I, es unicuspidado, apicalmente cónico y curvado distalmente. Los dientes IX a XI son romos y robustos. El dientes IX presenta sección transversal circular, pero en los restantes es ligeramente oval. Estos tres dientes presentan una nítida cresta mesodistal sobre la cara oclusal. En la parte posterior de la serie dentaria se conservan dientes de reemplazo en posición lingual-posterolingual sobre los alvéolos de reemplazo. El diente de reemplazo VI es unicuspidado, el VII es más robusto y lateralmente comprimido, mientras que los dientes de reemplazo IX-X son romos y robustos. La conservación anterior del maxilar derecho es pobre y dificulta determinar el número de dientes. Se conservan los últimos siete alvéolos. Del 
diente anterior (a) se conserva sólo la base de sección circular. Los tres dientes siguientes (b, c y d) son robustos, de sección circular, con una marcada cresta oclusal. Los restantes dientes (e, fy g) son similares, pero de menores dimensiones. Entre los dientes (e) y (f) se conserva un pequeño diente en posición labial, que se interpreta como de una serie de reemplazo anterior a los dientes funcionales.

Posterolingualmente, sobre los alvéolos funcionales de los dientes (a) a (e), se conservan dientes de reemplazo robustos y romos.

En vista ventral, entre los maxilares, se conservan los huesos correspondientes al paladar. En la porción más anterior se observa la cara ventral de los vómeres, de los cuales anteriormente sólo se distingue la cresta ventral del vómer izquierdo.

Posteriormente, los vómeres se prolongan hasta los palatinos, en contacto estrecho medialmente. Lateralmente los vómeres delimitan el borde medial de la fenestra del órgano vómero-nasal y la parte anterior de la coana; el borde posteromedial de la coana lo delimita el palatino. Los palatinos están algo comprimidos dorsoventralmente y no conservan los procesos pterigoideos. Ha quedado expuesta la cara dorsal del palatino izquierdo (Fig. 46 D), donde se alcanza a distinguir el surco anteroposterior.

El ectopterigoides derecho se encuentra desplazado de su posición. Es robusto, en especial los procesos anterolateral y posterolateral. El proceso maxilar es largo, y, aunque desplazado, se infiere que articula con el palatino excluyendo al maxilar de la fenestra suborbital. Al estar desplazado el ectopterigoides, se observa nítidamente la cresta palatina del proceso maxilar.

El yugal derecho no conserva el proceso temporal. Sobre el profundo y levemente cóncavo proceso maxilar, se observan dos forámenes suborbitales.

El estado de conservación del prefrontal derecho es pobre, de modo que sólo se distingue su depresión posterior y, con escasa definición, las crestas que la delimitan.

El cuadrado izquierdo (MACN Pv 14310-7) no conserva su parte ventromedial ni el cóndilo mandibular. Es robusto y presenta una expansión anteroposterior en vista lateral, la cual es oblicua a la horizontal (ocurre en sentido anterodorsal). La cresta timpánica presenta las mismas características. El cuadrado presenta desarrollo medial a la cresta posterior. El cóndilo cefálico está posteroventralmente orientado. 


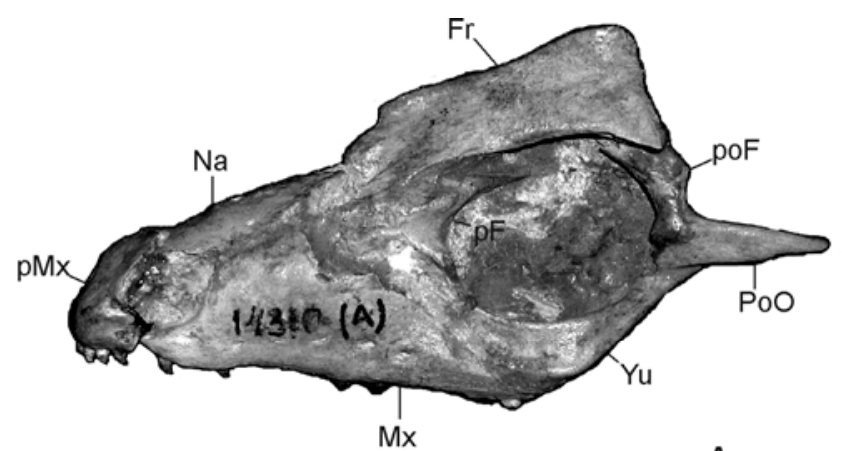

A

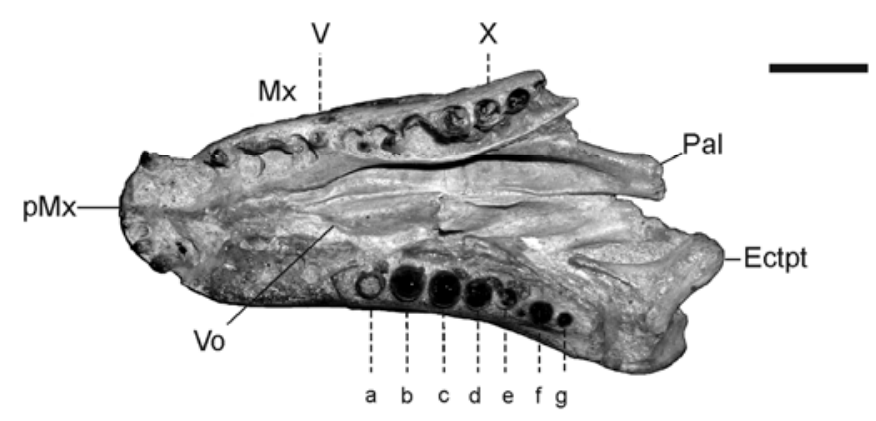

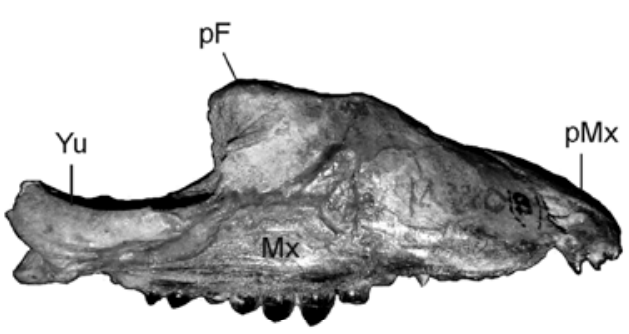

B

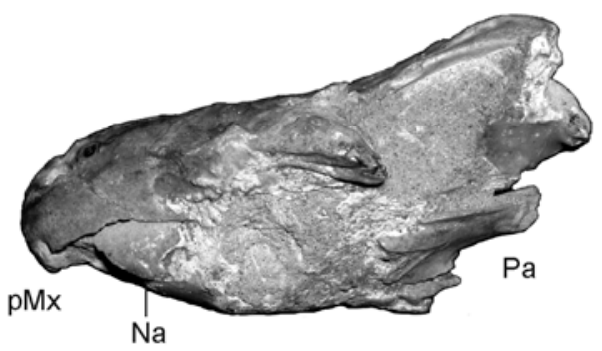

C

D

Figura 46. Elementos craneales de Tupinambis sp. ("T. preteguixin" juvenil, Rovereto, 1914) de la Formación Monte Hermoso. A, cráneo incompleto MACN Pv 14310-1 labial; B, C, D, cráneo incompleto MACN Pv 14310-1 en vistas lateral (B), ventral (C) y dorsal (D). Abreviaturas: d.o.vn; depresión del órgano vómero-nasal; c.sl, cresta semilunar; Es, esplenial; e.sd, estante subdental; f.al foramen alveolar; f.infc; faceta infracoronoidea; f.mh.a, foramen milohioideo anterior. Números romanos indican posición absoluta de alvéolos. Escala $=10 \mathrm{~mm}$.

La hemimandíbula izquierda MACN Pv 14310-3 no conserva el articular (Fig. 47 A-C). El dentario es un hueso grande, profundo, de superficie labial lisa con seis forámenes mentales; el último a la altura del IX diente. El contorno del borde dorsal es cóncavo, con una convexidad menor anterior. Su borde posterior es profundamente escotado labialmente entre los procesos posterodorsal y posteroventral, donde recibe al suprangular y angular. Lingualmente, por detrás de la sínfisis, el estante subdental se presenta con forma de silla de montar. Éste se continúa posteriormente plano, sin perder mayor profundidad hasta la altura del coronoides. El canal de Meckel, cubierto por el esplenial, está medialmente abierto a lo largo de todo el dentario y termina en la sínfisis. El surco dental porta 16 alvéolos funcionales. Se conservan pocos dientes, faltando los siete primeros. Los dientes VIII y IX son unicuspidados, algo robustos, cónicos, de punta levemente curvada distalmente. El diente X es bicuspidado, robusto, 
y de sección circular. La cúspide mesial es cónica, recta y baja; mientras que la cúspide dominante es un cono romo. Los tres dientes siguientes faltan. Los dientes XIV y XV son dientes romos, lateralmente comprimidos. Presentan un clara cresta mesodistal en su cara oclusal. El diente XVI falta. Entre el diente XV y el alvéolo XVI, labialmente ubicado, se observa un pequeño diente que se interpreta como de una serie de reemplazo anterior a los dientes funcionales.

El esplenial no conserva el proceso posteroventral. Se trata de un hueso plano, cuneiforme, cóncavo en vista lateral y levemente excavado en su cara lingual, anterior al foramen alveolar. El esplenial cubre gran parte del canal de Meckel, dejando una pequeña abertura anterior.

El coronoides no conserva la parte distal del proceso posteromedial. El proceso dorsal es vertical, lingualmente cóncavo, con una marcada cresta oblicua labialmente. Los procesos anteriores, anterolateral y anteromedial, son cortos, extendiéndose solamente a nivel del último alvéolo. El vértice de la escotadura posterior del dentario está adelantada respecto al extremo distal del proceso anterolateral del coronoides. En vista lingual los procesos mediales delimitan dorsalmente la fenestra subcoronoidea.

El suprangular se dispone en forma vertical, ocupa el vértice y gran parte de la escotadura posterior del dentario. Dorsolingualmente forma el robusto borde dorsal de la fosa mandibular. Más anteriormente, entre los procesos mediales del coronoides, se distingue la faceta intercoronoides, ventral a la cual se continúa la lámina lingual.

El angular delimita el borde ventral de la hemimandíbula. Ocupa poco lugar en la escotadura posterior de dentario. Posterolabialmente se observa la suave cresta correspondiente al músculo adductor.

El esplenial del fragmento MACN Pv 14310-4 se conserva casi completo (Fig. $47 \mathrm{D})$. Su forma es algo cóncava anteriormente a los forámenes alveolar y milohioideo anterior. El dentario no conserva una buena parte de su cara posterodorsal, dejando expuesto al esplenial en vista labial. Es labialmente liso y conserva cinco forámenes mentales, el último a la altura del diente X. El estante subdental está bien desarrollado pero no conserva su parte anterior. Sobre el surco dental se conserva la serie dentaria completa con 15 alvéolos funcionales, pero con sólo los dientes VIII, IX y X conservados. Se trata de dientes robustos, de sección circular, altos y formando un gradiente de altura creciente hacia el extremo posterior. Los dientes VIII y IX son apicalmente cónicos, la punta del diente VIII es más 
punzante y distalmente curvada. El diente X es apicalmente romo. No presenta alvéolos de reemplazo.

El esplenial y dentario MACN Pv 14310-5 articulados no conservan los extremos posterodorsales (Fig. 47 E). Estos huesos son más gráciles que los previamente descriptos pero responden a las mismas características. El dentario conserva los 14 alvéolos anteriores, en las que sólo persisten los dientes XI, XII y XIII. Se trata de dientes bicuspidados robustos, condición que se aprecia mejor en el diente XII. La cúspide mesial es cónica y recta, poco diferenciada de la dominante. Está última es roma, con una protuberancia central y una cresta mesodistal que la atraviesa. Posterolingualmente, sobre los alvéolos funcionales de los dientes XI y XIII, se encuentran dos profundos alvéolos de reemplazo con dientes. Estos dientes son robustos y romos. El esmalte de los dientes funcionales y de reemplazo presenta finas estrías verticales que convergen apicalmente.

El dentario y esplenial MACN Pv 14310-6 son gráciles, menos profundos posteriormente que los previamente descriptos (Fig. 47 F). Ambos huesos carecen de su parte posterior. El dentario está muy mal preservado anterolingualmente y sólo tiene cuatro forámenes mentales. En el surco dental se conservan los 12 alvéolos anteriores, en los cuales se preservan siete dientes. La serie dentaria se encuentra en pleno recambio dentario. Los dientes I y $\mathrm{V}$ son pequeños, unicuspidados y apicalmente cónicos. Los dientes IX al XII son dientes de reemplazo que se encuentran lingualmente en alvéolos funcionales que han perdido sus dientes. En el alvéolo XII se observan ambas generaciones de dientes. Entre los alvéolos IX y X, puede notarse un diente de reemplazo que no se corresponde a estos alvéolos funcionales. Este diente es unicuspidado, recto y alto, sin compresión lateral. El diente IX está colapsado en el alvéolo funcional, es apicalmente cónico y comprimido lateralmente. El diente X es robusto, romo y aparentemente comprimido lateralmente; labialmente se observa parte de la base del diente funcional. El diente funcional XI es basalmente robusto y comprimido lateralmente, no conserva su extremo apical. Del diente de reemplazo XI se observa su cara oclusal que es robusta, roma y lateralmente comprimida. El diente XII es un diente bicuspidado robusto, con una cúspide mesial cónica y poco diferenciada de la dominante. Sobre la cara oclusal de la cúspide dominante se observa una cresta mesodistal. 

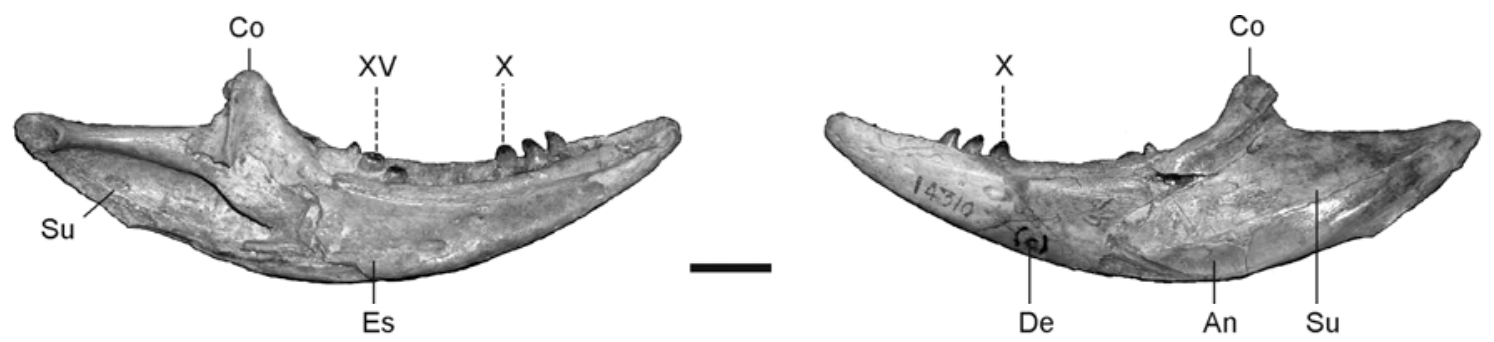

A

B
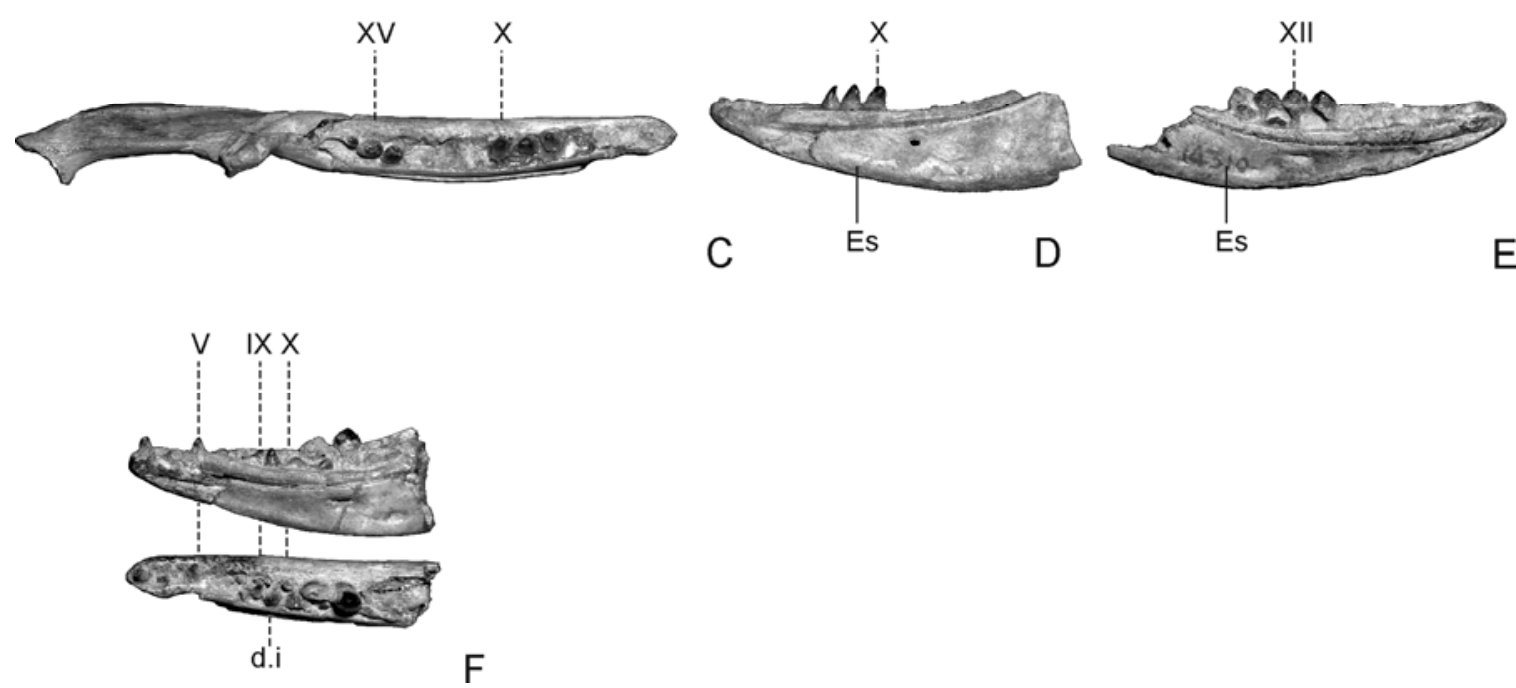

Figura 47. Elementos mandibulares de Tupinambis sp. ("T. preteguixin" juvenil, Rovereto, 1914) de la Formación Monte Hermoso, Farola Monte Hermoso, provincia de Buenos Aires. A-C; hemimandíbula MACN Pv 14310-3 en vista lingual (A), labial (B) y oclusal (C); D, dentario y esplenial MACN Pv 143104 en vista lingual; E, dentario y esplenial MACN Pv 14310-5 en vista lingual; F, dentario y esplenial MACN Pv 14310-6 en vista lingual y oclusal. Escala $=10 \mathrm{~mm}$.

En un bloque sedimentario se conservan diez vértebras (MACN Pv 14310-8) expuestas en vista ventral (Fig. 48 A). Las vértebras son procélicas, de centro vertebral cónico y posteriormente truncado. Los procesos transversos están bien desarrollados en la parte anterior de cada vértebra. La cara ventral del centro vertebral presenta una cresta sagital baja, ancha, en forma de lomada. El cótilo y el cóndilo son ovales e inclinados anteriormente. Este último está precedido por un marcado cuello condilar. La octava vértebra (h) está algo desplazada y deja ver claramente al zigósfeno, que es escotado, con carillas de articulación verticales. La novena vértebra (i) permite la observación de la carilla de articulación de la postzigapófisis izquierda, que es oval y está orientada lateralmente. Las ocho vértebras anteriores conservan al menos parte de una de sus costillas, las cuales son holocéfalas, con una leve 
compresión anteroposterior. Anteriormente a la primer vértebra (a), se conserva la costilla izquierda de la vértebra precedente.

El carpo derecho (MACN Pv 14310-9) se conserva incompleto y articulado (Fig. 48 B). El ulnar-intermedio se conserva proximalmente. Dos fragmentos de huesos, de pobre definición, se conservan lateralmente al ulnar-intermedio; éstos serían partes del radial y del central. Sólo se observan los carpales I, III y V. Los metacarpales centrales (II, III y IV) están claramente expuestos; el primer metacarpal subduce por debajo de los centrales. El V metacarpal está pobremente preservado. Los dedos II y III conservan todas sus falanges, el IV sólo conserva las tres falanges proximales y el dedo $\mathrm{V}$ carece de la falange ungeal. 

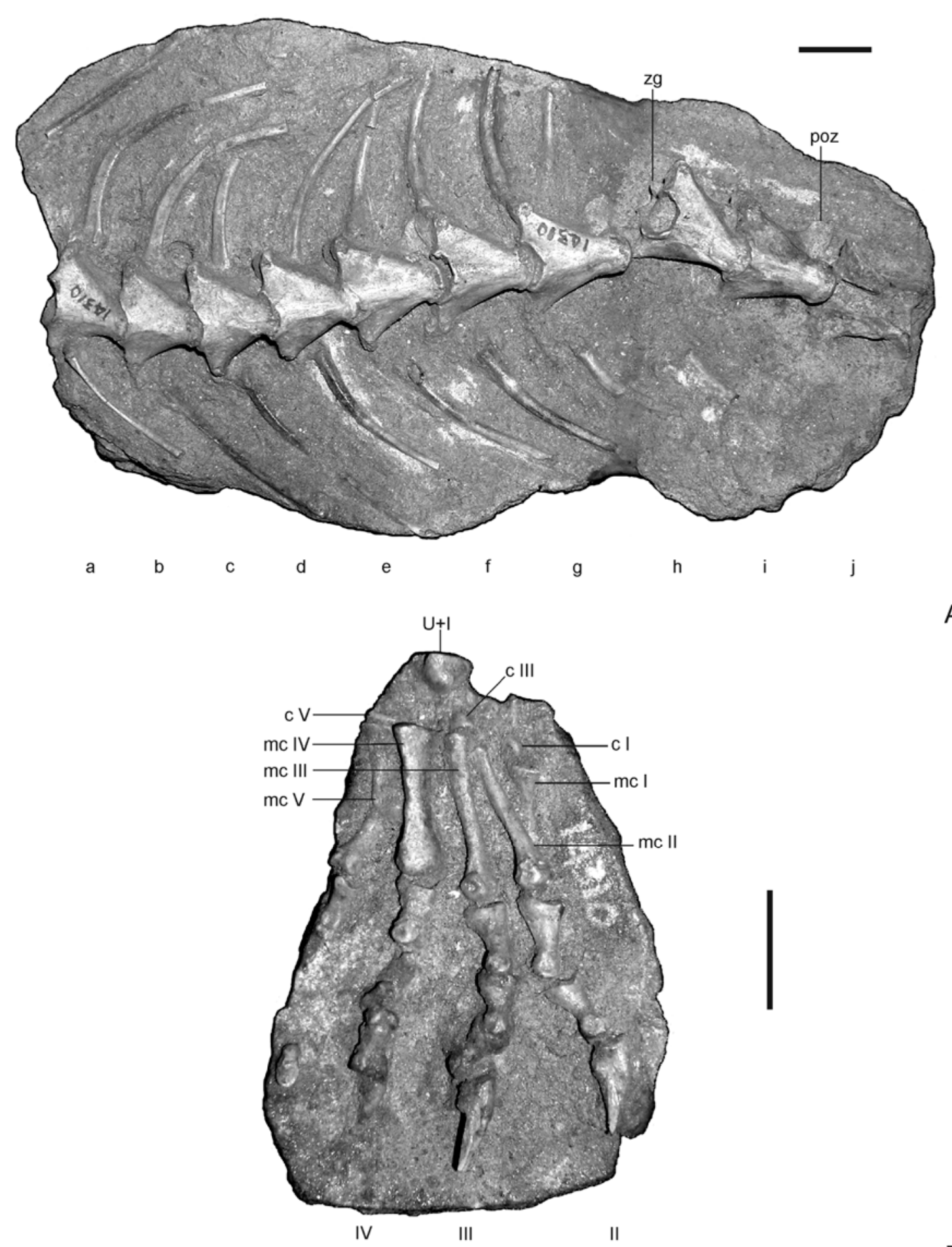

A

Figura 48. Elementos postcraneales de Tupinambis sp. (“T. preteguixin" juvenil, Rovereto, 1914) de la Formación Monte Hermoso, Farola Monte Hermoso, provincia de Buenos Aires. A, conjunto articulado de vértebras dorsales MACN Pv 14310-8 ventralmente expuestas; B, carpo derecho MACN Pv 14310-9 en vista dorsal. Abreviaturas: c, carpal; mc, metacarpal; U+I, ulnar-intermedio. Escala $=10 \mathrm{~mm}$. 
Comentarios taxonómicos. La presencia de alvéolos de reemplazo profundos y subcirculares (MACN Pv 14310-2/3, MACN Pv 14310-5/6), el abundante cemento basal y el esplenial hipertrofiado, anteriormente desarrollado (MACN Pv 14310-3 MACN Pv 14310-5) son características que permiten la inclusión de los fósiles en el clado Borioteiioidea-Teiioidea (Nydam et al., 2007; Cap. III). Estos estados se revierten en los Gymnophthalmidae (Nydam et al., 2007; Cap. III), y, junto con otros caracteres (véase Cap. V), sostienen la distinción del material fósil respecto a esta familia.

El frontal impar (MACN Pv 14310-1), el proceso posterodorsal del dentario sin cubrir al proceso anterolateral del coronoides ([C86]), y este último bien desarrollado ([C98]) son característicos de los Teiioidea.

Entre los Teiioidea (excluidos los Gymnophthalmidae) un conjunto de caracteres permite la inclusión de los fósiles en la subfamilia Tupinambinae: premaxilares (MACN Pv 14310-1/2) con constricción basal ([C3]) y una marcada concavidad sobre los procesos maxilares que reciben a los procesos premaxilares de los maxilares ([C7]); proceso maxilar del yugal ligeramente cóncavo ([26]) (MACN Pv 14310-1/2) (contra Rovereto, 1914) ([C26]); postfrontal (MACN Pv 14310-1) independiente del postorbital (i.e. no fusionado) ([40]), de extremo distal asimétrico con un muy reducido proceso posteromedial ([C41]); expansión medial del cuadrado (MACN Pv 14310-7) ([C61]); canal de Meckel medialmente abierto, sin constricción ([C65]), y terminado en la sínfisis ([C61]) (MACN Pv 14310-3 a MACN Pv 143106); borde posterior del dentario (MACN Pv 14310-3) ampliamente cóncavo y que recibe al suprangular (principalmente) y al angular ([C92]); proceso anterolateral del coronoides, aunque desarrollado, relativamente corto comparado con lo observado en los “cnemidoforinos" ([C98]) y extendido aproximadamente a la misma altura que las proyecciones anteriores del suprangular y angular ([C99]); y esplenial (MACN Pv 14310-3 a MACN Pv 14310-6) con una depresión medial anterior a los forámenes milohioideo anterior y alveolar ([C97]).

Varios de los caracteres mencionados en el párrafo precedente, así como otros del postfrontal, maxilar, cuadrado, dentario, implantación dentaria y dentición permiten excluir los fósiles de los géneros Callopistes y Dracaena (véase Cap. V). Por el contrario, la rama labial del proceso premaxilar del maxilar fósil MACN Pv 14310-1, cónica y robusta, es similar a la observada en Tupinambis y Crocodilurus ([C9]). La expansión oblicua del cuadrado respecto a la horizontal (i.e. ocurre en 
sentido anterodorsal) es como en Tupinambis ([C60]). El borde dorsal del dentario en los fósiles MACN Pv 14310-3 a MACN Pv 14310-6 es poco cóncava como en Crocodilurus y Tupinambis ([C85]). El tipo particular de implantación dentaria, donde el depósito de cemento sobre las bases de los dientes disimula los septos interdentales, se asemeja a lo observado en Crocodilurus y Tupinambis (Cap. III). Además, estos géneros, al igual que los fósiles (MACN Pv 14310-1/2) presentan dientes premaxilares espatulados, con cúspides accesorias de menor desarrollo que la central y poco diferenciadas (excepto T. quadrilineatus [C117]). Sin embargo, dientes robustos, ya sea cuspidados o romos, como los presentes en el material fósil, sólo se observan en Tupinambis (Cap. III), en particular, en las especies T. merianae, $T$. duseni, T. rufescens y T. teguixin.

Al comparar el material fósil con la serie ontogenética de T. merianae se puede asumir que la ausencia de dientes posteriores tricuspidados está indicando una talla de $\mathrm{LHC}>315 \mathrm{~mm}(\mathrm{LSDd}>36,69 \mathrm{~mm}$ y LSDm $>31,71)$ para todos los materiales fósiles; es decir, comparable a la talla de formas adultas de esta especie. Las longitudes de las series dentarias de MACN Pv 14310-1 (LSDm = 37,11 mm), MACN Pv 14310-2 (LSDm = 36,88 mm) y MACN Pv 14310-1 (LSDd = 40,11 mm) sugieren que estos individuos eran aún jóvenes (Cap. III). Por la talla y la presencia de dientes bicuspidados robustos, los fósiles MACN Pv 14310-3, MACN Pv 14310-5 y MACN Pv 14310-6 corresponderían a individuos con tamaño también moderado (Cap. III). Los fósiles MACN Pv 14310-1/2 habrían pertenecido a ejemplares algo mayores debido a la presencia solamente de dientes robustos y romos en la parte posterior de la dentición marginal. Estas inferencias son contrarias a la suposición de una condición juvenil para estos materiales dada por Rovereto (1914).

Las vértebras (MACN Pv 14310-8) aportan pocos caracteres útiles para la determinación sistemática de estos fósiles a bajos niveles taxonómicos. Los caracteres observados en el fósil MACN Pv 14310-8 coinciden con los observados en los Teiidae (Cap. III). Se destacan las crestas sagitales poco marcadas como las observadas en los Tupinambinae ([C155]). Los elementos del carpo MACN Pv 14310-9, aunque bien conservados, son menos informativos. Si bien el material postcraneal figura bajo el mismo número que el material craneal que aquí es asignado a Tupinambis, Rovereto (1914: 173) no hace referencia sobre si todo este material, que consta de más de un individuo (como mínimo cuatro ejemplares), se encontró o 
no asociado; sin embargo, sus dimensiones y sus caracteres, indistinguibles de lo observado en Tupinambis, permiten asignar todo el material al mismo taxón.

\section{Tupinambis sp.}

(“T. preteguixin” adulto, Rovereto, 1914)

(Fig. 49, 50)

Material referido: MACN Pv 14312. Incluye varios elementos, aislados y articulados, catalogados bajo el mismo número. Estos elementos representan como mínimo a tres individuos. Rovereto (1914) describió parte de estos restos como pertenecientes a un individuo adulto de la especie "T. preteguixin" sobre la base de algunos elementos de este conjunto, como la hemimandíbula izquierda, dentario y esplenial derechos articulados y parte posterior del cráneo. Este último se ha roto con posterioridad a la descripción de Rovereto (1914), pero corresponderían a los materiales actualmente reconocidos por la numeración MACN Pv 14312-2/3, MACN Pv 14312-5 y posiblemente al MACN Pv 14312-7. Los restantes huesos no fueron descriptos por este autor. Los elementos referidos son: maxilar izquierdo incompleto (MACN Pv 14312-1); yugal izquierdo (MACN Pv 14312-2); parietal incompleto, postorbital y escamoso izquierdos reconstruidos (MACN Pv 14312-3); ectopterigoides derecho (MACN Pv 14312-4); pterigoides izquierdo (MACN Pv 14312-5); pterigoides y ectopterigoides derechos reconstruidos articulados (MACN Pv 14312-6); tres cuadrados izquierdos (MACN Pv 14312-7 a MACN Pv 14312-9); proótico derecho incompleto (MACN Pv 14312-10); proótico izquierdo incompleto (MACN Pv 14312-11); parabasiesfenoides (MACN Pv 14312-12); hemimandíbula izquierda incompleta (MACN Pv 14312-13); dentario y coronoides derechos incompletos y articulados (MACN Pv 14312-14); MACN Pv 14312-miscelánea: tres fragmentos craneales indeterminados.

Procedencia geográfica: Farola Monte Hermoso (38 $\left.58^{\prime} \mathrm{S}, 61^{\circ} 41^{\prime} \mathrm{O}\right)$ (Cione y Tonni, 1995a: 54), provincia de Buenos Aires.

Procedencia estratigráfica: Formación Monte Hermoso (Zavala, 1993), Montehermosense s.l., Mioceno tardío - Plioceno temprano. 
Re-descripción. La dentición en los elementos portadores de dientes descriptos en esta sección es subpleurodonte, los dientes presentan depósitos abundantes de cemento sobre sus bases que disimula los septos interdentales (Cap. III).

El fragmento MACN Pv 14312-1 corresponde a la parte media-anterior de un maxilar izquierdo (Fig. 49 A). Labialmente es liso y conserva cuatro forámenes mentales. El proceso premaxilar es bífido, la rama labial es robusta y cónica. Dorsalmente al proceso premaxilar se observa la fenestra exonarina, la cual es marcadamente vertical en su parte posterior. Lingualmente, desde el foramen de egreso del canal alveolar, se proyecta anteromedialmente la lámina transversal anterior que porta una cresta dorsal en su extremo medial. La superficie cóncava que soporta al órgano vómero-nasal se encuentra por detrás del la fenestra exonarina y está delimitada posteriormente por un rudimentario soporte narial posterior. La cresta semilunar se desarrolla dorsoposteriormente sobre la lámina facial. En la parte anterior del estante supradental se observa la superficie de articulación con el vómer. El estante tiende a engrosarse posteriormente. En vista ventral, el estante supradental divide a la fenestra exocoana en una parte anterior para el órgano vómero-nasal y una posterior para la coana. El surco dental conserva los ocho alvéolos anteriores. Los dientes no ocupan todo el ancho del surco dental dejando un nítido sulcus dentalis. Los dientes conservados son similares entre sí, aunque varían en sus dimensiones. Son dientes unicuspidados, cónicos, punzantes y distalmente curvados. Los dientes II, III y IV son mayores que los dientes I, V y VI. El diente VII recupera tamaño pero se encuentra apicalmente roto. Del diente VIII se conserva sólo su base. Sobre el sulcus dentalis se observan esbozos de alvéolos de reemplazo.

El yugal izquierdo (MACN Pv 14312-2) presenta forma de bumerang (Fig. 49 B). El proceso maxilar es robusto y profundo. La cara labial es cóncava y porta un foramen suborbital. Medialmente se observa un foramen del nervio maxilar. El proceso temporal es más grácil, la carilla de articulación para el postorbital está posteriormente orientada.

El techo del cráneo se halla reconstruido (MACN Pv 14312-3) (Fig. 49 C); están presentes el postorbital y escamoso izquierdos y el parietal incompleto. El parietal no conserva gran parte del proceso supratemporal derecho y la parte distal del izquierdo. La sutura del parietal con el frontal es transversal y recta. Anteriormente, los procesos anterolaterales se disponen transversalmente. En vista lateral, la musculatura adductora ocupa más de la mitad de la longitud del parietal. La meseta 
parietal es triangular y los bordes posteriores, suaves y cóncavos, se continúan posteriormente como una alta cresta medial. El proceso supratemporal izquierdo es robusto, largo y diverge posteriormente. En vista lateral se observa la carilla de articulación para el supratemporal izquierdo. También en vista lateral, pero en la parte medial del parietal, se observan los marcados procesos descendentes. Ventralmente el parietal es plano, la fosa parietal es terminal y está abierta posteriormente.

Anteriormente se conservan sólo bases de los procesos anteromediales. El postfrontal no se conserva. El postorbital es un hueso esencialmente temporal, con un desarrollado proceso posterior y procesos ventral y medial reducidos. Las carillas de articulación para el yugal y el escamoso están nítidamente diferenciadas. El escamoso está desplazado, es cilíndrico, ligeramente comprimido dorsoventralmente, y presenta una ligera convexidad dorsal en su extremo posterior.

El ectopterigoides y pterigoides izquierdos (MACN Pv 14312-6) han sido reunidos (Fig. 49 D), pero también se conservan aisladamente un ectopterigoides derecho (MACN Pv 14312-4) y un pterigoides izquierdo (MACN Pv 14312-5). El pterigoides derecho no conserva el proceso transverso ni el extremo posterior del proceso cuadrado. El pterigoides izquierdo se conserva completo. En vista ventral, el área entre los procesos palatino y transverso está ligeramente excavada, lateralmente abierta. El proceso cuadrado presenta una marcada fosa pterigoidea, la cual no presenta expansión medial. En vista dorsal se observa la fosa columelar. Los ectopterigoides presentan robustos procesos anterolateral y posterlateral. El proceso maxilar se conserva sólo en el fragmento MACN Pv 14312-4, con una marcada cresta palatina.

Los tres cuadrados izquierdos (MACN Pv 14312-7 a MACN Pv 14312-9) son similares entre sí, aunque varían en sus dimensiones. El cuadrado MACN Pv 14312-7 es el más robusto y no conserva su parte ventromedial (Fig. 49 E). La cresta timpánica es robusta, especialmente en el ejemplar MACN Pv 14312-7, anterodorsalmente desarrollada. Los cuadrados presentan desarrollo medial; sobre la cresta medial se desarrolla el ala pterigoidea (MACN Pv 14312-8, MACN Pv 14312-9).

El proótico derecho (MACN Pv 14312-10) no conserva el proceso posterior, ni el extremo distal del proceso alar (Fig. 49 F). La escotadura del trigémino es estrecha, desarrollada anteroposteriormente. Del proótico izquierdo (MACN Pv 14312-11) se conserva sólo el proceso posterior. El parabasiesfenoides (MACN Pv 14312-12) se conserva casi completo (Fig. 49 G). Los procesos basipterigoideos son 
robustos y cortos. La superficie de articulación de estos procesos son ligeramente cóncavas. En vista anterior se observan ambos procesos alares del basiesfenoides, la cristae sellae está cubierta por sedimento. Más ventralmente se observa la dorsum sellae, con los canales de la rama cerebral de la carótida. Los canales vidianos se ubican lateralmente al paraesfenoides.
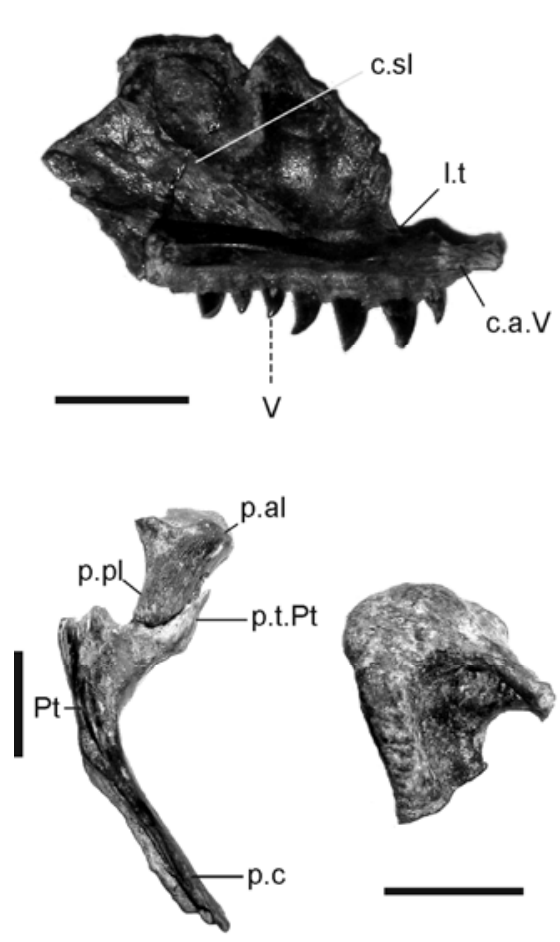

D

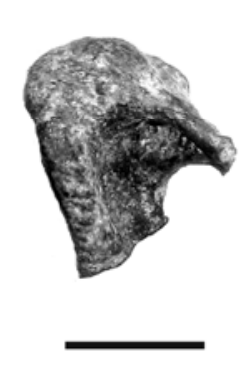

$\mathrm{E}$

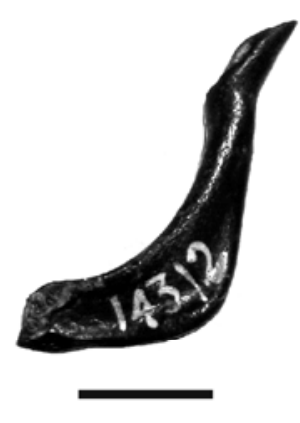

A

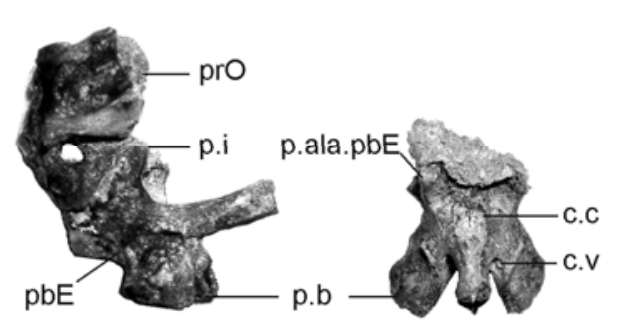

$\mathrm{F}$

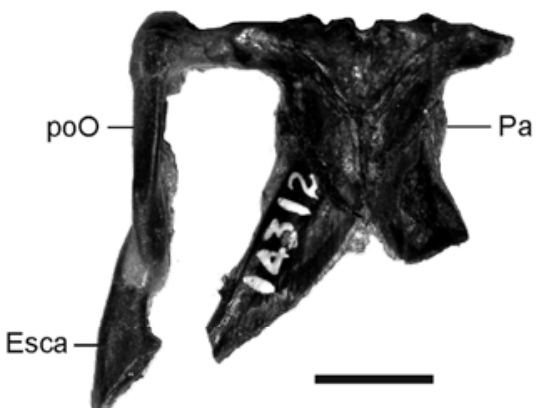

B

C

Figura 49. Elementos craneales de Tupinambis sp. ("T. preteguixin" adulto, Rovereto, 1914) de la Formación Monte Hermoso, Farola Monte Hermoso, provincia de Buenos Aires. A, maxilar MACN Pv 14312-1 en vista lingual; B, yugal MACN Pv 14312-2 en vista labial; C, parietal, postorbital y escamoso izquierdos articulados (MACN Pv 14312-3); D, pterigoides y ectopterigoides izquierdos (MACN Pv 14312-6) articulados, en vista ventral; E, cuadrado izquierdo (MACN Pv 14312-7); F, parabasiesfenoides (MACN Pv 14312-12) y proótico (MACN Pv 14312-10) articulados, en vista lateral; G, basiesfenoides MACN Pv 14312- en vista anterior. Abreviaturas: c.a.V, carilla de articulación para el vómer; c.c, canal de la carótida; c.sl, cresta semilunar; c.v, canal vidiano; Esca, escamoso; Pa, parietal; p.al, proceso anterolateral; p.ala.pbE, proceso alar del parabasiesfenoides; p.b, proceso basipterigoideos; pbE, parabasiesfenoides; p.c, proceso cuadrado; p.i, proceso inferior; poO, postorbital; p.pl, proceso posterolateral; prO, proótico; Pt, pterigoides; p.t.Pt, proceso transverso del pterigoides. Escala $=10 \mathrm{~mm}$. 
La hemimandíbula izquierda (MACN Pv 14312-13) no conserva gran parte del esplenial (Fig. 50). El dentario ha perdido la cara mediolabial y ha sido reconstruido. Se trata de un hueso grande, cuneiforme, y posteriormente profundo. Labialmente es convexo, liso y presenta cinco forámenes mentales; el último entre los dientes (a) y (b). El contorno dorsal es cóncavo, con una convexidad menor en la parte anterior. El borde posterior del dentario es profundamente escotado entre los procesos posterodorsal y posteroventral; donde recibe al suprangular y angular. Lingualmente se observa un amplio y medialmente abierto canal de Meckel, sin constricción anterior, que termina en la sínfisis. Está última es simple. El estante subdental está roto inmediatamente por detrás de la sínfisis; posteriormente se continúa en forma vertical y algo convexa, y pierde progresivamente desarrollo dorsoventral más posteriormente. Ventralmente, el estante subdental presenta una amplia superficie de articulación para el esplenial. Dorsalmente se observa el surco dental que porta la serie dentaria. Se observan 15 alvéolos funcionales, separados por un faltante en la parte media de dos o tres dientes posteriores (Fig. 50 B, C). Los tres dientes anteriores son unicuspidados, apicalmente cónicos y curvados distalmente. El diente IV falta. El diente $\mathrm{V}$ es similar a los precedentes pero más pequeño. No es posible inferir el número de dientes en la sección faltante posterior al diente V. Los dos dientes posteriores a la rotura, (a) y (b), son unicuspidados robustos, basalmente cilíndricos y apicalmente cónicos con la punta distalmente curvada. El diente (c) es similar a los precedentes pero recto y levemente más bajo. Esta tendencia a un diente robusto y bajo se verifica en los dientes subsiguientes (d, e, g y h), aunque los dientes (g) y (h) son romos distalmente. El diente (f) falta. De los dos dientes posteriores, el (i) y el (j) están pobremente conservados. No se observan alvéolos de reemplazo. Del esplenial se conservan pequeños fragmentos del borde posterior. El coronoides no conserva el proceso posteromedial ni la parte distal del proceso dorsal. El proceso posterolateral es pequeño. Los procesos anteriores son cortos, alcanzan el nivel del diente (h). El extremo anterior del proceso anterolateral se encuentra por detrás del vértice de la escotadura del borde posterior del dentario (Fig. 50 A). En vista lingual, se observa la fenestra subcoronoidea, la cual no contacta con el esplenial (i.e. no hay contacto lingual entre el suprangular y esplenial). El suprangular se conserva completo. La superficie labial es ligeramente cóncava y conserva los forámenes anterior y posterior. Anteriormente, el suprangular ocupa el vértice y más de la mitad de la escotadura del borde posterior del dentario. Lingualmente, delimita la fosa mandibular; el borde 
dorsal es robusto, con mayor desarrollo anterior. El borde ventral del suprangular se ubica más lateralmente que el borde ventral, quedando el suprangular con una disposición ligeramente oblicua (Fig. 50 B). El angular se conserva completo, se dispone verticalmente, y es recorrido ventrolabialmente por una sutil cresta adductora. Del articular se conserva sólo el proceso anterior. Posteriormente conforma el borde ventral de la fosa mandibular. Ventralmente se observa la cresta prearticular, que es de contorno lateral recto, oblicuamente dispuesto. Más anteriormente se observa la superficie de articulación para el proceso posteromedial del coronoides.

Anteriormente a esta carilla de articulación, el articular contacta con el esplenial, cerrando ventralmente la fenestra subcoronoidea.

El dentario y coronoides derechos (MACN Pv 14312-14) se conservan articulados (Fig. 50 D). El dentario no conserva la parte posteroventral. La superficie labial es lisa, y presenta tres forámenes mentales, el último a la altura del VIII diente. En vista lingual, se aprecia el canal de Meckel ampliamente abierto, sin mayor constricción anterior, y que termina en la sínfisis. El estante subdental presenta forma de silla de montar inmediatamente por detrás de la sínfisis; posteriormente es planoconvexo y pierde progresivamente desarrollo dorsoventral. Ventralmente presenta una importante superficie de articulación para el esplenial. Conserva 17 alvéolos, todos con sus respectivos dientes excepto el último. Los primeros cinco dientes son unicuspidados, apicalmente cónicos, de punta punzante y distalmente curvada. De estos dientes, el II es más alto que los restantes. El V diente está roto apicalmente. Los dientes VI a VIII son más robustos, especialmente en la base, y menos curvos distalmente. El diente IX es unicuspidado, robusto y recto; apicalmente es cónico, comprimido lateralmente. Los dientes $\mathrm{X}$ a XV son robustos, romos $\mathrm{y}$ levemente comprimidos lateralmente. Apicalmente presentan una cresta mesodistal con una protuberancia central poco marcada, sobre la que convergen finas estrías. El diente XVI es bajo, pero similar a los anteriores. El último diente falta. No se observan alvéolos de reemplazo. Del coronoides se conserva el proceso anterolateral y la parte proximal del proceso dorsal. El proceso anterolateral es corto, alcanzando al XV diente. 

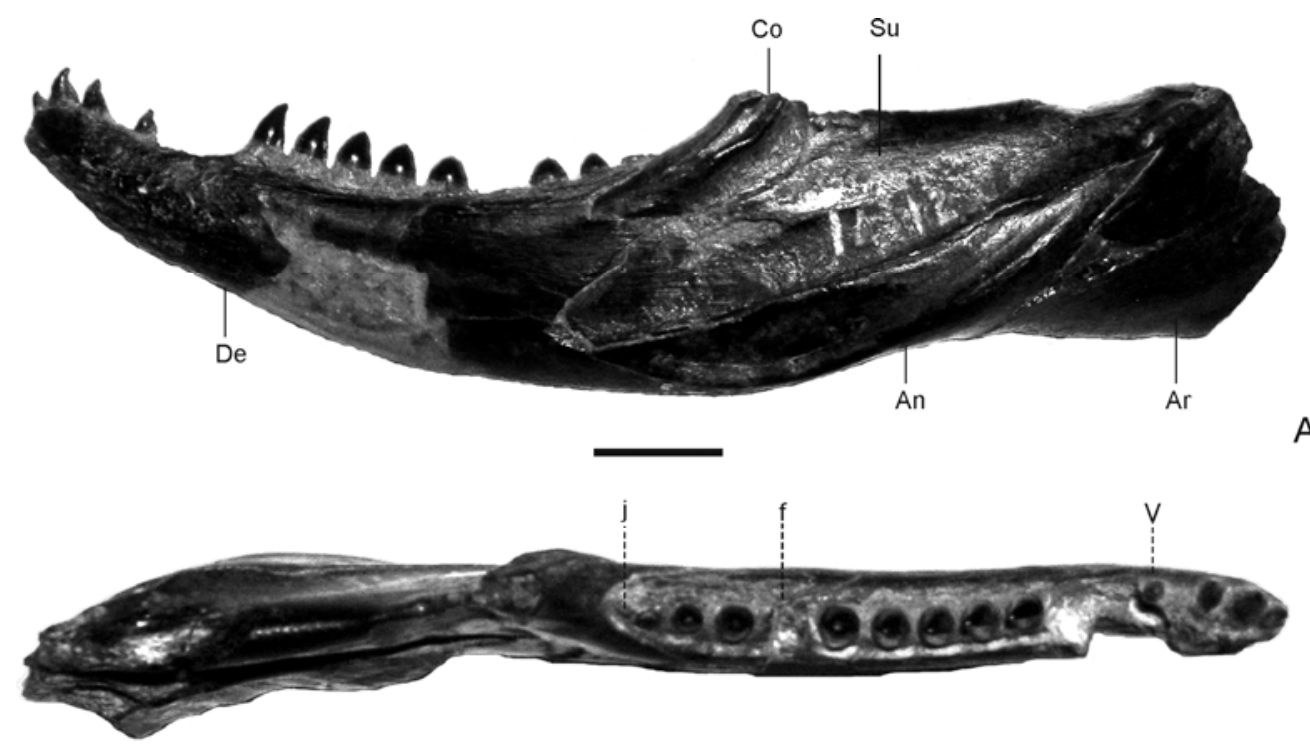

A

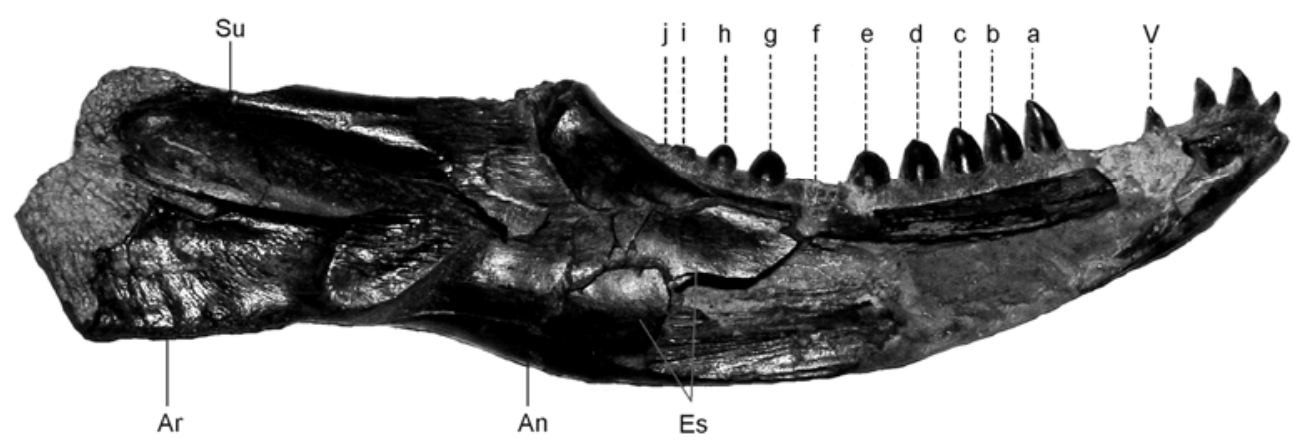

C

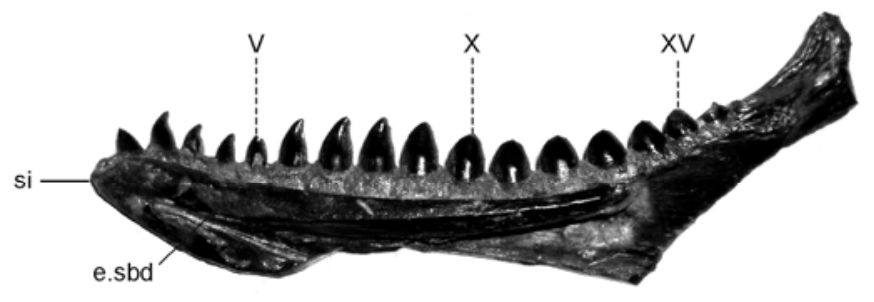

D

Figura 50. Elementos mandibulares de Tupinambis sp. ("T. preteguixin" adulto, Rovereto, 1914) de la Formación Monte Hermoso, Farola Monte Hermoso, provincia de Buenos Aires. A, hemimandíbula MACN Pv 14312-13 en vista labial (A), oclusal (B) y lingual (C); dentario y coronoides MACN Pv 14312-14 en vista lingual. Abreviaturas: An, angular; Ar, articular; Co, coronoides; De, dentario; e.sbd, estante subdental; si, sínfisis; $\mathrm{Su}$, suprangular. Escala $=10 \mathrm{~mm}$. 
Del esqueleto axial se conserva una vértebra aislada (MACN Pv14312-15), mal preservada. Es una vértebra procélica, que no conserva las postzigapófisis, espina neural, ni prezigapófisis izquierda. El arco neural es bajo. El canal neural en vista anterior es triangular. La prezigapófisis derecha se orienta lateralmente, la superficie de articulación nace a nivel medio del canal neural y está ligeramente inclinada dorsalmente respecto a la horizontal. El cótilo y el cóndilo son ovales, dorsoventralmente comprimidos, y ventral y dorsalmente inclinados respectivamente. El cóndilo esta precedido por un nítido cuello condilar.

Comentarios taxonómicos. La presencia de alvéolos de reemplazo profundos y subcirculares (MACN Pv 14312-1), el abundante cemento basal y el esplenial hipertrofiado, anteriormente desarrollado (MACN Pv 14312-14, inferido en MACN Pv 14312-13), son características que permiten la inclusión de los fósiles en el clado Borioteiioidea-Teiioidea excluyendo a los Gymnophthalmidae (Nydam et al., 2007; Cap. III).

Estos fósiles comparten con los Teiioidea varios caracteres craneales y mandibulares (Denton y O’Neill, 1995; Nydam y Cifelli, 2002b; Nydam et al., 2007), como carecer de soporte narial anterior (MACN Pv 14312-1); presentar el parietal más ancho que largo (ver Cap. VI); y tener un parietal con procesos descendentes ([C50]) y sin foramen parietal (MACN Pv 14312-3) ([C45]). La fosa parietal posterior y abierta, contrasta con la posteriormente cerrada o anteriormente desplazada de los Borioteiioidea ([C58]). La musculatura adductora abarca más de dos tercios del parietal en vista lateral ([C47]), mientras que en los Borioteiioidea su desarrollo es menor. En la mandíbula de los fósiles aquí descriptos (MACN Pv 14312-13/14), el proceso posterodorsal del dentario no cubre anteriormente al proceso anterolateral del coronoides ([C86]) y el proceso anterolateral del coronoides avanza sobre el dentario ([C98] en parte); ambos caracteres sólo son observados en los Teiioidea.

Dentro de los Teiidae, los siguiente caracteres, presentes en los fósiles, se observan solamente en los Tupinambinae: soporte narial posterior desdibujado (MACN Pv 14312-1) ([C17]); cresta sobre la lámina transversal del maxilar (MACN Pv 14312-1) ([C18]); avance hasta el plano sagital de la musculatura adductora sobre el parietal (MACN Pv 14312-3) ([C46]); bordes anteromediales de las fenestras supratemporales delimitados por los procesos anterolaterales del parietal (MACN Pv 14312-3) ([C54]); cuadrado con expansión medial ([C61]); extremo anterior del 
proceso anterolateral del coronoides a la misma distancia que la proyección anterior del suprangular/angular (MACN Pv 14312-13) ([C99]); canal de Meckel medialmente abierto (MACN Pv 14312-13/14) ([C87]), sin restricción anterior (MACN Pv 1431213) ([C88]) y terminado en la sínfisis (MACN Pv 14312-13/14) ([C89]); proceso cuadrado del pterigoides sin expansión medial (MACN Pv 14312-6) ([C81]); y cara labial del proceso maxilar del yugal ligeramente cóncava (MACN Pv 14312-2) ([C26]).

Entre los Tupinambinae, los materiales fósiles comparten con Crocodilurus y Tupinambis los siguientes caracteres: borde dorsal del dentario cóncavo (MACN Pv 14312-13/14) ([C85]) y tipo de implantación dentaria ([C120], Cap. III). Sin embargo, difiere de Crocodilurus por presentar una desarrollada cresta angular (MACN Pv 14312-13) ([C104]). La expansión anterodorsal del cuadrado (y de la cresta timpánica) asemeja al material fósil con Tupinambis (MACN Pv 14312-7 a MACN Pv 14312-9) ([C60], [C63]). Además, la presencia de dientes posteriores robustos molariformes también excluye a Crocodilurus y a las especies de Tupinambis, $T$. quadrilineatus y T. longilineus ([C127], Cap. III). En el ejemplar MACN Pv 1431213 se observa la fenestra subcoronoidea delimitada ventralmente sólo por el articular, de modo que no hay contacto entre el esplenial y la faceta infracoronoidea del suprangular ([C100]); este esquema se observa sólo en T. teguixin y T. merianae. El contorno de la cresta angular también indica afinidad con esta última especie ([C105]).

Al comparar los dientes de los fósiles con la serie ontogenética de T. merianae se nota la presencia únicamente de dientes romos y robustos en la parte posterior de las series dentarias; esto sugiere que la LSDd debería ser mayor a 51,49 mm (ver Cap. III). Esta inferencia se verifica para MACN Pv 14312-13, cuya LSDd es de 52,32 mm, pero para MACN Pv 14312-14 este valor es levemente menor al límite (LSDd = $48,05 \mathrm{~mm}$ ), a pesar de lo cual, se considera que los fósiles aquí descriptos corresponden a individuos adultos

Por todo lo expuesto, los materiales considerados como un estadío adulto de $T$. preteguixin por Rovereto (1914) son reasignados a Tupinambis sp. La hemimandíbula MACN Pv 14312-13 puede ser referida como Tupinambis $\mathrm{cf}$. merianae por presentar un mayor número de elementos diagnósticos a nivel específico ([C100], [C105]). 
Observaciones sobre la descripción de "Tupinambis preteguixin" presentada por Rovereto (1914). Rovereto (1914) asignó los fósiles MACN Pv 14310 y MACN Pv 14312 a la especie extinta "T. preteguixin". Entre este conjunto de materiales fósiles, Rovereto (1914) reconoció ejemplares juveniles (MACN Pv 14310) y adultos (MACN Pv 14312) aunque no argumentó las bases de esta distinción, la cual se supone fue el tamaño. En esta Tesis se considera que las características dentarias de varios elementos catalogados bajo el número MACN Pv 14310 permiten diferenciar ejemplares de diferentes tallas: los fósiles MACN Pv 14310-3, MACN Pv 14310-5 y MACN Pv 14310-6 corresponden a individuos de menores dimensiones que los fósiles MACN Pv 14310-1/2.

Rovereto (1914) nominó la nueva especie extinta "T. preteguixin" en base a medidas comparadas de estos fósiles con las dos especies de Tupinambis que se distribuyen en Argentina, T. merianae y T. rufescens. Aparentemente, la muestra de ejemplares actuales utilizada por Rovereto (1914), le indicaba que T. merianae es de mayores dimensiones que $T$. rufescens. Sin embargo, la LHC máxima registrada para T. merianae y T. rufescens es de 420 mm (Yanosky y Mercolli, 1995) y 614 mm (Péres Jr. y Colli, 2004) respectivamente, que son valores contrarios a los supuestos por Rovereto (1914). Independientemente, los valores aportados por dicho autor no presentan grandes diferencias entre sí ni con el material fósil, por lo que son desestimadas como discriminatorias. Las variaciones observadas por Rovereto (1914) en la dentición son consideradas normales para ejemplares de Tupinambis de ambas especies.

Entre los caracteres cualitativos, Rovereto (1914) menciona un lacrimal con surcos pronunciados. Sin embargo, dicho lacrimal no fue identificado entre el material depositado bajo los números MACN Pv 14310 y MACN Pv 14312. Este autor también hace mención a la presencia de un surco labial sobre el yugal, pero el yugal examinado (MACN Pv 14312-2) no presenta dicho surco. Por último, Rovereto (1914: 173) considera como un carácter importante la forma del dentario (y la serie dentaria) en vista oclusal, la que considera recta en $T$. rufescens y arqueada en $T$. merianae. Estas afirmaciones no se pudieron ser confirmar en el material de referencia.

La presencia de dientes molariformes robustos y romos permiten la asignación al género Tupinambis de todo el material fósil referido por Rovereto (1914) 
diferencialmente a ejemplares adultos y juveniles de la especie extinta " $T$. preteguixin” (MACN Pv 14310 y 14312), la cual se considera inválida.

\section{Tupinambis sp.}

(T. prerufescens Rovereto, 1914)

(Fig. 51, 52, 53, 54)

Material referido: MACN Pv 14314. Incluye varios elementos catalogados bajo el mismo número. Estos elementos representan como mínimo a dos individuos. Rovereto (1914) describió la especie “T. prerufescens" sobre la base de sólo dos elementos de este conjunto (frontal y dentario-esplenial izquierdos), pero los restantes huesos no fueron descriptos por este autor. Los elementos referidos son: frontal (MACN Pv 14314-1); prefrontal derecho (MACN Pv 14314-2); proceso posterior de ambos maxilares (MACN Pv 14314-3/4); postfrontal-postorbital derecho (MACN Pv 14314-5); yugal derecho (MACN Pv 14314-6); ambos palatinos incompletos (MACN Pv 14314-7/8); pterigoides izquierdo incompleto (MACN Pv 14314-9); ectopterigoides izquierdo (MACN Pv 14314-10); ambos cuadrados (MACN Pv 14314-11/12); parabasiesfenoides (MACN Pv 14314-13); supratemporal? izquierdo incompleto (MACN Pv 14314-14); escamoso? derecho (MACN Pv 14314-15); fragmento anterior de hemimandíbula izquierda que incluye dentario con dientes, esplenial, coronoides y fragmentos del suprangular, articular y angular, todos articulados (MACN Pv 14314-16); articular derecho (MACN Pv 14314-17); suprangular y coronoides derechos articulado (MACN Pv 14314-18); nueve vértebras (MACN Pv 14314-19 a MACN Pv 14314-27); clavícula derecha (MACN Pv 1431428); escápula y coracoides incompleto derechos articulados (MACN Pv 14314-29); tibia derecha incompleta (MACN Pv 14314-30); fémur izquierdo incompleto (MACN Pv 14314-31); dos epífisis (MACN Pv 1431-32/33); MACN Pv14314-miscelánea: 45 fragmentos indeterminados.

Procedencia geográfica: Farola Monte Hermoso (38 $\left.58^{\prime} \mathrm{S}, 61^{\circ} 41^{\prime} \mathrm{O}\right)($ Cione y Tonni, 1995a: 54), provincia de Buenos Aires.

Procedencia estratigráfica: Formación Monte Hermoso (Zavala, 1993), Montehermosense s.l., Mioceno tardío - Plioceno temprano. 
Redescripción. La dentición en los elementos portadores de dientes descriptos en esta sección es subpleurodonte, los dientes presentan depósitos abundantes de cemento sobre sus bases que disimula los septos interdentales (Cap. III).

El frontal (MACN Pv 14314-1) se conserva prácticamente completo, pero no se ha preservado el proceso lateral izquierdo (Fig. 51 A, B). Se trata de un frontal de bordes ligeramente cóncavos. En detalle, se nota que cada lado se subdivide en dos concavidades; la anterior donde articula con el prefrontal y la posterior, de mayor extensión, que conforma el borde dorsal de la órbita. El proceso medial es similar al proceso lateral derecho. La superficie dorsal presenta irregularidades superficiales y termina posteriormente en una recta sutura con el parietal. Una sutil depresión anteroposterior en la parte media posterior del frontal corresponde a la unión de las escamas supratemporales. Ventralmente, los procesos ventrales no se unen en la línea media; presentan mayor desarrollo posterior y se disponen siguiendo el contorno del frontal. Los procesos ventrales están presentes sólo en la mitad posterior del frontal, indicando que el prefrontal excluía en gran medida al frontal de la fenestra orbitonasal.

El prefrontal derecho (MACN Pv 14314-2) (Fig. 51 C) se conserva completo. El proceso maxilar es una amplia superficie levemente convexa. El borde de la órbita está delimitado por el proceso supraorbital y el proceso lacrimal; entre ambos hay una importante depresión. Proximalmente, sobre el proceso supraorbital, se observa un importante engrosamiento. Uno similar, pero de menor desarrollo, se advierte sobre el proceso lacrimal. El proceso palatal se conserva deficientemente; sin embargo, puede notarse el borde medial del foramen lacrimal.

Se conservan los procesos posteriores de un maxilar izquierdo (MACN Pv 14314-3) y de uno derecho (MACN Pv 14314-4) (Fig. 51 D, E). En ambos, en vista lingual, se puede apreciar el canal posterior al foramen de ingreso al canal alveolar superior, y más lingualmente, parte del angosto surco que recibe al yugal. No se conserva el estante supradental en ninguno de ellos. Los últimos cuatro y tres alvéolos funcionales se conservan en el maxilar izquierdo y el derecho respectivamente. Sólo los últimos tres dientes están presentes en ambos casos. Todos los dientes conservados son robustos. En el maxilar izquierdo el diente (b) es romo, aunque se insinúan leves protuberancias mesial y distal; mientras que los dientes (c) y (d) son bicuspidados, con cúspides más nítidamente diferenciadas en el diente (c). En el maxilar derecho los dientes (a) y (b) son similares al (b) del maxilar izquierdo; el restante diente es 
robusto y bicuspidado. Los dientes presentan finas estrías que convergen apicalmente. En ambos maxilares, lingualmente a los dientes funcionales, se observa importantes alvéolos de reemplazo, los que abarcan casi todo el alvéolo funcional, pero no se conservan dientes de reemplazo.

El postfrontal-postorbital derecho (MACN Pv 14314-5) se conserva completo (Fig. 51 F, G) y no se observa línea de fusión entre ambos huesos. La región dorsal, correspondiente al postfrontal, presenta un desarrollado proceso anteromedial y un reducido proceso posteromedial. La región correspondiente al postorbital se orienta horizontalmente. Las superficies de articulación con el yugal y el escamoso se observan en posición anterior y posterior respectivamente, aunque con escasa definición.

El yugal derecho (MACN Pv 14314-6) se conserva completo (Fig. $51 \mathrm{H}$ ). Tiene forma de bumerang, con un delgado proceso temporal y un desarrollado proceso maxilar. Este último es ligeramente cóncavo y los límites de las superficies de articulación con el maxilar y lacrimal están muy marcados. El borde posterolateral se encuentra engrosado. El extremo dorsal del proceso temporal se curva algo posteriormente donde articula con el postfrontal-postorbital.

El palatino izquierdo (MACN Pv 14314-7) se conserva mejor que el derecho (MACN Pv 14314-8) (Fig. 51 I). El palatino izquierdo no conserva los extremos distales de los procesos maxilar y vomerino; del proceso pterigoideo sólo se conserva su extremo distal lateral. Ventralmente, entre los procesos maxilar y vomerino, se observa un profundo surco palatino. Medialmente, en vista dorsal, está la parte posterior del surco anteroposterior; no hay forámenes. Del palatino izquierdo se conserva el techo del surco palatino y el borde anteromedial de la fenestra suborbital.

El pterigoides izquierdo (MACN Pv 14314-9) (Fig. 51 J) no conserva la mayor parte de sus procesos. Dorsalmente, en la parte media, se observa la fosa columelar, mientras que posteriormente se continúa el proceso cuadrado. La fosa pterigoidea se encuentra excavada sobre la cara ventral del proceso cuadrado. Anteriormente a la fosa columelar, en posición lateral, se advierte el extremo final del surco transverso que recibe al proceso medial del ectopterigoides, el cual no se conserva. En una posición más anterior y medial se observa la superficie de articulación para el palatino.

El ectopterigoides izquierdo (MACN Pv 14314-10) (Fig. $51 \mathrm{~K}$ ) se conserva casi completo. El proceso posterolateral es de mayor tamaño y más robusto que el 
proceso anterolateral. En vista lingual se observa la parte proximal de la cresta palatina poco definida. Dorsalmente sólo conserva las partes proximales de los procesos maxilar y distal.

Los cuadrados (MACN Pv 14314-11/12) se conservan completos (Fig. 51 L, M). Son huesos robustos, que en vista lateral presentan desarrollo anterodorsal (Fig. 51 L). La cresta timpánica está desarrollada, más engrosada anterodorsalmente (MACN Pv 14314-12). Posteriormente a la cresta timpánica se desarrolla una moderada concha timpánica. En vista posterior, la cresta posterior delimita dos superficies similares. Sobre la cresta medial se observa una desarrollada ala pterigoidea. Ventralmente, el cóndilo articular no ocupa toda la superficie del cuadrado.

El parabasiesfenoides (MACN Pv 14314-13) (Fig. 51 N, N) no conserva el proceso basipterigoideo derecho, el proceso lateral izquierdo ni el extremo distal del proceso paraesfenoides. El proceso basipterigoideo izquierdo es corto, robusto, y su extremo distal es más largo que alto, de mayor desarrollo anterior y de superficie articular cóncava. Las crestas trabeculares y la placa dorsum sella delimitan la silla turca, ventral y posteriormente. En la parte central de la misma se observan los forámenes carotoideos. Los procesos alares son nítidos y se encuentran unidos mediante la crista sellaris.

Un fragmento (MACN Pv 1431-14) plano de deficiente preservación es interpretado como un supratemporal izquierdo (Fig. $51 \mathrm{O}$ ). Otro fragmento pobremente conservado (MACN Pv 1431-15) es interpretado como el escamoso derecho (Fig. 51 P). El proceso anterior del escamoso es cilíndrico; dorsalmente conserva la superficie de articulación para el postorbital. El proceso posterior está pobremente conservado; es corto y robusto, y no se infiere proceso dorsal. 

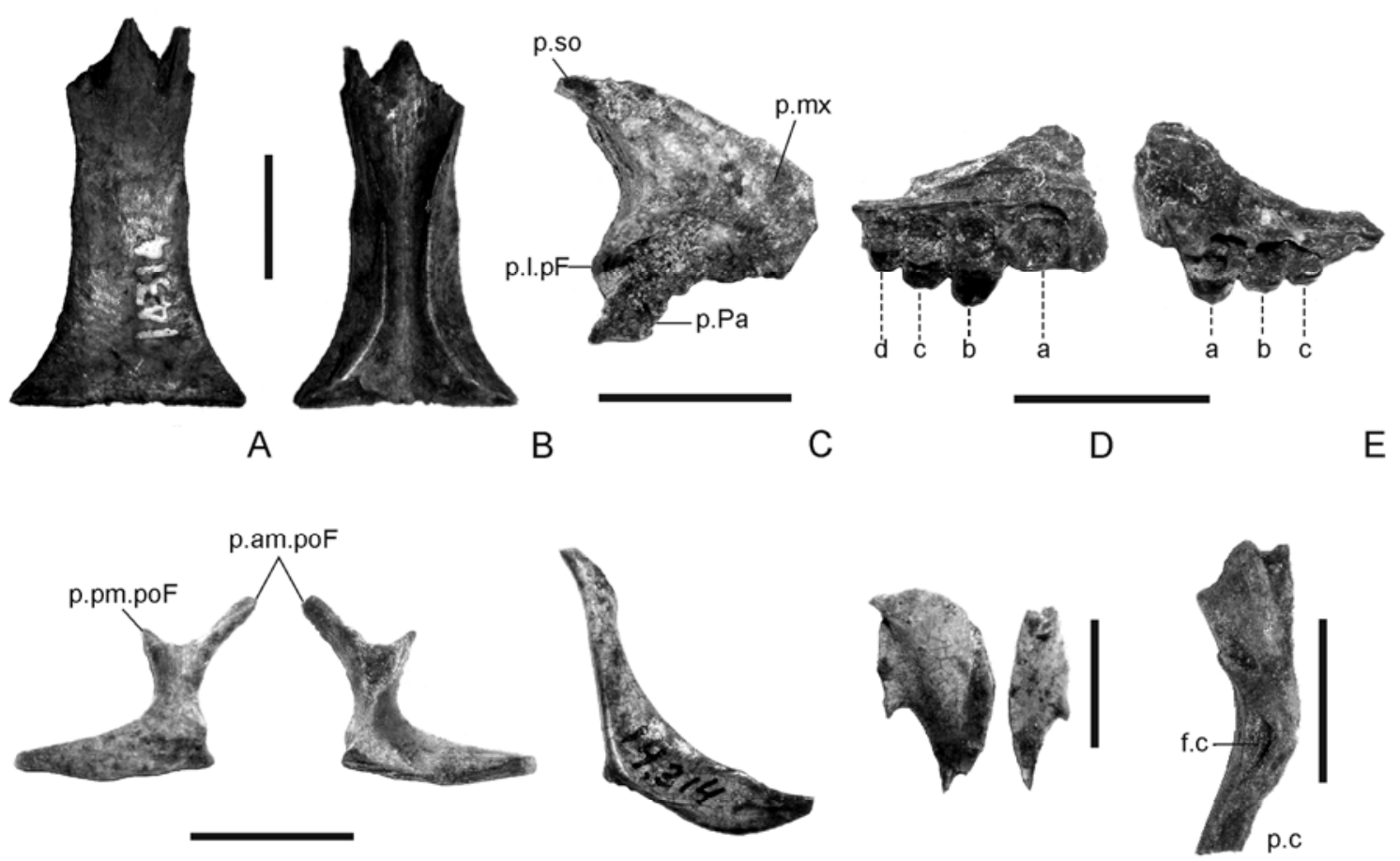

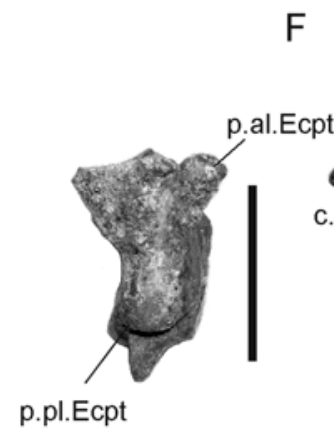

$\mathrm{F}$
G

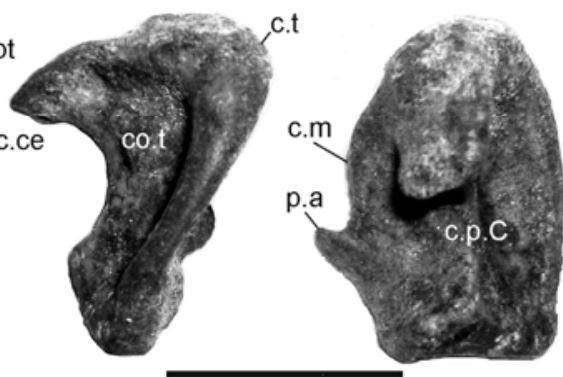

$\mathrm{L}$

$\mathrm{H}$

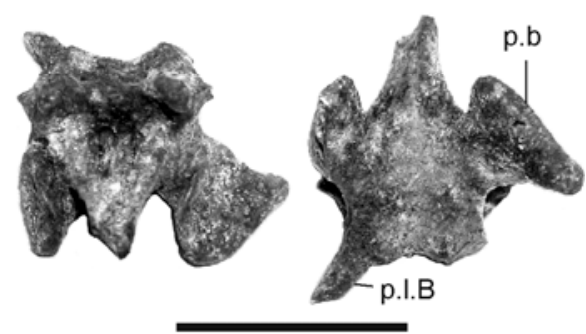

$\mathrm{M}$

$\mathrm{N}$

$\tilde{\mathrm{N}}$

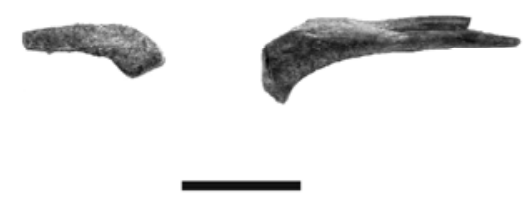

O P

Figura 51. Fragmentos craneales de Tupinambis sp. ("T. prerufescens" Rovereto, 1914) de la Formación Monte Hermoso, Farola Monte Hermoso, provincia de Buenos Aires. A, B, frontal (MACN Pv 14314-1) en vista dorsal (A) y ventral (B); C, prefrontal (MACN Pv 14314-2) en vista lateral; D, maxilar izquierdo (MACN Pv 14314-3) en vista lingual; E, maxilar derecho (MACN Pv 14314-4) en vista lingual; F, G, postorbital-postfrontal derechos (MACN Pv 14314-5) en vistas lateral (F) y medial (G); H, yugal derecho 
(MACN Pv 14314-6) en vista lateral; I, palatinos (MACN Pv 14314-7/8) en vista dorsal; J, pterigoides izquierdos (MACN Pv 14314-9) en vista dorsal; K, ectopterigoides izquierdo (MACN Pv 14314-10); L, M, cuadrado derecho (MACN Pv 14314-11) en vista lateral (L) y posterior (M); N, N, parabasiesfenoides (MACN Pv 14314-13) en vista anterodorsal (N) y ventral (Ñ); O, supratemporal? izquierdo (MACN Pv 14314-14) en vista lateral (MACN Pv 14314-14); P, escamoso? (MACN Pv 14314-15) derecho (MACN Pv 14314-15) en vista lateral. Abreviaturas: c.ce, cóndilo cefálico; c.m, cresta medial;co.t, concha timpánica;c.p.C, cresta posterior del cuadrao; c.t, cresta timpánica; f.c, fosa columelar; p.al.Ecpt, proceso anterolateral del ectopterigiodes; p.am.poF, proceso anteromedial; p.b, proceso basipterigoideos; p.c, proceso cuadrado; p.l.pF, proceso lacrimal; p.1.B, proceso lateral del basiesfenoides; p.Mx, proceso maxilar; p.Pa, proceso palatino; p.pl.Ecpt, proceso posterolateral; p.pm.poF, proceso posteromedial; p.so, proceso supraorbital. Escala $=10 \mathrm{~mm}$.

La hemimandíbula izquierda (MACN Pv 14314-16) conserva el dentario, esplenial, coronoides y fragmentos del suprangular, articular y angular (Fig. 52 A-C). El dentario y esplenial fueron originalmente descriptos por Rovereto (1914) pero erróneamente los describe como derechos, e incluso la figura no coincide con la descripción. En algún momento posterior a la descripción original, este fragmento fue reconstruido. El dentario no conserva su parte posterodorsal. Es poco profundo y largo; labialmente es liso y con cinco forámenes mentales, el último a la altura de la diente X. El contorno del borde dorsal es ligeramente cóncavo, con una leve convexidad anterior. El contorno del borde posterior no se puede observar por efecto de la reconstrucción. En vista lingual se observa un desarrollado estante subdental, que posterior a la sínfisis presenta forma de silla de montar; más posteriormente es plano y pierde progresivamente altura. El canal de Meckel está cubierto por el esplenial, pero se infiere que está expuesto medialmente a lo largo de toda su extensión. Anteriormente, no presenta una marcada constricción y termina en la sínfisis. Dorsalmente se observa el surco dental que aloja a la serie dentaria, la cual está flanqueada lingualmente por un desarrollado sulcus dentalis. Se conservan los 14 alvéolos anteriores. La primeros seis dientes faltan, mientras que de los dientes VII y VIII se conservan sólo las bases. Los dientes IX a XI son rectos, altos, robustos y unicuspidados. El diente XII es similar a los anteriores pero más bajo. El diente XIII es bicuspidado robusto y de sección longitudinalmente oval. La cara labial es más convexa que la lingual. La cúspide distal es la dominante, no presenta mayor diferenciación de la mesial, que es cónica y recta. Sobre la cara oclusal, se observa una cresta mesodistalmente orientada, que se desarrolla posteriormente a la cúspide 
mesial. El extremo distal de esta cresta se curva un poco lingualmente. El diente XIV es similar al anterior pero tricuspidado. La cúspide central es claramente dominante, mientras que la cúspide mesial es mayor a la distal. La diferenciación entre las cúspides anteriores (mesial y media) es más pobre que lo que se observa en el diente bicuspidado anterior. Sobre el sulcus dentalis se presenta una serie de alvéolos de reemplazo mal conservados, ubicados lingualmente a los funcionales. Se conservan dientes en los alvéolos de reemplazo VII, IX a XII y XIV. El diente de reemplazo anterior es unicuspidado, labiolingualmente comprimido. Los centrales son robustos, pero el estado de conservación de los mismos no permite observar adecuadamente sus extremos apicales. El último diente de reemplazo es robusto y tricuspidado. El esplenial se encuentra levemente desplazado. Es cuneiforme, muy extendido anteriormente; plano, pero levemente cóncavo anteriormente a los forámenes labial anterior y milohioideo anterior. El foramen labial anterior se encuentra anterodorsalmente al foramen milohioideo anterior y se ubican a la altura de los dientes XI y XII respectivamente. Del articular se conserva la parte medial de su proceso anterior; que es plana y articula con el dentario anteriormente y con el suprangular dorsalmente. El coronoides no conserva el proceso posteromedial y los procesos anteriores no conservan sus extremos distales. El proceso dorsal es grande, robusto y presenta una marcada cresta labial. El proceso posterolateral es reducido y anteriormente solapa al suprangular. El coronoides delimita una clara fenestra coronoidea donde está expuesta la faceta infracoronoides del suprangular. Del suprangular se conserva su extremo anterior, que labialmente conserva el foramen anterior. El suprangular abarca la mayor parte de la cuña del borde posterior del dentario, dejando al fragmento del angular restringido a una pequeña parte ventral de esta cuña.

La hemimandíbula derecha está representada por el articular (MACN Pv 14314-17) y el suprangular articulado con el coronoides (MACN Pv 14314-18) (Fig. $52 \mathrm{D})$. El coronoides conserva el proceso dorsal y el proceso posterolateral. El primero presenta una fuerte cresta oblicua labialmente, mientras que el segundo está reducido. Del suprangular se conserva la parte dorsal que delimita el borde de la fosa mandibular, que se encontraría engrosado con respecto a la parte ventral del suprangular. Antreolingualmente conserva el foramen anterior. El articular no conserva el proceso anterior. La superficie articular está marcadamente delimitada. Posteriormente se desarrolla un corto y robusto proceso retroarticular. Dorsalmente, la 
cresta timpánica se orienta oblicuamente y la superficie lingual que delimita es suavemente cóncava. En vista lingual, presentan una recta cresta horizontal. El proceso angular es nítido, oblicuo y no sobresale de la cresta articular. El contorno lateral de la cresta prearticular es ligeramente cóncavo y de disposición oblicua, no diferenciado del proceso articular.

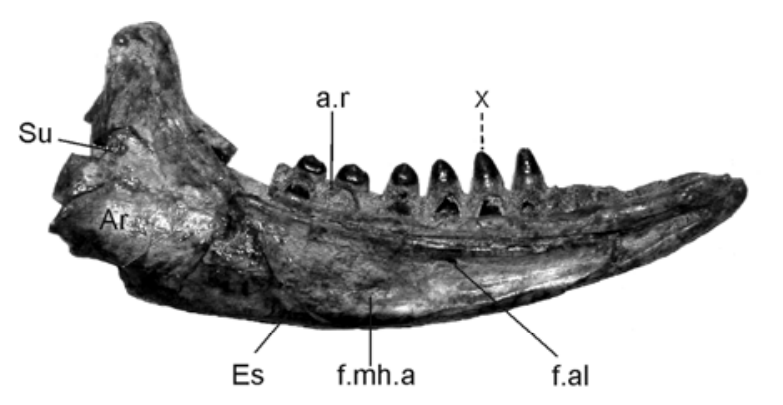

A

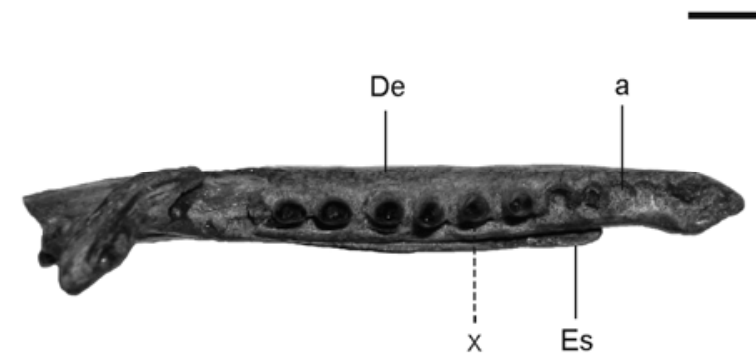

C

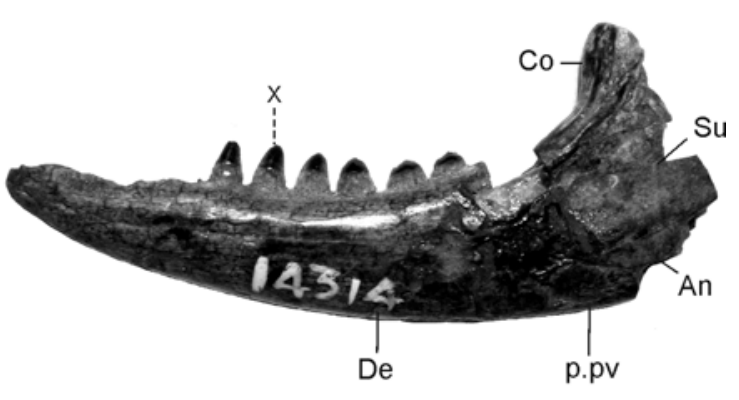

B

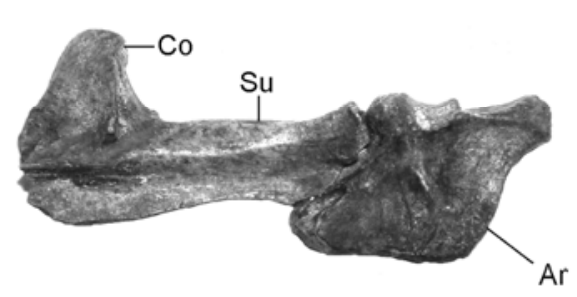

Figura 52. Fragmentos mandibulares de Tupinambis sp. ("T. prerufescens" Rovereto, 1914) de la Formación Monte Hermoso, Farola Monte Hermoso, provincia de Buenos Aires. A, B, C, hemimandíbula izquierda (MACN Pv14314-16) en vista lingual (A), labial (B) y oclusal (C); D, articula (MACN Pv1431417) y suprangular-coronoides (MACN Pv14314-18) en vista lingual y articulados. Abreviaturas: a, alvéolo funcional; An, angular; Ar, articular; a.r, alvéolo de reemplazo; Co, coronoides; De, dentario, Es, esplenial; f.al, foramen alveolar; f.mh.a, foramen milohioideo anterior; p.pv, proceso posteroventral; $\mathrm{Su}$, suprangular. Escala $=10 \mathrm{~mm}$.

Se conservan nueve vértebras (MACN Pv 14314-19 a MACN Pv 14314-27) procélicas y con articulación zigósfeno-zigantro. Las vértebras MACN Pv 14314-19 (Fig. 53 A-E) y MACN Pv 14314-20 están completas. Un conjunto de las vértebras restantes tienen diferentes grados de conservación de su lado derecho, en algunas no se conservan la prezigapófisis y proceso transverso (MACN Pv 14314-21/23), la parte derecha del zigósfeno (MACN Pv 14314-21), del cóndilo (MACN Pv 14314-23) o 
postzigapófisis (MACN Pv 14314-23/24 y MACN Pv 14314-26). La vértebra MACN Pv 14314-23 tampoco presenta la prezigapófisis izquierda y mientras que la vértebra MACN Pv 14314-26 no conserva la parte posterior al cótilo del centro vertebral. La vértebra MACN Pv 14314-22 esta pobremente conservada, ha perdido la prezigapófisis izquierda, el proceso transverso izquierdo, la parte izquierda del zigósfeno, ni el cóndilo; la vértebra MACN Pv 14314-23 no conserva las prezigapófisis, el proceso transverso derecho ni la parte derecha del cóndilo. La vértebra MACN Pv 14314-25 no conserva la espina neural ni postzigapófisis izquierda, mientras que todo el arco neural falta en la vértebra MACN Pv 14314-27. Estas vértebras son dorsales, excepto la MACN Pv 14314-21, que es una vértebra cervical.
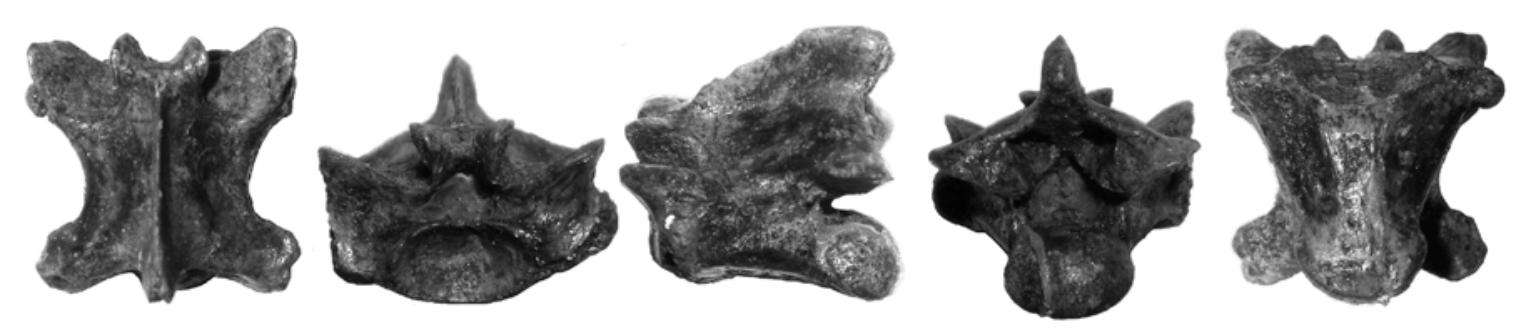

A

B

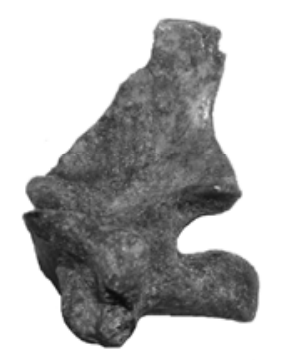

F

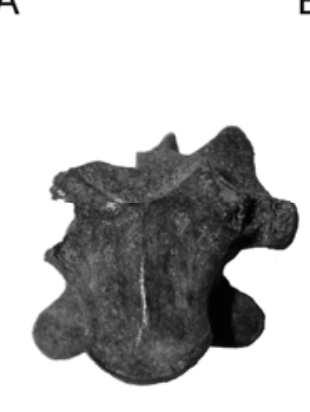

Figura 53. Vértebras de Tupinambis sp. (“T. prerufescens" Rovereto, 1914) de la Formación Monte Hermoso, Farola Monte Hermoso, provincia de Buenos Aires. A-E, vértebra dorsal MACN Pv 14314-19 en vistas dorsal (A), frontal (B), lateral (C), posterior (D) y ventral (E). F, G, vértebra cervical MACN Pv 14314-21 en vista lateral $(F)$ y ventral $(G)$. Escala $=10 \mathrm{~mm}$.

En todas las vértebras dorsales se advierte que el arco neural es largo y bajo. La espina neural es baja, ensanchada posterodistalmente, e inclinada posteriormente; su extensión posterior no supera el nivel del cóndilo. El canal neural, en vista anterior, 
es triangular, bajo y de tamaño moderado mientras que en vista posterior es algo más grande. El zigósfeno está marcadamente escotado y es menos ancho que el cótilo, con las carillas de articulación casi paralelas al plano sagital. Los contornos de estas carillas son subcirculares a subtriangulares, variación que podría deberse, al menos en parte, al estado de conservación del extremo distal en relación al proximal. Las prezigapófisis y postzigapófisis se orientan anterolateralmente y posterolateralmente en forma respectiva. El desarrollo lateral de las prezigapófisis es levemente inferior al de las postzigapófisis. Las superficies de articulación de las prezigapófisis se encuentran inclinadas respecto a la horizontal; los contornos de las carillas de articulación varían entre oval y subtriagular. Los procesos transversos son robustos, se desarrollan verticalmente, en una posición ventral a las prezigapófisis, sobre la parte anterior de las vértebras. En vista anterior son levemente cóncavos, de contorno recto y vertical. En vista dorsal, los procesos transversos levemente superan la longitud de las prezigapófisis. Sobre el extremo distal de los procesos transversos se dispone la sinapófisis, que es oval y está verticalmente dispuesta. Los centros vertebrales son cónicos, truncados posteriormente. Su superficie ventral es recorrida anteroposteriormente por una ancha y poco definida cresta sagital. El cótilo es grande, transversalmente oval, excavado y anteriormente inclinado. El cóndilo es oval, dorsalmente inclinado y se encuentra precedido por un marcado cuello condilar.

La vértebra MACN Pv 14314-21 es similar a las previamente descripta, sin embargo, difiere por presentar la espina neural más alta y de orientación vertical (Fig. $53 \mathrm{~F}$ ), y sobre el centro vertebral se observa una cresta sagital en forma de un delgado filo longitudinal (Fig. $53 \mathrm{G}$ ). Estos caracteres permiten inferir que se trata de una vértebra cervical.

De la cintura pectoral se conserva la clavícula derecha (MACN Pv 14314-28) (Fig. 54 A) y la escápula articulada a parte del coracoides derecho (MACN Pv 1431429) (Fig. 54 B, C). La clavícula es robusta, subcilíndrica y sigmoide. El extremo ventral está dorsoventralmente aplanado; aunque no se conserva completo, se infiere que presentaba cierto desarrollo posterior. La escápula derecha se conserva completa, es un trapezoide irregular de mayor desarrollo dorsal, plano, lateralmente convexo y medialmente cóncavo. Ventralmente, la escápula articula con el coracoides que no conserva el extremo distal del proceso procoracoides, ni los procesos mesocoracoides y metacoracoides. Anterior a la cavidad glenoidea se presenta un desarrollado foramen supracoracoideo. 
De la tibia izquierda se conserva el extremo proximal (MACN Pv 14314-30) (Fig. 54 D). La superficie articular dorsal es amplia, ligeramente convexa y triangular; de ápice posteriormente dirigido. Ventral a la superficie articular, la tibia se hace más angosta; medialmente posee presenta una nítida cresta cnemial. Del fémur izquierdo no se conserva el extremo distal (MACN Pv 14314-31) (Fig. 54 E). Es un hueso robusto y cilíndrico. La cabeza articular del fémur se orienta paralela al eje longitudinal del hueso; ventralmente, y separada por la fosa intertrocantérica, se observa un desarrollado trocánter interno. Se conservan dos epífisis, una (MACN Pv 14314-32) corresponde a la distal de un fémur derecho, diferenciándose los cóndilos anterior y posterior. La otra epífisis (MACN Pv 14314-33) es indeterminada.

Bajo el mismo número de colección se conservan 45 fragmentos pequeños (MACN Pv14314-misceláneas), entre los cuales se destacan tres posibles metacarpales o metatarsales (Fig. 54 F) y cuatro falanges (Fig. 54 G).
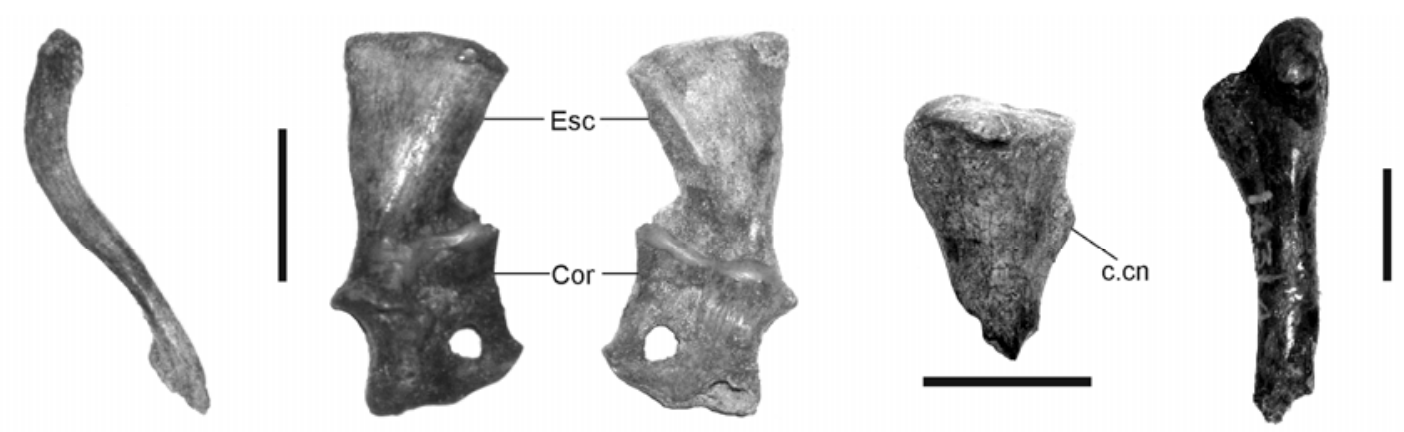

A

B

C

$\mathrm{D}$

E

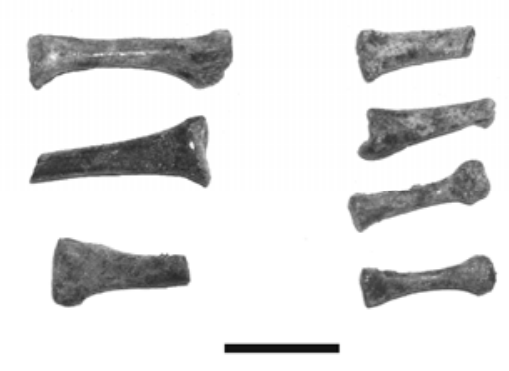

$\mathrm{F}$

G

Figura 54. Fragmentos del esqueleto apendicular de Tupinambis sp. ("T. prerufescens" Rovereto, 1914) de la Formación Monte Hermoso, Farola Monte Hermoso, provincia de Buenos Aires. A, clavícula derecha (MACN Pv14314-28) en vista lateral; B, C, escápula y coracoides derechos (MACN Pv 14314-29) en vista lateral (B) y medial (C); D, tibia izquierda (MACN Pv 14314-30) en vista posterior; E, fémur izquierdo (MACN Pv 14314-31) en vista ventral. F, metacrapales o metatarsal; G, falanges. Abreviaturas: c.cn, cresta cnemial; Cor, coracoides; Esc, escapula. Escala $=10 \mathrm{~mm}$. 
Comentarios taxonómicos. La presencia de alvéolos de reemplazo profundos y subcirculares (MACN Pv 14314-3/4; MACN Pv 1431-16), el abundante cemento basal (MACN Pv 14314-3/4, MACN Pv 14314-16) y un esplenial hipertrofiado, anteriormente desarrollado (MACN Pv 14314-16), son características que permiten la inclusión de los fósiles en el clado Borioteiioidea-Teiioidea. Estos caracteres, así como otros (véase Cap. V), los excluyen de los Gymnophthalmidae. Los fósiles presentan el proceso posterodorsal del dentario cubierto por el proceso anterolateral de coronoides (MACN Pv 1431-16) ([C86], [C98]) y el frontal impar (MACN Pv 1431-1) caracteres compartidos con los Teiioidea y ausentes en los Borioteiioidea (Cap. V). Además, el cóndilo articular de los cuadrados (MACN Pv 14314-11/12) no ocupa todo el extremo ventral del hueso como ocurre en los Borioteiioidea, sino que ocupa aproximadamente 2/3 del extremo distal, como en los Teiioidea, (Denton y O’Neill, 1995; Nydam y Cifelli, 2002b; Nydam et al., 2007) (Cap. V).

Entre los Teiidae, varios caracteres confirman la afinidad de los fósiles con los Tupinambinae: proceso maxilar del yugal ligeramente cóncavo labialmente (MACN Pv 14314-6) ([C26]); cuadrados robustos ([C59]), con expansión anterolateral ([C65]) y medial ([C61]), y con el cóndilo cefálico ventralmente curvado (MACN Pv 1431411/12) ([C62]); canal de Meckel sin restricción anterior ([C88]) y finalizando en la sínfisis ([C89]) (MACN Pv 14314-16); esplenial (MACN Pv 14314-16) ligeramente cóncavo anteriormente a sus forámenes ([C97]); y cresta timpánica de disposición oblicua sobre el proceso retroarticular (MACN Pv 14314-17) (excepto Callopistes y T. quadrilineatus) ([C111]).

Entre los Tupinambinae es posible hacer algunas diferenciaciones genéricas a través de caracteres del cráneo, mandíbulas y dentición (véase Cap. V). En este contexto, los fósiles comparten con Tupinambis y Callopistes la cresta articular (MACN Pv14314-18) desarrollada ([C104]) (excepto T. quadrilineatus), y el contorno de la cresta prearticular, ligeramente cóncavo y oblicuo ([C105]). Sin embargo el material fósil difiere de Callopistes por carecer, en la región correspondiente al postfrontal, de la proyección anterior hacia la órbita ([C42]) y por el desarrollado proceso posterodorsal del esplenial (MACN Pv 14314-16 ([C95]). Los fósiles comparten con Tupinambis y Crocodilurus el tipo de implantación dentaria ([C120]), el contorno dorsal cóncavo del dentario (MACN Pv 14314-16) ([C85]) y el borde posterior del dentario en cuña que recibe al suprangular (mayoritariamente) y al angular ([C92]). Sin embargo, difieren de Crocodilurus y se asemejan a Tupinambis 
por los dientes posteriores robustos ([C121], [C127]), la depresión dorsal somera sobre el proceso retroarticular (tampoco presente en Callopistes y T. quadrilineatus) ([C110]) y el borde medial del proceso retroarticular de desarrollo medial ([C113]). La expansión anterodorsal del cuadrado (y cresta timpánica) diferencia al material fósil de todos los Tupinambinae excepto Tupinambis ([C60]).

La fenestra subcoronoidea en el fósil MACN Pv 14314-16 es nítida, aunque sus bordes no son tan claros por ligeros desplazamientos de los huesos; sin embargo, se infiere claramente que no hay contacto esplenial - faceta infracoronoidea del suprangular. Estas configuración entre las diferentes especies de Tupinambis, se observa sólo en T. merianae y T. teguixin ([C100], [C101]). Sin embargo en el fósil MACN Pv 14314-17 el proceso angular no se encuentra libre como en T. teguixin, sino que se asemeja a la condición observada en T. merianae ([C105]).

Por otro lado, la fusión postfrontal-postorbital (MACN Pv 14314-5) ([C40]) no se observa en el género Tupinambis. Contrariamente a lo que ocurre entre los "cnemidoforinos", donde esta fusión es sinapomórfica (Cap. V), entre los Tupinambinae el postfrontal se fusiona con el postorbital sólo en Dracaena.

La presencia de dientes posteriores cuspidados robustos, con tendencia a la molarización coincide con la asignación genérica deducida por los caracteres craneales y mandibulares. Al comparar la dentición de los maxilares con la serie ontogenética de T. merianae se observa que dientes bicuspidados robustos como los de los maxilares MACN Pv 14314-3/4, corresponden a individuos subadultos, de una LSDd no mayor a 51,49 mm $(=\mathrm{LSDm}=44,48 \mathrm{~mm})(\mathrm{UNMdP}-\mathrm{O} 17)$. La dentición del dentario MACN Pv 14314-16, que presenta dientes posteriores robustos, bicuspidados y tricuspidados, y ausencia de dientes robustos romos, indica que se trataría de un subadulto con 36,69 mm (UNMdP-O 14) < LSDd < 41,69 mm (UNMdP-O 6). El límite mayor corresponde a individuos que no presentan dientes robustos y romos; sin embargo, como se describió en el Capítulo III, dientes robustos y romos también se encuentran en individuos subadultos. La longitud de la serie dentaria de MACN Pv 14314-16 (LSDd $\approx 40,92 \mathrm{~mm}$, contra $43 \mathrm{~mm}$ descriptos por Rovereto (1914)) coincide con lo inferido previamente. El dentario MACN Pv 14314-16 presenta 14 dientes, el cual, a pesar de ser un valor bajo, se encuentra dentro de la variación observada en la muestra de T. merianae utilizada (Tabla 9). Incluso, Barberena et al. (1970) mencionan valores aún menores para dentarios de esta especie. 
Como ya se mencionó, no hay caracteres vertebrales diagnósticos para los Teiidae, sin embargo las vértebras fósiles son grandes y coinciden con las características presentes en las vértebras de Tupinambis (Cap. III). Como se observa en toda la familia, el género Tupinambis presenta ocho vértebras cervicales (Krause, 1978a; Veronese y Krause, 1997; obs. pers.). Sólo las seis primeras vértebras presentan hipapófisis, mientras que sobre el centro vertebral de las vértebras séptima y octava, puede observarse una cresta sagital en forma de un filo longitudinal, como en la vértebra MACN Pv 14314-21 (Fig. 53 G).

Con respecto al esqueleto apendicular, Krause (1990) sostiene que existe diferencia en el desarrollo de la cresta cnemial de la tibia entre los Teiidae. Sin embargo, esta afirmación no se verificó en el material de referencia debido a la variabilidad intragenérica que presenta (e.g. Tupinambis) y lo subjetivo de la valorización de su desarrollo. Un conjunto de caracteres de la cintura pectoral muestra afinidad con los Tupinambinae: escápula (MACN Pv 14314-13) levemente excavada medialmente ([C131]), sin fenestra escapular (compartido con "Ameiva”) ([C132]); y clavícula de extremo ventral no perforado ([C133]) y con forma de gancho ([C134]).

En su conjunto, los materiales fósiles presentan una morfología craneal y postcraneal como la de Tupinambis. Sin embargo, en el género actual, el postfrontal y el postorbital siempre se encuentran como huesos individuales, y éste no es el caso del fósil MACN Pv 14314-5. Esta condición podría ser una autapomorfía de una especie extinta de Tupinambis, o la fusión de postfrontal-postorbital podría ser resultado de un evento particular (e.g. teratológico, etc.). Entre todos los postfrontales y postorbitales (MACN Pv 14310, MACN Pv 14311) recuperados en el sitio Farola Monte Hermoso, y asignados a este género, éste es el único caso donde se presentan fusionados. Por esta razón y la presencia de postfrotal y postorbital separados en el material actual de Tupinambis, se favorece la segunda hipótesis. Dentro del género Tupinambis, las características del fósil MACN Pv 14314-17 se asemejan especialmente a $T$. merianae.

\section{Observaciones sobre la descripción de "Tupinambis prerufescens" presentada} por Rovereto (1914). Rovereto (1914: 174) considera que esta especie "tiene muchos puntos de contacto con (el) T. rufescens, si bien comparándosele con éste, se nota que tienen dimensiones más pequeñas". En primer lugar, en cuanto al tamaño relativo de los lagartos comparados por Rovereto (1914), se recuerda que la muestra utilizada por 
este autor no refleja la relación de tamaño real entre las especies $T$. merianae y $T$. rufescens (ver MACN Pv 14312) y que los valores que este autor considera significativos, no lo serían. En segundo lugar, Rovereto (1914) no explicita estos "puntos en común" a los que hace referencia. Además, este autor sólo describió muy escuetamente la hemimandíbula MACN Pv 14314-16, considerándola recta como la de T. rufescens, diferente de la arqueada de T. merianae (ver MACN Pv 14312), pero esta diferencia que no ha podido ser corroborada sobre los materiales comparativos. De esta manera, las conclusiones de Rovereto (1914) son aquí desestimadas.

Tupinambis sp.

(T. brevirostris, Rovereto, 1914)

(Fig. 55, 56, 57)

Material referido: MACN Pv 14311. Incluye varios elementos catalogados bajo el mismo número, que corresponderían como mínimo a un individuo. Rovereto (1914) describió la especie " $T$. brevirostris" sobre la base de sólo dos elementos de este conjunto (maxilar izquierdo y dentario-esplenial derecho), pero los restantes huesos no fueron descriptos por este autor. Los elementos referidos son: maxilar izquierdo con dientes (MACN Pv 14311-1); maxilar derecho incompleto con dientes (MACN Pv 14311-2); dentario derecho, con dientes, y esplenial articulado (MACN Pv 143113); suprangular derecho incompleto (MACN Pv 14311-4); postorbital derecho (MACN Pv 14311-5); yugal derecho (MACN Pv 14311-6); postorbital izquierdo incompleto (MACN Pv 14311-7); ambos pterigoides incompletos (MACN Pv 143118/9); axis (MACN Pv 14311-10); vértebra cervical (MACN Pv 14311-11); tres vértebras dorsales (MACN Pv 14311-12 a MACN Pv 14311-14); dos vértebras caudales (MACN Pv 14311-15/16); escápula derecha (MACN Pv 14311-17); coracoides derecho (MACN Pv 14311-18); ulna derecha (MACN Pv 14311-19); fémur izquierdo (MACN Pv 14311-20) y derecho (MACN Pv 14311-21); epífisis distal de fémur izquierdo (MACN Pv 14311-22); fíbula derecha (MACN Pv 1431123); MACN Pv 14311-miscelánea: nueve fragmentos de costillas, siete falanges (una articulada a una octava falange ungeal) y cinco fragmentos indeterminados.

Procedencia geográfica: Farola Monte Hermoso (38 $58^{\prime}$ S, 61 $41^{\circ}$ O) (Cione y Tonni, 1995a: 54), provincia de Buenos Aires. 
Procedencia estratigráfica: Formación Monte Hermoso (Zavala, 1993),

Montehermosense s.l., Mioceno tardío - Plioceno temprano.

Redescripción: La dentición en los elementos portadores de dientes descriptos en esta sección es subpleurodonte (ver Cap. III). Los dientes presentan depósitos abundantes de cemento sobre sus bases que disimula los septos interdentales. Lingualmente, entre las bases de los dientes y el estante dental se presenta un definido sulcus dentalis.

El maxilar izquierdo (MACN Pv 14311-1) es un hueso robusto que se conserva completo (Fig. 55 A, B). Labialmente es liso, sin ornamentación; presenta cinco forámenes labiales, el último de los cuales se encuentra a la altura del IX diente. El proceso premaxilar es bífido; la rama lingual de este proceso es larga mientras que la rama labial es más corta, robusta y cónica. En vista lingual, sobre la superficie dorsal del proceso premaxilar, se observa una nítida lámina transversal anterior, dorsomedialmente recorrida por una cresta. Ventral a esta lámina se conserva la superficie de articulación para el vómer que recorre medialmente toda la rama lingual del proceso premaxilar. Posterior a la lámina, se advierte la depresión donde se ubica el órgano vómero-nasal, detrás de la cual se encuentra la cresta semilunar sobre la lámina facial. No presenta un nítido soporte narial posterior. El estante supradental varía en su desarrollo; el borde de la fenestra del órgano vómero-nasal es aplanado, mientras que el borde de la coana aumenta progresivamente en altura (profundidad) hasta alcanzar el nivel donde se produciría la articulación del palatino y el ectopterigoides (correspondiente a las cinco últimas posiciones dentarias). El proceso frontal del maxilar no se conserva, mientras que el proceso prefrontal está bien desarrollado. La serie dentaria está completa, con 13 dientes. Los primeros siete dientes son unicuspidados, cónicos y distalmente punzantes. De éstos, los dientes II, III y IV son más grandes, robustos y curvos. Los dientes V, VI y VII son más pequeños, menos robustos y similares al I. El VIII es un diente unicuspidado, robusto, recto y alto. Los dientes siguientes son romos, robustos, de sección circular y progresivamente más bajos hacia el extremo posterior de la serie. El último diente no está conservado. El maxilar derecho (MACN Pv 14311-2) es esencialmente igual al izquierdo pero no conserva gran parte de la lámina facial (Fig. 55 C). De la serie dentaria se conservan sólo los 12 primeros alvéolos funcionales en los cuales se alojan dientes completos, excepto en los dos últimos. Los tipos morfológicos dentales y su patrón de distribución son como los descriptos para el maxilar izquierdo. 
El dentario y esplenial derecho se conservan articulados (MACN Pv 14311-3)

(Fig. 55 D). El dentario está parcialmente preservado, no conserva el proceso posteroventral. Se trata de un hueso robusto y profundo; labialmente liso, con al menos tres forámenes mentales, el último de los cuales se ubica a nivel de los alvéolos (f) y (g). El contorno dorsal del dentario es cóncavo, con una muy leve convexidad anterior. En vista lingual se observa el estante subdental bien desarrollado a lo largo de todo el dentario, aunque pierde desarrollo dorsoventral posteriormente. Si bien se encuentra cubierto por el esplenial, se advierte que el canal de Meckel está ampliamente abierto hasta la sínfisis mandibular y no presenta constricción anterior. Dorsalmente, sobre el surco dental, se observa la serie dentaria incompleta, ya que faltan las posiciones dentarias anteriores. Se infiere que lleva unos 16 dientes en total, de los cuales sólo se preservan 14 alvéolos. Los primeros cuatro dientes (a-d) están mal preservados; los siguientes (e-g) son unicuspidados, cónicos, rectos, altos y robustos. Los dientes posteriores (h-m) son robustos, romos y muy poco espaciados entre sí. Falta el diente del último alvéolo conservado (n). Los contornos laterales de los dientes romos presentan una protuberancia apical ubicada posteriormente al eje central de los dientes. Anteriormente a dicha protuberancia, el contorno es recto con una leve pendiente mesial. El esplenial es cuneiforme, profundo posteriormente y muy extendido anteriormente, de modo que llega hasta una corta distancia detrás de la sínfisis, dejando una muy pequeña abertura anterior del canal de Meckel. Se trata de un hueso plano, levemente cóncavo anteriormente al foramen alveolar, el cual se encuentra a la altura del diente $(\mathrm{h})$, mientras que el foramen milohioideo anterior se ubica a la altura del diente (i).

El suprangular derecho (MACN Pv 14311-4) se conserva completo (Fig. 55 E, F). Labialmente, se observa la superficie de articulación para el dentario en posición anterior, y, dorsalmente una superficie menor para el coronoides. El foramen anterior se encuentra posteroventralmente a la suave cresta que delimita la unión con el dentario. Sobre la lámina lingual se observa la faceta infracoronoidea de contorno subcircular.

El yugal y postorbital derechos se encuentran desarticulados (Fig. $55 \mathrm{G}$ ). El yugal (MACN Pv 14311-5) tienen forma de bumerang; presenta un delgado proceso temporal y un robusto proceso maxilar. La cara labial del proceso maxilar es levemente cóncava. En la parte anterior se observan las superficies de articulación para el maxilar (ventral) y lacrimal (dorsal). Labialmente, se conservan dos forámenes 
suborbitales. El postorbital derecho (MACN Pv 14311-6) es un hueso esencialmente de la región temporal; es largo $(18,16 \mathrm{~mm})$, de desarrollo anteroposterior, con el proceso medial de ubicación anterior. Las carillas de articulación para el yugal y el escamoso están bien definidas y diferenciadas. Del postorbital izquierdo (MACN Pv 14311-7) se conserva sólo el extremo anterior, que participa de la órbita.

De los pterigoides (MACN Pv 14311-8/9) se conservan únicamente los procesos cuadrados (Fig. $55 \mathrm{H}$ ), de los cuales el mejor preservado es el izquierdo (MACN Pv 14311-8). Presentan una bien desarrollada fosa pterigoidea sin expansión medial marcada. 

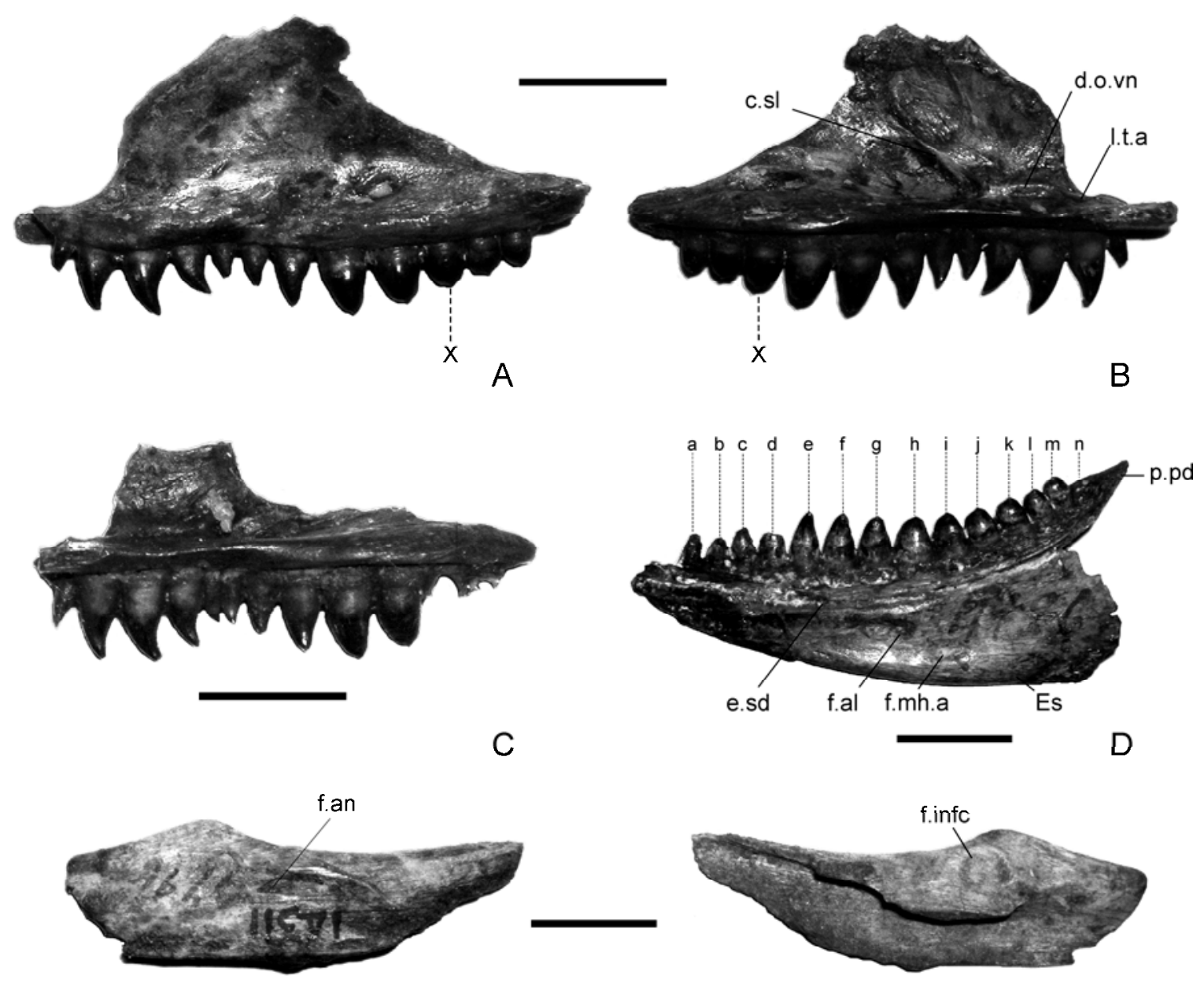

E

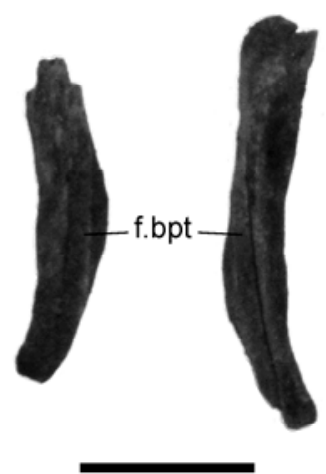

F

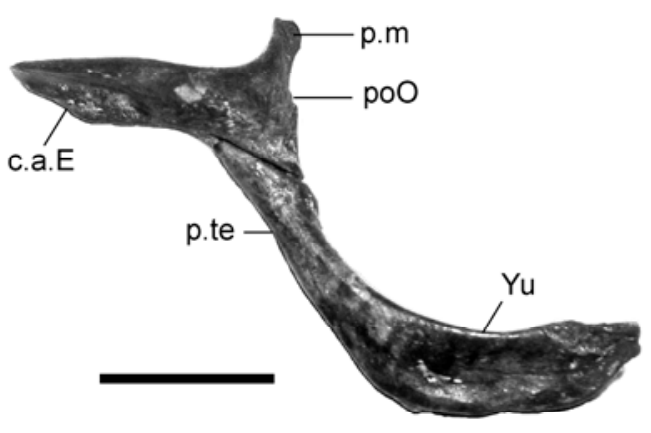

G 
Figura 55. Elementos craneales de Tupinambis sp. ("T. brevirostris" Rovereto, 1914) de la Formación Monte Hermoso, Farola Monte Hermoso, provincia de Buenos Aires. A, B, maxilar izquierdo (MACN Pv 14311-1) en vista labial (A) y lingual (B); C, maxilar derecho (MACN Pv 14311-2) en vista lingual; D, dentario y esplenial derechos (MACN Pv 14311-3) vista lingual; E, F, suprangular derecho (MACN Pv 14311-4); G, yugal (MACN Pv 14311-6) y postorbital (MACN Pv 14311-5) derechos, en posición articulada y en vista labial; H, pterigoides izquierdo (MACN Pv 14311-8) y derecho (MACN Pv 14311-9), en vista ventral, el pterigoides derecho a la izquierda de la figura. Abreviaturas: c.a.E, carilla de articulación para es escamoso; c.o.vn, cuenco del órgano vomero-nasal; c.sl, cresta semilunar; Es, esplenial; e.sd, estante subdental; f.al, foramen alveolar; f.an, foramen anterior del suprangular; f.infc; faceta infracoronoidea; f.bpt, fosa basipterigoidea; f.mh.a, foramen milohioideo anterior; pm, proceso medial; poO, postorbital; p.te, proceso temporal; Yu, yugal. Números romanos indican posición absoluta de posiciones dentarias. Escala $=10 \mathrm{~mm}$.

Del esqueleto axial se conserva un conjunto de vértebras procélicas: el axis, una vértebra cervical, tres vértebras dorsales y dos vértebras caudales. El axis (MACN Pv 14311-10) es alto, largo y angosto (Fig. 56 A). No se conserva la hipapófisis ni los extremos distales de los procesos transversos. El arco neural es alto y largo. La espina neural, aunque pobremente conservada, es elevada, con un importante desarrollo anteroposterior que acompaña toda la longitud de la vértebra y sobrepasando posteriormente el nivel de las postzigapófisis. Posterodistalmente está ensanchada y excavada en su parte ventral (Fig. 56 B). En vista anterior, se conserva sólo la parte proximal de las prezigapófisis. Las postzigapófisis tienen las carillas de articulación casi horizontales, y ubicadas elevadas, a la altura del techo del canal neural. En vista ventral (Fig. 56 C), son subtriangulares y se orientan posterolateralmente. Entre las postzigapófisis se observa, poco definido, el zigantro. La cresta interzigapofisiaria y el margo ventralis están bien demarcados. El canal neural es más alto que ancho; se encuentra mal preservado anteriormente donde es grande y oval, mientras que en vista posterior es pequeño y triangular. El centro vertebral es rectangular, algo ensanchado anteriormente. Una marcada cresta sagital recorre anteroposteriormente su superficie ventral. En la parte anterior, se observa la cicatriz dejada por la pérdida de la hipapófisis. El proceso odontoideo está mal preservado. El cóndilo es pequeño, circular, dorsalmente inclinado y está diferenciado por un cuello condilar claramente demarcado.

La vértebra cervical (MACN Pv 14311-11) (Fig. 56 D-G) se conserva completa, sólo le falta la hipapófisis y los extremos más distales de los procesos transversos. La espina neural es larga, alta e inclinada hacia el extremo posterior. El 
arco neural es alto, más largo que ancho. El borde anterior del zigósfeno está profundamente escotado; las carillas de articulación se encuentran desarrolladas, orientadas casi paralelas al plano sagital. El zigósfeno no supera el ancho del cótilo. Las prezigapófisis están incompletas; son grandes, nacen a nivel medio del canal neural y se orientan anterolateramente en el plano horizontal. Las postzigapófisis son levemente más pequeñas que las prezigapófisis, presentan las carillas de articulación subcirculares, posterolingualmente orientadas y sin inclinación sobre el plano horizontal. La distancia entre las postzigapófisis es menor que la existente entre las prezigapófisis. Los procesos transversos son cortos, ubicados en la parte anterior de la vértebra, dorsoventralmente comprimidos. Distalmente, sobre los procesos transversos, se observan las sinapófisis, que son ovales, con el eje mayor horizontal. El centro vertebral es largo, cilíndrico y robusto. Ventralmente, en su extremo anterior, bordeando el cótilo, se observa la cicatriz de ubicación de la hipapófisis. El cótilo es transversalmente oval, levemente inclinado anteriormente y profundo. El cóndilo es circular, dorsalmente inclinado, y se encuentra precedido por un bien definido cuello condilar.

Se conservan tres vértebras dorsales (MACN Pv 14311-12 a MACN Pv 14311-14), muy similares entre sí. La vértebra MACN Pv 14311-12 no conserva el zigósfeno; la MACN Pv 14311-13 no conserva su parte posterodorsal; y la MACN Pv 14311-14 (Fig. $56 \mathrm{H}-\mathrm{L}$ ) no conserva el proceso transverso izquierdo ni la postzigapófisis izquierda. El arco neural es más ancho que alto en vista lateral. La espina neural es alta, ensanchada posterodistalmente (MACN Pv 14311-14); en vista lateral su borde anterior es cóncavo y se extiende hasta la base del techo zigosfenal, mientras que posteriormente supera el nivel de los extremos postzigapofisarios. El zigósfeno es marcadamente escotado anteriormente; sus carillas de articulación son subtriangulares y se disponen casi paralelas al plano sagital. La distancia entre los extremos del zigósfeno es similar, pero no superan el ancho del cótilo. Las prezigapófisis y postzigapófisis se encuentran muy bien desarrolladas, con orientación anterolateral y posterolateral respectivamente. Sus superficies de articulación están inclinadas aproximadamente $45^{\circ}$ respecto a la horizontal y son de forma entre subcircular a subtriangular. Los procesos transversos son robustos, anteroposteriormente restringidos y dorsoventralmente desarrollados, no superando el borde ventral del cótilo. Sobre el extremo distal de los procesos se encuentra la sinapófisis oval, con sus eje mayor vertical. Los centros vertebrales son cónicos. Los 
cótilos son ovales, más anchos que altos, profundos, anteriormente inclinados con sus circunferencias completas, indicando la ausencia de hipapófisis. Los cóndilos son ovales muy inclinados dorsalmente, y se encuentran precedidos por marcados cuellos condilares.

Se conservan dos vértebras caudales; la vértebra MACN Pv 14311-15 (Fig. 56 $\mathrm{M}, \mathrm{N}$ ) corresponde a una vértebra más anterior que la MACN Pv 14311-16, ambas carecen del plano de autotomía y pertenecen a la región caudal proximal. El arco neural es más largo que alto. La espina neural de la vértebra MACN Pv 14311-15 es grande, alta, larga, angosta e inclinada posteriormente, sobrepasando posteriormente a las postzigapófisis pero no al cóndilo. El zigósfeno es más angosto que el cótilo y está profundamente escotado en su parte media. Las carillas de articulación son prácticamente paralelas al plano sagital. Las prezigapófisis nacen a una altura media respecto al canal neural. Las carillas de articulación de las prezigapófisis y postzigapófisis son ovales, están orientadas más anterior que lateralmente, e inclinadas unos $45^{\circ}$ respecto al plano horizontal. La cresta interzigapofisiaria que une ambas zigapófisis es tenue. El zigantro es pequeño y poco definido. Los procesos transversos presentan una marcada compresión dorsovental, un importante desarrollo antreposterior a lo largo del centro vertebral y se proyectan posterolateralmente. El cótilo es grande, de contorno circular, profundamente cóncavo e inclinado anteriormente. El centro vertebral es cilíndrico, más estrecho en la parte media. El cóndilo está bien diferenciado por un cuello condilar claramente demarcado. En vista posterior, el cóndilo es circular, dorsalmente orientado. La vértebra MACN Pv 1431116 difiere de la descripta por presentar zigósfeno y postzigapófisis de menor tamaño relativo, prezigapófisis orientadas más anteriormente y procesos transversos orientados más lateralmente. 


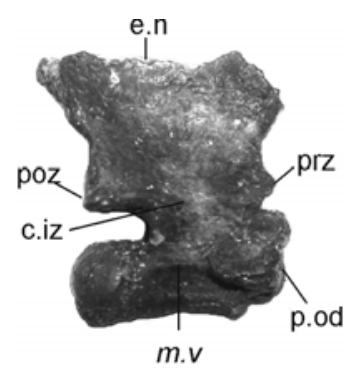

A

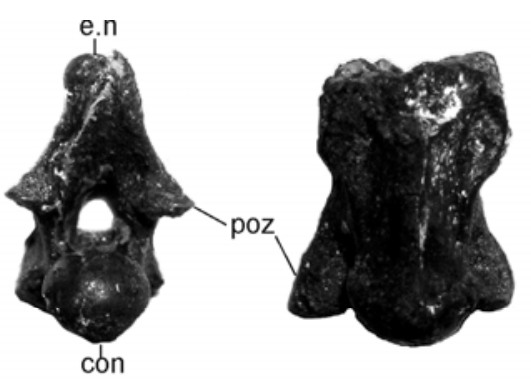

B

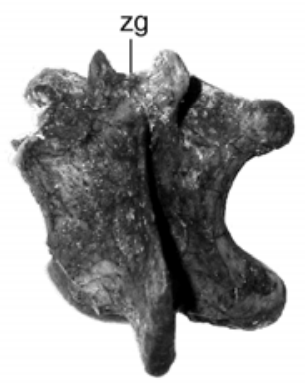

C

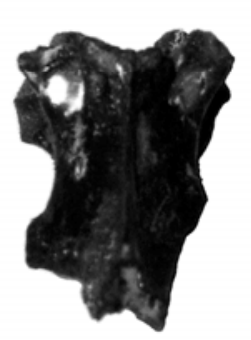

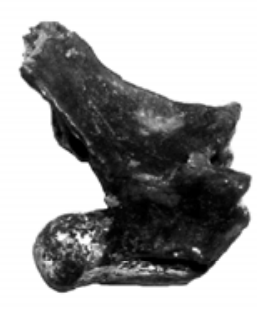
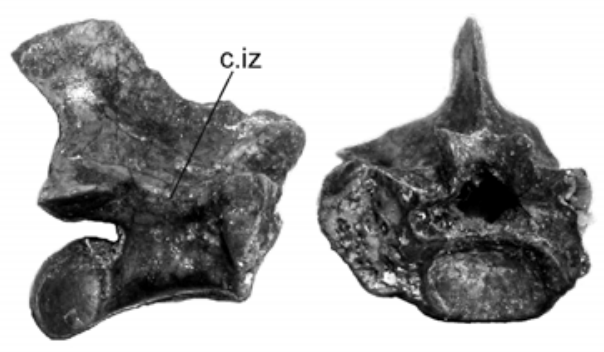

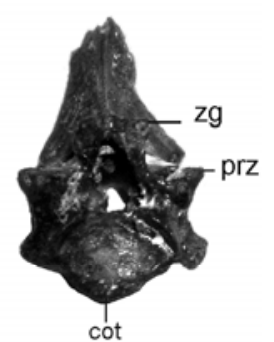

E

F

G

H

I J

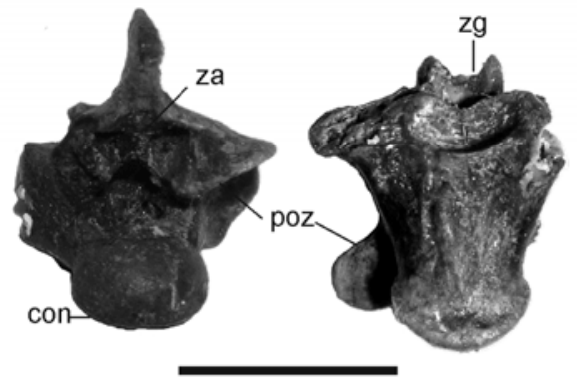

K
L
M
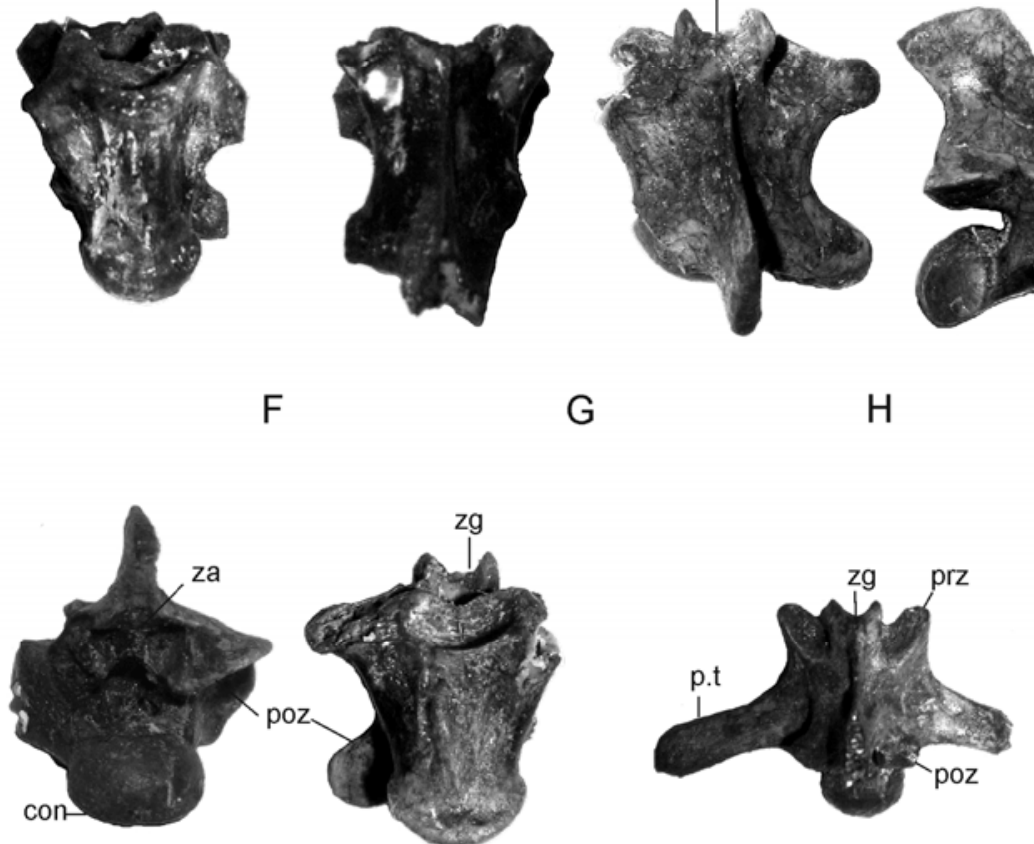

G

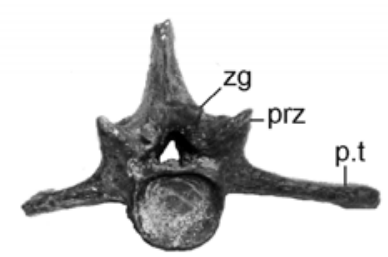

$\mathrm{N}$

Figura 56. Vértebras de Tupinambis sp. (“T. brevirostris" Rovereto, 1914) de la Formación Monte Hermoso, Farola Monte Hermoso, provincia de Buenos Aires. A-C, axis (MACN Pv 14311-10) en vista lateral (A), posterior (B) y ventral (C); D-F, vértebra cervical (MACN Pv 14311-11) en vista lateral (D), anterior, ventral (F) y dorsal (G); H-L, vértebra dorsal (MACN Pv 14311-14) en vista dorsal (H), lateral (I), frontal (J), posterior (K) y ventral (L); M, N, vértebra caudal (MACN Pv 14311-15) en vista dorsal (M) y frontal (N). Abreviaturas: c.iz; cresta interzigapofisiaria; cot, cótilo; con, cóndilo; e.n, espina neural; m.v, margo ventralis; p.od; proceso odontoideo; poz, postzigapófisis; prz, prezigapófisis; p.t, proceso transverso; za, zigantro; zg, zigósfeno. Escala $=10 \mathrm{~mm}$.

Se conservan dos elementos desarticulados de la cintura pectoral: la escápula (MACN Pv 14311-17) y el coracoides derechos (MACN Pv 14311-18) (Fig. 57 A). La escápula es un trapezoide irregular, de mayor desarrollo dorsal, aplanado, convexo lateralmente y cóncavo medialmente. En vista lateral su borde dorsal es convexo, 
mientras que el posterior es cóncavo y engrosado, el borde posterior es recto y el anterior está roto. Del coracoides se conservan los tres procesos: procoracoides (Krause, 1978b; precoracoides para Krause 1990 y Montero et al., 2004), mesocoracoides y metacoracoides. Sobre el cuerpo principal del coracoides, a una altura entre los procesos procoracoides y mesocoracoides, se preserva el foramen supracoracoideo.

La ulna derecha (MACN Pv 14311-19) no conserva sus epífisis (Fig. 57 C). Es un hueso dorsoventalmente aplanado, expandido proximalmente. El contorno lateral (externo) es cóncavo mientras que el medial es recto. Distalmente se observa una nítida cresta longitudinal en la parte mediadistal.

Se conservan los dos fémures (MACN Pv 14311-20/-21), pero sólo la epífisis distal del fémur izquierdo (MACN Pv 14311-22) (Fig. 57 D). Son huesos cilíndricos, robustos, con una muy leve curvatura posterior. Proximalmente, la fosa intertrocantérica es somera y el trocánter interno está bien desarrollado. Distal y dorsalmente, el surco intercondilar es marcado y moderadamente excavado, mientras que ventralmente la fosa popliteal es más profunda y amplia. Sobre la epífisis (MACN Pv 14311-22) se distinguen los cóndilos anterior y posterior.

La fíbula derecha (MACN Pv 14311-23) se conserva completa aunque está mal preservada distalmente. Es un hueso delgado, con el extremo proximal aplanado lateromedialmente, ancho y desviado del eje principal. Sobre el borde anterior se observa la cresta "innominada" (Montero et al., 2004).

Se conserva aislado un hueso del metapodio que correspondería al primer metatarsal izquierdo (Fig. 57 G). Es un hueso relativamente corto (14,29 mm), lateralmente comprimido, con mayor desarrollo dorsoventral en su parte proximal. El contorno del borde dorsal presenta una concavidad más somera pero más larga que la del borde ventral. También se conservan seis falanges desarticuladas, una de las cuales articula con la falange ungeal. Asimismo, se conservan nueve fragmentos incompletos de costillas. La mayoría son holocéfalas, como lo demuestran sus extremos distales ensanchados. Dos costillas son bicéfalas, diferentes al resto y no corresponderían a vértebras de lagartos (Hoffstetter y Gasc, 1969). 


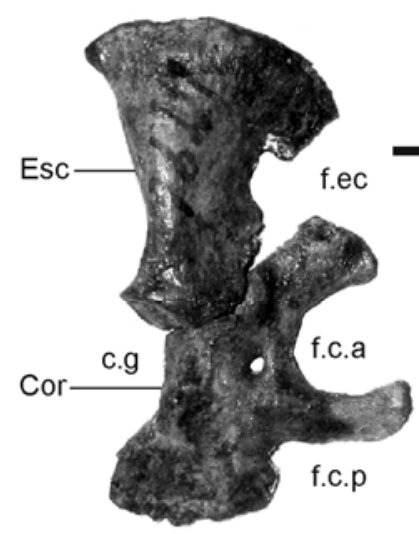

A

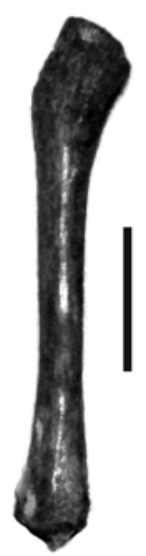

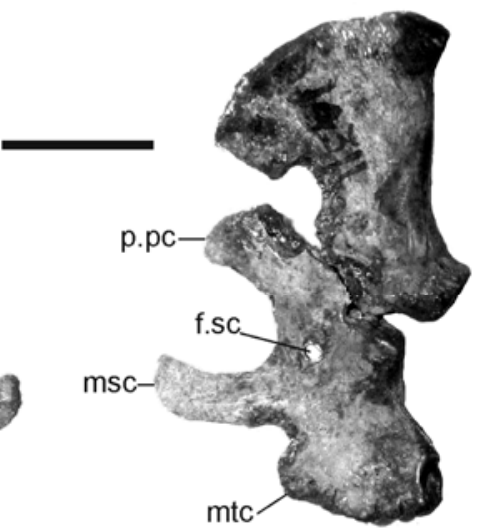

B
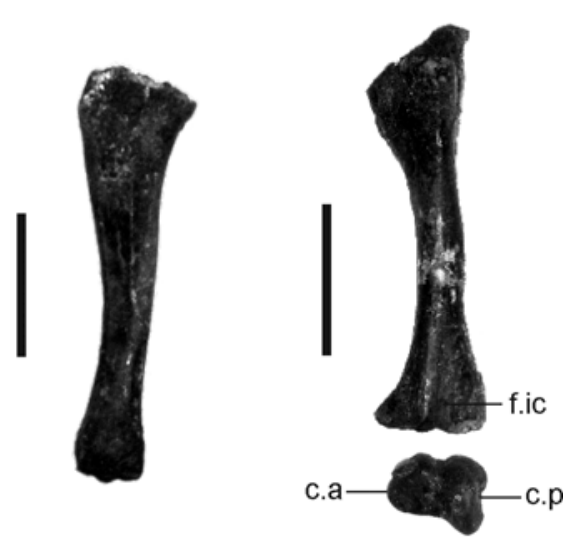

C

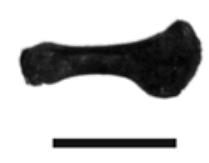

$\mathrm{F}$

G

Figura 57. Elementos del esqueleto apendicular de Tupinambis sp. ("T. brevirostris" Rovereto, 1914) de la Formación Monte Hermoso, Farola Monte Hermoso, provincia de Buenos Aires. A, B, escápula (MACN Pv 14311-17) y coracoides (MACN Pv 14311-18) derechos, en posición articulada, en vista lateral (A) y medial (B); C, ulna derecha (MACN Pv 14311-19) en vista dorsal; D, fémur izquierdo (MACN Pv 1431120) y epífisis distal (MACN Pv 14311-22), fémur en vista dorsal, epífisis en vista distal; F, fíbula derecha (MACN Pv 14311-23), vista dorsal; G, ¿primer metatarsal izquierdo, vista lateral. Abreviaturas: Cor, coracoides; c.a, cóndilo anterior; c.p, cóndilo posterior; c.g, cavidad gleniodea; Esc, escápula; f.c.a, fenestra coracoidea anterior; f.c.p, fenestra coracoidea posterior; f.ec, fenestra escapulocoracoidea; f.ic, fosa intercondilar; f.sc, foramen supracoracoideo; msc, mesocoracoides; mtc, metacoracoides; p.pc, proceso procoracoides. Escala $=10 \mathrm{~mm}$.

Comentarios taxonómicos. La presencia de abundante cemento basal (MACN Pv 14311-1/2) y un esplenial hipertrofiado, anteriormente desarrollado (MACN Pv 14311-3), son características que permiten la inclusión de los fósiles en el clado Borioteiioidea-Teiioidea, y su exclusión de los Gymnophthalmidae, junto con otros caracteres que surgen del análisis realizado en el Capítulo V. De los Borioteiioidea difiere por la ausencia de soporte narial anterior y la falta de contribución del 
postorbital a la órbita (excepto Chamops y Prototeius) (Denton y O’Neill, 1995; Nydam y Cifelli, 2002b; Nydam et al., 2007) (Cap. V).

Entre los Teiidae, los fósiles comparten con los Tupinambinae los siguientes caracteres: cresta sobre la lámina transversal del maxilar ([C18]); soporte narial posterior del maxilar (MACN Pv 14311-1/2) poco nítido ([C17]); proceso maxilar de yugal ligeramente cóncavo labialmente ([C26]); postorbital no fusionado al postorbital (excepto Dracaena) ([C40]); proceso cuadrado de los pterigoides no expandido ([C81]); canal de Meckel medialmente abierto ([C87]), sin restricción anterior ([C88]) y finalizando en la sínfisis ([C89]) (MACN Pv 14311-3).

Entre los Tupinambinae los fósiles difieren de Callopistes, Crocodilurus y Dracaena por no presentar varios caracteres diagnósticos para estos géneros ([C29], [C58], [C85], [C100], [C121], [C127]) (Cap. V). Otros caracteres, como la rama labial del proceso premaxilar del maxilar (MACN Pv 14311-1) cónica, robusta ([C9]) y paralela a la rama lingual ([C11]), asemeja los fósiles a Crocodilurus, Tupinambis y Paradracaena. La presencia de dientes robustos en la parte posterior de la serie dentaria es como en Tupinambis (excepto T. quadrilineatus y T. longilineus) (Cap. III).

El material fósil presenta 13 y 16 posiciones dentarias en el maxilar (MACN Pv 14311-1) y dentario (MACN Pv 14311-3) respectivamente; valores similares a la mayoría de los Tupinambinae (Tabla 8). Al comparar las series dentarias fósiles con la serie ontogenética de T. merianae se infiere, por la presencia de dientes robustos y romos, que se trataría de un ejemplar adulto. Los valores registrados en el fósil (LSDd $=39,94 \mathrm{~mm} ; \mathrm{LSDm}=34,09 \mathrm{~mm}$ ) se acercan a los valores de especímenes adultos de esta especie (LSDd > 41,69 mm, LSDm > 37,90 mm). Si bien los fósiles presentan dientes robustos y romos, éstos son más altos, algo cónicos, como los de ejemplares adultos de menor talla, y no marcadamente molariformes como los observados en los ejemplares adultos de mayor talla. La ausencia de dientes robustos cuspidados refuerza la idea de que se trata de un espécimen adulto que no alcanzó el estadío final de su dentición.

Del esqueleto postcraneal se conserva un importante número de vértebras procélicas grandes que no se diferencian de las observadas en Tupinambis (Cap. III). Los procesos de la vértebra cervical MACN Pv 14311-11, dorsoventralmente comprimidos y cercanos a la horizontal, indican que se trataría de la tercer vértebra 
cervical. Contrariamente a lo expresado por Veronese y Krause (1997: 21) la hipapófisis de la tercer vértebra cervical se observa en todos los Teiidae ([C152]).

La ulna MACN Pv 14311-19 muestra una marcada cresta longitudinal dorsal, similar a la observada en ejemplares de Tupinambis. Krause (1990) destaca varios aspectos de la ulna de Tupinambis en relación con la de los otros Teiidae, como lo marcado de esta cresta, el desarrollo del surco intercondilar y la fosa popliteal. Estos caracteres son de valoración muy subjetiva, razón por la cual no son considerados. La mayoría de las costillas conservadas son holocéfalas, como la que se observa en Tupinambis (Krause, 1978a; obs. pers.).

Al comparar los fósiles con la serie ontogenética de T. merianae, se aprecia que la dentición de los primeros corresponde a un ejemplar de talla cercana a la adulta sin los típicos dientes romos robustos y bajos observados en los ejemplares de tamaños cercanos al máximo. Como se mencionó en el Capítulo III, las hembras de $T$. merianae alcanzan la madurez sexual con una $\mathrm{LHC}=300 \mathrm{~mm}$ (no existen datos para los machos) (Yanosky y Mercolli, 1995); este valor de LHC es similar al de ejemplares en los cuales se observan cambios en la dentición de juvenil a adulto (i.e. de dientes comprimidos labiolingualmente a robustos) (Cap. III). Maisano (2002) analiza la fusión de diferentes elementos óseos y su relación con la madurez sexual en los Squamata. Este autor sostiene que para la mayoría de las especies, la fusión completa de escápula-coracoides y las epífisis (entre otras fusiones) son indicadores de madurez sexual, auque su ausencia no necesariamente indica lo contrario. El material fósil no presenta estas fusiones, indicando que posiblemente aún no alcanzó la madurez sexual, lo cual coincide con las características de la dentición.

El material aquí descripto es asignado a Tupinambis sp. por varios caracteres craneales y mandibulares. Si bien los dientes posteriores romos y robustos, permiten excluir a T. longilineus y T. quadrilineatus, no son lo suficientemente particulares como para sostener su afinidad con ninguna de las restantes especies. De estas últimas, sólo difiere de T. duseni por la ausencia de contacto yugal - escamoso ([C58]).

\section{Observaciones sobre la descripción de "Tupinambis brevirostris" presentada por}

Rovereto (1914). Este autor sostiene que "T. brevirostris" difiere de " $T$. prerufescens" por presentar una mandíbula más profunda y corta. En relación a esta afirmación de Rovereto (1914) primero hay que destacar que las características 
dentarias de ambos fósiles permiten inferir que "T. prerufescens" corresponde a un ejemplar más joven que “T. brevirostris”. Por otro lado, como se observa en la figura 58 , existe un aumento de profundidad de la mandíbula al aumentar la talla de los individuos de T. merianae, donde individuos más jóvenes presentan mandíbulas menos profundas. Por lo tanto, la diferencia notada por Rovereto (1914) es descartada como indicadora de una especie distinta.

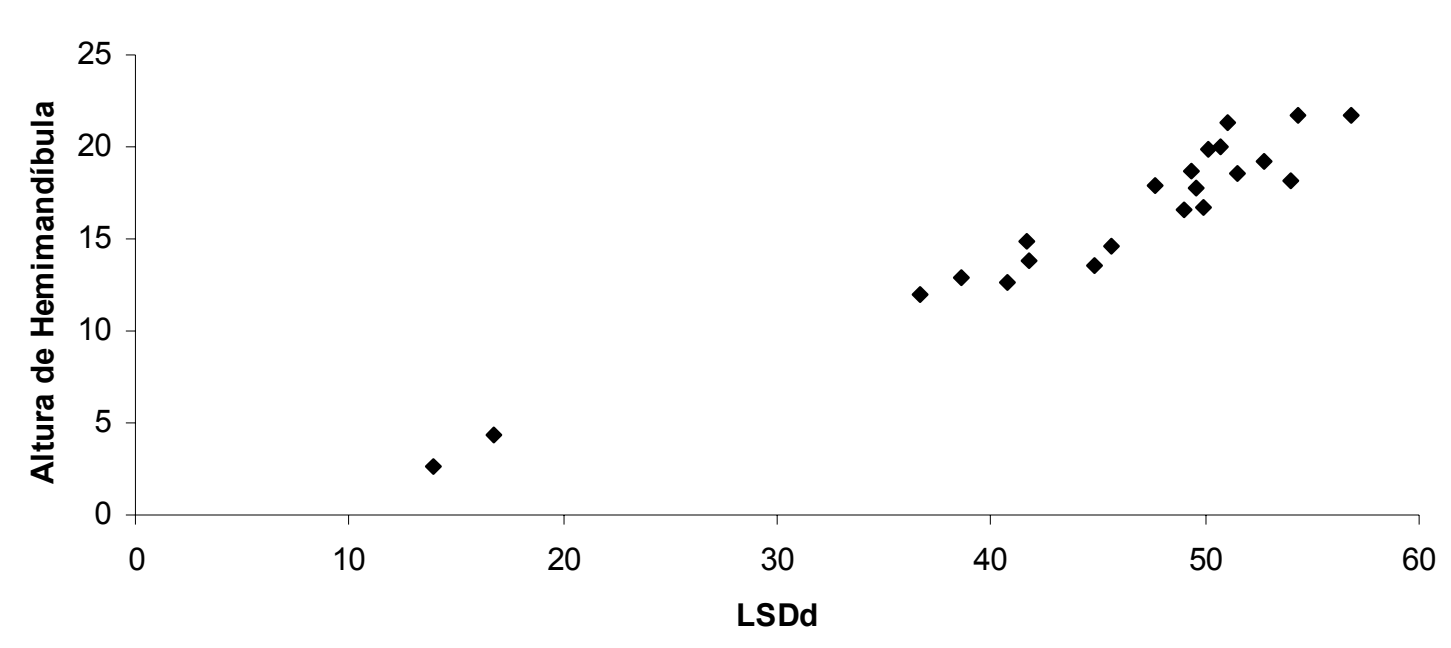

Figura 58. Valores de LSDd vs la altura de las hemimandíbulas. La altura de las hemimandíbulas fue tomada por detrás del último diente de la serie dentaria. Los valores representados son el promedio de las hemimandíbulas izquierda y derecha. $\mathrm{N}=22$.

Rovereto (1914) plantea diferencias en el número de dientes de estas especies; sin embargo, los 13 dientes del maxilar MACN Pv 14311-1, los 12 del maxilar MACN Pv 14311-2 y los 16 del dentario MACN Pv 14311-3, se encuentran dentro del rango de variación de T. merianae (Tabla 9), demostrando que pueden variar dentro de una misma especie.

La principal característica utilizada por Rovereto (1914) para justificar la nominación de una nueva especie fue la forma plana del maxilar, el cual, según este autor, no se curva medialmente. De esta observación, Rovereto (1914) concluyó que los maxilares estaban más cercanos entre sí y que el lagarto tendría entonces un hocico más estrecho. Sin embargo, la forma del maxilar MACN Pv 14311-1 no difiere de los maxilares observados en T. merianae. 
Tupinambis sp.

(T. multidentatus, Rovereto, 1914)

(Fig. 59, 60, 61)

Material referido: MACN Pv 14313. Incluye varios elementos aislados catalogados bajo el mismo número, que corresponderían como mínimo a un individuo. Rovereto (1914) describió la especie “T. multidentatus” sobre la base de sólo algunos elementos de este conjunto y de forma muy superficial (parietal, dentario izquierdo y maxilar), pero los restantes huesos no fueron descriptos por este autor. Los elementos referidos son: maxilar izquierdo con dientes (MACN Pv 14313-1); parietal (MACN Pv 14313-2); yugal izquierdo (MACN Pv 14313-3); postorbital izquierdo (MACN Pv 14313-4); escamoso derecho (MACN Pv 14313-5); cuadrado derecho (MACN Pv 14313-6); epipterigoides derecho (MACN Pv 14313-7); articular y suprangular izquierdos articulados (MACN Pv 14313-8); dentario izquierdo, con dientes, y esplenial articulado (MACN Pv 14313-9); vértebra cervical (MACN Pv 14313-10); cuatro vértebras dorsales parcialmente completas (MACN Pv 14313-11/14) y dos muy incompletas (MACN Pv 14313-15/16); dos vértebras lumbares (MACN Pv 14313-17/18); ileon izquierdo (MACN Pv 14313-19); fragmentos indeterminados (MACN Pv 14313-20); MACN Pv 14313-miscelánea: tres falanges, dos fragmentos de costillas y tres fragmentos indeterminados.

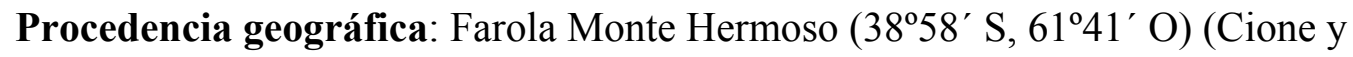
Tonni, 1995a: 54), provincia de Buenos Aires.

Procedencia estratigráfica: Formación Monte Hermoso (Zavala, 1993), Montehermosense s.l., Mioceno tardío - Plioceno temprano.

Re-descripción. El maxilar izquierdo MACN Pv 14313-1 se conserva casi completo, sólo le falta el proceso posterior (Fig. 59 A). Labialmente es liso y presenta seis forámenes labiales, el último de los cuales se ubica posteriormente al último diente conservado. El proceso premaxilar no conserva su rama lingual, mientras que la rama labial es robusta, cónica y curvada dorsalmente. Dorsalmente, sobre el proceso premaxilar se observa el borde posteroventral de la fenestra exonarina; el cual es muy cóncavo, de contorno posterior vertical. El proceso frontal está bien desarrollado aunque mal conservado, particularmente en su parte posterior. El proceso prefrontal no se conserva. Anterolingualmente se conserva la depresión que sostiene al órgano 
vómero-nasal, por detrás de la cual se observa el soporte narial posterior en forma de una loma vertical de escasa definición que se continúa sobre la lámina facial como la cresta semilunar. La cresta semilunar delimita ventralmente el receso lateral del saco nasal. El estante supradental presenta menor desarrollo dorsoventral anteriormente donde delimita la fenestra del órgano vómero-nasal; posteriormente, donde delimita la coana, éste desarrollo es mayor. La carilla de articulación para el palatino, sobre el estante supradental, comienza a la altura del IX diente. En vista ventral se observa el surco dental que alberga la serie dentaria. Los dientes son de implantación subpleurodonte, ubicados en alvéolos delimitados por septos interdentales. Las bases de los dientes presentan abundante depósito de cemento, que disimula los septos interdentales y, en menor medida, el sulcus dentalis. Este último es más nítido posteriormente. De la serie dentaria se conservan los 11 alvéolos anteriores, en los que se conservan 10 dientes, de los cuales falta el último. La preservación de los seis primeros dientes no es buena, basalmente son de sección circular y apicalmente cónicos, con la punta dirigida posteriormente. Estos dientes, los seis anteriores, varían en tamaño; forman una parábola, con los dientes centrales (II y III) más altos que los restantes. Los dientes posteriores progresivamente recuperan la altura. Los dientes VII y VIII son unicuspidados, rectos y apicalmente comprimidos lateralmente. El diente IX es similar pero más robusto y alto. El diente $\mathrm{X}$ es romo, robusto y alto. Lingualmente a la serie dentaria, sobre el sulcus dentalis, se observa una serie de nueve alvéolos de reemplazo ubicados lingualmente sobre los alvéolos funcionales II a X; estos alvéolos son subcirculares, profundos y no conservan dientes.

El parietal no conserva el extremo distal del proceso temporal izquierdo (MACN Pv 14313-2) (Fig. 59 B). De los procesos anteromediales se conserva sólo la base del izquierdo. La sutura con el parietal es recta e irregular. Los procesos anterolaterales se orientan lateralmente, conformando el borde anteromedial de la fenestra supratemporal. Distalmente, los procesos anterolaterales presentan forma de pinza, con una proyección dorsal mayor y una ventral, que se unen mediante una fina cresta posterior, la cual forma parte de la fenestra supratemporal. Esta estructura recibe al postfrontal y postorbital. La meseta parietal es triangular, con muy leves rugosidades. Su contorno está delimitado por crestas sigmoidales, anteriormente cóncavas y posteriormente convexas. Estas crestas se unen en una fina y marcada cresta sagital. Los procesos supratemporales están bien desarrollados; en vista lateral el proceso supratemporal derecho presenta una amplia superficie oval de articulación 
para el supratemporal que se extiende casi hasta el proceso descendente. Los procesos descendentes están bien desarrollados, son de contorno triangular, con el borde posterior vertical. En vista ventral, la fosa parietal se encuentra en la parte posterior y abierta posteriormente.

El yugal izquierdo se conserva casi completo, carece sólo de la parte anterior del proceso maxilar (MACN Pv 14313-3) (Fig. 59 C). Presenta forma de bumerang, con un robusto proceso maxilar y un grácil proceso temporal. El proceso maxilar es profundo, robusto y su superficie lateral es plano-cóncava. Sobre esta superficie se aprecia un nítido foramen suborbital. El proceso temporal es más estilizado, termina en una cuña que recibe al postorbital.

El postorbital izquierdo no conserva el extremo caudal del proceso posterior (MACN Pv 14313-4) (Fig. 59 D). Se trata de un hueso principalmente de la región temporal. La superficie de articulación para el yugal se encuentra claramente diferenciada de la superficie de articulación para el escamoso.

El escamoso derecho (MACN Pv 14313-5) (Fig. 59 E) es un hueso corto y cilíndrico. Anterodorsalmente se observa la carilla de articulación para el postorbital. Posteriormente se observa la carilla de articulación para el supratemporal, orientada posteromedialmente. No presenta proceso dorsal.

El cuadrado derecho se conserva completo (MACN Pv 14313-6) (Fig. 59 F, G). Es un hueso robusto, con una marcada cresta timpánica que tiene mayor desarrollo anterodorsal, lo cual le infiere al cuadrado un desarrollo anteroposterior oblicuo. El cóndilo cefálico es robusto y orientado ventralmente. En vista posterior se observa la expansión medial del cuadrado; la cresta posterior delimita dos superficies, lateral y medial, de similar desarrollo. A media altura sobre la cresta medial, se desarrolla el ala pterigoidea. El cóndilo mandibular no ocupa toda la superficie ventral del cuadrado.

El epipterigoides derecho es un hueso medialmente plano y lateralmente convexo, del cual se conserva la parte medioventral, sin el cóndilo articular (MACN Pv 14313-7) (Fig. 59 H, I). 


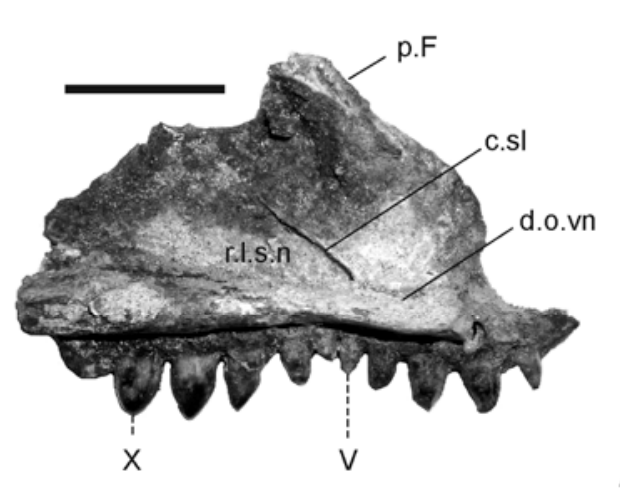

A
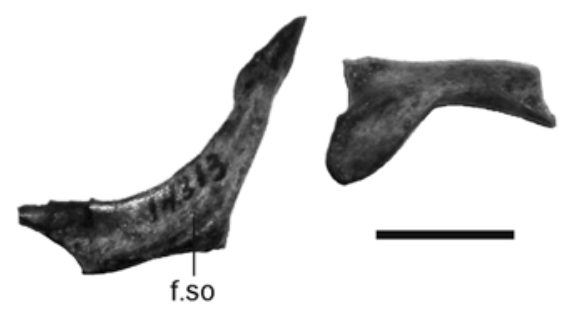

C

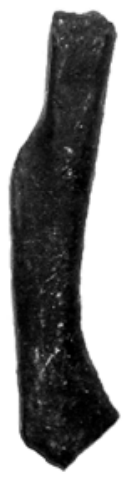

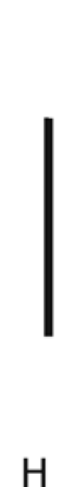

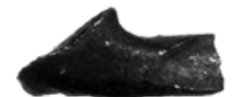

D

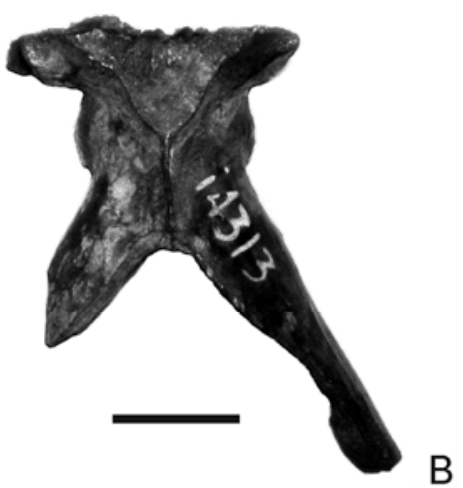

B

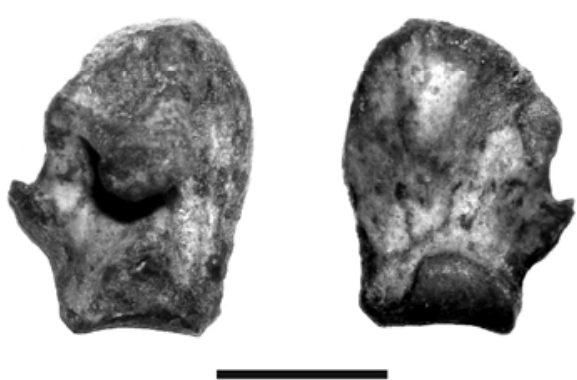

E
F

G

Figura 59. Elementos craneales de Tupinambis sp. ("T. multidentatus" Rovereto, 1914) de la Formación Monte Hermoso, Farola Monte Hermoso, provincia de Buenos Aires. A, maxilar izquierdo ((MACN Pv 14313-1) en vista labial; B, parietal (MACN Pv 14313-2) en vista dorsal; C, yugal izquierdo (MACN Pv 14313-3) en vista lateral; D, postorbital izquierdo (MACN Pv 14313-4) en vista lateral; E, escamoso derecho (MACN Pv 14313-5) en vista dorsal; F, G, cuadrado derecho (MACN Pv 14313-6) en vistas posterior (F) y anterior (G); H, I, epipterigoides derecho (MACN Pv 14313-7) en vistas medial (H) y lateral (I). Abreviaturas: d.o.vn, depresión del órgano vómero-nasal; c.sl, cresta semilunar; f.so, foramen suborbital; pF, proceso frontal; r.l.s.n., receso lateral del saco nasal. Escalas $=10 \mathrm{~mm}$.

La hemimandíbula izquierda está representada por dos fragmentos (MACN Pv 14313-8/9) (Fig. 60). El suprangular y articular se conservan articulados (MACN Pv 14313-8) (Fig. 60 A, B). El suprangular se conserva completo, la parte posterior constituye el borde lateral de la fosa mandibular. Lateralmente es plano, algo 
excavado anteriormente; la superficie expuesta en vida está nítidamente delimitada por suaves crestas donde articulan el coronoides (dorsal) y el angular (ventral). Se conservan los dos forámenes laterales; el anterior, de mayor tamaño y el posterior, más pequeño. El borde dorsal de la fosa mandibular es cilíndrico y robusto, algo más desarrollado anteriormente. La parte anterior del suprangular, en vista lateral, se orienta anteroventralmente respecto a la horizontal. Lingualmente, sobre la lámina facial, se observa una nítida faceta infracoronoidea. El articular también se conserva completo; presenta un corto proceso retroarticular y una importante cresta articular. Por detrás de la superficie articular, sobre el proceso retroarticular, se dispone en forma oblicua la cresta timpánica. Medialmente, se desarrolla una corta y nítida cresta horizontal. El proceso angular se encuentra incluido en la cresta articular; no está bien definido, pero tiene desarrollo vertical. Lingualmente, el articular constituye el borde ventral de la fosa mandibular, el cual presenta un importante desarrollo dorsoventral. El proceso anterior se continúa anteriormente a la fosa mandibular, donde presenta la carilla de articulación para el proceso posteromedial del coronoides.

El dentario y esplenial izquierdo se conservan articulados (MACN Pv 143139) (Fig. 60 C) en un fragmento robusto, profundo y grande. Ambos huesos están casi intactos, pero han perdido algo de su parte posterior. El esplenial está partido, pero se preserva en su posición natural. Es un hueso cuneiforme, con el extremo agudo dirigido anteriormente y algo curvado dorsalmente. Lingualmente es plano, aunque presenta una depresión longitudinal anterior a los forámenes milohioideo anterior y alveolar. Cubre gran parte del canal de Meckel, excepto por una pequeña abertura anterior. El dentario es labialmente liso, con cuatro forámenes mentales, el último a la altura del diente VIII. Su contorno dorsal en vista lateral es cóncavo con una leve, pero extendida, convexidad anterior. Del borde posterior se conserva sólo el proceso posterodorsal, sobre el cual se observa la superficie de articulación del proceso anterolateral del coronoides. Esta última se extiende anteriormente unas tres posiciones dentarias. Lingualmente se infiere un amplio canal de Meckel, medialmente abierto hasta la sínfisis y sin constricción anterior. El estante subdental se presenta a lo largo de todo el dentario; es plano-convexo, bien desarrollado y más bajo posteriormente. Dorsalmente, el dentario presenta un amplio surco dental que porta la serie dentaria. Las características de implantación son como las descriptas para el maxilar. Se conserva la serie dentaria completa que consta de 20 alvéolos funcionales. En vista oclusal (Fig. 60 D), la serie dentaria es cóncava lingualmente 
hasta el diente $\mathrm{X}$, luego continúa recta. Los dientes se encuentran en estrecho contacto basal. Los tres primeros son unicuspidados cónicos, con el extremo apical curvado distalmente y de base circular. Los tres dientes siguientes (IV-VI) son similares, pero más pequeños y sin mayor curvatura de su extremo apical. El VII diente es similar pero más alto. Del diente VIII al X son rectos, altos y más robustos que los precedentes. Apicalmente, terminan en un cono vertical robusto. El diente XI es basalmente robusto, como los dientes precedentes, sin embargo su extremo apical es un cono comprimido lateralmente, ligeramente curvado apicalmente y presenta una leve cresta sobre su cara mesial. El diente XII es similar a los VIII-X, algo más grande y roto apicalmente. De los dientes XII-XV se conservan sólo sus bases circulares. Los últimos cuatro dientes, del XVI al XIX son robustos y romos y forman una serie decreciente de tamaño. De estos dientes, los dos centrales (XVII y XVIII) son de sección oval, mientras que los del extremo posterior (XVI y XIX) son de sección circular. En la última posición dental se encuentra un diente robusto, pequeño, que está terminando su proceso de reemplazo. Se conserva una serie de 19 alvéolos de reemplazo, todos linguales a los alvéolos funcionales. 


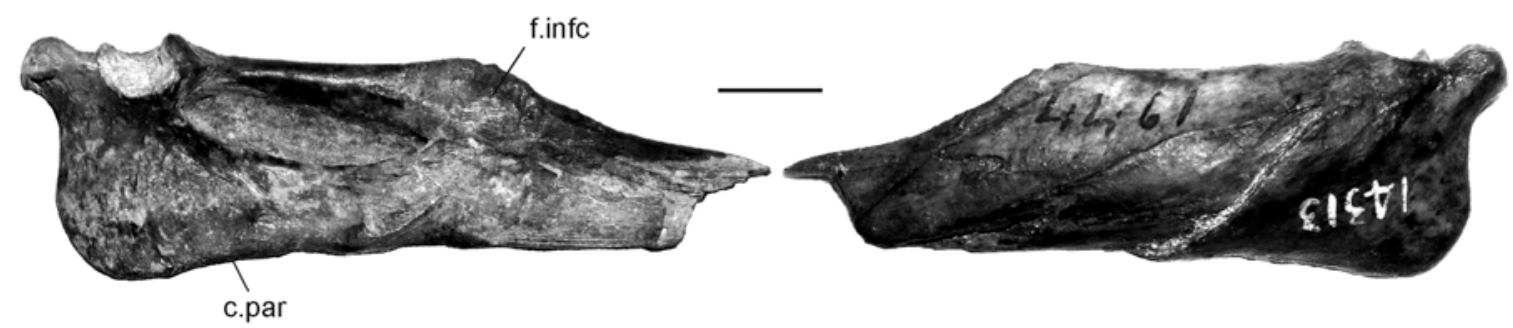

A
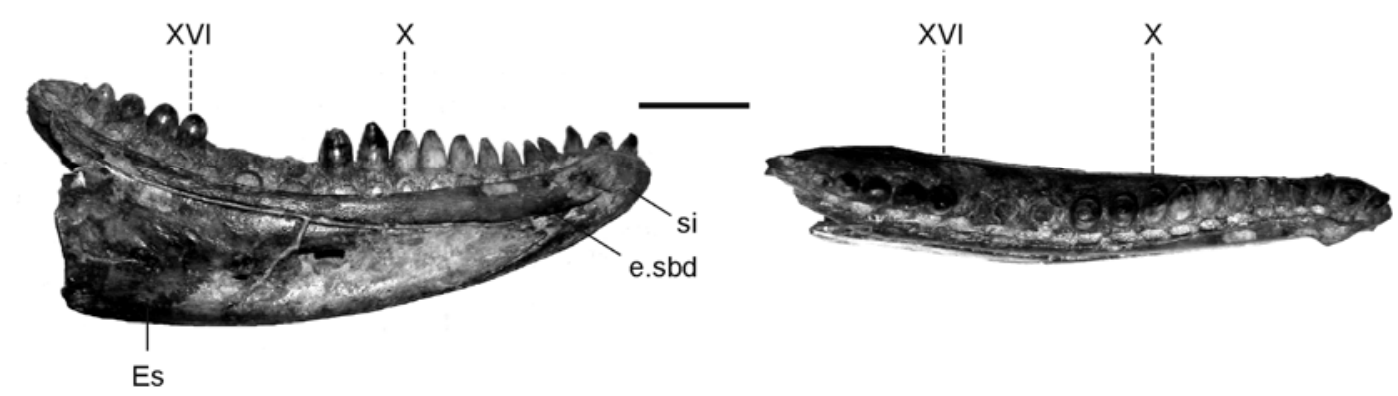

C

$\mathrm{D}$

Figura 60. Elementos hemimandibulares de Tupinambis sp. ("T. multidentatus" Rovereto 1914) de la Formación Monte Hermoso, Farola Monte Hermoso, provincia de Buenos Aires. A, B, articular y suprangular izquierdos (MACN Pv 14313-8) en vistas lingual (A) y labial (B); C, D, dentario y esplenial izquierdos (MACN Pv 14313-9) en vistas lingual (C) y oclusal (D). Abreviaturas: e.sbd, estante subdental; f.infc, faceta infracoronoidea; si, sínfisis. Escalas $10 \mathrm{~mm}$.

Del esqueleto axial se conserva una vértebra cervical (MACN Pv 14313-10), seis vértebras dorsales (MACN Pv 14313-11 a MACN Pv 14313-16), dos vértebras lumbares (MACN Pv 14313-17/18), y una vértebra indeterminada (MACN Pv 1431318) (Fig. 61). La vértebra cervical (MACN Pv 14313-10) no conserva el extremo distal de la espina neural, los extremos de los procesos transversos, el lado derecho del zigósfeno, ni el cóndilo (Fig. 61 A-E). El arco neural es bajo y largo. El canal neural es triangular en vista anterior. La espina neural probablemente estaba bien desarrollada en altura. Posteriormente, la espina no está muy extendida y anteriormente alcanza al zigósfeno. El zigósfeno es escotado y más angosto que el arco neural; la carilla de articulación izquierda es grande, de contorno circular y orientada paralela al plano sagital. Las prezigapófisis se originan a nivel medio del canal neural; son grandes y se orientan anterolateralmente. Las superficies de articulación son ovales e inclinadas sobre la horizontal. Las prezigapófisis y postzigapófisis se unen a través de una cresta interzigapofisiaria de escasa definición. 
Las postzigapófisis se orientan lateralmente; tienen carillas de articulación de contorno subcircular y de menor desarrollo que las de las prezigapófisis. El centro vertebral es robusto, cónico, posteriormente truncado. Sobre el centro vertebral se observa una pequeña y nítida cresta, desarrollada en sentido anteroposterior. El cótilo es oval, más ancho que el arco neural, excavado y levemente inclinado ventralmente. El borde ventral del cótilo está interrumpido por la superficie de articulación de la hipapófisis. Las vértebras dorsales se conservan parcialmente completas: la vértebras MACN Pv 14313-11 y MACN Pv 14313-12 no conservan el extremo distal de la espina neural; la vértebra MACN Pv 14313-13 (Fig. 61 F-J) tampoco conserva el extremo distal de la espina neural ni la postzigapófisis derecha; la vértebra MACN Pv 14313-14 no conserva la prezigapófisis ni el proceso transverso izquierdo; la vértebra MACN Pv 14313-15 no conserva la parte posterior a los procesos transversos, ni el arco neural; la vértebra MACN Pv 14313-16 no conserva su lado izquierdo. En estas vértebras, como en la vértebra cervical, el arco neural es bajo y largo, y el canal neural es triangular en vista anterior. La espina neural es de desarrollo moderado, posteriormente inclinada y extendida, de modo que supera a las postzigapófisis (MACN Pv 14313-13, MACN Pv 14313-14). Anteriormente, la espina neural se extiende hasta el zigósfeno. Este último es escotado, casi tan ancho como el canal neural. Las carillas de articulación son circulares, dispuestas algo más inclinadas que en la vértebra cervical, especialmente en el ejemplar MACN Pv 14313-14. Las prezigapófisis se orientan anterolateralmente, desarrollándose a media altura del canal neural, y en vista anterior nunca superan la longitud de los procesos transversos. Las carillas de articulación son ovales y se inclinan marcadamente sobre la horizontal. La poco marcada cresta interzigapofisiaria une las prezigapófisis con las postzigapófisis de cada lado. Las postzigapófisis, en vista dorsal, se orientan lateralmente. Posteriormente no superan al cóndilo. La forma de las carillas de articulación varía desde circular a levemente oval, pero no marcadamente oval como las de la prezigapófisis. En la parte anterior de la vértebra, por debajo de las prezigapófisis, se desarrollan los procesos transversos. Estos últimos son robustos, de desarrollo vertical. Distalmente presentan sinapófisis ovales, también de disposición vertical. El centro vertebral es cónico, distalmente trunco. El cótilo es oval, profundo, ventralmente inclinado y de perímetro continuo. El cótilo es ligeramente más ancho que el canal neural. Ventralmente, el centro vertebral es levemente convexo por una ancha, baja y poco nítida cresta sagital. El cuello condilar está nítidamente marcado 
por delante del cóndilo. A ambos lados del cuello condilar, sólo en la vértebra MACN Pv 14313-13, se observan robustas protuberancias ovales, anteroposteriormente orientadas (Fig. $61 \mathrm{~J}$ ). El cóndilo es oval e inclinado dorsalmente. Las vértebras lumbares MACN Pv 14313-17/18 difieren de las vértebras dorsales por presentar los procesos transversos marcadamente reducidos, de modo que en vista lateral las sinapófisis son pequeñas superficies redondeadas para articulación con las costillas (Fig. $61 \mathrm{~K}, \mathrm{M}$ ). El centro vertebral es corto, casi triangular (más marcado en la vértebra MACN Pv 14313-18). La cara ventral del centro vertebral es suavemente convexa. El centro vertebral de la vértebra MACN Pv 14313-18 es recorrido anteriormente por una irregular cresta anteroposterior. El cótilo es grande, ligeramente oval, profundo, inclinado ventralmente y de contorno continuo. El cóndilo es circular en vista posterior, se orienta dorsalmente y se encuentra precedido por un marcado cuello condilar.

De la cintura pélvica se conserva el ilion izquierdo (MACN Pv 14313-19) (Fig. 61 N). Se destacan el robusto proceso sacro y el proceso preacetabular ubicado anteriormente. En vista lateral se observa la porción dorsal del acetábulo. Anteriormente al acetábulo se proyecta el proceso púbico.

El fragmento MACN Pv 14313-20 corresponde, posiblemente, a un isquion derecho del que se conserva su parte media (Fig. 61 O). Es un hueso plano que ventralmente presenta un mayor desarrollo anteroposterior. Su contorno lateral posterior es marcadamente cóncavo, dorsalmente al proceso isquial, el cual no se conserva. Lateralmente presenta una concavidad triangular de vértice dorsalmente orientado.

Por último, entre este material se conservan tres falanges, dos fragmentos de costillas y tres fragmentos indeterminados (MACN Pv 14313-misceláneas). 

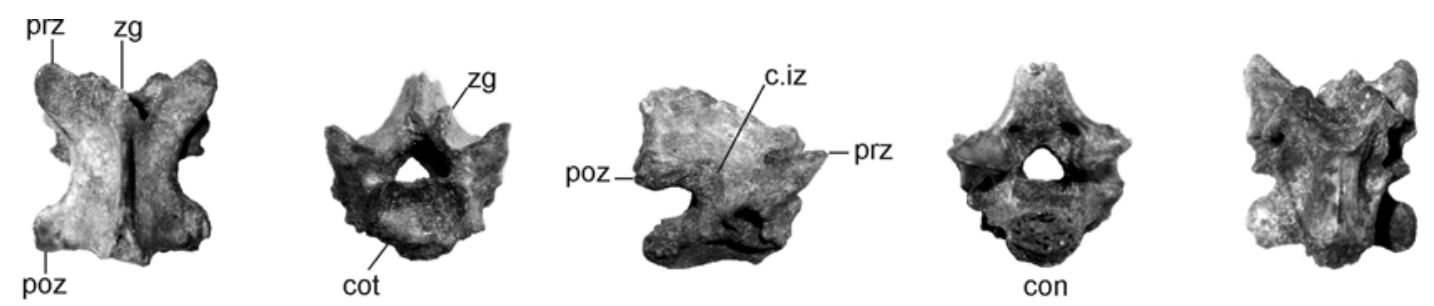

A

B

C

D

$E$
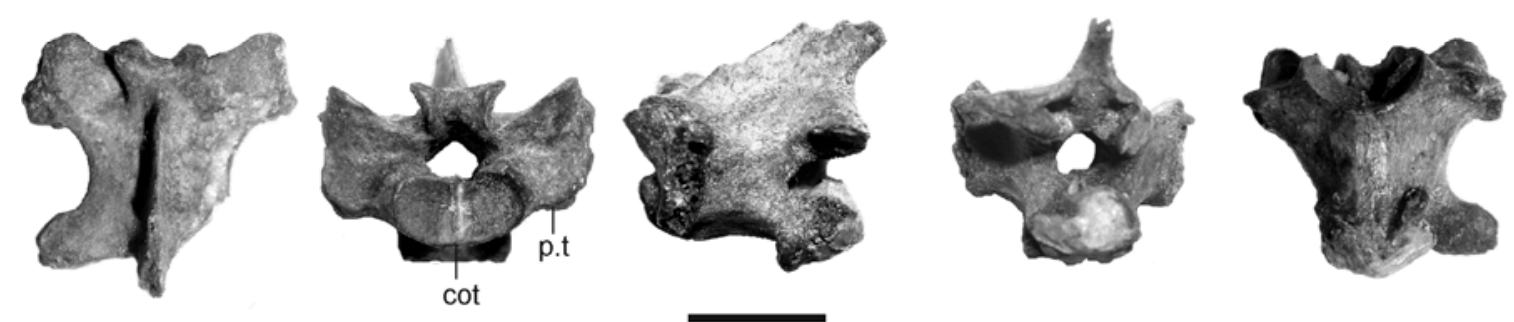

F

G

$\mathrm{H}$
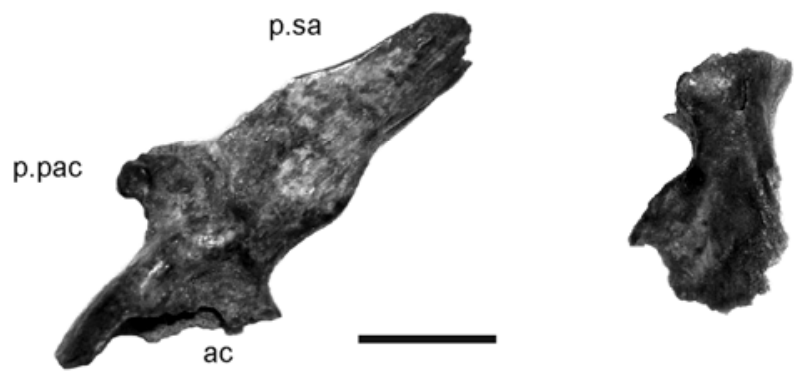

L

M

Figura 61. Elementos postcraneales de Tupinambis sp. (“T. multidentatus" Rovereto 1914) de la Formación Monte Hermoso, Farola Monte Hermoso, provincia de Buenos Aires. A-E, vértebra cervical MACN Pv 14313-10 en vistas dorsal (A), frontal (B), lateral (C), posterior (D) y ventral (E); F-J, vértebra dorsal MACN Pv 14313-13 en vistas dorsal (F), anterior (G), lateral (H), posterior (I) y ventral (J); K, vértebra lumbar (MACN Pv 14313-17) en vista lateral; L-N, vértebra lumbar MACN Pv 14313-18 en vistas dorsal (L), lateral (M) y ventral (N): Ñ, ilion izquierdo (MACN Pv 14313-19) en vista lateral; O, isquion? derecho MACN Pv 14313-i vista lateral; P, Q, fragmentos indeterminados. Abreviaturas: ac, acetábulo; c.iz; cresta interzigapofisiaria; cot, cótilo; con, cóndilo; poz, postzigapófisis; prz, prezigapófisis; p.pac, proceso preacetabular; p.sa, proceso sacro; p.t, proceso transverso; zg, zigósfeno. Escala $10 \mathrm{~mm}$. 
Comentarios taxonómicos: La presencia de abundante cemento basal, alvéolos de reemplazo subcirculares y profundos (MACN Pv 14313-1, MACN Pv 14313-9) y un esplenial hipertrofiado, anteriormente desarrollado (MACN Pv 14311-9), son características que permiten la inclusión de los fósiles en el clado BorioteiioideaTeiioidea (Nydam et al., 2007; Cap. III). Estos caracteres se revierten en los Gymnophthalmidae, posibilitando la exclusión de los fósiles de esta familia, en adición a otros caracteres diagnósticos ausentes en los fósiles (Cap. V).

El material estudiado se asigna a los Teiidae por compartir con este grupo los siguientes caracteres diferentes a Borioteiioidea (Cap. V): ausencia de soporte narial anterior; parietal impar, más ancho que largo, con procesos descendentes ([C50]), sin foramen parietal ([C45]) y con fosa parietal posterior y abierta ([C52]); musculatura adductora abarca más de dos tercios del lateral del parietal ([C42]); cóndilo articular del cuadrado no ocupa todo el extremo ventral del hueso; y proceso posterodorsal del dentario no cubre al proceso anterolateral del coronoides ([C86], [C98 en parte]).

Entre los Teiidae, el material fósil se asigna a los Tupinambinae por presentar: un poco nítido proceso narial posterior ([C17]); cresta sobre la lámina transversal del maxilar ([C18]); musculatura adductora muy extendida sobre el parietal ([C46]); borde anteromedial de la fenestra supratemporal delimitado por el parietal ([C54]); proceso maxilar del yugal ligeramente cóncavo ([C26]); canal de Meckel sin restricción anterior ([C88]) y terminado en la sínfisis ([C89]); y cresta timpánica oblicua sobre el proceso retroarticular (excepto T. quadrilineatus) ([C111]). El suprangular MACN Pv 14313-9 permite inferir que el borde posterior del dentario (que se encuentra deficientemente preservado) tenía forma de cuña, diferente a las condiciones observadas en los “cnemidoforinos" y Teius ([C92]).

Entre los Tupinambinae, la combinación de los siguientes caracteres sólo ocurre en Tupinambis: un moderado proceso maxilar del yugal ([C29]); ausencia de contacto yugal-escamoso sobre el arco supratemporal (excepto T. duseni) ([C58]); postorbital no fusionado con el postfrontal ([C40]); cuadrado sin un bulbo marcadamente desarrollado ([C65]); borde dorsal del dentario de contorno moderadamente cóncavo ([C85]); presencia de la fenestra subcoronoidea, inferida de la faceta infracoronoidea del suprangular MACN Pv 14313-8 ([C100]); esplenial levemente cóncavo sólo anteriormente a los forámenes ([C97]); cresta articular bien desarrollada (excepto T. quadrilineatus) ([C104]); desarrollado proceso angular ([C106]); y cresta horizontal sobre el proceso retroarticular ([C113]). A su vez, la 
meseta parietal triangular como la del fósil MACN Pv 14313-2 sólo se observa en Callopistes y Tupinambis; pero únicamente en Tupinambis las crestas de la meseta parietal son suaves ([C46]). Sin embargo, a diferencia de la forma levemente cóncava que presenta Tupinambis, las crestas del fósil son sigmoidales. Entre las especies de Tupinambis, el contorno oblicuo de la cresta prearticular sin el extremo libre del proceso angular se observa en T. merianae ([C105]); mientras que el proceso angular vertical es como en T. rufescens ([C107]).

El tipo de implantación subpleurodonte se asemeja a la presente en Crocodilurus y Tupinambis (Cap. III). Sin embargo, los dientes posteriores robustos, molariformes, sólo se encuentran en Tupinambis (excepto T. quadrilineatus y $T$. longilineus). Los dientes de los fósiles no pueden ser atribuidos con certeza a ninguna de las especies, aunque se parecen más a los de T. merianae por ser romos, sin vestigios de cúspides y de sección transversal circular (Cap. III).

Al comparar el material con la serie ontogenética de T. merianae, la falta de dientes robustos cuspidados y la presencia de dientes posteriores romos y robustos sugiere que se trata de un ejemplar con la dentición madura (LSDd $>51,49 \mathrm{~mm}$ ). La LSDd del fósil MACN Pv 14313-9 es de 46,42 mm, que es un valor menor al esperado; sin embargo, los dientes romos y robustos se registran a partir de LSDd = 41,69 mm (ver Cap. III). La dentición del dentario MACN Pv 14313-9 no se ajusta perfectamente a los resultados obtenidos de la serie ontogenética, pero tampoco representa una contradicción. El fósil presenta 20 dientes, número que supera el máximo observado entre los Tupinambis, excepto T. quadrilineatus y T. teguixin (Tabla 8). Sin embargo de T. quadrilineatus el material fósil se distingue claramente por los dientes posteriores robustos (Cap. III).

En suma, los restos aquí descriptos son asignados a Tupinambis sp.. A pesar de la similitud con T. merianae, la forma de los bordes de la meseta parietal y el proceso angular impiden la asignación de MACN Pv 14313-1, MACN Pv 14313- 8/9 a esta especie. También se destaca el alto número de dientes que no sólo supera al máximo registrado en T. merianae sino que excede el intervalo de confianza obtenido a partir de los dentarios izquierdos de la muestra de esta especie: 15,26 -16,41 ( $\alpha=$ 0.01). Estos caracteres, por separado o en su conjunto, no se consideran suficientes para la diagnosis de una nueva especie dado que sólo el número de dientes parece significativo, mientras que la orientación del proceso angular es variable (al menos en T. merianae) y de difícil definición en algunos casos. Si bien el número de dientes es 
diferente al de a la mayoría las especies de Tupinambis con dientes molariformes posteriores (excepto T. teguixin), sólo se ha registrado en un único dentario (MACN Pv 14313-9) y podría corresponder a un valor extremo para alguna de las especies actuales, ya que la muestra estudiada no es muy abundante. Por dichas razones, no pueden establecerse con bases sólidas las afinidades del material fósil con ninguna especie en particular.

Los elementos postcraneales no aportan caracteres diagnósticos particulares, aunque son indistinguibles de los de Tupinambis. Las protuberancias anteriores al cóndilo observadas en la vértebra MACN Pv 14313-13 no se presentan en ninguna vértebra del material de referencia o fósil disponible para esta tesis y podrían tratarse de una patología.

\section{Observaciones sobre la descripción de "Tupinambis multidentatus" presentada} por Rovereto (1914). Según Rovereto (1914), esta especie sería el taxón del Montehermosense que más difiere de las especies actuales de Tupinambis con distribución en Argentina. Rovereto (1914) indica que la principal diferencia radica en el número de dientes; sin embargo, y como ya se mencionó, este carácter resulta insuficiente para sustentar una nueva especie. Rovereto (1914) también menciona diferencias en las dimensiones del parietal, siendo el de "T. multidentatus" más corto y ancho anteriormente. Sin embargo, esta afirmación no pudo ser verificada (Fig. 62).

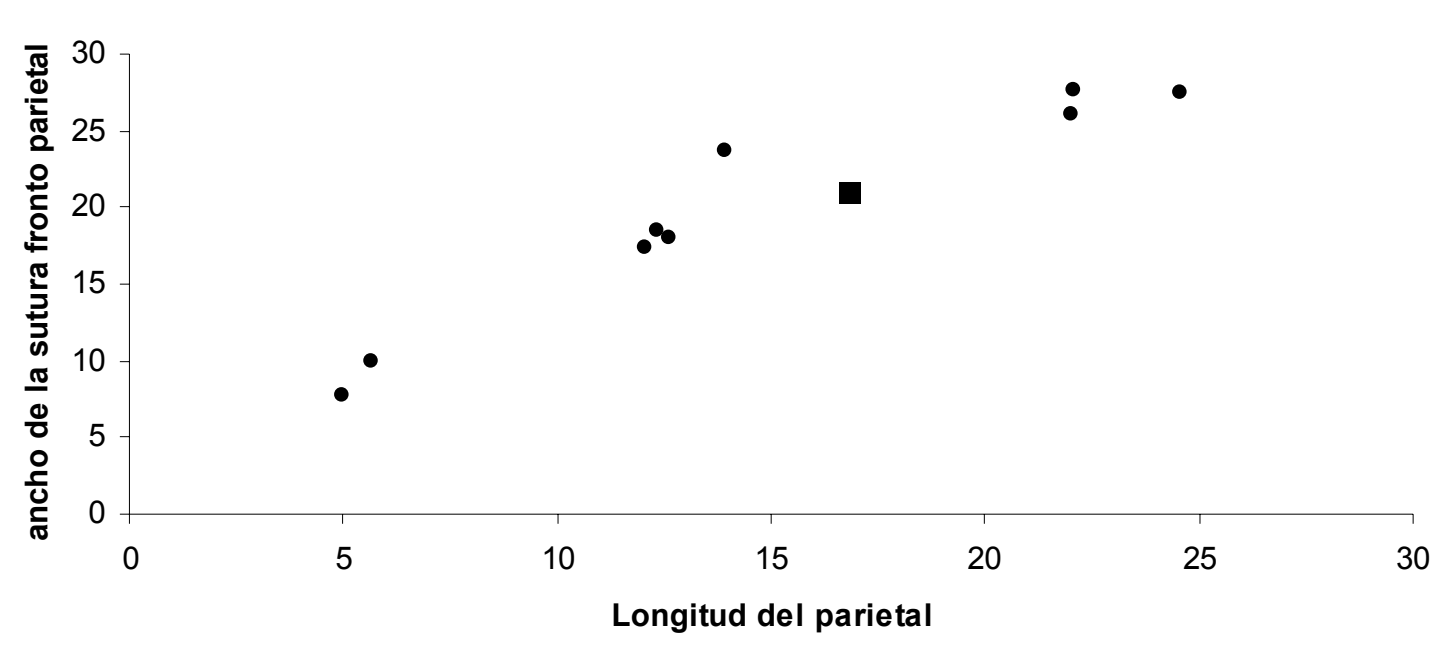

Figura 62. Largo del parietal vs ancho de la sutura fronto-parietal en T. merianae. Círculos, T. merianae $(\mathrm{N}=9)$; cuadrado, parietal MACN Pv 14313-2. 
Los valores del parietal fósil se encuentran entre los valores de los ejemplares actuales UNMdP-O 10 y UNMdP-O 12, cuyas LSDd son 41,76 mm y 47,66 mm. Estas medidas coinciden con la LSDd del fósil MACN Pv 14313-2 (=46,42 mm), indicando que se trata de un ejemplar adulto que no ha alcanzado la LHC máxima.

Conclusiones sobre "los Tupinambis de Rovereto". La revisión del material descripto inicialmente por Rovereto (1914) permite asignarlo en su conjunto al género Tupinambis. Algunos ejemplares (MACN Pv 14312-13 y MACN Pv 14314-16) muestran caracteres más afines a T. merianae que a cualquier otra especie. Considerando que ésta es la única especie que actualmente se distribuye en la provincia de Buenos Aires, se pude considerar que probablemente todos los especímenes de la colección estudiada por Rovereto (1914) pueden corresponder a la misma. No obstante, debido a que sólo los elementos mencionados muestran caracteres que pueden ser comparados a nivel específico y que el resto de los ejemplares son compatibles con otras especies además de T. merianae, se sigue un criterio conservador y se atribuyen todos los restos a Tupinambis sp. Esta decisión se refuerza por el hecho de que en la muestra comparativa utilizada, los especímenes de T. merianae son mucho más numerosos que los de las restantes especies (véase Cap. III) y ésto podría estar sesgando el resultado de las observaciones.

Se destaca que en el elemento MACN Pv 14314-5 se observa la fusión del postfrontal y el postorbital, lo cual difiere de la condición observada en Tupinambis. Es posible que dicha fusión represente una teratología o sea parte de las variaciones posibles en el género. Entre los materiales referidos a Tupinambis sp., el maxilar MACN Pv 14313-9, por su elevado número de dientes (entre otros caracteres), es el fósil que más difiere respecto a T. merianae.

En suma, se acuerda con los diferentes autores que invalidaron las especies descriptas por Rovereto, aunque los mismos no destacaron los caracteres que sostenían su propuesta (Reig, 1958; Báez y Gasparini, 1977, 1979; Donadío, 1978, 1983b; Estes, 1983a). Se disiente parcialmente con Estes (1983a) en cuanto a " $T$. multidentatus" (MACN Pv 14313-9), cuyo alto número de dientes no puede ser fácilmente explicado por variación individual u ontogenética, aunque el material disponible no permite, por el momento, convalidar esta especie. 
Sistemática y descripción de materiales inéditos de Fm. Monte Hermoso

\section{Tupinambis sp.}

(Fig. 63)

Material referido: MACN Pv 14338, serie dentaria; MACN Pv 14344, dentario derecho parcialmente conservado. No descripto previamente.

Procedencia geográfica: Farola Monte Hermoso (38 $\left.58^{\prime} \mathrm{S}, 61^{\circ} 41^{\prime} \mathrm{O}\right)$ (Cione y Tonni, 1995a: 54), provincia de Buenos Aires.

Procedencia estratigráfica: Formación Monte Hermoso (Zavala, 1993),

Montehermosense s.l., Mioceno tardío - Plioceno temprano.

Descripción. La serie dentaria MACN Pv14338 (Fig. 63 A), corresponde a un dentario izquierdo, el cual no se conserva. Hay 15 dientes preservados y falta el diente XII, ya que la serie completa consta de 16 dientes. Los dientes I a V son pequeños, apicalmente cónicos. Los dientes VI a VIII son mayores, distalmente cónicos, punzantes, de punta distalmente curvada. El extremo apical del diente IX es un cono lateralmente comprimido, sin cúspides pero con una cresta mesodistal en su mitad mesial. Los dientes X y XI son romos y robustos. Apicalmente en el diente X se observa una protuberancia que se encuentra algo distalmente desplazada en vista lateral. Los dientes subsiguientes son similares, con una leve compresión labiolingual.

El fragmento MACN Pv 14344 corresponde a la parte anterior de un robusto dentario derecho (Fig. 63 B, C). Labialmente es liso, con tres forámenes mentales, el último a la altura del diente IV. Lingualmente se observa un importante estante subdental que recorre todo el dentario desde la sínfisis. El estante subdental tiene la típica forma de silla de montar anteriormente, mientras que es planoconvexo posteriormente, perdiendo desarrollo dorsoventral hacia el extremo posterior. Ventral al estante subdental, el canal de Meckel está medialmente expuesto, sin constricción alguna. Aunque no se ha conservado, es posible inferir que el esplenial cubría ampliamente el canal de Meckel como lo demuestran las importantes carillas de articulación. La carilla ventral para el esplenial se desarrolla inmediatamente después del primer diente conservado. Dorsalmente, sobre el surco dental, se conservan los primeros 11 alvéolos funcionales, acompañados lingualmente por el sulcus dentalis. Se conservan todos los dientes, excepto el I y III. Los dientes son de implantación 
subpleurodonte, con abundante cemento basal que disimula los septos interdentales. El diente II es robusto, cónico, de punta dirigida posteriormente, mientras que los dientes IV a VI son de menor tamaño, pero igualmente unicuspidados y punzantes, con la punta dirigida distalmente. El diente VII es similar al II. Los dientes VIII y IX conservan la misma morfología pero son de dimensiones mayores, más robustos y más altos (el VIII es el diente más alto conservado). Los dientes X y XI son robustos, romos y altos. Sobre el extremo distal del diente XI se observa una pequeña protuberancia. El contorno lateral del extremo apical de este diente es recto, horizontal.

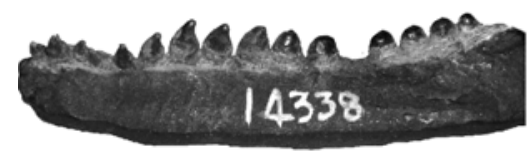

A

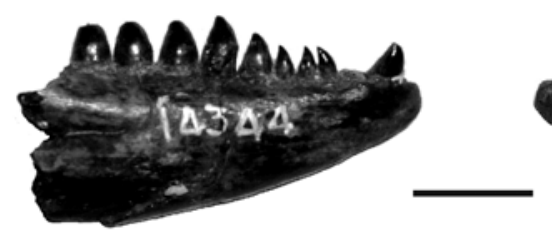

B

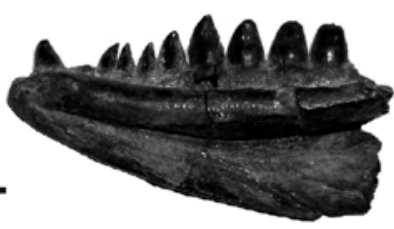

C

Figura 63. Tupinambis sp. de la Formación Monte Hermoso, Farola Monte Hermoso, provincia de Buenos Aires. A, serie dentaria MACN Pv 14338 en vista labial; B, C, dentario MACN Pv 14344 en vista labial (B) y lingual $(C)$. Escala $=10 \mathrm{~mm}$.

Comentarios taxonómicos. Estos fragmentos fueron depositados en la colección del MACN previamente al año 1930, con datos de procedencia estratigráfica inciertos. El abundante depósito de cemento sobre las bases de los dientes y el esplenial hipertrofiado anteriormente desarrollado, permiten incluir al fósil MACN Pv 14344 en el clado Borioteiioidea-Teiioidea, al mismo tiempo que lo excluye de los Gymnophthalmidae (Nydam et al. 2007; Cap. III). El ejemplar no presenta caracteres que permitan la distinción entre Borioteiioidea-Teiioidea; sin embargo, en la comparación con los Teiidae, presenta afinidad con los Tupinambinae por el tamaño y desarrollo del hueso, y por carecer de la restricción anterior del canal de Meckel ([C88]), el cual, además, termina en la sínfisis ([C89]). Adicionalmente, el tipo de implantación subpleurodonte, con septos interdentales disimulados por la abundante depositación de cemento, se asemeja a lo observado en Crocodilurus y Tupinambis (Cap. III). El fósil y Tupinambis (excepto T. quadrilineatus y T. longilineus) se diferencian de Crocodilurus por presentar dientes posteriores robustos, mientras que los dientes posteriores de Crocodilurus son comprimidos lateralmente. No es posible 
una determinación específica del material aunque se descarta su pertenencia a $T$. quadrilineatus y T. longilineus por sus características dentarias.

Los 16 dientes del fósil MACN Pv 14338 coincide con el rango de variación de todas las especies de Tupinambis, salvo T. quadrilineatus (Tabla 8). La presencia de dientes romos y robustos en la parte posterior de la serie, y la ausencia de dientes robustos cuspidados, hace suponer, al comparar con la serie ontogenética de $T$. merianae, que se trataría de un ejemplar con LSDd $>51,49 \mathrm{~mm}$. Sin embargo, el valor registrado en el fósil es menor ( $\mathrm{LSDd}=40,02 \mathrm{~mm}$ ). Según la serie ontogenética, a partir de una $\mathrm{LSDd}=41,69 \mathrm{~mm}$ aparecen los dientes robustos romos, lo que permite interpretar que el ejemplar fósil correspondía a un individuo adulto de talla pequeña.

Reevaluación sistemática y redescripción de materiales descriptos previamente por Chani (1976)

\section{Callopistes Gravenhorst, 1838}

Callopistes bicuspidatus Chani, 1976

(Fig. 64, 65, 66)

Holotipo: FML 4618. Incluye varios elementos correspondientes a un mismo individuo. Se conservan: lacrimal, maxilar, prefrontal, yugal y palatino izquierdos articulados (FML 4618-1); parietal aislado (FML 4618-2); postorbital y postfrontal izquierdos articulados (FML 4618-3); dentario derecho aislado (FML 4618-4); hemimandíbula izquierda (FML 4618-5) con angular, articular, dentario y suprangular. El maxilar y los dentarios conservan casi completas sus series dentarias. Se conservan cuatro fragmentos indeterminados (FML misceláneas).

Procedencia geográfica: Farola Monte Hermoso (38 $\left.58^{\prime} \mathrm{S}, 61^{\circ} 41^{\prime} \mathrm{O}\right)$ (Cione y Tonni, 1995a: 54), provincia de Buenos Aires.

Procedencia estratigráfica: Banco $\mathrm{N}^{\circ} 3$ de la Formación Monte Hermoso, "Hermosense típico" (Bonaparte, 1960). El Banco N 3 corresponde a la Biozona de Trigodon gaudryi, base bioestratigráfica del Piso/Edad Montehermosense (Cione y Tonni, 1995a, b, 2005), Mioceno tardío-Plioceno temprano (Cione et al., 2007).

Re-diagnosis: Los caracteres de la osteología que son diagnósticos del género (Cap. V) y están presentes en el material fósil son: la presencia de una marcada proyección 
hacia la órbita del postfrontal ([C42]); meseta parietal triangular, de bordes rectos ([C46]); y fosa parietal anteriormente desplazada, al final de un surco sobre la cara ventral del parietal ([C52]). Difiere de C. maculatus por la ausencia de una marcada escotadura entre las ramas del proceso premaxilar del maxilar ([C10]); proceso posteromedial del postfrontal muy reducido ([C41]); contacto postfrontal-yugal ([C43]); canal de Meckel extendido anteriormente por debajo de la sínfisis ([C89]); y proceso anteromedial del coronoides corto y por detrás de la extensión anterior del suprangular/angular ([C99]). De ambas especies actuales, C. maculatus y $C$.

flavipunctatus, difiere por la presencia únicamente de dientes bicuspidados posteriores en el dentario y maxilar.

Re-descripción: El fragmento FML 4618-1 (Fig. 64 A, B) corresponde a la parte anterior-izquierda del cráneo, incluyendo el maxilar, prefrontal, lacrimal, yugal y palatino. El maxilar es el hueso más grande del conjunto; es labialmente liso, sin ornamentación y conserva seis forámenes labiales. La lámina facial presenta, dorsalmente, un importante desarrollo anteroposterior. Distalmente, se observa la ancha base del proceso frontal, que es la única parte conservada; posterior a la misma se desarrolla el proceso prefrontal. El borde anterior de la lámina facial conforma el borde posterior de la fenestra exonarina, cuyo contorno es ligeramente cóncavo y muy vertical. No se conservan los extremos distales de las ramas labial y lingual del proceso premaxilar. Medialmente, sobre la rama lingual del proceso premaxilar, se observa parte de la superficie de articulación para el vómer, que está extendida dorsoventralmente. Dorsalmente, se observa la lámina transversal y su cresta, ambas en deficiente estado de conservación. Posteriormente a la lámina transversal se observa la depresión donde se ubica el órgano vómero-nasal; se trata de un cuenco somero sobre el estante supradental, ubicado por detrás de la fenestra exonarina y flanqueado posteriormente por el soporte narial. El soporte narial es una cresta vertical, dorsalmente simple, con una leve constricción sobre el estante supradental. La cresta semilunar está bien definida, termina sobre el soporte narial y dorsalmente delimita un profundo receso del saco nasal sobre la lámina facial. El estante supradental se encuentra fracturado por detrás del soporte narial; presenta poco desarrollo dorsoventral donde delimita a la fenestra del órgano vómero-nasal y mayor desarrollo anteriormente a la articulación con el palatino, donde delimita a la coana. El surco supradental está definido por una pared labial alta y una pared lingual más baja, entre las cuales se encuentra la serie dentaria, anteriormente incompleta. Se 
conservan 15 alvéolos con 13 dientes completos; faltan los de las posiciones (i) y (n). Los dientes son de implantación subpleurodonte, ubicados en alvéolos delimitados por finos septos interdentales de hueso alveolar. En estos alvéolos los dientes se unen al maxilar principalmente a través de sus bases, las que además están cubiertas por abundante cemento. Entre las bases de los dientes y el estante supradental se desarrolla un moderado sulcus dentalis. El primer diente conservado (a) es unicuspidado, alto y de base mesodistalmente comprimida. Apicalmente termina en un cono que no conserva su extremo y se curva poco distalmente. El siguiente diente (b) presumiblemente se desprendió y fue pegado en su lugar pero en una orientación errónea, de modo tal que la cara anterior ha quedado expuesta lingualmente. De esta forma, es posible observar una fina cresta que recorre la cara mesial en su parte apical y que se orienta mesodistalmente. En otros aspectos es similar a los dientes (a) y (c). Los dientes (d) a (f) son unicuspidados pequeños; apicalmente se encuentran comprimidos labiolingualmente y menos curvados que los precedentes. Los dientes (g) y (h) aumentan en tamaño, pero sin llegar a igualar a los dientes más anteriores. En la cara mesial del diente (h) se insinúa una pequeña protuberancia, por detrás de la cual se desarrolla una cresta apical de orientación mesodistal. Los dientes (j) a ( $\tilde{n})$ son de mayores dimensiones y levemente bicuspidados; sus bases son similares a la del primer diente conservado. Las cúspides están separadas por un surco vertical superficial y corto. La cúspide posterior es la dominante; tiene forma de cono no punzante, comprimido labiolingualmente y algo inclinado distalmente. La cúspide mesial es mucho más pequeña y presenta grados de diferenciación variables entre los distintos dientes. Es comprimida y con poco desarrollo apical (i.e. la cúspide anterior no altera en forma importante al contorno lateral de la cúspide posterior). Se conservan alvéolos de reemplazo lingualmente sobre los dientes (a), (c), (e), (g), (j) y (1), los que son nítidos, subcirculares y profundos.

El prefrontal se conserva casi completo y levemente desplazado de su posición original, razón por la cual está algo expuesta la superficie de articulación para el proceso prefrontal del maxilar. El proceso supraorbital está bien desarrollado; ventralmente y sobre el borde de la órbita se observa una cresta oval grande y robusta. El prefrontal está muy excavado posteriormente a dicha cresta. El proceso lacrimal no conserva su extremo distal. El proceso palatino presenta un importante desarrollo y se extiende medialmente hasta el palatino; se infiere que delimitaba en gran medida a la fenestra órbito-nasal, excluyendo al frontal de la misma. La unión con el palatino es a 
través de una sutura larga y cóncava. Lateralmente, el proceso lacrimal y el proceso palatino delimitan el foramen lacrimal.

El lacrimal es un hueso plano; en vista lateral, su grosor es constante, con un mayor desarrollo dorsal. El borde orbital es algo más robusto que el borde maxilar. La sutura con el prefrontal es recta y de disposición oblicua, mientras que con el yugal es en forma de una cuña corta, pasando por detrás del yugal.

El yugal presenta forma de bumerang. No se conserva la parte distal del proceso temporal. El proceso maxilar es robusto, algo cóncavo lateralmente. Conserva cuatro forámenes suborbitales y dos forámenes del nervio maxilar. Ventralmente, se observa la superficie de articulación para el ectopterigoides.

El palatino no conserva el proceso vomerino ni la parte distal del proceso pterigoideo. El proceso maxilar presenta un importante desarrollo anteroposterior. El surco palatino es profundo; dorsalmente, sobre el surco anteroposterior, se conservan tres forámenes del plexo palatino. Lateralmente, el proceso maxilar delimita el borde medial del foramen infraorbital. Dorsalmente, el palatino articula con el prefrontal. 


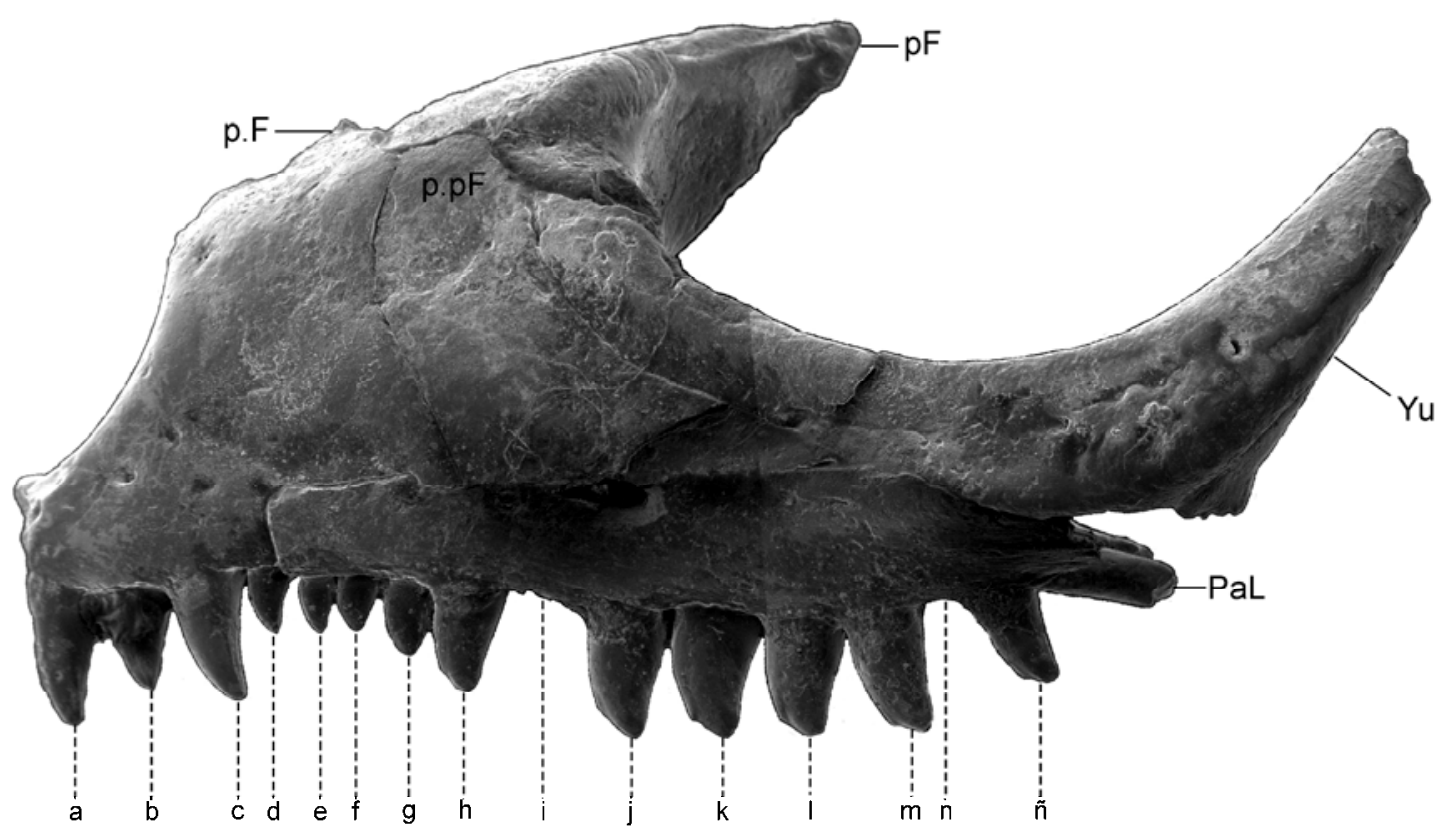

A

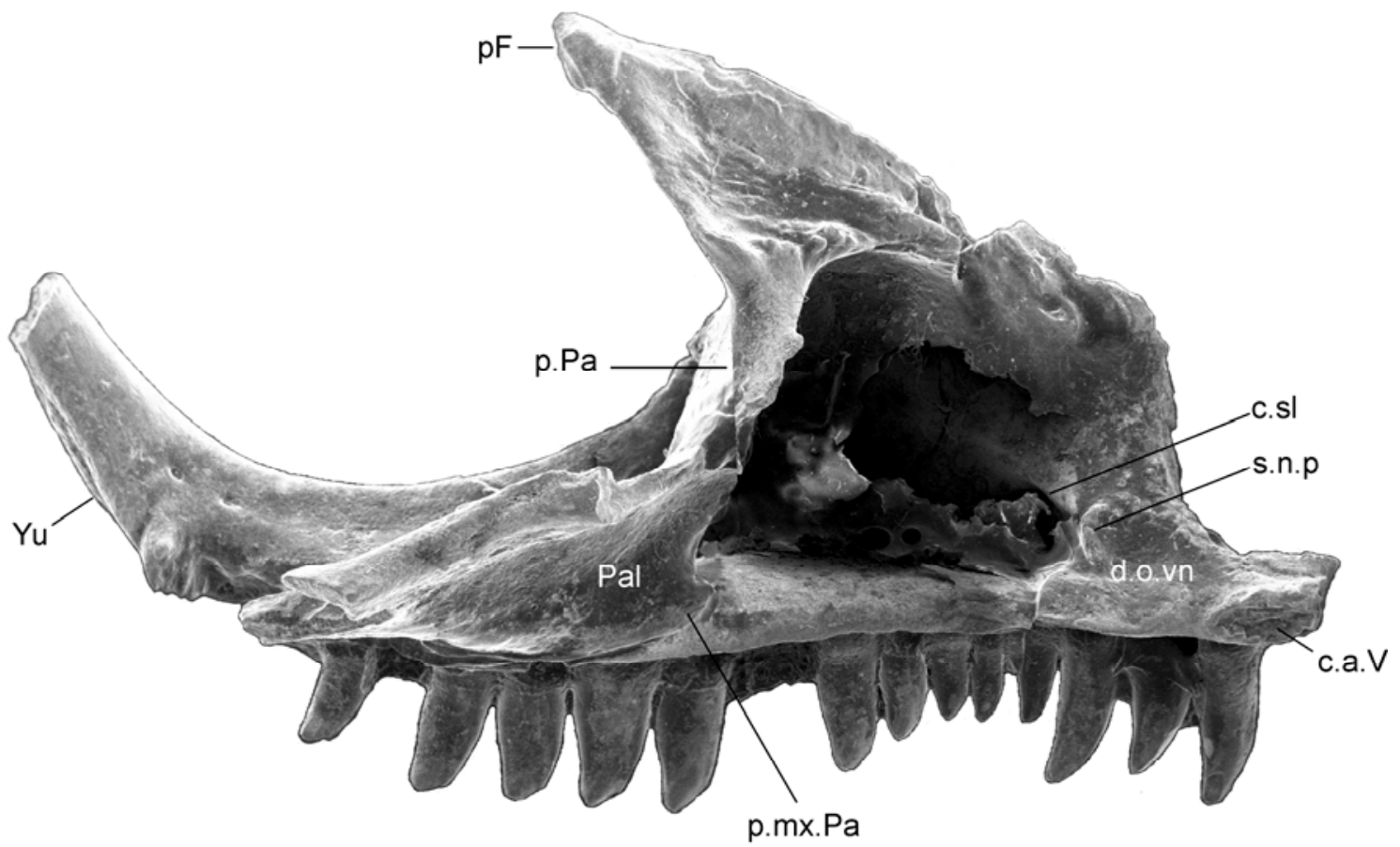

B 
Figura 64. Parte anterior del cráneo de Callopistes bicuspidatus Chani, 1976 (FML 4618-1) de la Formación Monte Hermoso, Farola Monte Hermoso, provincia de Buenos Aires. A, vista labial; B, vista lingual. Abreviaturas: c.a.V, carilla de articulación para el vómer; c.sl, cresta semilunar; d.o.vn, depresión del órgano vómero-nasal; Pal, palatino; pF; prefrontal; p.F, proceso frontal; p.mx.Pa; proceso maxilar del palatino; p.Pa; proceso palatino; p.pF, proceso prefrontal; s.n.p, soporte narial posterior; Yu, yugal. Escala $=2 \mathrm{~mm}$.

El parietal (FML 4618-2) (Fig. 65 A) se conserva en forma aislada y casi completo; carece del proceso anterolateral izquierdo, proceso descendente izquierdo y los extremos distales de los procesos supratemporales. El proceso anterolateral derecho se encuentra bien desarrollado, está transversalmente orientado y constituye el borde anteromedial de la fenestra supratemporal. En vista ventral, y medialmente a la base del proceso anterolateral, se conserva el borde lateral del proceso anteromedial derecho. Es posible deducir que la musculatura adductora mandibular avanzaba sobre la superficie dorsal del parietal, de ambos lados, hasta unirse en la línea media, sobre la parte posterior del parietal; por este motivo, la meseta parietal es de forma triangular, de base anterior, formando la sutura frontoparietal, y el ápice se encuentra dirigido posteriormente, sobre el eje sagital. Los bordes laterales de la meseta parietal están definidos por dos marcadas crestas rectas, robustas e irregulares, las cuales se unen en el extremo formando la cresta sagital, que se continúa posteriormente. La superficie dorsal de la meseta parietal se encuentra en un plano algo inferior al de las crestas laterales. Es una superficie irregular, con surcos y rugosidades. El proceso descendente derecho es grande y triangular. La fosa parietal se ubica caudalmente y está posteriormente abierta. Sobre los procesos supratemporales se observan, claramente marcados, los extremos anteriores de las carillas de articulación para los supratemporales.

El postfrontal y postorbital izquierdos se conservan articulados (FML 4618-3) (Fig. 65 B). Se trata de dos huesos firmemente unidos, pero no fusionados, ya que se diferencian nítidamente uno del otro. El postfrontal presenta un gran proceso anteromedial y un pequeño proceso posteromedial. Dorsalmente, sobre el proceso posteromedial, se observa una cresta transversal que separaría las superficies de articulación para el frontal (anterior) y parietal (posterior). El proceso lateral es cilíndrico y se prolonga ventralmente, excluyendo a gran parte del postorbital del borde de la órbita. Ventralmente se ensancha, conformando una robusta protuberancia irregular que se proyecta hacia la órbita. El postorbital es esencialmente un hueso de 
la región temporal, fuertemente articulado a la parte posterior del postfrontal, al que excluiría de la fenestra supratemporal. El proceso yugal se extiende anteriormente hasta la órbita, pasando ventralmente al postfrontal como una delgada cuña que participa escasamente del contorno de la órbita. En vista lateral, el postorbital presenta mayor desarrollo anteriormente, conformando una continuidad con la protuberancia del postfrontal. La carilla de articulación para el yugal se orienta ventrolateralmente; se encuentra separada de la carilla de articulación para el escamoso, la cual se orienta ventromedialmente.

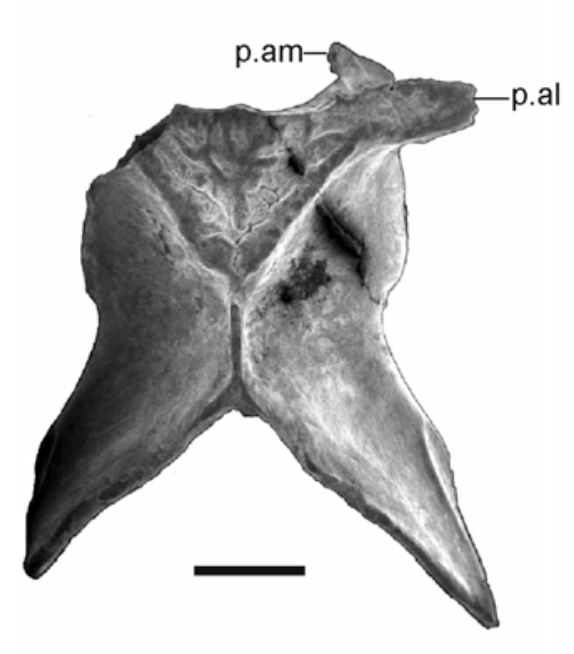

A

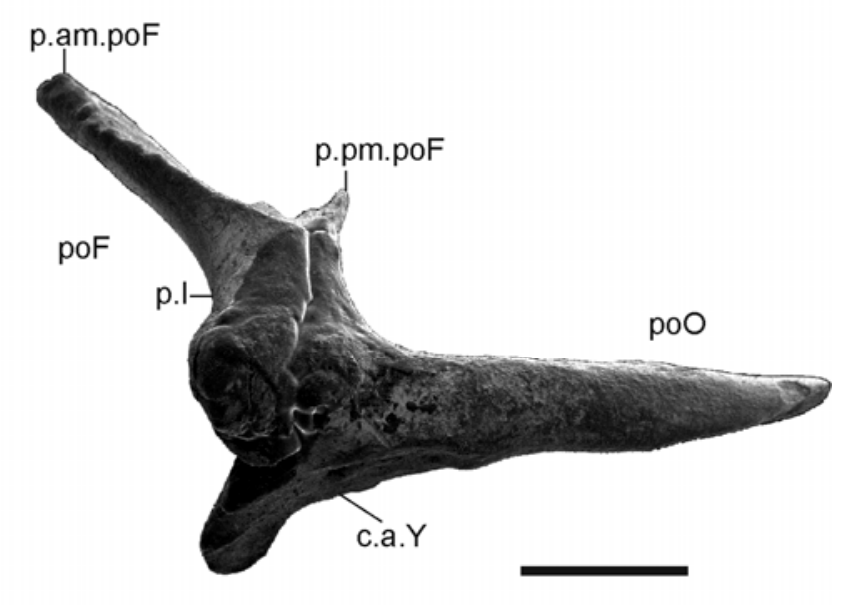

B

Figura 65. Elementos craneales de Callopistes bicuspidatus Chani, 1976 de la Formación Monte Hermoso, Farola Monte Hermoso, provincia de Buenos Aires. A, frontal (FML 4618-2) en vista dorsal; B, postfrontal y postorbital (FML 4618-3) izquierdos en vista lateral. Abreviaturas: c.a.Y, carilla de articulación para el yugal; poF, postfrontal; poO, postorbital; p.al, proceso anterolateral; p.am.poF, proceso anteromedial del postfrontal; p.l, proceso lateral; p.pm.poF, proceso posteromedial del postfrontal. Escalas $=2 \mathrm{~mm}$.

El fragmento FML 4618-4 corresponde a la parte anterior del dentario derecho (Fig. $66 \mathrm{~A}$ ). Es un hueso robusto, de superficie labial lisa con cinco forámenes mentales; el último de los cuales se ubica entre los dientes XII y XIII. La parte posterior de la cara labial del dentario se encuentra fracturada y algo desplazada. En vista lingual se observa el surco dental, con la serie dentaria casi completa y un estrecho, pero nítido, sulcus dentalis. Ventralmente a estas estructuras se encuentra la sínfisis mandibular simple en el extremo anterior, y el estante subdental, posterior a la sínfisis, a lo largo de todo el dentario. El estante subdental presenta forma de silla de 
montar inmediatamente posterior a la sínfisis, mientras que más posteriormente es plano, con menor desarrollo dorsoventral. El canal de Meckel está ampliamente abierto hasta el extremo anterior del dentario, terminando ligeramente ventral a la sínfisis. La carilla dorsal de articulación para el esplenial se desarrolla hasta la posición dentaria VIII; por delante de este punto el canal de Meckel quedaría expuesto anteriormente. A la altura del diente XIV, sobre el techo del canal de Meckel, está expuesto el canal alveolar inferior. Las características dentales son similares a las descriptas para el maxilar; se conservan los primeros 15 alvéolos funcionales, todos con dientes excepto el IV y XV. Los dientes se encuentran en estrecho contacto y se diferencian dos tipos dentarios: uno de dientes bajos, ubicados anteriormente (I-VIII), y otro de dientes más altos, localizados posteriormente (IX-XV). Los tres primeros dientes son unicuspidados y forman un gradiente creciente de tamaño. Tienen base cilíndrica, alta, con una leve compresión mesodistal. Apicalmente, terminan en un cono alto, comprimido labiolingualmente, con cierta curvatura distal y una fina cresta anteroposterior en su cara mesial, que es más nítida en los dientes III a VII. Sus caras labiales son convexas y las linguales cóncavas. Los dientes hasta la posición VII son similares al II. A partir del diente VIII, el contorno lateral distal presenta el borde mesial recto y oblicuo, recorrido oclusalmente por una cresta mesodistal, anterior a la cual se observa una sutil protuberancia. En la zona ventral a dicha cresta, se desarrolla un somero surco vertical que diferencia la cúspide posterior de la anterior. Al igual que lo que ocurre en el maxilar, la cúspide distal es claramente dominante; la cúspide mesial presenta un grado de diferenciación variable entre los dientes, pero todos ellos son levemente bicuspidados. Posteriormente a la última posición dentaria (XV) que no conserva diente, se conserva la pared anterior de la base del último diente (XVI). Se conservan seis alvéolos de reemplazo lingualmente sobre los alvéolos funcionales II, IV, VII, IX, XI y XIII; son subcirculares, los posteriores más profundos, posiblemente por estar en un estado más avanzado de desarrollo.

La hemimandíbula izquierda (FML 4618-5) está compuesta por huesos robustos; se conserva incompleta, astillada y reconstruida (Fig. 66 B, C). Todos los huesos de la hemimandíbula están preservados, en forma más o menos completa, excepto el articular. El dentario está casi completo, aunque le falta el extremo labial más anterior. Su superficie labial es lisa y porta al menos tres forámenes mentales Una grieta atraviesa longitudinalmente al hueso sobre la línea de los alvéolos mentales, de modo que es posible que tenga más. El contorno dorsal del dentario es recto; 
posteriormente presenta forma de una cuña delimitada por los procesos posterodorsal y posteromedial, que recibe casi exclusivamente al suprangular. Dorsalmente se observa el surco dental con la serie dentaria y el estrecho sulcus dentalis. Posteriormente a la sínfisis, se desarrolla el estante subdental, el cual presenta forma de silla de montar anteriormente, mientras que posteriormente es plano y disminuye el desarrollo dorsoventral. El canal de Meckel está cubierto por el esplenial; es amplio, abierto medialmente y se continúa por debajo de la sínfisis. La abertura anterior del canal de Meckel comienza a la altura del diente IV, sin una constricción marcada. Las características de implantación de los dientes son como las previamente descriptas. La serie dentaria se conserva completa, con 16 alvéolos funcionales donde sólo faltan los dientes I, IV, IX y XIV. Los seis primeros dientes forman un gradiente de tamaño creciente, mientras que los últimos forman una empalizada de altura constante. Los dientes II y III son unicuspidados, rectos y pequeños. Sus bases están mesodistalmente comprimidas, de modo que la sección es oval. Sus caras labiales son convexas y las linguales cóncavas. El diente V está apicalmente roto. El diente VI es similar al II y III pero más grande y con algo de curvatura distal en su extremo apical. Los dientes VII y VIII son similares, algo más grandes y se encuentran labiodistalmente rotos. Los dientes X al XVI son altos y levemente bicuspidados, como los descriptos del dentario derecho y maxilar izquierdo. El esplenial es triangular, plano y se extiende muy anteriormente, hasta la altura del diente IV. Su extremo anterior se encuentra fracturado y desplazado, mientras que el posterior no se conserva completo. El foramen alveolar, que es de ubicación anterior y de mayor tamaño, y el foramen milohioideo anterior, que es posterior y más pequeño, se ubican aproximadamente entre los dientes XI a XIV. El coronoides se conserva completo; sus procesos laterales son cortos, el anterolateral no supera la posición del último diente, mientras que el posterolateral es muy reducido y apoya sobre el suprangular. El proceso posteromedial es el mayor de los procesos ventrales del coronoides y no conserva el extremo distal; es robusto, largo y curvado posteriormente. Su cara anterior es recorrida por una robusta cresta vertical. El proceso anteromedial está fracturado, algo desplazado y mal conservado. Es corto, no supera la posición del último diente, y poco profundo, de modo que el borde ventral del proceso anteromedial y del estante subdental se continúan horizontalmente. Entre los procesos mediales se encuentra un fragmento de hueso que correspondería a la faceta coronoidea del suprangular, rota y desplazada. El proceso dorsal está bien 
desarrollado; es alto y se caracteriza por una importante cresta lateral oblicua, ventralmente a la cual el coronoides está profundamente excavado. El suprangular está astillado y no conserva la parte posteroventral. Presenta una importante depresión, ventralmente al coronoides, donde se encuentra el foramen suprangular anterior. La parte más anterior del suprangular ocupa casi totalmente la cuña posterior del dentario. En vista lingual, el borde dorsal de la fosa mandibular es cilíndrico, robusto y algo más desarrollado anteriormente. Del angular sólo se conserva el fragmento anterior, parcialmente cubierto por el proceso posteroventral del dentario.

Se conservan también cuatro fragmentos aislados indeterminados, dos de ellos posiblemente correspondientes al neurocráneo (FML misceláneas). 


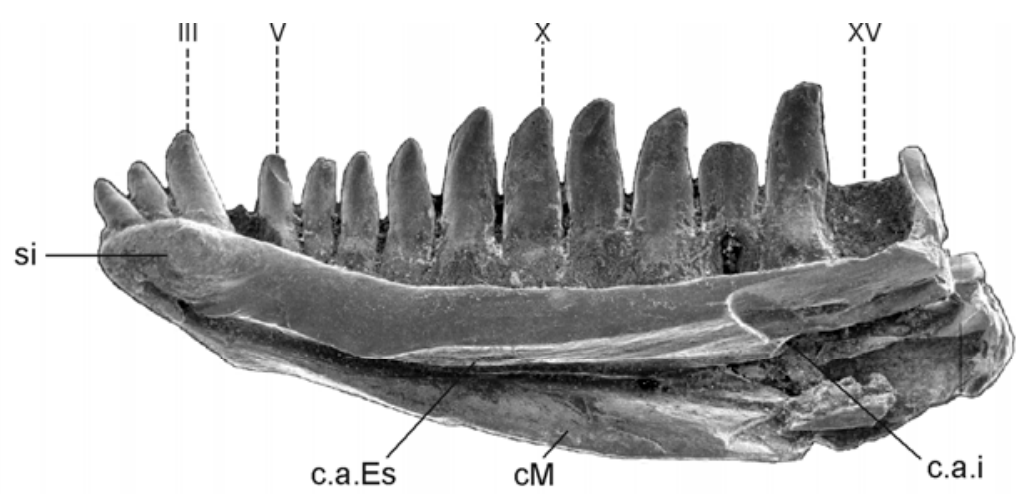

A
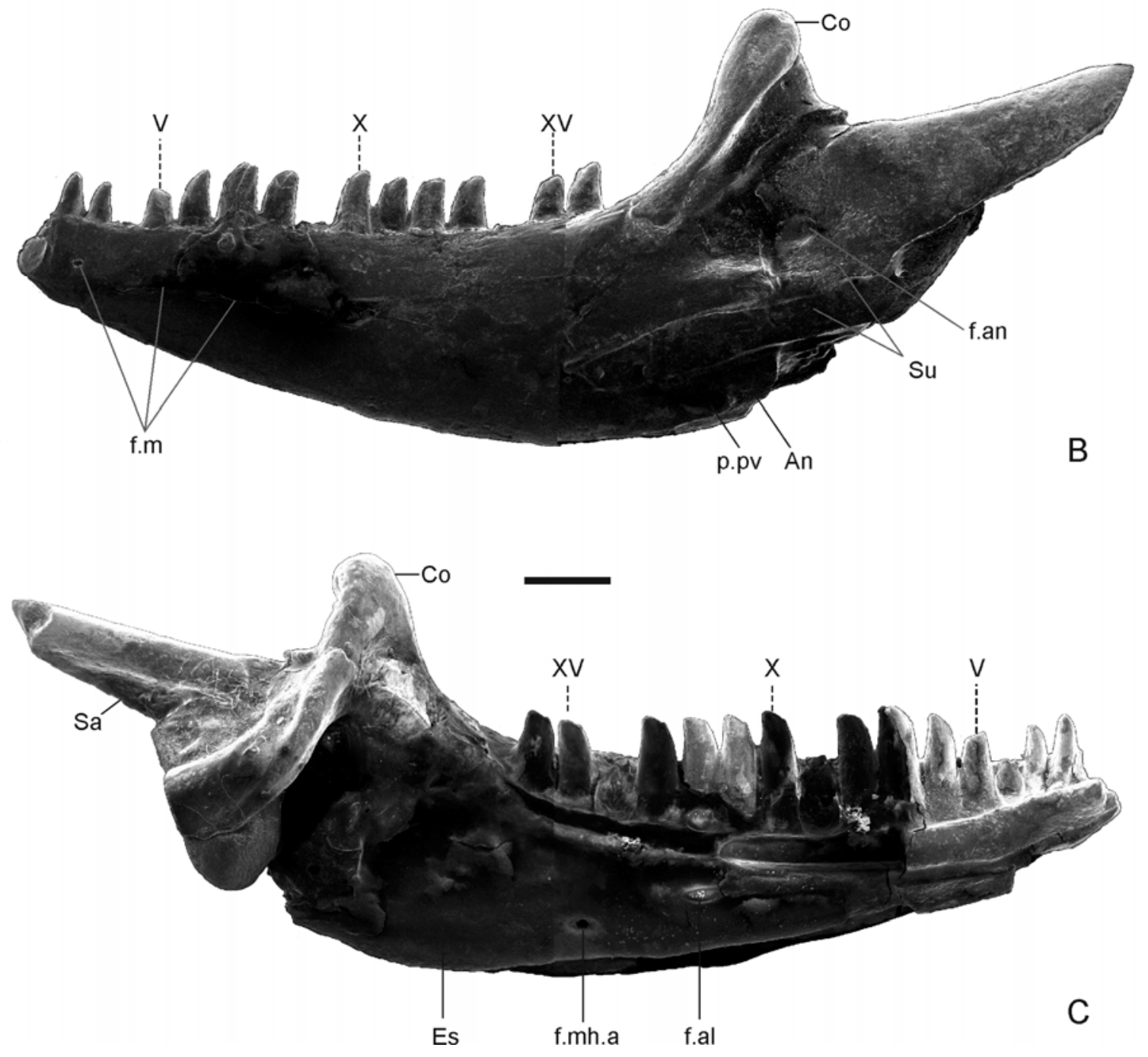
Figura 66. Elementos mandibulares de Callopistes bicuspidatus Chani, 1976 de la Formación Monte Hermoso, Farola Monte Hermoso, provincia de Buenos Aires. A, dentario derecho (FML 4618-4) en vista lingual; B, C, hemimandíbula izquierda (FML 4618-5) en vista labial (B) y lingual (C). Abreviaturas: An, angular; cM, canal de Meckel; Co, coronoides; c.a.Es, carilla de articulación para el esplenial; De, dentario; Es, esplenial; f.al, foramen alveolar; f.an, foramen anterior; f.c.a.i; foramen del canal alveolar inferior; f.la, foramen labial; f.m, foramen mental; f.mh.a, foramen milohioideo anterior; p.pv, proceso posteroventral; si, sínfisis mandibular; $\mathrm{Su}$, suprangular. Escalas $=2 \mathrm{~mm}$.

Comentarios taxonómicos. Los fósiles presentan los tres caracteres que definen el clado Borioteiioidea-Teiioidea: abundante cemento sobre las bases de los dientes (FML 4618-1, 4618-4 y 4618-5), alvéolos de reemplazo profundos y subcirculares (FML 4618-1 y 4618-4), y esplenial hipertrofiado, anteriormente desarrollado (FML 4618-4/5). Varios caracteres permiten la asignación a los Teiioidea. Contrariamente a lo sostenido por Chani (1976), el parietal FML 4618-2 es más ancho que largo ( $\mathrm{L}=$ 6,44 mm; $\mathrm{A} \approx 10,44 \mathrm{~mm}$ ) como en los Teiioidea, mientras que en los Borioteiioidea es más largo que ancho (Denton y O’Neill, 1995; Nydam y Cifelli, 2002b; Nydam et $a l .$, 2007). Adicionalmente, el parietal comparte con los Teiioidea: la ausencia de foramen parietal ([C45]), la presencia de procesos descendentes ([C50]), la musculatura adductora que habría ocupado más de 2/3 del largo del parietal ([C47], ver Cap. V) y la fosa parietal abierta (Denton y O’Neill, 1995; Nydam y Cifelli, 2002b; Nydam et al., 2007; Cap. VI). La ausencia del soporte narial anterior es otro carácter que se presenta en los Teiioidea (Cap. III). En la mandíbula FML 4618-5, el proceso anterior del coronoides solapa al proceso posterior del dentario, y no a la inversa como en los Borioteiioidea ([C86], [C98]).

Los tres caracteres que definen al clado Borioteiioidea-Teiioidea (Cap. III) se revierten en los Gymnophthalmidae (Nydam et al., 2007), lo que posibilita excluir a los fósiles de esta familia. Además, los Gymnophthalmidae presentan una combinación de caracteres ausentes en los fósiles (Cap. V), lo cual permite asignar los mismos a la familia Teiidae.

Chani (1976) utiliza la relación entre la longitud y la altura del maxilar para diferenciar el maxilar fósil del de los restantes géneros de Teiidae. Sin embargo, este carácter es considerado inválido, ya que como se observa en la figura 67 esta relación es constante entre los miembros de esta familia. 


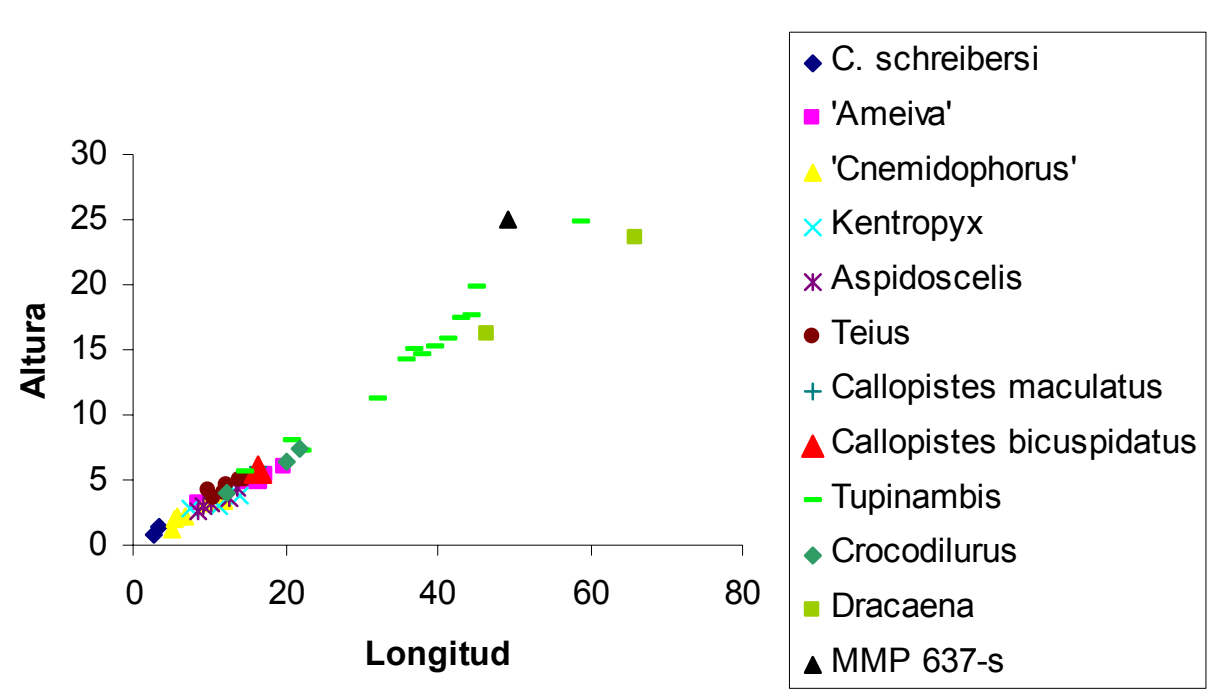

Figura 67. Longitud vs. altura de maxilares de Teiidae. Altura tomada al proceso prefrontal.

El material puede ser asignado a los Tupinambinae por presentar varios caracteres craneales y mandibulares. Entre los caracteres craneales, comparten: cresta sobre la lámina transversal del maxilar ([C18]); soporte narial posterior débilmente marcado ([C17]); musculatura adductora muy extendida sobre el parietal, uniéndose en la línea media ([C46]); borde anteromedial de la fenestra supratemporal delimitado por el parietal ([C54]); proceso maxilar del yugal ligeramente cóncavo ([C26]); canal de Meckel sin restricción anterior([C88]); y borde posterior del dentario, con forma de amplia cuña, recibiendo principalmente al suprangular que casi excluye al angular ([C92]).

Entre los Tupinambinae, la meseta parietal triangular, como la del fósil FML 4618-2, se presenta en Callopistes, Paradracaena y Tupinambis ([C46]). La afinidad de los fósiles con el primero de estos géneros se manifiesta por: bordes de la meseta parietal rectos y marcados ([C46]); un mayor desarrollo de la parte dorsal de un soporte narial poco nítido ([C17]); suprangular casi excluyendo al angular de la cuña posterior del dentario ([C91]); y contorno dorsal del dentario recto ([C85]). Además comparte con este género la marcada proyección anterior del postfrontal hacia la órbita ([C42]). El fósil presenta implantación subpleurodonte, con alvéolos delimitados por septos interdentales. Estos septos no están disimulados por depósito de cemento sobre la base de los dientes, condición que, entre los Tupinambinae, sólo se registra en Callopistes ([C120]) (Cap. III). Callopistes presenta una leve heterodoncia, la cual, según Presch 
(1974b), varía en las dos especies actuales; mientras que C. flavipunctatus presenta dientes posteriores bicuspidados y tricuspidados en el maxilar y el dentario, $C$. maculatus sólo tendría dientes bicuspidados. En el material de referencia utilizado, contrariamente a lo sostenido por Presch (1974b), se observó que en C. maculatus había entre dos y tres dientes tricuspidados ubicados posteriormente a los dientes bicuspidados (Fig. 68). En estos dientes tricuspidados la cúspide central es la dominante, mientras que las accesorias son pequeñas, con un desarrollo menor de la distal respecto a la mesial. En la familia Teiidae existen cambios ontogenéticos en la dentición como los descriptos en el Capítulo III, pero no hay mención en la literatura de estos cambios en Callopistes. Por lo tanto, el fósil difiere tanto de C. maculatus como de C. flavipunctatus porque todos los dientes posteriores de la serie dentaria son bicuspidados.

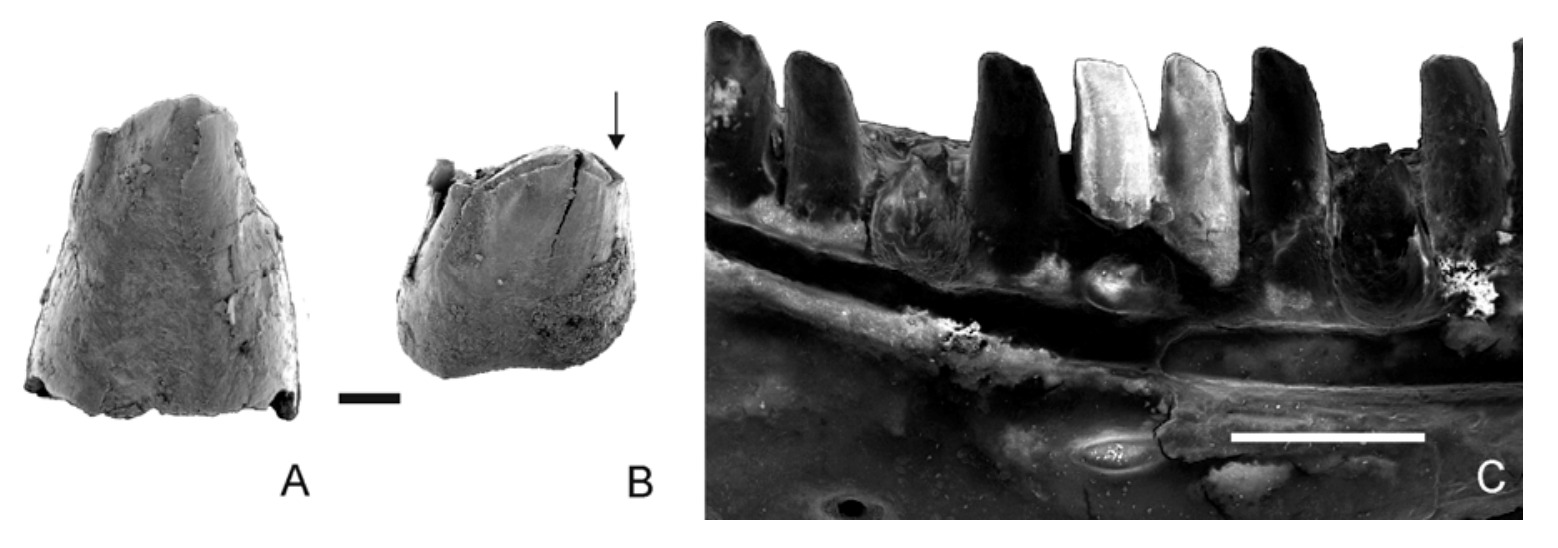

Figura 68. Dientes de Callopistes maculatus y C. bicuspidatus. A, diente bicuspidado de C. maculatus (MNHN cl 4113); B, diente tricuspidado de C. maculatus (MNHN cl 4113), flecha indica cúspide distal; C, detalle de la dentición de C. bicuspidatus (FML 4618-5) Escala $0.2=\mathrm{mm}$.

Los fósiles también difieren de C. maculatus por el corto proceso anterolateral del coronoides ([C98]), que no supera la proyección anterior del suprangular ([C99]), y por carecer de la marcada escotadura sobre la rama lingual del proceso premaxilar del maxilar (MNHN cl 4113) ([C13]).

Estes (1983a) sostiene que la identificación del fósil como Callopistes por Chani (1976) es correcta, aunque no fundamenta su comentario. Ester autor, siguiendo a Presch (1974a), considera como caracteres craneales diagnósticos de Callopistes la ausencia del proceso dorsal del escamoso ([C56]), la poca contribución del ectopterigoides a la fenestra subaorbital (mencionado como foramen orbital inferior) ([C77]) y la presencia de una marcada cresta sagital sobre el parietal ([C46]). Entre 
estos caracteres, solamente el último está conservado en el fósil, pero, como ya se mencionó, esta cresta es similar a la de Callopistes, Paradracaena y Tupinambis. Los restantes caracteres se observan en la mayoría de los Tupinambinae; por lo cual, el género Callopistes no puede ser definido por autapomorfias craneales. Según el análisis filogenético de la familia Teiidae realizado por Nydam et al. (2007), este género únicamente se destaca por la condición plesiomórfica de su implantación dental. Sin embargo, como se discutió anteriormente (Cap. III), el tipo de implantación observado en Callopistes también se encuentra en los "cnemidoforinos". La revisión del material de referencia permitió reconocer varios caracteres que sirven de nuevos elementos diagnósticos para el género, algunos de los cuales están presentes en el material fósil. La especie extinta nominada por Chani (1976) difiere de los actuales Callopistes por la presencia únicamente de dientes bicuspidados en la parte posterior de la serie dentaria y por la posición posterior del proceso anterolateral del coronoides respecto al extremo anterior del suprangular. Se destaca, además, que esta especie presenta una extensión anterior del canal de Meckel ventralmente a la sínfisis mandibular, como también se observa en los Teiidae no Tupinambinae. Por todo lo expuesto, se reconoce como válida la especie C. bicuspidatus pero sobre la base de fundamentos diferentes a los expuestos originalmente por Chani (1976).

\section{Comentarios biogeográficos sobre los lagartos de Farola de Monte Hermoso}

El sitio Farola Monte Hermoso se encuentra en la zona costera de la Pampa seca. Esta última forma parte de la provincia biogeográfica Pampeana (Dominio Chaqueño) que abarca las llanuras del este de Argentina (entre los paralelos $30^{\circ}-39^{\circ} \mathrm{S}$ ), Uruguay y parte del sur de Brasil. Esta provincia biogeográfica presenta un clima templadocálido, con temperaturas medias entre $13-17^{\circ} \mathrm{C}$, y lluvias anuales, cuya media varía entre 1200 y 600 mm/año (Cabrera y Willink, 1980). La variación de la precipitación anual permite reconocer, en la provincia de Buenos Aires, una región húmeda en el noreste (Pampa húmeda) y una región más seca (Pampa seca) en el sudoeste. Los límites de precipitación de la Pampa seca son de 500-600 mm/año y 700-800 mm/año en el oeste y este respectivamente (Prieto, 2000). Contrastando con el presente, el hallazgo en los sedimentos de la Fm. Monte Hermoso de un Boinae y el Testudinidae Geochelone gallardoi estarían indicando condiciones más cálidas y húmedas para el Montehermosense de Farola Monte Hermoso que en la actualidad (Gasparini et al., 1986; Albino, 1992; Albino et al., 2009). Sin embargo, Chani (1976), a partir del 
análisis de la fauna de roedores que acompaña la distribución actual de Callopistes, y su comparación con la fauna de roedores de la Fm. Monte Hermoso, considera que el ambiente en el Montehermosense habría sido algo más seco, de transición entre una zona árida y una húmeda, similar al Bosque Chaqueño.

El género Callopistes se distribuye actualmente al oeste de los Andes, desde Ecuador hasta Chile, atravesando Perú (Krause, 1985). Esta zona corresponde a la provincia biogeográfica del Desierto (Dominio Andino-Patagónico), que abarca la costa pacífica de América del Sur entre los paralelos $5^{\circ} \mathrm{S}$ y $30^{\circ} \mathrm{S}$ (Cabrera y Willink, 1980). Se trata de una amplia zona de clima cálido y muy seco por efecto de la corriente fría de Humbolt. Las precipitaciones, que no superan los $110 \mathrm{~mm} / \mathrm{año,} \mathrm{son}$ máximas en los extremos norte y sur, mientras que en la zona central (Arica e Iquique, Chile) llega a cero (Cabrera y Willink, 1980). En esta amplia zona C. flavipunctatus se distribuye al norte y C. maculatus al sur (Chani, 1976; Vidal, 2004; Venegas, 2005). En el norte, Callopistes flavipunctatus se encuentra en la vertiente occidental del Bosque Seco Ecuatorial, aunque su distribución llegan al Desierto Pacífico más al sur (Venegas, 2005). En la región serrana del norte de Perú (departamentos de Piura, Lambayeque, Cajamarca, La Libertad), donde se desarrolla el Bosque Seco Ecuatorial, la temperaturas medias son aproximadamente de $15,47^{\circ} \mathrm{C}$, mientras que sobre la costa las temperaturas son mayores, con una media de $28,8^{\circ} \mathrm{C}$ (datos tomados de Fierro Zapata y Pérez Díaz, 2007). Callopistes maculatus llega al sur hasta la VII Región (Maule) de Chile (Vidal, 2004). Allí (Parque Nacional Bosque Fray Jorge) las temperaturas varían entre $\approx 25^{\circ} \mathrm{C}$ en el verano $\mathrm{y} \approx 21^{\circ} \mathrm{C}$ en el invierno (Kelt et al. 2004). Según la distribución de estas especies, la presencia del género Callopistes en el sur de la provincia de Buenos Aires estaría indicando un clima más cálido y mucho más árido para el Montehermosense con respecto a la actualidad. La mayor aridez del paleoclima contrasta con opiniones previas (Gasparini et al., 1986; Pascual y Odreman Rivas, 1971). Considerando la fauna asociada, las precipitaciones durante el Montehermosense deberían haber superado los $200 \mathrm{~mm} /$ año para permitir la presencia del género Tupinambis, cuya especie más xerófila, T. rufescens, es característica del Chaco árido (ver Cap. VI). Esto mismo es válido para el caso del Boinae reconocido en la Formación Monte Hermoso, ya que la especie actual con requerimientos ecológicos más plásticos es Boa constrictor occidentalis, característica del ambiente del Chaco árido (Albino, 1992). Asimismo, los parámetros paleoambientales inferidos a partir de la fauna de mamíferos fósiles indican un 
régimen de precipitaciones como mínimo de 500 mm/año (Pascual y Odreman Rivas, 1971; Chani, 1976). De esta forma, se interpreta que los requerimientos climáticos de C. bicuspidatus habrían sido diferentes a los de sus congéneres actuales especialmente en cuanto a las condiciones de humedad.

Por otro lado, Chani (1976) propone que Callopistes se habría originado durante el Mioceno. Contrariamente, datos moleculares sostienen que este género se habría diferenciado de los restantes Tupinambinae en el Paleoceno, y que la divergencia entre las dos especies actuales habría ocurrido durante el Oligoceno (Giugliano et al., 2007). La posición basal de Callopistes entre los Tupinambinae, aceptada por la mayoría de las hipótesis filogenéticas, y la presencia de Tupinambinae en el Eoceno (véase Fm. Lumbrera) argumentan a favor de un origen temprano del género como lo indican los datos moleculares de Giugliano et al. (2007). Callopistes bicuspidatus sería descendiente de las poblaciones ancestrales del género que habrían quedado al este de los Andes como consecuencia de la elevación de la cordillera durante el Eoceno. El género habría tenido una prolongada y desconocida historia evolutiva en América del Sur, donde las poblaciones al este de los Andes se habrían extinguido. La distribución actual del género sería relictual, mientras que el momento calculado de especiación de las dos especies actuales coincide con importantes eventos tectónicos que provocaron una mayor elevación de la cordillera de los Andes (fase Pehuenche, $30 \mathrm{Ma}$ ). Esta larga historia podría explicar las diferencias en cuanto a las preferencias climático-ambientales entre $C$. bicuspidatus y las especies actuales del género.

\subsection{7. “Formación” Chapadmalal}

\section{Geología}

En 1908, Ameghino reconoce la "Formación" Chapadmalal en la base de los acantilados costeros entre Miramar y Mar del Plata (Fig. 69). El esquema de Ameghino fue posteriormente modificado por Kraglievich $(1952,1953,1959)$ quien presenta un diagrama más complejo con diferentes "Formaciones" (no definidas litológica ni fosilíferamente, Cione y Tonni, 1995c). En la base de los acantilados, la "Fm." Chapadmalal de Kraglievich, está definida por la biozona Paraglyptodon chapadmalensis, que corresponde al piso/edad Chapadmalalense superior (Plioceno temprano-medio, Cione y Tonni, 1995a, b; 2005). 


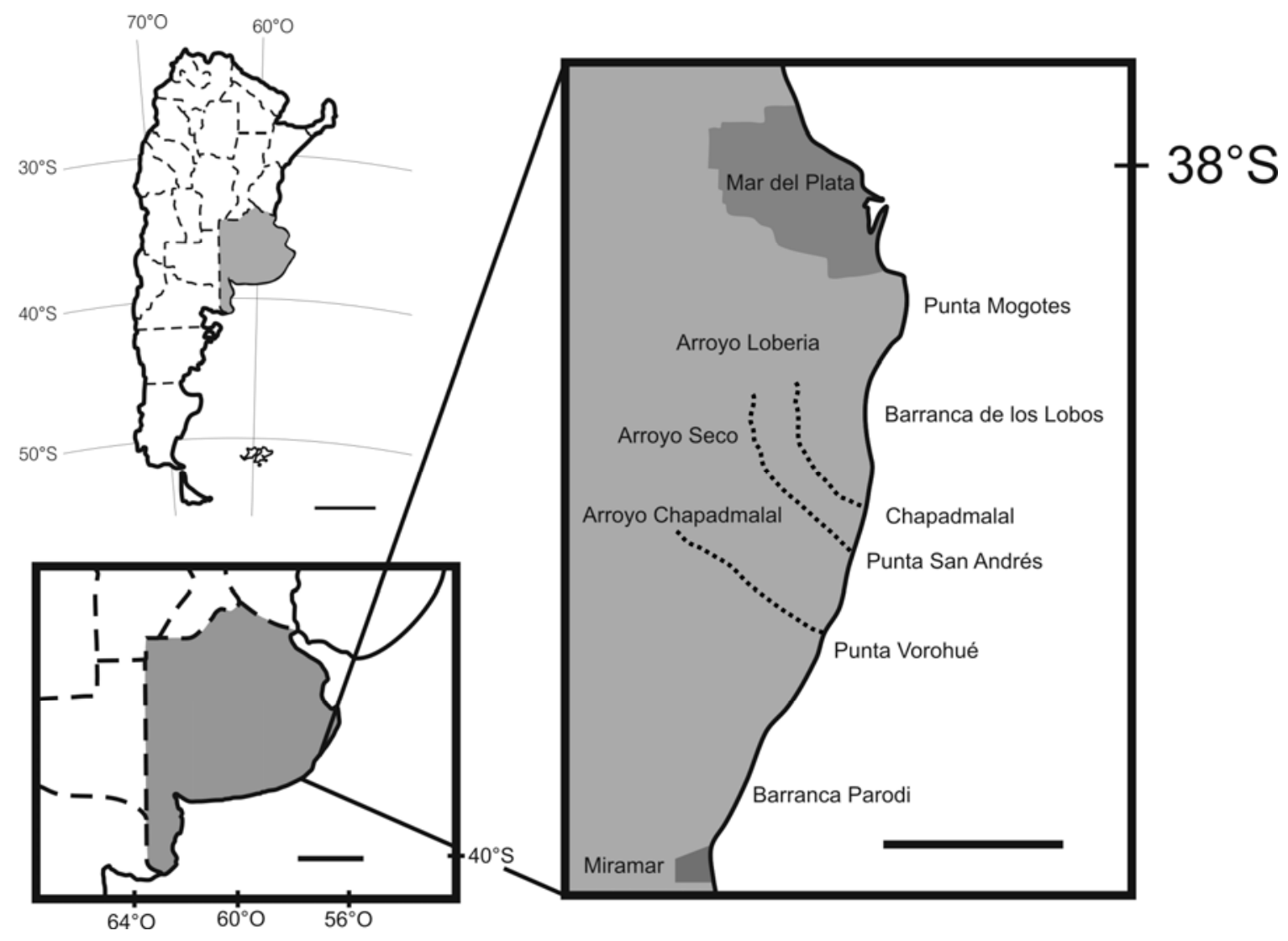

Figura 69. Costa del sudeste bonaerense con diferentes localidades del Chapadmalalense superior y Marplatense. Escala $=500 \mathrm{~km}, 200 \mathrm{~km}$ y $10 \mathrm{~km}$.

\section{Antecedentes}

En el trabajo de Alberdi et al. (1995) se resumen las características de la fauna de la región Pampeana desde el Montehermosense al Holoceno, y se detallan los diferentes grupos de vertebrados representados (peces, aves y gran cantidad de mamíferos). Sin embargo, no se hace referencia de los reptiles, evidenciándose así la escasez de registros bien documentados, especialmente en cuanto a sus procedencias. Entre los Squamata reconocidos en el Chapadmalalense superior de la zona de Chapadmalal se han citado al teido Tupinambis merianae (citado como T. teguixin) y anfisbénidos indeterminados (Reig, 1958; Báez y Gasparini, 1977; Donadío, 1982; Gasparini et al., 1986; Albino, 1996a). Esta última cita corresponde a restos vertebrales recolectados por Lorenzo Parodi 1919 y depositados en la colección del Museo Nacional de Ciencias Naturales (MACN Pv 6878) como Ophidia.

Posteriormente, Donadío (1982) los asigna a Amphisbaenia, sin describir ni figurar. A 
continuación se describen restos de lagartos y anfisbenios citados por Reig (1958) y Donadío (1982) y que fueran referidos por otros autores, así como un fósil inédito (MACN Pv 19394).

\author{
SQUAMATA Oppel 1811 \\ SCLEROGLOSSA Estes, de Queiroz y Gauthier 1988 \\ SCINCOMORPHA Camp 1923 \\ TEIIOIDEA Estes, de Queiroz y Gauthier 1988 \\ TEIIDAE Gray 1827 \\ TUPINAMBINAE Presch 1974a \\ Tupinambis Daudin 1802 \\ Tupinambis sp
}

(Fig. 70)

Material referido: MACN Pv 10247, hemimandíbula muy fragmentada; MACN Pv 19394 dentario derecho parcialmente conservado.

Procedencia geográfica: Chapadmalal, Buenos Aires.

Procedencia estratigráfica: "Fm." Chapadmalal, Chapadmalalense superior, Plioceno temprano-medio (Cione et al., 2007).

Descripción. El material consiste en una hemimandíbula derecha totalmente astillada. Se conservan tres fragmentos significativos, dos de los cuales corresponden a dentarios y otro a parte del coronoides. Uno de los fragmentos es la parte anterior de un dentario (MACN Pv 10247-1), que conserva cinco alvéolos con las bases de los respectivos dientes. El otro fragmento de dentario corresponde a la parte posterior (MACN Pv 10247-2) (Fig. 70 A) y presenta los últimos cinco alvéolos, anteriormente a los cuales, se observa un fragmento de la pared distal del diente anterior. Los dientes son de implantación subpleurodonte, ubicados en alvéolos delimitados por septos interdentales muy disimulados por el abundante depósito de cemento basal. Lingualmente a la serie dentaria, se observa un marcado sulcus dentalis. Los dientes (a) y (b) están fusionados, son robustos y romos, de sección transversal subcircular. El diente (c) es un típico diente robusto, romo y de sección oval. Centralmente, sobre la superficie oclusal, se observa un nítida protuberancia, pero no se advierte cresta mesodistal. El esmalte está finamente estriado, por estrías poco nítidas. El diente (d) 
conserva sólo la base, que es similar a la del diente precedente. El último diente (e) también está roto; se conserva su base de sección circular y menor a la de los dientes anteriores. Lingualmente a los dientes (a), (b) y (c), hay someros alvéolos de reemplazo. El tercer fragmento (MACN Pv 10247-3) corresponde al proceso dorsal de un robusto coronoides derecho. Labialmente presenta una marcada cresta oblicua y lingualmente se conserva la parte proximal del proceso posteromedial, con una marcada cresta anterior, de disposición vertical.

Con respecto al fragmento MACN Pv 19394, corresponde a la parte anterior de un robusto dentario derecho (Fig. 70 B). Labialmente es liso y conserva cuatro forámenes mentales a la altura de los dientes II, IV, VII y IX. Lingualmente se observa una simple sínfisis, seguida posteriormente por el estante subdental, el cual en su extremo anterior presenta forma de silla de montar desdibujada y posteriormente es plano-convexo. Ventralmente se observa la abertura anterior del canal de Meckel, que no presenta mayor constricción. La superficie de articulación del esplenial, ventralmente al el estante subdental, se infiere que llegaba a la VII posición dentaria. Dorsalmente se observa el surco dental con los diez alvéolos anteriores. Los dientes son de implantación subpleurodonte, se ubican en alvéolos delimitados por septos interdentales disimulados por el abundante depósito basal de cemento. Lingualmente a la serie dentaria se observa un marcado sulcus dentalis. Los primeros seis dientes son unicuspidados, cónicos, de punta punzante y distalmente orientada. Varían en tamaño, siendo el II y III mayores que el VI y éste mayor a los restantes. Del diente VII sólo se conserva la base. Los dientes VIII y IX son similares a los anteriores pero de mayor tamaño, mientras que el diente IX presenta una ligera compresión lateral de su extremo distal. El diente X es robusto y comprimido lateralmente en su parte distal. El contorno lateral muestra una incipiente protuberancia mesial. No se observan alvéolos de reemplazo. 

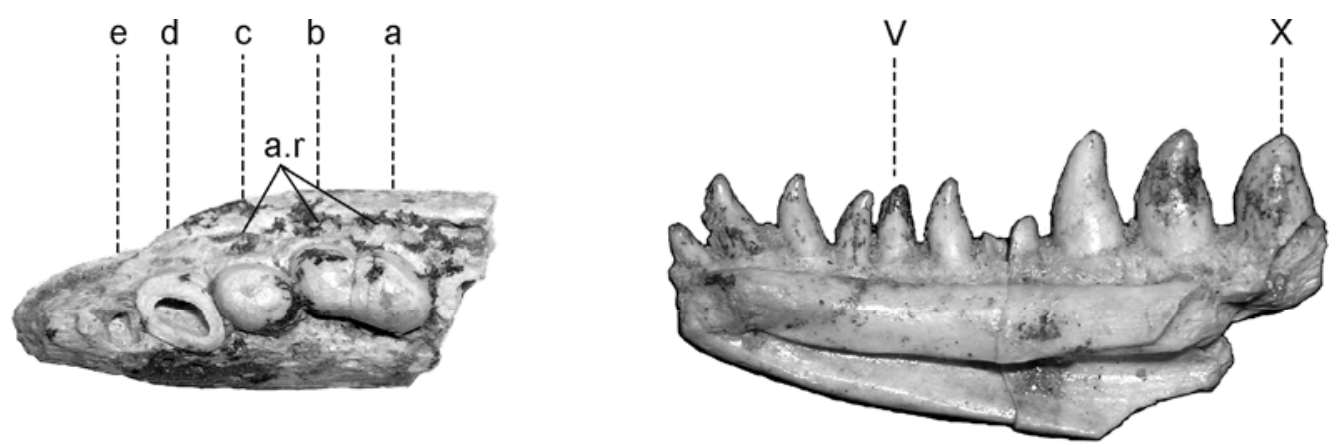

A

B

Figura 70. Dentarios de Tupinambis sp. de la "Fm." Chapadmalal (Plioceno temprano-medio). A, dentario MACN Pv 10247-2 en vista dorsal; B, dentario MACN Pv 19394 en vista lingual. Escala = 10 $\mathrm{mm}$.

Comentarios taxonómicos. El abundante cemento basal (MACN Pv 10247-2, MACN Pv 19394), los alvéolos subcirculares y profundos (MACN Pv 10247-2) así como la presencia de un esplenial hipertrofiado, anteriormente desarrollado (inferido de MACN Pv 19394) permiten incluir estos fósiles en el clado BorioteiioideaTeiioidea, y a su vez, excluirlos de los Gymnophthalmidae (Nydam et al., 2007). Los alvéolos de reemplazo del fósil MACN Pv 10247-2 son someros, pero se interpreta que se debe al estado de desarrollo incipiente de los dientes de reemplazo. La implantación subpleurodonte coincide con su inclusión en los Teiidae ([C120]). El tamaño de los fósiles, y el canal de Meckel abierto medialmente, que termina en la sínfisis ([C89]) y sin restricción anterior ([C88]) es como en los Tupinambinae. Dentro de éstos, el tipo particular de implantación dentaria, con el cemento disimulando los septos interdentales, se asemeja a la de Crocodilurus y Tupinambis. Sin embargo, Crocodilurus no presenta dientes posteriores expandidos como los observados en Tupinambis. Los dientes posteriores del fósil MACN Pv 10247-2 no se diferencian de los de T. merianae, mientras que los del fósil MACN Pv 19394 se ajustan al patrón de distribución de tipos morfológicos dentarios esperado en esta especie (Cap. III). Como se mencionara en el Capítulo III las diferencias específicas entre los dientes posteriores robustos de Tupinambis no son definitorias; motivo por el cual, los restos son asignados a Tupinambis sp. 
? Tupinambis Daudin 1802

(Fig. 71)

Material referido: Varios elementos postcraneales del esqueleto axial y apendicular. MACN Pv 16831-1/2 vértebras sacras incompletas y desarticuladas; MACN Pv 16831-3 húmero izquierdo incompleto; MACN Pv 16831-4 extremo distal de fémur izquierdo; MACN Pv 16831-5 tibia derecha; MACN Pv 16815, vértebra caudal; MACN Pv 17452, vértebra dorsal; MACN Pv 16791, vértebra lumbar.

Procedencia geográfica: MACN Pv 16791, MACN Pv 16815 y MACN Pv 16831, Barranca de los Lobos, Chapadmalal, Buenos Aires. MACN Pv 17452 Chapadmalal, Buenos Aires.

Procedencia estratigráfica: "Formación” Chapadmalal, Chapadmalalense superior, Plioceno temprano-medio (Cione et al., 2007).

Descripción. El húmero izquierdo (MACN Pv 16831-3) es un hueso robusto y largo que no conserva las epífisis (Fig. 71 A). Proximalmente se encuentra más desarrollado y ventralmente la fosa coracobranquial está delimitada en su parte anterior por la cresta deltopectoral. Distalmente está roto. La depresión sobre el área condilar está mal preservada, pero por su contorno se infiere que es circular. Se observa un débil proceso supinatorio.

Se conserva el extremo distal, diáfisis y epífisis, de un fémur izquierdo (MACN Pv 16831-4) (Fig. 71 B). Ventralmente, en la fosa poplítea se observa el foramen homónimo. La epífisis se encuentra levemente desplazada pero completa, con los cóndilos anterior y posterior.

La tibia derecha (MACN Pv 16831-5) se conserva completa (Fig. 71 C). La superficie de articulación proximal es ligeramente convexa, de contorno irregular, triangular, y de ápice posteriormente dirigido. Medialmente, se desarrolla una nítida cresta cnemial. Distalmente, sobre el borde posterior, se observa una segunda cresta (cresta innominada de Montero et al., 2004).

Se conservan las dos vértebras sacras. La vértebra MACN Pv 16831-1, corresponde a una sacra anterior, en la cual no se conserva la parte dorsal izquierda ni posterodorsal (Fig. 71 D, E). El arco neural es corto y bajo. La espina neural no se conserva completa, pero llegaba anteriormente hasta el zigósfeno. El zigósfeno es relativamente grande y marcadamente escotado. La carilla de articulación derecha es grande, circular y levemente inclinada respecto al plano sagital. El arco neural es 
triangular en vista anterior; tan ancho como el zigósfeno. Las prezigapófisis se originan a media altura del arco neural; son grandes, de orientación anterolateral e inclinadas sobre la horizontal. Los procesos transversos (pleurapófisis) son robustos y grandes; ventalmente, cerca del centro, son ligeramente cóncavos. El centro vertebral es corto, cilíndrico y débilmente convexo ventralmente. El cótilo es grande, levemente más ancho que el canal neural, circular y profundo. El cóndilo es de contorno circular y poco inclinado dorsalmente, precedido por un marcado cuello condilar. El fósil MACN Pv 16831-2 corresponde a una vértebra sacra posterior que no conserva el proceso transverso y la prezigapófisis izquierda (Fig. $71 \mathrm{D}, \mathrm{E})$. El arco neural es alto y corto. El canal neural es grande, alto y subcircular. La espina neural es alta, con poca inclinación posterior, y no supera posteriormente a las postzigapófisis ni al cóndilo; presenta el mismo desarrollo anteroposterior a lo largo de toda su altura (i.e. no se aguza distalmente). El zigantro está apenas desarrollado. Las prezigapófisis son similares a las descriptas para la vértebra sacra anterior pero más pequeñas, de dimensiones similares a las postzigapófisis. El proceso transverso derecho es robusto, con un desarrollo menor al de la vértebra sacra anterior. En vista ventral, presenta una levemente concavidad, en la cual se encuentra el foramen mayor (Krause, 1978a). Sobre el proceso transverso se observan dos forámenes adicionales: el posterodorsal (Krause, 1978a) y uno pequeño en vista anterior. El centro vertebral es corto y cilíndrico; a la derecha se observa un pequeño foramen subcentral. El cótilo y el cóndilo son subcircular y circular respectivamente, sin mayor inclinación.

La vértebra dorsal MACN Pv 17452 no conserva la espina neural (Fig. 71 HJ). El arco neural es bajo y largo. Sobre el arco neural, la cicatriz de la espina neural se prolonga hasta el zigósfeno. Posterodistalmente, la espina neural aparenta ensancharse lateralmente (Fig. $71 \mathrm{H}$ ). El canal neural es moderado, tan ancho como el zigósfeno, y de contorno anterior triangular. El zigósfeno está pobremente conservado; es angosto y escotado en vista dorsal. Las prezigapófisis se desarrollan a media altura del canal neural; están orientadas lateralmente y presentan superficies de articulación ovales. Una moderada cresta interzigapofisiaria une la pre y la postzigapófisis del mismo lado. Las postzigapófisis se orientan lateralmente como las prezigapófisis pero son de menor tamaño, con carillas de articulación son subtriangulares. En la parte anterior de la vértebra, ventralmente a las prezigapófisis, se desarrollan los procesos transversos, que están orientados verticalmente, portando distalmente una sinapófisis oval. La cara anterior de los procesos transversos es 
ligeramente cóncava. El centro vertebral es de contorno cónico, truncado posteriormente. Ventralmente es ligeramente convexo, por la débil cresta sagital (Fig. $71 \mathrm{~J})$. El cótilo es oval, comprimido dorsoventralmente, profundo y ventralmente inclinado. El cóndilo es oval e inclinado dorsalmente; se proyecta posteriormente superando la extensión posterior de la espina neural y postzigapófisis. El cóndilo es precedido por un marcado cuello condilar.

La vértebra MACN Pv 16791 no conserva completa la espina neural, la prezigapófisis ni el proceso transverso izquierdo. En general esta vértebra es similar a la vértebra MACN Pv 17452, de la cual difiere sólo en el menor desarrollo del proceso transverso, que distalmente presentan una pequeña sinapófisis de contorno circular. Esta característica permite afirmar que este fósil corresponde a una vértebra lumbar.

La vértebra caudal MACN Pv 16815 no conserva la espina neural ni los extremos distales de los procesos transversos (Fig. 71 K-Ñ). El arco neural es bajo y corto. El canal neural es de tamaño moderado y triangular en vista anterior. La espina neural se prolonga anteriormente hasta el zigósfeno, el cual es angosto y marcadamente escotado, con las carillas de articulación poco inclinadas respecto al plano sagital. Las prezigapófisis se originan cerca del nivel dorsal del canal neural; se orientan más lateralmente que anterolateralmente y se inclinan $45^{\circ}$ (aprox.) sobre la horizontal. Lateralmente, se observa una nítida cresta interzigapofisiaria. Las prezigapófisis son de mayor tamaño que las postzigapófisis, las cuales están orientadas lateralmente, con las carillas de articulación inclinadas sobre la horizontal de forma similar a en las prezigapófisis. Entre las postzigapófisis se destaca el zigantro (Fig. 71 N). Sobre el centro vertebral, en vista lateral, se conservan las partes proximales de los procesos transversos, que presentan compresión dorsoventral y desarrollo anteroposterior (Fig. $71 \mathrm{M}$ ). El centro vertebral es cilíndrico, más estrecho en su parte media. El cótilo es grande, circular, profundo e inclinado ventralmente. El cóndilo, precedido por un marcado cuello condilar, es circular y dorsalmente inclinado. 

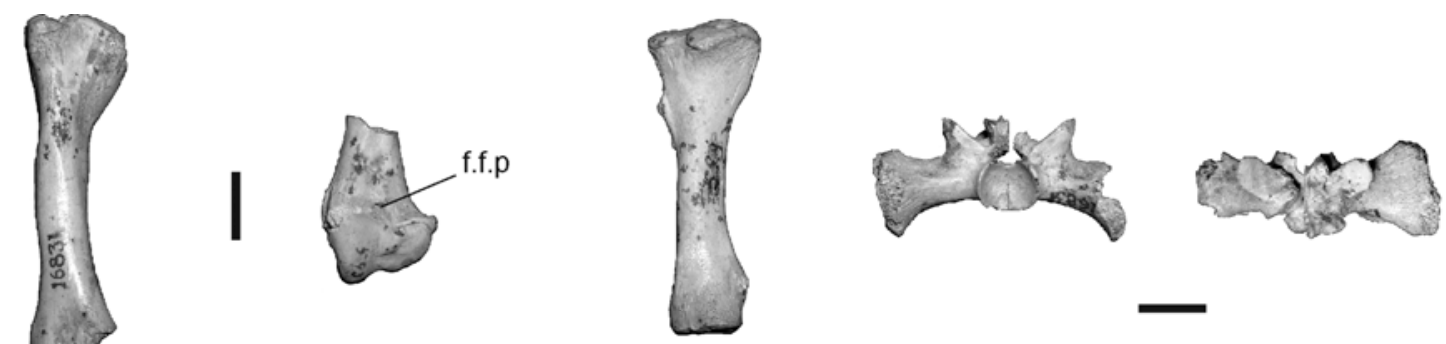

lis

A

B

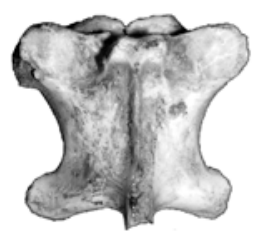

G

K

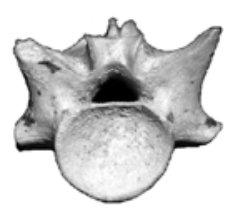

L

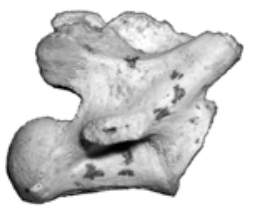

M

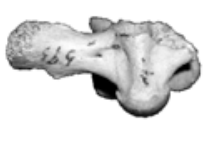

F

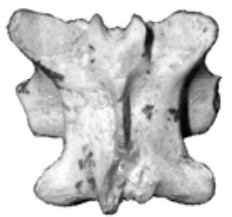

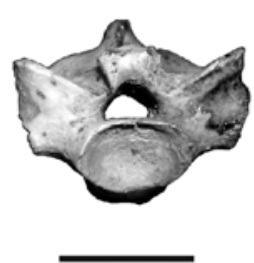

$\mathrm{H}$

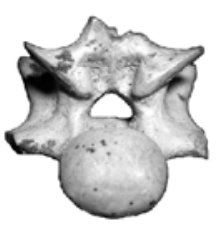

$\mathrm{N}$

I
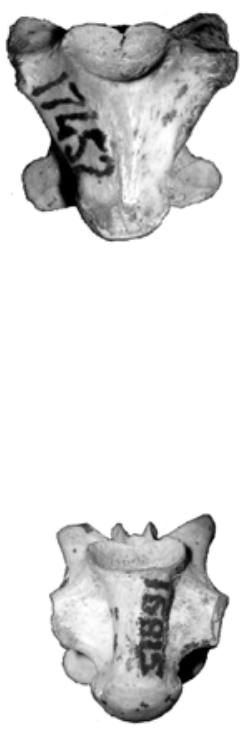

$\tilde{N}$

Figura 71. Restos de ?Tupinambis de la "Fm." Chapadmalal (Plioceno temprano-medio). A, húmero izquierdo MACN Pv 16791-3 en vista dorsal; B, fémur izquierdo MACN Pv 16831-4 en vista ventral; C, tibia derecha MACN Pv 16831-5 en vista posterior; D, E, vértebra sacra anterior MACN Pv 16831-1, en vista frontal (D) y dorsal (E); F, G, vértebra sacra posterior MACN Pv 16831-2, en vista frontal (F) y ventral (G); H-J, vértebra dorsal MACN Pv 17452 en vistas dorsal (H), frontal (I) y ventral (J); K-Ñ, vértebra caudal MACN Pv 16815 en vistas dorsal $(\mathrm{K})$, frontal $(\mathrm{L})$, lateral $(\mathrm{M})$, posterior $(\mathrm{N})$ y ventral $(\tilde{\mathrm{N}})$. Abreviaturas: f.f.p, foramen de la fosa poplítea. Escala $=10 \mathrm{~mm}$.

Comentarios taxonómicos. El trabajo de Krause (1990) permite una comparación de los fósiles con los elementos apendiculares de los diferentes géneros de la familia Teiidae. Esta autora sostienen que el área excavada sobre el extremo distal-ventral de la diapófisis del húmero es de contorno circular en Tupinambis, Callopistes, 
Dicrodon, "Ameiva" y Kentropyx, mientras que en los restantes Teiidae es triangular. En la revisión del material de referencia se observa que estas diferencias son muy sutiles, y no siempre se respeta la distribución planteada por Krause (1990) (e.g. T. teyou UNMdP-O 22). El foramen epicondilar del húmero es nítido en el fósil MACN Pv 16831-3, como en la mayoría de los Teiidae, excepto Dracaena (Krause, 1990). El surco intercondilar del fémur fósil MACN Pv 16831-4 es marcado, como en la mayoría de los Teiidae, contrastando con el débilmente macado observado en Crocodilurus y Dracaena guianensis (Krause, 1990). La cresta cnemial del la tibia fósil MACN Pv 16831-5 es marcada, como se observa en Tupinambis, Crocodilurus, Callopistes, Teius y Cnemidophorus (Krause, 1990). La región sacra de los Teiidae es morfológicamente homogénea (Veronese y Krause, 1997) observándose sutiles diferencia en el grado de fusión entre los procesos transversales (pleurapófisis) siendo la misma más acentuada en Callopistes, Dicrodon y Tupinambis. Sin embargo, ésto no siempre se verifica (e.g. " $A$ ”. ameiva UNMdP-O 27). Las vértebras dorsal (MACN Pv 17452), lumbar (MACN Pv 16791), sacras (MACN Pv 16831-1/2) y caudal (MACN Pv 16831-1) presentan las características observadas en las vértebras de los Teiidae (Cap. III). El tamaño, el arco neural triangular en vista anterior y la cresta subcentral débilmente desarrollada indican afinidad con los Tupinambinae. Teniendo presente la variabilidad observada en los estados de carácter notados por Krause (1990) y Veronese y Krause (1997), el conjunto de elementos aquí descriptos no se diferencia de los Tupinambinae Callopistes y Tupinambis. Tanto Callopistes como Tupinambis están representados en el Montehermosense de Farola Monte Hermoso, pero sólo Tupinambis ha sido registrado en sedimentos del Chapadmalalense inferior (Albino et al., 2009) y superior (MACN Pv 10247, MACN Pv 19394), por lo cual parece más probable que se trate de este último.

SQUAMATA Oppel, 1811

AMPHISBAENIA Gray, 1844

Amphisbaenoidea Gray, 1865

Amphisbaenidae Gray, 1865

Género y especie indeterminados

(Fig. 72) 
Material referido: MACN Pv 6878. Dos vértebras articuladas, (MACN Pv 6878-1); dos vértebras articuladas pobremente conservadas (MACN Pv 6878-2); vértebra parcialmente conservada (MACN Pv 6878-3); varios fragmentos, mayoritariamente de costillas y en menor medida vértebras (MACN Pv 6878-misceláneas).

Procedencia geográfica: Acantilados costeros cercanos a la ciudad de Miramar, provincia de Buenos Aires.

Procedencia estratigráfica: "Formación" Chapadmalal, Chapadmalalense superior, Plioceno temprano-medio (Cione et al., 2007).

Descripción. Todas las vértebras son similares en cuanto a sus dimensiones y morfología. Se trata de vértebras cortas, anchas y bajas. Anteriormente, el arco neural es tan alto como el centro vertebral, mientras que posteriormente es más alto.

Dorsalmente, en la parte anterior del arco neural se desarrolla el proceso medial, mientras que la parte media-posterior es recorrida por una baja espina neural. Las prezigapófisis y postzigapófisis se encuentran bien desarrolladas, se originan a media altura del arco neural, se orientan lateralmente y se encuentran inclinadas sobre la horizontal. En la parte anterior de las prezigapófisis (MACN Pv 6878-1) se encuentra un pobremente desarrollado proceso prezigapofisiario. Ventralmente a las prezigapófisis se observan desarrolladas sinapófisis semiesféricas. Posteriormente a la sinapófisis, la superficie lateral de la vértebra se encuentra ligeramente excavada. El centro vertebral es corto, ancho y plano ventralmente. En vista ventral es rectangular de bordes paralelos. El cótilo y cóndilo son ovales, comprimidos dorsoventralmente, profundos y sin mayor inclinación. El cóndilo no se encuentra diferenciado del cuerpo vertebral. 

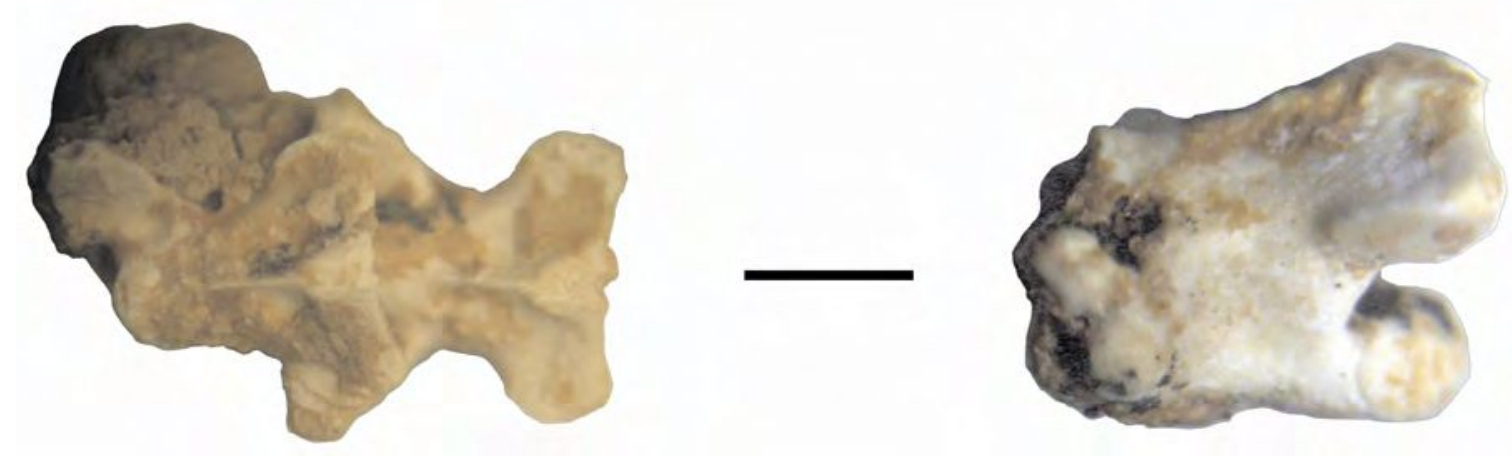

A

B

Figura 72. Amphisbaeidae (MACN Pv 6878) de la "Fm" Chapadmalal (Plioceno temprano-medio), entre Mar del Plata y Miramar, provincia de Buenos Aires. A, vértebras articuladas (MACN Pv 6878-1) en vistas dorsal; B, vértebra desarticulada (MACN Pv 6878-3) en vista lateral. Escala = $1 \mathrm{~mm}$.

Comentarios taxonómicos. La coexistencia en las vértebras de proceso medial, proceso prezigapofisiario y centro vertebral ventralmente plano sólo se encuentra en Amphisbaenia (Hoffstetter y Gasc, 1969). El borde posterior del arco neural liso, permite excluir a los Rhineuroidae cuyo borde es denticulado (Kearney, 2003). En el análisis cladístico de Amphisbaenia realizado por Kearney (2003), los integrantes de Amphisbaenoidea, grupo hermano de los Rhineuroidae, no pueden ser diferenciados por caracteres vertebrales. Los Amphisbaenoidea son un grupo diverso, que incluye una gran cantidad de especies (Kearney, 2003); sin embargo, se pueden hacer algunas comparaciones con algunas de las especies del grupo distribuidas en Argentina. El cuerpo vertebral ancho y arco neural relativamente alto de las vértebras fósiles difiere del cuerpo vertebral elongado y arco neural bajo de Amphisbaena heterozonata, Amphisbaena bolivica y Anops kingii (Torres y Montero, 1998b). Amphisbaena alba y Amphisbaena fuliginosa difieren de las vértebras fósiles por presentar procesos prezigapofisarios desarrollados y digitiformes (Torres y Montero, 1998b), mientras que Amphisbaena marellii y Amphisbaena angustifrons no sólo poseen cuerpo vertebrales cortos y anchos, sino que además sus procesos prezigapofisarios son cortos (Torres y Montero, 1998b), como en el material fósil. La longitud de los centros vertebrales completos varía entre 2,6 - 2,67 $\mathrm{mm}$ de manera que es similar a la observada en A. marellii y A. angustifrons (Torres y Montero, 1998b). De esta 
manera, entre las especies confrontadas, los fósiles no se diferencian de $A$. angustifrons y A. marellii.

\section{Comentarios biogeográficos sobre los lagartos de Mar del Plata-Miramar}

Los fósiles de Tupinambis aquí descriptos son los únicos registrados para el Plioceno temprano - medio (Chapadmalalense) de América del Sur (Tabla 2) y, en conjunto con una hemimandíbula recuperada de sedimentos del Vorohuense, constituye todo el registro fósil conocido del género para el Plioceno. La pobre presencia de Tupinambis durante el Plioceno probablemente sea aparente, ya que en el Pleistoceno se observa una amplia distribución geográfica del género, encontrándoselo en Bolivia, Brasil y Uruguay (Hoffstetter, 1963; Estes, 1983a; Ubilla y Perea, 1999; Hsiou, 2007). Se observa así que el registro conocido de Tupinambis para el Plioceno está restringido a Argentina, mientras que en el Pleistoceno el género está ausente de este territorio, excepto por la cita de Rusconi (1937) para el Pleistoceno tardío - Holoceno, pero se trata de un material que está perdido.

Con respecto al Amphisbaenia, estos restos corresponden al más antiguo registro del grupo en América del Sur (Albino, 1996a; Torres y Montero 1998b; de la Fuente, 1999); aunque, como se ha mencionado previamente, podrían existir registros más antiguos a partir de un centro vertebral del Mioceno temprano de Patagonia (Colhuehuapense, este trabajo) y restos preliminarmente dados a conocer en Hsiou et al. (2007) del Mioceno de Brasil. Las vértebras de anfisbenas de la "Fm" Chapadmalal se asemejan a las de la especie fósil $A$. marellii y a la actual $A$. angustifrons. Amphisbaena marellii se registra en el Ensenadense (Pleistoceno medio) de la provincia de Buenos Aires (Torres y Montero, 1998b), mientras que $A$. angustifrons, junto con Anops kingii y Amphisbaena heterozonata, conforman la fauna actual de anfisbenas de la provincia de Buenos Aires (Montero, 1996). Por lo tanto, la presencia de Amphisbaenia con estas afinidades es concordante con el registro fósil y la distribución actual del grupo. 


\subsection{8. “Formación" Vorohué}

\section{Geología}

Florentino Ameghino (1908) reconoció entre el Chapalmalense y

Ensenadense, expuestos en los acantilados costeros al sur de la ciudad de Mar del Plata, un hiato postchapalmalense. Carlos Ameghino correlaciona este hiato con sedimentos aflorantes en la localidad de Uquía (o Senador Perez; $23^{\circ} 18^{\prime} \mathrm{S}, 65^{\circ} 21^{\prime} \mathrm{O}$ ), Quebrada de Humahuaca (Cione y Tonni, 1995c). La fauna de las tres "Formaciones" pre Ensenadenses (“Fm.” Barranca de los Lobos, "Fm." Vorohué y "Fm." San Andrés de Kraglievich (1952, 1953, 1959), corresponde a este hiato postchapadmalense (Pascual et al., 1996). Kraglievich (1952) correlacionó sólo la "Fm.” Barranca de los Lobos con la Fm. Uquía, mientras que Pascual et al. (1965) refirieron la fauna de la Fm. Uquía a la Edad Mamífero Uquiense, cuya localidad tipo es la localidad homónima (Marshall et al., 1982a). Cione y Tonni (1995c) proponen reemplazar al Uquiense por una nueva edad/piso, denominada Marplatense, que está definida estratigráficamente en los acantilados costeros entre Punta Mogotes (Mar del Plata) y Miramar. Estos autores definen tres biozonas que sirven de base estratigráfica para las "Formaciones" de Kraglievich $(1952,1953,1959)$ y que definen los subpisos Barrancalobense, Vorohuense y Sanandresense.

\section{Antecedentes}

Si bien la fauna de vertebrados del Montehermosense al Holoceno es abundante y bien conocida para la zona costera de Buenos Aires (e.g. Alberti et al., 1995), no ocurre lo mismo con los reptiles de este período. En 1947, Kraglievich describe una nueva especie extinta del género Tupinambis a la cual nomina "T. onyxodon", basándose en una hemimandíbula recuperada en sedimentitas aflorantes en la Barranca Parodi, Miramar (Fig. 69). Kraglievich (1947) considera a estos sedimentos como Chapadmalalense, pero Reig (1958) sostiene que dicho fósil proviene de la "Fm." Vorohué, correspondiendo al subpiso medio (Vorohuense). Este material se redescribe a continuación. 
SQUAMATA Oppel 1811

SCLEROGLOSSA Estes, de Queiroz y Gauthier 1988

SCINCOMORPHA Camp 1923

TEIIOIDEA Estes, de Queiroz y Gauthier 1988

TEIIDAE Gray 1827

Tupinambis Daudin, 1802

Tupinambis sp.

(Fig. 73 A-C)

Material referido: MACN Pv 17136 (ex 735 Colección Reig). Hemimandíbula izquierda parcialmente completa. Originalmente descripto como "Tupinambis onyxodon” Kraglievich, 1947. Conserva el dentario con toda la serie dentaria y el esplenial completos. El coronoides, el suprangular y el angular se conservan parcialmente.

Procedencia geográfica: Barranca Parodi, entre Baliza Chica y Arroyo Las Brusquitas, Miramar, provincia de Buenos Aires (Kraglievich, 1947).

Procedencia estratigráfica: Nivel I (inferior) de la "Formación" Vorohué (Reig, 1958), piso/edad Marplatense medio, subpiso/subedad Vorohuense (Cione y Tonni, 1995c), Plioceno medio (Cione et al., 2007).

Re-descripción: Se conserva el dentario y el esplenial completos, y restos del coronoides, suprangular y angular. Todos los elementos se encuentran articulados.

El dentario es alto, carece de ornamentación y presenta cinco forámenes mentales, el último de los cuales está a la altura del IX diente. En vista labial, su contorno dorsal es cóncavo, especialmente en su parte posterior (Fig. 73 A). El proceso posterodorsal del dentario recibe labialmente al proceso anterolateral del coronoides, que alcanza el nivel de los dos últimos dientes. El borde posterior del dentario forma una profunda cuña entre el proceso posterodorsal y posteroventral, la cual recibe al suprangular y angular. El ápice de esta cuña está a la misma distancia que el extremo anterior del proceso anterolateral del coronoides. Lingualmente se observa el estante subdental. Posterior a la sínfisis, el estante subdental tiene su mayor desarrollo y adquiere forma de silla de montar. Posteriormente, es plano, vertical y progresivamente disminuye su desarrollo dorsoventral. Si bien el esplenial se preserva articulado, se observa que el canal de Meckel está ampliamente abierto hasta la sínfisis, sin restricción anterior. Dorsalmente, los dientes se ubican en un amplio surco 
dental. Los dientes no ocupan completamente el surco dental, de modo que, lingualmente, se observa un definido sulcus dentalis ocupado por los alvéolos de reemplazo.

La serie dentaria se conserva completa, con 18 alvéolos funcionales (Fig. 73 C). Los dientes son subpleurodontes, con los septos interdentales disimulados por abundante cemento depositado sobre las bases de los dientes. El primer diente conservado es el VI; es cónico y recto, aunque apicalmente está roto. Los dientes del VII-X son más robustos, principalmente en sus bases; apicalmente son cónicos, punzantes y curvados distalmente. El diente VIII es el más alto de la serie. El diente $\mathrm{XI}$ es robusto y recto. Los dientes siguientes son romos y robustos, decrecen en altura, y del XII al XV son de sección circular mientras que los más posteriores presentan compresión lateral (i.e. por lo tanto, su sección es oval). Lingualmente, sobre los alvéolos funcionales, se observa una serie de 17 alvéolos de reemplazo, algunos ovales y otros circulares, todos profundos y excavados en el cemento. Solamente se conserva un diente en el alvéolo de reemplazo XI. Este diente de reemplazo es romo y su esmalte es estriado, con las estrías convergentes en el centro oclusal.

El esplenial (Fig. 73 B) es cuneiforme, profundo posteriormente, y muy extendido anteriormente, llegando a la posición dentaria VI, de modo que la abertura anterior del canal de Meckel es pequeña. Lingualmente, el esplenial es plano, algo cóncavo anteriormente al foramen alveolar. Este último es nítido, ubicado a la altura del diente XII, mientras que el foramen milohioideo anterior está cubierto de sedimento, aunque se infiere que se abre a la altura de los dientes XIII a XIV.

El coronoides no conserva el proceso posteromedial. Se destaca el desarrollo del proceso dorsal y la marcada cresta labial. El proceso anterolateral, como ya se mencionó, se extiende anteriormente hasta el nivel de los dos dientes posteriores. El proceso anteromedial es corto y delimita la parte dorsoanterior de la fenestra subcoronoidea. Su extremo distal es horizontal, ligeramente cóncavo. El proceso posterolateral está reducido, cubriendo levemente al suprangular.

Del suprangular y angular sólo se conservan sus extremos anteriores que están encajados en la cuña del borde posterior del dentario. El suprangular ocupa la mayor parte de la misma, incluyendo el vértice. Labialmente, el suprangular está algo excavado y conserva el foramen anterior. El angular está cubierto por el proceso posteroventral del dentario. Lingualmente, en posición casi ventral, se conserva el foramen milohioideo posterior. 


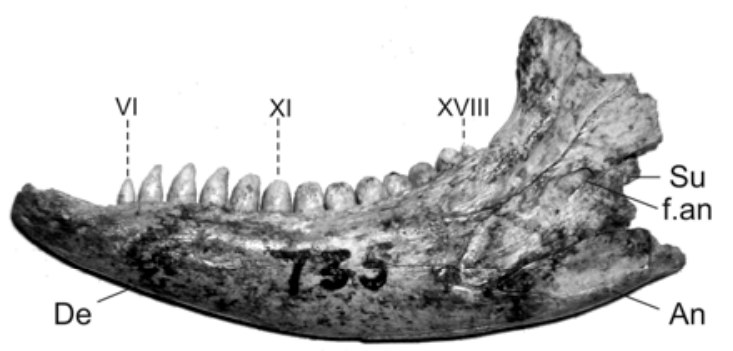

A

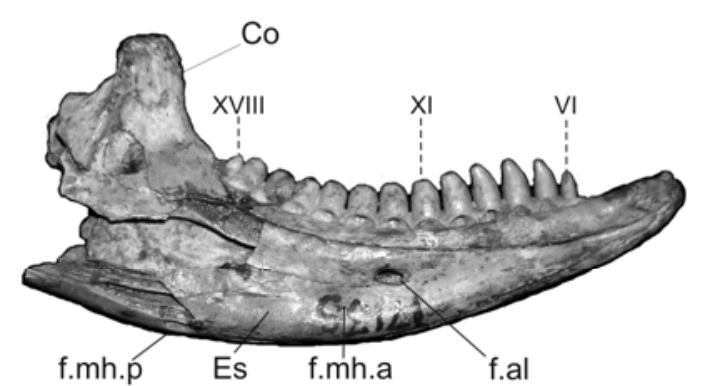

B

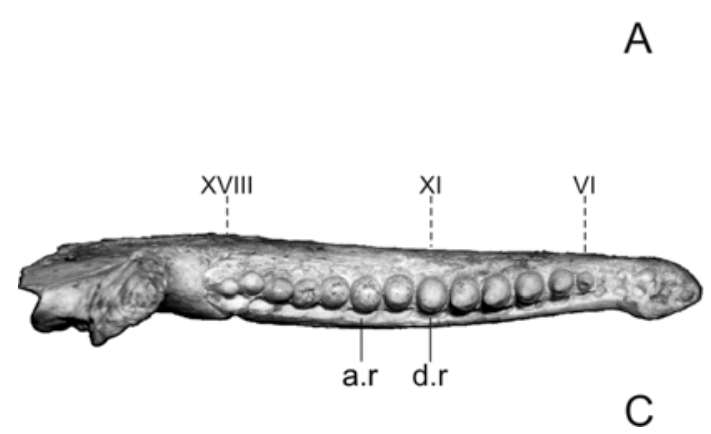

Figura 73. Tupinambis sp. (MACN Pv 17136: originalmente descripto como "T. onyxodon" Kraglievich, 1947) de la "Fm." Vorohué, Barranca Parodi, Bs. As. A, labial; B, lingual; C, oclusal. Abreviaturas: a.r, alvéolo de reemplazo; An, angular; Co, coronoides; De, dentario; d.r, diente de reemplazo; Es, esplenial; f.al foramen alveolar; f.an, foramen anterior; f.mh.a, foramen milohioideo anterior; f.mh.p, foramen milohioideo posterior; Su, suprangular. Los números romanos indican la ubicación absoluta de las posiciones dentarias funcionales. Escala $=10 \mathrm{~mm}$.

Comentarios taxonómicos. El fósil presenta los tres caracteres que definen al clado Borioteiioidea-Teiioidea (Cap. III), permitiendo su inclusión en el mismo a la vez que excluye a los Gymnophthalmidae. Además, de estos últimos se diferencia por su tamaño, la dentición subpleurodente ([C120]) y por el estante subdental que pierde altura posteriormente ([C91]). El fósil se asemeja a los Teiidae por presentar el proceso posterodorsal del dentario solapado por el proceso anterolateral del coronoides ([C86], [C98]). Como en los Tupinambinae, el canal de Meckel del dentario fósil no presenta restricción anterior ([C88]), no se continúa anteriormente por debajo de la sínfisis ([C89]), y el contorno dorsal del dentario no es recto ([C85]). El borde posterior no presenta forma de "W" como en los "cnemidoforinos", ni una cuña ventral que recibe sólo al angular como en Teius ([C92]).

Entre los Tupinambinae, el contorno dorsal del dentario moderadamente cóncavo ([C85]); la participación - aunque menor que la del suprangular - del angular en la cuña posterior del dentario ([C92]); una moderada abertura anterior del canal de 
Meckel ([C93]); el esplenial con una somera depresión por delante de los forámenes ([C97]); la presencia de una fenestra subcoronoidea ([C100]); y más de 13 dientes

(Tabla 8) son todos caracteres compartidos con Crocodilurus y Tupinambis (Cap. V).

El tipo de implantación supleurodonte, con los septos interdentales disimulados por el depósito de cemento, recuerda lo observado en Crocodilurus y Tupinambis. Sin embargo, Crocodilurus no presenta dientes posteriores expandidos como los de la mayoría de las especies de Tupinambis. La dentición del fósil se asemeja en cuanto a morfología y patrón de distribución de los tipos dentarios al género Tupinambis. Los dientes robustos, romos y de sección transversal circular se parecen en particular a T. merianae.

La presencia solamente de dientes posteriores robustos y romos, y la ausencia de diente robustos cuspidados, sugieren que se trata de un individuo adulto, con una LSDd $>$ 51,49 mm (Cap. III). La serie dentaria del fósil presenta una LSDd $=42,14$ mm. Como en los casos de los ejemplares MACN Pv 14312-14 y MACN Pv 14313-9 del Montehermosense, el material descripto en esta sección presenta una dentición "madura" con una longitud de la serie dentaria menor a la esperada. En este caso tampoco se contradice lo observado en la serie ontogenética, auque el fósil presenta todos los dientes posteriores romos y robustos con una LSDd más cercana a los 41,69 $\mathrm{mm}$, que es el valor que corresponde a la primer aparición de este tipo morfológico.

\section{Observaciones sobre la descripción de "Tupinambis onyxodon" presentada por} Kraglievich (1947). Kraglievich (1947) sostiene que "T. onyxodon” presenta diferencias con la especies actuales y con las descriptas por Rovereto (1914), y que, dada la procedencia estratigráfica y cronológica distinta, amerita la nominación de una nueva especie. En particular, Kraglievich (1947) considera la diferencia numérica como el carácter diagnóstico más importante, pero como se discutió previamente, el número de dientes del fósil se encuentra dentro de la variación interespecífica registrada para T. merianae. Los restantes caracteres mencionados en la diagnosis de la especie (mandíbula robusta y suavemente arqueada) también se observa en Tupinambis. Esto detalles ya fueron mencionados por otros autores (Donadío, 1983b; de la Fuente, 1999) quienes atribuyen estos fósiles a la especie T. merianae. Sin embrago, y a pesar de la afinidad manifiesta con la misma, el ejemplar no presenta caracteres robustos que permitan una aproximación a la asignación específica. 


\section{Comentarios biogeográficos}

Como ocurre con el registro del Plioceno temprano-medio, el registro fósil de los Teiidae en el Plioceno medio es pobre y se encuentra restringido a la hemimandíbula parcial aquí descripta, de la costa de la provincia de Buenos Aires. Donadío (1983b) hace referencia a "nuevos materiales fósiles de la Fm. Vorohué" dando a entender que se tratarían del género Tupinambis, pero lamentablemente no ofrece datos para localizarlos en ninguna colección en particular, de manera que debe considerarse como una referencia inválida. El género Tupinambis se encuentra actualmente representado en la provincia de Buenos Aires sólo por T. merianae (Cei, 1986, 1993), de modo que su hallazgo en el Plioceno medio es coherente con la distribución actual.

\subsubsection{Las Grutas - Punta Negra, Necochea}

\section{Geología}

Aproximadamente a $10 \mathrm{~km}$ al sur de la ciudad de Necochea se encuentra una zona de acantilados costeros conocidos como Las Grutas - Punta Negra, sectores norte y sur respectivamente. Los sedimentos allí expuestos han sido descriptos recientemente por Tonni et al. (1996), Vucetich et al. (1997) y Verzi et al. (2004). Estos acantilados alcanzan una altura de 4-6 m, donde se distinguen seis sectores (Fig. 74). 


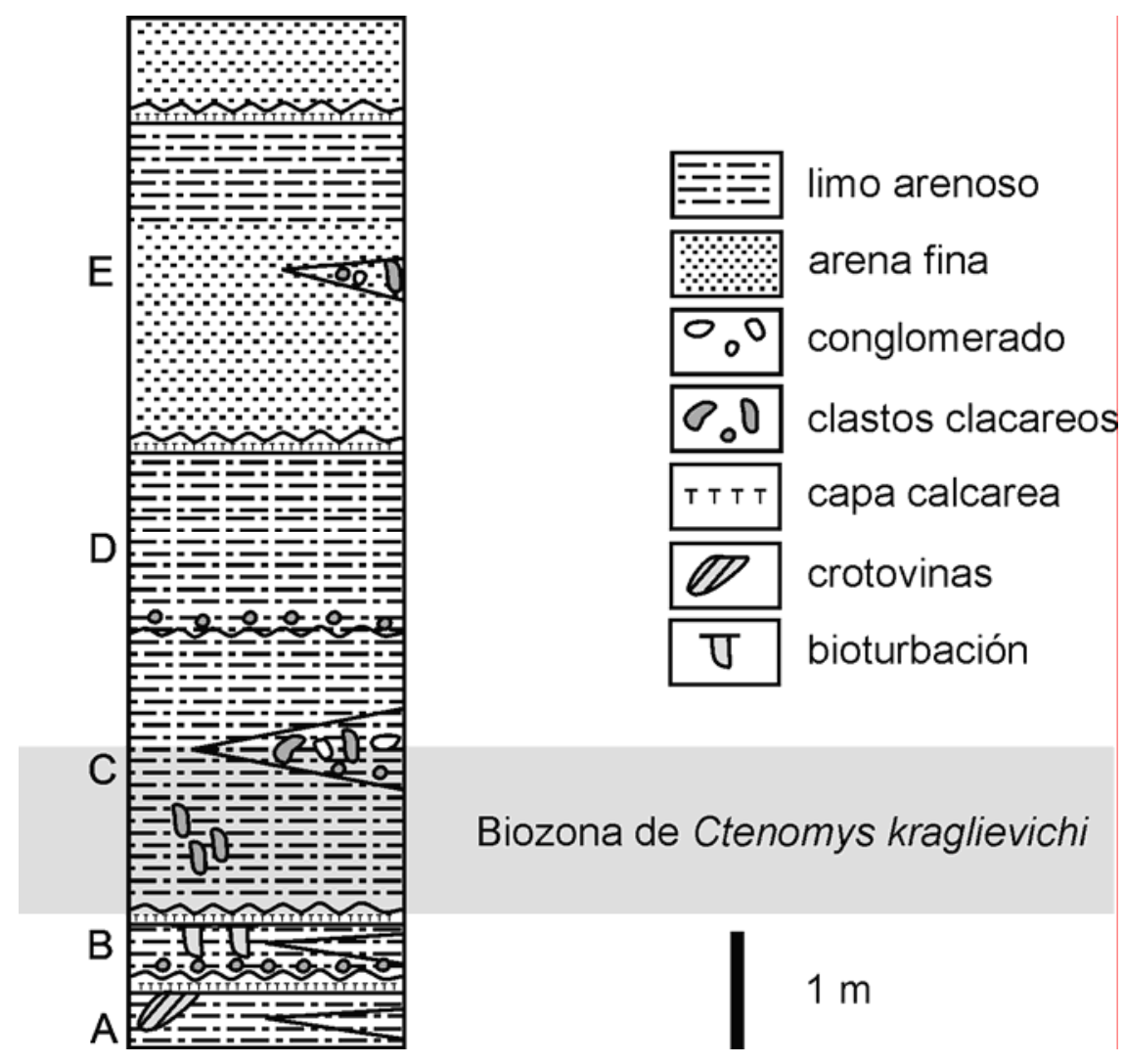

Figura 74. Perfil estratigráfico de Las Grutas - Punta Negra, Necochea, Buenos Aires. Modificado de Verzi et al. (2004).

Vucetich et al. (1997) consideran que los dos sectores inferiores (A y B), que en su conjunto no superan los $0,7 \mathrm{~m}$, podrían ser considerados, en base a su bioestratigrafía, como Sanandresense tardío (Plioceno tardío). Así, este sector basal de los acantilados estaría representando la biozona de Ctemomys chapalmalensis (Cione y Tonni, 2005). El sector C de los acantilados, también según Vucetich et al. (1997), estaría representando a la biozona de Mesotherium cristatum (dando como biozona Tolypeutes pampaeus-Daedicuroides), correspondiéndose con el Ensenadense.

Posteriormente Verzi et al. (2004) en base a datos paleomagnéticos y biocronológicos refieren la sección $\mathrm{C}$ a la biozona de Ctenomys kraglievichi confieréndole una edad Bonaerense, más joven que la propuesta por Vucetich et al. (1997). Es así que la parte basal de los acantilados estaría representando al Sanandresense (hasta 0,7 m) y al Bonaerense (hasta 1,7 - $2 \mathrm{~mm}$ ). No se conocen datos que permitan asignarlas secciones superiores a una edad determinada. 


\title{
Antecedentes
}

De estos acantilados L. Kraglievich y L. J. Parodi recolectaron, y luego depositaron en el MACN, restos que consideraron de Ophidia. Estos restos permanecieron en la colección del MACN hasta que Donadío (1982) los reasignó a Amphisbaenia. En la publicación de Donadío (1982) y la de otros autores posteriores que lo siguieron (Torres y Montero, 1998b, Albino, 1996a; de la Fuente, 1999), se observa una discrepancia en torno a la procedencia estratigráfica de los restos con los datos que figuran en la colección del MACN. En la ficha del MACN se menciona "Horizonte: Ensenadense", mientras que Donadío (1982) considera que los restos provienen del Marplatense (dado como Uquiense); de la Fuente (1999) restringe la procedencia al subpiso Sanandresense. Como se comentó en el punto anterior, estudios recientes reconocen al ?Sanandresense y Bonaerense (biozona de Ctenomys kraglievichi), en la base de estos acantilados, pero no el Ensenadense. Probablemente, la la ficha del MACN estaría designando al horizonte fosilífero correspondiente a la biozona de Ctenomys kraglievichi, o sección C, previamente considerada Ensenadense. Sin embargo, debido a que la procedencia estratigráfica de los restos es incierta no se lo atribuye a ninguna edad en particular.

\section{Sistemática}

\author{
SQUAMATA Oppel, 1811 \\ AMPHISBAENIA Gray, 1844 \\ Amphisbaenoidea Gray, 1865 \\ Amphisbaenidae Gray, 1865 \\ Amphisbaena cf. marellii
}

(Fig. 75)

\begin{abstract}
Material referido: MACN Pv 10577. Columna vertebral, con varias vértebras (al menos 47) y costillas. Estas últimas se encuentran articuladas en dos bloques de sedimento, en un segmento de tres vértebras y tres segmentos de dos vértebras; 12 vértebras se encuentran desarticuladas. Se conservan 22 fragmentos de costillas además de las conservadas en los bloques de sedimento. Todo el material correspondería a un mismo individuo.
\end{abstract}


Procedencia geográfica: Necochea, en cercanías de Punta Negra (38 $34^{\circ}$ S, $58^{\circ} 45^{\prime} \mathrm{O}$ aprox.), provincia de Buenos Aires.

Procedencia estratigráfica: indeterminada.

Descripción. Se trata de un conjunto de al menos 47 vértebras procélicas. Uno de los bloques de sedimento presenta las cinco vértebras anteriores expuestas ventral y lateralmente (lado izquierdo). Posteriormente a estas cinco vértebras se encuentra una zona sin preparar completamente y cubierta por las costillas del lado izquierdo, donde se conservarían dos o tres vértebras. Las últimas ocho vértebras preservadas en este bloque están expuestas ventralmente. El otro bloque de sedimento conserva 13 vértebras articuladas. Las vértebras están ventral y lateralmente expuestas. Las tres vértebras anteriores además presentan expuesto el techo del arco neural. Se conservan varias costillas derechas, las que están colapsadas medialmente.

Las vértebras, articuladas y desarticuladas, no presentan mayores diferencias entre sí en cuanto a sus dimensiones ni a su morfología. Se encuentran muy apretadamente articuladas, sin mayor desarrollo del espacio intervertebral lateral, el cual está reducido a una angosta hendidura vertical cuando las vértebras están alineadas sobre el eje sagital. Las vértebras corresponden a la región dorsal, ya que la ausencia de hipapófisis y hemapófisis permite excluirlas de la región cervical y caudal respectivamente. Se trata de vértebras cortas, anchas y bajas. Dorsalmente, sobre el arco neural, se observa una baja y marcada espina neural, la cual se ensancha posteriormente (Fig. 75 B). El borde anterior del techo del canal neural termina en un marcado proceso medial. El borde posterior es recto y suave en vista dorsal. El arco neural es de dimensiones moderadas, mientras que el canal neural es amplio y subcircular. Las prezigapófisis nacen a media altura del arco neural, se encuentran inclinadas sobre la horizontal y orientadas lateralmente. Distalmente presentan un poco desarrollado proceso prezigapofisiario. Las postzigapófisis son de dimensiones ligeramente menores a las prezigapófisis e igualmente inclinadas en forma complementaria. Ventral a las prezigapófisis se observan marcadas sinapófisis semiesféricas. El cótilo y cóndilo son ovales, comprimidos dorsoventralmente y sin mayor inclinación ventral ni dorsal respectivamente. El centro vertebral es corto, de superficie ventral plana, cuyo contorno presenta bordes paralelos con una ligera constricción en la parte media. No hay diferenciación de cuello condilar. En forma irregular, en diferentes vértebras, se observan forámenes subcentrales pequeños en la 
parte anterior ventral del centro vertebral. Las costilla son holocéfalas, con un marcado proceso posterodorsal y un reducido proceso anteroventral.

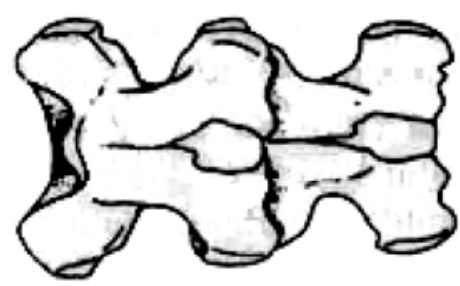

A

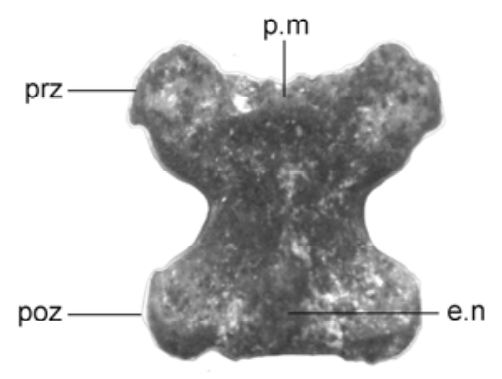

D
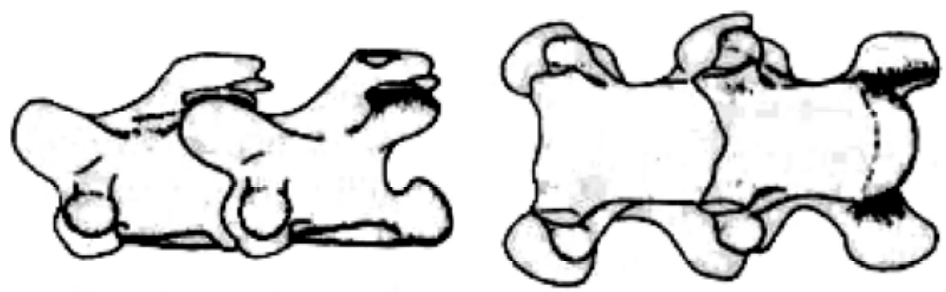

C

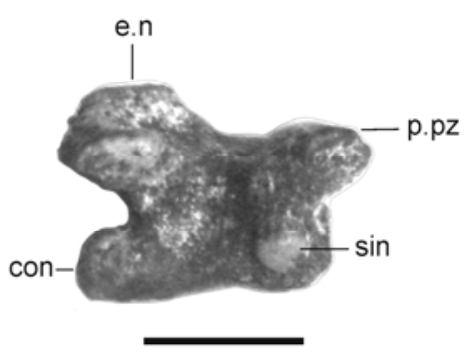

E

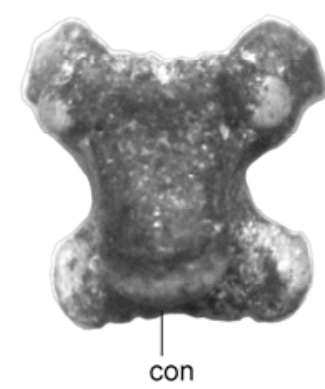

$\mathrm{F}$

Figura 75. Amphsibaena cf. marellii (MACN 10577) recuperada de sedimentos en cercanías de Punta Negra, Necochea, provincia de Buenos Aires. A-C, vértebras articuladas en vistas dorsal (A), lateral (B) y ventral (C); D-F, vértebra desarticulada en vista dorsal (D), lateral (E) y ventral (F). Figuras A-C tomadas de de la Fuente (1999). Abreviaturas: con, cóndilo; e.n, espina neural; p.m, proceso medial; prz, prezigapófisis; poz, postzigapófisis; sin, sinapófisis. Escala $=2 \mathrm{~mm}$.

Comentarios taxonómicos. El canal neural con proceso medial anterior, la presencia de proceso prezigapofisiario y el centro vertebral plano son caracteres que sólo coexisten en Amphisbaenia (Hoffstetter y Gasc, 1969).

El borde posterior del arco neural suave, presente en las vértebras fósiles, difiere del borde denticulado de los Rhineuroidea (que incluye a Leposternon) (Kearney, 2003), permitiendo la exclusión de este grupo de anfisbenas. Aunque no existen caracteres vertebrales diagnósticos a nivel genérico entre los Amphisbaenoidea (Torres y Montero, 1998b; Kearney, 2003), es posible realizar una comparación del material fósil con diferentes géneros actualmente distribuidos en territorio argentino. Así, el fósil se diferencia de Anops kingii, Amphisbaena bolivica, Amphisbaena heterozonata y Amphisbaena prunicolor por presentar un cuerpo 
vertebral corto, ancho y un moderado arco neural, mientras que las otras formas mencionadas presentan un cuerpo vertebral elongado y arco neural más pequeño (Torres y Montero, 1998b; obs. pers.). Vértebras cortas, anchas y de arco neural moderado se observan en Amphisbaena marellii, Amphisbaena alba y Amphisbaena fuliginosa (Torres y Montero, 1998b). Las dos últimas especies mencionadas presentan proceso prezigapofisiario digitiforme y bien desarrollado, contrariamente a lo observado en el fósil. Torres y Montero (1998b), en la diagnosis de A. marellii, sostienen que esta especie sólo se diferencia de $A$. angustifrons por presentar una marcada espina dorsal ancha distalmente y espacios intervertebrales reducidos a hendiduras verticales. Estas características son compartidas con las vértebras fósiles aquí descriptas. Sin embargo, las vértebras MACN Pv 10577 se diferencian de las del Ensenadense (A. marellii) en la presencia más constante de los forámenes subcentrales en estas últimas.

La afinidad de estos fósiles con $A$. marellii y $A$. angustifrons se acentúa al comparar la longitud media de los centros vertebrales. El valor medio calculado para las vértebras MACN Pv 10577 es de 2,68 mm, un valor cercano a los 2,8 mm y 2,6 mm de A. angustifrons y A. marellii respectivamente (Torres y Montero, 1998b). Anops kingii y A. heterozonata tienen centros vertebrales de longitud menor a $2 \mathrm{~mm}$, mientras que los centros vertebrales de $A$. alba rondan los 4,5 mm.

El material fósil es por lo tanto asignado a Amphisbaena cf. marellii, diferenciándose del holotipo de dicha especie únicamente por la irregularidad en la presencia de los forámenes subcentrales.

\section{SITIOS ARQUEOLÓGICOS}

Los sitios arqueológicos de la Argentina de donde se han recuperados restos asignables a lagartos no iguanios son varios (Cap. I). Estos sitios se distribuyen en las provincias de Buenos Aires, Catamarca, Salta y Santiago del Estero. Lamentablemente, sólo los materiales de los sitios de Cueva Tixi y Cueva El Abra del sistema serrano de Tandilia (provincia de Buenos Aires), y del sitio "Lomas del Veinte" de Santiago del Estero, pudieron se revisados. 


\subsection{Cueva Tixi y Cueva El Abra.}

Estos sitios corresponde a dos aleros rocosos separados por unos $10 \mathrm{~km} \mathrm{y}$ ubicados en la Sierra La Vigilancia, la cual forma parte del Sistema Serrano de Tandilia (Quintana et al., 2000, 2004) (Fig. 76). Cueva Tixi presenta una superficie de $45 \mathrm{~m}^{2}$ donde se reconocen seis estratos litológicos, en los cuales se definieron cuatro niveles arqueológicos que abarca desde el Pleistoceno tardío al Holoceno tardío (Quintana et al. 2000). El nivel arqueológico superior se asemeja al componente superior de la Cueva El Abra.

La Cueva el Abra presenta una superficie aproximada de $25 \mathrm{~m}^{2}$ cuya secuencia arqueológica presenta tres componentes (niveles); el componente inferior y superior fueron datados mediante $\mathrm{C}^{14}$ obteniéndose limites de ocupación ente $9834 \pm 65 \mathrm{y}$ $958 \pm 32$ años AP (Quintana et al., 2000). La mayoría de los fósiles recuperados en Cueva El Abra provienen del componente superior, mientras que en Cueva Tixi provienen de los niveles medios (Quintana et al. 2000).

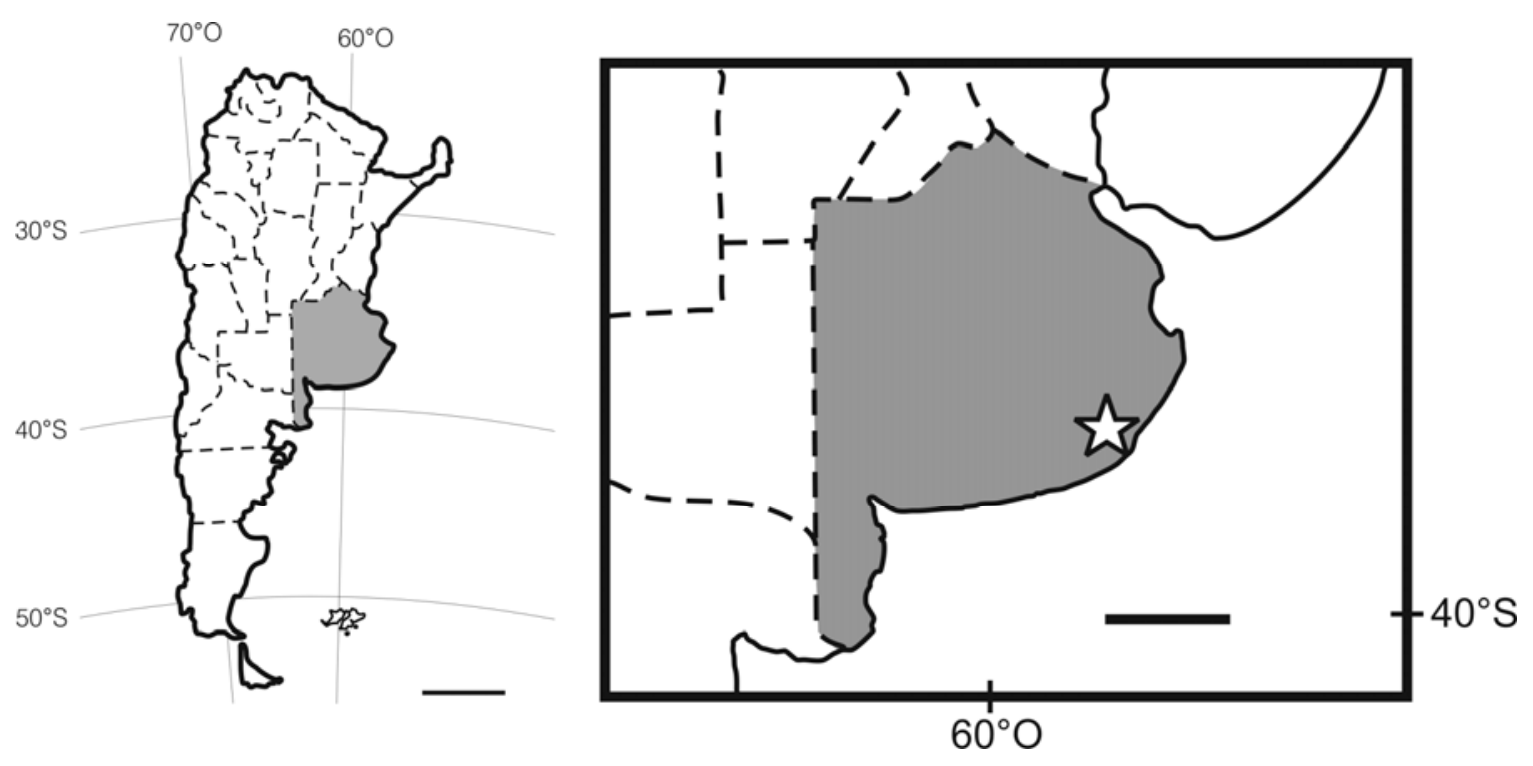

Figura 76. Sitios arqueológicos Cueva Tixi y Cueva El Abra. Escala $=500$ y $200 \mathrm{~km}$ respectivamente.

Mazzanti y Quintana (1997) y Quintana et al. (2000) detallan la fauna de vertebrados registrada en estos sitios. La herpetofauna está compuesta por una sola especie de lagarto y varias serpientes (Albino, 1999, 2000; Albino y Albino, 2004) (Tabla 10). 
Cueva Tixi

Cueva El Abra

\begin{tabular}{lc}
\hline Teiidae & Teiidae \\
Tupinambis cf merianae & Tupinambis cf merianae \\
Serpentes & Serpentes \\
Serpentes indet. & Serpentes indet. \\
Colubridae & Colubridae \\
Colubridae indet. & Colubridae indet. \\
Clelia rustica & \\
Philodryas patagoniensis & \\
Viperidae & Viperidae \\
Bothrops sp & \\
Bothrops alternatus & Bothrops alternatus \\
\hline
\end{tabular}

Tabla 10. Herpetofauna de Cueva Tixi y Cueva El Abra. Modificado de Albino y Albino (2004).

El material de lagartos no iguanios procedente de estos sitios ha sido previamente estudiado por Quintana et al. $(2000,2004)$ y Albino (2001) y asignado a Tupinambis cf merianae. Quintana et al. (2000) sostienen que su asignación abierta se debe a que no se conocen caracteres osteológicos que permitan diferenciar las especies de Tupinambis, las cuales se sustentan por caracteres de la morfología externa (Ávila-Pires, 1995; Manzani y Abe, 1997; Péres Jr y Colli; 2004).

El material recuperado es cuantitativamente similar en ambos sitios, con 150 elementos identificados en Cueva Tixi y 164 en Cueva El Abra. Se destacan huesos desarticulados, detallados por Quintana et al. $(2000,2004)$ y que han depositados sin numerar en la colección del Grupo de Arqueología de la Facultad de Humanidades de la UNMdP. Si bien el material carece de numeración, se encuentra rotulado según su procedencia particular, horizontal y vertical de cada sitio, lo cual permite su certera identificación. En Cueva El Abra hay una mayor representatividad de elementos correspondientes a hemimandíbulas, seguido por huesos largos, maxilares y vértebras. En Cueva Tixi los la relación es similar pero los huesos largos son muy escasos (Quintana et al., 2000). 


\author{
SQUAMATA Oppel 1811 \\ SCLEROGLOSSA Estes, de Queiroz y Gauthier 1988 \\ SCINCOMORPHA Camp 1923 \\ TEIIOIDEA Estes, de Queiroz y Gauthier 1988 \\ TEIIDAE Gray 1827 \\ TUPINAMBINAE Presch 1974a \\ Tupinambis Daudin 1802 \\ Tupinambis sp.
}

Comentarios taxonómicos. La implantación subpleurodonte, el abundante cemento sobre las bases de los dientes, los profundos alvéolos de reemplazo y los espleniales hipertrofiados, anteriormente desarrollados indican afinidad con los Teiidae.

El tamaño de los elementos óseos, y un conjunto de caracteres presentados a continuación permiten asignarlos a los Tupinambinae: constricción basal al proceso ascendente del premaxilar ([C3]); rama labial del proceso maxilar del maxilar cónica y robusta ([C9]); soporte narial posterior desdibujado ([C17]); cresta sobre la lámina transversal ([C18]); proceso maxilar del yugal ligeramente cóncavo ([C26]); postfrontal pequeño, sin mayor extensión posterior ([C39]), no fusionado al postorbital ([C40]); cuadrado con expansión medial ([C61]); pterigoides sin expansión medial del proceso cuadrado ([C81]); canal de Meckel medialmente abierto, terminando en la sínfisis ([C89]) y sin restricción anterior ([C88]); vértebras presacras presenta el canal neural subtriangular en vista frontal ([C158]) y cresta sagital poco marcada ([C155]).

El tipo de implantación subpleurodonte con los septos interdentales disimulados por el depósito de cemento, asemeja los fósiles a Crocodilurus y Tupinambis ([C120]). Los tipos morfológicos de dientes, así como su patrón de distribución a lo largo de la serie dentaria, no se diferencia de lo observado en la serie ontogenética de T. merianae, destacándose un pequeño dentario en pleno recambio con varios dientes bicuspidados (D7/C/10). A partir de aquellos restos que conservan la serie dentaria completa (C4/5/A198; TUPI 2OOO; F4/9/9 178; E5/D/3 179; D6/5/D(6); D6/6/A 177) se observa que el número de dientes oscila entre 16 y 17. Estos valores están incluidos en los rangos de T. merianae, T. rufescens y T. teguixin, mientras que es ligeramente menor al de T. quadrilineatus y ligeramente mayor al de T. duseni (Tabla 8). 
Los fósiles de ambos sitios son de dimensiones similares y morfológicamente indistinguibles de los de Tupinambis. Además, las características de la dentición con dientes posteriores romos, robustos, bajos y de sección transversal circular es como en varias especies del género (Cap. III). La referencia como Tupinambis cf merianae realizada por Quintana et al. $(2000,2004)$ se basa en que los sitios arqueológicos Cueva Tixi y Cueva El Abra se encuentran dentro del rango de distribución de esta especie (Cei, 1986, 1993), pero debido a que la similitud de la dentición por sí sola no permite la asignación específica, deben considerarse de especie indeterminada.

\section{Comentarios biogeográficos}

El análisis de la fauna de maníferos presentes en los sedimentos del Pleistoceno tardío - Holoceno de la región Pampeana le permiten a Tonni et al. (1999) sostener que desde el Plioceno tardío (Sanandresense) hasta tiempos recientes, se desarrolló un clima principalmente árido en la Región Pampeana. Al comparar la fauna de mamíferos de Cueva Tixi y Cueva El Abra (Quintana et al., 2000; Quintana, 2001), con los rangos de humedad y temperatura que presentan Tonni et al. (1999), se observa una mezcla de fauna de climas áridos (e.g. Lama guanicoe, Galea musteloides, Lagostomus maximus, Dolichotis patagonum; Reithrodon auritus, Ctenomys sp) y húmedos (e.g. Cavia aperea, Oxymyceterus rufus, Dasypus hybridus), con un ligero predomino de las formas áridas. El clima más calido que sucedió a la Pequeña Edad de Hielo (período frío y seco ocurrido durante los siglos XVII - XIX; Quintana, 2001) habría restringido la distribución de otros taxones, limitándolos a sus áreas actuales (e.g. Pseudorizomys simplex: Quintana, 2001).

La fauna de escamosos de Cueva Tixi y Cueva El Abra corresponden a taxones actualmente presentes en el área. Se puede entonces suponer que los cambios climáticos que afectaron a algunos mamíferos, no lo hicieron, o no fueron tan drásticos, para los las serpientes y lagartos reconocidos en el sitio. El límite inferior de temperatura para los escamosos no se habría modificado sustancialmente. Este límite para Tupinambis se corresponde con los $14^{\circ} \mathrm{C}$ (ver Cap. VI). Quattrocchio et al. (2008) estiman que durante el Pleistoceno tardío en el sur de la región Pampeana las precipitaciones eran $100 \mathrm{~mm} /$ año menores que las de la Pampa seca actual, que llevaría los limites de esta región a 400 - 700 mm (ver Fm. Monte Hermoso). La distribución actual de Tupinambis en territorio argentino, tanto respecto a su especie 
más xérica (T. rufescens) como la más mésica (T. merianae), incluye ese rango de precipitaciones.

Asimismo, es destacable la abundancia de restos de Tupinambis en estos sitios arqueológicos, y particularmente la cantidad de elementos óseos con marcas de corte, que demuestran que este lagarto era un recurso alimenticio importante para las comunidades de cazadores-recolectores que habitaban el área (Albino y Albino, 2004).

\section{2. "Lomas del Veinte"}

El sitio arqueológico "Lomas del Veinte" se encuentra localizado en la provincia de Santiago del Estero (Lorandi, 1974; Lorandi et al., 1979) (Fig. 77). La fauna del sitio ha sido descripta por Cione y Tonni (1981) quienes citan varios peces y mamíferos. De este sitio provienen restos craneales de un lagarto previamente referido a Tupinambis rufescens por Donadío (1983a), los cuales se describen a continuación.
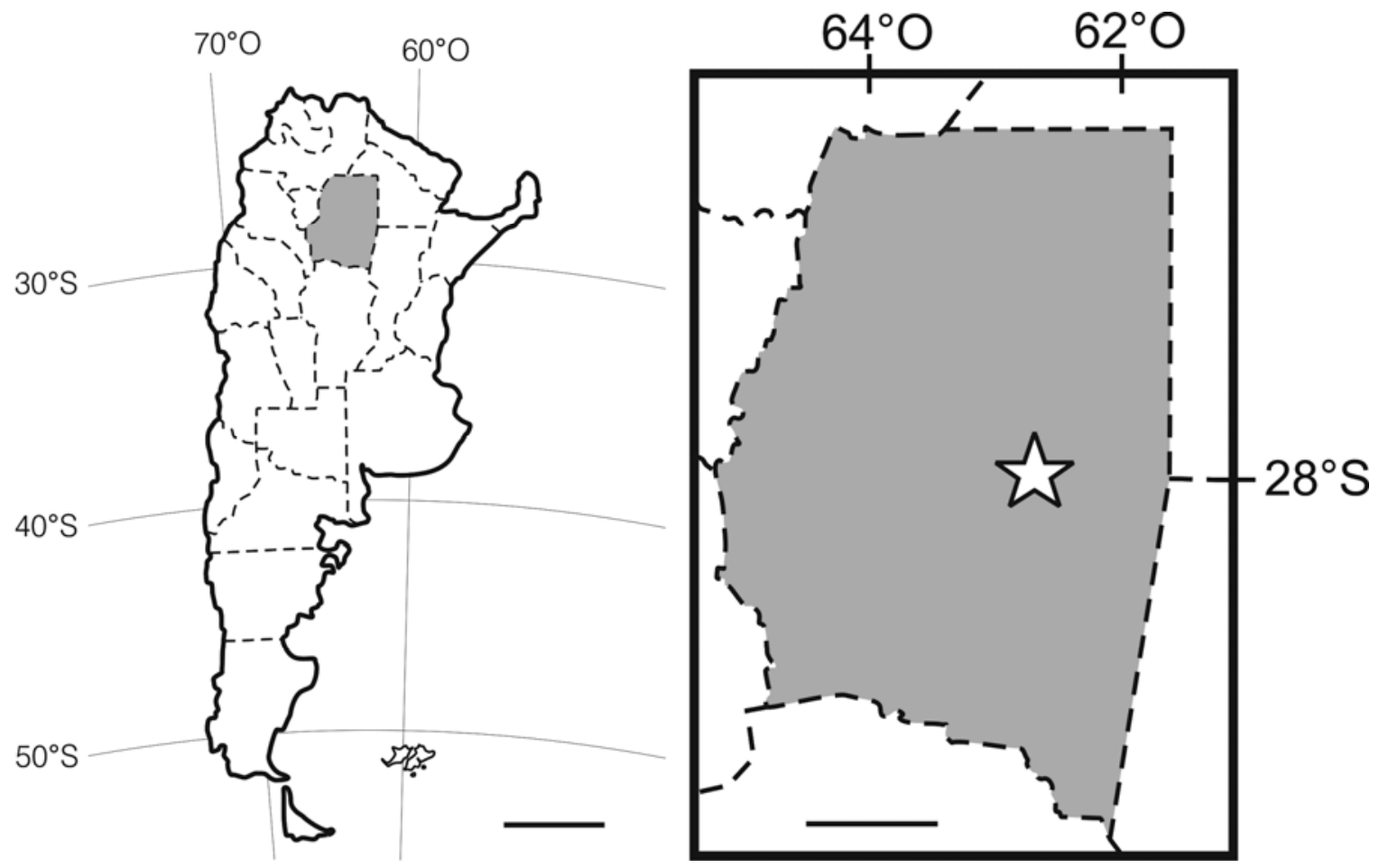

Figura 77. Sitio arqueológico "Lomas del Veinte" provincia de Santiago del Estero. Escala = $500 \mathrm{~km}$ y $100 \mathrm{~km}$ respectivamente. 
SQUAMATA Oppel 1811

SCLEROGLOSSA Estes, de Queiroz y Gauthier 1988

SCINCOMORPHA Camp 1923

TEIIOIDEA Estes, de Queiroz y Gauthier 1988

TEIIDAE Gray 1827

TUPINAMBINAE Presch 1974a

Tupinambis Daudin 1802

Tupinambis sp.

(Fig. 78 A-E)

Material referido: MACN Pv 18821, frontal; MACN Pv 18822, dentario derecho; MACN Pv 18823, maxilar izquierdo; MACN Pv 18824, maxilar derecho; MACN Pv 18825, maxilar izquierdo. Estos elementos corresponderían como mínimo a dos individuos.

Procedencia geográfica: "Lomas del Veinte" a $25 \mathrm{~km}$ al este del Río Salado y a 21 km de Matará, Departamento de J.F. Ibarra, en la provincia de Santiago del Estero (Donadío, 1983a)

Procedencia estratigráfica: sitio datado en 1000-1260 años (Lorandi et al., 1979). Descripción. El frontal (MACN Pv 18821) se conserva completo (Fig. 78 A). Es robusto, largo y de bordes levemente cóncavos. En vista dorsal presenta rugosidades muy débiles, que están más marcadas posteriormente. En su parte posterior, sobre la línea media, presenta una ligera depresión anteroposterior poco delimitada, que correspondería al límite entre las escamas frontoparietales. La sutura con el parietal es recta, con algunas irregularidades. Anteriormente, entre los procesos laterales y el medial, se extienden amplias suturas nasales. Los procesos laterales y el medial son de igual longitud. El contorno lateral del frontal presenta, a cada lado, dos concavidades, las que son más evidentes en vista ventral. La posterior corresponde a la parte dorsal de la órbita, mientras que la anterior corresponde a la sutura con el prefrontal. Se observan muy nítidamente las carillas de articulación para el parietal y prefrontal. Los procesos descendentes son moderados y delimitan la parte posterior del canal olfatorio, pero no se unen medialmente.

Los restantes restos portan dientes que presentan las mismas características de implantación. Se trata de dientes subpleurodontes con abundante depósito de cemento sobre sus bases, de forma tal que los septos interdentales quedan disimulados. 
Lingualmente no ocupan la totalidad del surco dental dejando un marcado sulcus dentalis.

El robusto dentario derecho (MACN Pv 18822) no conserva la parte ventral posterior (Fig. 78 B). Labialmente es liso y presenta seis forámenes mentales, el último de los cuales se ubica a la altura del diente XI. Sobre el proceso posterodorsal se observa la carilla de articulación para el proceso anterolateral del coronoides, que se extiende anteriormente hasta el diente XVI. Lingualmente se destaca un desarrollado estante subdental que recorre todo el dentario y tiene forma de silla de montar a la altura de la sínfisis. Posteriormente es plano-convexo y se aguza en su desarrollo posterior. En vista lingual, a la altura del diente X, aparece la carilla de articulación para el esplenial. Ventralmente al estante subdental, se observa un amplio y medialmente expuesto canal de Meckel, al que le falta su parte ventral posterior y no presenta restricción anterior. En la serie dentaria se conservan 18 dientes, entre los cuales los anteriores son unicuspidados, apicalmente cónicos, de puntas punzantes (pero desgastadas) y ligeramente curvos distalmente. El diente I es pequeño, los dos siguientes altos, los dientes IV y V son intermedios y del diente VI al VIII aumentan en tamaño hasta llegar al diente IX que es el más alto de la serie. A partir del diente X, los restantes dientes son más robustos, lateralmente comprimidos, más bajos y multicuspidados. Los dientes X y XI son bicuspidados (con la cúspide distal dominante), rectos, no tan robustos ni comprimidos como los subsiguientes. Los dientes siguientes son tricuspidados, rectos, robustos, bajos y lateralmente comprimidos. La cúspide dominante en estos dientes es la distal, mientras que la cúspide mesial es similar a la de los dientes bicuspidados, con la diferencia que se curva sobre la cúspide dominante. La cúspide distal es siempre de menor tamaño que la mesial, de forma tal que en algunos casos sólo se trata de una protuberancia (dientes XII y XIV) y no se curva sobre la cúspide central. Los dientes tricuspidados se destacan por disponerse intercalados, la cara mesial labial a la distal del diente precedente. El diente XVII es bicuspidado robusto, más pequeño que los previamente descriptos. El último diente es un cono comprimido lateralmente. No se observan alvéolos de reemplazo.

El maxilar izquierdo (MACN Pv 18823) no conserva la lámina facial (Fig. 78 C). Labialmente es liso, presenta cinco forámenes labiales, el último a la altura del diente XI. El contorno ventral, en vista labial, es sinuoso. El proceso premaxilar es bífido, la rama labial es cónica, robusta y más corta que la rama lingual. Lingualmente 
se observa un estante supradental bien desarrollado. Medialmente, sobre la rama lingual del proceso premaxilar, se observa la carilla de articulación para el vómer. Posteriormente, en posición dorsal y desde el foramen de egreso al canal alveolar superior (c.a.s.), se desarrolla la lámina transversal anterior, que porta una delgada y alta cresta en su extremo medial. Posteriormente a esta lámina, se observa la depresión que contiene al órgano vómero-nasal. En esta zona, el estante supradental presenta su mínimo desarrollo dorsoventral. Posteriormente a la depresión para el órgano vómero-nasal, sobre la lámina dorsal, se encuentra un muy poco desarrollado soporte narial posterior que se continúa dorsoposteriormente como la cresta semicircular. A partir del diente XI, el estante supradental se ensancha y se observa la carilla de articulación con el palatino. A la altura del diente XII, se observa el foramen de ingreso del c.a.s. El proceso posterior presenta una profunda y angosta articulación para el yugal y un amplio surco medial que conforma el piso del foramen infraorbital y lleva al foramen de ingreso del c.a.s. Se conserva la serie dentaria completa con 15 dientes. El primer diente es pequeño y unicuspidado, le siguen dos dientes de mayor tamaño, siendo el diente III el más grande de la serie. Son dientes unicuspidados, basalmente robustos, de sección circular, y apicalmente cónicos con punta punzante y distalmente dirigida. Los dientes IV y V son similares, pero decrecen en tamaño. Los dientes VI y VII son unicuspidados, rectos y pequeños, como el diente I. El diente VIII es unicuspidado, recto, de base robusta y de sección circular, su extremo apical es cónico, recto, algo comprimido lateralmente y de tamaño es similar al del diente IV. El diente IX es más grande, de base marcadamente robusta, diferenciada de su extremo apical, el cual es un cono alto y lateralmente comprimido. El diente X es el diente más alto de la parte posterior de la serie, mientras que los dientes que le siguen decrecen gradualmente en tamaño. El diente $\mathrm{X}$ es similar a su predecesor pero débilmente tricuspidado, y apicalmente con dos crestas relativamente altas, una mesial y otra distal. En los dientes XI al XIV, el cono apical se hace progresivamente más bajo y la base más ancha. Las crestas anterior y posterior son cúspides accesorias a la central. Estas cúspides accesorias son cónicas, rectas y bajas, pero bien diferenciadas apicalmente. La cúspide anterior es siempre de mayor o igual tamaño que la posterior. El último diente es recto, bicuspidado robusto y pequeño. A lo largo de la serie, ubicados en el sulcus dentalis, se observan alvéolos de reemplazo subcirculares y profundos lingualmente sobre los alvéolos funcionales. 
El maxilar derecho (MACN Pv 18824) se conserva casi completo (Fig. 78 D). En vista lateral es triangular, bajo y de base ancha. Se destaca el contorno convexo del borde anterior de la lámina facial. Carece de ornamentación labial y presenta cinco forámenes labiales, el último de los cuales se encuentra a la altura del diente IX. El borde ventral del maxilar presenta una marcada convexidad anterior que corresponde al borde ventral de la rama labial del proceso premaxilar. Esta rama es robusta, cónica y curvada dorsalmente. En vista medial, se observa el estante supradental que está completo excepto por una parte posterior a la carilla de articulación para el vómer. Dorsalmente, sobre la parte rota, se observa una fina cresta vertical que se desarrolla desde el borde de la fenestra exonarina hasta el foramen de egreso del c.a.s. y se que se continúa como la lámina transversa anterior. La depresión para el órgano vómeronasal es somera; posteriormente se observa un desdibujado soporte narial posterior que dorsalmente se continúa como la cresta semilunar sobre la lámina facial. La serie dentaria conserva los 12 dientes posteriores, aunque posiblemente haya habido uno o más dientes adicionales anteriormente. Lo dos primeros dientes (a y b) son unicuspidados, muy grandes, de base robusta, sección circular, cono punzante y distalmente dirigido. Los cuatro subsiguientes (c, d, e y f) son similares pero más pequeños, donde los dos centrales ( $\mathrm{d}$ y e) son de menor tamaño que los laterales (c y f). Los dientes (g) y (h) son dientes robustos débilmente bicuspidados, distalmente cónicos y lateralmente comprimidos, que presentan una protuberancia marcada en su cara mesial. Los tres dientes siguientes $(\mathrm{i}, \mathrm{j}$ y k) son tricuspidados, robustos y labiolingualmente comprimidos. La cúspide central es la dominante, mientras que la cúspide mesial es cónica, recta y diferenciada por un somero surco de la cúspide media. La cúspide distal es sólo una protuberancia pequeña, casi ausente en el diente (k). El último diente (l) es robusto, recto y bicuspidado. Labialmente sobre los alvéolos funcionales se observan profundos alvéolos de reemplazo.

El fragmento MACN Pv 18825 corresponde a la parte posterior de un maxilar izquierdo (Fig. 78 E). Labialmente es liso con dos forámenes labiales. Lingualmente se observa el estante supradental, con las carillas de articulación para el palatino y pterigoides. Dorsalmente se observa el foramen de ingreso al c.a.s y el surco que recibe al yugal. Se conservan nueve alvéolos, con ocho dientes. El primer diente (a) falta, y anteriormente a él se conserva parte de la base de un diente más anterior. El primer diente conservado (b) es unicuspidado, bajo y sin compresión lateral. Los dos dientes siguientes ( $\mathrm{c}$ y d) son robustos, distalmente cónicos con las cúspides dirigidas 
hacia el extremo distal. El diente (e) es robusto, apicalmente comprimido labiolingualmente y débilmente tricuspidado. La cúspide central es dominante, presenta una cresta que la recorre anteroposteriormente, y con dos protuberancias (mesial y distal) en sus extremos. El siguiente diente (g) es similar. Entre los dientes (e) y (g), se ubica labialmente la base de un diente pequeño (f) que ha sido reemplazado pero no terminó de desprenderse. Este diente es de una generación dental anterior a la que también pertenecen los dientes (h) e (i). El anteúltimo diente (h) es tricuspidado similar al (e), pero con cúspides y sin protuberancias. El último diente (i) es cónico, robusto y bajo. 

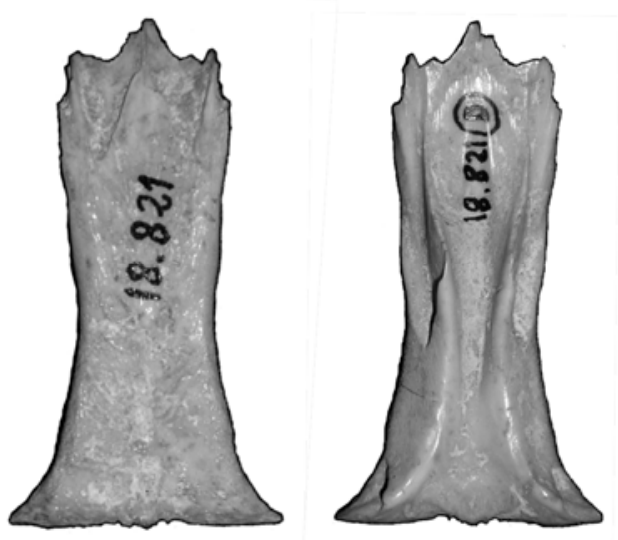

A
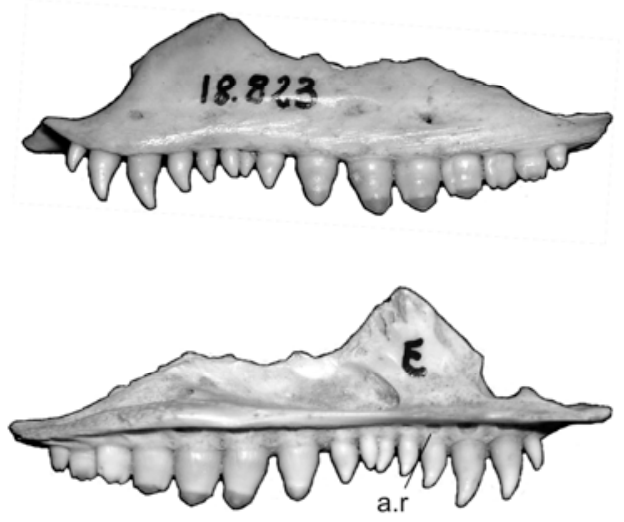

C
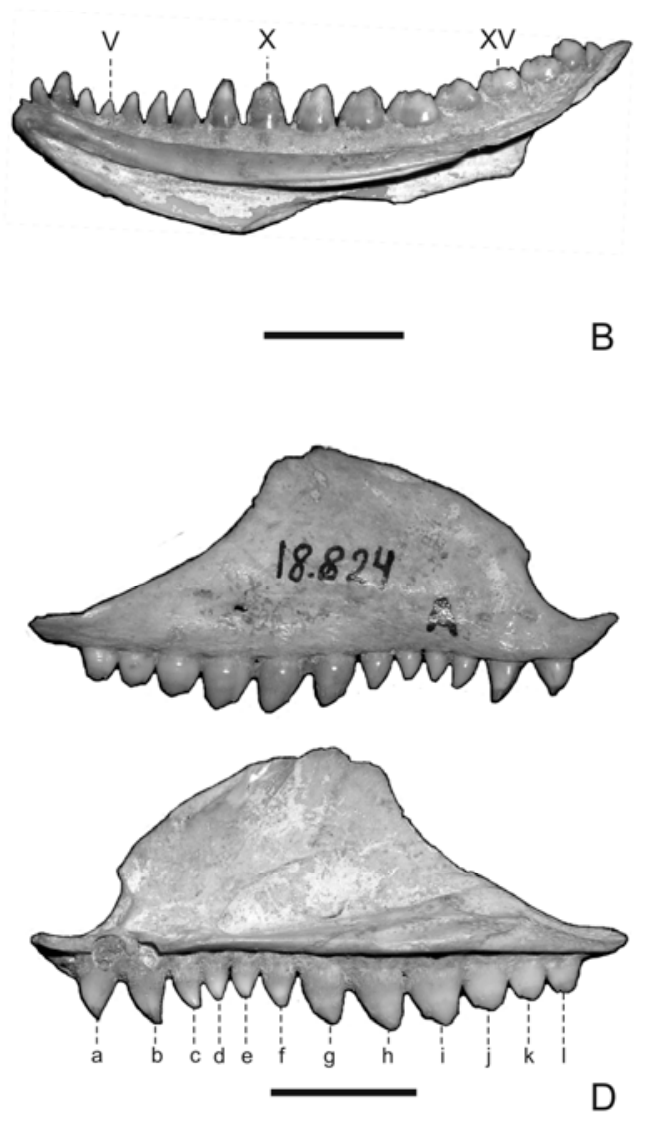

\section{A}

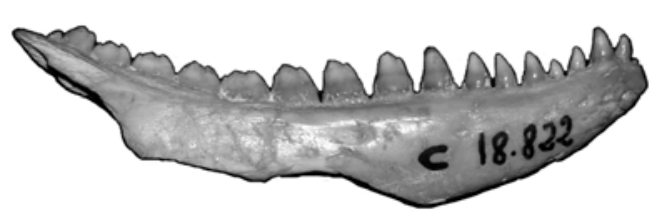

B
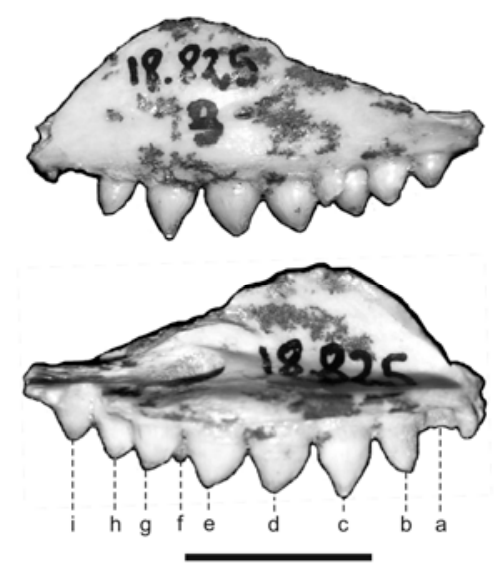

D

E

Figura 78. Elementos craneales de Tupinambis sp. del sitio arqueológico "Lomas del Veinte", Santiago del Estero. A, Frontal MACN Pv 18821 en vistas dorsal y ventral; B, dentario derecho MACN Pv 18822 en vistas labial y lingual; C, maxilar izquierdo MACN Pv 18823 en vistas labial y lingual; D, maxilar derecho MACN Pv 18824 en vistas labial y lingual; E, maxilar izquierdo MACN Pv 18825 en vistas labial y lingual. Abreviaturas: a.r, alvéolo de reemplazo. Escala $=10 \mathrm{~mm}$. 
Comentarios taxonómicos. Los fósiles pueden ser incluidos en el clado Borioteiioidea-Teiioidea por presentar abundante cemento sobre las bases de los diente (MACN Pv 18822 a 18825), alvéolos de reemplazo profundos y subcirculares (MACN Pv 18823, MACN Pv 18824) y un esplenial hipertrofiado anteriormente desarrollado como se infiere de la carilla de articulación sobre el dentario MACN Pv 18822. Estos mismos caracteres, el tamaño de los restos, el soporte narial posterior a la fenestra exonarina ([C16]) y la implantación subpleurodonte ([C120]) permiten la exclusión de los Gymnophthalmidae.

La ausencia del septo narial anterior (Cap. V) y el proceso anterolateral del coronoides solapando ampliamente al proceso posterodorsal del dentario ([C86], [C96]), son caracteres presentes en los fósiles y Teiioidea pero ausentes en los Borioteiioidea, permitiendo la exclusión de este último grupo. El contorno sigmoidal del margen ventral del maxilar ([C13]), el soporte narial posterior desdibujado ([C17]) y la cresta sobre la lámina transversal del maxilar ([C18]) son caracteres que comparten los Tupinambinae y se encuentran presentes en los fósiles.

El material del sitio "Lomas del Veinte" es asignado a Tupinambis sp. por la presencia de dientes posteriores cuspidados y robustos (Cap. III). Los tipos morfológicos presentes en el fósil, así como su patrón de distribución a lo largo de la serie dentaria concuerdan con lo observado en ejemplares subadultos de T. merianae con una LSDd $<41,69 \mathrm{~mm}$ (LSDm $<37,9 \mathrm{~mm}$ ) (Cap. III). Los especímenes de $T$. merianae con una LSDd en estos valaores no tienen dientes robustos y romos, pero sí cuspidados robustos. El fósil MACN Pv 18821 presenta una $\mathrm{LSDd}=$ 39,94 mm, mientras que los maxilares MACN Pv 18823 y MACN Pv 18824 presentan LSDm de $32,93 \mathrm{~mm}$ y $32,72 \mathrm{~mm}$ respectivamente, confirmando la inferencia previa. De esta manera, el patrón de distribución de los dientes y la longitud de las series dentarias, están indicando que los individuos representados por estos fósiles eran juveniles o subadultos.

Donadío (1983a) sostiene que este material puede ser asignado a T. rufescens por la forma del proceso medial del frontal (dado como proceso nasal) y de los dientes del dentario y maxilares. Sin embargo, este autor no explicita estas diferencias. En la revisión del material de referencia, se observaron sutiles variaciones en las dimensiones del proceso medial del frontal y de la relación de éste con los procesos laterales; sin embargo, estas variaciones no se consideran significativas pues no se 
observa una marcada diferencia entre las diferentes especies analizadas. Por lo tanto, se desestima el comentario de Donadío (1983a).

Como se mencionó en el Capítulo III, las sutiles diferencias observadas en los dientes robustos de las distintas especies de Tupinambis no son lo suficientemente confiables como para diferenciar a los fósiles a nivel específico, por lo que el material permanece indeterminado a este nivel.

\section{Comentarios biogeográficos}

La provincia de Santiago del Estero forma parte de la provincia biogeográfica Chaqueña, la cual está incluida en el Dominio Chaqueño (Cabrera y Willink, 1980). El bosque Chaqueño, como se describió previamente (ver C. bicuspidatus), presenta clima continental con una temperatura media anual de $20-23^{\circ} \mathrm{C}$ y precipitaciones en verano que varían de $500 \mathrm{~mm} /$ año al oeste a $1200 \mathrm{~mm} /$ año en el este. La provincia Chaqueña presenta cuatro distritos, la provincia de Santiago del Estero se encuentra comprendida en el distrito Oriental, el cual es más seco (500-800 mm/año) y más marcadamente continental (Cabrera, 1976; Cabrera y Willink, 1980). Bajo estas condiciones climáticas habita $T$. rufescens, que es la única especie presente en el área de "Lomas del Veinte" en la actualidad.

Donadío (1983a) infiere, al referir estos fósiles a T. rufescens, que hace 10001200 AP se habría desarrollado un clima tropical a templado de tipo semiárido en este sitio, con un régimen de precipitaciones de 200-700 mm/año, lo cual habría permitido el desarrollo de un bosque xerófilo o estepa arbustiva. Según Donadío (1983a), esta inferencia es coincidente con la fauna de vertebrados acompañante. Sin embargo, según Fernández (1994), en dicho lapso de tiempo, en el centro-sur de la provincia de Santiago del Estero, se habría desarrollo un clima cálido y húmedo que favoreció el desarrollo de un gran lago y pantanos. Estas condiciones húmedas difieren de las xéricas inferidas por Donadío (1983a). Los mamíferos recuperados en este sitio incluyen pecaríes (Catagonus wagneri), osos hormigueros (Myrmecophaga tridactyla), coipos (Myocastor coypus) y ratas nutria pequeñas (Holochilus chacarius) (Cione y Tonni, 1981; Prevosti et al., 2006) y coinciden con un ambiente húmedo. La retracción de estas condiciones cálidas y húmedas habría ocurrido durante la Pequeña Edad de Hielo en los siglos XVIII y XIX (Prevosti et al., 2006), dando lugar a las actuales condiciones ambientales presentes en Santiago del Estero. La contradicción entre las inferencias ambientales de Donadío (1983a) y aquellas obtenidas a partir de 
los peces y mamíferos fósiles recuperados en este sitio (Cione et al., 1979; Cione y Tonni, 1981) descansa en la asignación específica de los restos de Tupinambis. La imposibilidad de determinar a nivel específico estos fósiles no permite realizar inferencias paleoambientales, pero se destaca que la otra especie de Tupinambis que habita actualmente en la Argentina, T. merianae, es característica de ambientes más húmedos, como el propuesto para el sitio (Cione et al., 1979; Cione y Tonni, 1981), de modo que no se advierte una contradicción respecto a este hallazgo. 


\section{CAPÍtULO V}

\section{ANÁLISIS FILOGENÉTICO DE LA FAMILIA TEIIDAE}

Son varios los trabajos que han abordado la problemática de las relaciones filogenéticas en la familia Teiidae o en parte de ella. Sin embargo, la filogenia del grupo aún no está resuelta. A continuación se presenta un repaso de los principales trabajos sobre este tema, para luego abordar un análisis filogenético basado en caracteres osteológicos que incluye a los taxones extintos sudamericanos.

\section{ANTECEDENTES}

El trabajo de Presch (1974a) es el primer intento de clarificar las relaciones en la familia Teiidae. En ese trabajo, Presch adscribe a la escuela Fenética de clasificación, obteniendo, a partir de una matriz de 9 taxones y 21 caracteres, un fenograma donde se reconocen dos tribus, las cuales posteriormente fueron elevadas a subfamilias por Ávila-Pires (1995). Estas subfamilias son Teiinae y Tupinambinae (Fig. 79). Los Teiinae se diferencian en dos subgrupos: uno formado por teidos con dientes transversalmente bicuspidados (entre otros caracteres), que incluye los géneros Teius y Dicrodon; y el otro con tres géneros, donde Kentropyx se diferencia por un único carácter de "Ameiva"/“Cnemidophorus", los cuales serían indistinguibles osteológicamente (Presch, 1974a). A su vez, en la subfamilia Tupinambinae, Callopistes aparece separado de los restantes géneros, entre los cuales se destaca la semejanza de Tupinambis con Crocodilurus. 


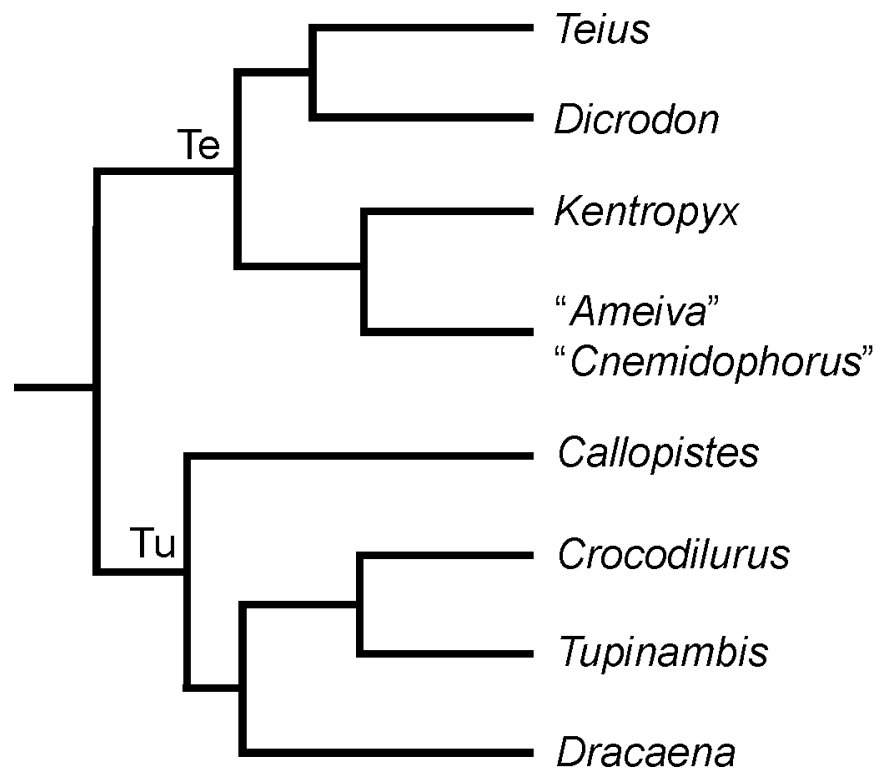

Figura 79. Relaciones fenéticas de la familia Teiidae según Presch (1974a). Abreviaturas: Te, Teiinae; $\mathrm{Tu}$, Tupinambinae.

Los trabajos posteriores sobre las relaciones de los Teiidae adhieren al Cladismo. El primero de estos trabajos es de 1995, donde Denton y O’Neill intentan resolver las relaciones filogenéticas de los géneros del Mesozoico de América del Norte Chamops y Prototeius. Además de estos fósiles, Denton y O’Neill (1995) incorporan a su análisis integrantes de los extintos Polyglyphanodontinae sensu Estes (1983a) (Cherminsaurus, Macrocephalosaurus y Polyglyphanodon). La matriz de Denton y O’Neill (1995) incluye 14 géneros y cuenta con 30 caracteres. Los caracteres son craneales, propuestos originalmente en dicho trabajo o tomados de Presch (1974a) y Estes et al. (1988). Las relaciones filogenéticas resultantes coinciden con la propuesta de Presch (1974a) (Fig. 80). Los géneros actuales se presentan separados de los géneros fósiles, y se agrupan en las dos subfamilias Teiinae y Tupinambinae. Las relaciones internas de los Tupinambinae y Teiinae son iguales a las propuestas por Presch (1974a) con la salvedad que Kentropyx, "Ameiva” y "Cnemidophorus" conforman una politomía. Una segunda politomía se observa entre los Teiidae extintos Cherminsaurus + Polyglyphanodon y Macrocephalosaurus. Prototeius y Chamops aparecen como basales a esta última politomía. En base a esta topología, la familia Teiidae sensu Denton y O’Neill (1995) queda conformada de la siguiente forma: Chamopsiinae $+($ Polyglyphanodontinae $($ Tupinambinae + Teiinae $)$ ) 
Posteriormente, Sullivan y Estes (1997) desestiman la subfamilia Chamopsiinae de Denton y O’Neill (1995) por considerar que varios de los taxones asignados a ella son compuestos (con diagnosis basadas en caracteres de elementos aislados) y que la única sinapomorfía válida para la familia no puede ser evaluada en los holotipos.

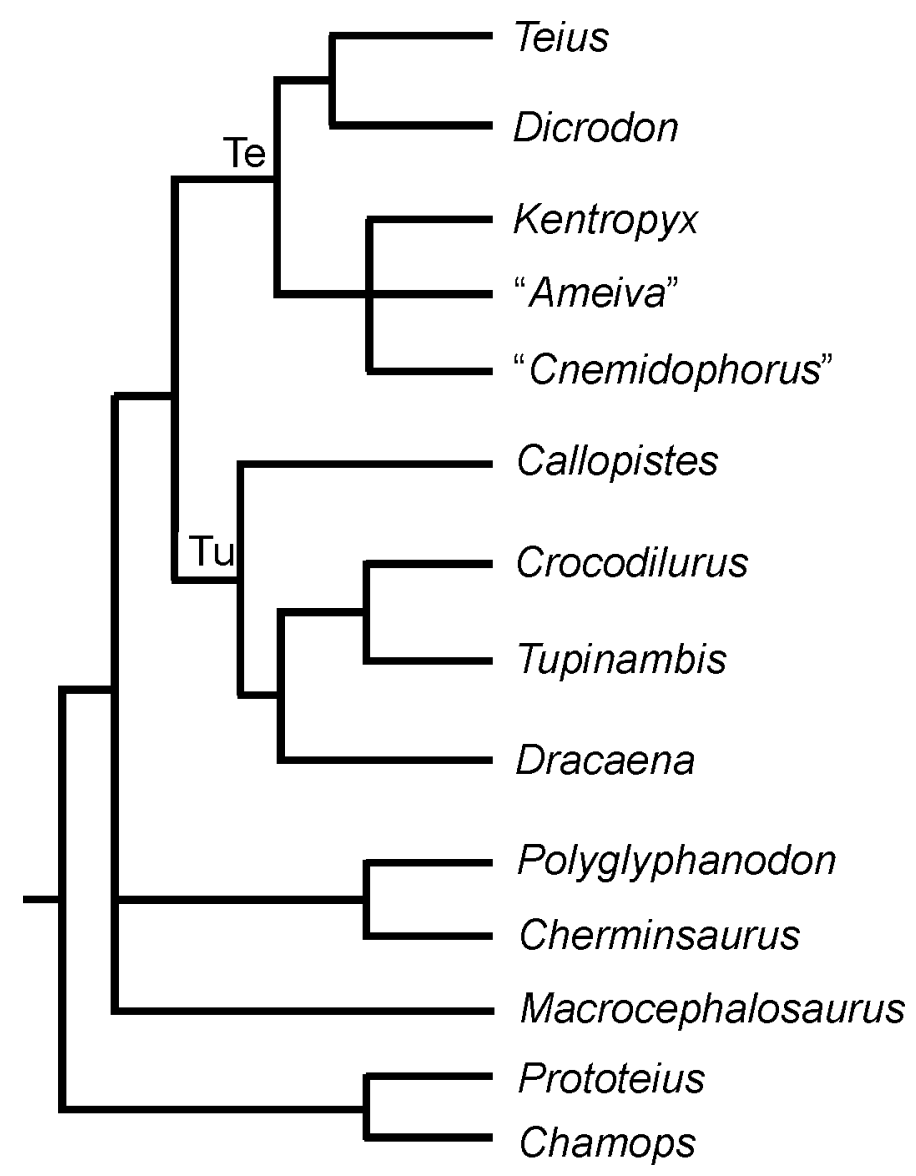

Figura 80. Hipótesis filogenética de la familia Teiidae según Denton y O’Neill (1995). Abreviaturas: Te, Teiinae; Tu, Tupinambinae.

Más recientemente, Mortari y Colli (1999) presentan resultados de un estudio donde analizan 54 caracteres osteológicos, merísticos y de la anatomía lingual de los géneros vivientes de la familia Teiidae. Estos autores obtienen cuatro árboles igualmente parsimoniosos (longitud $(\mathrm{L})=48$ pasos e Índice de Consistencia (IC) $=$ 0,78), y destacan que sus resultados muestran una mayor afinidad entre Crocodilurus y Dracaena, mientras que las relaciones entre los "cnemidoforinos" no pueden resolverse. 
Basados en la musculatura craneal de los Teiidae, Moro y Abdala (2000) registran 70 caracteres miológicos, que producen un único árbol más parsimonioso (L $=195$ pasos) (Fig. 81). Estas autoras reconocen la monofilia de los Teiidae sólo al incluir a Cercosaura schreibersii (Gymnophthalmidae) pero no la de los Gymnophthalmidae. Entre los Teiidae no encuentran sustento para la división en Teiinae y Tupinambinae.

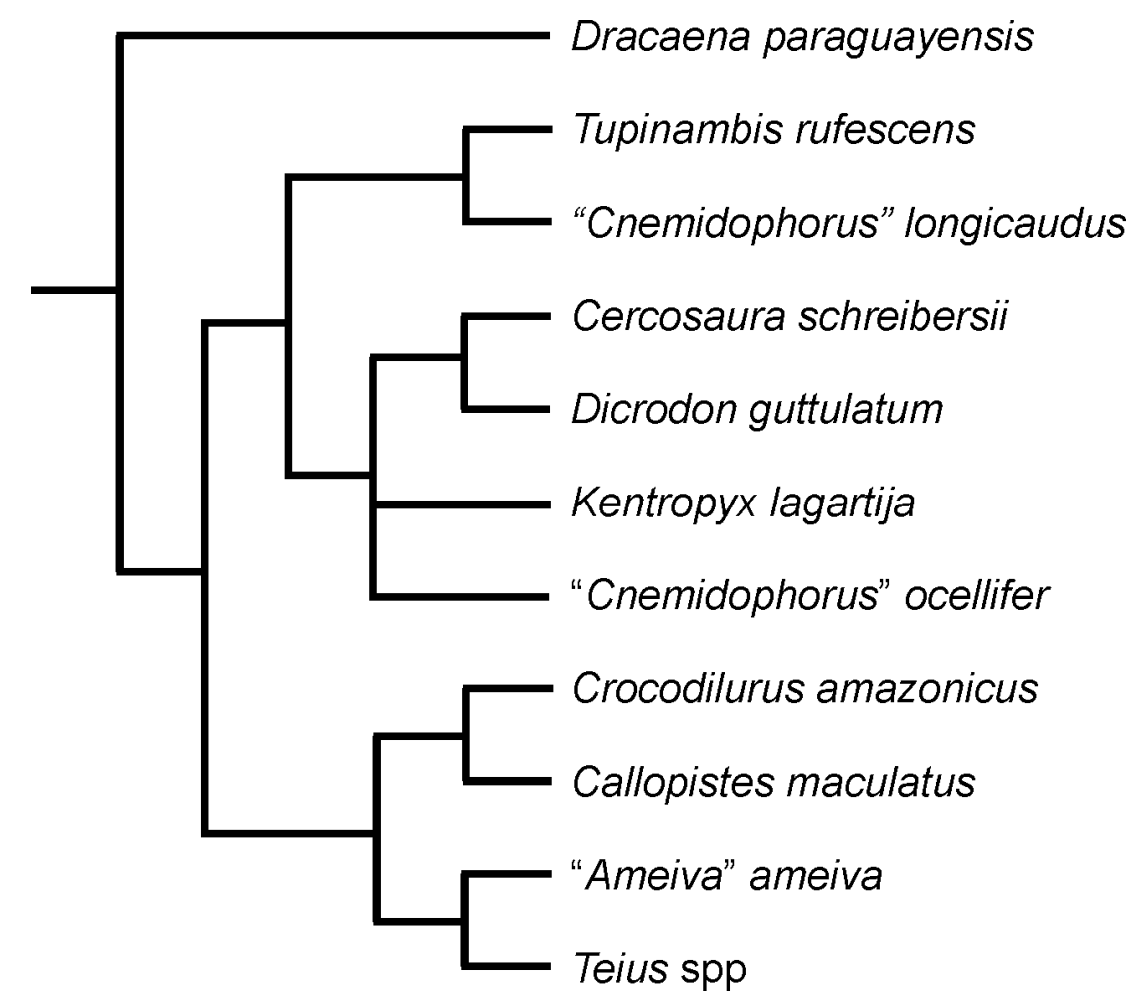

Figura 81. Hipótesis filogenética de la familia Teiidae simplificada de Moro y Abdala (2000).

Nydam y Cifelli (2002b) evalúan las relaciones filogenéticas de los Teiidae sensu Estes (1983a), incluyendo los fósiles cretácicos. Su análisis se basa en una revisión de los datos de Denton y O’Neill (1995), además de consideraciones sobre los caracteres planteados por McCord (1998) y la incorporación de los taxones extintos Peneteius y Bicuspidon. Nydam y Cifelli (2002b) obtuvieron 17 árboles filogenéticos igualmente parsimoniosos $(\mathrm{L}=55$ pasos, $\mathrm{IC}=0,62$, e Índice de Retención $(\mathrm{IR})=0,81)$. Según los autores, el bajo valor del IC se debería a la importante cantidad de datos ausentes en los géneros fósiles. El consenso estricto de estos árboles (Fig. $82 \mathrm{~A}$ ) presenta una gran dicotomía con sólo dos agrupamientos 
menores: los “cnemidoforinos" y Tupinambis $+($ Crocodilurus + Dracaena $)$. El Consenso de Mayoría (corte 50\%) muestra bajo valores de soporte para las dos subfamilias, en particular para los Tupinambinae que sólo mínimamente supera el límite (Fig. 82 B). Contrariamente a los trabajos previos con datos osteológicos (Presch, 1974a; Denton y O’Neill, 1995), Crocodilurus se asemeja más a Dracaena que a Tupinambis. Las relaciones entre los "cnemidoforinos" coinciden con las planteadas por Denton y O’Neill (1995).

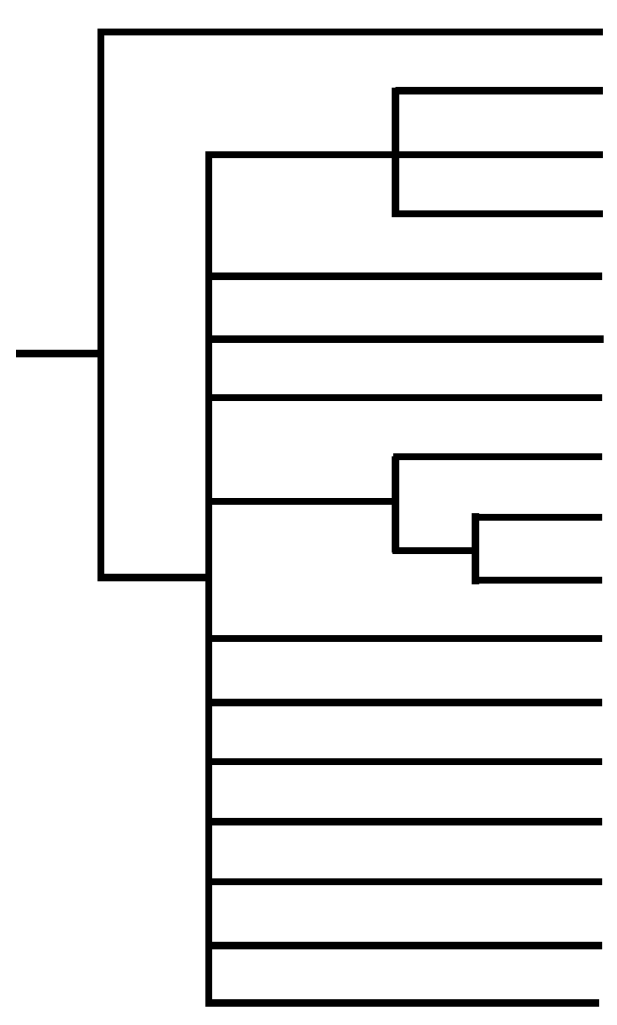

A

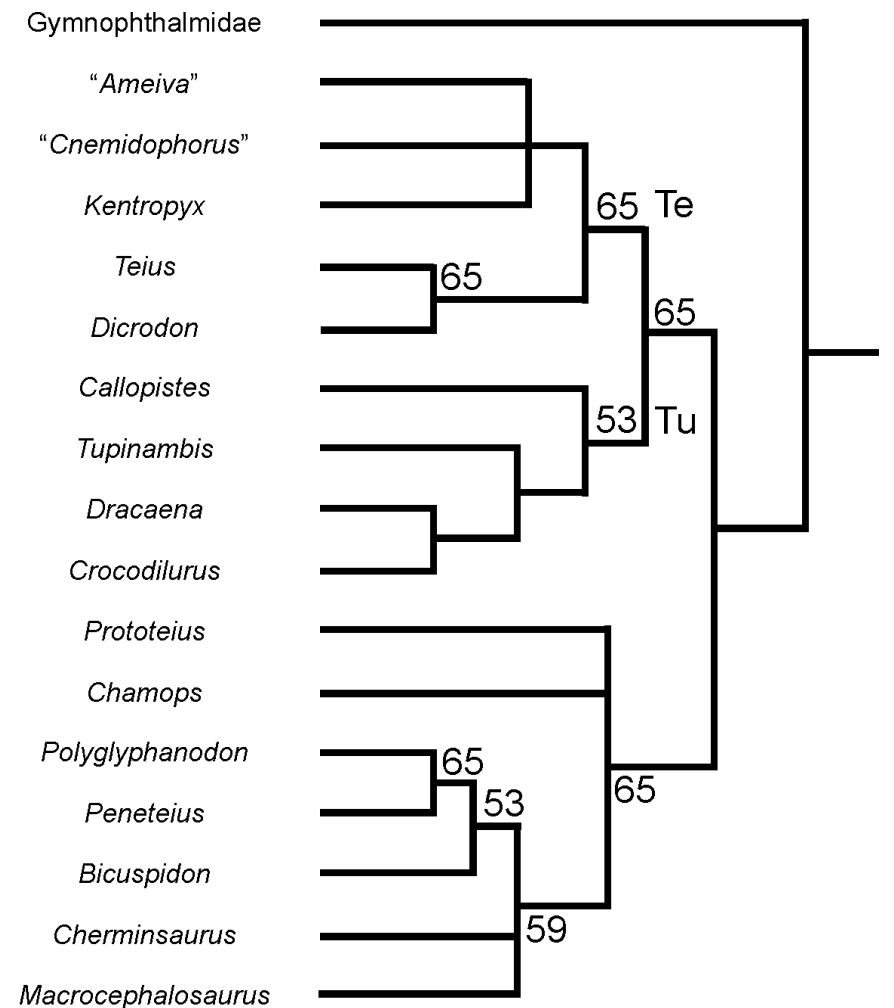

B

Figura 82. Hipótesis filogenética de la familia Teiidae según Nydam y Cifelli (2002b). A, Consenso Estricto; B, Consenso de Mayoría (corte 50\%). Abreviaturas: Te, Teiinae; Tu, Tupinambinae.

Nuevos fósiles asignados al extinto Dicothodon y la reasignación de Polyglyphanodon bajaensis al mismo, permitieron a Nydam et al. (2007) incorporar este género fósil al análisis filogenético de Nydam y Cifelli (2002b). Nydam et al. (2007) utilizan como grupo externo de los Scincomorpha a los Gekkonidae, reteniendo a los Gymnophthalmidae como grupo interno. El resultado de este análisis son tres árboles igualmente parsimoniosos $(\mathrm{L}=67$ pasos, $\mathrm{IC}=0,63, \mathrm{IR}=0,81)$. Según 
estos autores, los resultados son más robustos que los de Nydam y Cifelli (2002b) pero presentan una topología similar, en particular para los Teiidae (Fig. 83). El cambio más notorio de este estudio es la remoción de los lagartos cretácicos y su agrupamiento en los Borioteiioidea, como grupo hermano de los Teiidae.

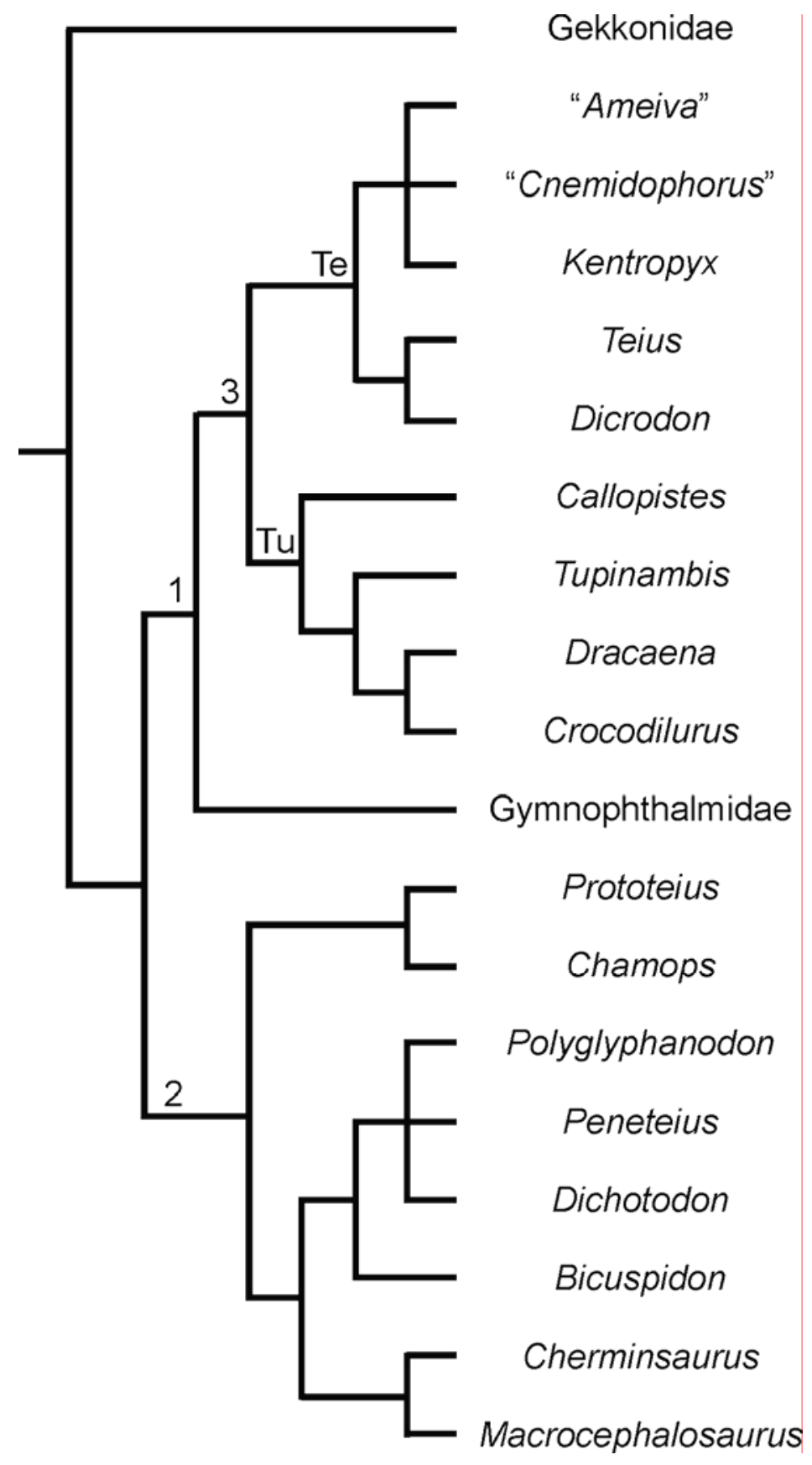

Figura 83. Hipótesis de las relaciones filogenéticas de la familia Teiidae según Nydam et al. (2007). Abreviaturas: 1, Teiioidea; 2, Borioteiioidea; 3, Teiidae; Te, Teiinae; Tu, Tupinambinae. 
Posteriormente, Giugliano et al. (2007) realizan un análisis filogenético de la familia Teiidae utilizando tanto caracteres moleculares (secuencias de ADN mitocondrial $12 \mathrm{~S}$ y $16 \mathrm{~S}$ ) como caracteres morfológicos y de ultraestructura de espermatozoides (datos tomados de Teixeira (2003)). A diferencia de los trabajos anteriores, que se basaron en métodos de parsimonia, los datos de Giugliano et al. (2007) fueron analizados con métodos probabilísticos: máxima verosimilitud (maximun likelihood) e inferencia bayesiana. La filogenia inferida del conjunto total de datos soporta la monofilia de los Teiidae y distingue a las subfamilias reconocidas previamente, donde los Teiinae tienen mayor soporte que los Tupinambinae. El análisis de máxima verosimilitud produce un único árbol más parsimonioso $(\mathrm{L}=1163$ pasos, $\mathrm{IC}=0,63, \mathrm{IR}=0,48$ ); mientras que la inferencia bayesiana produce una topología general similar, con diferencias entre los Tupinambinae. Con ambos métodos de análisis, los Teiinae se ordenan en un único grupo (Fig. 84 A, B). Estos autores no reconocen la diferenciación del grupo Teius + Dicrodon presente en otras filogenias (Presch, 1974a; Denton y O’Neill, 1995; Nydam y Cifelli, 2002b; Nydam et al., 2007), aunque soportan la posición basal de estos géneros respecto a los "cnemidoforinos", que conforman un grupo natural. Entre los Tupinambinae, ambos métodos reconocen a Callopistes como basal; sin embargo, se observan incongruencias entre los restantes géneros. El método de máxima verosimilitud considera a Tupinambis como grupo hermano de Crocodilurus mientras que la inferencia bayesiana obtiene a Dracaena como grupo hermano de Crocodilurus (Fig. 84 A, B). Giugliano et al. (2007) también utilizan datos del reloj molecular para calcular el momento en que se produjeron los eventos de diversificación genérica. Según estos autores, la familia se habría originado en el Cretácico superior-Paleoceno y durante el Eoceno-Oligoceno se habrían diferenciado la mayoría de los géneros (Giugliano et al., 2007). 


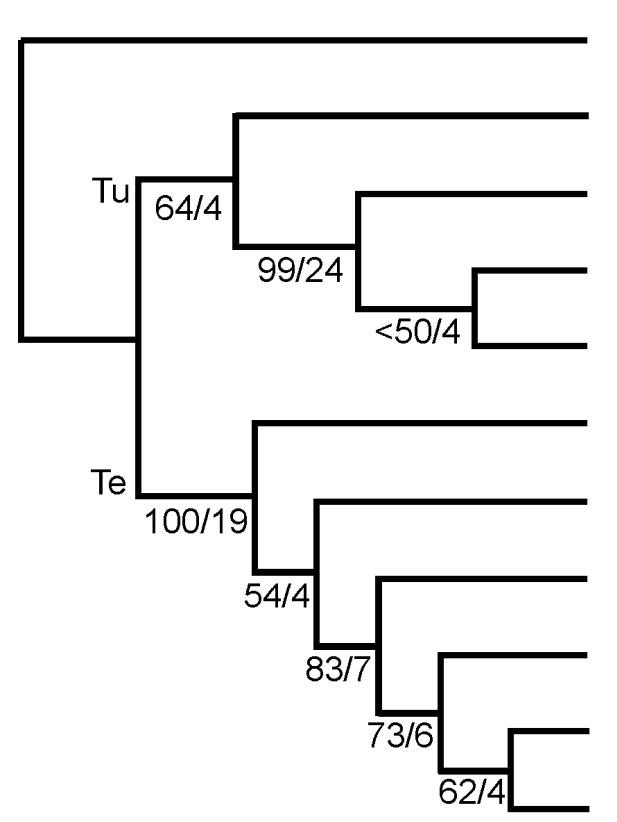

A

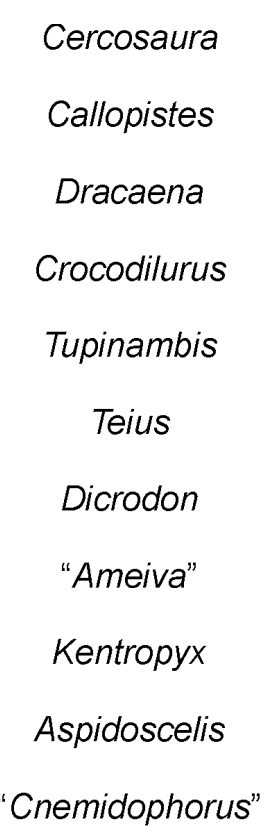

"Cnemidophorus"

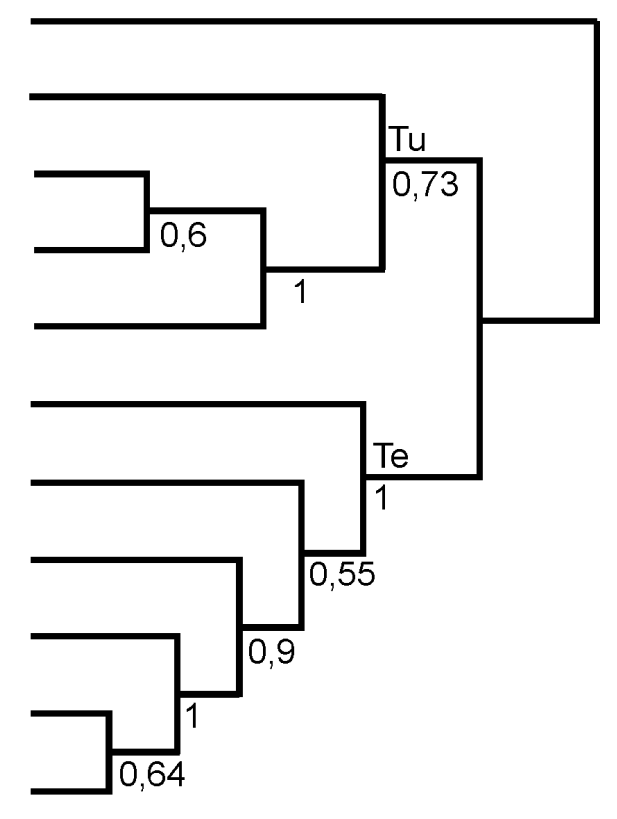

B

Figura 84. Hipótesis filogenética de la familia Teiidae según Giugliano et al. (2007). A, árbol más parsimonioso calculado por máxima verosimilitud, valores de Bootstrap/Bremer Support; B, árbol inferido por inferencia bayesiana, con valores de probabilidad posterior. Abreviaturas: Te, Teiinae; Tu, Tupinambinae.

Desde el trabajo de Presch (1974a) poco se ha avanzado en la resolución de las relaciones filogenéticas dentro de los Teiinae. Ésta es una de las razones por la cual Reeder et al. (2002) realizan un análisis filogenético integral del controversial género “Cnemidophorus". Estos autores utilizan datos morfológicos y moleculares (ADN mitocondrial y aloenzimas), los cuales son analizados de dos formas. Por un lado, consideran el peso uniforme de los caracteres obteniendo cuatro árboles igualmente parsimoniosos $(\mathrm{L}=1539$ pasos; $\mathrm{IC}=0,39 ; \mathrm{IR}=0,61)$, cuyo consenso estricto se observa en la figura 85. Al considerar los pesos en forma no uniforme (Análisis de Aproximación Sucesiva) obtienen un único árbol $(\mathrm{L}=43281$ pasos; $\mathrm{IC}=0,61 ; \mathrm{IR}=$ 0,79). Este segundo árbol es similar al anterior, difiriendo en: (1) la posición intercambiada de Dicrodon y Teius; y (2) las relaciones dentro del grupo "sexlineata". Los resultados de Reeder et al. (2002) no reconocen la monofilia de la familia Teiidae, pero su parafilia tiene poco soporte. Sin embargo, reconocen la monofilia de los Teiinae, donde se destaca la posición basal de Teius y Dicrodon respecto a los “cnemidoforinos”. Estos últimos son monofiléticos, pero entre ellos sólo se reconoce 
la monofilía de Kentropyx y el clado norteamericano de "Cnemidophorus" (= Aspidoscelis) (i.e. "Cnemidophorus" y "Ameiva" no son monofiléticos).

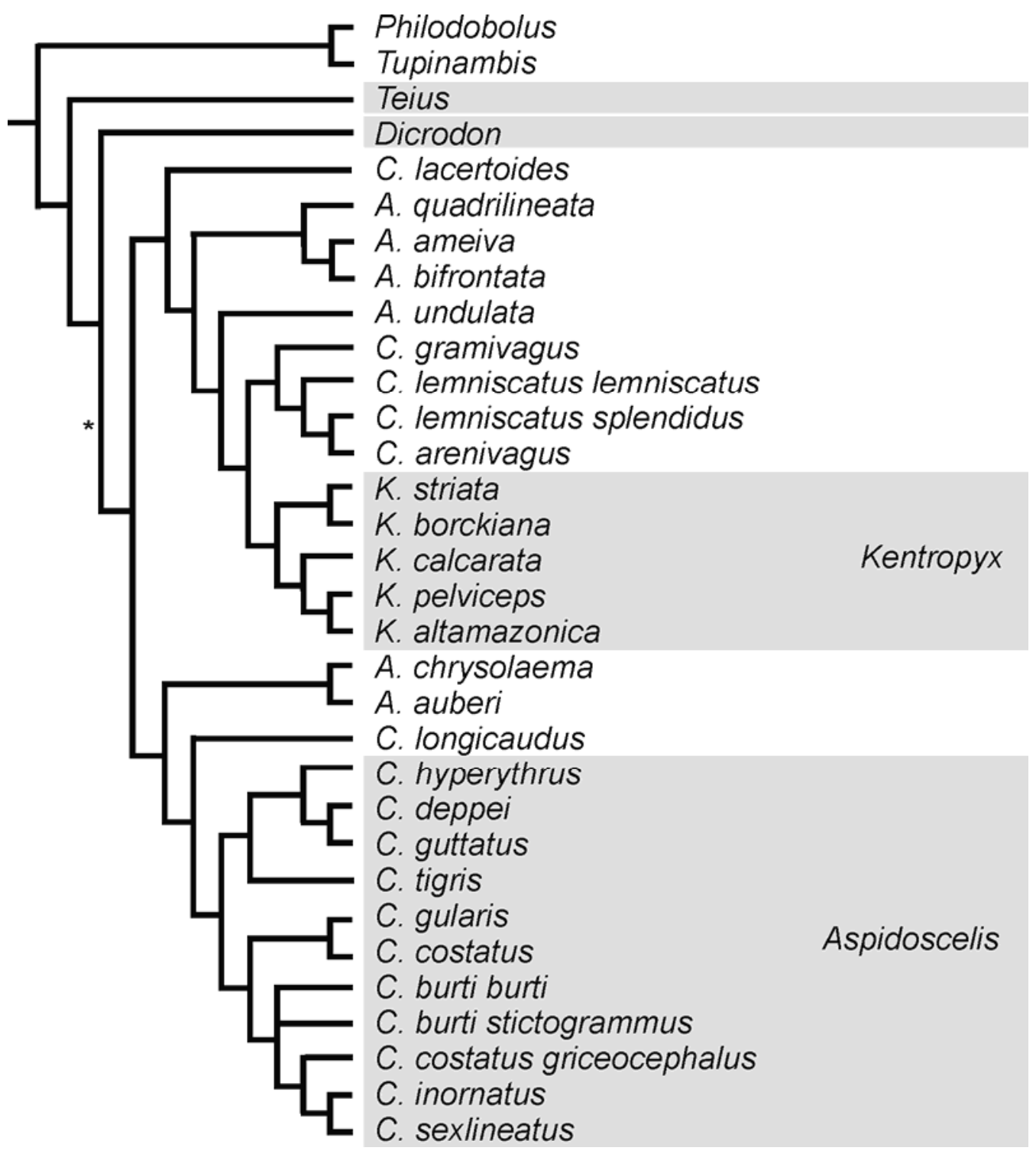

Figura 85. Hipótesis filogenética de la subfamilia Teiinae modificada de Reeder et al. (2002). Asterisco, posición de C. ocellifer.

Por otra parte, Sullivan y Estes (1997) realizan el análisis filogenético de la subfamilia Tupinambinae para dilucidar las afinidades de la especie Paradracaena colombiana del Mioceno de Colombia. Estos autores construyen una matriz de seis taxones y 30 caracteres osteológicos, parte de los cuales son tomados de Presch (1974a). Del análisis de la matriz de datos, estos autores obtienen un único árbol (L = 
37 pasos, IC = 0,89) (Fig. 86) donde Callopistes aparece en posición basal, mientras que Crocodilurus se relaciona más con el clado Paradracaena + Dracaena que con Tupinambis.

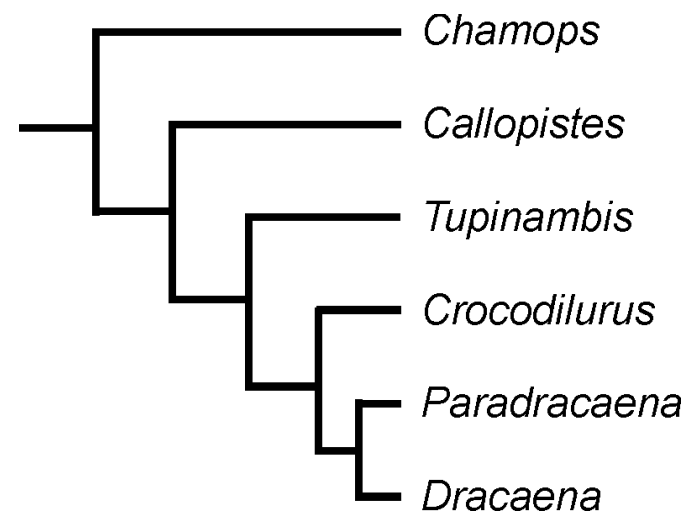

Figura 86. Hipótesis filogenética de los Tupinambinae según Sullivan y Estes (1997).

En 1999, Fitzgerald et al. realizan el primer estudio cladístico destinado a dilucidar las relaciones filogenéticas del género Tupinambis, que en ese momento y para estos autores constaba de cinco especies (excluía a T. quadrilineatus). Utilizan datos de morfología externa y moleculares (citocromo mitocondrial b (300pb) y ND4 (375pb)), obteniendo como resultado un único árbol más parsimonioso ( $\mathrm{L}=541$ pasos, $\mathrm{IC}=0,691, \mathrm{IR}=0,824$ ) (Fig. 87). Este género presenta una división entre las especies de distribución austral (T. merianae + (T. duseni - T. rufescens)) y las de distribución boreal ( $T$. longilineus $+T$. teguixin). 


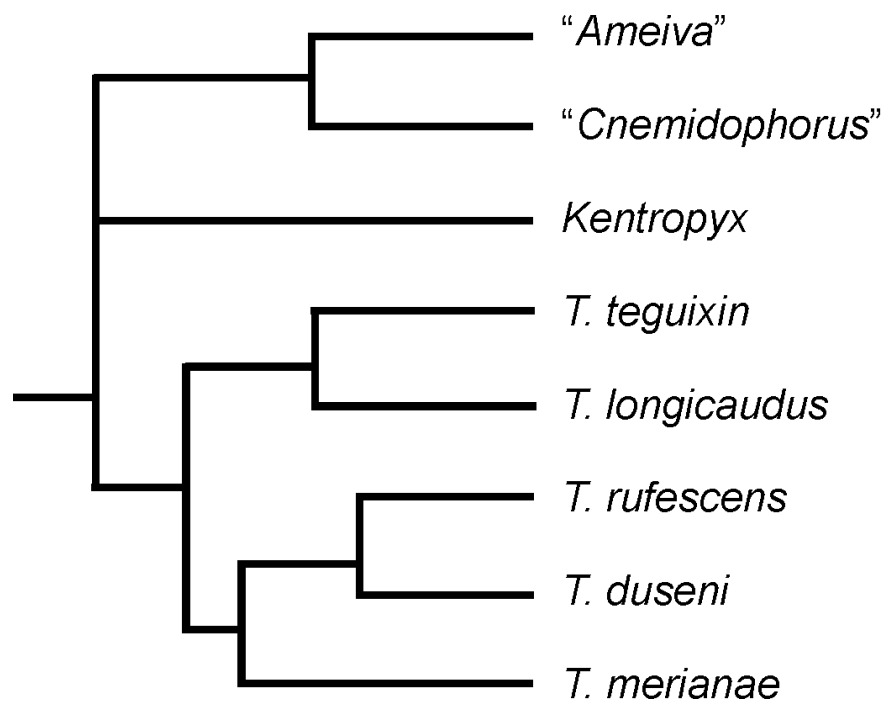

Figura 87. Hipótesis filogenética del género Tupinambis modificada de Fitzgerald et al. (1999).

En el mismo sentido, Péres Jr y Colli (1999) presentan los resultados del análisis de caracteres morfológicos de las seis especies del género Tupinambis, a partir del cual obtuvieron nueve árboles igualmente parsimoniosos. El género se divide en dos clados similares a los de Fitzgerald et al. (1999): grupo "teguixin" ( $T$. teguixin $+T$. quadrilineatus $+T$. longilineus $)$ y el grupo "merianae" $(T$. merianae $+T$. rufescens + T. duseni). En el trabajo doctoral de Péres $\operatorname{Jr}$ (2003) este autor profundiza el estudio de la relaciones filogenéticas de Tupinambis utilizando datos morfológicos y moleculares. El análisis combinado de caracteres produjo dos árboles igualmente parsimoniosos ( $\mathrm{L}=302$ pasos, $\mathrm{IC}=0,7, \mathrm{IR}=0,67)$ (Fig. 88). Péres $\mathrm{Jr}$ (2003) favorece la primer hipótesis en la cual Tupinambis resulta monofilético (Fig. 88 A). 


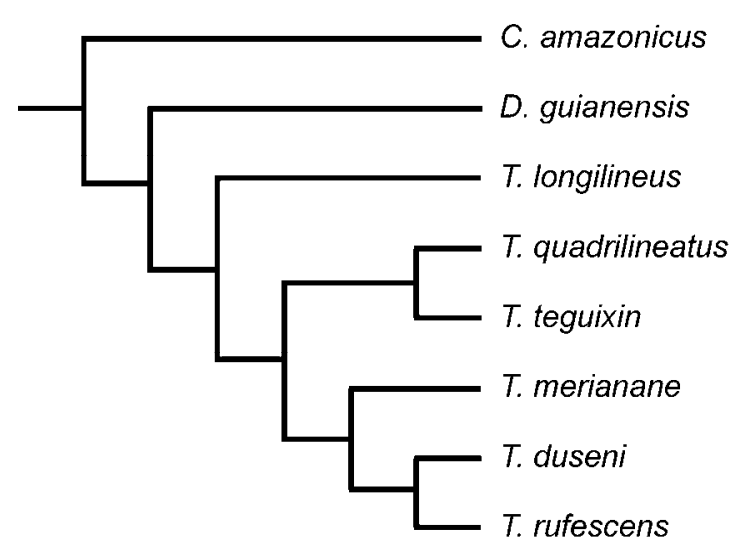

A

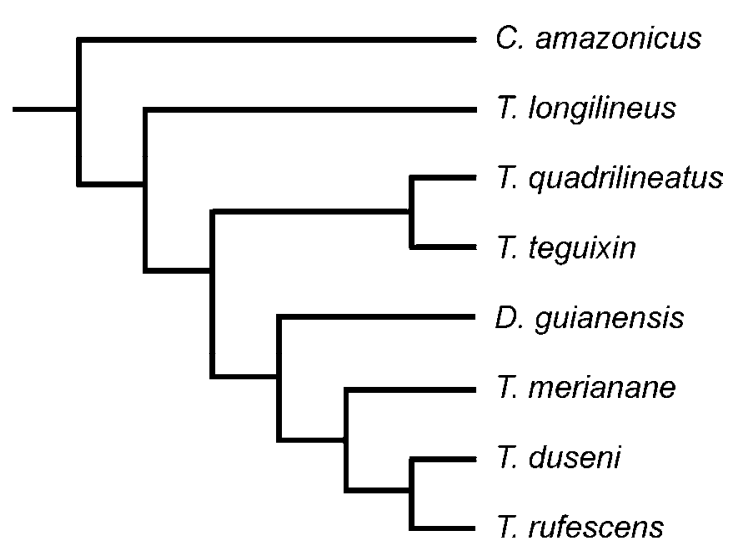

B

Figura 88. Hipótesis filogenética del género Tupinambis según Péres Jr (2003). A, sin árbol restringido; B, con árbol restringido.

A partir de lo anteriormente expuesto se puede concluir que la monofilia de los Teiidae se encuentra comprobada, y que los Gymnophthalmidae constituyen su grupo hermano (contra Moro y Abdala (2000) y Reeder et al. (2002)). Estas dos familias constituyen los Teiioidea de Estes et al. (1988). Los “teidos" cretácicos se agrupan por fuera de los géneros actuales componiendo los Borioteiioidea, grupo hermano de los Teiioidea (Nydam et al. 2007).

Las relaciones entre los géneros de la familia Teiidae todavía no presentan una clara resolución y la monofilia de los géneros "Ameiva" y "Cnemidophorus" está cuestionada. La división en las subfamilias Teiinae y Tupinambinae es reconocida por la mayoría de los autores (excepto Moro y Abdala, 2000), y todos los autores, excepto Teixeira (2003), coinciden en su composición genérica. Esta última autora considera que Callopistes debe ser excluido de los Tupinambinae e incluido en los Teiinae. Entre los Teiinae, hay acuerdo respecto a la posición basal de Teius y Dicrodon, pero no en cuanto a la relación entre ellos y con los "cnemidoforinos". Las relaciones entre los “cnemidoforinos" son las menos resueltas. Además, como se mencionó anteriormente, no está corroborada la monofilia de "Cnemidophorus" y "Ameiva", dos géneros históricamente aceptados. Entre los Tupinambinae, es aceptada la posición basal de Callopistes (ver comentario anterior) pero las relaciones entre los restantes géneros varía según la filogenia que se trate y los métodos implementados para el análisis de los datos (Giugliano et al., 2007). Respecto al género Tupinambis, la 
evidencia sostiene el reconocimiento del grupo de especies "merianae" minetras que las relaciones entre $T$. longilineus, $T$. quadrilineatus y $T$. teguixin son menos claras (Fitzgerald et al., 1999; Péres Jr, 2003).

\section{ANÁLISIS FILOGENÉTICO}

\subsection{Taxones}

Se evaluaron 29 especies de nueve de los diez géneros de Teiidae (Tabla 5). No se pudo evaluar ningún ejemplar de Dicrodon. Como grupo externo más cercano se utilizó a los Gymnophthalmidae, representado por Cercosaura schreibersii, Anadia bogotensis y Bachia dorbignyi. Adicionalmente, se incluyó a Mabuya frenata y a Ophiodes vertebralis. La primera de estas especies corresponde a la familia Scincidae que, junto a Xantusiidae, forman el grupo hermano de los Lacertoidea (Lacertidae + Teiioidea); mientras que O. vertebralis es un Anguidae que forma parte de los Anguimorpha, grupo hermano de los Scincomorpha. De esta forma, se obtuvo información de grupos externos cada vez más alejados de los Teiidae.

A esta matriz se incorporaron las especies extintas Paradracaena colombiana Sullivan y Estes 1997 y Callopistes bicuspidatus Chani 1976 cuyas afinidades con los Teiidae están bien documentadas. Por lo tanto, se analizaron 31 taxones internos (29 actuales y 2 fósiles) y 5 taxones externos resultando en un total de 36 taxones.

\subsection{Caracteres}

Para la elección del tipo de caracteres se tuvieron en consideración dos aspectos. Uno de ellos es que en la práctica paleontológica se trabaja con el concepto morfológico de especie debido a que el cambio morfológico es el único aspecto que puede ser evaluado directamente en los fósiles. El otro aspecto se relaciona con el proceso de fosilización, donde las características del ambiente de fosilización (energía, tipo de sedimento, etc.) determina el tipo de elementos que se conservará. Generalmente, se preservan elementos óseos aislados, aunque en algunos casos muy particulares (ambientes de baja energía y sedimentos finos), se conservan ejemplares de lagartos articulados, que incluso pueden incluir parte del tegumento (e.g. Tijubina pontei Bonfim Jr y Marques 1997).

En la presente tesis se utilizaron caracteres esqueletarios, la mayoría óseos, aunque también se analizaron algunos cartilaginosos (del aparato hioideo y de la cintura pélvica). A pesar que la morfología externa es la base de la sistemática actual 
de la familia (e.g. Cei, 1986, 1993; Ávila-Pires, 1995), no se evaluaron caracteres de este tipo.

En primer instancia se recopiló información de los diferentes caracteres mencionados en la literatura, ya sea de trabajos filogenéticos, fenéticos o descriptivos relacionados con los Teiidae. Esta información se ordenó según regiones anatómicas (cráneo, esqueleto axial, etc.) y se utilizó para sistematizar la observación exhaustiva del material de referencia. Durante el estudio de los diferentes materiales, pudieron ser registrados nuevos caracteres. Algunos caracteres considerados inicialmente resultaron no ser informativos, ya que no aportan información al nivel taxonómico abordado, por lo que fueron removidos del análisis. Además, la separación de los Borioteiioidea respecto a los Teiidae determinó la exclusión de varios caracteres utilizados en estudios previos (Denton y O’Neill, 1995; Nydam y Cifelli, 2002b; Nydam et al. 2007): fusión ontogenética del frontal, desarrollo del cóndilo articular, relación largo/alto del parietal, septo intermandibular y suspensión del reemplazo dentario posterior (caracteres 1, 13, 14, 23, y 27 de Denton y O’Neill (1995), Nydam y Cifelli (2002b) y Nydam et al. (2007)). En los trabajos descriptivos de Krause (1991), Tedesco y Cei (1997) y Veronese y Krause (1997) se describen caracteres osteológicos que, en gran parte, fueron desestimados para el análisis, debido a que no pudieron ser confirmados con la observación del material de referencia, o sus diferentes estados eran muy subjetivos (e.g. profundidad del surco intercondilar del fémur) o de difícil cuantificación. En suma, se utilizó una matriz de 159 caracteres: 83 craneales, 32 de la hemimandíbula, 14 relacionados a la dentición, 2 del aparato hioideo y 28 del esqueleto postcraneal (Anexo 1).

\subsubsection{Análisis de los Caracteres}

En la descripción de cada carácter figura, en forma abreviada, la publicación o publicaciones donde se ha mencionado previamente. La abreviatura es seguida por el número original asignado a dicho carácter en la correspondiente publicación. En el caso en que la fuente haya sido un trabajo descriptivo y el carácter no estaba numerado, la abreviatura no es seguida por un número. La ausencia de abreviaturas indica que se trata de un carácter nuevo no descripto previamente. En los comentarios de cada carácter se hace referencia, cuando no se trate de un carácter nuevo o de un 
carácter tomado de un trabajo descriptivo, si éste ha sido redefinido (y en consecuencia recodificado) o recodificado a partir de las observaciones realizadas. Abreviaturas: A, Arnol et al., 2007; C, Chani, 1976; Co, Conrad, 2006; D, Donadío, 1985; DO, Denton y O'Neill, 1995; E, Estes et al., 1988; EC, Evans y Chure, 1998;

K, Krause, 1990; L, Lee, 1997; L2, Lee, 1998; Mc, Maclean, 1974; M, Müller, 2001; N, Nydam et al., 2007; NQ, Norrel y de Queiroz, 1991; NC, Nydam y Cifelli, 2002b; P, Presch, 1974a; P2, Presch, 1980; R, Reynoso, 1998; SE, Sullivan y Estes, 1997; TC, Tedesco y Cei, 1997; VK, Veronese y Krause, 1997.

\section{CRÁNEO}

00. Estante palatal del premaxilar, desarrollo: escasamente desarrollado (0); desarrollado (1); muy desarrollado, con proyecciones posteriores (2); otro (3).

01. Estante palatal del premaxilar, contorno medio: cóncavo (i.e. "U”, abierta posteriormente) (0); bordes rectos (i.e. "V" invertida) (1); bordes rectos, marcadamente divergentes ("V" invertida, marcadamente abierta al superar la mitad del largo) (2).

02. Proceso ascendente del premaxilar, forma (TC): corto (i.e. no alargado), ancho distalmente (0); corto, ancho basalmente (1); alargado y estrecho (2); alargado y ancho (3).

03. Proceso ascendente del premaxilar, constricción basal: ausente (0); presente (1).

04. Proceso ascendente del premaxilar, avance entre nasales (SE[30], TC, M): poco, no supera la mitad de la longitud total de los nasales (0); mucho, supera la mitad de la longitud total de los nasales (1); existe contacto entre con el premaxilar y el frontal (2).

Comentario. Este carácter ha sido redefinido. Para cuantificar los diferentes estados se calculó la distancia entre el proceso medial del frontal al premaxilar (F-p.Mx) y del proceso medial del frontal a la proyección sobre el plano sagital del extremo más anterior de los nasales (F-N). Estos valores permiten calcular el porcentaje de avance del proceso ascendente del premaxilar entre los nasales.

05. Proceso ascendente del premaxilar, cresta ventral (cresta del septo nasal, Montero et al., 2004): presente (0); ausente (1). 
Comentario. Este carácter sólo puede ser observado en cráneos desarticulados, de ahí el importante número de datos faltantes.

06. Premaxilar, forámenes laterales (L2[2]): presentes (0); ausentes (1).

07. Unión maxilar-premaxilar, en vista lateral (L[7], L2[3]): el contacto es en un punto, sobre el mismo eje de la rama labial del proceso premaxilar (0); la rama labial del proceso premaxilar del maxilar se une ventralmente al proceso maxilar del premaxilar (1); la rama labial del proceso premaxilar del maxilar (de forma cónica) encastra lateralmente sobre el proceso maxilar del premaxilar, el cual presenta una agarradera terminal que sostiene a dicha rama dorsal y ventralmente (2).

Comentario. Este carácter ha sido redefinido. Lee (1998) se refiere al contacto maxilarpremaxilar haciendo hincapié en el contacto móvil de estos huesos en la serpientes y rígido en los lagartos. Aquí se hace referencia a las diferentes formas del contacto rígido observado.

08. Constricción del contorno del cráneo a nivel maxilar-premaxilar en vista dorsal (o ventral): ausente (0); presente (1).

09. Maxilar, rama labial del proceso premaxilar, forma (Estes, 1969; DO): cuña, plana, de desarrollo horizontal o ligeramente curvada dorsalmente (0); cónica (1); muy robusta y roma, curvada medialmente (2).

10. Maxilar, escotadura labial a la rama lingual del proceso premaxilar: ausente (0); presente (1).

11. Rama labial del proceso premaxilar del maxilar: recta (0); curvada, casi en contacto con la rama lingual (1).

12. Alto relativo del hocico: el maxilar no supera el $50 \%$ de la altura del cráneo (0); el maxilar supera el $50 \%$ de la altura del cráneo (1).

Comentario. El alto del maxilar fue tomado al proceso prefrontal y comparado con el alto del cráneo.

13. Maxilar, margen ventral ( $E[87], L 2[4])$ : recto en todo su desarrollo (0); sigmoidal, curvándose dorsalmente en su parte anterior (1).

Comentario. Este carácter ha sido recodificado.

14. Maxilar, procesos dorsales (proceso frontal): uno (0); dos, con el proceso frontal escasamente desarrollado (1); dos, la base del proceso frontal es angosta, resultando en un proceso digitiforme (2); dos, la base del proceso frontal es ancha, resultando en un proceso triangular (3); dos, similares, bajos y de base ancha (4). 
15. Maxilar, proceso posterior, altura (vista lateral): alto ("profundo") en vista lateral (0); aguzado posteriormente (1).

16. Soporte narial posterior, posición (DO[2], NC[2], N[2]) (Fig. 89): ubicado a la altura del borde posterior de la fenestra exonarina (0) (Fig. 89 A); posteriormente desplazado respecto del borde de la fenestra exonarina (1). Comentario. Este carácter ha sido redefinido, desdoblándolo en dos, según la posición relativa a la fenestra exonarina ([C16]) o la forma del soporte narial posterior ([C17]). Sólo puede ser observado en cráneos desarticulados, de ahí el importante número de datos faltantes.

17. Soporte narial posterior, forma (DO[2], NC[2], N[2]) (Fig. 89): tabique vertical muy robusto (0); grácil; dorsalmente expandido (subtriangular) formando un estante, ventralmente se presenta como una delgada lámina (1); similar al anterior pero más bajo, con su extremo dorsal robusto (2); similar al estado " 1 " pero sin la cresta ventral, aislada del estante supradental (3); cresta baja, ancha y desdibujada (no nítida), dorsalmente con una protuberancia amorfa (4); similar al anterior pero sin estructura dorsal (5). Comentario. Ver [C16]. 


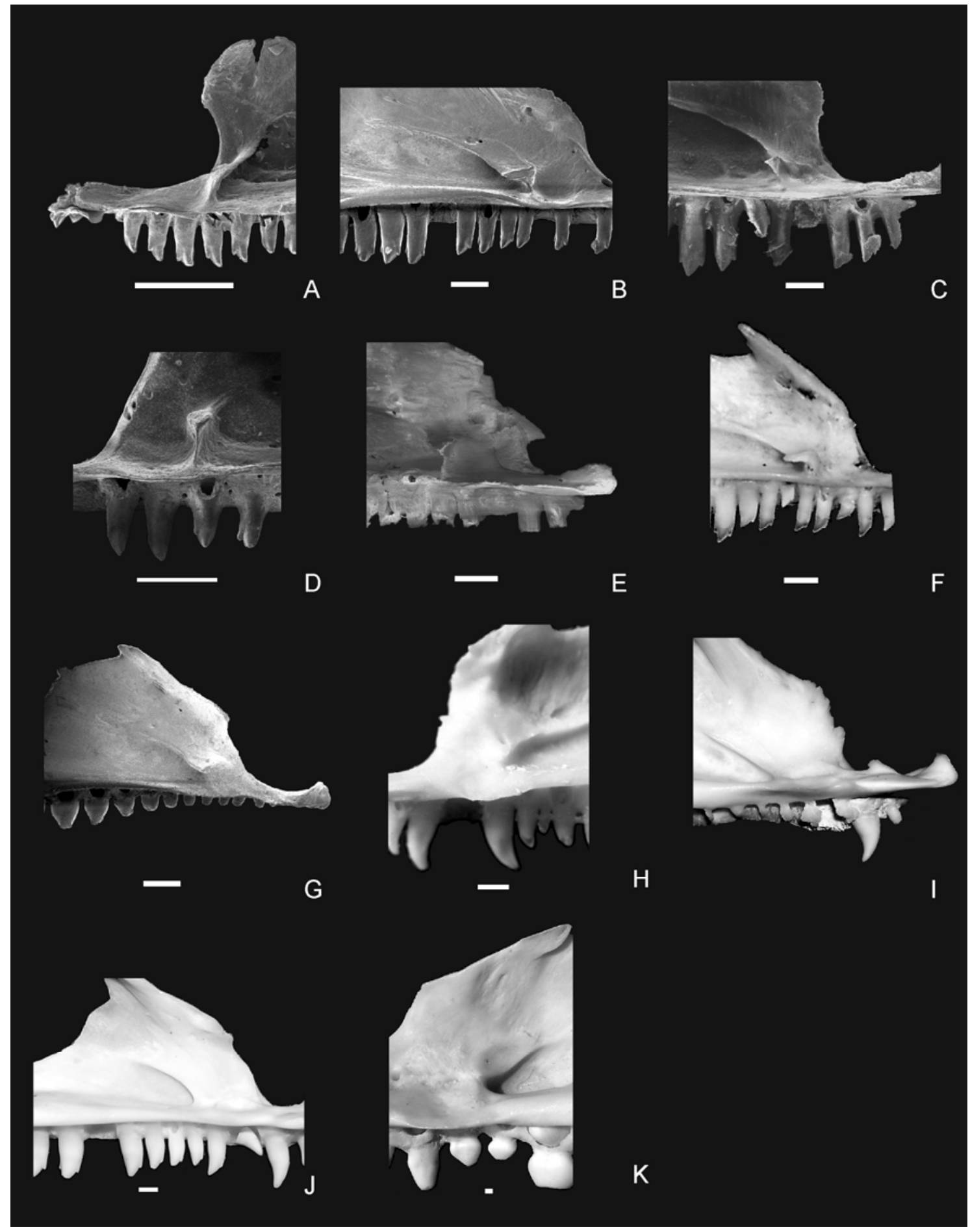

Figura 89. Vista lingual de maxilares de diferentes Teiioidea donde se observa el soporte narial posterior. A. Cercosaura schreibersii (Gymnophthalmidae) (UNRC 5058); B, "Ameiva” ameiva (UNMdP-O 27); C, “Cnemidophorus” lemniscatus (UMMZ 18945); D, “Cnemidophorus” longicaudus (HAA 115); E, Kentropyx viridistriga (UNNE 1062); F, Kentropyx calcarata (MZUSP 81580); G, Teius teyou (UNMdP-O 15); H, Callopistes maculatus (MNHN cl 4113); I, Tupinambis merianae (UMMdP-O 2); J, Crocodilurus amazonicus (MZUSP 92074); K, Dracaena paraguayensis (MZUSP 62489). Escala = 0,5 mm en A, C, D, E; 1 mm en B, F, G, H, L, K. 
18. Maxilar, cresta de la lámina transversa anterior: ausente (0); leve (1); marcada (2).

19. Maxilar, máximo número de forámenes labiales: menos de cinco (0); entre cinco y siete (1); más de siete (2).

20. Maxilar, desarrollo medial del estante supradental: muy desarrollado (0); poco desarrollado (1). Comentario. El estante se encuentra muy desarrollado entre los Gymnophthalmidae. Este desarrollo está relacionado con el desarrollo del paladar secundario.

21. Maxilar, articulación con yugal: surco de paredes similares, la labial algo más alta (0); similar, pero la pared lingual muy alta, visible en vista labial (1); sin surco, el yugal apoya sobre el maxilar y no encaja en él (2).

22. Septomaxilar, forma (NQ[20], $\mathrm{A}[06])$ : plano (0); convexo, recorrido transversalmente por una suave cresta lateral (1); similar, con una cresta longitudinal que delimita una cara externa muy expuesta en la exonarina (2); escalonado, presencia de una cresta transversal lateral (3). Comentario. Este carácter ha sido redefinido y desdoblado. Los atributos considerados difieren de los de Arnold et al. (2007) quienes consideran las proyecciones anteriores y posteriores.

23. Septomaxilar, proceso anteromedial (A[06]): ausente (0); presente, bien desarrollado en sentido anteromedial (1); reducido a pinzamiento, medialmente desplazado, sobre la cresta transversal lateral (2). Comentario. Idem ([C23]).

24. Lacrimal (P2 [9], E[28], R, L2 [8], Mc[8]): presente, como hueso aislado o fusionado al prefrontal durante la ontogenia (0); ausente (1).

25. Yugal, proceso maxilar: largo (0); corto (1).

26. Yugal, cara externa: plana (0); levemente cóncava (1).

27. Yugal, relación con maxilar $(\mathrm{Co}[14])$ : principalmente dorsal $(0)$; posteriorterminal (1).

Comentario. Este carácter es complementario con [C15].

28. Yugal, proceso zigomático: ausente (0); levemente desarrollado (1); marcadamente desarrollado (2).

29. Yugal, altura del proceso maxilar: normal (0); muy alto ("profundo") (1). Comentario. Este proceso se encuentra muy desarrollado en Dracaena y Paradracaena.

30. Nasal, forma: alargado (0); subcircular, no alargado (1). 
31. Contacto nasal-prefrontal (E[4], L2[15]): existe contacto (el maxilar queda separado del frontal) (0); no existe contacto (el maxilar y el frontal están en contacto) (1).

32. Prefrontal , forma (L2[17]): lateralmente plano (0); con una depresión posterolateralmente sobre la órbita, delimitada por dos crestas, dorsal (mayor y sobre el proceso supraorbital) y ventral (generalmente menor y sobre el proceso lacrimal) (1). Similar al anterior pero sin proceso lacrimal (2). Comentario. Este carácter ha sido redefinido. Originalmente fue planteado para rugosidades presentes en el borde orbital del frontal en Iguania (Gauthier, 1984). Aquí se hace referencia a estructuras más constantes.

33. Frontal, participación en la órbita (E[5], L2[22]): participa de la órbita (0); está excluido de la órbita por contacto entre el prefrontal y el postfrontal/postorbital (1).

34. Frontal, contacto ventral entre procesos ventrales (cristae cranii) ( $\mathrm{P} 2[1]$, M[6], Mc, L2[54]): presente, frontal tubular (0); ausente (1).

35. Frontal, procesos ventrales (cristae cranii), participación en fenestra órbitonasal (M[5], NQ[10]): desarrollados, mucha participación (0); poco desarrollados, poca o nula participación (1).

36. Frontal, contacto con palatinos $(\mathrm{Co}[18])$ : presente (0); ausente (1).

37. Sutura fronto-parietal, forma: recta $(0)$; con una ligera " $V$ " en la línea media, con el ápice posteriormente dirigido (1).

38. Sutura fronto-parietal, línea de sutura (Mc, P2[18], L2[21]): línea recta, lisa o variablemente irregular (0); presenta dos proyecciones convexas del frontal (procesos posteriores) sobre el parietal (1).

Comentario. Este carácter ha sido redefinido.

39. Postfrontal (P2[6], L2[23], M[7]): hueso grande, extendiéndose más allá de la órbita (0); hueso pequeño, no extendiéndose más allá de la órbita (1). Comentario. Se sigue a Lee (1998) aunque removiendo un tercer estado (ausente). En el caso de fusión con el postorbital se consideró el tamaño de la parte dorsal correspondiente al postfrontal.

40. Postfrontal, grado de fusión con postorbital ( $\mathrm{P}[1]$, $\mathrm{P} 2$ [5], E[14], L2[23], L2[24], DO[9], SE[1], NC[9], M[7], N[9]): nulo, no hay fusión (0); "parcial", los huesos se distinguen (1); total, los huesos no se distinguen (2). 
Comentario. Este carácter es complementario al grado de fusión del postorbital (E[16], P2[27]), razón por la cual este último no fue considerado. El carácter ha sido redefinido para considerar los casos de fusión "parcial" (1).

41. Postfrontal, extremo dorsomedial (E[13], M[8], L2[25]): muy desarrollado anteroposteriormente, principalmente a lo largo del parietal (0); bifurcado simétrico (1); proceso anteromedial más desarrollado que el posteromedial (2); proceso posteromedial muy reducido (3); bifurcado, el posteromedial no se observa en vista dorsal (4).

Comentario. El carácter ha sido redefinido.

42. Postfrontal, proyección hacia el centro de la órbita (Fig. 90): ausente (0); leve (1); marcada (2).
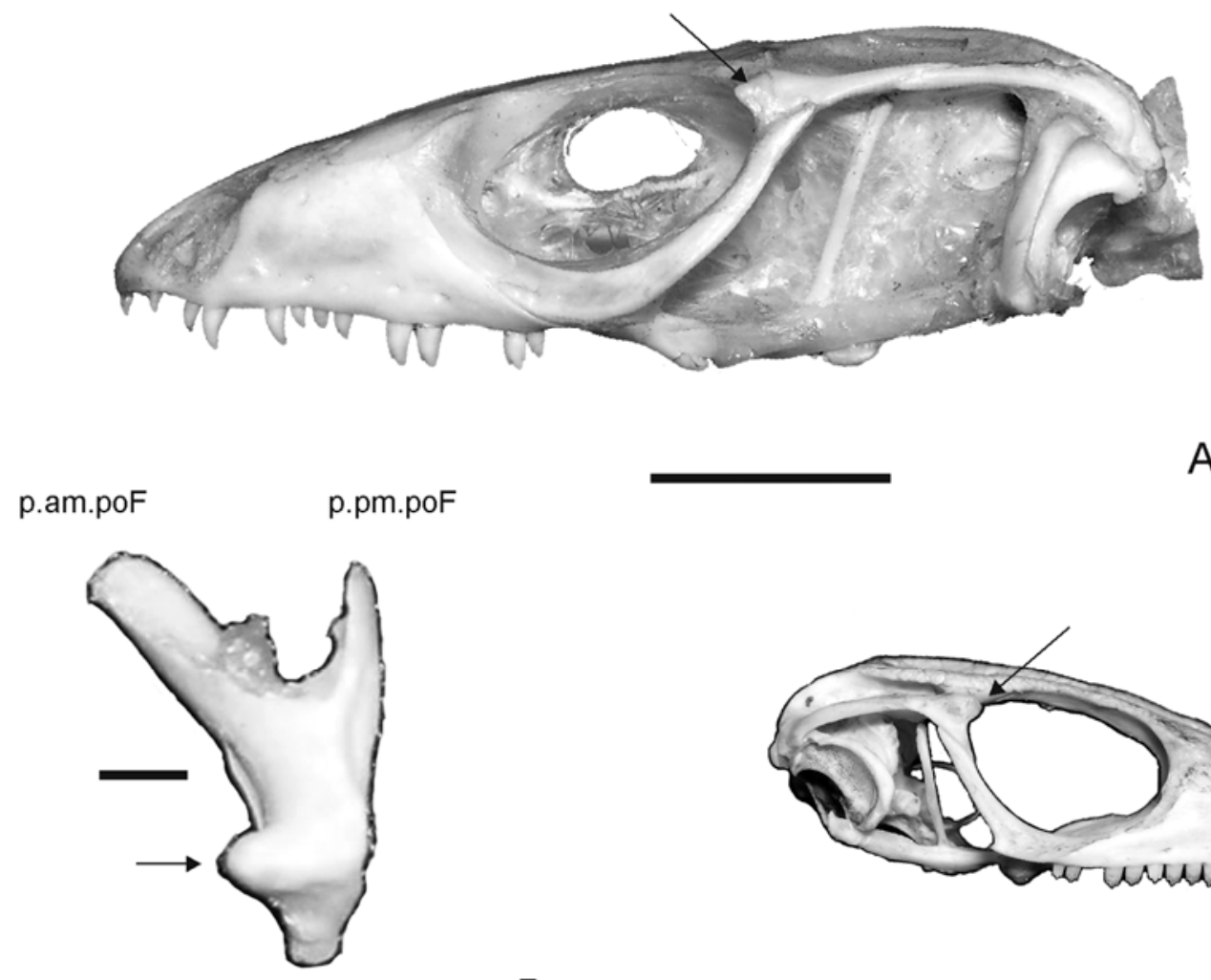

A

B

Figura 90. Postfrontales de Callopistes y Kentropyx. A, cráneo de C. maculatus (MNHN cl 4112) en vista lateral; B, detalle de postorbital izquierdo de C. maculatus (MNHN cl 4113) en vista lateral; C, cráneo de K. calcarata (MZUSP 81580). Flecha señala proyección anterior del postfrontal. Escala $=10 \mathrm{~mm}$ en A y C, $1 \mathrm{~mm}$ en B.

43. Contacto postfrontal-yugal ( $\mathrm{SE}[27])$ : no existe contacto ( 0$)$; no existe contacto por la intercalación de una delgada extensión anteroventral del 
postorbital (1); existe contacto (2); indeterminado, cuando hay fusión postfrontal-postorbital y los límites no están definidos se considera un estado diferente (3).

Comentario. Este carácter ha sido redefinido, ya que Sullivan y Estes (1997) al analizar únicamente a los Tupinambinae no consideran la fusión postfrontal-postorbital.

44. Tabla parietal (M[15]): amplia, fenestra supratemporal pequeña (0); reducida, fenestra supratemporal relativamente más grande (1). Comentario. Se modificó ligeramente el planteo de Müller (2001) al no considerar los procesos transversos.

45. Foramen parietal (E[25], E[26], L2[33], L2[24], DO[16], NC[16], N[16]): ausente (0); presente, sobre la línea de sutura frontal-parietal (1); presente, desplazado de la sutura frontal-parietal (2).

Comentario. El carácter se redefinió, considerando en simultáneo la presencia/ausencia y la posición de foramen parietal; características que otros autores consideraron por separados. En algunos pocos ejemplares (UNNE 4464, UMMZ 149574, UNRC 7523) se observó un foramen muy pequeño, el cual no fue considerado como foramen pineal.

46. Parietal, origen de la musculatura adductora (L2 [35]) (Fig. 91): parietal ancho con la musculatura adductora restringida a la superficie ventrolateral (0); parietal ancho con la musculatura adductora extendiéndose marginalmente sobre el parietal; en vista dorsal, el borde interno de la fenestra supratemporal es simétricamente cóncavo, aunque puede tener diferente grados de concavidad (1) (Fig. 91 A); similar, pero la parte posterior de la concavidad es más profunda, y existe una cresta horizontal que forma un reducido techo sobre el borde medial de la fenestra supratemporal (2) (Fig. 91 B); la musculatura adductora se extiende mucho sobre el parietal, pero no se yuxtaponen en la línea media, y la cresta sagital del parietal es ancha (3) (Fig. 91 C, D); la musculatura adductora se extiende mucho uniéndose medialmente y reduciendo la meseta parietal a un triángulo de bordes marcados y rectos que se continúa en una angosta cresta sagital posterior (4) (Fig. $91 \mathrm{E}$ ); similar pero la meseta parietal triangular es de bordes cóncavos y suaves (5) (Fig. $91 \mathrm{~F})$.

Comentario: Este carácter ha sido redefinido. 


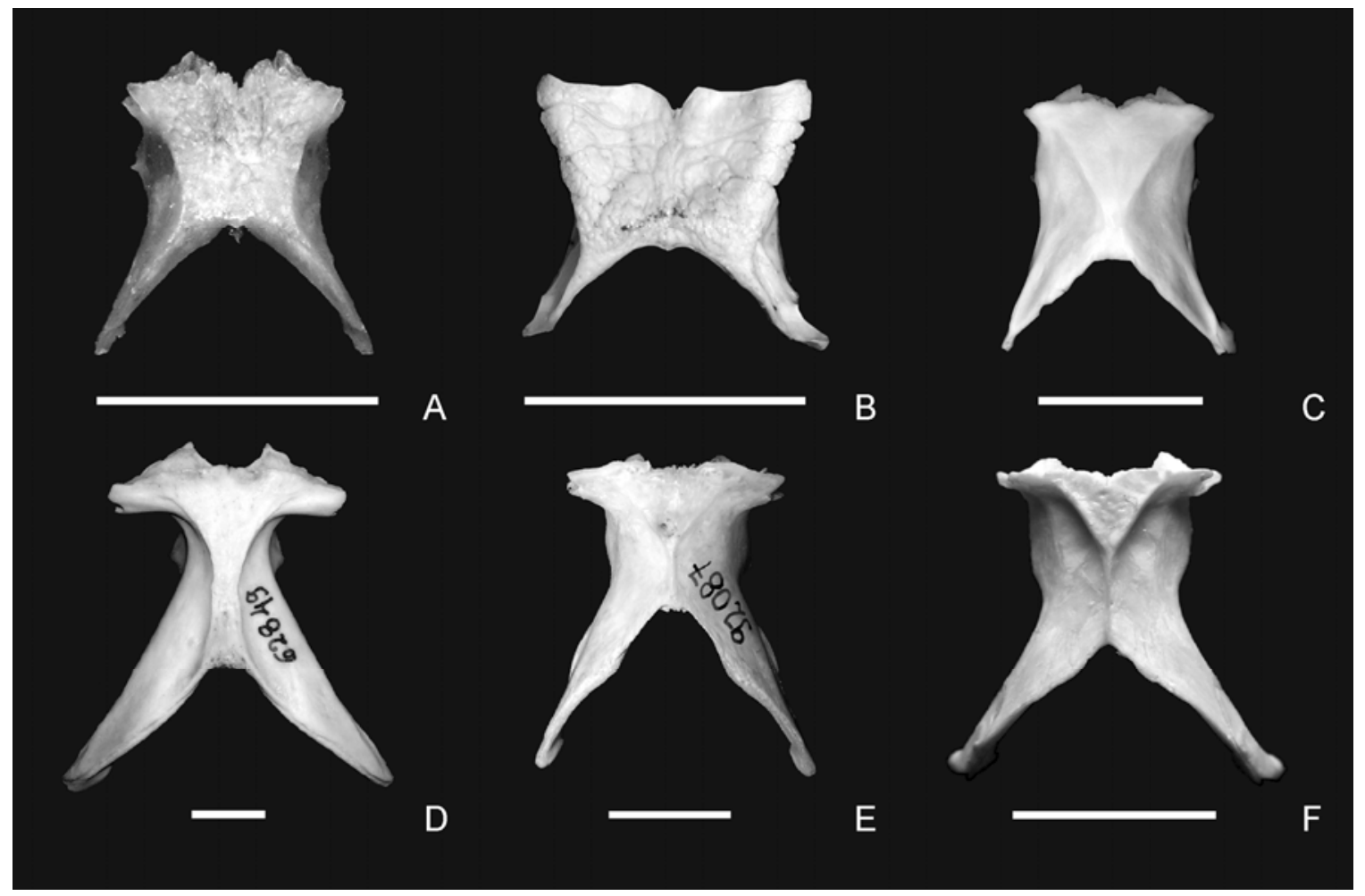

Figura 91. Parietales de diferentes Teiidae en vista dorsal. A, "Ameiva” ameiva (UNMdP-0 27); B, Kentropyx calcarata (MZUSP 81580); C, Crocodilurus amazonicus (MZUSP); D, Dracaena guianensis (MZUSP 62849); E, Tupinambis teguixin (MZUSP 92087); F, Callopistes maculatus (MNNH cl 4113). Escala $=10 \mathrm{~mm}$.

47. Parietal, origen de la musculatura adductora (DO[10], SE[24], NC[10], $\mathrm{N}[10])$ : ocupa casi la totalidad de la longitud de la superficie dorsolateral del parietal (0); la musculatura es ventral (1).

Comentario. Este carácter en las filogenias que incluyen a los Borioteiioidea permite diferenciar a éstos de los Teiioidea (e.g. Nydam et al., 2007). Si bien parece similar al [C46] y [C47], este carácter se refiere al desarrollo anteroposterior de la musculatura sobre el lateral del parietal (Fig. 8 de Denton y O’Neill (1995)), mientras que el carácter ([C46]) se refiere al avance medial de la musculatura sobre el parietal. Se removió el tercer estado, el cual es sinapomórfico de los Borioteiioidea, ya que no se observó en ningún ejemplar disponible.

48. Parietal, estante del occipucio: marcado, no se aprecia claramente la parte que contribuye al occipucio en vista dorsal (0); estante suave o poco marcado, se observa en vista dorsal la parte que contribuye al occipucio (1). Comentario. Entre los procesos supratemporales se desarrolla una escotadura posterior, donde la pared posterior contribuye al occipucio. 
49. Forma del techo fronto-parietal, en vista dorsal (P[20], Norell (1989), $\mathrm{SE}[17])$ : convexo (0); plano (1); de apariencia cóncava por engrosamientos periféricos del parietal (2).

Comentario. Este carácter se redefinió ya que la definición de Presch (1974a) se presta a confusión.

50. Parietal, procesos descendentes (E[23], DO[15]; NC[15], L2[56], M[14], $\mathrm{N}[15])$ : ausentes (0); poco desarrollados, lateralmente no son más que una loma dirigida ventralmente (1); desarrollados, de forma triangularsubtriangular, y dirigidos ventralmente (2). Comentario. Este carácter ha sido redefinido.

51. Parietal, procesos anteromediales: ausentes (0); presentes (1).

52. Posición de la fosa parietal ( $\mathrm{DO}[17], \mathrm{NC}[17], \mathrm{N}[17])$ : terminal, con margen posterior abierto (0), similar, pero desplazada algo anteriormente (1). Comentario. Se ha eliminado un tercer estado documentado para los Borioteiioidea y no observado en el material de referencia disponible.

53. Huesos temporales (DO[7], NC[7], N[7]): robustos, con importante contacto con el parietal (0); reducidos, con contacto limitado sobre la parte anterior del parietal (1).

Comentario. Si bien no ha sido redefinido, se hace notar que la característica más nítida a observar en el material osteológico es el contacto con el parietal, dado el importante rango de tamaño representado en el material de referencia. Esta diferencia en tamaño dificulta la comparación cualitativa del grado de "robustez".

54. Fenestra supratemporal, borde anteromedial (DO[6], NC[6], N[6]): formado por el postfrontal y/o el postorbital (0); formado por extensiones anterolaterales del parietal (1); ausente (2).

Comentario. Se ha adicionado un tercer estado (ausencia). Este último estado, si bien está presente en algunos taxones del grupo externo, es claro que es una carácter derivado entre los escamosos.

55. Fenestra supratemporal $(P 2[2,6]), L 2[42,43])$ : abierta (0); parcialmente cubierta anteriormente por expansión del postfrontal (1); parcialmente cubierta anteriormente por expansión del postorbital (2); parcialmente cubierta por el postfrontal-postorbital (3); totalmente cubierta por un techo (4).

Comentario. Este carácter ha sido redefinido. Se unifica el desarrollo/restricción de la fenestra con el elemento óseo (postfrontal/postorbital) responsable de la restricción cuando ésta está presente. 
56. Escamoso, proceso dorsal (Mc[6], E[34], P[4], SE[3], P2[4], L[41]): ausente (0); presente, ligeramente desarrollado desde una suave lomada dorsal a un proceso pequeño (1); presente, marcado, con diferente grado de desarrollo (2).

Comentario. Este carácter ha sido redefinido.

57. Escamoso, proceso anterior ( $\mathrm{SE}[23])$ : cilíndrico (0); comprimido dorsoventralmente (1).

58. Contacto yugal-escamoso sobre el arco supratemporal (E[18], $\mathrm{SE}[21]$, L2[39]): presente (0); ausente, pero extremos de los huesos muy cercanos entre sí (1); ausente, extremos de los huesos claramente distanciados (2). Comentario. Este carácter ha sido redefinido incorporando un tercer estado, permitiendo la cuantificación de la separación de ambos huesos sobre el arco supratemporal. Sullivan y Estes (1997) consideran que en Paradracaena no existe este contacto. Sin embargo, y a pesar de no haber revisado el material original, de la Fig. 7.2 de Sullivan y Estes (1997) es claro que el escamoso se encuentra desplazado, y no es posible afirmar que no existe contacto yugal-escamoso. No obstante este carácter para P. colombiana fue considerado como ausente como lo describen sus autores.

59. Cuadrado (SE[25]): robusto (0); muy robusto (1).

60. Cuadrado, expansión anteroposterior $(\mathrm{P}[5])$ : ausente $(0)$; presente, desarrollo horizontal (1); presente, desarrollo oblicuo (2). Comentario. Este carácter ha sido redefinido, incorporando la direccionalidad de la expansión.

61. Cuadrado, expansión medial (DO[12], NC[12], N[12]): ausente (0); presente (1).

Comentario: Se refiere a la expansión (en vista posterior) del cuadrado entre la cresta posterior y el borde medial. Hay expansión cuando el desarrollo en ambos lados es similar.

62. Cuadrado, orientación o curvatura de cóndilo cefálico: cóndilo corto, dirigido posteriormente (0); algo curvado ventralmente (1); muy curvo, dirigido ventralmente (2).

63. Cuadrado, cresta timpánica (DO): poco desarrollada, grácil, con forma de "C" abierta (0); desarrollada, robusta, con forma de "C" abierta (1); desarrollada, robusta, muy curvada, con mayor desarrollo de su parte anterodorsal (2); robusta, recta y vertical (3).

64. Cuadrado, ala pterigoidea ("pterigoid lappet") ( $\mathrm{P}[2], \mathrm{SE}[2] \mathrm{DO}[11]$, L2[52], NC[11], N[11]): ausente (0); presente (1). 
65. Cuadrado, bulbo (SE[31],): ausente (0); presente (1); muy desarrollada (2). Comentario: Se adiciona un estado (ausente) a la definición original de Sullivan y Estes (1997).

66. Fenestra orbitonasal (= fenestra nasoetmoidal) (L2[53]): ancha, no restringida por los prefrontales ni los frontales $(0)$; estrecha, restringida por los frontales y/o los prefrontales (1).

67. Procesos basipterigoideos: largos, gráciles, de extremos distales simétricos (0); robustos, extremos distales asimétricos, redondeados anteriormente y aguzados posteriormente (1).

68. Procesos basipterigoideos, superficie lateral de la carilla de articulación (Bell et al., 2003): plana (0); cóncava (1).

69. Tubérculos esfenooccipitales: poco desarrollados (0); desarrollados (1). Comentario. Se ha mencionado variación ontogenética en los tubérculos esfenoocipitales (Bell et al., 2003); por esta razón, sólo se consideró el estado de ejemplares adultos.

70. Foramen posterior del canal de Vidian: orientados ventralmente, quedando expuestos en vista ventral (0); orientados más lateralmente, no expuestos en vista ventral (1).

71. Proótico, escotadura del trigémino: abierta, proceso inferior de menor desarrollo que el proceso alar (0); similar al anterior, pero proceso inferior similar al proceso alar (1); escotadura cerrada por desarrollo dorsal del extremo anterior del proceso inferior (2).

72. Supraoccipital, relación con el parietal (L2[80]): importante, fenestra postemporal pequeña (0); leve, fenestra postemporal grande (1).

73. Supraoccipital: cresta supraoccipital y proceso ascendente poco marcados (0); similar, pero con procesos ascendentes marcados (1); sin cresta, en su lugar hay una surco marcado del que se continúa el proceso ascendente (2). Comentario. El carácter ha sido redefinido.

74. Fenestra vomeronasalis (Mc[10], E[42], L2[89]): cerrada parcialmente por el maxilar y vómer, pero continuo con fenestra endonarina (0); cerrada totalmente por el maxilar, vómer y a veces el septomaxilar, no confluye con la fenestra endonarina (1).

75. Contacto vómer-premaxilar ( $\mathrm{DO}[4], \mathrm{NC}[4], \mathrm{N}[4])$ : presente (0); ausente, separados por una extensión medial de los maxilares (1). 
76. Paladar secundario ( $\mathrm{P} 2[10]$, L2 [95]): ausente (0); presente, el maxilar participa de la fenestra endonarina (1); presente, fenestra endonarina delimitada por el palatino, sin participación del maxilar (2). Comentario. Este carácter ha sido redefinido.

77. Contribución del ectopterigoides a la fenestra suborbital (contacto labial ectopterigoides-palatino) (Mc[9], $\mathrm{P} 2[13], \mathrm{E}$ [45], DO[5], L2 [102], $\mathrm{NC}$ [5], $\mathrm{N}[5]$ ): contribuye mucho, excluyendo al maxilar de dicha fenestra, contacto lateral entre palatino y ectopterigoides ancho (0); similar, pero el contacto palatino-pterigoides es menor (1); contribuyen poco, el maxilar delimita externamente a la fenestra suborbital (2).

Comentario. Este carácter ha sido modificado. Cuando existe contacto se considera adicionalmente el dasarrollo transversal (i.e. ancho) del contacto palatino, característica inversamente proporcional al desarrollo de la fenestra suborbital.

78. Pterigoides, depresión ventral (L2[106]): presente (0); ausente (1). Comentario: se trata de una débil depresión ventral, somera, triangular, de lado externo, que se extiende desde la fenestra suborbital hasta la articulación del basicráneo.

79. Pterigoides, proceso transverso: con fuerte cresta, transversal al eje longitudinal, proceso palatino orientado verticalmente $(0)$, sin estas características (1); con cresta longitudinal y proceso palatino normal (2).

80. Pterigoides, fosa pterigoidea (Bell et al., 2003): presente (0); ausente (1).

81. Pterigoides, expansión medial del proceso cuadrado ( $\mathrm{P}[2], \mathrm{SE}[2])$ : marcada (0); ligera (1); ausente (2).

82. Pterigoides, depresión anterior (Fig. 92): ausente (0); presente (1). Comentario: se trata de una depresión marcada, que conforma un estante y se ubica en el borde posterior de la fenestra suborbital.

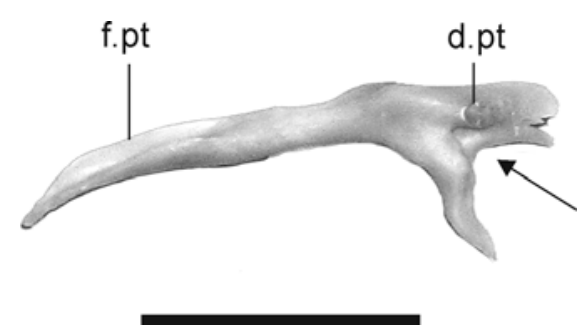

Figura 92. Pterigoides de Callopistes maculatus (MNHN cl 4113). Vista ventral. Abreviaturas: d.pt, dientes pterigoideos; f.pf, fosa pterigoidea. Flecha destaca depresión anterior sobre el pterigoides. Escala $10=\mathrm{mm}$. 


\section{HEMIMANDÍBULA}

83. Hemimandíbula, relación alto/largo: $<0,25(0) ;>0,25$ (1).

Comentario: La altura máxima se midió al proceso dorsal del coronoides.

84. Dentario, forámenes mentales (L2[111): entre cuatro y seis (0); más de seis (1).

85. Dentario, borde dorsal, vista lateral (L2[112]): recto (0); cóncavo (1); marcadamente cóncavo (2).

Comentario. El estado "marcadamente cóncavo" se adicionó a los dos estados presentados por Lee (1998).

86. Dentario, proceso posterodorsal (E[60], DO[20], L2[113], NC[20], N[20]): cubierto por el proceso anterolateral del coronoides (0); cubriendo al proceso anterolateral del coronides (1).

87. Canal de Meckel (E[55], DO[22], L2[114], NC[22], N[22]) (Fig. 93, 94): cerrado (0); muy restringido, el borde ventral del dentario está medialmente expuesto, yuxtapuesto al estante subdental, el esplenial es excluido de la abertura anterior del canal de Meckel (1); restringido anteriormente (2); abierto (3).

Comentario. Este carácter ha sido redefinido. En su definición, Denton y O’Neill (1995; tomada por Nydam y Cifelli, 2002b; Nydam et al., 2007) hacen referencia a la exposición en vista medial del borde labial del dentario; esta característica no es considerada en este carácter sino que se presenta en el [C93]. Aquí, como Estes et al. (1988) y Lee (1998), se considera la forma general del canal de Meckel. 


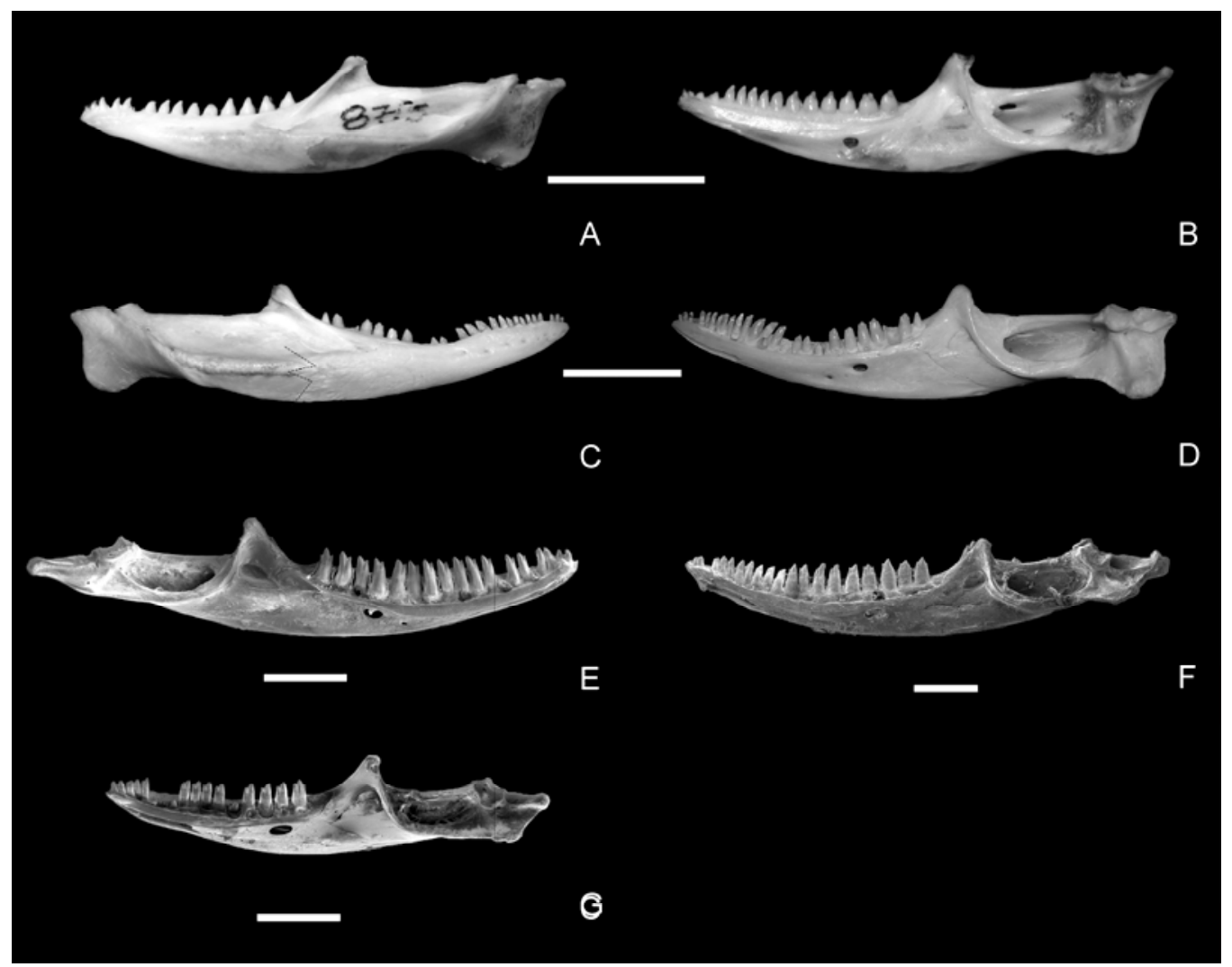

Figura 93. Hemimandíbulas de Teius y diferentes “cnemidoforinos”. A, B, Teius teyou (UNNE 8715), izquierda en vista labial (A) y derecha en vista lingual (B); C, D, “Ameiva” ameiva (UNMdP-O 769) derecha en vista labial (C) y lingual (D); E, Aspidoscelis sexlineatus (UMMZ 1494576) vista lingual; F, Kentropyx viridistriga (UNNE 1062); G, “Cnemidophorus" lacertoides (UNRC 4468). Escala $=10 \mathrm{~mm}$ en A-D, $2 \mathrm{~mm}$ en $\mathrm{E}-\mathrm{G}$. 

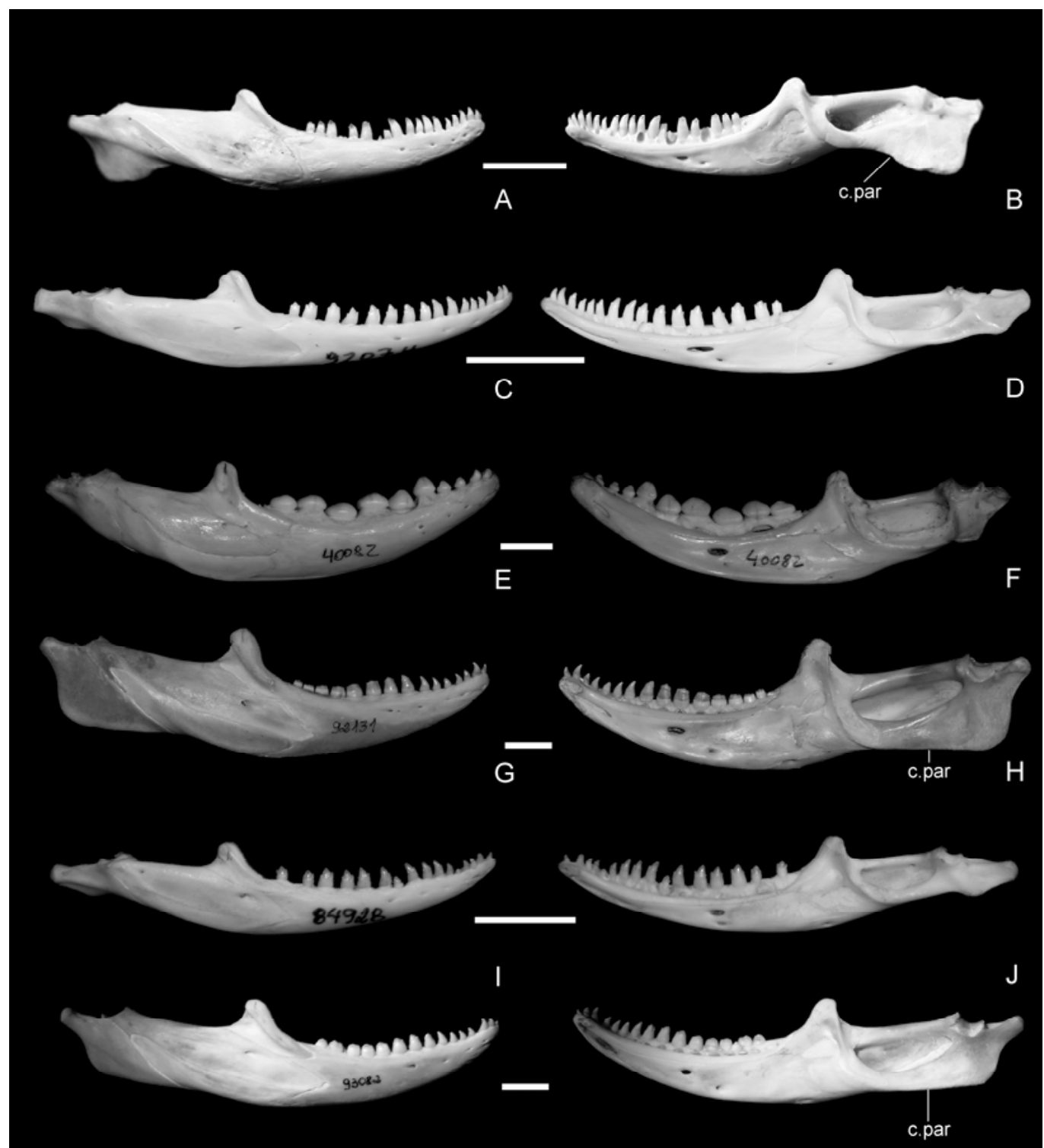

$\mathrm{K}$
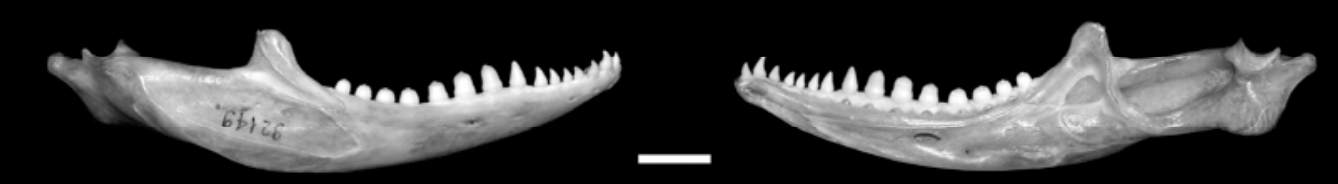

Figura 94. Hemimandíbulas de diferentes Tupinambinae. A, B, Callopistes bicuspidatus (MNHN cl 4113) en vista labial (A) y lingual (B); C, D, Crocodilurus amazonicus (MZUSP 92074) vista labial (C) y lingual (D); E, F, Dracaena guianensis (MZUSP 40082) en vista labial (E) y lingual (F); G, H, Tupinambis duseni (MZUSP 92131) en vista labial (G) y lingual (H); I, J, Tupinambis quadrilineatus (MZUSP 84928) en vista labial (I) y lingual (J); K, L, Tupinambis rufescens (MZUSP 93082) en vista labial (K) y lingual (L); M, N, Tupinambis teguixin (MZUSP 92149) en vista labial (M) y lingual (N). Abreviaturas: c.par, cresta prearticular. Escala $=10 \mathrm{~mm}$. 
88. Canal de Meckel, restricción anterior ( $\mathrm{DO}[22], \mathrm{NC}[22], \mathrm{N}[22])$ : restringida, por desarrollo del estante subdental, a un estrecho surco (0); más amplia, abierta, (auque se ve el borde ventral) (1); no aplicable (2). Comentario. El carácter está redefinido, destacando la restricción por el desarrollo del estante subdental, no por la curvatura medial del borde ventral del dentario [C93].

89. Canal de Meckel (EC[212]): termina en la sínfisis (0); se extiende anteriormente por debajo de la sínfisis (1).

Comentario. Evans y Chure (1998), en su análisis cladístico de los Squamata, describen un nuevo carácter relacionado a la forma de la sínfisis mandibular, en el cual hacen referencia a su relación con el canal de Meckel. Aquí el detalle es mayor, y el énfasis es puesto en la extensión del canal de Meckel.

90. Dentario, estante subdental (E[58], E[59], L2[117]): desarrollado (0); moderadamente desarrollado (1); ausente (2); no aplicable (3). Comentario. Este carácter ha sido redefinido. En los casos donde el dentario es tubular se consideró no aplicable.

91. Dentario, estante subdental desarrollo antero-posterior: de desarrollo dorsoventral ("profundidad") constante (0); desarrollo dorsoventral decreciente posteriormente (1); no aplicable (2).

92. Dentario, margen posterior en vista labial (E[63], L2[118]) (Fig. 93, 94): cuña que recibe exclusiva o casi exclusivamente al suprangular (0); cuña, de posición ventral, corta, que recibe al angular (1); cuña que recibe al suprangular y angular en forma variada (2); dos cuñas individuales para el suprangular y el angular, el borde se asemeja a una "W" girada $90^{\circ}$ (3). Comentario. Este carácter ha sido redefinido.

93. Canal de Meckel, abertura anterior, relación longitud abertura/longitud del dentario: pequeña, relación menor a $0,1(0)$; relación mayor a 0,1 (1). Comentario. El tamaño de la abertura anterior se estandarizó en relación a la longitud del dentario.

94. Canal de Meckel, abertura anterior, borde ventral: delimitado por curvatura medial el dentario (0); ventralmente libre (1). Comentario. Este carácter, si bien parece igual al [86] difiere, en que hace referencia sólo a la parte más anterior del canal de Meckel, la más cercana a la sínfisis. De esta forma se trata de evitar el problema suscitado por la definición de Denton y O'Neill (1995: [22]).

95. Esplenial, borde posterior: cuneiforme, horizontal, posteriormente dirigida (0); oblicuo, variable entre cóncavo a convexo (1); recto, vertical con cuña, 
anteriormente dirigida, a media altura, de borde irregular, no liso como el del resto (2).

96. Esplenial, extremo anterior (L2[122]): ventral al dentario (0); medial al dentario (1).

97. Esplenial, depresión medial ( $\mathrm{SE}[20])$ : ausente, esplenial plano (0); depresión somera desarrollada anteroposteriormente en la parte anterior, anteriormente a los forámenes (1); marcada y continua, el esplenial es cóncavo (2).

Comentario. El carácter ha sido ligeramente redefinido. Se reconocen tres estados, uno adicional a los reconocidos originalmente por Sullivan y Estes (1997).

98. Coronoides, proceso anterolateral, solapando al dentario ( $\mathrm{E}[68], \mathrm{DO}[21]$, $\mathrm{NC}[21], \mathrm{N}[21])$ : ausente, cubierto por el dentario (0); solapa levemente al dentario, no supera anteriormente más de dos posiciones dentarias (1); solapa extensamente al dentario, supera anteriormente más de dos posiciones dentarias (2).

Comentario. Este carácter es parcialmente complementario con el carácter [C85]. Sin embargo corresponde a otro elemento óseo y presenta un mayor nivel de discriminación.

99. Coronoides, relación del proceso anterolateral con las proyecciones anteriores de los huesos angular y suprangular (SE[19]) (Fig. 93, 94): el proceso anterolateral del coronoides está a la misma altura (aproximadamente) que las proyecciones anteriores de angular y/o suprangular (0); el proceso anterolateral del coronoides se encuentra marcadamente adelantado a las proyecciones del angular y suprangular (1); el proceso anterolateral está marcadamente posterior a las proyecciones del angular y suprangular (2).

Comentario. Este carácter ha sido redefinido. Se destaca su variabilidad (e.g. difiere en las dos especies de Dracaena), en particular el estado "0" (cero).

100. Coronoides, fenestra subcoronoidea (P[18], L2[129], SE[15]) (Fig. 93, 94): ausente, el articular (o prearticular) se expande dorsalmente obstruyéndola (0); ausente, por desarrollo ventral del coronoides (1); presente, el suprangular está expuesto por debajo del coronoides, ventralmente delimitado por el articular (2); presente, el esplenial participa levemente del borde anteroventral (3); presente, con el esplenial delimitando nítidamente el borde anterior (4). 
Comentario. Este carácter ha sido redefinido en función de los huesos que delimitan a dicha fenestra.

101. Contacto suprangular-esplenial: ausente (0); leve (1); marcado (2).

Comentario. Este carácter se relaciona al anterior; cuantifica, a grandes rasgos, el grado de contactos entre ambos huesos cuando existe fenestra subcoronoidea.

102.Suprangular, disposición (Hsiou, 2007): hueso principalmente vertical (0); hueso de disposición oblicua (1).

Comentario: contrariamente a Hsiou (2007), quien hace mayor referencia a la cresta adductora,

aquí se considera la orientación del angular.

103.Angular: hueso de desarrollo vertical a lo largo de toda su extensión (0); torsión anterior, quedando este extremo más horizontal (1); angular oblicuo (2); anteriormente vertical, posteriormente oblicuo (3).

Comentario. Este carácter complementa al cambio de orientación del suprangular [C101].

104. Articular, cresta articular (E[73], L2[134]) (Fig. 93, 94): ausente (0); presente, tenue o moderada (1); prominente (2) muy prominente (3). Comentario. Este carácter ha sido redefinido, ver Capítulo III.

105. Articular, cresta prearticular, vista lateral (Hsiou, 2007) (Fig. 93, 94): muy desarrollada, recta ventralmente, horizontal y no diferenciada del proceso angular (0); desarrollada, recta ventralmente, horizontal, diferenciada del proceso angular cuyo extremo distal permanece libre (1); desarrollada, cóncava o recta y oblicua (2); poco desarrollada, el proceso angular está claramente diferenciado (3); ausente, no desarrollada (4). Comentario. Este carácter ha sido codificado en forma diferente a las observaciones de Hsiou (2007).

106. Articular, proceso angular (= "proceso digitiforme" = falange retroarticular DO) (E[73], E[80], DO[25], L2[134], NC[25], N[25]): ausente (0); escasamente desarrollado (1); marcadamente desarrollado (2). Comentario. Este carácter ha sido redefinido.

107. Articular, proceso angular, orientación sobre la cresta articular ( $E[73]$, E[80], L2[134]) (vista lingual): vertical (0); oblicua (1); oblicua, corta (2); ausente (3).

Comentario. Este carácter ha sido redefinido. Además, se observa variación ontogenética en T. rufescens, razón por la cual sólo se evaluó ejemplares grandes/adultos. 
108. Fosa adductora (E[81], L2[138]): transversalmente angosta, no se expande medialmente (0); amplia, expandida medialmente (1).

109.Proceso retroarticular, orientación (E[75], L2[141]): se extiende posteriormente (0); se extiende posteromedialmente (1).

110.Proceso retroarticular, superficie dorsal (E[74], DO[24], L2[142], $\mathrm{NC}[24], \mathrm{N}[24])$ : es un filo, sin mayor desarrollo medial (0); presenta una depresión anteroposterior, por el desarrollo de la cresta o borde medial (1); similar, pero suavemente cóncava y somera (2).

111.Proceso retroarticular, cresta timpánica: labial sobre el proceso retroarticular, orientada anteroposteriormente $(0)$; orientada transversalmente, dejando un pequeño receso posterolabial (1).

112. Proceso retroarticular, borde dorsomedial (E[76], L2[143]): simple, sin tubérculo o falange (0); con tubérculo o falange discreta (1).

113.Proceso retroarticular, borde medial: ausente o muy poco desarrollado (0); recto, poco nítido, convexo a lo largo de todo su desarrollo (1); cresta fina, nítida y recta (2); cresta robusta, poco nítido (3); muy convexo, medialmente da lugar a una cresta ventralmente dirigida (4); vertical, recto y delgado (5).

Comentario. Tiene en cuenta, en parte, a los caracteres E[78] y L2[144].

114. Capa superficial del adductor externo avanza sobre el angular (Rieppel, 1980; Hsiou, 2007): no (0); si, cresta adductora sobre el angular (1); marcada cresta adductora sobre el angular (2).

\section{DENTICIÓN}

115.Dentición marginal (DO[18], $\mathrm{NC}[18], \mathrm{N}[18])$ : homodonte (0); heterodonte (1).

116. Dentición del premaxilar (DO[28], NC[28], N[28]): homodonte (0); heterodonte (1).

117.Dentición premaxilar, tipo morfológico dominante ( $\mathrm{P}[7], \mathrm{DO}[28], \mathrm{SE}[5]$, $\mathrm{NC}[28], \mathrm{TC}, \mathrm{N}[28])$ : dientes altos, cilíndricos, unicuspidados (0); dientes, cónicos unicuspidados, los más externos levemente comprimidos labiolingualmente y posteriormente dirigidos (1); leve heterodoncia con dientes débilmente bicuspidados y tricuspidados (2); dientes marcadamente 
tricuspidados; cúspides romas, labiolingualmnete comprimidas y desarrollo similar (3); distalmente comprimidos labiolingualmente de contorno romo; muy cóncavos lingualmente (4).

Comentario. Carácter redefinido.

118.Dentición maxilar, número máximo de dientes (L2[157]): de 10 a 14 dientes (0); entre 15 y 20 (1); más de 20 dientes (2).

119.Dentición dentario, número máximo de dientes (L2[153]): de 10 a 14 dientes (0); entre 15 y 20 (1); entre 21 y 25 (2); más de 25 dientes (3).

120.Implantación de dentición marginal (Presch, 1974b, E[84], DO[26], P2[146], NC[26], N[26] y ver Zaher y Rieppel, 1999; Cladwell et al., 2003; Budney et al., 2006): pleurodonte, los dientes se encuentran fijados a la pared labial, el borde ventral está expuesto, hay poco hueso alveolar (esbozos de septos interdentales) y poco o nada de cemento basal (0); subpleurodonte, poca depositación de cemento, los septos interdentales se observan claramente (1); subpleurodonte, importante depositación de cemento, los septos interdentales están disimulados (2); subpleurodonte con mucho depósito de cemento que cubre completamente los septos interdentales (3). Comentario. Carácter redefinido según criterios expuestos en el Capítulo III.

121. Tipo de expansión de la dentición posterior ( $\mathrm{DO}[19], \mathrm{NC}[19], \mathrm{N}[19])$ : ausente (0); transversal, labiolingual (1); longitudinal, mesodistal, sección oval (2); longitudinal y transversal, sección circular o cuadrangular (3). Comentario. Este carácter ha sido redefinido.

122. Proporción relativa de dientes unicuspidados anteriores en el maxilar $(\mathrm{P}[17], \mathrm{DO}[29], \mathrm{NC}[29], \mathrm{N}[29])$ : ningún unicuspidado (0); hasta 1/4 (1); entre $1 / 4$ y $1 / 2$ del total (2); más de la mitad (3); todos unicuspidados (4). Comentario. Se redefine el planteo de DO, NC y N, se estandariza el número de dientes unicuspidados anteriores en relación al total de dientes.

123.Proporción relativa de dientes unicuspidados anteriores en el dentario $(\mathrm{P}[17], \mathrm{DO}[29], \mathrm{NC}[29], \mathrm{N}[29])$ : todos unicuspidados (0); hasta 1/4 (1); entre $1 / 4$ y $1 / 2$ del total (2); más de la mitad (3). Comentario. Idem [C121].

124.Dientes longitudinalmente estriados ( $\mathrm{DO}[30], \mathrm{NC}[30], \mathrm{N}[30])$ : ausentes, esmalte liso (0); estrías leves (1); estrías marcadas (2); pocas estrías muy marcadas (crestas) (3). 
Comentario. Este carácter ha sido redefinido.

125.Dientes de reemplazo (E[85], L2[151]): Los dientes de reemplazo se encuentran en amplios huecos de reabsorción sobre las bases de los dientes (0); los dientes de reemplazo se encuentran en huecos de reabsorción moderados delimitados por cemento (i.e. "alvéolos" de reemplazo) (1). Comentario. Este carácter ha sido redefinido según los criterios expuestos en el Capítulo III.

126.Dientes pterigoideos ( $\mathrm{P}[6], \mathrm{E}[83], \mathrm{SE}[4]$, L2 [161]): ninguno (0); menos de tres (1); 3 o más (2).

Comentario. Se ha redefinido el carácter, cuantificando el número de dientes pterigoideos presentes.

127.Dientes molariformes (SE[14]): ausentes (0); romos y cuspidados, de sección variable entre oval y circular (1); muy desarrollados, formando placas (2).

Comentario. Este carácter se ha redefinido.

128. Número total de dientes marginales: hasta 60 dientes (0); entre 60-80 (1); más de 80 dientes (2).

\section{APARATO HIOIDEO}

129. Proceso entogloso, relación al basihial (P2[7]): unido (0); separado (1).

130.Segundo ceratobranquial $(\mathrm{P}[16], \mathrm{P} 2[8], \mathrm{E}[91], \mathrm{SE}[13], \mathrm{L} 2[226])$ : presente (0); ausente (1).

\section{ESQUELETO POSTCRANEAL}

131.Superficie medial de la escápula $(K)$ : levemente escavada, con un leve adelgazamiento óseo en sentido anterodorsal (0); muy excavada, con una cresta posterior marcada y roma (1).

132. Fenestra escapular ( $\mathrm{P}[11], \mathrm{E}[111], \mathrm{SE}[9], \mathrm{L} 2[191])$ : presente, marcada (0); presente, un simple emarginación (1); ausente (2).

Comentario. El carácter ha sido redefinido, al incluir un tercer estado que considera la emarginación, no reconocido por otros autores.

133. Clavícula, extremo ventral ( $\mathrm{P}[8], \mathrm{P}[9], \mathrm{P} 2[14]$, $\mathrm{SE}[6], \mathrm{SE}[7], \mathrm{K}, \mathrm{TC}$, L2[196]): perforado (0); no perforado (1).

Comentario. Se redefinieron los caracteres originalmente propuestos por Presch (1974a). Este carácter sólo considera la presencia/ausencia de una perforación del extremo ventral. 
134. Clavícula, extremo ventral ( $\mathrm{P}[8], \mathrm{P}[9], \mathrm{P} 2[14]$, SE[6], SE[7], K, L2[196]): no expandido (0); expandido (1); con forma de gancho (2). Comentario. Idem [C132], considerando sólo la forma del extremo ventral.

135. Contacto entre clavículas $(\mathrm{K})$ : ventral al proceso interclavicular de la interclavícula (0); dorsal al proceso interclavicular de la interclavícula (1).

136.Interclavícula, procesos laterales (K, E[119], L2[198]): ausente (0); presente (1). Comentario. Krause (1990) hace una diferenciación más fina, tomando en cuenta el desarrollo y la orientación de los procesos laterales; sin embargo, no siempre se pudo confirmar lo planteado por esta autora. Por lo tanto, el carácter quedó reducido a dos estados.

137. Costillas inscripcionales postxifiesternales (P2[12], E[110], L2[203]): ausente (0); presente (1).

138. Mesoesternón (K): par (0); impar (1); impar, con división posterior (2).

139.Ilion, proceso preacetabular (L2[208]): ausente (0); presente (1).

140. Isquion, contorno ventral: convexo (0); recto, horizontal (1).

141. Isquion, tubérculo isquiático: moderado (0); muy marcado (1).

142.Pubis, proceso prepúbico (K, E[124], L2[210]): ausente (0); presente (1). Comentario. El carácter ha sido modificado.

143.Pubis, proceso prepúbico, base: desarrollada (0); reducida (1).

144.Epipubis (cartílago calcificado) (K): localizado frente a la sínfisis pubiana (0); intercalado entre ambas ramas púbicas (1).

145. Hipoisquion, extremo distal $(\mathrm{K})$ : trunco $(0)$; redondeado (1); en forma de ganchos laterales (2).

146. Foramen hipoisquion $(\mathrm{K})$ : ausente $(0)$; presente (1).

147. Longitud relativa entre metacarpales $(\mathrm{K})$ : III $>$ II $>$ IV $>$ I $>$ V (0); III $>$ II

$$
=\mathrm{IV}>\mathrm{I}>\mathrm{V}(1) ; \mathrm{III}>\mathrm{IV}>\mathrm{II}>\mathrm{I}>\mathrm{V}(2) ; \mathrm{III}>\mathrm{IV}>\mathrm{II}>\mathrm{I}=\mathrm{V} \text { (3). }
$$

148. Quinto dedo del pie (K, $\mathrm{P}[21], \mathrm{SE}[18])$ : dedo desarrollado (0); dedo algo reducido, grácil (1); ausente (2).

Comentario. El carácter ha sido modificado para abarcar la variación notada por Krause (1990).

149. Cuello condilar (E[94], L2[164]): ausente (0); presente, leve (1); presente, marcado (2). 
Comentario. Los estados reconocidos son los presentados en Lee (1998) pero su distribución entre los ejemplares (y por ende su codificación) difiere con este autor. La diferencia responde a las escalas taxonómicas consideradas.

150.Zigósfeno/zigantro (L2[169], E[96]): presente (0); ausente (1).

151. Número de vértebras presacras (VK, P[14], P2[11], SE[12], L2[172]): 25

(0); 26 (1); más de 26 (2).

Comentario. Algunos autores restringen este carácter a las vértebras dorsales ya que el número de vértebras cervicales (8) y la lumbar (1) son constante en los Teiidae, así se observan 16 y 17 vértebras dorsales respectivamente.

152.Hipapófisis de la tercer vértebra cervical (C3) (VK): vertical, con diferentes grados de expansión distal (0); anteriormente orientada (1).

153. Hipapófisis de la quinta vértebra cervical (C5) (VK): ausente (0); vertical (1); anteriormente orientada (2); distalmente expandida anteroposteriormente (3).

\section{Hipapófisis (sin contemplar a los del atlas y axis) (E[98], L2[177]):} suturado al centro subsiguiente (0); fusionado al centro subsiguiente (1). Comentario. Se consideraron sólo dos de los tres estados reconocidos por Estes et al. (1988) y Lee (1998).

155. Cresta sagital de las vértebras dorsales $(\mathrm{D})$ : ausente, centro vertebral plano (0); cresta débil, centro suavemente convexo (1); cresta marcada, muy desarrollada (2).

156. Forámenes subcentrales en vértebras dorsales (D): ausente (0); presente, grandes, en todas las vértebras (2).

Comentario. Se hace referencia a forámenes subcentrales propiamente dichos, no se tiene en cuenta los pequeños forámenes que aparecen en forma irregular en una posición similar y que han sido registrados en diferentes especies (e.g. T. merianae, T. rufescens, $C$. amazonicus) (i.e. forámenes ventrales) por no tener suficientes elementos para sostener su homología.

157.Zigósfeno, contorno del borde anterior en vista dorsal (Fig. 95): zigósfeno escotado, de contorno cóncavo (0); zigósfeno escotado, de contorno recto (1); ausente (2). 


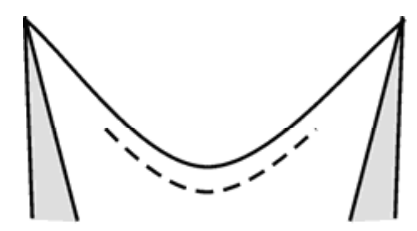

A
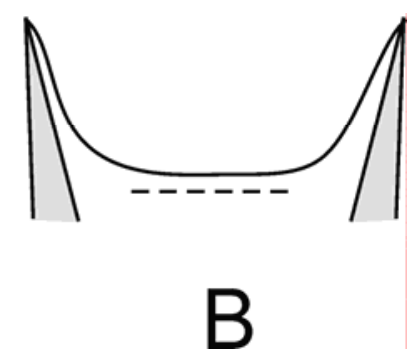

Figura 95. Esquema de carácter 157, contorno del borde anterior del zigósfeno. A, estado cero (0); B, estado uno (1). Línea punteada destaca al carácter.

158. Contorno del canal neural de vértebra dorsal (vista anterior): grande, oval (0); grande, horizontalmente oval con una importante evaginación ventral al zigósfeno (1); grande y triangular (2); moderado, triangularsubtriangular (3). 


\section{DESCRIPCIÓN DE LA CORRIDA.}

La matriz resultante fue analizada mediante una Búsqueda Tradicional disponible en programa TNT (Goloboff et al., 2008). La búsqueda partió de un árbol de Wagner que fue analizado mediante el algoritmo TBR (Tree Bisection Reconnection) conservando 10 árboles por réplica. Los caracteres fueron considerados no aditivos/no ordenados. Se obtuvieron 12 árboles igualmente parsimoniosos, a partir de los cuales se realizó una segunda Búsqueda Tradicional bajo los mismos parámetros. Finalmente se obtuvieron 12 árboles más parsimoniosos $(\mathrm{L}=536$ pasos; $\mathrm{IC}=0,517 ; \mathrm{IR}=0,72$ ).

A partir de estos árboles se calculó mediante la función Consensus el Consenso Estricto y el Consenso de Mayoría (50\%). Estos árboles presentan una topología similar con buena resolución, en particular el árbol de Consenso de Mayoría (Fig. 96 A-B). En ambos consensos los Anguimorpha (O. vertebralis) aparecen como grupo basal.

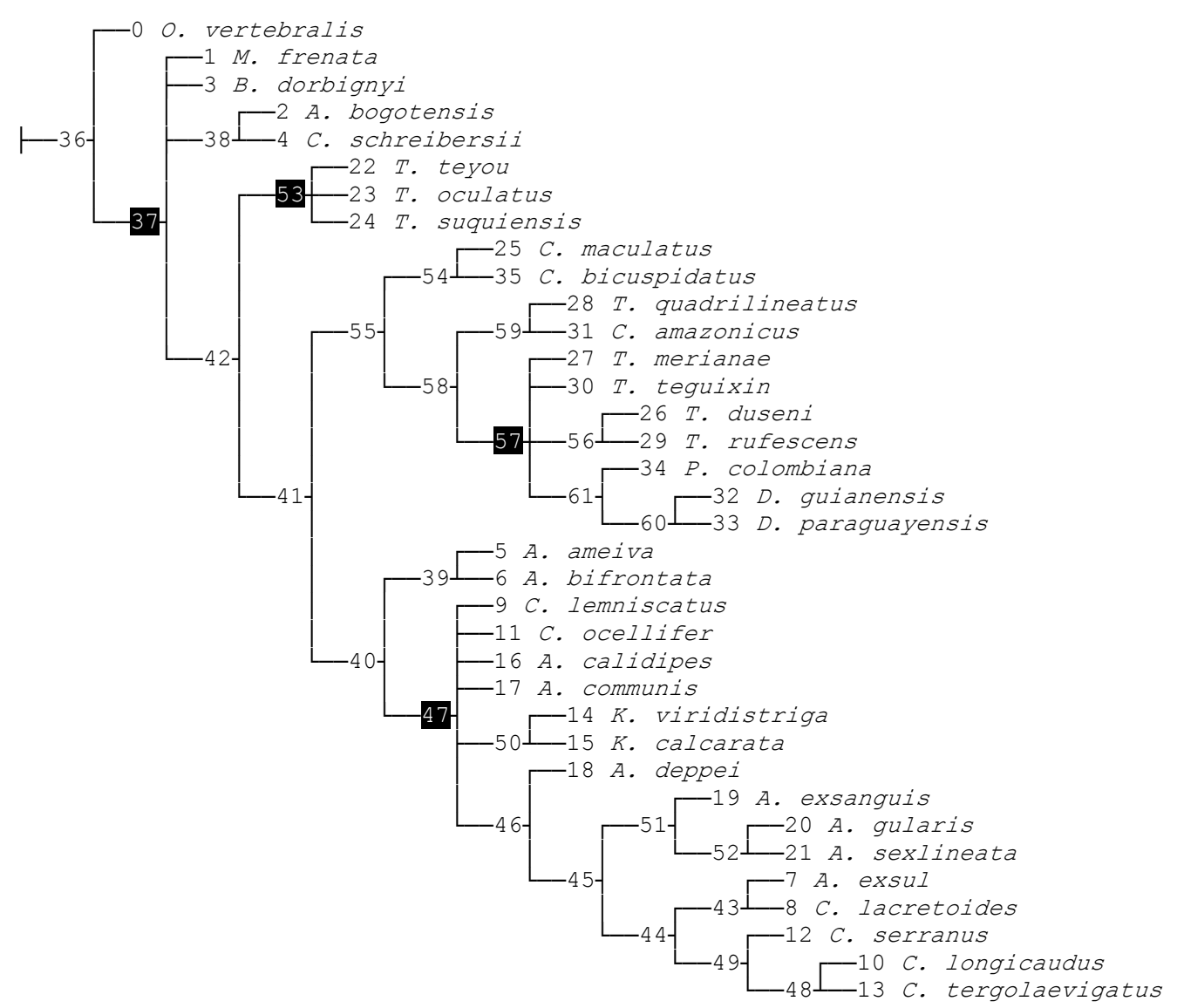




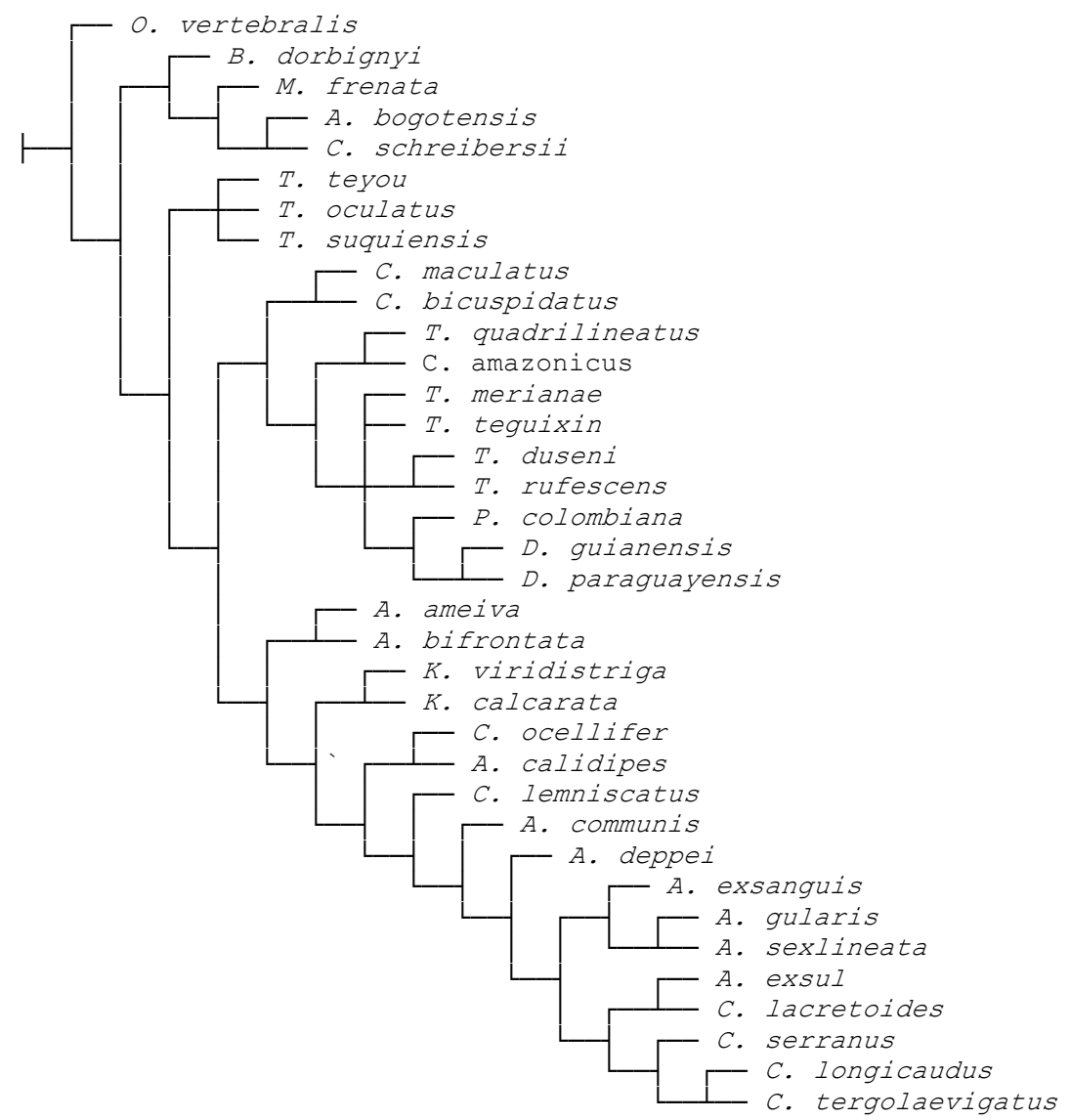

B

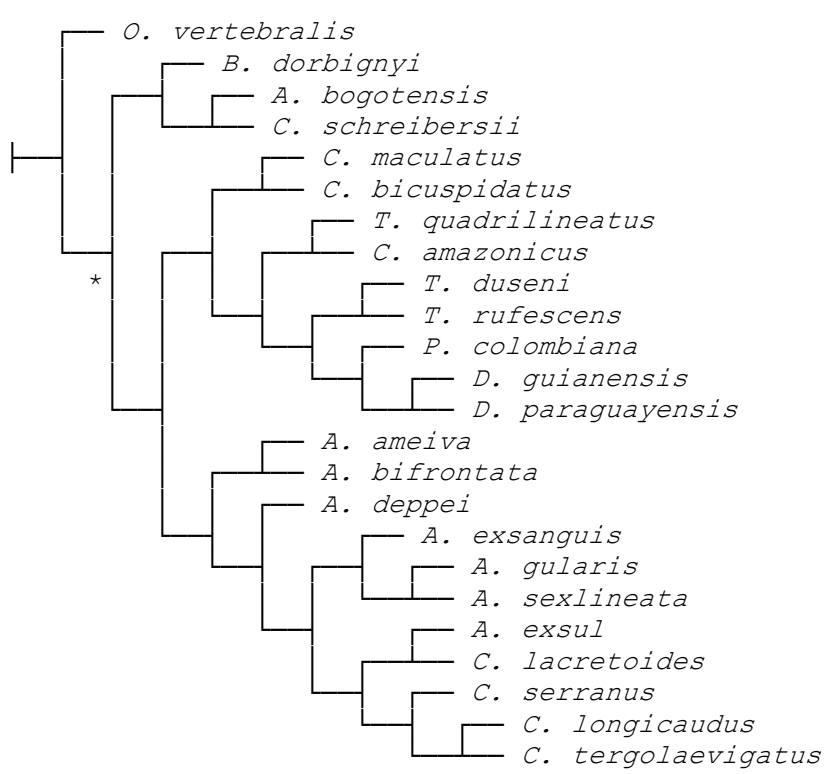


Figura 96. Resultado del análisis filogenético de la familia Teiidae según este trabajo. A, Consenso Estricto de 12 árboles; B, Consenso de Mayoría (12 árboles, corte 50\%); C, Consenso Estricto Reducido (29 taxones). Los nodos en el Consenso Estricto están numerados. En el Consenso Estricto las politomías estan resaltadas en negro. Asterisco en (C) indica Teiioidea.

En el Consenso Estricto se observan cuatro politomías. La primera de éstas es una tetratomía entre $M$. frenata, B. dorbignyi, los restantes Gymnophthalmidae y los Teiidae (nodo 37). Otra de ellas es una tricotomía entre las tres especies de Teius (nodo 53). La tercer politomía es un tetratomía que involucra a T. merianae, $T$, teguixin, T. duseni + T. rufescens y Paradracaena + Dracaena spp. (nodo 57). La última politomía del Consenso Estricto, corresponde a una séxtuple politomía entre “C." lemniscatus, “C." ocellifer, A. calidipes, A. communis, Kentropyx y los restantes "cnemidoforinos" (excepto “A." ameiva y "A." bifrontata) (nodo 47).

El Consenso de Mayoría resuelve la politomía basal nodo 37 (((B. dorbignyi (M. frenata + restantes Gymnophthalmidae))(Teiidae))) y las relaciones entre los “cnemidoforinos" del nodo 47, donde Kentropyx aparece basal a los restantes integrantes del clado. La politomía entre las especies de Teius y la que incluye a Tupinambis spp, Paradracaena y Dracaena spp no son resueltas con un corte de 50\%.

Para intentar dilucidar estas politomías no resueltas en el Consenso de Mayoría se calcularon árboles subóptimos (Comparisons $\rightarrow$ Agreemente subtrees) eliminando los taxones que causan las mismas. Como resultando de este cálculo se obtuvieron ocho árboles subóptimos igualmente parsimoniosos de 28 taxones (al excluir a 12 taxones: A. calidipes, A. communis, "C." lemniscatus, "C." ocellifer, Kentropyx spp, M. frenata, Teius spp, T. merianae y T. teguixin). El Consenso Estricto Reducido (Fig. 96 C), calculado a partir de los ocho árboles subóptimos, reconoce la monofilia de los Teiioidea y la de sus dos familias, los Gymnophthalmidae y los Teiidae. Entre los Teiidae, reconoce como monofiléticos a los Tupinambinae y Teiinae pero a costa de la exclusión de dos géneros y varias especies.

Teniendo en cuenta que el Consenso Estricto Reducido es topológicamente similar al Consenso Estricto, se optó por trabajar con este último dado que presenta mayor información. 


\section{RESULTADOS}

Los grupos externos, consistentemente con hipótesis previas (e.g. Estes et al., 1988), se ubican basalmente al grupo interno. Sin embargo, no se registran sinapomorfías que los diferencien (nodo 37). Las relaciones entre los Gymnophthalmidae (B. dorbignyi y A. bogotensis $+C$. schreibersii) y de éstos con los Scincidae (M. frenata) y Anguimorpha (O. vertebralis) no están resueltas en el Consenso Estricto.

Los Teiidae constituyen un grupo monofilético (nodo 42) sustentado por 36 sinapomorfías. Entre éstas se destacan el tipo particular de unión entre el maxilar y premaxilar ([C7]); dos procesos dorsales en el maxilar, el proceso frontal de base ancha ([C14]); prefrontal con depresión posterior delimitada por robustas crestas ([C32]); extremo dorsomedial del postfrontal bifurcado y asimétrico ([C41]); tabla parietal reducida ([C44]); musculatura adductora que avanza moderadamente sobre parietal ([C46]); ala pterigoidea sobre el cuadrado ([C64]); procesos basipterigoideos robustos, distalmente asimétricos, con carillas de articulación ligeramente cóncavas ([C67], [C68]); tubérculos esfenooccipitales desarrollados ([C69]); procesos ascendentes del supraoccipital marcados ([C73]); fenestra vomeronasalis continua con la endonarina ([C74]); sin insinuación de paladar secundario ([C76]); exclusión del maxilar de la fenestra suborbital ([C77]); somera depresión sobre la cara ventral del pterigoides ([C78]); estante subdental que pierde profundidad posteriormente ([C91]); cresta angular desarrollada ([C104]), con cresta prearticular ([C105]) y proceso angular ([C106]) marcados; superficie dorsal del proceso retroarticular con una depresión anteroposterior ([C110]), mientras que el borde medial es una nítida cresta horizontal ([C113]); ilion con presencia de proceso preacetabular ([C139]); marcado tubérculo isquíatico ([C141]); marcado cuello condilar ([C149]); presencia de zigósfeno/zigantro ([C150]); ausencia de forámenes subcentrales ([C156]). Otros caracteres a considerar son: la posición del soporte narial posterior, por detrás del borde de la fenestra exonarina ([C16]), y alvéolos de reemplazo excavados en el cemento dental ([C125]), caracteres que comparten con los Borioteiioidea (no incluidos en este análisis).

Entre los Teiidae no se reconoce a los Teiinae como grupo natural, ya que Teius (nodo 53) aparece como grupo hermano de los restantes Teiidae. Teius se caracteriza por 12 sinapomorfías: estante palatal del premaxilar desarrollado ([C0]); 
contacto yugal-escamoso sobre el arco supratemporal ([C58]); margen posterior del dentario con una cuña ventral que recibe únicamente al angular ([C92]); suprangular de disposición oblicua ([C102]); angular anteriormente horizontal ([C103]); proceso angular vertical ([C107]); marcada cresta adductora sobre el angular ([C114]); dientes posteriores transversalmente expandido ([C121]); mitad de la serie dentaria ocupada por dientes unicuspidados ([C122]); presencia de dientes pterigoideos ([C126]); fenestra escapular reducida a una emarginación ([C132]); y quinto dedo del tarso ausente ([C148]). Las relaciones entre las tres especies de Teius no pueden se resueltas como lo indica la politomía en el Consenso Estricto, de Mayoría y el consenso Estricto Reducido (Fig. 96). Sin embargo, es obvia la condición ancestral de T. teyou y T. oculatus respecto a T. suquiensis, especie híbrida de las dos anteriores (Ávila y Martori, 1991, Reeder et al., 2002).

Los restantes Teiidae (nodo 41) comparten cuatro sinapomorfías que los diferencian de Teius: marcado estante del occipucio ([C48]); borde ventral de la abertura anterior del canal de Meckel delimitado por la curvatura medial del dentario ([C94]); mesoesternon par ([C138]); y contorno ventral del isquion recto de disposición horizontal ([C140]). Los Teiidae del nodo 41 se diferencian en dos grupos: en el nodo 40 se agrupan los "cnemidoforinos" y en el nodo 55 los Tupinambinae. Los "cnemidoforinos" conforman un grupo natural (nodo 40) que se sustenta en: la fusión postfrontal-postorbital ([C40]); margen posterior del dentario con forma de "W" girada $90^{\circ}$, donde recibe al suprangular y angular en forma independiente ([C92]); proceso anterolateral del coronoides extendido marcadamente en dirección craneal ([C98]); 15-20 dientes maxilares ([C118]); y más de 80 dientes marginales ([C128]). Basalmente en este grupo se diferencian “A." ameiva y “A." bifrontata (nodo 39), sustentado por la presencia de más de siete forámenes labiales ([C19]), proceso zigomático del yugal levemente desarrollado ([C28]), musculatura adductora que delimita una simétrica fenestra supratemporal ([C46]), cuadrado desarrollado anteroposteriormente en sentido horizontal ([C60]), y más de seis forámenes mentales ([C84]). El nodo 47 incluye a los restantes “cnemidoforinos" analizados y se sustenta en: la leve proyección hacia la órbita del postfrontal ([C42]); cóndilo cefálico del cuadrado orientado posteriormente ([C62]); hasta 1/4 de la serie dentaria compuesta por dientes unicuspidados ([C123]); 3 o más dientes pteriogoideos ([C126]); fenestra escapular desarrollada ([C132]); y presencia de foramen hipoisquion ([C146]). Como se mencionó anteriormente, este nodo presenta una 
politomía donde se destacan dos agrupamientos mayores conformados por Kentropyx (nodo 50) y el nodo 56 que incluye a “ $A$.” exsul y la mayoría de las especies de Aspidoscelis y "Cnemidophorus". Esta politomía aparece resuelta en el Consenso de Mayoría (Fig. 96 B), donde Kentropyx forma un grupo natural basal (nodo 50) sostenido por nueve sinapomorfías: contorno de la plataforma palatal del premaxilar marcadamente divergente posteriormente ([C1]), mientras que el proceso ascendente del mismo hueso es alargado y ancho ([C2]); marcado proceso zigomático del yugal ([C28]); sutura fronto-parietal con débil forma de "V" posteriormente orientada ([C37]); techo fronto-parietal ligeramente cóncavo ([C49]); contorno dorsal del dentario cóncavo ([C85]); esplenial ligeramente cóncavo por delante de los forámenes milohioideo y anterior ([C97]); ausencia de la cresta prearticular ([C104]); y menos de tres dientes pterigoideos ([C126]). De las restantes especies de este clado, en el Consenso de Mayoría, A. calidipes + “C." ocellifer, "C." lemniscatus y A. communis conforman sucesivamente grupos hermanos de clados cada vez menos inclusivos hasta el nodo 46. Este nodo presenta tres sinapomorfías: postfrontal sin proyección anterior hacia la órbita ([C42]); canal de Meckel muy restringido anteriormente ([C87]); y entre 60-80 dientes marginales ([C128]). Aspidoscelis deppii aparece como grupo hermano del nodo 45. Dentro de este último clado, se agrupan las especies neárticas en el nodo 51 y las neotropicales en el nodo 44. El nodo 51 se sostiene por los procesos descendentes del parietal débilmente desarrollados ([C50]), extremo distal de hipoisquion trunco ([C145]), y la ausencia del foramen hipoisquion ([C146]); mientras que el nodo 44 se define por presentar el metacarpal III > II = IV ([C147]). El nodo 44 vuelve a dividirse en dos: nodo 43 (“A." exsul + “C." lacertoides) y nodo 49 (“C.” serranus + (“C.” longicaudus + “C.” tergolaevigatus)). El nodo 43 se sustenta en un mayor avance del proceso ascendente del premaxilar entre los nasales ([C4]), procesos basipterigoideos gráciles ([C67]), una importante relación entre el parietal y supraoccipital ([C72]), este último con una débil cresta supraoccipital ([C73]), los dientes premaxilares laterales con ligera compresión labiolingual ([C117]), y más de 80 dientes marginales ([C128]). Mientras tanto, el nodo 49 está definido por la sutura fronto-parietal con ligera forma de "V" dirigida posteriormente ([C37]), cresta articular moderada ([C104]), con proceso articular pobremente desarrollado ([C106]), y menos de tres dientes pterigoideos ([126]).

El grupo hermano del nodo 40, el nodo 55, comprende a los Tupinambinae. Este grupo se define por 14 sinapomorfías: borde ventral del maxilar sigmoide en 
vista lateral ([C13]); cara labial proceso maxilar del yugal ligeramente cóncava ([C26]); borde anteromedial de la fenestra supratemporal delimitada por el parietal ([C54]); maxilar excluido de la fenestra suborbital por moderado contacto entre el ectopterigoides y palatino ([C77]); canal de Meckel abierto medialmente ([C87]), sin restricción anterior ([C87]); proceso anterolateral del coronoides extendido anteriormente a la misma altura que lo hacen las proyecciones del suprangular y angular ([C99]); marcado contacto suprangular-esplenial ([C101]); cresta adductora sobre el angular ([C112]); escápula ligeramente excavada medialmente ([C131]); extremo ventral de la clavícula no perforado ([C133]); 25 vértebras presacras ([C151]); cresta sagital débil sobre el centro vertebral de las vértebras dorsales ([C155]) y contorno subtriangular del arco neural en las vértebras dorsales ([C158]).

Entre los Tupinambinae (nodo 55), Callopistes (nodo 54) aparece como basal respecto a los restantes géneros, y se define por la marcada proyección del postfrontal hacia la órbita ([C42]) y una fosa parietal anteriormente desplazada, al final de un surco ([C52]). Posiblemente otros caracteres, presentes en C. maculatus resulten sinapomórficos a nivel genérico; sin embargo, no figuran como tales al no estar disponibles para evaluar en el material de C. bicuspidatus (e.g. escalón anterior sobre el pterigoides [C82] o el marcado contacto esplenial-suprangular ([C100])). Los restantes Tupinambinae, nodo 58, se sustentan en 14 sinapomorfías: estante palatal del premaxilar en forma de "V" invertida ([C1]); proceso ascendente del premaxilar ancho y largo ([C2]), con constricción basal ([C3]); rama labial del proceso premaxilar del maxilar cónica ([C9]), que encaja sobre una concavidad del premaxilar ([C7]); base del proceso frontal del maxilar angosta, resultando en un proceso digitiforme ([C14]); septomaxilar escalonado, con cresta transversal lateral ([C22]) que tiene un pinzamiento medialmente desplazado ([C23]); ausencia de contacto nasal-prefrontal ([C31]); cuadrado con expansión anteroposterior en sentido oblicuo ([C60]) y medial ([C61]); borde dorsal del dentario cóncavo ([C85]); margen posterior del dentario en cuña que recibe al suprangular y angular ([C92]); e implantación subpleurodonte con cemento que disimula los septos interdentales ([C120]). El nodo 58 se divide en dos clados, C. amazonicus + T. quadrilineatus (nodo 59) y que es el grupo hermano de los restantes Tupinambinae que conforman una politomía (nodo 57). En forma general se puede caracterizar a estos clados como: Tupinambinae de dientes labiolingualmente comprimidos (nodo 59) y Tupinambinae de dientes molariformes (nodo 57); interpretando a estos últimos como más derivados. El nodo 
59 se sustenta en cuatro sinapomorfías: fenestra subcoronoidea ventralmente delimitada por el articular ([C100]); cresta articular no desarrollada ([C103]); proceso articular débilmente desarrollado ([C106]); y maxilar con 15-20 dientes ([C118]). El nodo 57 a su vez se sustenta en cinco sinapomorfías: superficie dorsal del proceso retroarticular suavemente cóncava ([C110]); dientes posteriores molariformes ([C127]), de sección circular o cuadrangular ([C121]), y de esmalte estriado ([C124]); y epipubis intercalado entre ambas ramas púbicas ([C144]). En la politomía del nodo 57 se observan dos agrupaciones mayores, los nodos 56 y 61 que reúnen a ( $T$. duseni + T. rufescens) y (P. colombiana (D. guianensis + D. paraguayensis $)$ ) respectivamente. El nodo 56 se define por la participación del esplenial en el borde ventral de la fenestra subcoronoidea ([C100]), cresta prearticular recta, horizontal ([C105]) y dientes expandidos mesodistalmente, de sección oval ([C121]). El nodo 61 se sustenta en siete sinapomorfías: proceso maxilar del yugal alto ([C29]); borde dorsal del dentario marcadamente cóncavo ([C85]); esplenial lingualmente cóncavo ([C97]); implantación subpleurodonte donde el cemento cubre completamente los septos interdentales ([C120]); dientes con marcadas estrías longitudinales ([C124]); dientes fuertemente molariformes, formando placas ([C127]) y con menos de 60 dientes marginales ([C128]). El nodo 61 se divide en Paradracaena y Dracaena (nodo 60). Paradracaena se diferencia de Dracaena por dos caracteres (sinapomorfías): un mayor número de dientes unicuspidados ([C123]) y la presencia de dientes pterigoideos ([C126]). Dracaena (nodo 60) presenta a su vez 12 sinapomorfías: rama labial del proceso premaxilar muy robusta y roma, curvada medialmente ([C9]); maxilar con más de siete forámenes labiales ([C19]); fusión postfrontal-postorbital ([C40]), esta fusión imposibilita definir si existe o no contacto postfrontal-yugal ([C43]); la musculatura adductora se extiende mucho sobre el parietal, aunque no se yuxtaponen en la línea media ([C46]); el escamoso dorsoventralmente comprimido ([C57]); existe contacto yugal-escamoso ([C58]); cuadrado muy robusto ([C59]), con desarrollo anteroposterior ([C60]), cóndilo cefálico muy curvado ventralmente ([C62]) y bulbo muy desarrollado ([C65]); y dentario con 10-14 dientes ([C119]). 


\section{DISCUSIÓN}

La tabla 11 muestra los parámetros de diferentes hipótesis filogenéticas de la familia Teiidae. El bajo valor de IC obtenido en este análisis, que refleja un elevado número de homoplasias (paralelismos, convergencias y reversiones), se debería en parte al importante número de datos faltantes en los caracteres postcraneales y el mayor número de caracteres y, principalmente, de taxones analizados, en relación a otros análisis presentados. El IR presenta un valor relativamente alto. Nydam y Cifelli (2002b) consideran a su hipótesis como tentativa por el bajo valor de IC. El valor obtenido aquí es aún menor al de estos autores, motivo por el cual se considera que esta hipótesis debe ser considera con reservas y requiere una reevaluación con incorporación de caracteres de otro tipo (merísticos, moleculares, etc.).

\begin{tabular}{lccccc} 
& $\begin{array}{c}\text { Matriz } \\
\text { (taxones x caracteres) }\end{array}$ & $\begin{array}{c}\text { Número de } \\
\text { árboles }\end{array}$ & L & IC & IR \\
\hline $\begin{array}{l}\text { Denton y O'Neill } \\
\text { (1995) }\end{array}$ & $14 \times 30$ & 1 & - & 0,875 & - \\
$\begin{array}{l}\text { Mortari y Colli (1999) } \\
\text { Moro y Abdala (2000) }\end{array}$ & $9 \times 54$ & 4 & 48 & 0,78 & - \\
$\begin{array}{l}\text { Nydam y Cifelli } \\
\text { (2002b) }\end{array}$ & $22 \times 70$ & 1 & 195 & - & - \\
Nydam et al. $(2007)$ & $17 \times 30$ & 17 & 55 & 0,62 & 0,81 \\
Giugliano et al. & $19 \times 30$ & 3 & 67 & 0,63 & 0,81 \\
(2007)* & $18 \times$ C & 1 & 1162 & 0,63 & 0,475 \\
Esta tesis & $\mathbf{3 6} \times \mathbf{~ 1 5 9}$ & $\mathbf{1 2}$ & $\mathbf{5 3 6}$ & $\mathbf{0 , 5 1 7}$ & $\mathbf{0 , 7 2}$ \\
& $\mathrm{CE}$ & - & 566 & 0,489 & 0,687 \\
& $\mathrm{C} 50 \%$ & - & 538 & 0,515 & 0,718 \\
\hline
\end{tabular}

Tabla 11. Parámetros de las diferentes hipótesis filogenéticas de la familia Teiidae. Asterisco, sólo datos del análisis combinado. $\mathrm{C}=807$ datos moleculares y 136 morfológicos; $\mathrm{CE}$, consenso Estricto; C50\%, Consenso de Mayoría (50\%).

En la observación de los resultados obtenidos, se destaca en primer término que todas las especies, excepto D. paraguayensis, O. vertebralis y T. teguixin presentan al menos una autapomorfía (ver Anexo 2). La ausencia de autapomorfías de $O$. vertebralis estaría contribuyendo a la imposibilidad de dilucidar las relaciones entre las cuatro familias de Autarchoglossa analizadas. La monofilia de 
Gymnophthalmidae puesta en duda en el Consenso Estricto, es confirmada en el Consenso Estricto Restringido, donde además se confirma la validez de los Teiioidea.

La monofilia de la familia Teiidae está bien corroborada por un importante número de sinapomorfías (36); sin embargo, el agrupamiento interno de la familia presenta diferencias con las hipótesis previas. En este sentido, la diferencia más notable es que los Teiinae aparecen como un grupo parafilético. Las tres especies de Teius conforman el grupo hermano de un clado que a su vez se divide en Tupinambinae y "cnemidoforinos". Si bien aquí se rechaza la monofilia de los Teiinae, se destaca la posición basal de Teius respecto a los “cnemidoforinos", que ya fuera reconocida en los trabajos previos.

Los "cnemidoforinos" conforman un grupo natural, donde el género "Ameiva" es parafilético. Dos de las tres especies de este género aquí consideradas, "A." ameiva $\mathrm{y}$ "A." bifrontata, conforman un clado basal respecto al resto de los "cnemidoforinos", mientras que " $A$." exsul se encuentra anidado entre las especies de "Cnemidophorus". La parafilia de "Ameiva" se verifica en el Consenso Estricto Restringido. La parafilia de "Ameiva" y la cercana relación entre "A." ameiva y "A." bifrontata también ha sido reconocida por Reeder et al. (2002); sin embargo, contradice la monofilia de "Ameiva" que observan Hower y Hedges (2003), aunque estos autores solo evalúan las especies caribeñas del género. Kentropyx es monofilético pero su posición entre los "cnemidoforinos" es incierta en el Consenso Estricto, aunque en el Consenso de Mayoría este género es el grupo hermano de "Cnemidophorus", Aspidoscelis y "A." exsul. En el trabajo de Reeder et al. (2002) se reconocen cinco grupos de especies de Aspidoscelis ("cozumela", "deppii”, "sexlineata", "tesselata" y "tigris") mientras que a las especies neotropicales las incluyen en un único grupo parafilético, el grupo "lemniscatus". Este último presenta una importante diversidad (Cabrera, 2004), dentro de la cual, Cei (1993) reconoce para territorio argentino tres grupos de especies: "lemniscatus", “longicaudus" y "lacertoides". En este estudio se pudieron evaluar especies de los grupos "longicaudus", "lacertoides", "lemniscatus", "sexlineata" y “deppii”. La relación entre los géneros “Cnemidophorus" y Aspidoscelis no puede resolverse, aunque en el Consenso de Mayoría conforman entre ambos un grupo monofilético con la inclusión de $A$. exsul. En el Consenso Estricto las relaciones filogenéticas de “C." lemniscatus, "C." ocellifer y A. deppii y A. communis no están resueltas, y estas especies son eliminadas de los árboles subóptimos, pero en el Consenso de Mayoría (“C.” ocellifer + A. calidipes), “C.” lemniscatus, A. communis y 
el nodo 45 forman sucesivamente grupos menos inclusivos. El nodo 45 presenta resolución en el Consenso Estricto, donde A. deppii (grupo “deppii”) es basal al restos de las especies, las cuales se agrupan en dos clados menores, uno representado por las especies del grupo "sexlinatus" de distribución neártica y otro con representantes del grupo "lemniscatus" sensu lato y A. exsul. Contrariamente a Reeder et al. (2002), la monofilia de "Cnemidophorus" es aceptada, con la inclusión de A. exsul. Otra diferencia con el trabajo de Reeder et al. (2002) es la posición derivada de " $C$." lacertoides y “C.” longicaudus. Las diferencias con Reeder et al. (2002) pueden estar relacionadas no sólo al uso de diferentes caracteres, sino también a los diferentes contenidos de especies analizados. Reeder et al. (2002) utilizaron un mayor número de especies en su análisis pero no incluyeron a $A$. calidipes, $A$. communis, $A$, exsanguis, “C.” serranus ni “C.” tergolaevigatus. No obstante, se observan algunas similitudes con el trabajo de Reeder et al. (2002): “C." ocellifer aparece en una posición basal y "C." lemniscatus es el grupo hermano de las restantes especies. En cuanto a los grupos de especies reconocidos por Cei (1993), el grupo "longicaudus" aparece como monofilético, no así el grupo "lacertoides". El grupo "lemniscatus" es parafilético en el Consenso de Mayoría, pero no puede ser evaluado en el Consenso Estricto. Se confirma la cercana relación de "C.” tergolaevigatus con “C." longicaudus propuesta por Cabrera (2004).

Los Tupinambinae conforman un grupo monofilético bien sustentado, con Callopistes en una posición basal, donde C. bicuspidatus (Mioceno tardío - Plioceno temprano de Argentina) se agrupa con C. maculatus. Las relaciones entre los restantes géneros no se hallan adecuadamente resueltas en el Consenso Estricto ni en el Consenso de Mayoría. La resolución del Consenso Estricto Reducido es a costa de la remoción de las especies T. merianae y T. teguixin. El género Crocodilurus resulta monofilético sólo con la inclusión de T. quadrilineatus, mientras que Tupinambis es grupo hermano de (P. colombiana (D. guianensis $+D$. paraguayensis)). Este arreglo genérico de los Tupinambinae, con Tupinambis más cercano a Dracaena, discrepa con las hipótesis de la mayoría de los autores que consideran a Tupinambis más cercano a Crocodilurus (Presch, 1974a; Denton y O’Neill, 1995; Giugliano et al. 2007) o a un clado conformado por Crocodilurus + Dracaena (Sullivan y Estes, 1997; Nydam y Cifelli, 2002b; Nydam et al., 2007; Giugliano et al. 2007). Sin embargo, coincide con la hipótesis presentada por Péres Jr (2003), y las conclusiones de Vanzolini y Valencia (1965), Gorman (1970) y Rieppel (1980) obtenidas a partir de la 
morfología externa, datos cromosómicos y de la musculatura adductora respectivamente.

El género Paradracaena fue propuesto por Sullivan y Estes (1997) para incluir diferentes elementos de lagartos del Mioceno de Colombia previamente asignados a Dracaena y Tupinambis. Recientemente, material del Mioceno de Perú ha sido referido a este género (Pujos et al., 2009). Las siete sinapomorfías del nodo 61 confirman la afinidad de Paradracaena con Dracaena, mientras que la presencia de dientes pterigoideos es un carácter que por si sólo justifica la diferenciación genérica de Paradracaena. Los caracteres relacionados al proceso premaxilar del maxilar, el cuadrado, el escamoso y la fusión postfrontal-postorbital que definen a Dracaena, no presentan diferencias entre Paradracaena y Tupinambis. Estos caracteres confirman la posición derivada de Dracaena y son elementos adicionales para sustentar genéricamente a Paradracaena.

Las relaciones específicas de Tupinambis no pueden resolverse. Sin embargo, se observa que T. quadrilineatus se diferencia marcadamente del resto de las especies agrupándose con C. amazonicus. Las restantes especies se reúnen en una politomía con (Paradracaena + Dracaena), en el Consenso Estricto Restringido. Entre estas especies se aprecia sólo la cercanía filogenética de $T$. rufescens y $T$. duseni, la cual ya fuera reconocida por otros autores (Fitzgerald et al., 1999; Péres Jr, 2003).

Si bien no fue incluido en el análisis filogenético, merece un comentario la especie extinta T. uruguaianensis Hsiou 2007 del Pleistoceno tardío de Brasil. Esta especie, de acuerdo a Hsiou (2007), es similar a T. merianae pero difiere de esta última por los siguientes caracteres: una cresta adductora protuberante, que le confiere a la cara externa del articular una disposición oblicua; el contorno de la cresta prearticular cóncavo y un proceso angular más redondeado, proyectándose de la cresta angular. La revisión del material de referencia ha llevado a la redefinición y recodificado de estos caracteres ([C105], [C106], [C107]). Es así que se discrepa con Hsiou (2007) en cuanto al contorno de la cresta prearticular ([C105]) que en $T$. uruguaianensis no se diferencia de T. merianae. La marcada cresta adductora protuberante también ha sido observada en los ejemplares actuales de mayor talla disponibles (i.e. UNMdP-O 1); este carácter presentaría variación ontogenética acompañando el desarrollo de la musculatura adductora. A su vez, las dimensiones de los dientes de T. uruguaianensis se encuentran dentro del rango observado para $T$. merianae (Fig. 97), aunque el tamaño de T. uruguaianensis (longitud de 
hemimandíbula $\sim 155,1 \mathrm{~mm}$ ) es superior al máximo registrado en la muestra disponible de T. merianae (longitud de hemimandíbula UNMdP-O $1 \sim 122,87 \mathrm{~mm}$ ). Entre las especies actuales de Tupinambis, sólo $T$, rufescens supera en tamaño a $T$. merianae con una LHC máxima de $614 \mathrm{~mm}$ y $420 \mathrm{~mm}$ respectivamente (Ávila-Pires, 1995; Péres Jr, 2003; Péres Jr y Colli, 2004). Esta marcada diferencia permite inferir que el tamaño de T. uruguaianensis no excedería el máximo registrado para el género. El estatus de T. uruguaianensis debiera ser revisado ya que sólo el tamaño lo diferencia de T. merianae. Aquí T. uruguaianensis es considerado como Tupinambis $\mathrm{sp}$, con afinidades con T. merianae.

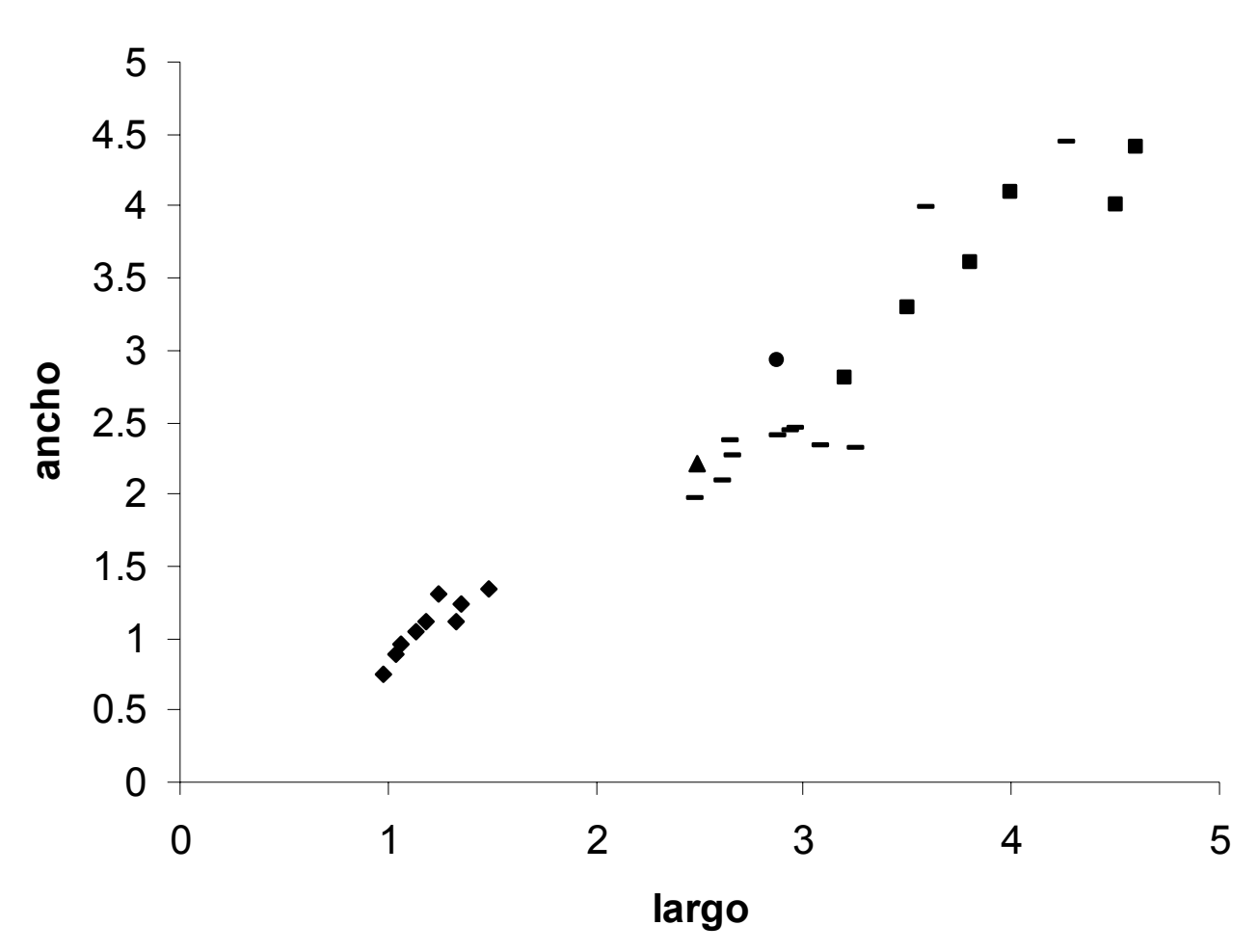

Figura 97. Relación largo vs ancho de dientes molariformes de Tupinambis. Rombo Tupinambis del Colhuehuapense; triangulo, Tupinambis del Santacrucense; circulo, Tupinambis del Huayqueriense; barra, T. merianae; cuadrado, T. uruguaianensis. Valores en $\mathrm{mm}$. 


\section{CONCLUSIONES}

Los Teiidae conforman un grupo natural y hermano de los Gymnophthalmidae, integrando en conjunto a los Teiioidea (Estes et al., 1988). Entre los Teiidae no se acepta la monofilia de Teiinae (Fig. 98). El género Teius se diferencia y constituye el grupo hermano de los restantes géneros analizados en este trabajo. Se supone, en base a otros análisis (ver sección 1), que Dicrodon se hallaría más cercanamente relacionado a Teius que a los demás géneros de Teiidae. Los restantes Teiidae se agrupan en dos clados hermanos: Tupinambinae y "cnemidoforinos".

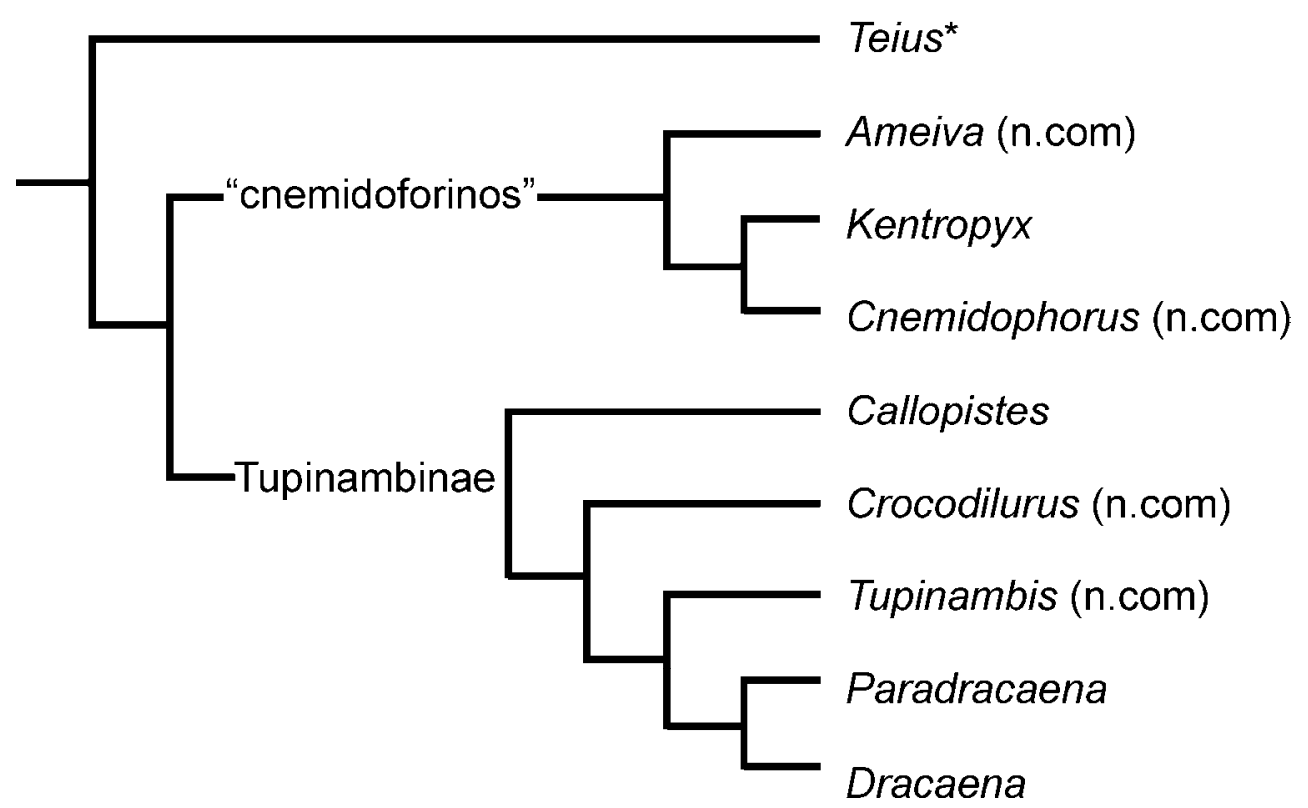

Figura 98. Hipótesis filogenéticas de la familia Teiidae según este trabajo. Asterisco, posición supuesta de Dicrodon.

Entre los “cnemidoforinos" se reconocen tres agrupamientos monofiléticos, Ameiva, Kentropyx y Cnemidophorus. De éstos, sólo Kentropyx presenta la combinación de especies tradicionalmente asignadas al género. Ameiva y Cnemidophorus presentan nuevas combinaciones de especies, dadas por el cambio de A. exsul a Cnemidophorus y la no diferenciación en este último de "Cnemidophorus" sensu Reeder et al. (2002) y Aspidoscelis. El ordenamiento genérico que se obtiene aquí para los "cnemidoforinos" concuerda con la hipótesis de Giugliano et al. (2007), pero no con la de Reeder et al. (2002). 
Los Tupinambinae presentan a Callopistes basal respecto a un segundo clado donde Crocodilurus es el grupo hermano de (Tupinambis (Paradracaena + Dracaena)). En este marco, Crocodilurus y Tupinambis presentan una nueva combinación de especies por el pasaje al primero de T. quadrilineatus. Se interpreta que el agrupamiento de T. quadrilineatus responde a que esta especie no presenta la condición derivada de dentición posterior molariforme presente en los restantes Tupinambis analizados. Una situación similar presentaría Tupinambis longilineus, no incluido en el análisis por falta de material osteológico disponible (Cap. VI), que de acuerdo con Ávila-Pires (1995) no presentaría dientes molariformes. Los caracteres osteológicos aquí considerados no permiten una clara definición de las relaciones filogenéticas de las especies de Tupinambis.

Las especies fósiles analizadas, $C$. bicuspidatus y $P$. colombiana, se ubican coherentemente con lo supuesto. Callopistes bicuspidatus es el grupo hermano de $C$. maculatus mientras que Paradracaena colombiana resulta el grupo hermano de Dracaena. Paradracaena presenta caracteres que coinciden con la posición intermedia entre Tupinambis y Dracaena. 


\section{CAPÍTULO VI}

\section{EVOLUCIÓN BIOGEOGRÁFICA DE LOS TEIDOS}

\section{INTRODUCCIÓN}

El origen de los Teiidae está íntimamente ligado al de los Gymnophthalmidae, con quienes conforman los Teiioidea, un grupo casi endémico de la herpetofauna Neotropical, que incluye un sólo género de distribución holártica (Reeder et al., 2002; Pough et al., 1998; Zug et al., 2001; Zug, 1993). Según Nydam et al. (2007), la divergencia entre teioideos y borioteioideos ("teidos cretácicos”) se habría producido antes del Aptiano en territorios de Laurasia, seguido de una dispersión de ancestrales teioideos hacia América del Sur a fines del Cretácico. Estes (1983b) y otros investigadores (Estes y Báez, 1985; Denton y O’Neill, 1995; Nydam y Cifelli, 2002b; Giugliano et al., 2007) consideraban un origen de los Teiidae en Laurasia y posterior dispersión a América del Sur. Sin embargo, la reciente remoción de los Borioteiioidea de los Teiidae (Nydam et al., 2007) favorece la hipótesis de una diferenciación de la familia en América del Sur, propuesta inicialmente por el propio Estes (1983b) y otros autores (Savage, 1966; Vanzolini y Heyer, 1985; Gayet et al., 1992).

Giugliano et al. (2007), a partir de datos moleculares y morfológicos, ubican el origen de la familia Teiidae en el lapso Cretácico superior - Paleoceno. Estos autores sostienen que Callopistes fue el primer género en diferenciarse en el Paleoceno, mientras que los restantes lo hicieron durante el Eoceno - Oligoceno, excepto Cnemidophorus que se habría originado recién en el Oligoceno - Mioceno. Es de notar que Giugliano et al. (2007) calibraron su reloj molecular sobre la base de registros más modernos que los reconocidos en esta tesis; es así que para estos autores Tupinambis se registra a partir del Laventense (Mioceno medio) y los “cnemidoforinos" hace sólo 5 Ma. Es posible, por lo tanto, que la antigüedad de la familia y del origen de los géneros hayan sido subestimadas.

A pesar que se han reportado hallazgos de probables teidos para el Cretácico inferior y superior de América del Sur, éstos no han podido ser corroborados (Albino, 2007). Los restos citados como Teiidae del Cretácico inferior de Chile (Valencia et al. en Gayet et al., 1992) y mencionados por Albino (1996a), nunca fueron publicados 
(Albino, 2007); mientras que el dentario de la Formación Anacleto de Argentina (Albino, 2002a) es considerado en este trabajo un probable Scincoidea (Cap. IV). Aunque la posición sistemática de Pristiguana del Cretácico de Brasil ha sido también propuesta dentro de los teidos (Borsuk-Bialinycka y Moody, 1984), la posición más ampliamente aceptada es considerarlo un Iguania (Estes y Price, 1973). De esta manera, no es posible corroborar el origen Mesozoico de la familia Teiidae, aunque la ausencia de hallazgos podría responder a una deficiencia del registro.

El más antiguo registro de fósiles de la familia es del Eoceno de Argentina y Brasil (Donadío, 1985; Carvalho, 2001; Cap. IV de este trabajo) (Fig. 99 A). Durante el Eoceno temprano de América del Sur se desarrollaron extensas planicies aluviales como consecuencia del retiro del "Mar Salamanquense", una transgresión atlántica que cubrió gran parte del sur del continente austral durante el Cretácico tardío Paleoceno temprano (Pascual et al., 1996; Ortiz Jaureguizar y Cladera, 2006). Esta barrera geográfica, que dividió el territorio en dos (noreste y sudoeste), habría generado importantes endemismos de mamíferos en las regiones patagónica y extrapatagónica, que se reflejan en diferentes unidades biogeográficas (Pascual et al., 1996). Los sedimentos portadores de mamíferos extrapatagónicos del Paleógeno fueron depositados bajo un clima subtropical, con condiciones cálidas y de marcada estacionalidad (Pascual et al., 1996). Estos depósitos son de donde provienen los restos de Tupinambinae del Paleógeno.

El hecho de registrar restos de Tupinambinae en el Eoceno de Argentina y Brasil, aunque Carvalho (2001) no explicita la asignación subfamiliar del material de Brasil, implica que ya para entonces, según la hipótesis filogenética presentada en este trabajo (Cap. V), se habría producido la divergencia entre los "cnemidoforinos" y los tupinambinos, a pesar que aún no hay registro de los primeros para esa edad. De esta manera, se puede corroborar que el origen de la familia ocurrió anteriormente al Itaboraiense (Eoceno temprano). Augé (2005) describe una nueva especie de Teiidae sensu Nydam et al. (2002a), Brevisaurus smithi, del Eoceno tardío de Francia. Esta cita corresponde al único registro Cenozoico fuera de América del Sur para esta familia. Dicho material no pudo ser revisado pero su inclusión entre los Teiidae es al menos dudosa. En la publicación de Augé (2005) se observa que la dentición de este fósil es compacta, en empalizada y de una heterodoncia muy leve. Asimismo, el maxilar aparentemente carece de soporte narial posterior y presenta soporte narial anterior. Estos caracteres no se observan en los Teiidae (Cap. V). 
Desde el Eoceno temprano al Mioceno temprano hay un significativo hiato en el registro documentado de teidos, pero es destacable que ya en el Colhuehuapense de Patagonia se reconoce al género actual Tupinambis (Brizuela y Albino, 2004; Cap. IV). Este género está muy extensamente representado desde entonces hasta la actualidad. En particular, se reconoce en sedimentos del Mioceno desde el sur de Patagonia hasta Colombia (Sullivan y Estes, 1997; Albino et al., 2006; Brizuela y Albino, 2008a, b), representando el período de mayor expansión geográfica, con la presencia en latitudes mucho más australes que en el presente.

Para una mirada más detallada del registro miocénico de teidos hay que tener en cuenta que, a fines del Oligoceno - principios del Mioceno, se registró una nueva transgresión atlántica de importantes dimensiones, el "Mar Patagoniense" (transgresiones Superpatagoniense, Leonense y Juliense), con una distribución similar al "Mar Salamanquense" (Ortiz Jaureguizar y Cladera, 2006). Entre las diferentes transgresiones del "Mar Patagoniense", se depositaron los sedimentos del Colhuehuapense (Goin et al., 2007), de donde se ha recuperado una importante asociación de lagartos incluyendo teidos e iguanios (Brizuela y Albino, 2004; Albino, 2008; Cap. IV). La localidad de Gaiman, de donde provienen estos hallazgos, habría estado ubicada en cercanías de la costa, en la península Tehuelche o Protopatagonia (Goin et al., 2007). Allí se habría desarrollado un ambiente de planicie costera bordeada por un mar somero, mientras que en las zonas elevadas o alejadas del mar, el ambiente dominante habría sido de bosque, bajo un clima templado-cálido a cálido afectado por el mar circundante (Barrera et al., 2007; Goin et al., 2007). La existencia de dunas en la localidad de Gaiman es soportada por varias evidencias (Vucetich y Verzi, 1993; Albino, 1996b). Estas propuestas paleoambientales son consistentes con la presencia de Tupinambis en el Mioceno de esta localidad (Cap. IV).

$\mathrm{Al}$ retirarse el "Mar Patagoniense", su cuenca es nuevamente invadida por el "Mar Paranaense/Entrerriense" a partir del Mioceno medio (transgresiones Paranaense, Entrerriense y Rionegrense) (Pascual et al., 1996; Ortiz Jaureguizar y Cladera, 2006). El "Mar Paranaense" se une con una importante transgresión que ocupa la parte norte del continente (existen diferentes interpretaciones paleoambientales del Lago Pebas o Tethys Waterspout; e.g. Lundberg et al. (1998) y Ortiz Jaureguizar y Cladera (2006)), de manera tal que el continente queda, durante el Mioceno medio - tardío, ocupado por un gran cuerpo de agua que lo divide en dos (Fig. 99 B). 
El Óptimo Climático del Mioceno (Böhme, 2003: 17 - 15 Ma), permitió la máxima extensión geográfica de Tupinambis durante el Santacrucense, en que alcanzó $\operatorname{los} 50^{\circ} \mathrm{S}$, y, en general, de los tupinambinos, que incluso se distribuían en el noroeste de Patagonia durante el Colloncurense (Cap. IV). Luego del Óptimo Climático se produce un progresivo enfriamiento (Böhme, 2003). El retroceso del "Mar Paranaense", acompañado del levantamiento de la cordillera Principal y Patagónica (Fase Quechua de la orogenia andina), permitió el desarrollo de extensas planicies dando inicio a la "Edad de las Planicies Australes" a fines del Mioceno (Pascual y Bondesio, 1982; Pascual et al., 1996; Ortiz Jaureguizar y Cladera, 2006). Es entonces cuando comienzan a tomar forma las subregiones biogeográficas actuales de Patagonia, estableciéndose la provincia paleofitogeofráfica de Proto Espinal/Estepa (Barreda et al., 2007), en un clima más frío y estacionalmente más marcado que en el Mioceno medio (Ortiz Jaureguizar y Cladera, 2006).

Mientras se presentaban estos cambios en la región patagónica, en el extremo norte de América del Sur, en Colombia (La Venta), se desarrolló durante el Mioceno medio, un terreno bajo, de bosque tropical, con un régimen pluvial de $2000 \mathrm{~mm} / \mathrm{año} \mathrm{y}$ una estación seca de duración menor a tres meses (Kay y Madden, 1997), donde habitaban Tupinambis y el extinto Paradracaena (Sullivan y Estes, 1997; Albino et al., 2006). Esta zona se encontraría delimitada al este por la transgresión marina del Lago Pebas/Tethys Waterspout. Más al sur, en el actual territorio de Perú, también asociado a este gran cuerpo de agua y en un ambiente de bosque tropical denso, se ha registrado el género Paradracaena (Pujos et al., 2009). La identificación de estos dos tupinambinos en el Mioceno medio implica que ya para entonces estarían diferenciados la mayoría de los géneros de Tupinambinae actuales (Cap. V). El clima en Colombia se volvió más árido como consecuencia de la elevación de las Cordilleras Central y Oriental, lo cual habría determinado la desaparición de Tupinambis de esta zona y la extinción de Paradracaena (Ávila-Pires, 1995; Albino et al., 2006; Mesquita et al., 2006). Mientras tanto, cambios ambientales asociados a la modificación de la transgresión marina Lago Pebas/Tethys Waterspout serían responsables de la desaparición de Paradracaena de Perú (Pujos et al., 2008).

Así, contrariamente a lo que ocurre en el Paleógeno, en que los Tupinambinae sólo aparecen en la parte central del continente sudamericano, en el Mioceno temprano y medio se los encuentra en territorios patagónicos y del noroeste del continente, no habiendo registro de ellos en latitudes medias (Fig. 99). A su vez, se 
observa que los Tupinambis del Mioceno se distribuyen en dos áreas de ambientes diferentes: selva tropical húmeda en Colombia y una fisonomía más abierta en Patagonia, bajo un clima templado - cálido.
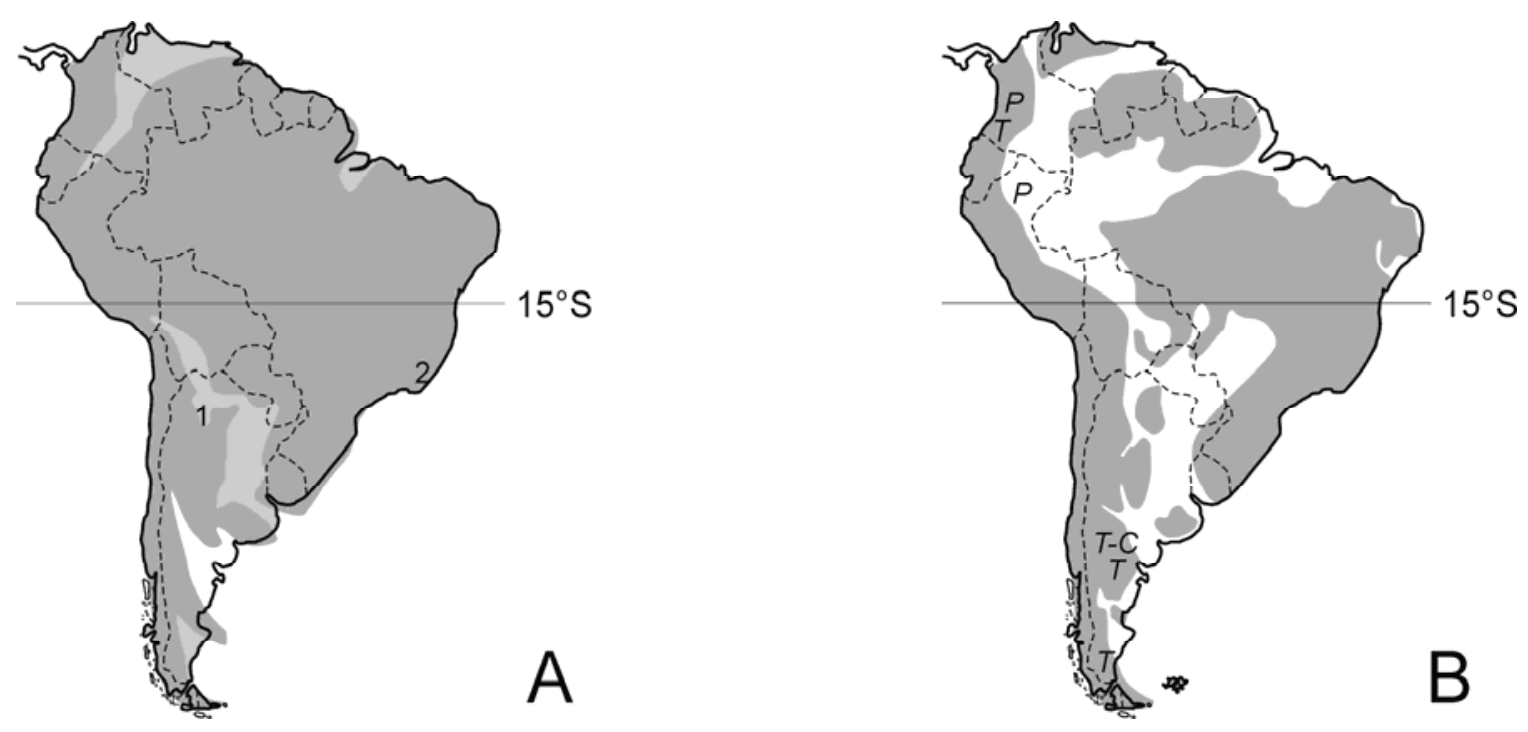

Figura 99. Registro fósil temprano de la familia Teiidae. A, Eoceno (mapa base del Cretácico tardío Paleoceno temprano); B, Mioceno (mapa del Mioceno medio - tardío). Tierra emergida en gris oscuro; zona de donde se retiró el Mar Salamanquese en gris claro. Abreviaturas: 1, Tupinambinae de Fm. Lumbrera; 2, Tupinambinae del Itaboraiense; $P$, Paradracaena; $T$, Tupinambis; T-C, Tupinambis o Crocodilurus. Mapas modificados de Ortiz Jaureguizar y Cladera (2006).

Con respecto a otros géneros de Tupinambinae, la presencia de Callopistes en el Mioceno tardío - Plioceno temprano es coherente con su posición basal (Cap. V) y el hallazgo en sedimentos del Mioceno temprano y medio de los más derivados Paradracaena y Tupinambis. Sin embargo, se destaca la ubicación geográfica del registro de Callopistes en el sur de la provincia de Buenos Aires, en Argentina, que contrasta llamativamente con la distribución transandina actual del género en Chile y Perú (Cap. IV). Es posible suponer que Callopistes ya estaría representado durante el Paleógeno con una más amplia distribución en gran parte de América del Sur. La progresiva elevación de los Andes durante el Eoceno tardío (Fase Incaica) podría haber determinado la divergencia entre las poblaciones al este y oeste de la cordillera. Los descendientes de las poblaciones al oeste de los Andes se habrían adaptado a los ambientes áridos que allí evolucionaron sobreviviendo hasta la actualidad, mientras que en el resto del continente habrían subsistido al menos hasta el Plioceno temprano 
en ambientes más templados y húmedos que los habitados por sus congéneres transandinos. Esta antigua historia del género se condice con las diferencias morfológicas entre las especies actuales de distribución occidental (C. maculatus y $C$. flavipunctatus) y la especie extinta del extremo oriental (C. bicuspidatus) (Cap. IV).

En cuanto a los "cnemidoforinos", que, de acuerdo a la hipótesis de este trabajo resulta el grupo hermano de los Tupinambinae (Cap. V), se reconoce que aparecen registrados por primera vez en el Mioceno tardío sudamericano (Cap. IV), aunque en territorios holárticos se los registra desde el Mioceno temprano (Florida) y tardío (Nebraska) de Estados Unidos de América (Estes, 1983a). Esta amplia distribución miocénica, desde el centro de Argentina hasta América del Norte, podría explicarse a través de un proceso de migración hacia el norte de los "cnemidoforinos" en el Oligoceno-Mioceno. Hower y Hedges (2003) concluyen, a partir de datos moleculares, que el "cnemidoforino" Ameiva colonizó las Antillas a través de un evento fortuito de dispersión sobre el agua hace 30-25 Ma (Oligoceno). Esta dispersión habría estado favorecida por la dirección predominante América del Sur Antillas de las corrientes marinas durante el Cenozoico (Hedges, 2001). Los registros más antiguos de "cnemidoforinos" en América del Norte se encuentra en el estado de Florida (Mioceno temprano, Estes, 1983a), geográficamente coincidente con esta hipótesis, desde donde luego habrían radiado al resto del continente (e.g. Mioceno tardío, Nebraska; Estes, 1983a). Esta hipótesis es compatible con la presencia de un "cnemidoforino" en el Mioceno tardío sudamericano (Cap. IV). La imposibilidad de una asignación genérica del fósil y la falta de registros adicionales, impide mayores especulaciones sobre la historia evolutiva de este grupo de lagartos en América del Sur. Los "cnemidoforinos" recién vuelven a aparecer en este registro en el Pleistoceno de Brasil (Ameiva y Cnemidophorus) y Pleistoceno - Holoceno de Argentina (Cnemidophorus) (Albino, 2005; Camolez, 2006).

De esta manera, se observa que el registro fósil de la familia Teiidae en América del Sur está prácticamente restringido a los Tupinambinae y, en particular, al género Tupinambis. Debido a ésto, se hace necesaria una revisión de los caracteres ambientales que afectan la distribución actual de Tupinambis en territorio argentino, con el fin de identificar las variables que definen la distribución de las especies $T$. merianae y T. rufescens, que son las de alcanzan las latitudes más australes. Estos datos permiten inferencias paleoambientales más acotadas a partir del registro fósil y 
entender más adecuadamente los cambios ambientales que tuvieron mayor repercusión sobre su distribución pasada.

\section{PARÁMETROS CLIMÁTICOS Y AMBIENTALES DE LA DISTRIBUCIÓN DE TUPINAMBIS EN ARGENTINA}

El uniformismo o actualismo es el principio según el cual se puede aceptar que los procesos naturales que actuaron en el pasado son los mismos que actúan en el presente. Este principio permite inferir condiciones ambientales, climáticas y ecológicas bajo las cuales vivieron los taxones fósiles a partir de la comparación con los taxones vivientes. En los Squamata este principio es más confiable cuando los fósiles están filogenéticamente relacionados a grupos vivientes o cuando presentan caracteres morfológicos que con seguridad se correlacionan con alguno de estos aspectos (Albino, 1994).

El registro fósil de los lagartos no iguanios de Argentina está compuesto principalmente por la familia Teiidae (Cap. I y IV); en particular, y como se remarcó al comienzo de este Capítulo, dominado por el género Tupinambis. Como destacan diferentes autores (Donadío, 1985; Krause, 1985; Péres Jr., 2003), la distribución de esta familia desde el punto de vista zoogeográfico ofrece numerosos ejemplos de adaptaciones a distintos ambientes (Tabla 12) y tipos ecológicos (e.g. alimentación). Donadío (1984b), a partir de las distribuciones espaciales en Argentina de las dos especies de Tupinambis, describió las condiciones ambientales para cada una de ellas. Esta información ha sido utilizada por otros autores para inferir condiciones paleoambientales en aquellos sitios donde se registran restos fósiles de Tupinambis (e.g. Brizuela y Albino, 2004; Albino et al., 2006). Sin embargo, hoy en día existen nuevos datos que permiten reanalizar estas distribuciones. 
Tupinambis

Bioma Sudamericano

País

\begin{tabular}{lll}
\hline T. duseni & Cerrado & Brasil \\
T. longilineus & Amazonia & Brasil \\
T. merianae & Caatinga, Cerrado, Chaco y áreas abiertas & Argentina, Bolivia, Brasil, \\
& de la costa atlántica & Paraguay y Uruguay \\
T. quadrilineatus & Cerrado & Brasil \\
T. rufescens & Chaco & Argentina, Bolivia y Paraguay \\
T. teguixin & Amazonia, Cerrado (norte y centro-este) & Brasil, Colombia, Ecuador, \\
& & Guyana, Guyana Francesa, \\
& & Perú, Venezuela y Surinam \\
\hline
\end{tabular}

Tabla 12. Distribución geográfica y ambiental de Tupinambis. Datos de Péres Jr (2003).

Para la evaluación de los requerimientos ambientales de las especies argentinas de Tupinambis, se ploteó la distribución actual de ambas especies ( $T$. merianae y T. rufescens) y se las confrontó con mapas de las regiones biogeográficas, precipitación media anual, temperatura media anual e índice hídrico. El mapa de distribución se realizó utilizando como base los mapas presentados en Cei (1986, 1993), a los cuales se le incorporaron datos de otros autores (Vega y Bellagamba, 1990; Williams, 1991; Chani y Fitzgerald, 1991; Montanelli y Acosta, 1991; Yanosky y Mercolli, 1992; Protomastro et al., 1992; Tiranti y Ávila, 1997, Cruz, 1996, Wichmann, 1996; Martori y Juárez,1998; Haro et al., 2000; Cruz et al., 2002; Juárez et al., 2003; Kacoliris et al., 2006). Los mapas de índice hídrico, temperatura media anual y precipitación media anual fueron tomados de Burgos y Vidal (1951) y Cuello (1982a, b) respectivamente.

\section{DISTRIBUCIÓN DE LAS DIFERENTES ESPECIES DE TUPINAMBIS EN AMÉRICA DEL SUR}

Al considerar a Tupinambis palustris como sinónimo júnior de Tupinambis teguixin, el género Tupinambis queda constituido por seis especies (Tabla 7) (ÁvilaPires, 1995; Manzani y Abe, 1997; Péres Jr, 2003). La distribución del género Tupinambis es muy amplia en toda América del Sur, desde Colombia hasta la provincia de Río Negro en Argentina, y desde las tierras bajas al este de los Andes hasta el océano Atlántico (Krause, 1985; Ávila-Pires, 1995; Péres Jr, 2003) (Fig. 100). 
La confusa historia sistemática del género, el reciente establecimiento de especies poco conocidas (T. longilineus y $T$. quadrilineatus) y la muy extendida distribución de otras (T. merianae y T. teguixin) son todos elementos que contribuyen a la pobre resolución de la distribución geográfica de las especies del género. En los trabajos más recientes en los que se ha revisado esta distribución (Cei, 1993; Ávila-Pires, 1995; Péres Jr, 2003) se destaca el importante número de citas que deben ser revisadas. Por estos motivos, en la figura 100 se presenta una aproximación de la distribución de cada una de las especies reconocidas del género, y se las confronta con las temperaturas y precipitaciones medias del continente. A continuación se hará un breve repaso de los datos de distribución continental de estas especies.

Tupinambis duseni. Recientemente Péres Jr y Colli (2004) confirmaron la validez de esta especie al diferenciarla de T. rufescens. Ambas especies, de coloración rojiza, han sido sinominizadas por algunos autores (e.g. Presch, 1973) mientras otros las consideraban especies distintas (e.g. Peters y Donoso-Barros, 1970). Se trata de un lagarto grande, máxima $\mathrm{LHC}=410$, endémico de la provincia biogeográfica del Cerrado (Péres Jr y Colli, 2004). Este bioma se encuentra sobre el "planalto" o escudo brasilero, ocupando una importante parte de Brasil (Minas Gerais, Mato Grosso, Goias, São Paulo, Paraná, Maranhao y Piaui) y el noroeste de Paraguay. El Cerrado se caracteriza por el predominio de bosques abiertos de poca altura que se desarrollan bajo un clima con precipitación anual entre los 1200 - 2000 mm/año y temperatura media de $21^{\circ} \mathrm{C}$ a $25^{\circ} \mathrm{C}$ (Cabrera y Willink, 1980).

Tupinambis longilineus. Es una especie pequeña, con una máxima $\mathrm{LHC}=202$ $\mathrm{mm}$, que ha sido recientemente reconocida (Ávila-Pires, 1995). Son muy pocos los datos de distribución disponibles, estando la especie restringida al suroeste de la Amazonia (Ávila-Pires, 1995; Fitzgerald et al. 1997; Colli et al., 1998; Pérez Jr, 2003). La provincia biogeográfica Amazónica se caracteriza por un clima estable, con una temperatura media de $26^{\circ} \mathrm{C}$ y un régimen de precipitación que varía entre 2000 $2600 \mathrm{~mm} / \mathrm{año}$. Este clima permite el desarrollo de la selva pluvial, densa y alta (Cabrera y Willink, 1980).

Tupinambis merianae. Se trata de un lagarto grande, con LHC máxima $=420$ $\mathrm{mm}$, y una muy amplia distribución, que es la mayor entre las diferentes especies. Se distribuye al sur de la Amazonia, ocupando las provincias biogeográficas de la Caatinga, Atlántica, Cerrado, Paranaense, Pampeana, del Espinal y del Chaco (Péres Jr, 2003). Se los encuentra asociados a ambientes abiertos (Ávila-Pires, 1995). Esta 
amplia distribución podría ser indicativa de un complejo de especies; sin embargo, Péres Jr (2003) no encuentran diferencias entre las poblaciones evaluadas (Caatinga, Chaco, Cerrado).

Tupinambis quadrilineatus. Es la especie más recientemente reconocida (Manzani y Abe 1997; Colli et al., 1998). Se trata de un lagarto pequeño, con máxima $\mathrm{LHC}=254 \mathrm{~mm}$, y restringido a la provincia biogeográfica del Cerrado (Manzani y Abe 1997; Colli et al., 1998; Péres Jr, 2003).

Tupinambis rufescens. Es la mayor de las especies de Tupinambis, con una LHC máxima registrada de 614 mm (Péres Jr y Colli, 2004). Se distribuye en la provincias biogeográficas del Chaco, del Monte y del Espinal en Argentina, Bolivia y Paraguay (Péres Jr y Colli, 2004).

Tupinambis teguixin. Se trata de una especie pequeña - mediana, con una LHC máxima de 362 mm (Ávila-Pires, 1995). Presenta una muy amplia distribución a lo largo de toda la Amazonia, encontrándoselo también en el norte y centro-este del Cerrado. Fitzgerald et al. (1999) reconocieron importantes distancias filogenéticas entre diferentes poblaciones de T. teguixin, sin embargo al igual que T. merianae no se trataría de un complejo de especies (Péres Jr, 2003). 


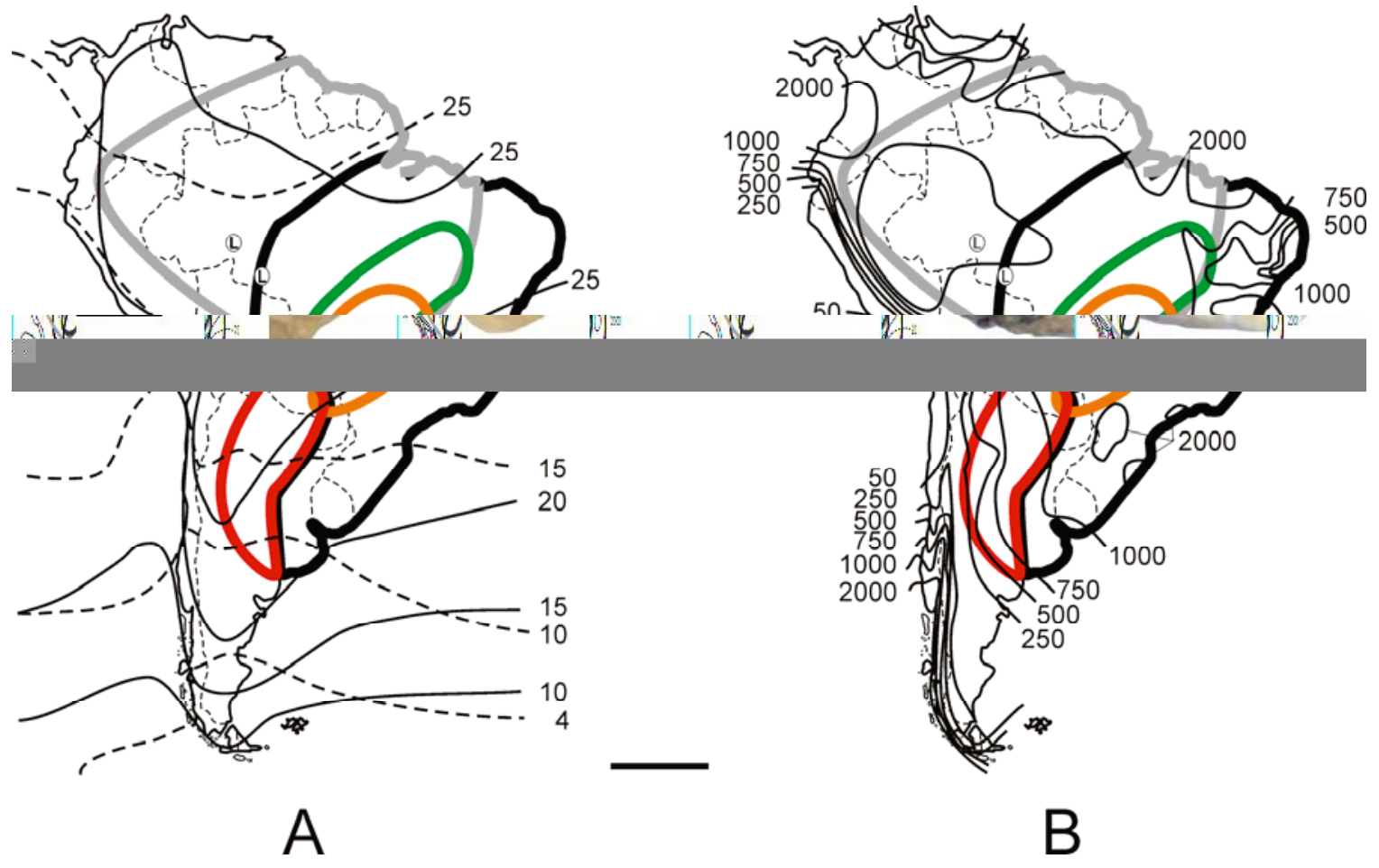

Figura 100. Distribución simplificada del género Tupinambis. A, Distribución confrontada con temperaturas medias de julio (líneas cortadas) y enero (líneas continuas); B, Distribución confrontada con precipitación media anual. Referencias: naranja, T. duseni; L, T. longilineus; negro, T. merianae; verde, T. quadrilineatus; rojo T. rufescens; gris, T. teguixin. Mapas de factores climáticos modificados de Tonni et al. (1999) Escala $=1000 \mathrm{~km}$

\section{DISTRIBUCIÓN ACTUAL DE TUPINAMBIS EN ARGENTINA.}

De las seis especies reconocidas del género mencionadas en la sección anterior, sólo T. rufescens y T. merianae se encuentran en Argentina, distribuidas en la mayoría de las provincias biogeográficas del Dominio Chaqueño (excepto en la Prepuna) y del Dominio Amazónico, al norte del paralelo $40^{\circ} \mathrm{S}$, con una distribución principalmente alopátrida (Fig. 101). Tupinambis rufescens se encuentra en las provincias Chaqueña, del Monte y la parte sur del Espinal, mientras que T. merianae, en las provincias biogeográficas Pampeana y Paranaense, la parte norte del Espinal y la región más húmeda del Chaco. Existen zonas de simpatría en la provincia del Espinal y la Chaqueña (Fig. 101 A). 
Cabrera y Willink (1980) definen las regiones biogeográficas (i.e. dominios, provincias, etc.) sobre la base de la flora. Ésta es dependiente de la topografía, factores edáficos y variables climáticas, entre las que se destacan la temperatura y la precipitación. Por lo tanto, y en función de las provincias biogeográficas de Cabrera y Willink (1980), la distribución de las especies de Tupinambis responde a diferentes preferencias ecológicas. Mientras que T. merianae es mesófila, T. rufescens es más xerófila (Donadío, 1984b; Brizuela y Albino, 2004; Albino et al., 2006). Sin embargo, es posible una mejor aproximación a las preferencias climáticas de Tupinambis si se confrontan en forma independiente los principales parámetros climáticos (régimen de precipitaciones y temperatura media anual) con su distribución. 

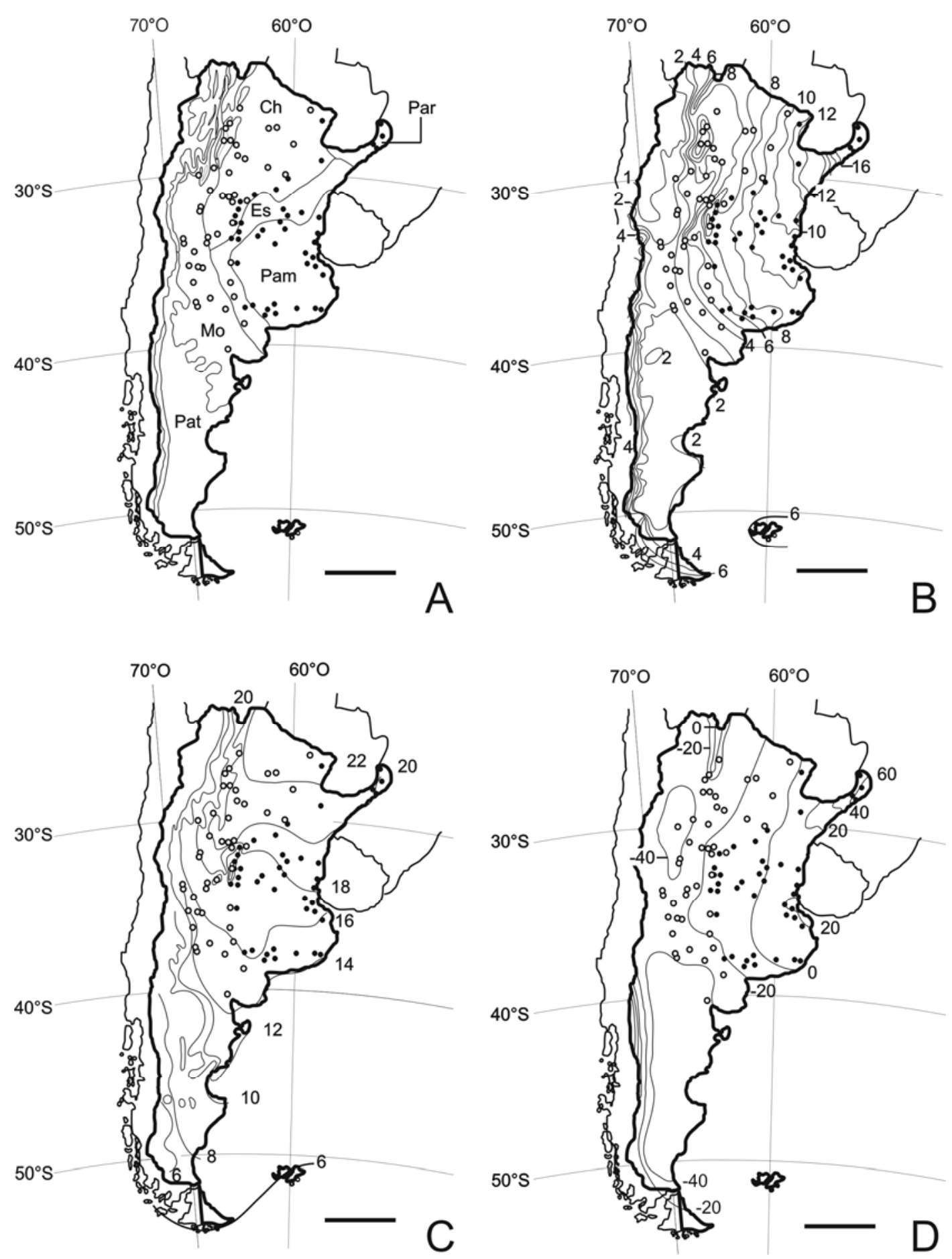

Figura 101. Distribución de Tupinambis en Argentina. A, regiones biogeográficas (Cabrera y Willink, 1980); B, precipitación media anual (mm/año; valores en centenas); $\mathrm{C}$, temperatura medial anual $\left({ }^{\circ} \mathrm{C}\right)$; $\mathrm{D}$, índice hídrico. Abreviaturas: $\mathrm{Ch}$, provincia biogeográfica Chaqueña; Es, provincia biogeográfica del Espinal; provincia biogeográfica Pampeana; provincia biogeográfica Paranaense; Pat, provincia biogeográfica Patagónica. Escala $=500 \mathrm{~km}$. 


\section{PARÁMETROS AMBIENTALES.}

Al confrontar la distribución de Tupinambis con la precipitación anual se observa que el género se distribuye por sobre la isohieta de $200 \mathrm{~mm} / \mathrm{año}$, aunque en algunos pocos casos T. rufescens ha sido citado sobre el límite de la misma en las provincias de San Juan y La Rioja (Fig. 101 B). Esta isohieta, que marca el límite oeste y sur de la distribución del género, se corresponde a grandes rasgos con el límite de la provincia biogeográfica del Monte. Por sobre la isohieta de $200 \mathrm{~mm} / \mathrm{año}$, se observa una distribución diferencial de las dos especies de Tupinambis en relación a la precipitación. Mientras que T. rufescens se distribuye entre los 200-1000 mm/año, $T$. merianae tiene como límite inferior a la isohieta de 600 mm/año (Fig. 101 B). En algunos casos se ha registrado a esta última especie en sitios que se ubican por debajo de esta isohieta en las provincias de La Pampa y Córdoba. Sin embargo, y como se mencionó en el Capítulo IV, las citas de la Provincia de La Pampa de T. merianae serían erróneas (Donadío, 1984b; Cei, 1993; Tiranti y Ávila, 1997). Donadío (1984b) limitó la distribución de T. rufescens al oeste de la isohieta $700 \mathrm{~mm} / \mathrm{año}$, lo cual es real en la mitad sur de la distribución de esta especie (latitud mayor a $32^{\circ} \mathrm{S}$, aproximadamente). Sin embargo, datos de Cei $(1986,1993)$ ubican a T. rufescens por sobre los $700 \mathrm{~mm} /$ año, pero por debajo de la isohieta de $1000 \mathrm{~mm} / \mathrm{año}$, en la parte norte de su distribución. Allí, T. rufescens se encuentra en el Chaco más húmedo, presencia que debería confirmarse.

La confrontación de la distribución de Tupinambis con las temperaturas medias anuales (Fig. $101 \mathrm{C}$ ) permite observar que la isoterma de $14^{\circ} \mathrm{C}$ marca el límite austral de la distribución del género. Sin embargo, y a diferencia del régimen de precipitaciones, la temperatura no tiene efecto diferencial sobre la distribución de las dos especies de Tupinambis. Este límite térmico es levemente inferior al valor mínimo estimado de $22^{\circ} \mathrm{C}$ para la digestión óptima en T. merianae (Giambelluca y Casciario, 1999). Sin embargo, la capacidad de los lagartos de regular comportamentalmente la temperatura corporal permite su presencia en zonas donde la temperatura media ambiental es menor a la temperatura óptima de digestión. En este sentido, Yanosky y Mercolli (1991) presentan datos de temperatura medida en la cloaca de $26,1^{\circ} \mathrm{C}$ cuando en el sustrato la temperatura es de $21,7^{\circ} \mathrm{C}$. Böhme (2003) sostiene que los vertebrados ectotérmicos no permiten reconocer adecuadamente climas tropicales ya que se encuentran adaptados fisiológicamente (e.g. torpor) para tolerar cambios 
climáticos estacionales. Por lo tanto, en las reconstrucciones paleoambientes, en la mayoría de los casos, sólo el límite de temperatura inferior es indicativo. En el caso de Tupinambis este valor es de $14^{\circ} \mathrm{C}$.

Por último, se comparó la distribución de Tupinambis con el Índice Hídrico (IH) de Thornthwaite (Burgos y Vidal, 1951). De esta forma, es posible evaluar simultáneamente la precipitación y temperatura (a través de la evapotranspiración). Este índice en particular integra índices de aridez y humedad de tal forma que se desvincula de la vegetación y queda sujeto sólo a la variación del exceso/deficiencia de agua (Burgos y Vidal, 1951). Tupinambis se distribuye en regiones por sobre IH 40, auque hay registros claramente menores en La Rioja y Río Negro. La distribución de las dos especies siguen el gradiente definido por el IH. Tupinambis rufescens se distribuye sólo desde HI -40 hasta IH -20, en el rango HI -20 a HI 0 se encuentran ambas especies, mientras que a partir de un $\mathrm{IH}>0$ sólo se encuentra T. merianae.

Los resultados de la confrontación entre la distribución de las dos especies de Tupinambis de Argentina con diferentes parámetros ambientales se resumen en la Tabla 13. La temperatura media anual determina la distribución hacia el sur del género, pero no tiene efectos sobre la distribución de las especies, sino que esta última está más relacionada con la cantidad de humedad en el ambiente. Tanto el IH como la precipitación media anual describen las preferencias de estas especies, T. rufescens a ambientes más áridos y T. merianae a ambientes más húmedos. Sin embargo, es la precipitación media anual la que permite una diferenciación más fina, con una menor área de superposición de las distribuciones. Así, la distribución de T. rufescens queda comprendida entre las isohietas de $200 \mathrm{~mm} /$ año y $1000 \mathrm{~mm} / \mathrm{año}$, mientras que la de $T$.

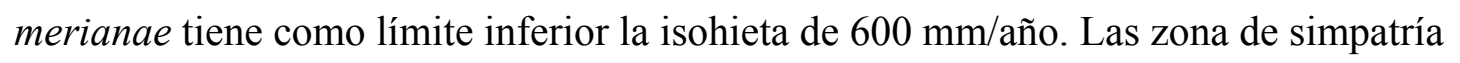
entre los $600 \mathrm{~mm} /$ año y $1000 \mathrm{~mm} /$ año ocurre sólo al norte del paralelo $32^{\circ} \mathrm{S}$; aunque aún debe confirmarse la presencia de T. rufescens en el Chaco húmedo. 


\begin{tabular}{lcccccc} 
& \multicolumn{2}{c}{$\begin{array}{c}\text { Precipitación } \\
(\mathrm{mm} / \mathrm{año})\end{array}$} & \multicolumn{2}{c}{ Temperatura Media } & \multicolumn{2}{c}{ Índice Hídrico } \\
& Mínimo & Máximo & mínimo & máximo & Mínimo & máximo \\
\hline Tupinambis & 200 & $>1600$ & 14 & $>22$ & -40 & $>60$ \\
T. rufescens & 200 & 1000 & 14 & $>22$ & -40 & $-20^{*}$ \\
T. merianae & 600 & $>1600$ & 14 & $>22$ & -20 & $>60$ \\
\hline
\end{tabular}

Tabla 13. Parámetros climáticos máximos y mínimos de Tupinambis en Argentina. Asterisco, en el norte del Chaco el valor es más cercano a cero.

\section{HISTORIA EVOLUTIVA Y BIOGEOGRÁFICA DE TUPINAMBIS}

Si bien las relaciones filogenéticas de las diferentes especies de Tupinambis no pueden ser dilucidadas satisfactoriamente sólo por caracteres osteológicos (Cap. V), cuando se utilizan datos moleculares y de la morfología externa es posible una mayor aproximación (Fitzgerald et al., 1999; Péres Jr y Colli, 1999; Péres Jr, 2003). La hipótesis filogenética de Fitzgerald et al. (1999) (Fig. 87) resulta en una división ancestral entre los Tupinambis de distribución amazónica (T. teguixin y T. longilineus) y los de distribución austral (T. merianae (T. duseni - T. rufescens)). Péres Jr y Colli (1999) incorporan a T. quadrilineatus en su análisis del género, el cual queda agrupado con las especies de distribución más boreal dentro del continente. Estos autores denominan a este grupo "teguixin", mientras que se utiliza el nombre “merianae" para el grupo de especies de distribución más austral. Posteriormente, Péres $\operatorname{Jr}$ (2003) arriba a conclusiones filogenéticas algo diferentes a las de Fitzgerald et al. (1999) y Péres Jr y Colli (1999). Según este autor, T. longilineus es basal respecto a las restantes especies, las cuales se reúnen en dos clados (Fig. 88): uno que incluye a $T$. teguixin y T. quadrilineatus y el otro conformado por (T. merianae ( $T$. $d u s e n i+T$. rufescens)) y equivalente al clado austral o grupo "merianae" de Fitzgerald et al. (1999) y Péres y Colli (1999). En la hipótesis filogenética del Capítulo V, si bien no son resueltas las relaciones entre las diferentes especies de Tupinambis, se observan puntos en común con las hipótesis anteriormente mencionadas: T. quadrilineatus es basal a las restantes especies analizadas y se reconoce la relación de especies hermanas entre $T$. duseni y $T$. rufescens. 
Sobre la base de sus resultados filogenéticos y a partir del reloj molecular, Péres Jr (2003) estima que el género se habría originado hace $32 \mathrm{Ma}$ (Oligoceno temprano) en un ambiente de bosque tropical. En este ambiente se habría diferenciado inicialmente T. longilineus de los restantes Tupinambis, de los que luego se diferenció el ancestro de (T. teguixin + T. quadrilineatus) y el del grupo "merianae" o austral. La división entre T. merianae y (T. duseni $+T$. rufescens) habría ocurrido hace $10 \mathrm{Ma}$ (Péres Jr, 2003), lo que la ubica en el Mioceno medio - tardío, mientras que la divergencia entre $T$. teguixin $+T$. quadrilineatus sería más reciente, hace $3 \mathrm{Ma}$, en el Plioceno (Péres Jr, 2003).

Aunque, según las hipótesis de Péres Jr (2003) y Giugliano et al. (2007), Tupinambis se habría diferenciado de los restantes Tupinambinae durante el Oligoceno temprano (32 Ma) o durante el Eoceno - Oligoceno respectivamente, el género aparece en el registro recién en el Mioceno temprano. Durante el Oligoceno se habría producido un importante elevamiento de los Andes Centrales (fase Pehuenche), superando los 3000 m.s.n.m., y actuando como barrera de los vientos húmedos del Océano Pacífico entre los paralelos $12^{\circ} \mathrm{S}$ y $37^{\circ} \mathrm{S}$ (Lündberg et al., 1998). Este cambio, en conjunto con la disminución de la temperatura media mundial, habría conducido a la retracción de los ambientes tropicales más ampliamente extendidos durante el Eoceno. Es posible considerar que el origen del género Tupinambis se produjo en un ambiente de bosque tropical con parámetros de temperatura y humedad similares a los que habita actualmente T. longilineus, que es la especie más basal del género (Péres Jr, 2003). Esta consideración se ve también soportada por la distribución limitada a ambientes boscosos húmedos de los géneros más cercanos a Tupinambis (Crocodilurus y Dracaena, Cap. V). La modificación de estos ambientes boscosos tropicales durante el Oligoceno habría sido responsable de la diferenciación temprana del género. Si bien no se conocen caracteres osteológicos que diferencien los restos de Tupinambis del Mioceno temprano (Colhuehuapense) y Mioceno temprano-medio (Santacrucense) de Patagonia de los del Mioceno medio de Colombia (Laventense), este último además representado por un único ejemplar juvenil (longitud del cráneo 27,42 mm: Sullivan y Estes, 1997), su presencia en ambientes marcadamente diferentes permite suponer que la diferenciación entre los clados de Tupinambis de bosque tropical y de áreas abiertas ya se habría producido, de manera tal que los ancestros del clado T. quadrilineatus $+T$. teguixin se distribuían en el norte del continente y los del clado "merianae, en el sur. 
Durante el Mioceno temprano, en el norte de Argentina, se desarrollaba la provincia paleo-fitogeográfica Neotropical, que alcanzó los paralelos $28^{\circ} \mathrm{S}$ y $32^{\circ} \mathrm{S}$, mientras que más hacia el sur, se encontraría la provincia de Transición, con elementos de los Dominio Chaqueño y Austral (Barrera et al., 2007). En estos momentos, en Patagonia, se habría instalado un definido clima estacional (Ortiz Jaureguizar y Cladera, 2006), con el desarrollo de un ambiente complejo, que según Barreda et al. (2007), alternaba entre bosques abiertos, bosque xérofilos, sabanas y estepas. Este ambiente, relativamente abierto, coincide con el explotado por los Tupinambis del grupo "merianae" (Péres Jr, 2003). En contraste, en el Mioceno medio del noroeste de América del Sur (Colombia), se desarrollaba un ambiente de bosque tropical (Kay y Madden, 1997) donde habrían prosperado las formas del grupo $T$. teguixin $+T$. quadrilineatus.

Los fósiles del Colhuehuapense (Mioceno temprano) de Gaiman se destacan por presentar dientes posteriores molariformes y un tamaño relativamente pequeño, menor que los del grupo "merianae” y T. teguixin (Brizuela y Albino, 2004; Cap. IV) (Fig. 97). Los dientes molariformes son considerados como un carácter derivado, al compararlo con Callopistes (Tupinambinae basal) y Crocodilurus [grupo hermano de (Tupinambis (Dracaena + Paradracaena)), Cap. V], quienes presentan dientes labiolingualmente comprimidos. Se destaca también que $T$. longilineus, que es la especie más basal del género Tupinambis, tiene dientes marcadamente tricuspidados, no molariformes (Cap. III), caracteristica que comparte con T. quadrilineatus. Sin embargo, el menor tamaño de los fósiles de Gaiman respecto a los del grupo "merianae" y T. teguixin puede ser considerado como una condición primitiva, dado que los tupinambinos más primitivos son más pequeños que estos últimos y $T$. longilineus es la de menores dimensiones de todas las especies del género. El material de Gaiman se considera insuficiente para sostener la diagnosis de una especie extinta, ya que el tamaño es el único carácter relevante diferencial respecto a las especies de dientes molariformes: grupo "merianae" y T. teguixin. Sin embargo se destaca que el ambiente propuesto para la Formación Sarmiento en Gaiman es compatible con un tipo de ambiente abierto como el que explotan las especies del grupo "merianae".

Con respecto a los materiales asignados a Tupinambis sp. del Santacrucense de Patagonia (Mioceno temprano - medio), puede advertirse que son de dimensiones algo mayores respecto a los del Colhuehuapense, pero dentro de los valores mínimos observados para T. merianae (Cap IV) (Fig. 97). Posiblemente, se haya producido un 
progresivo aumento de tamaño en los Tupinambis con dientes molariformes durante el Mioceno, ya que los fósiles del Huayqueriense (Mioceno tardío) ya muestran un rango de tamaño similar al observado en los T. merianae actuales.

Durante el Santacrucense (Mioceno temprano - medio), se registra la máxima extensión austral de la historia del género, llegando a una latitud de $50^{\circ} \mathrm{S}$. En el sitio de Monte León, las condiciones climáticas debieron ser al menos las mínimas reconocidas para $T$. rufescens, que es la especie de distribución ambiental más extrema: temperatura media anual sobre $\operatorname{los} 14^{\circ} \mathrm{C}$ y precipitaciones mayores a 200 $\mathrm{mm} / \mathrm{año}$. Las condiciones climáticas que permitieron la extendida distribución austral de Tupinambis durante el Mioceno temprano - medio se habrían prolongado durante el Mioceno medio, cuando tiene lugar el Óptimo Climático (Böhme, 2003; Ortiz Jaureguizar y Cladera, 2006).

Luego del Óptimo Climático, comienza un enfriamiento sostenido que, con el retroceso del "Mar Paranaense" y la fase Quechua de la orogenia andina marcan el inicio de la "Edad de las Planicies Australes" al final del Mioceno. En este momento, Tupinambis se encontraba en la provincia de La Pampa y Buenos Aires como en la actualidad (Albino et al., 2006). El retroceso de la temperatura media anual que ocurre durante el Mioceno tardío, por ser un parámetro climático que actualmente delimita la frontera sur de Tupinambis, probablemente haya determinado el comienzo de la retracción del género hacia el norte. La presencia de $T$. rufescens en el norte de Patagonia en la actualidad (Gran Bajo del Gualicho) se interpreta como un relicto de la distribución más austral de Tupinambis en el Mioceno (Albino et al., 2006).

El desarrollo de la "Edad de la Planicies Australes" coincide con el momento estimado por Péres Jr (2003) para la divergencia entre $T$. merianae y el ancestro de $T$. duseni + T. rufescens. Albino et al. (2006) sugieren que el "Mar Paranaense", que se extendía desde el norte de Patagonia hasta el sur de Paraguay, y desde el este de los Andes al oeste de Uruguay, habría favorecido la diversificación del grupo "merianae". El ascendente de T. duseni $+T$. rufescens se habría diferenciado en los ambientes más áridos del sur, acompañando el desarrollo de las amplias planicies, mientras que $T$. merianae se habría diferenciado en los ambientes más cálidos y húmedos del este de Brasil, al sur de la Amazonia, para colonizar el Chaco en tiempos más recientes. Dado que la humedad (i.e. régimen de precipitaciones) es el factor ambiental que tiene un efecto diferencial sobre la distribución de T. merianae y T. rufescens en Argentina, es posible considerar que la elevación de los Andes habría actuado como barrera de la 
humedad procedente del Pacífico, de tal manera que se estableció un gradiente de zonas áridas al oeste y zonas húmedas al este, favoreciendo la divergencia de las especies luego del retiro del "Mar Paranaense", cuando las poblaciones se pusieron nuevamente en contacto. Posteriormente, con la elevación final del Escudo Brasileño, se produciría la diferenciación de T. duseni y T. rufescens (Péres Jr, 2003), quedando estas especies en el Cerrado y Chaco, respectivamente.

Los materiales asignados a Tupinambis recuperados de las diferentes localidades desde Mioceno tardío a la actualidad coinciden con la distribución actual del género (Cap. IV), de modo que se puede asumir que las características paleoclimáticas de estos sitios habrían estado comprendidas dentro del rango de temperaturas y precipitaciones en que habita el género en el presente.

Como se mencionó anteriormente (Cap. V), la especie extinta $T$. uruguaianensis (Pleistoceno tardío de Brasil) se sustenta como especie sólo en lo referido a su tamaño, el cual excede el registrado en la muestra disponible de $T$. merianae aquí analizada. En este trabajo, la diferencia de tamaño por sí sola no se considera diagnóstica, por los cual los fósiles deberían ser considerados como Tupinambis sp (Cap. V). 


\section{CAPÍTULO VI}

\section{CONCLUSIONES FINALES}

La revisión del material fósil de los lagartos no iguanios continentales de la Argentina ha permitido actualizar dicho registro de acuerdo con criterios modernos y en un marco cladístico. Diferentes trabajos referidos a la osteología de los escamosos, así como nuevas observaciones realizadas durante el desarrollo de esta tesis, especialmente el análisis filogenético que proveyó caracteres osteológicos útiles para una mejor definición taxonómica de los fósiles asignados a la familia Teiidae, han posibilitado una reevaluación de los fósiles, cuyos resultados se presentan en la tabla 14.

A partir de esta revisión, se logró la invalidación de un importante número de géneros y especies, entre las cuales se destaca la falta de fundamentación para el género Lumbrerasaurus del Eoceno del noroeste argentino, que debe ser considerado como un Teiidae Tupinambinae indeterminado. Asimismo, los géneros Diasemosaurus y Dibolosodon del Mioceno del extremo austral de nuestro país, se sinonimizaron con el género actual Tupinambis, y su asignación específica permanece indeterminada. Las especies extintas de Tupinambis de la provincia de Buenos Aires descriptas por Rovereto en 1914 y Kraglievich en 1947 (T. preteguixin, T.

prerufescens, T. multidentatus, T. brevirostris y T. onyxodon) son reevaluadas en este trabajo, de modo tal que se designan como Tupinambis sp.. De forma comparable, las asignaciones a especies actuales de Tupinambis realizadas por Donadío (1983, 1985) y Quintana et al. (2000) (Tabla 14), fueron desconsideradas, dado que no es posible, con los materiales disponibles, lograr una determinación a nivel específico. Dichos registros son considerados en este trabajo como Tupinambis sp. Contrariamente a estos casos, fue posible validar la única especie extinta del género Callopistes procedente del Mioceno tardío-Plioceno temprano de la provincia de Buenos Aires, descripta por Chani en 1976 como C. bicuspidatus. En este caso, la reevaluación permitió fundamentar el reconocimiento de una entidad taxonómica distinta a las dos especies actuales del género pero sobre la base de caracteres completamente diferentes a aquellos considerados por el autor original del nombre. Por último, las 
revisiones obtenidas de otros materiales del Mesozoico y Cenozoico de Argentina permitieron lograr una más exacta evaluación taxonómica del registro de distintos grupos.

Las reconsideraciones sistemáticas realizadas respondieron a que varios de los caracteres que se consideraban diagnósticos de determinados taxones resultaron no serlos al confrontar los fósiles con el material osteológico de referencia y advertir las variaciones existentes en los especímenes actuales.

En suma, el registro revisado de lagartos no iguanios continentales de Argentina, a nivel de géneros y especies, es menos diverso que sus versiones previas. Este registro está claramente dominado por los teidos tupinambinos, posiblemente debido al tamaño de estos lagartos, que propiciaría la mejor conservación de sus huesos y una mayor posibilidad de ser encontrados a simple vista, con relación a otros taxa.

\begin{tabular}{|c|c|c|c|}
\hline Localidad & Formación-Edad & $\begin{array}{c}\text { Sistemática } \\
\text { original }\end{array}$ & $\begin{array}{c}\text { Sistemática } \\
\text { revisada }\end{array}$ \\
\hline $\begin{array}{l}\text { Cinco Saltos, Río } \\
\text { Negro }\end{array}$ & Fm. Anacleto & Squamata indet & ? Scincoidea \\
\hline $\begin{array}{l}\text { Ea. Pampa Grande, } \\
\text { Salta }\end{array}$ & Fm. Lumbrera & $\begin{array}{l}\text { Lumbrerasaurus } \\
\text { scagliai }\end{array}$ & Tupinambinae indet. \\
\hline Gaiman, Chubut & $\begin{array}{l}\text { Fm. Sarmiento, } \\
\text { Miembro Trelew }\end{array}$ & Tupinambis sp & $\begin{array}{l}\text { Tupinambis sp. } \\
\text { (nuevo material) }\end{array}$ \\
\hline Gaiman, Chubut & $\begin{array}{l}\text { Fm. Sarmiento, } \\
\text { Miembro Trelew }\end{array}$ & - & Scleroglossa indet. \\
\hline $\begin{array}{l}\text { Monte León, Santa } \\
\text { Cruz }\end{array}$ & Fm. Santa Cruz & $\begin{array}{l}\text { Diasemosaurus } \\
\text { occidentalis }\end{array}$ & $\begin{array}{l}\text { Tupinambis sp. } \\
\text { (Brizuela y Albino, } \\
\text { 2008a) }\end{array}$ \\
\hline $\begin{array}{l}\text { Monte León, Santa } \\
\text { Cruz }\end{array}$ & Fm. Santa Cruz & Dibolosodon typicus & $\begin{array}{c}\text { Tupinambis sp. } \\
\text { (Brizuela y Albino, } \\
\text { 2008a) }\end{array}$ \\
\hline $\begin{array}{l}\text { Cañadón del Tordillo, } \\
\text { Neuquén }\end{array}$ & Fm. Collón Cura & - & $\begin{array}{c}\text { Tupinambis o } \\
\text { Crocodilurus } \\
\text { (Brizuela y Albino, } \\
\text { 2008b) }\end{array}$ \\
\hline Telén, La Pampa & Fm. Cerro Azul & - & $\begin{array}{c}\text { Tupinambis sp. } \\
\text { (Albino et al., 2006) }\end{array}$ \\
\hline
\end{tabular}




\begin{tabular}{|c|c|c|c|}
\hline $\begin{array}{l}\text { Bajo Giuliani, La } \\
\text { Pampa }\end{array}$ & Fm. Cerro Azul & - & $\begin{array}{c}\text { Tupinambis sp. } \\
\text { (Albino et al., } 2006 \mathrm{y} \\
\text { nuevo material) }\end{array}$ \\
\hline Quehué, La Pampa & Fm. Cerro Azul & - & $\begin{array}{c}\text { Tupinambis sp. } \\
\text { (Albino et al., 2006) }\end{array}$ \\
\hline Loventué, La Pampa & Fm. Cerro Azul & - & $\begin{array}{c}\text { Tupinambis sp. } \\
\text { (Albino et al., 2006) }\end{array}$ \\
\hline Caleufú, La Pampa & Fm. Cerro Azul & - & $\begin{array}{c}\text { Tupinambis sp. } \\
\text { (Albino et al., } 2006 \mathrm{y} \\
\text { nuevo material) }\end{array}$ \\
\hline $\begin{array}{l}\text { Chacharramendi, La } \\
\text { Pampa }\end{array}$ & Fm. Cerro Azul & - & "cnemidoforino" \\
\hline $\begin{array}{l}\text { Cantera de Tuclame, } \\
\text { Córdoba }\end{array}$ & Fm. La Playa & Tupinambis merianae & Tupinambis sp. \\
\hline $\begin{array}{l}\text { Farola Monte Hermoso, } \\
\text { Buenos Aires }\end{array}$ & Fm. Monte Hermoso & $\begin{array}{l}\text { Tupinambis } \\
\text { multidentatus, } T \text {. } \\
\text { brevirostris, } T \text {. } \\
\text { prerufescens, } T \text {. } \\
\text { preteguixin }\end{array}$ & $\begin{array}{c}\text { Tupinambis sp. } \\
\text { (y nuevo material) }\end{array}$ \\
\hline $\begin{array}{l}\text { Farola Monte Hermoso, } \\
\text { Buenos Aires }\end{array}$ & Fm. Monte Hermoso & $\begin{array}{l}\text { Callopistes } \\
\text { bicuspidatus }\end{array}$ & $\begin{array}{c}\text { Callopistes } \\
\text { bicuspidatus }\end{array}$ \\
\hline $\begin{array}{l}\text { Chapadmalal, Buenos } \\
\text { Aires }\end{array}$ & "Fm." Chapadmalal & Tupinambis sp. & $\begin{array}{c}\text { Tupinambis sp. } \\
\text { (y nuevo material) }\end{array}$ \\
\hline $\begin{array}{l}\text { Barranca de los Lobos, } \\
\text { Buenos Aires }\end{array}$ & "Fm." Chapadmalal & Tupinambis sp. & Tupinambis sp. \\
\hline Miramar, Buenos Aires & "Fm." Chapadmalal & Amphisbaenia indet & Amphisbaenidae indet. \\
\hline $\begin{array}{l}\text { Barranca Parodi } \\
\text { Miramar, Buenos Aires }\end{array}$ & "Fm.” Vorohué & Tupinambis onyxodon & Tupinambis $\mathrm{sp}$ \\
\hline $\begin{array}{l}\text { Las Grutas - Punta } \\
\text { Negra, Necochea, } \\
\text { Buenos Aires }\end{array}$ & $?$ & Amphisbaenia indet & $\begin{array}{c}\text { Amphisbaena cf. } \\
\text { marellii }\end{array}$ \\
\hline $\begin{array}{l}\text { Cueva Tixi, Buenos } \\
\text { Aires }\end{array}$ & sitio arqueológico & $\begin{array}{l}\text { Tupinambis } \mathrm{cf} . \\
\text { merianae }\end{array}$ & Tupinambis sp \\
\hline $\begin{array}{l}\text { Cueva El Abra, Buenos } \\
\text { Aires }\end{array}$ & sitio arqueológico & $\begin{array}{l}\text { Tupinambis } \mathrm{cf} . \\
\text { merianae }\end{array}$ & Tupinambis sp \\
\hline $\begin{array}{l}\text { "Lomas del Veinte" } \\
\text { Santiago del Estero }\end{array}$ & sitio arqueológico & Tupinambis rufescens & Tupinambis sp. \\
\hline
\end{tabular}

Tabla 14. Registro fósil de lagartos continentales (excepto Iguania) de la Argentina revisado en este trabajo. 
Sobre la base de este registro, pueden plantearse los siguientes puntos sobresalientes en la historia de los lagartos no iguanios.

1. El clado Scleroglossa tiene su registro más temprano en América del Sur en el Cretácico superior de la provincia de Neuquén, con un resto de un probable Scincoidea.

2. No se ha podido confirmar la existencia de representantes de la familia Teiidae en el Cretácico del territorio argentino; sin embargo, el registro de un Tupinambinae indeterminado en el Eoceno del Noroeste, favorece la idea de una diferenciación muy temprana de los teidos en América del Sur, seguida de una diversificación en los principales agrupamientos. Esta posibilidad está apoyada por los registros del Paleógeno de Brasil (Carvalho, 2001) y diferentes hipótesis filogenéticas (e.g. Nydam et al., 2007).

3. Los hallazgos de lagartos en el Paleógeno de Argentina son escasos; contrariamente, el Neógeno es muy rico en restos de lagartos, especialmente del Mioceno, destacándose la primer aparición de géneros actualmente presentes en la fauna sudamericana (Tupinambis, Callopistes). En este sentido, el Mioceno también ha provisto los primeros géneros vivientes de iguanios de América del Sur (Albino, 2008).

4. Luego del hiato del Eoceno temprano-Mioceno temprano, el registro de la familia Teiidae presenta su máxima extensión geográfica en el Mioceno temprano- medio, en que alcanza aproximadamente los $50^{\circ} \mathrm{S}$ y los $70^{\circ} \mathrm{O}$. Los hallazgos de restos de Tupinambis son abundantes durante todo el Mioceno, con presencias destacables en sitios de la región pampeana y patagónica, que no pueden ser referidos a ninguna especie en particular pero que evidencian un aumento progresivo de tamaño desde el Mioceno temprano al Mioceno tardío.

5. Los registros patagónicos de tupinambinos (provincias de Neuquén, Chubut y Santa Cruz) denotan condiciones climáticas y ambientales drásticamente diferentes a las actuales durante el Mioceno, con parámetros que habrían superado como mínimo los $200 \mathrm{~mm}$ de precipitación media anual y $14^{\circ} \mathrm{C}$ de temperatura, de acuerdo a la distribución actual de las especies de Tupinambis de Argentina, que son los tupinambinos que alcanzan la distribución más austral en el presente.

6. El género de Tupinambinae basal Callopistes habría tenido una desconocida historia temprana en territorio sudamericano que le habría permitido poblar 
extensamente regiones al este de los Andes, donde hoy en día no se encuentra, bajo condiciones climático ambientales diferentes a las que explotan actualmente.

7. El Neógeno también se caracteriza por la manifestación de una diversidad creciente en algunos sitios. Se destaca la localidad de Gaiman (Mioceno temprano de la provincia de Chubut) en Argentina (scleroglosos no Teiidae y Tupinambis) y La Venta (Mioceno medio) de Colombia (Tupinambis y Paradracaena).

8. Paradracaena representa el único género extinto de Teiidae, el cual, de acuerdo a los resultados filogenéticos obtenidos en este trabajo, resulta un género válido y grupo hermano de Dracaena. Paradracaena persiste hasta el Mioceno tardío de Perú (Pujos et al., 2009), pero no vuelve a aparecer con posterioridad a este registro. Los cambios ambientales producidos en el norte del territorio sudamericano habrían provocado su extinción.

9. En el Mioceno tardío de Argentina se registra por primera vez un teido “cnemidoforino", que, según la filogenia lograda en esta tesis, es el grupo hermano de los Tupinambinae. Este clado, de un origen probablemente más temprano, no vuelve a aparecer hasta el Pleistoceno tardío - Holoceno temprano (Albino, 2005).

10. El primer registro de Amphisbaenia de América del Sur, descripto hasta el momento, corresponde a un Amphisbaenidae indeterminado del Plioceno temprano-medio de la provincia de Buenos Aires. Este clado está poco representado en el registro pero puede reconocerse una especie extinta, Amphisbaena marellii, en el Ensenadense (Pleistoceno temprano-medio) de la provincia de Buenos Aires (Torres y Montero, 1998a, 1998b). Restos compatibles con los de $A$. marellii, de procedencia estratigrafica incierta, ha sido recuperados de los acantilados costeros cercanos a Necochea (Las Grutas - Punta Negra) provincia de Buenos Aires. También se reconocen restos atribuibles a especies actuales en el Lujanense de la provincia de Buenos Aires (Amphisbaena heterozonata) y en sitios arqueológicos de las provincias de Salta (Amphisbaena heterozonata) y Catamarca (Amphisbaena camura y Amphisbaenia indet.) (de la Fuente, 1999; Tobisch et al., 2005; Scanferla et al., 2006; Albino y Kligmann, en prensa). 
11. La supremacía de restos fósiles asignados a Tupinambis y el conocimiento sobre la distribución actual de sus especies y sobre la historia paleoclimática y paleoambiental sudamericana, permite una mayor aproximación a la historia evolutiva de este género. Tupinambis, que representa el grupo hermano del clado conformado por Dracaena + Paradracaena, se habría originado en ambientes de bosques tropicales cerrados durante el Eoceno. Los cambios climáticos acontecidos durante el Oligoceno habrían provocado la retracción de estos ambientes, resultado en la primera diversificación del género. En el Mioceno, Tupinambis se encuentra en dos ambientes contrastantes: mientras en el norte del continente (Colombia) está asociado a escenarios de bosques cerrados, en la Patagonia se los encuentra en áreas más abiertas. Estos disímiles ambientes son los que explotan actualmente $T$. quadrilineatus y $T$. teguixin, por un lado, y el grupo "merianae" (T. duseni, T. merianae y $T$. rufescens), por el otro. Se puede suponer que la dicotomía entre estas especies ya se habría producido al comienzo del Mioceno. Luego del Óptimo Climático del Mioceno temprano-medio, el retroceso de la temperatura media sería responsable de la retracción de la distribución del género a menores latitudes. La diferenciación de T. merianae del clado T. duseni $+T$. rufescens habría ocurrido como consecuencia de la transgresión del mar "Paranaense", el cual, actuando como una barrera geográfica, permitió el desarrollo del ancestro de T. duseni + T. rufescens en los ambientes más áridos del sur, y la diferenciación de T. merianae en los ambientes más húmedos del norte. Al desaparecer la barrera, se habría producido un fenómeno de dispersión que pondría en contacto a las poblaciones de T. rufescens del sur y oeste de Argentina con las de T. merianae, que avanzarían por el noreste. Los gradientes de precipitación media anual, ascendentes en sentido oeste-este, habrían profundizado la diferenciación de estas dos especies de modo tal que la primera quedaría adaptada a condiciones más áridas que la segunda. La divergencia entre T. duseni y T. rufescens, según datos de reloj molecular, habría ocurrido recientemente (10 Ma), con la elevación final del escudo brasilero, mientras que la separación de T. quadrilineatus y T. teguixin fue propuesta para hace tan sólo 3 Ma (Péres Jr, 2003); sin embargo, esta última estimación no coincide con la filogenia presentada en esta tesis, de donde se infiere que T. quadrilineatus se habría diferenciado más tempranamente. 
Con una historia desarrollada desde el Mesozoico hasta nuestros días, los lagartos continentales no iguanios de nuestro país componen el registro más abundante y completo de lagartos fósiles sudamericanos. La marcada dominancia de la actual familia Teiidae se traduce en la posibilidad de evaluar restos fósiles de reptiles con una sólida base sustentada en el conocimiento de la osteología de las formas vivientes, de forma tal que hace posible limitar la nominación de nuevos taxa. Su evolución biogeográfica, dramáticamente influenciada por los cambios climáticos y ambientales de comienzos del Neógeno, adquiere fundamental importancia al momento de interpretar las filogenias moleculares, y al mismo tiempo, aportan información útil sobre la antigüedad mínima de sus componentes para utilizar como referencias en el reloj molecular. Estos motivos hacen particularmente interesante la continuación del desarrollo de un tema que aún no está agotado y que, lejos de representar un item restringido dentro de la paleontología de vertebrados, puede ser profundizado a la luz de nuevos hallazgos. 


\section{Anexo I: Matriz de datos utilizada en el análisis cladistico}
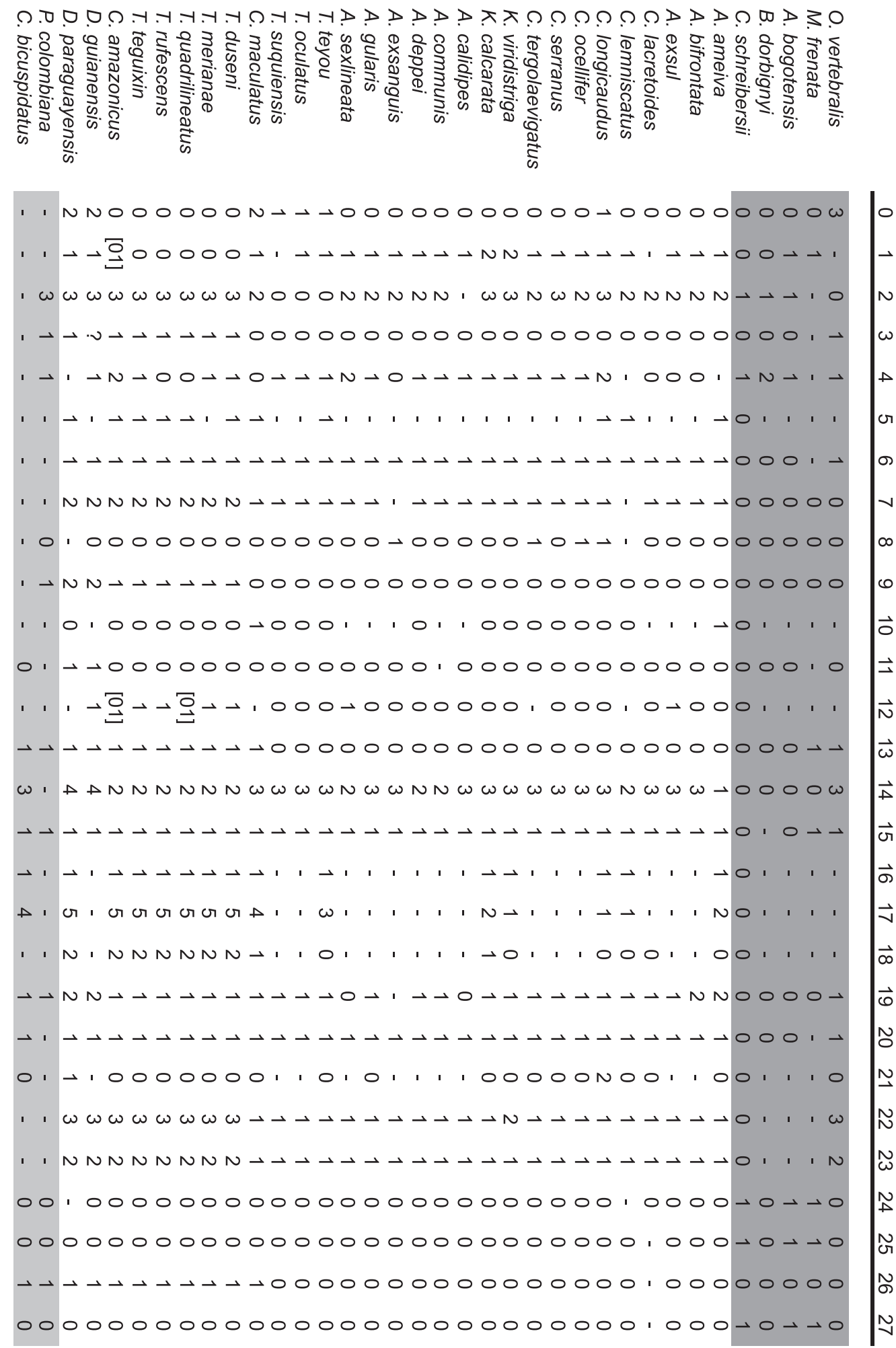


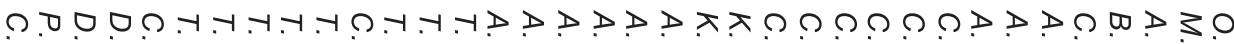

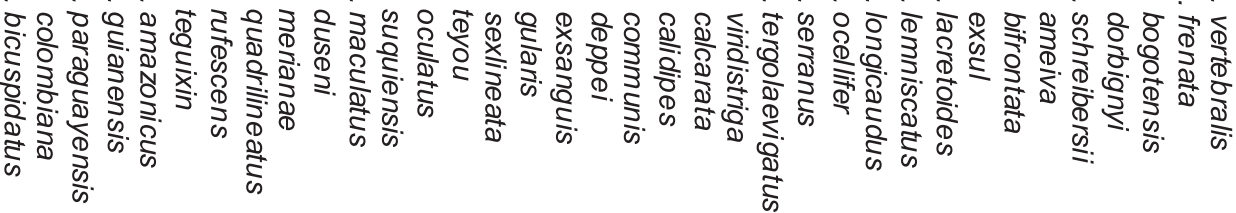

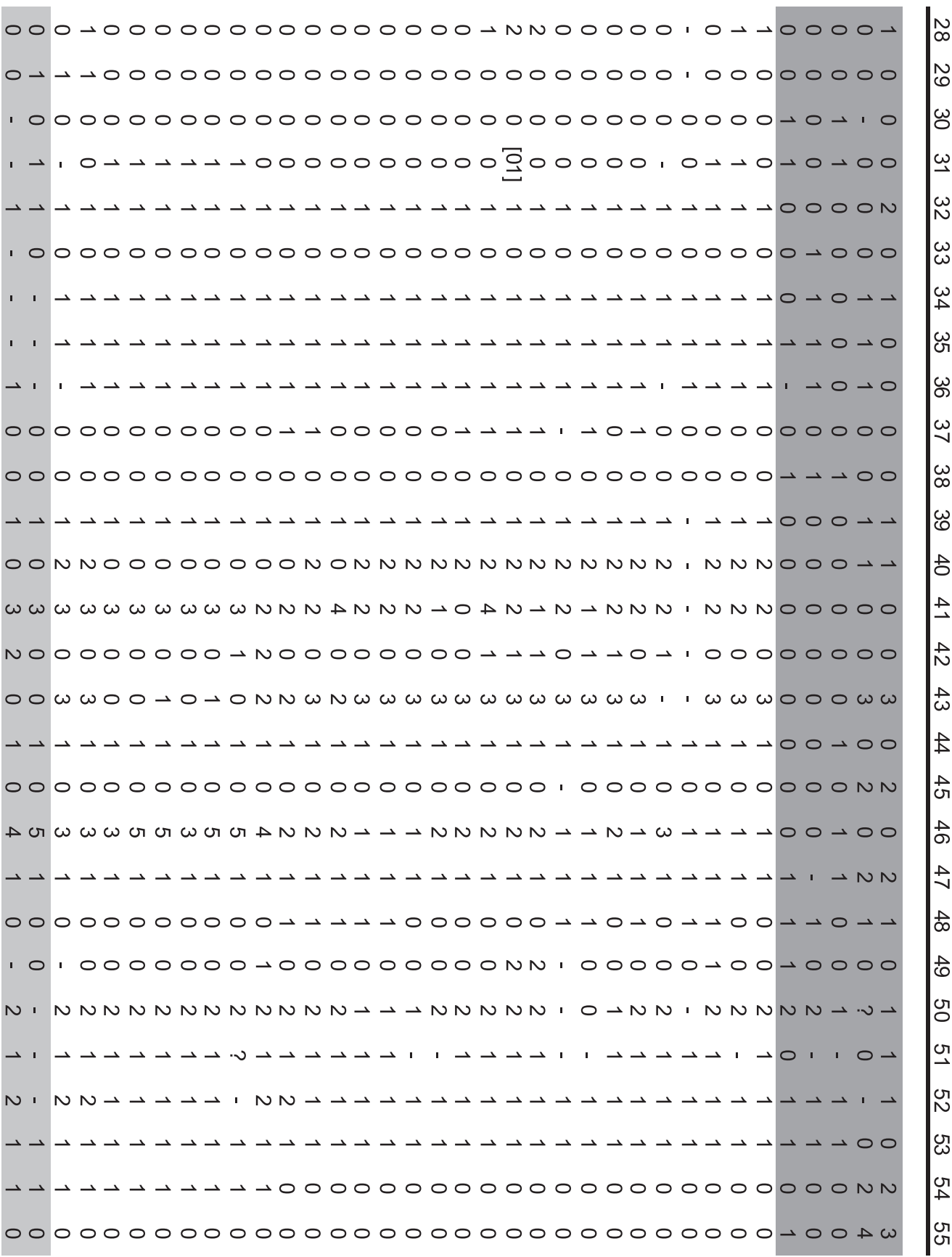




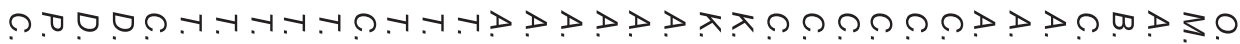

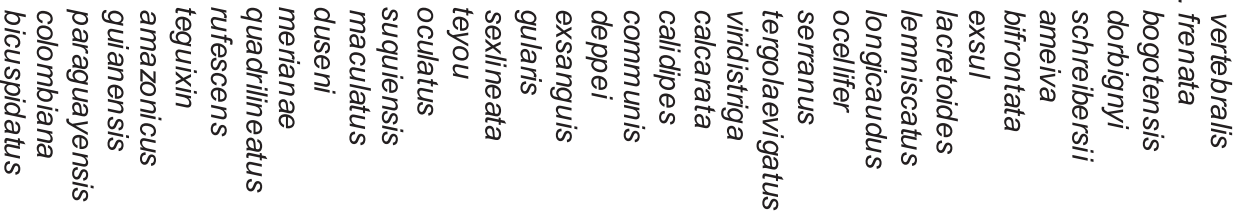

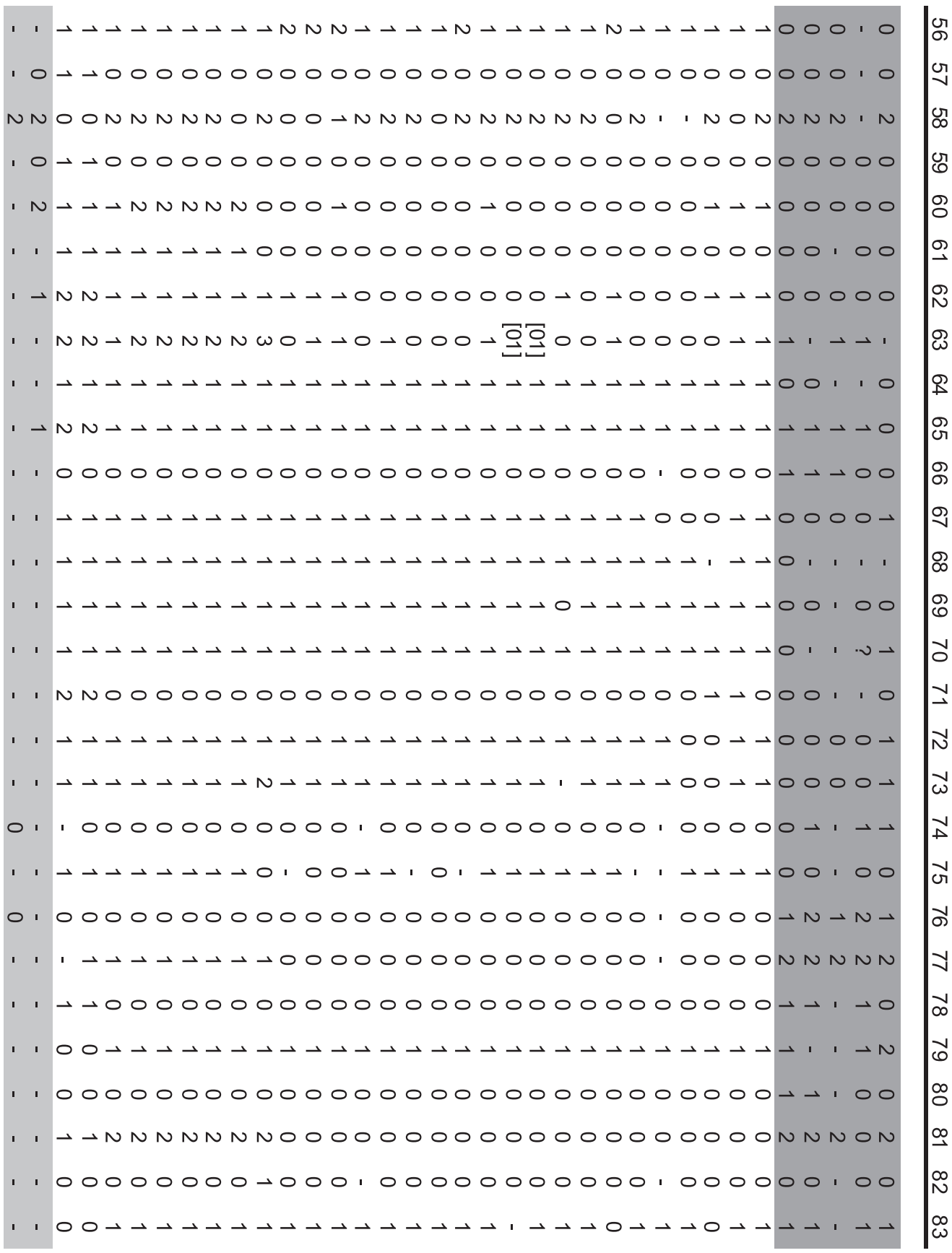




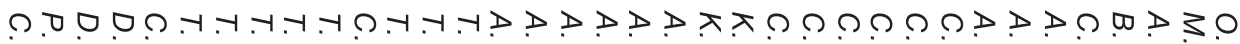

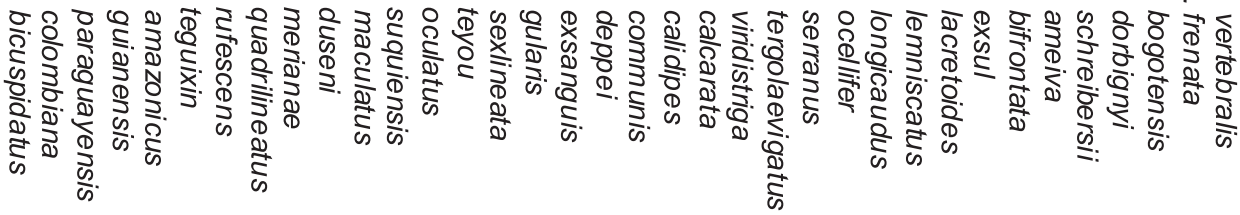

I $1000000000000000000000000-0+-100000$

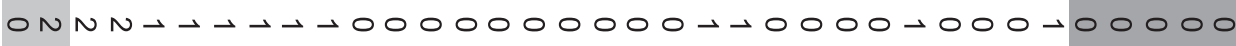
$0000000000000000000010000000000000 \rightarrow-$ $\omega \omega \omega \omega \omega \omega \omega \omega \omega \omega \omega N N N \rightarrow \rightarrow \rightarrow-\rightarrow N N N \rightarrow \rightarrow \rightarrow \rightarrow N N \rightarrow N N O N O O \rightarrow$ $\rightarrow+\rightarrow+\rightarrow+\rightarrow+\rightarrow-100000000000000000000 N 0 N N \rightarrow$

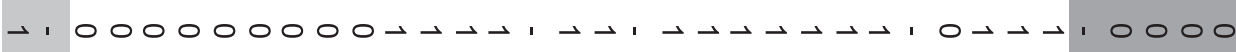
$00000000000000000000000000-0000 \omega 0 \omega \omega N$

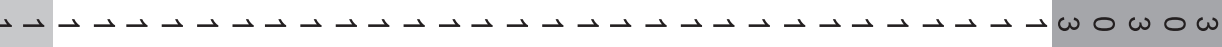

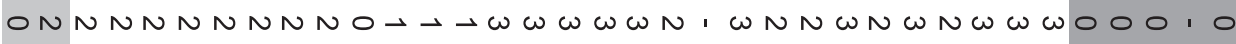

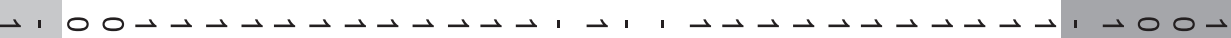
$0.000000000 \rightarrow-100000000-00 \rightarrow 000001+01+$

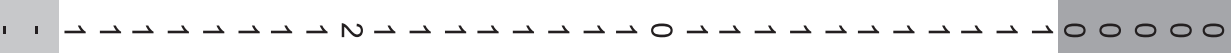

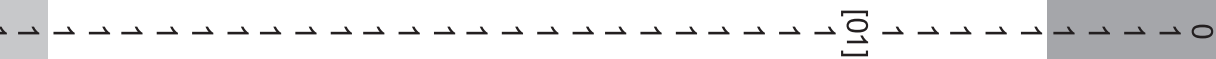
$\rightarrow N n N \rightarrow-\rightarrow+\rightarrow-\rightarrow-\rightarrow 00-000 \rightarrow-00000000000000$ $\rightarrow \rightarrow-\rightarrow+\rightarrow-\rightarrow+\rightarrow-\rightarrow \rightarrow-\rightarrow N N N N N N \rightarrow N N N N \rightarrow N N N N \rightarrow \rightarrow 00$

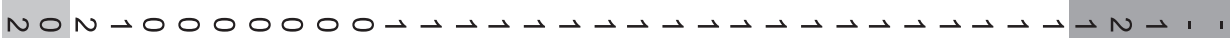
$\rightarrow-\omega N \omega \omega N \omega \rightarrow N N N N N N N N N N N N N N N N N N N N O N \omega N N$ O ONNN苂ONNO00.N00000000000-000000n00 $00000000000 \rightarrow-\rightarrow 0000 \rightarrow-0000-000 \rightarrow 0 \rightarrow 00000$ $00000000000 \rightarrow-\rightarrow 000000000000000-N \omega \omega 000$ ○ 0 N $1 \rightarrow+\rightarrow \rightarrow 0 \omega N O N N N N N N N N N N N N \rightarrow N N N N N \rightarrow \rightarrow N N A N A+$ , $1 N-N N \rightarrow N N N N N N N N N N N N N N \rightarrow \rightarrow N, N N N N N \rightarrow 0,00$ '

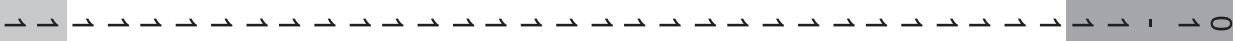
$000000000000000000000000000000000 . \cdots \cdots$

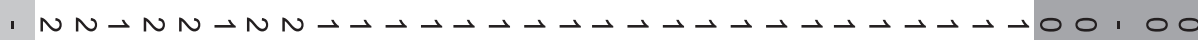
$1,+\rightarrow \rightarrow-0 \rightarrow-0000000000 \rightarrow 0000000000011,00$ 
ט.

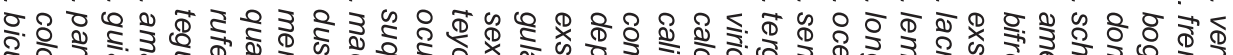

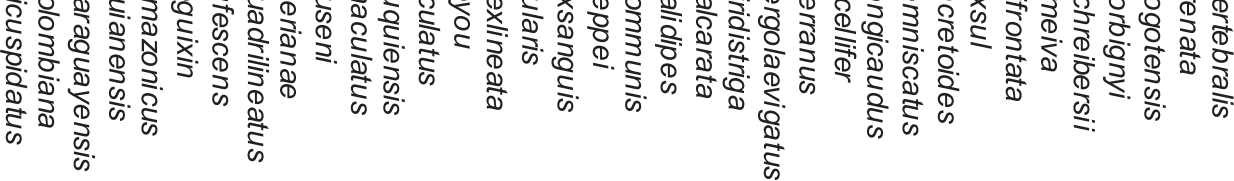

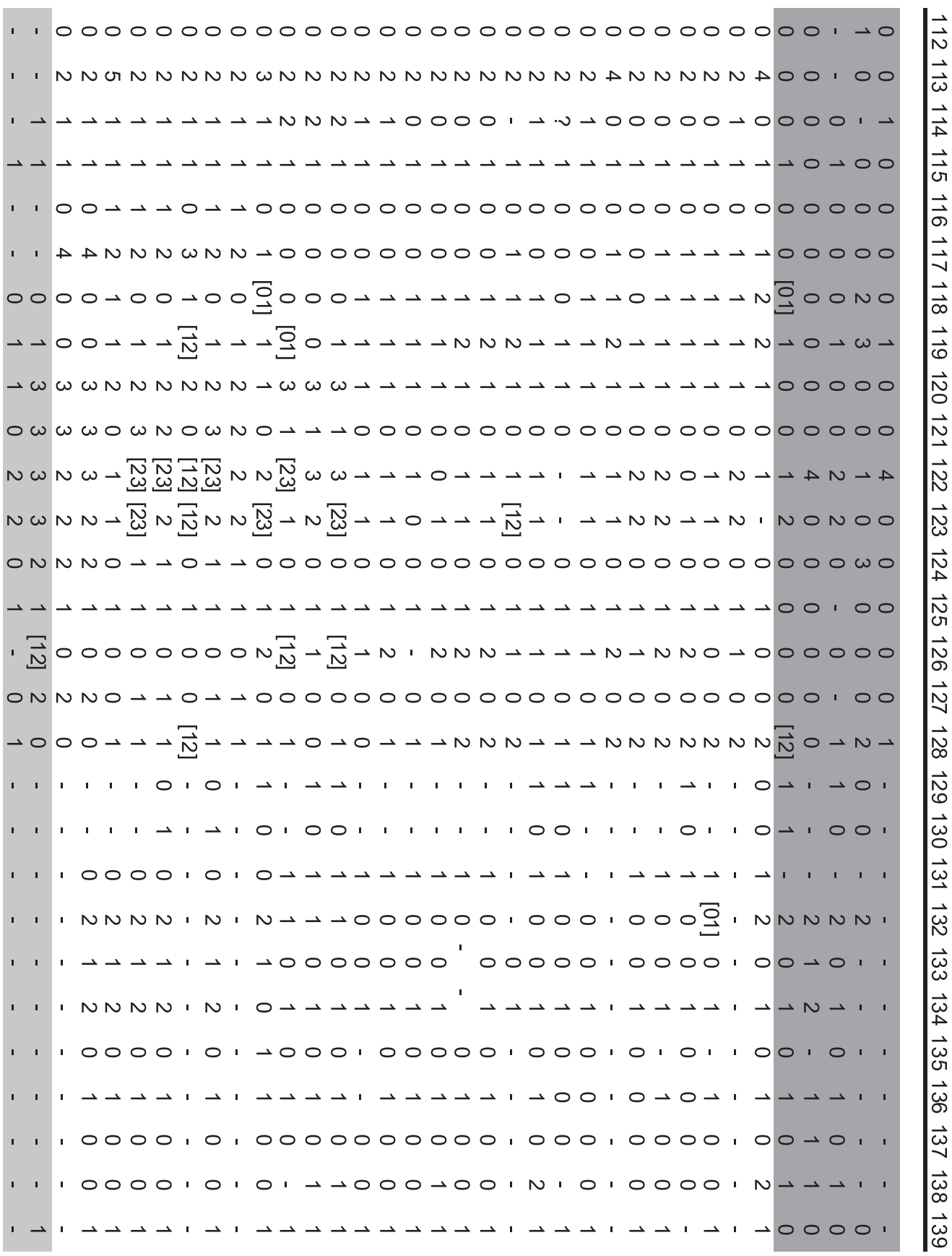




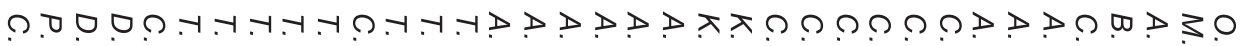

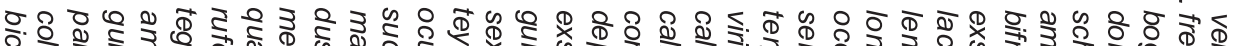

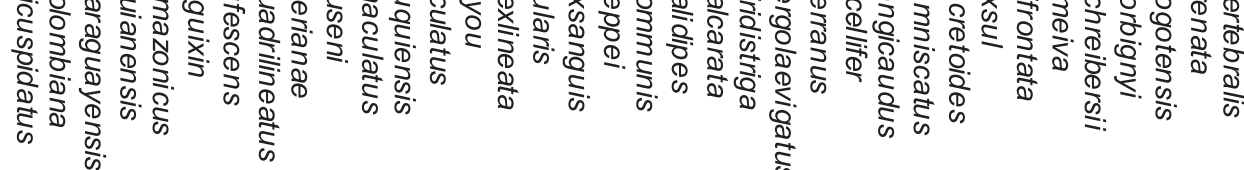

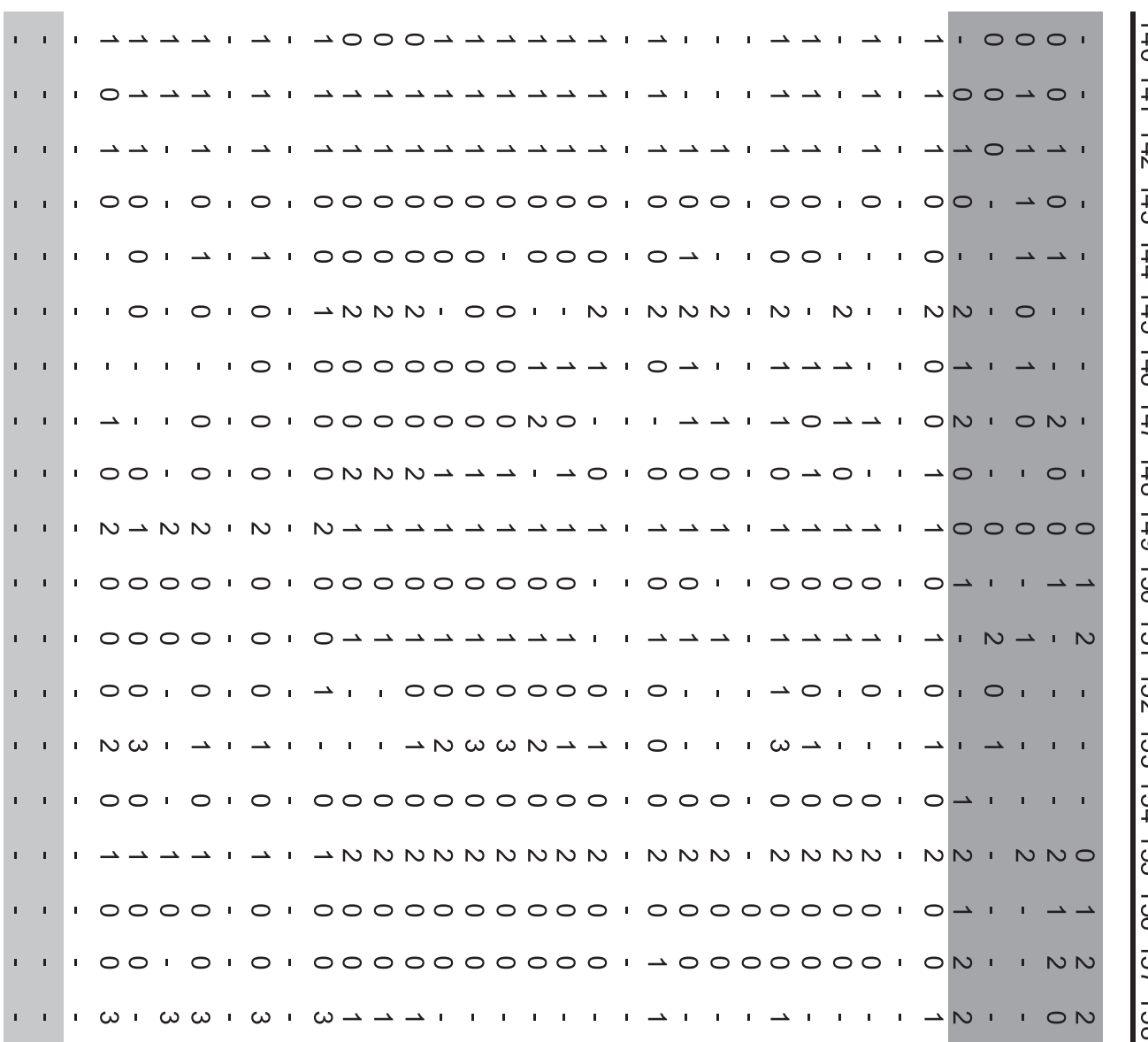




\section{Anexo II: Sinapomorfías del Consenso Estricto}

O. vertebralis :

No autapomorphies

M. frenata :

Char. 13: $0-->1$

Char. 24:0 $0->1$

Char. 25: $0-->1$

Char. 27: $0-->1$

Char. 40: $0-->1$

Char. 45: $0-->2$

Char. 53: $1-->0$

Char. 54: $0-->2$

Char. 55: $0-->4$

Char. 81: $2-->0$

Char. 86: $0-->1$

Char. 93: $1-->0$

Char. 98: $1-->0$

Char. 109: $0-->1$

Char. 112: $0-->1$

Char. 118: $0-->2$

Char. 119: $1-->3$

Char. 124: $0-->3$

Char. 128: $1-->2$

Char. 129: $1-->0$

Char. 158: $2-->0$

A. bogotensis :

Char. 35: $1-->0$

Char. 44: $0-->1$

Char. 46: $0-->1$

Char. 48: $1-->0$

Char. 50: $2-->1$

Char. 101: $0-->2$

Char. 122: $1-->2$

Char. 141: $0-->1$

Char. 143: $0-->1$

Char. 145: $2-->0$

B. dorbignyi :

Char. 1: $1-\rightarrow 0$

Char. 4: $1-->2$

Char. 33: $0-->1$

Char. 38: $0-->1$

Char. 39: 1 -->0

Char. 66: $0-->1$

Char. 80: $0-->1$

Char. 99: $1-->2$

Char. 103: $0-->3$

Char. 107: $1-->3$

Char. 119: $1-->0$

Char. 122: $1-->4$

Char. 128: $1-->0$

Char. 133: $0-->1$

Char. 134: $1-->2$

Char. 137: $0-->1$

Char. 142: $1-->0$

C. schreibersii :

Char. 1: $1-->0$

Char. 49: $0-->1$

Char. 55: $0-->1$ 
Char. 98: $1-->2$

Char. 103: $0-->3$

Char. 130: $0-->1$

A. ameiva :

Char. 14: $3-->1$

Char. 85: $0-->1$

Char. 102: $0-->1$

Char. 113: $2-->4$

Char. 118: $1-->2$

A. bifrontata :

Char. 31: $0-->1$

Char. 58: $2-->0$

Char. 71: $0-->1$

Char. 105: $2-->1$

Char. 114: $0-->1$

Char. 122: $1-->2$

Char. 126: $0-->1$

A. exsul :

Char. 12: $0-->1$

Char. 31: $0-->1$

Char. 49: $0-->1$

Char. 60: $0-->1$

Char. 62: $0-->1$

Char. 71: $0-->1$

Char. 83: $1-->0$

Char. 84: $0-->1$

Char. 102: $0-->1$

Char. 105: $2-->1$

Char. 126: $2-->0$

C. lacretoides :

Char. 87: $1-->2$

Char. 89: $1-->0$

Char. 98: $2-->1$

Char. 107: $1-->2$

Char. 122: $1-->0$

C. lemniscatus :

Char. 14: $3-->2$

Char. 46: $2-->3$

Char. 67: $1-->0$

Char. 84: $0-->1$

Char. 85: $0-->1$

Char. 90: $0-->1$

Char. 101: $0-->1$

Char. 122: $1-->2$

Char. 123: $1-->2$

C. longicaudus :

Char. 0: $0-->1$

Char. 4: $1-->2$

Char. 21: $0-->2$

Char. 128: $1-->2$

C. ocellifer :

Char. 8: $0-->1$

Char. 50: $2-->1$

Char. 56: $1-->2$

Char. 58: $2-->0$

Char. 62: $0-->1$

Char. 83: $1-->0$

Char. 87: $2-->1$

Char. 102: $0-->1$

Char. 113: $2-->4$ 
C. serranus :

Char. 41: $2-->1$

Char. 42: $0-->1$

Char. 50: $2-->0$

Char. 114: $0-->1$

C. tergolaevigatus :

Char. 62: $0-->1$

Char. 69: $1-->0$

Char. 98: $2-->1$

Char. 105: $2-->4$

Char. 144: $0-->1$

K. viridistriga :

Char. 22: $1-->2$

Char. 41: $2-->1$

Char. 128: $2-->1$

K. calcarata :

Char. 17: $1-->2$

Char. 18: $0-->1$

Char. 111: $0-->1$

A. calidipes :

Char. 19: $1-->0$

Char. 28: $0-->1$

Char. 37: $0-->1$

Char. 41: $2-->4$

Char. 60: $0-->1$

Char. 92: $3-->2$

Char. 95: 1 -->0

Char. 102: $0-->1$

A. communis :

Char. 14: $3-->2$

Char. 37: $0-->1$

Char. 41: $2-->0$

Char. 42: $1-->0$

Char. 56: $1-->2$

Char. 87: $2-->1$

Char. 102: $0-->1$

A. deppei :

Char. 14: $3-->2$

Char. 41: $2-->1$

Char. 58: $2-->0$

Char. 75: $1-->0$

Char. 122: $1-->0$

Char. 138: $0-->1$

Char. 147: $0-->2$

A. exsanguis :

Char. 4: $1-->0$

Char. 8: $0-->1$

Char. 97: $0-->1$

Char. 123: $1-->0$

A. gularis :

Char. 63: $0-->1$

A. sexlineata :

Char. 4: $1-->2$

Char. 12: $0-->1$

Char. 14: $3-->2$

Char. 19: $1-->0$

Char. 98: $2-->1$

Char. 126: $2-->1$

Char. 128: $1-->0$

Char. 153: $3-->2$ 
T. teyou :

Char. 41: $2-->4$

Char. 58: $0-->1$

Char. 60: $0-->1$

T. oculatus :

Char. 40: $0-->2$

Char. 119: $1-->0$

Char. 128: $1-->0$

T. suquiensis :

Char. 52: $1-->2$

Char. 63: 1-->0

Char. 123: $2-->1$

C. maculatus :

Char. 43: $0-->2$

T. duseni :

Char. 42: $0-->1$

Char. 58: $2-->0$

T. merianae :

Char. 43: $0-->1$

Char. 101: $2-->0$

T. quadrilineatus :

Char. 117: $2-->3$

T. rufescens :

Char. 4: $1-->0$

Char. 43: $0-->1$

Char. 107: $1-->0$

T. teguixin :

No autapomorphies

C. amazonicus :

Char. 60: $2-->1$

Char. 113: $2-->5$

D. guianensis :

Char. 28: $0-->1$

D. paraguayensis :

No autapomorphies

P. colombiana :

Char. 123: $2-->3$

Char. 126: $0-->12$

C. bicuspidatus :

Char. 99: $0-->2$

Node 37 :

No synapomorphies

Node 38 :

Char. 15: $1-->0$

Char. 24: $0-->1$

Char. 25: $0-->1$

Char. 27: $0-->1$

Char. 30: $0-->1$

Char. 31: $0-->1$

Char. 34: 1 $->0$

Char. 38: $0-->1$

Char. 39: $1-->0$

Char. 66: $0-->1$

Char. 104: $0-->1$

Char. 105: $4-->2$

Char. 115: $0-->1$

Char. 123: $0-->2$

Node 39 :

Char. 19: $1-->2$

Char. 28: $0-->1$ 
Char. 46: $2-->1$

Char. 60: $0-->1$

Char. 84: $0-->1$

Node 40 :

Char. 40:0 $-->2$

Char. 92: $0-->3$

Char. 98: 1 --> 2

Char. 118: $0-->1$

Char. 128: $1-->2$

Node 41 :

Char. 48: $1-->0$

Char. 94: $1-->0$

Char. 138: $1-->0$

Char. 140: $0-->1$

Node 42 :

Char. 7: $0-->1$

Char. 14: $0-->3$

Char. 19: $0-->1$

Char. 32: $0-->1$

Char. 41: $0-->2$

Char. 44:0 $-->1$

Char. 46: $0-->2$

Char. 62: $0-->1$

Char. 64: $0-->1$

Char. 67: $0-->1$

Char. 69: $0-->1$

Char. 72: $0-->1$

Char. 73: $0-->1$

Char. 74: $1-->0$

Char. 76: $12-->0$

Char. 77: $2-->0$

Char. 78: $1->0$

Char. 91: $03-->1$

Char. 95: $0-->1$

Char. 104: $0-->2$

Char. 105: $4-->2$

Char. 106: $0-->2$

Char. 110: $0-->1$

Char. 113: $0-->2$

Char. 115: $0-->1$

Char. 123: $0-->2$

Char. 125: $0-->1$

Char. 139: $0-->1$

Char. 141: $0-->1$

Char. 144: $1-->0$

Char. 149: $0-->1$

Char. 150: $1-->0$

Char. 156: $1-->0$

Char. 157: $2-->0$

Char. 158: $2-->1$

Node 43 :

Char. 4: $1-->0$

Char. 67: $1-->0$

Char. 72: $1-->0$

Char. 73: 1 -->0

Char. 117: $0-->1$

Char. 128: $1-->2$

Node 44 :

Char. 147: $0-->1$

Node 45 :

Char. 46: $2-->1$ 
Node 46 :

Char. 42: $1-->0$

Char. 87: $2-->1$

Char. 128: $2-->1$

Node 47 :

Char. 42: $0-->1$

Char. 62: $1-->0$

Char. 123: $2-->1$

Char. 126: $0-->2$

Char. 132: $2-->0$

Char. 146: $0-->1$

Node 48 :

Char. 8: $0-->1$

Char. 94: $0-->1$

Char. 118: $1-->0$

Node 49 :

Char. 37: $0-->1$

Char. 104: $2-->1$

Char. 106: $2-->1$

Char. 126: $2-->1$

Node 50 :

Char. 1: $1-\rightarrow 2$

Char. 2: $2-->3$

Char. 28: $0-->2$

Char. 37: $0-->1$

Char. 49: $0-->2$

Char. 85: $0-->1$

Char. 97: $0-->1$

Char. 104: $2-->0$

Char. 126: $2-->1$

Node 51 :

Char. 50: $2-->1$

Char. 145: $2-->0$

Char. 146: $1-->0$

Node 52 :

Char. 114: $0-->1$

Node 53 :

Char. 0: $0-->1$

Char. 58: $2-->0$

Char. 92: $0-->1$

Char. 102: $0-->1$

Char. 103: $0-->1$

Char. 107: $1-->0$

Char. 114: $0-->2$

Char. 121: $0-->1$

Char. 122: $1-->3$

Char. 126: $0-->1$

Char. 132: $2-->1$

Char. 148: $0-->2$

Node 54 :

Char. 42: $0-->2$

Char. 52: $1-->2$

Node 55 :

Char. 13: $0-->1$

Char. 26: $0-->1$

Char. 54: $0-->1$

Char. 77: $0-->1$

Char. 87: $2-->3$

Char. 88: $0-->1$

Char. 99: 1 -> 0

Char. 101: $0-->2$ 
Char. 114: $0-->1$

Char. 131: 1 -->0

Char. 133: $0-->1$

Char. 151: $1-->0$

Char. 155: $2-->1$

Char. 158: $1-->3$

Node 56 :

Char. 100: $2-->3$

Char. 105: $12-->0$

Char. 121: $3-->2$

Node 57 :

Char. 110: $1-->2$

Char. 121: $0-->3$

Char. 124: $0-->1$

Char. 127: $0-->1$

Char. 144: $0-->1$

Node 58 :

Char. 1: $1-->0$

Char. 2: $2-->3$

Char. 3: $0-->1$

Char. $7: 1-->2$

Char. 9: $0-->1$

Char. 14: $3-->2$

Char. 22: $1-->3$

Char. 23: $1-->2$

Char. 31: $0-->1$

Char. 60: $0-->2$

Char. 61: $0-->1$

Char. 85: $0-->1$

Char. 92: $0-->2$

Char. 120: $1-->2$

Node 59 :

Char. 100: $2-->3$

Char. 104: $2-->0$

Char. 106: $2-->1$

Char. 118: $0-->1$

Node 60 :

Char. 9: $1-->2$

Char. 19: $1-->2$

Char. 40: $0-->2$

Char. 43: $0-->3$

Char. 46: $5-->3$

Char. 57: $0-->1$

Char. 58: $2-->0$

Char. 59: $0-->1$

Char. 60: $2-->1$

Char. 62: $1-->2$

Char. 65: $1-->2$

Char. 119: $1-->0$

Node 61 :

Char. 29: $0-->1$

Char. 85: $1-->2$

Char. 97: $1-->2$

Char. 120: $2-->3$

Char. 124: $1-->2$

Char. 127: $1-->2$

Char. 128: $1-->0$

0.02 secs. 


\section{AGRADECIMIENTOS}

Este trabajo no se hubiese realizado sin los invalorables aportes de la dirección de Adriana M. Albino, cuyo esfuerzo, tiempo, dedicación y paciencia le agradezco. En igual sentido quiero expresar mi agradecimiento a Zulma Gasparini cuyo aporte para la realización de este trabajo ha sido indispensable. A ambas les agradezco sinceramente sus aportes en mi formación académica.

El material fósil estudiado en este trabajo fue gentilmente facilitado por A. Kramarz (Museo Argentino de Ciencias Naturales "Bernardino Rivadavia”, Ciudad Autónoma de Buenos Aires, Argentina), J. E. Powell (Universidad Nacional de Tucumán, Tucumán, Argentina), C. I. Montalvo (Universidad Nacional de La Pampa, La Pampa, Argentina), M. G. Vucetich (Museo de La Plata, Buenos Aires, Argentina), A. Dondas (Museo Municipal de Ciencias Naturales "Lorenzo Scaglia", Buenos Aires, Argentina), C. A. Quintana (Laboratorio de Arqueología, Universidad Nacional de Mar del Plata), A. Yapur e I. Cerda (ambos de la Comisión de Amigos del Museo Regional Cinco Saltos, Río Negro, Argentina).

Expreso mi gratitud a G. Schneider (University of Michigan, Michigan, EE.UU.), E. R. Heyer (National Museum of Natural History, Washington, D.C., EE.UU.), L. Vega (Universidad Nacional de Mar del Plata, Buenos Aires, Argentina), M. E. Tedesco (Universidad Nacional del Noreste, Corrientes, Argentina), R. A. Martori (Universidad Nacional de Río Cuarto, Córdoba, Argentina), por ceder en calidad de préstamo los ejemplares bajo su cuidado en sus respectivas instituciones. Jorge Williams (Museo de La Plata, Buenos Aires, Argentina), L. Giambelluca (Instituto de Fisiología, Biología Molecular y Neurociencias - CONICET, Argentina) y R. L. Nydam (Midwestern University, Glendale, Arizona, EE.UU.), cedieron material de referencia adicional.

Mario Cabrera (Universidad Nacional de Córdoba, Córdoba Argentina), H. Zaher (Universidade de São Paulo, Estado de São Paulo, Brasil), S. Kretzschmar (Universidad Nacional de Tucumán, Tucumán, Argentina) y H. Núñez (Museo Nacional de Historia Natural, Santiago, región Metropolitana, Chile) por permitirme revisar el material de referencia alojado en sus respectivas instituciones.

Quiero agradecer además a:

A L. Palazzesi (CONICET), A. I. Olivares (CONICET), J. L. Carballido (CONICET), A. Hsiou (Universidade Federal do Rio Grande do Sul, Instituto de Geociências, Brasil), A. Prieto (Universidad Nacional de Mar del Plata, Buenos Aires, Argentina), M. Augé (Muséum National Histoire Naturelle, Paris, Francia), S. E. Evans (University College London, Londres, 
Inglaterra) y R. L. Nydam por facilitarme material bibliográfico y fotografico. Nuevamente a Luis Palazzesi por alojarme cuando viajaba a Buenos Aires.

A C. I. Montalvo por los dibujos del material del Mioceno de La Pampa y a F. Tricárico (Museo Argentino de Ciencias Naturales "Bernardino Rivadavia", Ciudad Autónoma de Buenos Aires, Argentina) por su trabajo con el Microscopio Electrónico de Barrido.

A la Universidad Nacional de Mar del Plata, en particular a C. Busch y M. Barg por permitirme utilizar su laboratorio, recursos y guiarme en técnica de tinción y transparentación de material actual.

Al Museo Municipal de Ciencias Naturales "Lorenzo Scaglia” de la ciudad de Mar del Plata, en particular a A. Dondas, O. Scaglia, F. Scaglia y M. Castillo quienes me facilitaron las instalaciones del museo y materiales indispensables para la tesis.

A R. L. Nydam y F. Isla (Universidad Nacional de Mar del Plata, Buenos Aires, Argentina) quienes con su ayuda me permitieron aclarar algunos aspectos referidos a la osteología y geología, respectivamente.

A la Comisión de Investigaciones Científicas (CIC) de la Provincia de Buenos Aires y a el Consejo Nacional de Investigaciones Científicas y Técnicas (CONICET) quienes mediante diferentes becas permitieron el desarrollo de este trabajo.

A la Universidad Nacional de La Plata y nuevamente a Z. Gasparini por hacer este trabajo posible en esta institución.

A mamá, papá, Javier, Fernando, Luciana, Alejandra e Isabella. 


\section{REFERENCIAS BIBLIOGRÁFICAS}

Alberdi, M. T., Leone, G. y E. P. Tonni. 1995. Evolución climática y biológica de los últimos cinco millones de años. Un ensayo de correlación con el Mediterráneo occidental, Monografías del Museo Nacional de Madrid, 12.

Albino, A. M. 1989. Los Boiidae (Reptilia: Serpentes) extinguidos del territorio argentino. Tesis Doctoral, Universidad Nacionla de La Plata, Buenos Aires.

Albino, A. M. 1992. Primer registro de un Boidea (Reptilia: Serpentes) en el Plioceno de la provincial de Buenos Aires. Pesquisas 10(1): 106-109.

Albino, A. M. 1993. Snakes from the late Plaeocene and early Eocene of Patagonia (Argentina): paleoecology and coevolution with mammals. Historical Biology 7(1): 51-69.

Albino, A. M. 1994. Estado actual del registro de escamados extinguidos de América del sur y sus implicancias paleoambientales. Cuadernos de Herpetología 8(1): 146-154.

Albino, A. M. 1996a. The South American Fossil Squamata (Reptilia: Lepidosauria). Münchner Geowissenchaftliche Abhandlungen A 30: 185-202.

Albino, A. M. 1996b. Snakes from the Miocene of Patagonia (Argentina) Part I: the Booidea. Neues Jahrbuch für Paläontologie und Geologie, Abhandlungen 199: 417-434.

Albino, A. M. 1996c. Snakes from the Miocene of Patagonia (Argentina) Part II: The Colubridae. Neues Jahrbuch für Geologie und Paläontologie, Abhandlungen 200: 353-360.

Albino, A. M. 1998. Primer registro fósil de Liolaemus (Squamata: Iguania) Argentina. VII Congreso Argentino de Paleontología y Bioestratigrafía, Bahia Blanca, Resúmenes: 57.

Albino, A. M. 1999. Serpientes del sitio arqueológico Cueva Tixi (Pleistoceno tardíoHoloceno), Provincia de Buenos Aires, Argentina. Ameghiniana, 36(3): 269-273.

Albino, A. M. 2001. Reptiles; pp 65-74. En: Mazzanti, D. y C. Quintana (Eds.), Cueva Tixi: Cazadores y recolectores de las Sierras de Tandilia Oriental. Tomo I. Geología, Paleontología y Zooarqueología. Universidad Nacional de Mar del Plata, Publicación Especial 1, Mar del Plata.

Albino, A. M. 2002a. El lagarto más antiguo de la Argentina. I Congreso "Osvaldo A. Reig" de Vertebradología básica y evolutiva e Historia y Filosofía de la Ciencia, Resúmens: 21.

Albino, A. M. 2002b Los lagartos del Cuaternario del sur de la Región Pampeana. Congreso "Osvaldo A. Reig" de vertebradología básica y evolutiva e historia y filosofía de la ciencia, Actas: 21.

Albino, A. M. 2005. A late Quaternary lizard assemblage from the southern Pampean Region of Argentina. Journal of Vertebrate Paleontology 25(1): 185-191. 
Albino, A. M. 2007. Lepidosauromorpha; pp. 87-115. En: Gasparini, Z., Salgado, L. y R. A. Coria (Eds.), Patagonian Mesozoic Reptiles. Indiana University Press, Bloomington.

Albino, A. M. 2008. Lagartos iguanios del Colhuehuapense (Mioceno temprano) de Gaiman (provincia del Chubut, Argentina). Ameghiniana 45(4): 775-782.

Albino, A. M. y A. A. Carlini. 2008. First record of Boa constrictor (Serpentes, Boidae) in the Quaternary of South America. Journal of herpetology, 42(1):82-88.

Albino, A. M. y R. Etheridge. 2000. Pristidactylus Fitzinger, 1843 (Iguania: Polychridae) remains from the Early Miocene of Patagonia. Ameghiniana 37(Suplemento): 69.

Albino, A. M. y R. H. Albino. 2004. Los Reptiles de los sitios arqueológicos de la Argentina y la bibliografía para su estudio. Comunicaciones del Museo Provincial de Ciencias Naturales "Florentino Ameghino" (Nueva Serie) 9: 1-16.

Albino, A. M. y C. I. Montalvo. 2006. Snakes from the Cerro Azul Formation (Upper Miocene), central Argentina, with a review Of Fossil Viperids from South America. Journal of Vertebrate Paleontology 26(3): 581-587.

Albino, A. M. y D. M. Kligmann. 2007. An accumulation of bone remains of two Liolaemus species (Iguanidae) in an Holocene archaeological site of the Argentine Puna. AmphibiaReptilia 28: 154-158.

Albino, A. M. y D. M. Kligmann. En prensa. Inusual hallazgo de anfisbenas (Squamata, Amphisbaenidae) en un sitio arqueológico del Noroeste argentino. ¿?

Albino, A. M. y S. Brizuela. En prensa. Los reptiles escamosos de la Provincia de Buenos Aires: la perspectiva paleontológica. Boletín del Centro $\mathrm{N}^{\circ} 6$.

Albino, A. M., Brizuela S. y C. I. Montalvo. 2006. New Tupinambis remains from the Late Miocene of Argentina and a review of the South American Miocene teiids. Journal of Herpetology 40(1): 206-213.

Albino, A. M., Tomassini, R. y S. Brizuela. 2009. Presencia del lagarto teido Tupinambis en la Formación Monte Hermoso de Farola Monte Hermoso, sur de la provincia de Buenos Aires (Argentina). Ameghiniana 46(1): 177-187.

Alifanov, V. R. 1989. The most ancient gekkos (Lacertilia: Gekkonidae) from the Lower Cretaceous of Mongolia. Paleontologicheskii Zhurnal 1: 124-126.

Alifanov, V. R. 1992. The oldest Gecko (Lacertilia, Gekkonidae) from the Lower Cretaceous of Mongolia. Paleontological Journal (English translation) 1989: 124-126.

Alifanov, V. R. 1993. Some peculiarities of the Cretaceous and Palaeogene lizard faunas of the Mongolian People's Republic. Kaupia 3: 9-13. 
Alifanov, V. R., 2000. The fossil record of Cretaceous lizards from Mongolia; pp 368-389. En: Benton, M. J., Shishkin, M. A., Unwin, D. M., Kurochkin, E. N. (Eds.), The Age of Dinosaurs in Russia and Mongolia. Cambridge University Press, Cambridge.

Amaral, A. do. 1950. Two new South American lizards. Copeia 1950 (4): 281-284.

Ambrosetti, J. B. 1890. Observaciones sobre los reptiles fósiles oligocénicos de los terrenos Terciarios antiguos del Paraná. Boletin de la Academia Nacional de Ciencias de Córdoba 10: 409-426.

Ameghino, F. 1880. La formación Pampeana o estudio de los terrenos de transporte de la cuenca del Plata. París.

Ameghino, F. 1887. El yacimiento de Monte Hermoso y sus relaciones con las formaciones cenozoicas que lo han precedido y sucedido. Diario "La Nación” de Buenos Aires: 12.

Ameghino, F. 1889. Contribución al conocimiento de los mamíferos fósiles de la República Argentina. Actas de la Academia Nacional de Ciencias de Córdoba 6: 1-1027.

Ameghino, F. 1893. Sobre la presencia de vertebrados de aspecto Mesozoico en la Formación Santacruceña de Patagonia austral. Revista del Jardín Zoológico de Buenos Aires 1: 75-84.

Ameghino, F. 1895. Sinopsis geológico-paleontológico. En: Segundo Censo Nacional. Buenos Aires.

Ameghino, F. 1898. Sinopsis Geológico-Paleontológica de la Argentina; pp. 487-734. En:

Torcelli, A. J. (Ed.), Obras Completas, tomo 12 capitulo CIV, La Plata.

Ameghino, F. 1899. Sinopsis Geológico-Paleontológica. Suplemento (Adiciones y

Correcciones); pp. 706-708. En: Torcelli, A. J. (Ed.), Obras Completas, tomo 12, capitulo CIX, La Plata.

Ameghino, F. 1908. Las formaciones sedimentarias de la región litoral de Mar del Plata y chapalmalán. Anales del Museo Nacional, Buenos Aires 3(10): 343-428.

Ameghino, F. 1909. Le Diprothomo Platensis. Un precurseur de l'homme du Pleistocene inferieur de Buenos Aires. Anales del Museo Nacional de Buenos Aires 3: 107-207.

Apesteguía, S., Agnolin, F. L. y G. L. Lio. 2005. An early Late Cretaceous lizard from Patagonia, Argentina. C.R. Palevol 4: 311-315.

Arias, F. y F. Lobo. 2006. Patrones de osificación en Tipinambis merianae y Tupinambis rufescens (Squamata: Teiidae) y patrones generales en Squamata. Cuadernos de Herpetología 20(1): 3-23.

Arnold, E. N., Arribas, O. y S. Carranza. 2007. Systematics of the Palaearctic and Oriental lizard tribe Lacertini. Zootaxa 1430: 1-86. 
Augé, M. 2005. Evolution des lézards du Paléogène en Europe, Mémoires du Muséum National d'Historie Naturalle. Publication Scientifiques du Muséum (Paris) 129.

Ávila-Pires, T. C. S. 1995. Lizards of Brazilian Amazonia (Reptilia: Squamata). Zoologische Verhandelingen 299: 1-706.

Babot, M. J., J. E. Powell y C. de Muizon. 2002. Callistoe vincei, a new Proborhyaenidae (Borhyaenoidea, Metatheria, Mammalia) from the Early Eocene of Argentina. Geobios 35: $615-629$.

Báez, A. M. y Z. Gasparini. 1977. Orígenes y Evolución de los Anfibios y Reptiles del Cenozoico de América del Sur. Acta Geológica Lilloana 14: 149-232.

Báez, A. M. y Z. Gasparini. 1979. The South America herpetofauna: an evaluation of the fossil record; pp. 29-54. En: Duellman, W. E. (Ed.), The South American Herpetofauna: Its Origin, Evolution, and Dispersal. University of Kansas Museum of Natural History Monograph 7.

Barberena, M. C., Gomes, N. M. y L. M. Sanchotene. 1970. Osteología craneana de Tupinanbis teguixin (Lacertilia, Teiidae). Publicação Especial Escola de Geologia, Porto Alegre 21: 1-32.

Barreda V., L. M. Anzótegui, A. R. Prieto, P. Aceñolaza, M. M. Bianchi, A. M. Borromei, M. Brea, M. Caccavari, G. A. Cuadrado, S. Garralla, S. Grill, G. R. Guerstein, A. I. Lutz, M. V. Mancini, L. R. Mautino, E. G. Ottone, M. E. Quattrocchio, E. J. Romero, M. C. Zamaloa y A. Zucol. 2007. Diversificación y cambios de las angiospermas durante el Neógeno en Argentina. ; pp 173-191. En: Archangelsky, S., Sánchez, T. y E. P. Tonni (Eds.), Publicación Especial 11 Ameghiniana 50 Aniversario. Ameghiniana.

Bell, C. J., Evans, S. E. y J. A. Maisano. 2003. The skull of the gymnophthalmid lizard Neusticurus ecpleopus (Reptilia: Squamata). Zoological Journal of the Linnean Society 139: 283-304.

Bellaris, A. d'A. 1957. Reptiles. Hutchinson's University Libary, London.

Böhme, M. 2003. The Miocene Climatic Optimum: evidence from ectothermic vertebrates of Central Europe. Palaeogeography, Palaeoclimatology, Palaeoecology 195: 389-401.

Bonaparte, J. 1960. La sucesión estratigráfica de Monte Hermoso (provincia de Buenos Aires). Acta Geológica Lilloana 3: 273-287.

Bond, M. y G. López. 1993, El primer Notohippidae (Mammalia, Notoungulata) de la Formación Lumbrera (Grupo Salta) del Noroeste Argentino: Consideraciones sobre la Sistemática de la Familia Notohippidae. Ameghiniana 30(3): 59-68. 
Bondesio, P. 1978. Nuevos restos de Cardiatheriinae (Rodentia, Hydrochoeridae) en el territorio argentino. Infcrencias paleoambientales. Nota preliminar. Ameghiniana. 15 (1-2): 229-234.

Bondesio, P. y R. Pascual. 1981. Un Cardiatherinae (Mammalia, Rodentia, Hydrochoeridae) de los calcareos Travertínicos de Las Playas (Córdoba). Edad y correlaciones. Ameghiniana 18(3-4): 169-175.

Bondesio, P., Rabassa, J. Pascual, R., Vucetich, M. G., y G. J. Sccillato Yane. 1980. la Formación Collón Cura de Pilcaniyeu Viejo y sus alrededores (Río Negro, República Argentina). Su antigüedad y las condiciones ambientales según su distribución, su litogénesis y sus vertebrados. II Congreso Argentino de Paleontología y Bioestratigrafía y I congreso Latinoamericano de Paleontología, Actas (3): 85-99.

Bonfim Jr., F. y R. B. Marques. 1997. Um novo lagarto do Cretáceo do Brazil (Lepidosauria, Squamata, Lacertilia - Formaçao Santana, Aptiano da Bacia do Araripe). Anuário do Instituto de Geociencias 20: 233-240.

Borsuk Bialynica, M. y S. M. Moody. 1984. Priscagaminae, a new subfamily of the Agamidae (Sauria) from the Late Cretaceous of thec Gobi Desert. Palaeontologia Polonica 29(1-2): 5181 .

Boulenger, G. A. 1885. Catalogue of the Lizards in the British Museum (Natural History). British Museum of Natural History, London.

Bown, T. H. y J. G. Fleagle. 1993. Systematics, biostratigraphy, and dental evolution of the Palaeothentidae, Later Oligocene to Early-Middle Miocene (Deseadan - Santacrucian) caenolestoid marsupials of South America. Paleontological Society, Memoir 29, Journal of Paleontology 67 (Suppl. 2): 1-76.

Bravard, A. 1857. Geología de las Pampas, República Argentina. Registro Estadístico de la Provincia de Buenos Aires 1: 1-2.

Brizuela, S. y A. M. Albino. 2004. The earliest Tupinambis teiid from South America and its palaeoenvironmental significance. Journal of Herpetology 38(1): 113-119.

Brizuela, S. y A. M. Albino. 2008a. Re-evaluation of the type material of "Diasemosaurus occidentalis" Ameghino and "Dibolosodon typicus" Ameghino (Squamata: Teiidae) from the Miocene of Argentina. Journal of Vertebrate Paleontology 28(1): 253-257.

Brizuela, S. y A. M. Albino. 2008b. Tupinambine teiids from the middle Miocene of northwestern Patagonia (Argentina). Amphibia-Reptilia 29(3): 425-431. 
Budney, L. A., Caldwell, M. W. y A. M. Albino. 2006. Tooth socket histology in the Cretaceous snake Dinilysia, with a review of amniote dental attachment tissues. Journal of Vertebrate Paleontology 26(1): 138-145.

Burgos, J. J. y A. L Vidal. 1951. Los climas de la República Argentina, según la nueva clasificación de Thornthwaite. Meteoros: Revista de Meteorología y Geofísisca del Servicio Meteorológico Nacional 1: 3-32.

Cabrera, A. L. 1976. Regiones fitogeográficas argentinas; pp 1-85. En: Kluger, W. F. (Ed.), Enciclopedia Argentina de agricultura y jardineria. Segunda Edición. Tomo II.

Cabrera, M. R. 2004. A new species of Cnemidophorus (Squamata: Teiidae) from western Argentina. Amphibia-Reptilia 25(3): 265-275.

Cabrera, A. L. y A. Willink. 1980. Biogeografia de Ame'rica Latina. Secretaría General de la O.E.A., Washington DC.

Caldwell, M. W., Budney, L. A. y D. O. Lamoureux. 2003. Histology of tooth attachment tissues in the Late Cretaceous mosasaurid Platecarpus. Journal of Vertebrate Paleontology 23(3): 622-630.

Camp, C. L. 1923. Classification of the lizards. Bulletin of the American Museum of Natural History 48: 289-481.

Camolez, T. 2006. Levantamento, identificação e descrição da fauna de Squamata do Quaternário brasileiro (Lepidosauria). Tesis pp 224. Instituto de Biociências, Departamento de Zoologia, Universidade de São Paulo, São Paulo.

Camolez, T., Zaher, H. y Kipnis, R. 2005. A fauna de Squamata do Quaternário superior encontrada em três sítios arqueológicos no Estado de Minas Gerais. II Congresso Latinoamericano de Paleontologia de Vertebrados. Rio de Janeiro. Resúmenes: 64-65.

Candeiro, C. R. A. 2007. Paleogeographic distribution of the terrestrial squamate reptiles from the Cretaceous of Brazil. Bioscience Journal 23(1): 65-74.

Capparelli, A. y R. Raffino. 1997. Arqueoetnobotánica de El Shincal I: tallos finos, frutos y semillas. Tawantinsuyu 3: 40-57.

Carbajal, E., Pascual, R., Pinedo, R., Salfity, J. A. y M. G. Vucetich. 1977. Un nuevo mamífero de la Formación Lumbrera (Grupo Salta) de la Comarca de Carahuasi (Salta, Argentina). Edad y correlaciones. Publicaciones del Museo Municipal de Ciencias Naturales de Mar del Plata “Lorenzo Scaclia” 2(7): 148-163.

Carroll, R. L. 1997. Patterns and processes of vertebrate evolution. Cambridge University Press, Cambridge. 
Carvalho, A. B. 2001. Estudo taxonomico dos "lagartos" fósseis (Lepidosaurua: Squamata) da Bacia de Sao José de Itaboraí (Paleoceno), Estado do Rio de Janeiro. Tesis 82 pp. Museu Nacional/UFRJ, Universidade Federal do Rio de Janeiro, Rio de Janeiro.

Carvalho, A. B. y H. Zaher. 1998. Os "lagartos" fósseis de Itaboraí: descricao do material osteológico craniano. I Simposio Brasileiro de Paleontología de Vertebrados, Resúmenes: 31.

Casamiquela, R. M. 1962. Sobre la pisada de un presunto sauria aberrante en el Liásico del Neuquén (Patagonia). Ameghiniana 2(10): 183-186.

Casamiquela, R. M. 1975. La presencia de un sauria (Lacertilia) en el Liásico de Patagonia austral. I Congreso Argentino de Paleontología y Bioestratigrafía, Actas: 57-70.

Casamiquela, R. M. 1980. Nuevos argumentos en favor de la transferencia de Rotodactylus, icno-genero reptiliano Triasico, de los "Crocodiloides" (Archosauria) a los "Lacertoides" (incertae sedis). Ameghiniana 17(2): 121-129.

Cazau, L. y M. Uliana. 1973. El Cretácico Superior continental de la Cuenca Neuquina. $5^{\circ}$ Congreso Geológico Argentino (Villa Carlos Paz), Actas 3: 131-163.

Cei J. M. 1986. Reptiles del Centro, Centro-Oeste y Sur de la Argentina. Herpetofauna de Zonas Áridas y Semiáridas. Museo Regionale di Scienze Naturali Torino. Monografie (IV): $1-527$.

Cei J. M. 1993. Reptiles del noreste, nordeste y este de la Argentina. Herpetofauna de las selvas subtropicales, Puna y Pampas. Torino, Museo Regionale di Scienze Naturali, Monografie (XIV): 1-943.

Chani, J. M. 1976. Relaciones de un nuevoTeiidae (Lacertilia) fosil del Plioceno superior de Argentina - Callopistes Bicuspidatus n. sp. Revista del Instituto Miguel Lillo 1: 133-153.

Chani J. M. y L. A. Fitzgerald. 1991. Problemas en las estimaciones de densidad poblacional en el género Tupinambis. VIII Reunión de Comunicaciones Herpetológicas (Córdoba) Resúmenes: 5-6.

Chani, J. M., Cruz, F., Perotti, G., Aguirre, M. y S. Rufino. 1993. Rol de la hembra de Tupinambis teguixin (Teiidae) durante la nidificación. Acta Zoológica Lilloana 42(2): 295299.

Chiappe, L. M., Dingus, L, Jackson, F., Grellet-Tinner, G., Aspinall, R., Clarke, J., Coria, R. A., Garrido, A. y D. Loope. 2000. Sauropod eggs and embryos from the late Cretaceous of Patagonia. I Sympoium on Dinosaur Eggs and Babies. Extended Abstract: 23-29.

Cifelli, R. L. 1985. Biostratigraphy of the Casamayoran, early Eocene, of Patagonia. American Museum Novitates 2820: 1-26. 
Cione, A. L. y E. P. Tonni. 1981. First record of some fishes and mammals from Santiago del Estero province, Argentina. Studies on Neotropical Fauna and Environment 16(1): 1-7.

Cione, A. L. y E. P. Tonni. 1995a. Bioestratigrafía y cronología del Cenozoico superior de la región pampeana; pp 49-74. En: Alberti, M. T., Leone, G. y E. P. Tonni (Eds.), Evolución climática y biológica de los últimos cinco millones de años. Un ensayo de correlación con el Mediterráneo occidental, Monografías del Museo Nacional de Madrid 12: 49-74.

Cione, A. L. y E. P. Tonni. 1995b. Chronostratigraphy and "Land-mammal ages" in the Cenozoic of southern South America: Principles, practices and the "Uquian" problem. Journal of Palaeontology 69(1): 135-159.

Cione, A. L. y E. P. Tonni. 1995c. El estratotipo de los pisos Montehermosense y Chapadmalalense (Plioceno) del esquema cronológico sudamericano. Ameghiniana 32(4): 369-374.

Cione, A. L. y E. P. Tonni. 1996. Reassessment of the Pliocene-Pleistocene continental time scale of Southern South America. Correlation of the type Chapadmalalan with Bolivian sections. Journal of South American Earth Sciences 9: 221-236.

Cione, A. L. y E. P. Tonni. 2005: Bioestratigrafía basada en mamíferos del Cenozopico Superior de la provincia de Buenos Aires, Argentina. Geología y recursos minerales de la provincia de Buenos Aires. Relatorio del XVI Congreso Geológico Argentino: 183-200.

Cione, A. L. y A. M. Báez. 2007. Peces, anfibios e invertebrados cenozoicos; pp 195-220. En: Archangelsky, S., Sánchez, T. y E. P. Tonni (Eds.), Publicación Especial 11 Ameghiniana $50^{\circ}$ Aniversario. Ameghiniana.

Cione, A. L., Lorandi, A. M. y E. P. Tonni. 1979. Patrón de subsistencia y adaptación ecológica en la aldea prehispánica "El Veinte", Santiago del Estero. Relaciones de la Sociedad Argentina de Antropología 13 (nueva serie): 103-116.

Cione, A. L., Tonni, E. P., Bargo, S., Bond, M., Candela, A. M., Carlini, A. A., Deschamps, C. M., Dozo, M.T., Esteban, G., Goin, F. J., Montalvo, C. I., Nasif, N., Noriega, J. I., Ortiz Jaureguizar, E., Pascual, R., Prado, J. L., Reguero, M. A., Scillato-Yané, G, J., Soibelzon, L., Verzi, D. H., Vieytes, E. C., Vizcaíno S. F. Y M. G. Vucetich. 2007. Mamíferos continentales del Mioceno tardío a la actualidad en la Argentina: cincuenta años de estudios; 257-278. En: Archangelsky, S., Sánchez, T. y E. P. Tonni (Eds.), Publicación Especial 11 Ameghiniana 50 Aniversario. Ameghiniana.

Colli, J. M., Péres Jr., A. K. y H. J. da Cunha. 1998. A new species of Tupinambis (Sauria, Teiidae) from central Brazil. Herpetologica 54(4): 477-492. 
Conrad, J. L. 2006. An Eocene Shinisaurid (Reptilia, Squamata) from Wyoming, U.S.A. Journal of Vertebrate Paleontology 26(1): 113-126.

Conrad, J. L. 2008. Phylogeny and systematics of Squamata (Reptilia) based on morphology. Bulletin of the American Museum of Natural History 310: 1-182.

Coria, R. A., Currie, P. J., Eberth D. y A. Garrido. 2002a. Bird footprints from the Anacleto Formation (Late Cretaceous) in Neuquén Province, Argentina. Ameghiniana 39 (4): 453463.

Coria, R. A., Chiappe, L. M. y L. Dingus. 2002b. A new close relative of Carnotaurus sastrei Bonaparte 1985 (Theropoda: Abelisauridae) from the Late Cretaceous of Patagonia. Journal of Vertebrate Paleontology 22 (2): 460-465.

Cruz, F. B. 1996. Reproducción en un ensamble de saurios del Chaco Occidental, Salta, Argentina. IV Congreso Latino americano de Herpetología (Santiago), Resúmenes: 3.

Cruz, F. B., Torres, M., Fitzgerald L. A. y J. J. Vitt. 2002. Estructura de un ensamble de saurios chaqueños: un ensamble? XVII Reunión de Comunicaciones Herpetológicas (La Plata) Resúmenes: 47.

Cuello, A. I. 1982a. Temperaturas; pp 204-209. En: Chiozza E. y Figueira (Eds.), Atlas Total de la Republica Argentina (volumen 2). Centro Editor de América Latina, Argentina.

Cuello, A. I. 1982b. Precipitaciones; pp 222-241. En: En: Chiozza E. y Figueira (Eds.), Atlas Total de la Republica Argentina (volumen 2), Centro Editor de América Latina, Argentina.

Dalrymple, G. H. 1979. On the jaw mechanism of the snail-crushing lizards, Dracaena Daudin 1802 (Reptilia, Lacertilia, Teiidae). Journal of Herpetology 13(3): 303-311.

Darwin, C. 1846. Geological observations on South America. Smith, Elder y Co., London, VII: $1-279$.

Daudin, F. M. 1802. Histoire Naturelle, Générale et Particulière des Reptiles; ouvrage faisant suit à l'Histoire naturell générale et particulière, composée par Leclerc de Buffon; et rédigee par C.S. Sonnini, membre de plusieurs sociétés savantes, Volume 2. F. Dufart, Paris.

de la Fuente, M. S. 1999. A review of the Pleistocene reptiles of Argentina: taxonomic and palaeoenvironmental considerations. Quaternary of South America and Antarctic Peninsula 12:109-136.

de la Fuente, M. S., Salgado, L., Albino, A. M., Báez, A. M., Bonaparte, J. F., Calvo, J. O., Chiappe, L. M., Codorniú, L. S. Coria, R. A. Gasparini, Z., González Riga, B. J., Novas, F. E. y D. Pol. 2007. Tetrápodos continentales del Cretácico de la Argentina: una síntesis actualizada; pp. 137-153. En: Archangelsky, S., Sánchez, T. y E. P. Tonni (Eds.), Publicación Especial 11 Ameghiniana 50 Aniversario. Ameghiniana. 
del Papa, Estratigrafía. 2006. Estratigrafía y paleoambientes de la Formación Lumbrera, Grupo Salta, Noroeste Argentino. Revista de la Asociación Geológica Argentina 61 (3): 313-327.

Dalrymple, G. H. 1979. On the jaw mechanism of the snail-crushing lizards, Dracaena Daudin 1802 (Reptilia, Lacertilia, Teiidae). Journal of Herpetology 13(3): 303-311.

Denton Jr, R. K., y R. C. O'Neill. 1995. Prototeius stageri, gen. et sp. nov., a new teiid lizard from the upper Cretaceous Marshalltown Formation of New Jersey, with a preliminary phylogenetic revision of the Teiidae. Journal of Vertebrate Paleontology 15(2): 235-253.

Deraco, M V., Powel, J. E. y G. Lopez. Primer leontínido (Mammalia, Notoungulata) de la Formacón Lumbrera (Subgrupo santa Bárbara, Grupo Salta-Paleógeno) del noroeste argentino. Ameghiniana 45(1): 83-91.

Dessem, D. 1985. Ontogenetic changes in the dentition and diet of Tupinambis (Lacertilia: Teiidae). Copeia 1985: 245-247.

Dingus, L., Clarke, J., Scott, G. R., Swisher III, C. C., Chiappe, L. M. y R. A. Coria. 2000. First magnetostratigraphic/faunal constraints for the age of sauropod embryo-bearing rocks in the Neuquén Group (Late Cretaceous, Neuquén Province, Argentina). American Museum Novitates 3290:1-11.

Doan, T. M. 2003. A new phylogenetic classification for the gymnophtalmid genera Cercosaura, Pantodactylus and Prionodatylus (Reptilia: Squamata). Zoological Journal of the Linnean Society 137:101-115.

Donadío, O. E. 1978. Los teidos (Sauria, Squamata) del género Tupinambis de la Formación Monte Hermoso (Plioceno tardío), provincia de Buenos Aires. Tesina de Grado, Universidad de Buenos Aires, Ciudad Autonoma de Buenos Aires.

Donadío, O. E. 1982. Restos de anfisbénidos fósiles de Argentina (Squamata, Amphisbaenidae) del Plioceno y Pleistoceno de la provincia de Buenos Aires. Circular Informativa, Asociación Paleontológica Argentina 10: 10.

Donadío, O. E. 1983a. Restos de lacertilios asociados a asentamientos indigenas (Sauria, Teiidae) en la provincia de Santiago del Estero, Argentina. Boletin de la Asociación Herpetológica Argentina 1(3): 13.

Donadío, O. E. 1983b. Estado sistemático de los representantes fósiles del género Tupinambis en Argentina (Squamata, Sauria, Teiidae) y consideraciones paleoambientales. Boletín de la Asociasión Herpetológica Argentina 1(3): 8. 
Donadío, O. E. 1984a. Teidos del Mioceno temprano (Squamata, Sauria, Teiidae) de la Provincia de Santa Cruz, Argentina. Circular Informativa de la Asociación Paleontológica Argentina 12: 2-3.

Donadío, O. E. 1984b. Los Lacertilos Fosiles de la Provincia de Cordoba (Sauria, Teiidae) y sus implicancias Paleoambientales. III Congreso Argentino de Paleontología y Bioestratigrafia, Actas: 217-223.

Donadío, O. E. 1985. Un nuevo Lacertilo (Squamata, Sauria, Teiidae) de la Formación Lumbrera (Eoceno temprano) Provincia de Salta, Argentina. Ameghiniana 22(3-4): 221228.

Duméril, A. M. C. y G. Bibron. 1839. Erpétologie Générale on Histoire Naturelle Complète des Reptiles. Vol.5. Roret/Fain et Thunot, Paris.

Eaton, J. G., R. L. Cifelli, J. H. Hutchison, J. I. Kirkland y J. M. Parrish. 1999. Cretaceous vertebrate faunas from the Kaiparowits Plateau, south-central Utah; pp. 345-353. En D. G. Gillette (Ed.), Vertebrate Paleontology in Utah; Utah Geological Survey Miscellaneous Publication 99-1. Utah Geological Survey, Salt Lake City.

Edmund, A. G. 1969. Dentition; pp 117-200. En; Gans, C. y T. S. Parsons (Eds.), Biology of the Reptilia (Vol. 1). Academic Press, New York.

Estes, R. 1961. Miocene Lizard from Colombia South America. Breviora 143: 1-11.

Estes, R. 1969. Relationships of two Cretaceous lizards (Sauria, Teiidae). Breviora, Mus. of Comparative Zoology, Cambridge 317: 1-8.

Estes, R. 1970. Origin of the recent North American lower vertebrate fauna: an inquiry into the fossil record. Forma et Funtio 3: 139-163.

Estes, R. 1983a. Sauria terrestria, Amphisbaenia; pp. 1-249. En: Wellnhofer P. (Ed.), Handbuch der Paläoherpetologie, Part 10A. Gustav Fischer Verlag, Stuttgart.

Estes, R., 1983b. The fossil record and early distribution of lizards; pp. 365-398 En Rodin A. G. J. y K. Kiyata (Eds.), Advances in Herpetology and Evolutionary Biology: Essays in Honor of Ernest E. Williams. Museum of Comparative Zoology, Harvard University, Cambridge.

Estes, R. y L. I. Price. 1973. Iguanid lizard from the upper Cretaceous of Brazil. Science 180: 748-751.

Estes, R. y E. E. Williams. 1984. Ontogenetic variation in the molariform teeth of lizards. Journal of Vertebrate Paleontology 4(1): 96-107. 
Estes, R., de Queiroz, K. y J. Gauthier. 1988. Phylogenetic relationships within Squamata; pp 119-281. En: Estes R. y G. Pregill (Eds.), Phylogenetic Relationships of the Lizard Families: Essays Commemorating Charles L. Camp. Stanford University Press, Stanford.

Etheridge, R. 1967. Lizard caudal vertebrae. Copeia 1967(4): 699-721.

Evans, S. E. 2003. At the feet of the dinosaurs: the early history and radiation of lizards. Biological Review 78: 513-551.

Evans, S. E. y L. J. Barbadillo. 1997. Early Cretaceous lizards from Las Hoyas, Spain. Zoological Journal of the Linnean Society 119:23-49.

Evans, S. E. y L. J. Barbadillo. 1998. The lizard Rubiessaurus Gómez Pallerola, 1979 from the lower Cretaceous of Catalonia (Montsec, Lllida, Spain). Treballs del Museu de Geologia de Barcelona: 5-11.

Evans, S. E. y D. C. Chure. 1998. Paramacellodid lizard skulls from the Jurassic Morrison Formation at Dinosaur National Monument, Utah. Journal of Vertebrate Paleontology 18(1): 99-114.

Evans, S. E. y Y. Yabumoto. 1998. A lizard from the early Cretaceous Crato Formation, Araripe Basin, Brasil. Neues Jahrbuch für Paläontologie und Geologie, Monatshefte 1198: 349-364.

Evans, S. E., Prasad, G. V. R. y B. K. Manhas. 2002. Fossil Lizards from the Jurassic Kota Formation of India. Journal of Vertebrate Paleontology 22(2): 299-312.

Fernández, C. A. 1994. An outline of paleolimnology in Argentina. Journal of Paleolimnology 10: $3-14$.

Fidalgo, F. y E.P. Tonni. 1982. Observaciones geológicas y paleontológicas en las "Barrancas de Monte Hermoso" (provincia de Buenos Aires). III Congreso Paleontológico Argentino, Resúmenes: 16.

Fierro Zapata, D. y N. Pérez Díaz, 2007. Condiciones agrometeorologicas en el Perú. Boletín Agroclimático del Perú 24(2): 1-17.

Fitch, W. M. 1971. Towards defining the course of evolution: Minimum change for a specific tree topology. Systematic Zoology 20: 406-416.

Fitzgerald, L. A., Cook, J. A. y A. L. Aquino. 1999. Molecular phylogeny and conservation of Tupinambis. Copeia 1999: 894-905.

Fleagle J. G. yT. M. Bown. 1983. New primate fossils from late Oligocene (Colhuehuapian) localities of Chubut Province, Argentina. Folia Primatologica 41: 240-266. 
Fleagle, J. G., Bown, T. M., Swisher, C. y G. A. Buckley. 1995. Age of the Pinturas and Santa Cruz Formations. VI Congreso de Paleontología y Bioestratigrafía (Trelew) Actas: 129-135.

Flynn, J. J., Novacek, M. J., Dodson, H. E., Frassinetti, D., McKenna, M. C., Norell, M. A., Sears, K. E., Swisher III, C. C. y A. R. Wyssd. 2002. A new fossil mammal assemblage from the southern Chilean Andes: implications for geology, geochronology, and tectonics. Journal of South American Earth Sciences 15: 285-302

Flynn, J. J., Wyss, A. R., Croft, D. A. y R. Charrier. 2003. The Tinguiririca Fauna, Chile: biochronology, paleoecology, biogeography, and a new earliest Oligocene South American land mammal “age”. Palaeogeography, Palaeoclimatology, Palaeoecology 195, 229-259.

Folie, A. y V. Codrea. 2005. New lissamphibians and squamates from the Maastrichtian of Hapeg Basin, Romania. Acta Palaeontologica Polonica 50: 57-71.

Fossa Mancini, E., Feruglio, E. y J. Yussen de Campana. 1938. Una reunión de geólogos de YPF y el problema de la terminología estratigráfica. Boletín de Informaciones Petroleras 15:1-67. Buenos Aires.

Fry, B. G., Vidal, N., Norman, J. A., Vonk, F. J., Scheib, H. G., Ramjan, S. F. R., Kuruppu, S., Fung, K., Hedges, S. B., Richardson, M. K., Hodgson, W. C., Ignjatovic, V., Eummerhayes, R. y E. Kochva. 2006. Early evolution of venom system in lizards and snakes. Nature 439: 584-588.

Fucks, E. y C. M. Deschamps. 2008. Depósitos continentales Cuaternarios en el noreste de la provincia de Buenos Aires. Revista de la Asociación Geológica Argentina 63(3): 326-343.

Gans, C. 1978. The characteristics and affinities of the Amphisbaenia. Transactions of the Zoological Society of London 34: 347-416.

Gans, C. y R. Montero. 1998. Two new sossil amphisbaenids (Reptilia: Squamata) from the Pleistocene of Lagoa Santa (Minas Gerais, Brazil). Steenstrupia 24(1): 9-22.

Gasparini, Z. 1984. New Tertiary Sebecosuchia (Crocodylia: Mesosuchia) from Argentina. Journal of Vertebrate Paleontology 4(1): 85-95.

Gasparini, Z. y A. M. Báez. 1975. Aportes al conocimiento de la herpetofauna Terciara de la Argentina. Primer Congreso Argentino de Paleontología y Bioestratigrafía (Actas) 2: 377415.

Gasparini, Z., de la Fuente, M. S. y O. E. Donadío. 1986. Los Reptiles Cenozoicos de la Argentina: implicancias paleoambientales y evolución biogeográfica. IV Congreso Argentino de Paleontología y Bioestratigrafía, Mendoza. Resumenes (2): 119-130. 
Gao, K. y R. C. Fox. 1991. New Teiid lizard from the upper Cretaceous Oldman formation (Judithian) of southeastern Alberta, Canada, with a review of the Creataceous record of Teiids. Annal of Carnegie Museum 60(2): 145-162.

Gao, K. yR. C. Fox. 1996. Taxonomy and evolution of Late Cretaceous lizards (Reptilia: Squamata) from western Canada. Bulletin of the Carnegie Museum of Natural History 33: 1-107.

Gao, K. y L. A. Nessov. 1998. Early Cretaceous squamates from the Kyzylkum Desert, Uzbekistan. Neues Jahrbüch für Geologische und Paläontologische Abhandlungen 207: 289309.

Gauthier, J. A. 1984. A cladistic analysis of the higher systematic categories of the Diapsida. Tesisi Doctoral. University of Michigan, Ann Arbor.

Gayet, M., Rage, J. C., Sempere, T. y P. Y. Gagnier. 1992. Modalités des échanges de vertébrés continentaux entre l'Amérique du Nord et l'Amérique du Sud au Crétacé supérieur et au Paléocéne. Bulletin Société Géologique de France 163: 781-791.

Gelfo, J. N., Goin, F. J., Woodburne, M. O. y C. de Muizon. 2009. Biochronological relationships of the Earliest South American Paleogene mammalian faunas. Palaeontology 52(1): 251-269.

Giambelluca, L. A. y M. Casciaro. 1999. Manejo de Lagarto Overo y Lagarto Colorado en ECAS. Revista Argentina de Producción Animal 19(3-4): 471-480.

Giugliano, L. G., Garcia Collevatti, R. y G. R. Colli. 2007. Molecular dating and phylogenetic relationships among Teiidae (Squamata) inferred by molecular and morphological data. Molecular Phylogenetics and Evolution 45: 168-179.

Goin, F. J., Tejedor, M., Bond, M., López, G. y M. Reguero. 2000a. Mamíferos Eocenos de Paso del Sapo, Chubut. Ameghiniana 37 (4). suplemento, 25R.

Goin, F. J., Montalvo, C. I. y G. Visconti. 2000b. Los marsupiales (Mammalia) del Mioceno superior de la Formación Cerro Azul (provincia de La Pampa, Argentina). Estudios Geológicos 56: 101-126.

Goin, F. J., Zimicz, N., Reguero, M. A., Santillana, S. N., Marenssi, S. A. y J. J. Moly. 2007. New Marsupial (Mammalia) from the Eocene of Antarctica, and the origins and affinities of the Microbiotheria. Revista de la Asociación Geológica Argentina 62 (4): 597 603.

Goloboff, P., Farris, J. y K. Nixon. 2003. T.N.T.: tree analysis using new technology. Version 1.0 (http://www.zmuc.dk/public/phylogeny).

Goloboff, P., Farris, J. y K. Nixon. 2008. TNT: a free program for phylogenetic 
analysis. Cladistics 24(5): 774-786.

González Riga, B. J.; Calvo, J. O. y Porfiri, J. D. 2008. An articulated titanosaur from Patagonia (Argentina): new evidence of neosauropod pedal evolution. Palaeoworld, 17(1): $33-40$.

Gordillo, C. E. y A. M. Lencinas, 1979. Sierras pampeanas de córdoba y San Luis. Segundo Simposio de Geología Regional Argentina 1: 577-650.

Gorman, G. C. 1970. Chromosome and the systematics of the family Teiidae. Copeia 1970: 230-245.

Gray, J. E. 1827. A synopsis of the genera of saurian reptiles, in which some new genera are indicated, and the others reviewed by actual examination. Annals of Philosophy 2(2): 54-58.

Gray, J. E. 1844. Catalogue of the tortoises, crocodiles, and amphisbaenians in the collection of the BritishMuseum. London, British Museum.

Gray, J. E. 1865. A revision of the genera and species of amphisbaenians with the descriptions of some new species now in the collection of the British Museum. Proceedings of the Zoological Society of London 1865: 442-455

Gravenhorst, J. L. C. 1837. Beiträge zur genauern Kenntniss einiger Eidechsengattungen. Nova Acta Academiae Caesarae Liopoldina Carolinae Germaninicae Naturae Curisorum 18(2): 712-784.

Günther, A. 1871. Description of a new species of Tejus (Tejus rufescens) from Mendoza. Proceeding Science Meetings of the Zoological Society of London 1871: 541-543.

Haro, J. G., Sferco G. D. y Arcando U. 2000. Nueva localidad para Tupinambis rufescens (Gunther, 1871) en la provincia de Córdoba (Argentina). Cuadernos de Herpetología 14(1): 79.

Hedges, S. B. 2001. Biogeography of the West Indies: an overview; pp. 15-33. En: C. A. Woods y F. E. Sergile (Eds.), Biogeography of the West Indies: Patterns and Perspectives. CRC Press, Boca Raton.

Herrel, A., Vanhooydonck, B. y R. Van Damme. 2004. Omnivory in lacertid lizards: adaptive evolution or constraint? Journal of Evolutionary Biology 17: 974-984.

Hoffstetter, R. 1955. Squamates de type modeme; pp 606-662. En: Piveteau J. (Ed.), Traité de Paléontologie, Vol. 5. Masson et Cie., Paris.

Hoffstetter, R. 1962. Revue des recentes acquisitions concernant l'histoire et la systematique des squamates. Problemes Actuels de Paleontologie (Evolution des vertebres), Centre National de la Recherche Scientifique 1962: 243-285. 
Hoffstetter, R. 1963. La faune pléistocéne de Tarija (Bolivie). Note préliminaire. Bulletin du Muséum National d'Historie Naturelle, Series 2, 35(2): 195-203.

Hoffstetter, R. 1968. Na aupua, un gisement de vertébrés plestocenes dans le chaco bolivien. Bulletin du Muséum National d'Historie Naturelle, Series 2, 40(4): 823-836.

Hoffstetter, R. 1970. Vertebrados Cenozoicos del Ecuador. IV Congreso Latino Americano de Zoología, Actas (2): 955-970.

Hoffstetter, R. y J. P. Gasc. 1969. Vertebrae and ribs in modern reptiles. pp. 201-310. En: C. Gans, A. d'A. Bellairs y T. Parsons (Eds.), Biology of the Reptilia, Academic Press, London and New York.

Hower, L. M. y S. B. Hedges. 2003. Molecular phylogeny and biogeography of west indian teiid lizards of the genus Ameiva. Caribbean Journal of Science 39(3): 298-306.

Hsiou, A. 2007. A new Teiidae species (Squamata, Scincomorpha) from the late Pleistocene of Rio Grande do Sul State, Brazil. Revista Brasileira de Paleontologia 10: 181-194.

Hsiou, A., Ferigolo, J. y A. M. Albino. 2007. Sobre os Squamata (Lepidosauria) da Formação Solimões, Mioceno da Amazônia Sul-Ocidental, Brasil. Ameghiniana 44(Suplemento): 23.

Huene, F. Von. 1981. Verschiedene mesozoische Wirbeltierrerte aus Súdamerika. Neues Jahrbuch fúr Mineralogie, Geologie und evolution 135(1): 1-59.

Juárez, R., Aguer, I. y M. R. Martori. 2003. Biodiversidad y actividad estacional de un ensamble de reptiles del Monte. XVIII Reunión de Comunicaciones Herpetológicas (Puerto Madryn) Resúmenes: 63.

Kacoliris, F. P., Berkunsky, I. y J. D. Williams. 2006. Herpetofauna of the argentinean Impenetrable Great Chaco. Phyllomedusa 5(2): 149-157.

Kay, R. F. y R. Madden. 1997. Paleogeography and Paleoecology; pp 520-550. En: R. F. Kay, R. H. Madden, R. L. Cifelli y J. J. Flynn (Eds.), Vertebrate Paleontology in Neotropics. Smithsonian Institution Press, Washington D. C.

Kay, R. F., Madden, R., Vucetich, M. G., Carlini, A., Mazzoni, M. y G. Re. 1999. Revised geochronology of the Casamayoran South American land mammal age: climatic and biotic implications. Proceedings National Academy of Science 96(23): 13235-13240.

Kearney, M. 2003. Systematics of the Amphisbaenia (Lepidosauria: Squamata) based on morphological evidence from recent and fossil forms. Herpetological Monographs 17: 1-74.

Kearney, M. y O. Rieppel. 2006. An investigation into the occurrence of plicidentine in the teeth of Squamate reptiles. Copeia (3): 337-350. 
Kelt, D. A., Meserve, P. L. Nabors, L. K., Forister, M. L. y J. R. Gutiérrez. 2004. Foraging ecology of small mammals in semiarid Chile: the interplay of biotic and abiotic effects. Ecology, 85(2): 383-397.

Kraglievich, L. J. 1930. La formación friaseana del Río Frías, Río Fénix, Laguna Blanca, etc. y su fauna de mamíferos, Physis, Revista de la Sociedad Argentina de Ciencias Naturales 10: 127-161.

Kraglievich, L. J. 1947. Presencia de lagartos del género Tupinambis en la fauna Pliocena Chapadmalalense. Anales de la Sociedad Científica Argentina 143: 253-257.

Kraglievich, L. J. 1952. El perfil geológico de Chapadmalal y Miramar, prov. de Bs. As. Revista del Museo de ciencias Naturales de Mar del Plata 1(1): 8-37.

Kraglievich, L. J. 1953. La llanura bonaerense a través de un perfil geológico. Revista Mundo Atómico, 14: 88-89.

Kraglievich, L. J. 1959. Contribuciones al conocimiento de la geología costera en la desembocadura del arroyo Malacara (provincia de Buenos Aires). Revista del Museo de Ciencias Naturales “Bernardino Rivadavia” Geología 1: 3-9.

Kraglievich, J. L. y O. A. Reig. 1954. Un nuevo procionido del Plioceno de Las Playas (Provincia de Córdoba). Revista de la Asociación Geológica Argentina 9(4): 210-231.

Kramarz, A. G. 2001. Registro de Eoviscaccia (Rodentia, Chinchillidae) en estratos Colhuehuapenses de Patagonia, Argentina. Ameghiniana 38(2): 237-242.

Krause, L. 1978a. Osteologia pos-craniana de Tupinambis teguixin (L., 1758) sensu Boulenger, 1885. Parte I: esqueleto axial (vértebras e costelas). (Lacertilia, Scincomorpha, Teiidae). Revista Brasileira de Biologia 38(2): 481-499.

Krause, L. 1978b. Osteologia pós-craniana de Tupinambis teguixin (L., 1758) sensu Boulenger, 1885. Parte II: esqueleto apendicular (cintura e membros). (Lacertilia, Scincomorpha, Teiidae). Revista Brasileira de Biologia 38(3): 509-521.

Krause, L. 1985. Fossil Record of the Family Teiidae. Notes on Paleobiogeography, Current Distribution, and Habits of Macorteiids. (Sauria, Scincomorpha, Teiidae). Studies on Neotropical Fauna and Environment 20(3): 175-188.

Krause, L. 1990. Morfologia e aspectos funcionais de esqueleto apendicular de macroteiídeos (Sauria, Scincomorpha, Teiidae). Boletim do Instituto de Biociéncias, UFRGS. 47: 1-114.

Leanza, H. A. 1948. Nota preliminar sobre la geología de las barrancas de Monte Hermoso (provincia de Buenos Aires). Notas del Museo de La Plata, Geología 48: 3-6. 
Leanza, H. A. y Hugo, C. A. 2001. Cretaceous red beds from southern Neuquén Basin (Argentina): age, distribution and stratigraphic discontinuities. Asociación Paleontológica Argentina, Publicación Especial 7: 117-122.

Leanza, H. A., Apesteguía, S., Novas, F. E. y M. de la Fuente. 2004. Cretaceous terrestrial beds from the Neuquén Basin (Argentina) and their tetrapod assemblages. Cretaceous Research, 25: 61-87.

Lee, M. S. Y. 1997. The phylogeny of varanoid lizards and the affinities of snakes. Philosophical Transactions of the Royal Society London B 352: 53-91.

Lee, M. S. Y. 1998. Convergent evolution and character correlation in burrowing reptiles: towards a resolution of squamate relationships. Biological Journal of the Linnean Society 65: 369-453.

Lee, M. S. Y. y J. D. Scanlon. 2001. On the lower jaw and intramandibular septum in snakes and anguimorph lizards. Copeia 2001: 531-535.

Linares, E., Llambías, E. y C. Latorre. 1980. Geología de la provincia de La Pampa, República Argentina y geocronología de sus rocas metamórficas y eruptivas. Revista de la Asociación Geológica Argentina 35(1): 87-146.

Linnaeus, C. 1758. Systema naturæ per regna tria naturæ, secundum classes, ordines, genera, species, cum characteribus, differentiis, synonymis, locis. 10, Reformata Edition, Volume 1.

Lönnberg, E. 1896. Linnean type-specimens of birds, reptiles, batrachians, and fishes in the Zoological Museum of the Royal Univeristy of Upsala. Bihang till Kongliga Svenska Vetenskaps-Akademiens. Handlingar, Stockholm 22(4) 1: 1-45

López, A. M. y M. R. Cabrera. 1995. Osteología Craneal de Pantodactylus schreibersii schreibersii (Wiegmann, 1834) y su contribución a la discusión de Gymnophthalmidae (Reptilia). Anales del Museo de Historia Natural del Valparaíso 23: 3-62.

Lorandi, A. M. 1974. Espacio y tiempo en la prehistoria Santagueña. Relaciones (n.s.) 8: 199236.

Lorandi, A. M., Crisci, J. V., Gonaldi, M. E. y S. E. Caramazana. 1979. El cambio cultural en Santiago del Estero. Un estudio de taxonomía numérica sobre morfología de bordes de alfarería ordinaria. Relaciones (n.s.) 13: 85-101.

Lündberg, J. G., Marshall, L. G., Guerrero, J., Horton, B., Malabarba, C. S. L. y F. Weeselingh. 1998. The stage for Neotropical Fish Diversification: A history of tropical South American rivers; pp. 603. En: L. R. Malabarba, R. P. Reis, R. P. Vari, Z. M. Lucena, y C. A. S. Lucena (Eds.), Phylogeny and Classification of Neotropical Fishes. Edicucrus, Porto Alegre. 
MacLean, W. P. 1974. Feeding and locomotor mechanisms of teiid lizards: functional morphology and evolution. Papéis Avulsos de Zoologia, Museu de Zoologia de São Paulo 27(15): 179-213.

Madden, R. H., Guerrero, J., Kay, R. F., Flynn, J. J., Swisher III, C. C. y A. W. Walton. 1997. The Laventan stage and age. pp. 499-519. En: Kay, R. F., Madden, R. H., Cifelli, R. L. y J. J. Flynn (Eds.), Vertebrate Paleontology in the Neotropics: The Miocene Fauna of La Venta, Colombia. Smithsonian Institution Press, Washington DC.

Maisano, J. A. 2002. Terminal fusions of skeletal elements as indicators of maturity in Squamates. Journal of Vertebrate Paleontology 22(2): 268-275.

Makádi, L. 2006. Bicuspidon aff. hatzegiensis (Squamata: Scincomorpha: Teiidae) from the Upper Cretaceous Csehbánya Formation (Hungary, Bakony Mts). Acta Geologica Hungarica 49: 373-385.

Malabarba, M. C., Zuleta, O. y C. del Papa. 2006. Proterocara argentina, a new fossil cichlid from the Lumbrera Formation, Eocene of Argentina. J Journal of Vertebrate Paleontology 26(2): 267-275

Manzani, P. R., y A. S. Abe. 1997. A new species of Tupinambis Daudin, 1802 (Squamata, Teiidae) from central Brazil. Boletim do Museu Nacional, nova série, Zoologia, Rio de Janeiro 382: 1-10.

Manzani, P. R. y A. S. Abe. 2002. A new species of Tupinambis Daudin, 1803 from southeastern Brazil (Squamata, Teiidae). Arquivos do Museu Nacional, Rio de Janeiro 60: 295-302.

Marshall, L. G. 1990. The fossil Marsupialia from the type Friasian Land Mammal Age (Miocene), alto Río Cisnes, Aisen, Chile. Revista Geológica de Chile 17(1): 19-55.

Marshall, L. G. y P. Salinas. 1990. Stratigraphy of the Río Frías Formation (Miocene), along the Alto Río Cisnes, Aisen, Chile. Revista Geológica de Chile 17(1): 57-87.

Marshall, L. G, Butler, R., Drake, R. E. y G. H. Curtis. 1982a. Geochronology of type Uquian (Late Cenozoic) land mammal age, Argentina. Science 216: 986-989.

Marshall, L. G., Hoffstetter, R. y R. Pascual. 1983. Geochronology of the continental mammal bearing Tertiary of South America. Paleovertebrata, Mémoire Extraordinaire: 1-93.

Marshall, L. G., Drake, R. R., Curtis, G. H., Butler, R. F., Flanagan, K. M. y C. W. Naeser. 1986. Geochronology of type Santacrucian (Middle Tertiary) land mammal age. Patagonia. Argentina. Journal of Geology 94(4): 449-457. 
Marshall, L. G., Sempere, T. y R. F. Butler. 1997. Chronostratigraphy of the mammalbearing Paleocene of South America. Journal of South American Earth Sciences 10 (1): 4970.

Martori, R. y R. Juárez. 1998. Caracterización de un ensamble herpetológico. XIII Reunión de Comunicaciones Herpetológicas (Santa Fe) Resúmenes: 29-30.

Moro, S., y V. Abdala. 2000. Cladistic analysis of the Teiidae (Squamata) based on myological characters. Russian Journal of Herpetology 7(2): 87-102.

Mortari, M. R., y G. R. Colli. 1999. Anaíse filogenética dos lagartos da familia Teiidae (Reptilia: Squamata). V Congreso Latinoamericano de Herpetología, resúmenes: 88.

Massary, J. C., and M. S. Hoogmoed. 2001. Crocodilurus amazonicus Spix, 1825: the valid name for Crocodilurus lacertinus auctorum (nec Daudin, 1802) (Squamata:Teiidae). Journal of Herpetology 35(2): 253-357.

Mazzanti, D. y C. Quintana. 1997. Asociación cultural con fauna extinguida en el sitio arqueológico Cueva Tixi, provincia de Buenos Aires, Argentina. Revista Esoañola de Antropología Americana 27: 11-21.

Mazzoni, M. M. y A. Benvenuto. 1990. Radiometric ages of Tertiary ignimbrites and the Collón Cura Formation, northwester Patagonia. XI Congreso Geológico rgentino, Actas 2: 87-90.

McCord, R. D. 1998. A new genus and species of Cretaceous polyglyphanodontine lizard (Squamata, Teiidae) from the Kaiparowits Plateau, Utah; pp 281-292. En, Tomida, Y. Flynn, L. J. y L. L. Jacobs (Eds.), Advances in Vertebrate Paleontology and Geochronology. National Science Museum Monographs 14.

Melchor, R., Visconti, G. y C. I. Montalvo. 2000. Late Miocene calcic vertisols from central La Pampa, Argentina. II Congreso Latinoamericano de Sedimentología and VII Reunión Argentina de Sedimentología, Actas: 119-120.

Merrem, B. 1820. Versuch eines Systems der Amphibien I (Tentamen Systematis Amphibiorum). J. C. Kriegeri, Marburg.

Mendía, J. E. y A. Bayarsky. 1981. Estratigrafia del Terciario en el valle inferior del Río Chubut. VIII Congreso Geológico Argentino, Actas 3: 593-606.

Mesquita, D. O., Colli, G. R., Costa, G. C., Franca, F. G. R., Garda, A. A. y A. K. Péres Jr. 2006. At the water's edge: ecology of semiaquatic teiids in brazilian amazon. Journal of Herpetology 40(2): 221-229. 
Meyer, F. A. A. 1795. Synopsis Reptilium, novam ipsorum sistens generum methodum Gottingensium huius ordinis animalium enumerationem. Vandenhoek et Ruprecht, Gottingae.

Montalvo, C. I., Cardonatto, M. c., Visconti, G., Verzi, D. H. y Vucetich, M. G. 1996. Vertebrados de la Formación Cerro Azul (Mioceno tardío) del Valle de Quehué, provincia de La Pampa, Argentina. Actas de las VI Jornadas Pampeanas de Ciencias Naturales, Santa Rosa, La Pampa 1: 159-165.

Montalvo, C. I. y D. H. Verzi. 2004. El registro de roedores Octodontoidea (Caviomorpha) de la formación Cerro Azul (Mioceno tardío, La Pampa, Argentina): sistemática, biocronologáa, evolución y paleoclimas. Ameghiniana 41 (4, Suplemento): 56.

Montalvo, C. I., Verzi, D., Vucetich, M. G. y G. Visconti. 1998. Nuevos Eumysopinae (Rodentia, Echimyidae) de la Formación Cerro Azul (Mioceno tardío) de La Pampa, Argentina. V Jornadas Geológicas y Geofísicas Bonaerenses, Actas 1: 57-64.

Montalvo, C. I., Verzi, D. y G. Visconti. 2002. Hallazgo de un pequeño Octodontoidea (Rodentia, Caviomorpha) en Loventué, La Pampa (Formación Cerro Azul, Mioceno tardío). VIII Jornadas Pampeanas de Ciencias Naturales, Actas: 157-158.

Montanelli, S. B. y S. Acosta. 1991. Lista preliminar de la herpetofauna del Parque Nacional Iguazú. VIII Reunión de Comunicaciones Herpetológicas (Córdoba) Resúmenes: 9-10.

Montero, R. 1996. Lista de las localidades de los Amphisbaenidae de la Republica Argentina. Cuadernos de Herpetología 10(1-2): 25-45.

Montero, R., Abdala, V., Moro, S. y G. Gallardo. 2004. Atlas de Tupinambis rufescens (Squamata: Teiidae). Anatomía externa, osteología y bibliografía. Cuadernos de Herpetología 18(1): 17-32.

Moreno, J. A. 1970. Estratigrafía y paleogeografía del Cretácico superior en la cuenca del noroeste argentino, con especial mención de los Subgrupos Balbuena y Santa Bárbara. Revista de la Asociación Geológica Argentina, 25(1): 9-44.

Moro, S. y V. Abdala. 2000. Cladistic analysis of the Teiidae (Squamata) based on myological characters. Russian Journal of Herpetology 7(2): 87-102.

Musacchio, E. A. 2006. Charophyta del Cretácico tardío y el Paleoceno del centro oeste de Argentina. Revista Brasileira de Paleontologia 9(1): 93-100.

Muizon, C. de, Gayet, M., Lavenu, A., Marshall, L. G., Sigé, B. y C. Villarroel. 1983. Late Cretaceous vertebrates, including mammals, from Tiupampa, South Central Bolivia. Geobios 16: 747-753. 
Müller, J. 2001. Osteology and relationships of Eolacerta robusta, a lizard from the Middle Eocene of Germany (Reptilia, Squamata). Journal of Vertebrate Paleontology 21(2): 261278.

Norrel, M. A. 1989. Late Cenozoic lizards of the Anza Borrego Desert, California. Contributions in Science, Natural History Museum of Los Angeles County 414: 1-31.

Norell, M. A. y K. de Quieroz. 1991. The earliest Iguanine lizard (Reptilia: Squamata) and its bearing on Iguanine phylogeney. American Museum Novitates 2997: 1-16

Núñez, H., Stafford, T. W. y D. Frassinetti. 2005. Primer registro de fósiles de Liolaemus en Chile (Reptilia, Sauria). Noticiario Mensual del Museo Nacional de Historia Natural 356: 37.

Nydam, R. L. 2000. A new taxon of Helodermatid-Like lizard from the Albian-Cenomanian of Utah. Journal of Vertebrate Paleontology 20(2): 285-294.

Nydam, R. L. y R. L. Cifelli. 2002a. Lizards from the Lower Cretaceous (Aptian-Albian) Antlers and Cloverly Formations. Journal of Vertebrate Paleontology 22(2): 286-298.

Nydam, R. L. y R. L. Cifelli. 2002b. A new Teiid from the Cedar Moutain Formation (AlbianCenomanian boundary) of Utah. Journal of Vertebrate Paleontology 22(2): 276-285.

Nydam, R. L. y G. E. Voci. 2007. Teiid-Like Scincomorphan Lizards from the Late Cretaceous (Campanian) of Southern Utah. Journal of Herpetology 41(2): 211-219.

Nydam, R. L., Eaton, J. G. y J. Sankey. 2007. New taxa of transversely-toothed lizards (Squamata: Scincomorpha) and new information on the evolutionary history of "teiids". Journal of Paleontology 81(3): 538-549.

Oelrich, T. M. 1956. The anatomy of the head of Ctenosaura pectinata (Iguanidae). Miscellaneous Publications, Museum of Zoology, University of Michigan 94: 1-122.

Ortiz Jaureguizar, E. 1986. Evolución de las comunidades de mamíferos cenozoicos sudamericanos: un estudio basado en técnicas de análisis multivariado. IV $^{\circ}$ Congreso Argentino de Paleontología y Bioestratigrafía (Mendoza), Actas 2: 191-207.

Ortiz-Jaureguizar, E. y G. A. Cladera. 2006. Paleoenvironmental evolution of southern South America during the Cenozoic. Journal of Arid Environment 66: 498-532.

Oppel, M. 1811. Die ordnungen familien und Gattungen der Reptilien, als Prodrom einer Naturgeschichte derselben. Joseph Lindauer, München.

Olsacher, J. 1960. Descripción geológica de la Hoja 20h - Los Gigantes, Provincia de Córdoba. Dirección Nacional de Minería y Geología, Anales XII. Vol. 90: 5-46.

Owen, R. 1866. The Anatomy of Vertebrates, Vol. 1: Fishes and Reptiles. Longmans, Green, and Co., London. 
Pardiñas, U. F. J. 1991. Primer registro de primates y otros vertebrados para la Formación Collón Cura (Mioceno medio) del Neuquén, Argentina. Ameghiniana 28 (1-2): 197-199.

Pascual, R., Bondesio, P., 1982. Un roedor Cardiatheriinae (Hydrochoeridae) de la Edad Huayqueriense (Mioceno tardío) de La Pampa. Sumario de los ambientes terrestres en la Argentina durante el Mioceno. Ameghiniana 19(1-2): 19-35.

Pascual, R. y O. E. Odreman Rivas. 1971. Evolución de las comunidades de los vertebrados del Terciario Argentino, los aspectos paleozoogeográficos y paleoclimáticos relacionados. Ameghiniana 7(3-4): 372-412.

Pascual, R. y O. E. Odreman Rivas. 1973. Las unidades estratigraficas del Terciario portadoras de mamíferos. Su distribución y sus relaciones con los acontecimientos diastróficos. V Congreso Geológico Argentino, Anales 3: 293-338.

Pascual, R. y Ortiz Jaureguizar, E. 1990. Evolving climates and mammal fauna in Cenozoic South America. Journal of Human Evolution 19: 23-60.

Pascual, R., Ortega Hinojosa, E. J., Gondar, D. y E. P. Tonni. 1965. Las edades del Cenozoico mamalífero de la Argentina, con especial atención a aquéllas del territorio bonarense. Comisión Investigaciones Científicas de la Provincia de Buenos Aires, Anales 6: $165-1$.

Pascual, R., Vucetich, M. G. y J. Fernandez. 1978. Los primeros mamíferos (Notoungulata, Henricosborniidae) de la Fm. Mealla (Grupo Salta, Subgrupo Santa Bárbara). Sus implicancias filogenéticas, taxonómicas y cronológicas. Ameghiniana, 15(3-4): 366-390.

Pascual, R., Bond, M. y M. G. Vucetich. 1981. El Subgrupo Santa Bárbara (Grupo Salta) y sus vertebrados. Cronología, paleoambientes y paleobiogeografía. VIII Congreso Geológico Argentino, Actas 3: 743-758.

Pascual, R., Ortiz Jaureguizar, E. y J. L. Prado. 1996. Land mammals: Paradigm for Cenozoic South American Geobiotic evolution. Münchner Geowissenchaftliche Abhandlungen A 30: 265-320.

Péres Jr., A. K. 2003. Sistemática e conservacao de lagartos do genero Tupinambis. Tesis Doctoral; 193 pp. Instituto de Ciencias Biologicas, Universidade de Brasilia, Brasilia.

Péres Jr., A. K. y G. R. Colli. 1999. Análise filogenética do género Tupinambis (Squamata, Teiidae). V Congreso Latinoamericano de Herpetología, resúmenes: 96.

Péres Jr., A. K. y G. R. Colli. 2004. The taxonomic status of Tupinambis rufescens and $T$. duseni (Squamata: Teiidae), with a redescription of the two species. Occasional Papers, University of Oklahoma 15: 1-12. 
Peters, J. A. y R. Donoso-Barros. 1970. Catalogue of the Neotropical Squamata. Part II, Lizards and Amphisbaenians. Smithsonian Institution Press, Washington D. C..

Peyer. B. 1968. Comparative Odontology. The Univertsity of Chicago Press, Chicago.

Pomi, L. H. 2008. Una nueva asociación de vertebrados fósiles de edad Ensenadense (Plioceno tradío-Pleistoceno medio) de la provincia de Buenos Aires, Argentina. Ameghiniana 45(2): 503-510.

Pough, F.H., Andrews, R. M., Cadle, J. E., Crump, M. L., Savítzky, A. H. y K. D. Well. 1998. Herpetology. Prentice Hall, New Jersey.

Powell, J. E. y M. V. Deraco. 2003. Un nuevo leontinido (Mammalia, Notoungulata) del miembro superior de la Formación Lumbrera (Subgrupo Santa Bárbara) del noroeste Argentino. Ameghiniana 37(4: suplemento): 68-69.

Presch, W. 1973. A review of the Tegus, lizard genus Tupinambis (Sauria:Teiidae) from South America. Copeia: 740-746.

Presch, W. 1974a. Evolutionary Relationships and Biogeography of Macroteiidae Lizards (Family Teiidae, Subfamaly Teiinae). Bulletin of the Southern California Academy of Sciences 73(1): 23-32.

Presch, W. 1974b. A survey of the dentition of the macroteiid lizards (Teiidae: Lacertilia). Herpetologica 30(4): 344-349.

Presch, W. 1980. Evolutionary history of South America Microteiid Lizards (Teiidae: Gymnophthalmidae). Copeia 1980: 36-56.

Prieto, A. R. 2000. Vegetational history of the Late glacial-Holocene transition in the grasslands of eastern Argentina. Palaeogeography, Palaeoclimatology, Palaeoecology 157: 167-188.

Prevosti, F. J., Bonomo, M. y E. P. Tonni. 2006. La distribución de Chrysocyon brachyurus (illiger, 1811) (Mammalia: Carnivora: canidae) durante el Holoceno en la Argentina: implicancias paleoambientales. Mastozoología Neotropical / Journal of Neotropical Mammalogy 11(1): 27-43.

Protomastro, J. J., Porini, G. y S. M. Caziani. 1992. Disturbio del hábitat y abundancia en la iguana colorada (Tupinambis rufescens Gunther). II Congreso Argentino de Herpetología (La Plata) Resúmenes: 63.

Pujos, F., Albino, A. M., Baby, P., Goyout, J. L. y R. Salas Gismodi. 2009. Presence of the extinct lizards Paradracaena (Teiidae) in the middle Miocene of the Peruvian Amazon. Journal of Vertebrate Paleontology 29(2): 594-598. 
Quattrocchio, M. E. 2006. Palynology and palaeocommunities of the paleogene of Argentina. Revista Brasileira de Paleontologia 9(1): 101-108.

Quattrocchio, M. E., Durango de Cabrera, J. y C. Galli. 2003. Formación Anta (Mioceno Temprano/Medio), Subgrupo Metán (Grupo Orán), en el río Piedras, Pcia. de Salta. Datos palinológicos. Revista de la Asociación Geológica Argentina 5(1): 117-127.

Quattrocchio, M. E., Borromei, A. M. Deschamps, C. M. Grill, S. C. y C. A. Zavala. 2008. Landscape evolution and climate changes in the Late Pleistocene - Holocene, southern Pampa (Argentina): Evidence from palynology, mammals and sedimentology. Quaternary Internacional 181: 123-138.

Quintana, C. A. 2001. Galea (Rodentia, Caviidae) del Pleistoceno superior y Holoceno de las sierras de Tandilia oriental, provincia de Buenos Aires, Argentina. Ameghiniana 38(4): 399407.

Quintana, C. A., Valverde, F. y D. L. Mazzanti. 2000. Roedores y lagartos como emergentes de la diversificación de la subsistencia durante el Holoceno tardío de la región Pampeana Argentina. Latin American Antiquity 13(2): 455-473.

Quintana, C. A., Mazzanti, D. L. y F. Valverde. 2004. El lagarto overo como recurso faunístico durante el Holoceno de las sierras de Tandilia Oriental, provincia de Buenos Aires; pp 347-353. En: Grandin C. J. y F. Oliva (Eds.), La región Pampeana. Su pasado arqueológico. Laborde, Buenos Aires.

Rage, J. 1992. Squamate Reptiles from the early Paleocene of the Tiupampa area (Santa Lucia Formation), Bolivia; pp 503-508. En: Suárez-Soruco, R. (Ed.), Fósiles y facies de Bolivia. Volúmen 1. Revista de Yacimientos Petrolíferos Fiscales Bolivianos 12(3-4).

Reeder, T. W., Cole, C. J. y H. C. Dessauer. 2002. Phylogenetic relationships of whiptail lizards of the genus Cnemidophorus (Squamata: Teiidae): a test of monophyly, reevaluation of karyotypic evolution, and review of hybrid origins. American Museum Novitates 3365: $1-61$.

Reese, A. M. 1923. Osteology of Tupinambis nigropunctatus. Journal of Morphology 38(1): 118.

Reig, O. 1958. Notas para una actualización del conocimiento de la fauna de la Formación Chapadmalal. II Amphiabia, Reptilia, Aves, Mammalia (Marsupialia, Didelphidae, Boriiyaenidae). Acta Geológica Lilloana 2: 255-283.

Reguero, M. A, Croft D. C., López G. M. y R. N. Alonso. 2008. Eocene archaeohyracids (Mammalia: Notoungulata: Hegetotheria) from the Puna, northwest Argentina. Journal of South American Earth Sciences 26: 225-233. 
Reynoso, V. H. 1988. Huehuecuetzpalli mixtecus gen. et sp. nov: a basal squamate (Reptilia) from the Early Cretaceous of Tepexi de Rodríguez, Central México. Philosophical Transactions of the Royal Society London B 353: 477-500.

Reynoso, V. H. y G. Callison. 2000. A new scincomorph lizard from the Early Cretaceous of Puebla, México. Zoological Journal of the Linnean Society 130: 183-212.

Richter, A. 1994. Lacertilier aus der Unteren Kreide von Uña und Galve (Spanien) und Anoual (Marokko). Berliner Geowissenschaftliche Abhandlungen 14: 1-147.

Rieppel, O. 1978. Tooth replacement in Anguinomorph lizards. Zoomorphologie 91: 77-90.

Rieppel, O. 1980. The trigerminal jaw musculature of Tupinambis, with comments on phylogenetic relationships of the Teiidae (Reptilia, Lacertilia). Zoological Journal of the Linnean Society 69: 1-29.

Rieppel, O. y H. Zaher. 2000. The intramandibular joint in squamates, and the phylogenetic relationships of the fossil snake Pachyrhachis problematicus Haas. Fieldiana, New Series, Geology 43: 1-69.

Rodríguez Loredo, C. 1998. Estudio arqueozoológico del sitio Inca Potrero Chaquiago, Barrios La Solana y Retambay, Andalgalá provincia de Catamarca, Argentina. Relaciones 22-23: 203-245.

Romer, A. S. 1956. Osteology of the Reptiles. University of Chicago Press, Chicago.

Romer, A. S. 1967. Vertebrate Paleontology. University of Chicago Press, Chicago.

Roth, S. 1899. Apuntes sobre la geología y paleontología de los territorios de Río Negro y Neuquén. Revista del Museo de La Plata, 9: 141-172

Rovereto, C. 1914. Los estratos araucanos y sus fósiles. Anales del Museo Nacional de Historia Natural 25: 1-250.

Rusconi, C. 1937. La presencia de lagartijas en el piso Ensenadense. Boletín Paleontológico 9: 6-7.

Salemme, M. C. 1990. Zooarchaeological studies in the humid Pampas, Argentina. Quaternary of South America and Antarctic Peninsula 6: 309-335.

Savage, J. 1966. The origins and history of the Central American Herpetofauna. Copeia 1966: 719-766.

Scanferla, C. A., Montero, R. yF. L. Agnolin. 2006. The first fossil record of Amphisbaena heterozonata from the late Pleistocene of Buenos Aires province, Argentina. South American Journal of Herpetology 1(2): 138-142. 
Spalletti, L. A., y M. M. Mazzoni. 1979. Sedimentología del Grupo Sarmiento en un perfil ubicado al sudeste del Lago Colhué Huapi, provincia de Chubut. Revista del Museo de La Plata, Obra del Centenario, Geología 4:261-283.

Spalletti, L. A., y M. M. Mazzoni. 1979b. Estratigrafía de la Formacion sarmiento en la Barranca sur del lago Colhué Huapi, provincia del Chubut. Revista de la Asociación Geológica Aregentina 34(4): 271-281

Sempere, T., Butler, R. F., Richards, D. R., Marshall, L. G., Sharp, W y C. C. Swisher III. 1997. Stratigraphy and chronology of Upper Cretaceous-lower Paleogene strata in Bolivia and northwest Argentina. Geological Society of America Bulletin 109(6): 709-727.

Simpson, G. G. 1935. Early and middle Tertiary geology of the Gaiman region, Chubut, Argentina. American Museum Novitates, 775: 1-29.

Simpson, G. G. 1940. Review of the mammal-bearing Tertiary of South America. Proceedings of the American Philosophical Society 83: 49-709.

Smith, J. B. y P. Dodson. 2003. A proposal for a standard terminology of anatomical notation and orientation in fossil vertebrate dentitions. Journal of Vertebrate Paleontology 23(1): 112.

Spix, J. B. v. 1825. Animalia nova sive species nova lacertarum quas in itinere per Brasiliam annis MDCCCXVII-MDCCCXX jussu et auspicius Maximiliani Josephi I Bavariae Regis suscepto collegit et descripsit Dr. J. B. de Spix; Lipsiae: T. O. Weigel; F. S. Monachii.

Stipanicic, P. N., Rodrigo, F., Baulies, O. L. y Martinez, C. G. 1968. Las formaciones presenonianas del denominado Macizo Nordpatagónico y regiones adyacentes. Revista de la Asociación Geológica Argentina, 23(2): 67-98.

Sulimski, A. 1975. Macrocephalosauridae and Polyglyphanodontidae (Sauria) from the Late Cretaceous of Mongolia. Palaeontologia Polonica 33:25-102.

Sulimski, A. 1978. New data on the genus Adamisaurus Sulimski 1972 (Sauria) from the Upper Cretaceous of Mongolia. Palaeontologia Polonica 38: 43-56.

Sullivan, R. M. y R. Estes. 1997. Paradracaena colombiana (Estes, 1961) new genus (Squamata, Teiidae): A reassessment of the Tupinambinae from the Miocene Honda Group of Colombia; pp 100-112. En: R. F. Kay, R. H. Madden, R. L. Cifelli, J. J. Flynn (Eds.), Vertebrate Paleontology in Neotropics. Smithsonian Institution Press, Washington D. C..

Tauber, A. A. 1997. Paleoecología de la Formación Santa Cruz (Mioceno inferior) en el extremo sudeste de la Patagonia. Ameghiniana 34(4): 517-529. 
Tauber, A. A., Vizcaíno, S. F., Brago, M. S., Kay, R. F. y C. Luna. 2004. Aspectos bioestratigráficos y paleoecológicos de la Formación Santa Cruz (Mioceno tempranomedio) de Patagonia. Ameghiniana 41(4) suplemento: 64.

Tarazona, O. A., Febrezi, M. y M. P. Ramírez-Pinilla. 2008. Cranial morphology of Bachia bicolor (Squamata: Gymnophthalmidae) and its postnatal development. Zoological Journal of the Linnean Society 152: 775-792.

Tedesco, M. E. y J. M. Cei., 1997. Osteological research on the genus Kentropyx from Argentina and revalidation of the specific status for Kentropyx lagartija (Gallardo, 1962) (Squamata: Teiidae). Bollettino del Museo Regionale di Scienze Naturali de Torino 15(1): $231-240$

Tedesco, M. E., Krause, L. y B. B. Alvarez. 1999. Descripción del sincraneo de Ameiva ameiva (Linnaeus) (Squamata, Teiidae). Revista Brasilera de Biología 16: 1025-1044.

Tejedor, M. F., Tauber, A. A., Rosenberger, A. L., Swisher III, C. C. y M. E. Palacios. 2006. New primate genus from the Miocene of Argentina. Proceedings of the National academy of Sciences (PNAS) 103: 5437-5441.

Teixeira, R.D. 2003. Análise Filogenética da Família Teiidae (Squamata, Reptilia), a Ultraestrutura de Espermatozóide e a sua Utilidade Filogenética. Tesis Doctoral. Departamento de Biologia Celular, Universidade Estadual de Campinas, Campinas.

Tiranti, S. y L. J. Ávila. 1994. Aportes a la herpetología de la Provincia de La Pampa. I. Lista de los taxa de presencia segura en la provincia. Boletín de la Asociación Herpetológica Argentina 10: 39-41.

Tiranti, S. y L. J. Ávila. 1997. Reptiles of La Pampa province, Argentina: an annotated checklist. Bulletin of the Maryland Herpetological Society 33: 97-117.

Tobisch, A., Padula, G., Drube, H. y Salceda, S. 2005. Sitio de entierro múltiple en la Mesada de Carrizal; pp. 423-440. En: Sempé, C., Salceda, S. y M. Mafia (Eds.), Azampay: Presente y Pasado de un Pueblito Catamarqueño. Antología de Estudios Antropológicos. Ediciones Al Margen, La Plata.

Tonni, E. P. y F. Fidalgo. 1978. Consideraciones sobre los cambios climáticos durante el Pleistoceno tardío-Reciente en la provincia de Buenos Aires. Aspectos ecológicos y zoogeográficosrelacionados. Ameghiniana 15(1-2): 235-253.

Tonni, E. P., A. L. Cione y A. J. Figini. 1999. Predominance of arid climates indicated by mammals in the pampas of Argentina during the Late Pleistocene and Holocene. Palaeogeography, Palaeoclimatology, Palaeoecology 147: 257-281. 
Tonni, E. P., D. H. Verzi, M. S. Bargo, G. J. Scillato-Yané y U. F. J. Pardiñas. 1996. Bioestratigrafía del Cenozoico Superior continental en las barrancas costeras de Necochea y Miramar, provincia de Buenos Aires, República Argentina. $4{ }^{\text {tas }}$ Jornadas de Geololgía y Geofísicas Bonaerenses (Junín) 1: 63-71.

Torres, S. E. y R. Montero. 1998a. Sobre algunas vértebras fósiles de Amphisbanidae (Reptilia: Amphisbaenia) de la Formación Ensenada (Pleistoceno Inferior) de la Provincia de Buenos Aires, Argentina. Acta Geológica Lilloana 18(10): 149-197.

Torres, S. E. y R. Montero. 1998b. Leiosaurus marelli Rusconi 1937, is a South American amphisbaenid. Journal of Herpetology 32(4): 602-604.

Townsend, T. M., Larson, A., Louis, E. y J. R. Macey. 2004. Molecular phylogenetics of Squamata: the position of snakes, amphisbaenians, and dibamids, and the root of the squamate tree. Systematic Biology 53: 735-757.

Tiranti S. I. y L. J. Ávila 1997. Reptiles of La Pampa, Argentina: an annotated checklist. Bulletin of the Maryland Herpetological Society 33(3): 97-117.

Ubilla, M. y D. Perea, 1999. Quaternary vertebrates of Uruguay: biostratigraphic, biogeographic and climatic overview. Quaternary of South America and Antarctic Peninsula 12: $75-90$.

Vanzolini, P. E. y J. Valencia. 1965. The genus Dracaena, with a brief consideration of macroteiid relationships (Sauria, Teiidae). Arquivos de Zoologia São Paulo 13: 7-46.

Vanzolini, P. E. y W. R. Heyer, 1985. The American herpetofauna and the interchange: pp. 475-487. En: Stehli, F. G. y S. D. Webb (Eds.), The Grate American Biotic Interchange. Plenum Press, New York and London.

Vidal, M. 2004. Reptiles terrestres de Chile. Guías de Identificación y Biodiversidad Fauna Chilena. Apuntes de Zoología, Universidad Arturo Prat, Iquique.

Vidal, N. y S. B. Hedges. 2005. The phylogeny of Squamate reptiles (lizards, snakes, and amphisbaenians) inferred from nine nuclear protein-coding genes. Comptes Rendus Biologies 328:1000-1008.

Videla, F., y S. Puig. 1994. Estructura de una comunidad de lagartos del Monte. Patrones de uso espacial y temporal. Multequina 3: 99-112.

Vega, L., y P. Bellagamba. 1990. Lista comentada de la herpetofauna de las sierras de Balcarce y Mar del Plata, Buenos Aires, Argentina. Cuadernos de Herpetología 5(2): 10-14.

Venegas, P. J. 2005. Herpetofauna del Bosque Seco Ecuatorial de Perú: taxonomía, ecología y biogeografía. Zonas Áridas 9: 9-26. 
Veralli C. y J. O. Calvo. 2004. Dientes de terópodos carcharodontosáuridos del Turoniano superior-Coniaciano inferior del Neuquén, Patagonia, Argentina. Ameghiniana 41 (4): 587590.

Veronese, L. B. y L. Krause. 1997. Esqueleto pré-sacral e sacral dos lagartos teiídos (Squamata, Teiidae). Revista Brasileira de Biologia 14(1): 15-34.

Verzi, D. H. 1999. The dental evidence on the differentiation of the ctenomyine rodents (Caviomorpha, Octodontidae, Ctenomyinae). Acta Theriologica 44(3): 263-282.

Verzi, D. H., Vucetich, M. G. y C. I. Montalvo. 1995. Un nuevo Eumysopinae (Rodentia, Echimyidae) del Mioceno tardío de la provincia de La Pampa y consideraciones sobre la historia de la subfamilia. Ameghiniana 32(2): 191-195.

Verzi, D. H., Montalvo, C. I. y M. G. Vucetich. 1999. Afinidades y significado evolutivo de Neophanomys biplicatus (Rodentia, Octodontidae) del Mioceno tard1 'o-Plioceno temprano de Argentina. Ameghiniana 36(1): 83-90.

Verzi, D. H., Montalvo, C. I. y S. I. Tiranti. 2003. Un nuevo Xenodontomys (Rodentia, Octodontidae) del Mioceno tardío de La Pampa, Argentina. Patrón evolutivo y bioestratigrafía. Ameghiniana 40(2): 229-238.

Verzi, D. H., Deschamps C. M. y E. P. Tonni. 2004. Biostratigraphic and palaeoclimatic meaning of the Middle Pleistocene South American rodent Ctenomys kraglievichi (Caviomorpha, Octodontidae). Palaeogeography, Palaeoclimatology, Palaeoecology 212: 315-329.

Vignati, M. 1925. La geología de Monte Hermoso. Physis, Revista de la Sociedad Argentina de Ciencias Naturales 8: 26-39.

Vucetich, M. G. 1985. Cephamolyopsis hipselodontus gen. et sp. nov. (Rodentia, Caviomorpha, Cephalomydae) de la edad Colhuehuapense (Oligoceno tardío) de Chubut, Argentina. Ameghiniana 22(3-4): 243-245.

Vucetich, M. G. 1990. Los roedores Caviomorpha de la edad Colhuehuapense (Oligoceno tardío?). Ameghiniana 26(3-4): 252.

Vucetich, M. G. y D. H. Verzi. 1991. Un nuevo Echimyidae (Rodentia, Hystricognathi) de la edad Colhuehuapense de Patagonia y consideraciones sobre la sistemática de la familia. Ameghiniana 28(1-2): 67-74.

Vucetich, M. G. y D. H. Verzi. 1993. Un nuevo Chinchillidae del Colhuehuapense (Mioceno inferior?) de Gaiman (Chubut): su aporte a la comprensión de la dicotomía vizcachaschinchillas. Ameghiniana 30(4: resúmenes): 115. 
Vucetich, M. G., Mazzoni, M. M. y U. F. J. Pardiñas. 1993. Los roedores de la Formación Collón-Cura (Mioceno medio) y la Ignimbrita Pilcaniyeu, Cañadón del Tordillo, Neuquén. Ameghiniana 30(4): 361-381.

Vucetich, M. G., D. H. Verzi, y E. P. Tonni. 1997. Paleoclimatic implications of the presence of Clyomys (Rodentia, Echimyidae) in the Pleistocene of central Argentina.

Palaeogeography, Palaeoclimatology, Palaeoecology 128.

Vucetich, M. G., Reguero, M. A., Bond, M., Candela, A. M., Carlini, A. A., Deschamps, C. M., Gelfo, J. N., Goin, F. J., López, G. M., Ortiz Jaureguizar, E., Pascual, R., ScillatoYané, G. J., Y E. C. Vieytes. 2007. Mamíferos continentales del Paleógeno argentino: las investigaciones de los últimos cincuenta años; pp 239-255. En: Archangelsky, S., Sánchez, T. y E. P. Tonni (Eds.), Publicación Especial 11 Ameghiniana 50 Aniversario. Ameghiniana.

Vullo, L. 1951. Informe geológico sobre la cantera de calcáreo travertínico de "La Playa" Pedanía Guasapampa - Departamento Minas. Provincia de Córdoba. Informe Inédito. Biblioteca de la Dirección de Minería. Córdoba.

Wassersug, R. J. 1976. A procedure for differential staining of cartilage and bone in whole formalin fixed vertebrates. Stain Technology 51: 131-134.

Weaver, C. 1931. Paleontology of the Jurassic and Cretaceous of West Central Argentina. University of Washington Memoir 1.

Wichmann S. 1996. Estudio preliminar de la herpetofauna de la Reserva Natural Sierra del Tigre. XII Reunión de Comunicaciones Herpetológicas (Río Cuarto) Resúmenes: 39.

Williams J. 1991. Anfibios y reptiles. En: Situación ambiental de la Provincia de Buenos Aires, (A) Recursos y rasgos naturales en la evaluación de impacto ambiental. Comisión de Investigaciones Científicas, La Plata.

Williams, V. I. 2003. Nuevos datos sobre la prehistoria local en la Quebrada de Tolombón, Provincia de Salta, Argentina; pp. 163-210. En: Cornell, P. y P. Stenborg (Eds.), Local, Regional, Global: Prehistoria, Protohistoria e Historia en los Valles Calchaquíes. Anales (Nueva Época) 6, Instituto Iberoamericano, Universidad de Gotemburgo, Gotemburgo.

Woodward, A. S. 1901. On some extinct reptiles from Patagonia, of the genera Meiolania, Dinilysia, and Genyodectes. Proceedings of the Zoological Society of London 1901: 169184.

Wu, X. -C., Brinkman, D. B., Russell, A. P., Dang, Z. -M, Currie, P. J., Hou, L. H. y G. H. Gui. 1993. The oldest known amphisbaenian from the Upper Cretaceous of Chinese Inner Mongolia. Nature 266: 57-59. 
Wu, X. -C., Brinkman, D. B. y A. P. Russell. 1996. Sineoamphisbaena hexatabularis, an amphisbaenian (Diapsida: Squamata) from the Upper Cretaceous redbeds at Bayan Mandahu (Inner Mongolia, People's Republic of china), and comments on the phylogenetic relationships of the Amphisbaenia. Canadian Journal of Earth Sciences 33: 541-577.

Yanosky, A. A. y C. Mercolli. 1991. Temperaturas interna y frecuencias de muda en crias de Tupinambis teguixin (Rptilia: Teiidae). Cuadernos de Herpetología 6(4): 23-26.

Yanosky, A. A. y C. Mercolli. 1992. Aportes ecológicos sobre la lacertofauna de la Reserva Ecológica El Bagual (Formosa, Argentina). II Congreso Argentino de Herpetología (La Plata) Resúmenes, 86.

Yanosky, A. A. y C. Mercolli. 1995. Un modelo de curva de crecimiento de la iguana overa (Tupinambis teguixin). Archivos de Zootecnia 44: 15-21.

Zaher, H. y O. Rieppel. 1999. Tooth implantation and replacement in squamates, with special reference to mosasaur lizards and snakes. American Museum Novitates 3271:1-19.

Zachos, J. C., Lohmann, K. C., Walker, J. C. G. y S. W. Wise. 1991. Early Oligocene ice sheet expansion on Antarctica: stable isotope and sedimentological evidence from Kerguelen Plateau, southern Indian Ocean. Geology 20: 569-573.

Zug, G. R. 1993. Herpetology. An introductory biology of Amphibians and Reptiles. Academic Press, London.

Zug, G. R., Vitt, L. G. y G. P. Caldwell. 2001. Herpetology. An Introductory Biology of Amphibians \& Reptiles. Second Edition. Academy Press, London.

Zavala, C. 1993. Estratigrafía de la localidad de Farola Monte Hermoso (Plioceno-reciente), Provincia de Buenos Aires. XII Congreso Geológico Argentino y II Congreso de Exploración de Hidrocarburos, Actas 2: 228-235.

Zavala, C. y E. Navarro. 1993 Depósitos fluviales en la Formación Monte Hermoso (Plioceno inferior-medio). Provincia de Buenos Aires. XII Congreso Geológico Argentino y II Congreso de Exploración de Hidrocarburos, Actas 2: 236-244. 